UCRL-ID-132300






\section{DISCLAIMER}

This document was prepared as an account of work sponsored by an agency of the United States Government. Neither the United States Government nor the University of California nor any of their employees, makes any warranty, express or implied, or assumes any legal liability or responsibility for the accuracy, completeness, or usefulness of any information, apparatus, product, or process disclosed, or represents that its use would not infringe privately owned rights. Reference herein to any specific commercial product, process, or service by trade name, trademark, manufacturer, or otherwise, does not necessarily constitute or imply its endorsement, recommendation, or favoring by the United States Government or the University of California. The views and opinions of authors expressed herein do not necessarily state or reflect those of the United States Government or the University of California, and shall not be used for advertising or product endorsement purposes.

This report has been reproduced directly from the best available copy.

Available to DOE and DOE contractors from the Office of Scientific and Technical Information P.O. Box 62, Oak Ridge, TN 37831

Prices available from (423) 576-8401

Available to the public from the National Technical Information Service

U.S. Department of Commerce

5285 Port Royal Rd.,

Springfield, VA 22161

Work performed under the auspices of the U.S. Department of Energy by Lawrence Livermore National Laboratory under Contract W-7405-ENG-48. 


\title{
Evaluation of the Hydrologic Source Term from Underground Nuclear Tests in Frenchman Flat at the Nevada Test Site: The CAmbric Test
}

\author{
Editors: \\ Andrew F. B. Tompson ${ }^{1}$ \\ Carol J. Bruton ${ }^{1}$ \\ Gayle A. Pawloski ${ }^{1}$ \\ Contributors: \\ William L. Bourcier ${ }^{1}$ \\ Carol J. Bruton ${ }^{1}$ \\ Steven F. Carle ${ }^{1}$ \\ Annie B. Kersting ${ }^{2}$ \\ Gayle A. Pawloski ${ }^{1}$ \\ Joseph A. Rard ${ }^{1}$ \\ Dana E. Shumaker ${ }^{3}$ \\ David K. Smith ${ }^{2}$ \\ Andrew F. B. Tompson ${ }^{1}$
}

March 23, 1999

\footnotetext{
${ }^{1}$ Geosciences and Environmental Technologies Division

${ }^{2}$ Isotope Sciences Division

${ }^{3}$ Center for Applied Scientific Computing

Lawrence Livermore National Laboratory

Livermore, CA 94551
} 



\section{Acknowledgments}

This work was performed by Lawrence Livermore National Laboratory under contract W-7405-ENG-48 for the U. S. Department of Energy. We are deeply indebted to Carl Steefel and Steven Yabusaki for providing the GIMRT/Os3D models and for their dedication in helping us move our applications forward. We would also like to thank Martin Blunt, Martha Crane, Jim Johnson, and Brian Viani for their collaboration and interest in various portions of this report.

This work has benefited from reviews by numerous people external to the Lawrence Livermore National Laboratory team that produced this document. We gratefully acknowledge technical review of the report by Underground Test Area (UGTA) Technical Working Group (TWG) Modeling Subcommittee members Sirous Djafari, Dave Morgan, Karl Pohlmann, Mike Sully, and Andrew Wolfsberg; Source Term Subcommittee members Roger Jacobson and Joe Thompson; and Ken Rehfeldt of HSI GeoTrans; and support and guidance of Robert Bangerter, UGTA Subproject Manager from the Department of Energy, Nevada Operations Office. Presentation of this information to the Technical Working Group and others produced thoughtful discussion and guidance. Additional working level review discussions with Jenny Chapman, Lambis Papelis, Chuck Russell, and Craig Shirley of the Desert Research Institute have been extremely beneficial.

This report is electronically available at the Lawrence Livermore National Laboratory Library of the Future at www.llnl.gov/tid/lof/lof_home.shtml 
Evaluation of the Hydrologic Source Term 


\section{Contents}

Acknowledgments $\quad$ i

List of Figures $\quad$ ix

List of Tables $\quad$ xxv

Executive Summary $\quad$ xxix

1 Introduction 1

1.1 The CAmbric test . . . . . . . . . . . . . . . . 1

1.2 Broader purpose for this work . . . . . . . . . . . . . 2

2 Impacts of Underground Nuclear Explosions 3

2.1 General phenomenology . . . . . . . . . . . . . . . 3

2.2 Early-time phenomenology . . . . . . . . . . . . . . . 3

2.3 Late-time phenomenology . . . . . . . . . . . . . . . 6

2.4 Other phenomena. . . . . . . . . . . . . 7

2.5 Radionuclide distribution and behavior . . . . . . . . . . 7

3 Physical and Chemical Setting 11

3.1 Structural and geologic setting of Frenchman Flat . . . . . . . 11

3.2 The near field environment at CAMBric . . . . . . . . . . . 11

3.2 .1 Nearby boreholes . . . . . . . . . . . . . . . . . 13

3.2.2 Alluvium composition . . . . . . . . . . . . . 13

3.2.3 Groundwater composition . . . . . . . . . . . . . . . 19

3.2.4 Radionuclide inventory . . . . . . . . . . . . . . . 20

3.2.5 Radionuclide data from groundwater and alluvium samples 20

3.3 Definition of the hydrologic source term . . . . . . . . . . 22

3.3.1 Radionuclide migration and speciation . . . . . . . . . 23

3.3.2 Exchange volume and melt glass source regions . . . . . . 25

3.3.3 Radionuclide decay . . . . . . . . . . . . . . . . . . 25

4 Modeling Approach $\quad 29$

5 Selection of Radionuclides for Analysis 31

6 Modeling Radionuclide Release from the Melt Glass 33

6.1 Glass composition . . . . . . . . . . . . . . . . 33

6.2 Glass dissolution model . . . . . . . . . . . . . . . . . 33

6.2 .1 General features . . . . . . . . . . . . . . . . . 33

6.2 .2 Rate equation . . . . . . . . . . . . . . 35

6.2.3 Rate equation parameters . . . . . . . . . . . . 37

6.2 .4 Glass surface area . . . . . . . . . . . . . . . . . . . 40 
6.3 Comparison with experimental data . . . . . . . . . . 43

6.4 Other factors affecting glass durability . . . . . . . . . . . . 47

6.5 Incorporation of glass dissolution in reaction path models . . . . 47

6.5.1 Glass data block . . . . . . . . . . . . . . . . . . . 47

6.5.2 Rate law..................... . . 48

6.6 Reaction rate of the melt glass . . . . . . . . . . . . . 51

7 Modeling Radionuclide Release and Chemical Interactions in the Cavity, Chimney, and Alluvium 53

7.1 Surface complexation . . . . . . . . . . . . . 54

7.2 Ion exchange . . . . . . . . . . . . . . . 56

7.3 Nature and distribution of radionuclides in the cavity/chimney region ................... . 57

7.4 Radiogenic versus non-radiogenic isotopes . . . . . . . . . 59

8 Geochemical Modeling of Radionuclide Migration 61

8.1 Geochemical modeling codes. . . . . . . . . . . . . 62

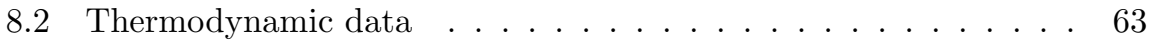

8.3 The ambient environment ............... 63

8.3.1 Groundwater chemistry .............. 63

8.3.2 Mineralogy .................... 65

8.3.3 Kinetic parameters of minerals ............ 68

8.4 Aqueous complexation and solubility limits for radionuclides . . . 70

8.4.1 Calculational method . . . . . . . . . . . . 70

8.4.2 Cesium $(\mathrm{Cs})$............................ 71

8.4.3 Strontium $(\mathrm{Sr})$. . . . . . . . . . . . . . 71

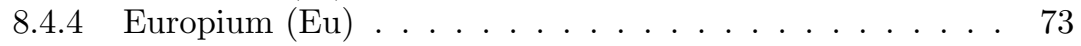

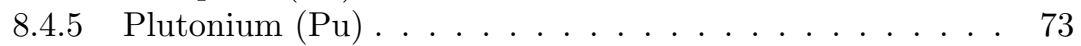

8.4.6 Americium (Am) . . . . . . . . . . . 75

9 One-Dimensional Reactive Transport Simulations using GIMRT 81

9.1 Four basic simulations ................ . 81

10 Near-Field Groundwater Flow at CAMBRIC 85

10.1 Model domain . . . . . . . . . . . . . . . . 85

10.2 Previous models and the radionuclide migration experiment . . . 85

10.2.1 LATA model . . . . . . . . . . . . . . . . . 87

10.2 LANL model . . . . . . . . . . . . . . . . . 90

10.2.3 Burbey and Wheatcraft model . . . . . . . . . . . . . . 90

10.2.4 Guell model . . . . . . . . . . . . . . . . . . . . . . . 92

10.3 Current model . . . . . . . . . . . . . . . . . . 92

10.3.1 Geometry and features of the disturbed zone . . . . . . . 92

10.3.2 Specification of flow properties . . . . . . . . . . . 93

10.3.3 Steady flow fields and tritium recovery . . . . . . . . 97 
10.3.4 Additional observations . . . . . . . . . . . 100

11 Integrated Radionuclide Migration away from CAMBRIC $\quad 105$

11.1 Streamline generation . . . . . . . . . . . . . . . 105

11.1.1 Streamline mapping procedure . . . . . . . . . . 106

11.2 Models of the mineralogic distribution . . . . . . . . . . 107

11.3 Geochemical analyses of single streamline simulations . . . . . 112

11.4 Integrated 3D simulations . . . . . . . . . . . . . . . 114

11.4.1 Results for Mineralogic Model 10 . . . . . . . . . . 115

11.4.2 Results for Mineralogic Model 11 . . . . . . . . . . . . . 123

11.4.3 Results for Mineralogic Model 12 . . . . . . . . . . . 123

11.4.4 $\mathrm{pH}$ distribution evolved from each model . . . . . . . . 129

12 Sensitivity Studies 133

12.1 Modified models of the mineralogic distribution . . . . . . . . 133

12.1.1 Retardation by reactive minerals - Goethite surface area . 133

12.1.2 Melt glass surface area . . . . . . . . . . . . . . . . 133

12.1.3 Spatial distribution of reactive minerals. . . . . . . . . 133

12.2 Results of integrated 3D simulations . . . . . . . . . 136

12.2.1 Results for Mineralogic Model 10a . . . . . . . . . 136

12.2.2 Results for Mineralogic Model 13a . . . . . . . . . . 136

12.2.3 Results for Mineralogic Model 10d . . . . . . . . . . . 136

12.2.4 Comparisons among all model results . . . . . . . . . 139

13 Extrapolating Results to Larger Scale Simulations 147

14 Comparison of Simulations with Observations: A Summary 149

14.1 Predicted breakthrough of tritium at RNM-2S vs. the migration test observations . . . . . . . . . . . . . . . 149

14.2 Initial exchange volume concentrations vs. RNM-1 measurements 149

14.3 Predicted retardation behavior in alluvium vs. batch test measurements . . . . . . . . . . . . . . . 150

14.4 Expected breakthrough of $\mathrm{Pu}$ and $\mathrm{Am}$ at RNM-2S vs. the migration test observations . . . . . . . . . . . . 151

15 Summary, Conclusions, and Recommendations 153

15.1 Summary . . . . . . . . . . . . . . . . . 153

15.1.1 Modeling framework . . . . . . . . . . . . . 153

15.1.2 Radionuclide selection, distribution, and release . . . . . 154

15.1.3 Radionuclide mobility at CAMBric . . . . . . . . . . . . 154

15.1.4 Radionuclide flux at CAMBRIC . . . . . . . . . . 155

15.2 Conclusions . . . . . . . . . . . . . . . . . 157

15.3 Radionuclide migration away from other tests in Frenchman Flat 160

15.4 Recommendations for future work . . . . . . . . . . . . . 161 
$\begin{array}{ll}\text { References } & 165\end{array}$

Appendix 1: Selected Radionuclide Decay Chains 175

Appendix 2: 1D Reactive Transport Equations in GIMRT and Os3D179

Appendix 3: Implementing Surface Complexation and Ion Exchange 183

Surface complexation . . . . . . . . . . . . . . . . . 183

Model and binding constants . . . . . . . . . . . . . 183

Goethite as sorbent . . . . . . . . . . . . . . . 188

Additional model assumptions . . . . . . . . . . . . . . . 188

Ion exchange . . . . . . . . . . . . . . . . . . . 188

Exchange models . . . . . . . . . . . . . . . . . 188

Incorporating homovalent exchange models in GimRT . . . . . 189

Exchange energies and cation exchange capacities . . . . . . . . 191

Adequacy of restriction to homovalent exchange . . . . . . . . . 191

Representing exchangers in GimRT . . . . . . . . . . . . . 192

Appendix 4: Thermodynamic Data 195

Appendix 5: Analyses of 1D Reactive Transport Simulations 197

Alluvium-melt glass-alluvium . . . . . . . . . . . . . . . 197

Major element chemistry . . . . . . . . . . . . . . . . 197

Radionuclide concentrations . . . . . . . . . . . . . . 197

Alluvium-exchange volume-alluvium . . . . . . . . . . . . . . 210

Alluvium-melt glass-exchange volume-alluvium . . . . . . . . . . . 213

Alluvium-exchange volume-melt glass-alluvium . . . . . . . . . 220

Appendix 6: Streamline Transport Model $\quad 227$

Basic concepts . . . . . . . . . . . . . . . . 227

Mapping streamlines . . . . . . . . . . . . . . . . . . 228

Time-of-flight formulation . . . . . . . . . . . . . . . . . 229

Relating streamline and grid-block quantities . . . . . . . . . 230

Adding dispersion, diffusion, and reaction processes . . . . . . . . 230

Appendix 7: Analyses of Single Streamline Simulations 233

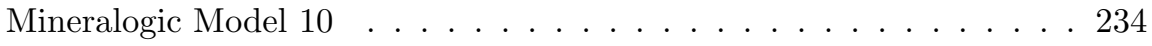

Mineralogic Model $11 \ldots \ldots$. . . . . . . . . . . . 250

Mineralogic Model $12 \ldots \ldots$. . . . . . . . . . . . . 251 


\section{Appendix 8: Sensitivity of Model Results to Iron Oxide and Melt}

Glass Surface Areas

Goethite (ferric iron oxide) surface area . . . . . . . . . . . 265

Mineralogic Model 10a versus Model 10: Effect of reducing goethite surface area . . . . . . . . . . . . . 266

Glass surface area . . . . . . . . . . . . . . . . 267

Mineralogic Model 10b versus Model 10a: Effect of increasing glass surface area by three orders of magnitude . . . . . 276

Mineralogic Model 10c and 10d versus 10a: Effect of increasing glass surface area by one and two orders of magnitude . . 277

Choice of glass surface area to be used in conservative source term calculations . . . . . . . . . . . . . . 297

\section{Appendix 9: Simplifying the Results for Larger Scale Applications301}

Effective retardation of radionuclide migration outside of the cavity and chimney region . . . . . . . . . . . . . . 301

Effective representation of glass dissolution and radionuclide flux out of the melt glass environment . . . . . . . . . . . . . . . 314 


\section{List of Figures}

1 Conceptual illustration of early time (above) and late time (below) phenomenology of an underground nuclear explosion in competent rock showing accretion of glass puddle and redistribution of more volatile radionuclides, initially as vapor, later as condensate. Some noncondensable radionuclides may migrate further upwards. . . . . . . . . . . . . . . . . . . .

2 In situ photograph of the melt glass at the RAINIER test (Wadman and Richards, 1961). Large blocks of the host tuff can be seen inside the melted glass zone. Vesicular zones (rich in bubbles) surround some of these inclusions. The photo shows a section of the pool about 2 meters across. The zone is obviously heterogeneous in textural and hydrologic properties. . . . . . . 5

3 Schematic map of the Nevada Test Site and surrounding areas. . 12

4 Conceptual structural model cross-section (W-E) for Frenchman Flat, after Grauch and Hudson (1995). Symbols: Tv $=$ Tertiary volcanic rocks; $\mathrm{Pz}=$ Paleozoic carbonate rock; QTal $=$ Quaternary/Tertiary alluvium. . . . . . . . . . . . . . .

5 Location of CAMBric test in Frenchman Flat, Nevada Test Site, Nevada (after Hoffman et al., 1977). Topographic gradients are indicative of principal alluvial depositional direction southeasterly toward Frenchman Lake. . . . . . . . . . . . . . . . . . .

6 Regional groundwater gradients in the alluvial and deeper carbonate aquifers in Frenchman Flat (after Hoffman et al., 1977). At the CAMBric site, flow in the alluvial system moves slowly in an approximately east-southeast direction due to a horizontal hydraulic gradient of 0.002 or less. . . . . . . . . . . . . . . Conceptual cross-section through the CAMBRIC test in Frenchman Flat showing the working point, cavity, chimney, and water table (after Hoffman et al. , 1977). The section transect is shown in Fig. 8. . . . . . . . . . . . . . . . . .

8 Plan view of the CAMBRIC site showing nearby boreholes and transect of cross-section shown in the previous figure. Large (blue) and small (pink outline) pie-shaped areas represent the areal extent of the LATA and LANL model domains, respectively. Small yellow square represents the domain of the Burbey and Wheatcraft (1986) model, while the dotted rectangle represents the model domain in this report. . . . . . . . . . . . . .

9 Variation of size fraction of alluvium with depth sampled from well UE5n using sieve and hydrometer analyses (after Ramspott and McArthur, 1977). Notice that the apparent lithologic break may be visible between 280 and $300 \mathrm{~m}$ depth beneath the ground surface. . . . . . . . . . . . . . . 
10 Vertical distribution of hydraulic conductivity beneath the water table, as measured from core and well-test analyses in RNM-1 and RNM-2S (from Hoffman et al. , 1977; Stone, 1975; and Ramspott and McArthur, 1977; as reinterpreted by Burbey and Wheatcraft, 1986). Depth refers to distance beneath ground surface. . . . . . 20

11 Generic illustration of geologic units that comprise the cavity/chimney system in a saturated environment (see text). . . . . . . . . . 26

12 Dissolution rates for synthetic volcanic glasses measured at $65^{\circ} \mathrm{C}$. $\quad 36$

13 Regression fits to experimental data at $65^{\circ} \mathrm{C}$ for synthetic volcanic glasses. Curves show 3rd order polynomial fits to data. Data for dacite shown as dark curve; line with circles shows fit to dacite data. Dotted line shows estimated $\mathrm{pH}$ dependence of $\log$ rate for rhyolite glass used as input for reactive transport codes.

14 Silica saturation value for CAMBRIC melt glass. If groundwater leachate has higher concentration than this value, glass dissolves at minimum "silica saturation" rate which is $2.4 \times 10^{-7} \mathrm{~g} / \mathrm{m}^{2} /$ day at $25^{\circ} \mathrm{C}$ (see text). . . . . . . . . . . . . . . . . .

Detail of a melt glass specimen about 2 centimeters across from the BILBY test (U3cn, September 13, 1963), showing cracks, abundant vesicles and flow textures. The permeability and available surface area of this type of glassy material is difficult to estimate without measurements. . . . . . . . . . . . . .

16 Measured release rates of elements from CAMBRIC melt glass in single pass flow-through tests at $25^{\circ} \mathrm{C}$. Bars show range of measured values. Horizontal line is predicted glass dissolution rate from model. . . . . . . . . . . . . . . . . . . . . .

17 Measured release rates of elements from CAMBRIC melt glasses in single pass flow-through tests at $25^{\circ} \mathrm{C}$. Bars show range of measured values for tests of three glass samples. Horizontal line is predicted glass dissolution rate from model. . . . . . . . . . . .

18 Comparison of field measured palagonitization rates of basaltic glasses in seawater with dissolution rates estimated from glass reaction model. . . . . . . . . . . . . . . . . . . . . . 46

19 Pre-exponential factor in rate equation vs. glass silica content. . 49

20 Estimate of mass of remaining CAMBRIC melt glass as a function of time calculated assuming a constant affinity term of 0.5 (half of saturation) at three different temperatures. The puddle surface area and geometry used are described in text. . . . . . . . . . . .

21 Conceptual illustration of the partitioning of radionuclides among the reactive minerals (green) and fluids (blue) in the exchange volume (see Table 12). Right side corresponds to lack of any reactive minerals, in which case all radionuclides are distributed as aqueous species. . . . . . . . . . . . . . . . . . 
22 Aqueous speciation of strontium ( $\mathrm{Sr}$ ) as a function of $\mathrm{pH}$ in representative CAMBRIC groundwater (Table 14). . . . . . . . . .

23 Calculated solubility of strontium ( $\mathrm{Sr}$ )-bearing solid phases as a function of $\mathrm{pH}$ in representative CAMBRIC groundwater (Table

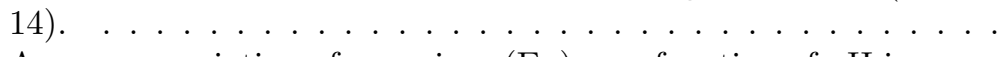

24 Aqueous speciation of europium (Eu) as a function of $\mathrm{pH}$ in representative CAMBrIC groundwater (Table 14). . . . . . . . . 74

25 Calculated solubility of europium (Eu)-bearing solid phases as a function of $\mathrm{pH}$ in representative CAMBRIC groundwater (Table 14). 75

26 Aqueous speciation of plutonium $(\mathrm{Pu})$ as a function of $\mathrm{pH}$ in representative CAmBric groundwater (Table 14). . . . . . . 76

27 Calculated solubility of plutonium $(\mathrm{Pu})$-bearing solid phases as a function of $\mathrm{pH}$ in representative CAMBRIC groundwater (Table 14). 77

28 Aqueous speciation of americium (Am) as a function of $\mathrm{pH}$ in representative CAMBRIC groundwater (Table 14). . . . . . . . 78

29 Calculated solubility of americium (Am)-bearing solid phases as a function of $\mathrm{pH}$ in representative CAMBRIC groundwater (Table 14). . . . . . . . . . . . . . . . .

30 (a, top) Conceptual model of fluid flow through the sequence of rock types alluvium, glass, and alluvium. (b, bottom) Grid and zones of rock type used in 1D GIMRT simulations of model in (a). 82

31 Grid and zones of rock type used in 1D GimRT simulations of fluid flow through the sequence of rock types alluvium, exchange volume, and alluvium. . . . . . . . . . . . .

32 Grid and zones of rock type used in 1D GIMRT simulations of fluid flow through the sequence of rock types alluvium, glass, exchange volume and alluvium. . . . . . . . . . . . . .

33 Grid and zones of rock type used in 1D GIMRT simulations of fluid flow through the sequence of rock types alluvium, exchange volume, glass and alluvium. . . . . . . . . . . . .

34 Localized perspective of the hydrogeologic flow region around CAmbric. The modeling domain in the current model lies beneath the white rectangle oriented in a NW-SE direction that is aligned with the hydraulic and topographic gradient. It extends from the water table to a final depth of $210 \mathrm{~m}$ below the water table and is composed of the same alluvial layers used in the Burbey and Wheatcraft (1986) model. Numbers represent porosities and geometric-mean conductivities used in the current model. . . . . . . . . . . . . . . . . . .

35 Decay-corrected tritium elution profiles obtained at the RNM-2S well. Times correspond to the number of days since pumping began in October 1975. . . . . . . . . . . . . . 88 
36 Generic illustration of geologic units that comprise the cavity/chimney system in the simulation models (see text). Numbers represent elevation above sea level. . . . . . . . . . . . . . . . . . . 89

37 Schematic of slanted RNM-1 monitoring hole (purposely expanded in the radial direction), measured gamma intensity profile, and measured tritium concentration profiles from water samples taken in ports $\mathrm{I}-\mathrm{V}$ and from borehole cores taken during construction (after Hoffman et al., 1977, and Burbey and Wheatcraft, 1986). The intersection with assumed 18-m radius exchange volume is also shown. . . . . . . . . . . . . . . . . . . . 94

38 Measured hydraulic conductivity data superposed on the layered distribution used by Burbey and Wheatcraft (1986) and a typical realization of the correlated Gaussian distribution of conductivity referred to in the text. . . . . . . . . . . . . .

39 A single realization of the three-dimensional, layered hydraulic conductivity distribution at the CAMBRIC model domain, looking to the North. This was developed from the statistical approach outlined in the text. Background hydraulic gradients induce flow from the Northwest (upper left) to the Southeast (lower left). . . 98

40 Decay-corrected tritium elution profiles at the RNM-2S well obtained from current simulations based upon three equally-likely conductivity realizations. Black dots represent the measured well concentrations. Times correspond to the number of days since pumping began in October 1975. . . . . . . . . . . . . 100

41 Expanded three dimensional view of the model domain showing selected streamlines moving through the exchange volume and melt glass areas. Flow proceeds from the upper left to the lower right. Streamline colors refers to time of flight relative to an initial point along the streamline (see text). Hydraulic conductivity scale is the same as that in Fig. 39. . . . . . . . . . . . 108

42 Close-up cross-sectional view of the model domain showing all streamlines in the section that move through the exchange volume and melt glass areas. Streamline colors refers to time of flight relative to an initial point along the streamline (see text). Hydraulic conductivity scale is the same as that in Fig. 39. . . . 109

43 Path length, $s(\mathrm{~m})$, versus time-of-flight, $\tau$ (yr), for lines 100 (red) and 145 (green) extracted out of the ambient flow simulation at CAMBrIC. Notice that the rate of travel is much faster along line 100 than line 145, indicating the influence of conductivity variability. Symbols correspond to the geologic unit traversed by the streamline (Table 30); line $=$ alluvium, open circles $=$ exchange volume, solid dots $=$ melt glass. $\ldots \ldots$. . . . . 110 
44 Radionuclide release out of the exchange volume is controlled by groundwater transport and retardation effects associated with equilibrium partitioning of the exchange volume radionuclide inventory among fluids and reactive solids. A greater abundance of reactive solids (green, left) promotes increased partitioning and retardation and an effectively slower release. No reactive minerals (gray, right) eliminates retardation such that release is maximized and controlled by the groundwater flow alone. A spatially mixed distribution (below) will lead to intermediate degrees of release in an integrated sense. Radionuclide release out of the melt glass is controlled by groundwater transport and kinetically-controlled glass dissolution. . . . . . . . . . . . . . . . . . 113

$453 \mathrm{D}$ perspective of decay-corrected total-americium plume at 100 years in Mineralogic Model 10. Molar concentrations $>10^{-15}$ are in purple; $>10^{-13}$, in blue, and $>10^{-11}$ in green. Portions originating in the exchange volume and melt glass are both evident.116

$463 \mathrm{D}$ perspective of decay-corrected total-americium plume at 600 years in mineralogic Model 10. Molar concentrations $>10^{-15}$ are in purple; $>10^{-13}$, in blue, and $>10^{-11}$ in green. Portions originating in the exchange volume have largely been flushed out of the domain or have decayed; other portions contained in the melt glass are still entering the domain, despite the effects of decay.117

$473 \mathrm{D}$ perspective of decay-corrected total-europium plume at 600 years in Mineralogic Model 10. Molar concentrations $>10^{-14}$ are in blue; $>10^{-13}$, in aqua, and $>10^{-10}$ in yellow. Portions originally in the exchange volume have been flushed out and have decayed; other portions contained in the melt glass are still entering the domain, despite the effects of decay. . . . . . . . 118

48 Integrated flux of individual Eu species out of the domain, uncorrected for decay, corresponding to Mineralogic Model 10. . . . 119

49 Integrated flux of individual Am species out of the domain, uncorrected for decay, corresponding to Mineralogic Model 10. . . . 120

50 Integrated flux of the total $\mathrm{Eu}, \mathrm{Am}, \mathrm{Pu}, \mathrm{Sr}$, and $\mathrm{Cs}$ species out of the domain under no-decay conditions. These results correspond to Mineralogic Model 10. The fluxes of $\mathrm{Pu}, \mathrm{Sr}$, and $\mathrm{Cs}$ flux should be considered zero, as they correspond to decayed "0" background values used in the model. . . . . . . . . . . . . . . . . . 121

51 Integrated flux of the total $\mathrm{Eu}, \mathrm{Am}, \mathrm{Pu}, \mathrm{Sr}$, and Cs species out of the domain under decay conditions corresponding to Mineralogic Model 10. . . . . . . . . . . . . . . . . . . . . . . . 122

52 Integrated flux of the total $\mathrm{Eu}, \mathrm{Am}, \mathrm{Pu}, \mathrm{Sr}$, and $\mathrm{Cs}$ species out of the domain under decay conditions corresponding to Mineralogic Model 11. . . . . . . . . . . . . . . . . . . . . . . . . . . . 124 
53 3D perspective of cesium plume at 100 years in mineralogic Model 12 in the absence of decay correction. Molar concentrations > $10^{-15}$ are in blue; $>10^{-12.5}$, in green, and $>10^{-10}$ in yellow. Most portions of the cesium were originally in the exchange volume, and can be seen moving well out into the domain. Smaller portions contained in the melt glass are slowly entering the do-

54 main as well. . . . . . . . . . . . . . . . . . . . . mineralogic Model 12. Molar concentrations $>10^{-15}$ are in blue. This image shows the strong effect of decay when the half life of a radionuclide is short. . . . . . . . . . . . . . 126

55 3D perspective of decay-corrected total-plutonium plume at 100 years based upon Mineralogic Model 12. Molar concentrations $>10^{-13}$ are in blue; $>10^{-11}$, in green, and $>10^{-9}$ in yellow. . . 126

$563 \mathrm{D}$ perspective of decay-corrected total-plutonium plume at 300 years based upon Mineralogic Model 12. Molar concentrations $>10^{-13}$ are in blue; $>10^{-11}$, in green, and $>10^{-9}$ in yellow. . . 127

57 3D perspective of decay-corrected total-plutonium plume at 600 years based upon Mineralogic Model 12. Molar concentrations $>10^{-13}$ are in blue; $>10^{-11}$, in green, and $>10^{-9}$ in yellow. . . 127

58 Integrated flux of the total $\mathrm{Eu}, \mathrm{Am}, \mathrm{Pu}, \mathrm{Sr}$, and Cs species out of the domain under decay conditions corresponding to Mineralogic Model 12. . . . . . . . . . . . . . . . . . . . . . 128

59 3D perspective of the above-background $\mathrm{pH}$ distribution after 600 years determined from the results using Mineralogic Model 10. Values above $8,8.5$, and 9 are shown in blue, brown, and red, respectively, and result from the influence of melt glass dissolution in the puddle area. The background $\mathrm{pH}$ is slightly below 8 and is not rendered. Buffering interactions with iron oxide (goethite) minerals in the system tend to reduce the $\mathrm{pH}$ of fluids leaving the glass to background levels. . . . . . . . . . . . . . . . . 130

$603 \mathrm{D}$ perspective of the above-background $\mathrm{pH}$ distribution after 600 years determined from the results using Mineralogic Model 11. Values above $8,8.5$, and 9 are shown in blue, brown, and red, respectively, and result from the influence of melt glass dissolution and the subsequent lack of buffering interactions with iron oxide (goethite) minerals in the system. The background $\mathrm{pH}$ is slightly below 8 and is not rendered. . . . . . . . . . . . 131 
$613 \mathrm{D}$ perspective of the above-background $\mathrm{pH}$ distribution after 600 years determined from the results using Mineralogic Model 12. Values above 8, 8.5, and 9 are shown in blue, brown, and red, respectively, and result from the influence of melt glass dissolution and the subsequent lack of buffering interactions with iron oxide (goethite) minerals in the system. The background $\mathrm{pH}$ is slightly below 8 and is not rendered. . . . . . . . . . . . . . . . 132

62 Integrated flux of the total $\mathrm{Eu}, \mathrm{Am}, \mathrm{Pu}, \mathrm{Sr}$, and $\mathrm{Cs}$ species out of the domain under decay conditions corresponding to Mineralogic Model 10a. The fluxes of $\mathrm{Pu}$ (for $t<250 \mathrm{yr}$ ), and $\mathrm{Sr}$ and $\mathrm{Cs}$ (for all $t$ ) should be considered zero, as they correspond to decayed "0" background values used in the model. . . . . . . . . . . . . . 137

63 Integrated flux of the total $\mathrm{Eu}, \mathrm{Am}, \mathrm{Pu}, \mathrm{Sr}$, and $\mathrm{Cs}$ species out of the domain under decay conditions corresponding to Mineralogic Model 13a. The fluxes of $\mathrm{Pu}$ (for $t<50 \mathrm{yr}$ ), and $\mathrm{Sr}$ and $\mathrm{Cs}$ (for $t>20 \mathrm{yr}$ ) should be considered zero, as they correspond to decayed "0" background values used in the model. . . . . . . . . .

$643 \mathrm{D}$ perspective of decay-corrected total-plutonium plume at 600 years based upon Mineralogic Model 13a. Molar concentrations $>10^{-15}$ are in blue; $>10^{-11}$, in green, $>10^{-9}$ in yellow, and $>10^{-8}$ in orange/red. . . . . . . . . . . . . . . . .

65 Integrated flux of the total $\mathrm{Eu}, \mathrm{Am}, \mathrm{Pu}, \mathrm{Sr}$, and $\mathrm{Cs}$ species out of the domain under decay conditions corresponding to Mineralogic Model 10d. The fluxes of Pu (for $t<250 \mathrm{yr}$ ), and $\mathrm{Sr}$ and $\mathrm{Cs}$ (for all $t$ ) should be considered zero, as they correspond to decayed " 0 " background values used in the model. . . . . . . . . . . . . . 140

$663 \mathrm{D}$ perspective of decay-corrected total-plutonium plume at 600 years based upon Mineralogic Model 10d. Molar concentrations $>10^{-15}$ are in blue; $>10^{-11}$, in green, $>10^{-9}$ in yellow, and $>10^{-8}$ in orange/red. . . . . . . . . . . . . . . . . 141

$673 \mathrm{D}$ perspective of the above-background $\mathrm{pH}$ distribution after 600 years determined from the Mineralogic Model 10d simulation. Values above 8, 9, 10, and 11 are shown in blue, red, yellow, and green, respectively. . . . . . . . . . . . . . . . . . 141

68 Integrated flux of the total $\mathrm{Pu}$ species out of the domain under decay conditions corresponding to Mineralogic Models 10, 10a, $10 \mathrm{~d}, 11,12$, and 13a. . . . . . . . . . . . . . 142

69 Integrated flux of the total Sr species out of the domain under decay conditions corresponding to Mineralogic Models 10, 10a, 10d, 11, 12, and 13a. . . . . . . . . . . . . . . . . 144

70 Integrated flux of the total Cs species out of the domain under decay conditions corresponding to Mineralogic Models 10, 10a, 10d, 11, 12, and 13a. . . . . . . . . . . . . 145 
71 Integrated flux of the total Am species out of the domain under decay conditions corresponding to Mineralogic Models 10, 10a, 10d, 11, 12, and 13a. . . . . . . . . . . 146

72 Comparison among the calculated sorption curve for $\mathrm{Sr}$ on goethite obtained using a 1-site non-electrostatic model (solid line), the sorption curve calculated with data from Dzombak and Morel (1990) using a 2-site diffuse double layer model (dashed line), and experimental data from Kinniburgh, Syers and Jackson (1975) (symbols). Experimental data represent $\mathrm{Sr}$ sorption onto hydrous ferric oxide in $1.0 \mathrm{M} \mathrm{NaNO}_{3}$ at $2 \times 10^{-6} \mathrm{M} \mathrm{Sr}$ and a sorbate-sorbent ratio of $2.6 \times 10^{-5} \mathrm{~mol} / \mathrm{mol}$. . . . . . . . . . . . . . 185

73 Comparison between the calculated sorption curve for $\mathrm{Pu}(\mathrm{V})$ on goethite obtained using a one-site non-electrostatic model (solid line) and experimental data from Sanchez, Murray and Sibley (1985) (symbols) for adsorption of $\mathrm{Pu}(\mathrm{V})$ on goethite in $0.1 \mathrm{M}$ $\mathrm{NaNO}_{3}$ solution at $10^{-11} \mathrm{M} \mathrm{Pu}$ and $28.5 \mathrm{~m}^{2} \alpha$-FeOOH/l-solution. 186

74 Comparison among the calculated sorption curve for Co on goethite obtained in this paper using a 1-site non-electrostatic model (solid line), the sorption curve calculated with data from Dzombak and Morel (1990) using a diffuse double layer 2-site model (dashed line), and experimental data from Duval and Kurbatov (1952) (symbols) as presented by Dzombak and Morel (1990). Experimental data represent adsorption of Co on hydrous ferric oxide in $0.0087 \mathrm{~N} \mathrm{NH}_{4} \mathrm{Cl}$ solution at $10^{-11} \mathrm{M}$ Co with a sorbate-sorbent ratio of $7.0 \times 10^{-4} \mathrm{~mol} / \mathrm{mol}$. . . . . . . . . . . . . . 187

75 Binary Na-Ca exchange isotherm for clinoptilolite calculated using a one-site Vanselow model at $0.01 \mathrm{~N}$ and $25^{\circ} \mathrm{C}$. . . . . . . . 193

76 Spatial distribution of total $\mathrm{Cs}, \mathrm{Sr}, \mathrm{Eu}, \mathrm{Pu}$ and $\mathrm{Am}$ molalities in solution at 1 year in alluvium-glass-alluvium 1D GimRT simulation. Non-reactive tracer concentration shown for reference. . . . 198

77 Spatial distribution of total $\mathrm{Cs}, \mathrm{Sr}, \mathrm{Eu}, \mathrm{Pu}$ and $\mathrm{Am}$ molalities in solution at 134 years in alluvium-glass-alluvium 1D GIMRT simulation. Non-reactive tracer concentration shown for reference. $\mathrm{Pu}$ and Cs concentrations are coincident from 10 to $20 \mathrm{~m}$. . . . . 199

78 Spatial distribution of total $\mathrm{Cs}, \mathrm{Sr}, \mathrm{Eu}, \mathrm{Pu}$ and $\mathrm{Am}$ molalities in solution at 5034 years in alluvium-glass-alluvium 1D GIMRT simulation. Non-reactive tracer concentration shown for reference. 200

$79 \mathrm{Pu}$ aqueous speciation at 1 year in alluvium-glass-alluvium 1D GIMRT simulation. . . . . . . . . . . . . . . . . . 201

$80 \mathrm{Eu}$ aqueous speciation at 1 year in alluvium-glass-alluvium 1D GimrT simulation. . . . . . . . . . . . . . . . . 202

81 Am aqueous speciation at 1 year in alluvium-glass-alluvium 1D GimRT simulation. . . . . . . . . . . . . . . . . . 203 
82 Log molality of surface complexes on goethite at 1 year in alluviumglass-alluvium 1D GimRT simulation. . . . . . . . . . . . . 205

83 Log molality of surface hydroxyl groups on goethite at 1 year in alluvium-glass-alluvium 1D GIMRT simulation. . . . . . . . . 206

84 Comparison of molalities of various forms of $\mathrm{Sr}$ at 1 year in alluvium-glass-alluvium 1D GIMRT simulation. $\mathrm{Sr}^{++}=$aqueous Sr, Sum Sr sorbed $=$ total Sr sorbed onto goethite, $\rangle$ Sr-clinopt $=$ Sr exchanged onto clinoptilolite, $>\mathrm{Sr}$-smec $=\mathrm{Sr}$ exchanged onto smectite. . . . . . . . . . . . . . . . . . 207

85 Comparison of molalities of various forms of $\mathrm{Sr}$ at 134 years in alluvium-glass-alluvium 1D GIMRT simulation. $\mathrm{Sr}^{++}=$aqueous $\mathrm{Sr}$, Sum Sr sorbed = total $\mathrm{Sr}$ sorbed onto goethite, $\rangle \mathrm{Sr}$-clinopt $=$ Sr exchanged onto clinoptilolite, $>\mathrm{Sr}$-smec $=\mathrm{Sr}$ exchanged onto smectite. . . . . . . . . . . . . . . . . 208

86 Comparison of molalities of various forms of $\mathrm{Sr}$ at 5034 years in alluvium-glass-alluvium 1D GIMRT simulation. $\mathrm{Sr}^{++}=$aqueous $\mathrm{Sr}$, Sum Sr sorbed $=$ total Sr sorbed onto goethite, $\rangle$ Sr-clinopt $=$ $\mathrm{Sr}$ exchanged onto clinoptilolite, $\rangle \mathrm{Sr}$-smec $=\mathrm{Sr}$ exchanged onto smectite. . . . . . . . . . . . . . . . . . . . 209

87 Comparison of molalities of various forms of Cs at 1 year in alluvium-glass-alluvium 1D GIMRT simulation. $\mathrm{Cs}^{+}=$aqueous $\mathrm{Cs},\rangle \mathrm{Cs}=\mathrm{Cs}$ exchanged onto illite/muscovite. . . . . . . . 210

88 Comparison of molalities of various forms of Cs at 134 years in alluvium-glass-alluvium 1D GIMRT simulation. $\mathrm{Cs}^{+}=$aqueous $\mathrm{Cs},\rangle \mathrm{Cs}=\mathrm{Cs}$ exchanged onto illite/muscovite. . . . . . . . 211

89 Comparison of molalities of various forms of Cs at 5034 years in alluvium-glass-alluvium 1D GIMRT simulation. $\mathrm{Cs}^{+}=$aqueous $\mathrm{Cs},\rangle \mathrm{Cs}=\mathrm{Cs}$ exchanged onto illite/muscovite. . . . . . . . 212

90 Spatial distribution of total $\mathrm{Cs}, \mathrm{Sr}, \mathrm{Eu}, \mathrm{Pu}$ and $\mathrm{Am}$ molalities in solution at 1 year in alluvium-exchange volume-alluvium 1D GIMRT simulation. Non-reactive tracer concentration shown for reference. . . . . . . . . . . . . . . . . . . 214

91 Spatial distribution of total $\mathrm{Cs}, \mathrm{Sr}, \mathrm{Eu}, \mathrm{Pu}$ and $\mathrm{Am}$ molalities in solution at 134 years in alluvium-exchange volume-alluvium 1D GIMRT simulation. Non-reactive tracer concentration shown for reference. . . . . . . . . . . . . . . . . . 215

92 Spatial distribution of total $\mathrm{Cs}, \mathrm{Sr}, \mathrm{Eu}, \mathrm{Pu}$ and $\mathrm{Am}$ molalities in solution at 5034 years in alluvium-exchange volume-alluvium 1D GIMRT simulation. Non-reactive tracer concentration shown for reference. . . . . . . . . . . . . . . . 2 216

93 Molalities of $\mathrm{Cs}, \mathrm{Sr}$ and $\mathrm{Pu}$ associated with solid phases in the exchange volume at 1 year. $>\mathrm{Ca}=\mathrm{Ca}$ exchanged onto clinoptilolite, $\mathrm{Sr}$ sorbed $=$ sum of molalities of $\mathrm{Sr}$ surface complexes on goethite, $\rangle \mathrm{FeOH}_{2} \mathrm{PuO}_{2} \mathrm{OH}^{+}=\mathrm{Pu}$ surface complex on goethite. . 217 
94 Molalities of $\mathrm{Cs}, \mathrm{Sr}$ and $\mathrm{Pu}$ associated with solid phases in the exchange volume at 134 years. $>\mathrm{Ca}=\mathrm{Ca}$ exchanged onto clinoptilolite, $\mathrm{Sr}$ sorbed $=$ sum of molalities of $\mathrm{Sr}$ surface complexes on goethite, $\rangle \mathrm{FeOH}_{2} \mathrm{PuO}_{2} \mathrm{OH}^{+}=\mathrm{Pu}$ surface complex on goethite. . 218

95 Molalities of $\mathrm{Cs}, \mathrm{Sr}$ and $\mathrm{Pu}$ associated with solid phases in the exchange volume at 5034 years. $>\mathrm{Ca}=\mathrm{Ca}$ exchanged onto clinoptilolite, $\mathrm{Sr}$ sorbed $=$ sum of molalities of $\mathrm{Sr}$ surface complexes on goethite, $>\mathrm{FeOH}_{2} \mathrm{PuO}_{2} \mathrm{OH}^{+}=\mathrm{Pu}$ surface complex on goethite. . 219

96 Spatial distribution of total $\mathrm{Cs}, \mathrm{Sr}, \mathrm{Eu}, \mathrm{Pu}$ and $\mathrm{Am}$ molalities in solution at 1 year in alluvium-glass-exchange volume-alluvium 1D GIMrT simulation. Non-reactive tracer concentration shown for reference. . . . . . . . . . . . . . .

97 Spatial distribution of total $\mathrm{Cs}, \mathrm{Sr}, \mathrm{Eu}, \mathrm{Pu}$ and $\mathrm{Am}$ molalities in solution at 134 years in alluvium-glass-exchange volume-alluvium 1D GimRT simulation. Non-reactive tracer concentration shown for reference. . . . . . . . . . . . . . .

98 Spatial distribution of total $\mathrm{Cs}, \mathrm{Sr}, \mathrm{Eu}, \mathrm{Pu}$ and $\mathrm{Am}$ molalities in solution at 5034 years in alluvium-glass-exchange volumealluvium 1D GIMRT simulation. Non-reactive tracer concentration shown for reference. . . . . . . . . . . . . . . . . 222

99 Spatial distribution of total $\mathrm{Cs}, \mathrm{Sr}, \mathrm{Eu}, \mathrm{Pu}$ and $\mathrm{Am}$ molalities in solution at 1 year in alluvium-exchange volume-glass-alluvium 1D GIMRT simulation. Non-reactive tracer concentration shown for reference. . . . . . . . . . . . . . . . . . 223

100 Spatial distribution of total $\mathrm{Cs}, \mathrm{Sr}, \mathrm{Eu}, \mathrm{Pu}$ and $\mathrm{Am}$ molalities in solution at 134 years in alluvium-exchange volume-glass-alluvium 1D GimRT simulation. Non-reactive tracer concentration shown for reference. . . . . . . . . . . . . . .

101 Spatial distribution of total $\mathrm{Cs}, \mathrm{Sr}, \mathrm{Eu}, \mathrm{Pu}$ and Am molalities in solution at 5034 years in alluvium-exchange volume-glassalluvium 1D GimRT simulation. Non-reactive tracer concentration shown for reference. . . . . . . . . . . . . . . 225

102 Spatial distribution of total $\mathrm{Cs}, \mathrm{Sr}, \mathrm{Eu}, \mathrm{Pu}$ and $\mathrm{Am}$ molalities in solution at $1 \times 10^{-5}$ years along streamline 100 in Mineralogic Model 10 simulation. Geologic units intersected along flow path shown at bottom of figure. . . . . . . . . . . . . 235

103 Spatial distribution of total $\mathrm{Cs}, \mathrm{Sr}, \mathrm{Eu}, \mathrm{Pu}$ and $\mathrm{Am}$ molalities in solution at 100 years along streamline 100 in Mineralogic Model 10 simulation. . . . . . . . . . . . . .

104 Spatial distribution of total $\mathrm{Cs}, \mathrm{Sr}, \mathrm{Eu}, \mathrm{Pu}$ and Am molalities in solution at 600 years along streamline 100 in Mineralogic Model 10 simulation. . . . . . . . . . . . . . . . . . 237 
105 Spatial distribution of total $\mathrm{Cs}$ and $\mathrm{Pu}$ molalities in solution at $1 \times 10^{-5}$ years along streamline 145 in the Mineralogic Model 10 simulation. Geologic units intersected along flow path shown at bottom of figure. . . . . . . . . . . . . . .

106 Spatial distribution of total $\mathrm{Sr}, \mathrm{Eu}$ and Am molalities in solution at $1 \times 10^{-5}$ years along streamline 145 in Mineralogic Model 10 simulation. . . . . . . . . . . . . . . . . 240

107 Spatial distribution of total $\mathrm{Cs}$ and $\mathrm{Pu}$ molalities in solution at 100 years along streamline 145 in Mineralogic Model 10 simulation.241

108 Spatial distribution of total $\mathrm{Sr}, \mathrm{Eu}$ and Am molalities in solution at 100 years along streamline 145 in Mineralogic Model 10 simulation. . . . . . . . . . . . . . . . . . . 242

109 Spatial distribution of total Cs and $\mathrm{Pu}$ molalities in solution at 600 years along streamline 145 in Mineralogic Model 10 simulation.243

110 Spatial distribution of total $\mathrm{Sr}, \mathrm{Eu}$ and Am molalities in solution at 600 years along streamline 145 in Mineralogic Model 10 simulation. . . . . . . . . . . . . . . . . . . 244

111 Values of $\mathrm{pH}$ (expressed as $-\mathrm{pH}$ ) at $1 \times 10^{-5}$ (solid with filled circle markers), 100 (dashed with filled square markers) and 600 years (solid with diamond markers) for Mineralogic Model 10, streamline 145 . . . . . . . . . . . . . . . . . . 245

112 Major element chemistry at 600 years for Mineralogic Model 10, streamline 145 . . . . . . . . . . . . . . . . . 247

113 Major element chemistry at 600 years for Mineralogic Model 10, streamline 145 from 250 to $262 \mathrm{~m}$. . . . . . . . . . . . . . 248

114 Volume percent of authigenic minerals precipitating in melt glass at $252.91 \mathrm{~m}$ along streamline 145 in Mineralogic Model 10. The calcite and beidellite-Ca curves are nearly coincident. . . . . . . . 249

115 Spatial distribution of total $\mathrm{Cs}, \mathrm{Sr}, \mathrm{Eu}, \mathrm{Pu}$ and $\mathrm{Am}$ molalities in solution at 100 years in Mineralogic Model 11 along streamline 100 . . . . . . . . . . . . . . . . . . 2 252

116 Spatial distribution of total $\mathrm{Cs}, \mathrm{Sr}, \mathrm{Eu}, \mathrm{Pu}$ and $\mathrm{Am}$ molalities in solution at 600 years in Mineralogic Model 11 along streamline $100 . \ldots \ldots \ldots \ldots \ldots \ldots$

117 Spatial distribution of total $\mathrm{Cs}, \mathrm{Sr}, \mathrm{Eu}, \mathrm{Pu}$ and $\mathrm{Am}$ molalities in solution at 100 years in Mineralogic Model 11 along streamline

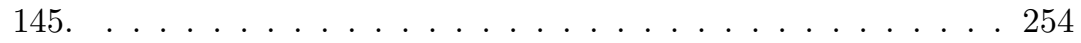

118 Concentrations of $\mathrm{Cs}, \mathrm{Sr}$ and $\mathrm{Pu}$ at 100 years along streamline 145 for Model 10 (solid curve) and Model 11 (dashed curve). . . 255

119 Spatial distribution of total $\mathrm{Cs}, \mathrm{Sr}, \mathrm{Eu}, \mathrm{Pu}$ and Am molalities in solution at 600 years in Mineralogic Model 11 along streamline

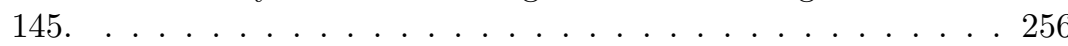


120 Spatial distribution of total $\mathrm{Cs}, \mathrm{Sr}, \mathrm{Eu}, \mathrm{Pu}$ and $\mathrm{Am}$ molalities in solution at 100 years in Mineralogic Model 12 along streamline

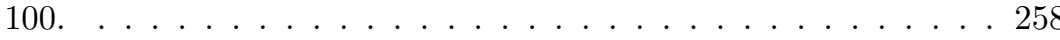

121 Spatial distribution of total $\mathrm{Cs}, \mathrm{Sr}, \mathrm{Eu}, \mathrm{Pu}$ and $\mathrm{Am}$ molalities in solution at 600 years in Mineralogic Model 12 along streamline 100. . . . . . . . . . . . . . . . . . . . 259

122 Spatial distribution of total $\mathrm{Cs}$ and $\mathrm{Pu}$ molalities in solution at 100 years in Mineralogic Model 12 along streamline 145. . . . . . 260

123 Spatial distribution of total $\mathrm{Sr}, \mathrm{Eu}$ and Am molalities in solution at 100 years in Mineralogic Model 12 along streamline 145. . . . 261

124 Spatial distribution of total $\mathrm{Cs}$ and $\mathrm{Pu}$ molalities in solution at 600 years in Mineralogic Model 12 along streamline 145. . . . . . 262

125 Spatial distribution of total $\mathrm{Sr}, \mathrm{Eu}$ and Am molalities in solution at 600 years in Mineralogic Model 12 along streamline 145. . . . 263

126 Comparison of spatial distribution of total $\mathrm{Pu}$ molality in solution at 100 years along streamline 100 for models 10 and 10a with goethite surface areas of 600 and $50 \mathrm{~m}^{2} / \mathrm{g}$, respectively. . . . . 268

127 Comparison of spatial distribution of total Sr molality in solution at 100 years along streamline 100 for models 10 and 10a with goethite surface areas of 600 and $50 \mathrm{~m}^{2} / \mathrm{g}$, respectively. . . . . . 269

128 Comparison of spatial distribution of total $\mathrm{Pu}$ molality in solution at 600 years along streamline 100 for models 10 and 10a with goethite surface areas of 600 and $50 \mathrm{~m}^{2} / \mathrm{g}$, respectively. . . . . . 270

129 Comparison of spatial distribution of total Sr molality in solution at 600 years along streamline 100 for models 10 and 10a with goethite surface areas of 600 and $50 \mathrm{~m}^{2} / \mathrm{g}$, respectively. . . . . . 271

130 Comparison of spatial distribution of total $\mathrm{Pu}$ molality in solution at 100 years along streamline 145 for models 10 and 10a with goethite surface areas of 600 and $50 \mathrm{~m}^{2} / \mathrm{g}$, respectively. . . . . . 272

131 Comparison of spatial distribution of total Sr molality in solution at 100 years along streamline 145 for models 10 and 10a with goethite surface areas of 600 and $50 \mathrm{~m}^{2} / \mathrm{g}$, respectively. . . . . . 273

132 Comparison of spatial distribution of total $\mathrm{Pu}$ molality in solution at 600 years along streamline 145 for models 10 and 10a with goethite surface areas of 600 and $50 \mathrm{~m}^{2} / \mathrm{g}$, respectively. . . . . . 274

133 Comparison of spatial distribution of total Sr molality in solution at 600 years along streamline 145 for models 10 and 10a with goethite surface areas of 600 and $50 \mathrm{~m}^{2} / \mathrm{g}$, respectively. . . . . . 275

134 Comparison of spatial distribution of total $\mathrm{Pu}$ molality in solution at 100 years along streamline 145 for models $10 \mathrm{a}, 10 \mathrm{c}$ and $10 \mathrm{~d}$ with glass surface areas of $5 \times 10^{-5}, 5 \times 10^{-4}$ and $5 \times 10^{-3} \mathrm{~m}^{2} / \mathrm{g}$, respectively, and goethite surface area of $50 \mathrm{~m}^{2} / \mathrm{g}$. . . . . . . 279 
135 Comparison of spatial distribution of total Sr molality in solution at 100 years along streamline 145 for models $10 \mathrm{a}, 10 \mathrm{c}$ and $10 \mathrm{~d}$ with glass surface areas of $5 \times 10^{-5}, 5 \times 10^{-4}$ and $5 \times 10^{-3} \mathrm{~m}^{2} / \mathrm{g}$, respectively, and goethite surface area of $50 \mathrm{~m}^{2} / \mathrm{g} . \ldots \ldots$.

136 Comparison of spatial distribution of total Am molality in solution at 100 years along streamline 145 for models $10 \mathrm{a}, 10 \mathrm{c}$ and $10 \mathrm{~d}$ with glass surface areas of $5 \times 10^{-5}, 5 \times 10^{-4}$ and $5 \times 10^{-3}$ $\mathrm{m}^{2} / \mathrm{g}$, respectively, and goethite surface area of $50 \mathrm{~m}^{2} / \mathrm{g} . \ldots 281$

137 Comparison of spatial distribution of total Eu molality in solution at 100 years along streamline 145 for models $10 \mathrm{a}, 10 \mathrm{c}$ and $10 \mathrm{~d}$ with glass surface areas of $5 \times 10^{-5}, 5 \times 10^{-4}$ and $5 \times 10^{-3} \mathrm{~m}^{2} / \mathrm{g}$, respectively, and goethite surface area of $50 \mathrm{~m}^{2} / \mathrm{g}$. . . . . . . . 282

138 Comparison of spatial distribution of total $\mathrm{Pu}$ molality in solution at 600 years along streamline 145 for models $10 \mathrm{a}, 10 \mathrm{c}$ and $10 \mathrm{~d}$ with glass surface areas of $5 \times 10^{-5}, 5 \times 10^{-4}$ and $5 \times 10^{-3} \mathrm{~m}^{2} / \mathrm{g}$, respectively, and goethite surface area of $50 \mathrm{~m}^{2} / \mathrm{g} . \ldots \ldots$.

139 Downstream movement of $\mathrm{Pu}$ concentration front as a function of time (labelled in years) along streamline 145 for Model 10d with glass surface area of $5 \times 10^{-3} \mathrm{~m}^{2} / \mathrm{g}$ and goethite surface area of

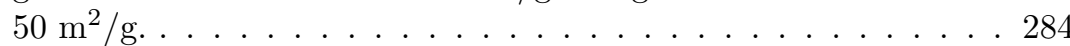

140 Comparison of spatial distribution of total Sr molality in solution at 600 years along streamline 145 for models $10 \mathrm{a}, 10 \mathrm{c}$ and $10 \mathrm{~d}$ with glass surface areas of $5 \times 10^{-5}, 5 \times 10^{-4}$ and $5 \times 10^{-3} \mathrm{~m}^{2} / \mathrm{g}$, respectively, and goethite surface area of $50 \mathrm{~m}^{2} / \mathrm{g}$. . . . . . . 285

141 Comparison of spatial distribution of total Am molality in solution at 600 years along streamline 145 for models 10a, 10c and $10 \mathrm{~d}$ with glass surface areas of $5 \times 10^{-5}, 5 \times 10^{-4}$ and $5 \times 10^{-3}$ $\mathrm{m}^{2} / \mathrm{g}$, respectively, and goethite surface area of $50 \mathrm{~m}^{2} / \mathrm{g}$. . . . . 286

142 Comparison of spatial distribution of total Eu molality in solution at 600 years along streamline 145 for models $10 \mathrm{a}, 10 \mathrm{c}$ and $10 \mathrm{~d}$ with glass surface areas of $5 \times 10^{-5}, 5 \times 10^{-4}$ and $5 \times 10^{-3} \mathrm{~m}^{2} / \mathrm{g}$, respectively, and goethite surface area of $50 \mathrm{~m}^{2} / \mathrm{g}$. . . . . . . 287

143 Comparison of spatial distribution of solution $\mathrm{pH}$ at 1e-5, 100 and 600 years along streamline 145 for Model 10c with glass surface area of $5 \times 10^{-4} \mathrm{~m}^{2} / \mathrm{g}$ and goethite surface area of $50 \mathrm{~m}^{2} / \mathrm{g}$. . . 289

144 Comparison of spatial distribution of solution $\mathrm{pH}$ at 1e-5, 100 and 600 years along streamline 145 for Model 10d with glass surface area of $5 \times 10^{-3} \mathrm{~m}^{2} / \mathrm{g}$ and goethite surface area of $50 \mathrm{~m}^{2} / \mathrm{g} . ~ . ~ . ~ 290$

145 Silica speciation in groundwater at 600 years along streamline 145 for Model 10d with glass surface area of $5 \times 10^{-3} \mathrm{~m}^{2} / \mathrm{g}$ and goethite surface area of $50 \mathrm{~m}^{2} / \mathrm{g}$. Note the dominance of $\mathrm{HSiO}_{3}$ over $\mathrm{SiO} 2(\mathrm{aq})$ when the $\mathrm{pH}$ is greater than 10 (Fig. 144). . . . . 291 
146 Plutonium speciation in groundwater at 600 years along streamline 145 for Model 10d with glass surface area of $5 \times 10^{-3} \mathrm{~m}^{2} / \mathrm{g}$ and goethite surface area of $50 \mathrm{~m}^{2} / \mathrm{g}$. Note the dominance of the neutral complex $\mathrm{PuO}_{2}(\mathrm{OH})_{2}(\mathrm{aq})$ over the anion $\mathrm{PuO}_{2}\left(\mathrm{CO}_{3}\right)^{-2}$ when the $\mathrm{pH}$ is highly alkaline (Fig. 144) . . . . . . . . . . .

147 Saturation index, defined as $\log Q / K$ (see text), with respect to radionuclide-bearing solids at 100 years along streamline 145 for Model 10c with glass surface area of $5 \times 10^{-4} \mathrm{~m}^{2} / \mathrm{g}$ and goethite surface area of $50 \mathrm{~m}^{2} / \mathrm{g} . \quad \ldots \ldots . \ldots . \ldots . \ldots 293$

148 Saturation states with respect to radionuclide-bearing solids at 600 years along streamline 145 for Model 10c with glass surface area of $5 \times 10^{-4} \mathrm{~m}^{2} / \mathrm{g}$ and goethite surface area of $50 \mathrm{~m}^{2} / \mathrm{g}$. . . . 294

149 Saturation states with respect to radionuclide-bearing solids at 100 years along streamline 145 for Model 10d with glass surface area of $5 \times 10^{-3} \mathrm{~m}^{2} / \mathrm{g}$ and goethite surface area of $50 \mathrm{~m}^{2} / \mathrm{g}$. . . .

150 Saturation states with respect to radionuclide-bearing solids at 600 years along streamline 145 for Model 10d with glass surface area of $5 \times 10^{-3} \mathrm{~m}^{2} / \mathrm{g}$ and goethite surface area of $50 \mathrm{~m}^{2} / \mathrm{g}$. . . 296

151 Volume percent of the solid $\mathrm{PuO}_{2}(\mathrm{OH})_{2} \cdot \mathrm{H}_{2} \mathrm{O}$ at 100 and 600 years along streamline 145 for Model 10d with glass surface area of $5 \times 10^{-3} \mathrm{~m}^{2} / \mathrm{g}$ and goethite surface area of $50 \mathrm{~m}^{2} / \mathrm{g}$. . . . 298

152 Retardation coefficients of $\mathrm{Cs}, \mathrm{Sr}$ and $\mathrm{Pu}$ in alluvium along streamline 100 in Mineralogical Model $10\left(600 \mathrm{~m}^{2} / \mathrm{g}\right.$ goethite surface area) at both 100 and 600 years. " $\mathrm{m}_{\text {sol }}$ " and " $\mathrm{m}_{a q}$ " represent $U_{j}$ and $U_{j}^{i m}$ in (21), respectively, the sum of the molalities of sorbed and exchanged radionuclides, and the sum of the molalities of the radionuclide-bearing aqueous species in solution. . . . . . . . .

153 Retardation coefficients of $\mathrm{Cs}, \mathrm{Sr}$ and $\mathrm{Pu}$ in alluvium along streamline 100 in Mineralogical Model 10a $\left(50 \mathrm{~m}^{2} / \mathrm{g}\right.$ goethite surface area) at both 100 and 600 years. " $\mathrm{m}_{\text {sol }}$ " and " $\mathrm{m}_{a q}$ " represent $U_{j}$ and $U_{j}^{i m}$ in (21), respectively, the sum of the molalities of sorbed and exchanged radionuclides, and the sum of the molalities of the radionuclide-bearing aqueous species in solution. . . . . . . . . 305

154 Retardation profiles of $\mathrm{Cs}, \mathrm{Sr}$ and $\mathrm{Pu}$ for Mineralogical Model 10 (goethite surface area $600 \mathrm{~m}^{2} / \mathrm{g}$ ) along streamline 145 at 100 and 600 years. " $\mathrm{m}_{\text {sol }}$ " and " $\mathrm{m}_{a q}$ " represent $U_{j}$ and $U_{j}^{i m}$ in (21), respectively, the sum of the molalities of sorbed and exchanged radionuclides, and the sum of the molalities of the radionuclidebearing aqueous species in solution. . . . . . . . . . 306 
155 Retardation profiles of $\mathrm{Cs}, \mathrm{Sr}$ and $\mathrm{Pu}$ for Mineralogical Model 10 (goethite surface area $600 \mathrm{~m}^{2} / \mathrm{g}$ ) along streamline 145 near the glass zones at 100 and 600 years. " $\mathrm{m}_{\text {sol }}$ " and " $\mathrm{m}_{a q}$ " represent $U_{j}$ and $U_{j}^{i m}$ in (21), respectively, the sum of the molalities of sorbed and exchanged radionuclides, and the sum of the molalities of the radionuclide-bearing aqueous species in solution. . . . . . . . . 307

156 Retardation profiles of $\mathrm{Cs}, \mathrm{Sr}$ and $\mathrm{Pu}$ for Mineralogical Model 10a (goethite surface area $50 \mathrm{~m}^{2} / \mathrm{g}$ ) along streamline 145 at 100 and 600 years. " $\mathrm{m}_{\text {sol }}$ " and " $\mathrm{m}_{a q}$ " represent $U_{j}$ and $U_{j}^{i m}$ in (21), respectively, the sum of the molalities of sorbed and exchanged radionuclides, and the sum of the molalities of the radionuclidebearing aqueous species in solution. . . . . . . . . . . 308

157 Retardation profiles of $\mathrm{Cs}, \mathrm{Sr}$ and $\mathrm{Pu}$ for Mineralogical Model 10a (goethite surface area $50 \mathrm{~m}^{2} / \mathrm{g}$ ) along streamline 145 near the glass zones at 100 and 600 years. " $\mathrm{m}_{\text {sol }}$ " and " $\mathrm{m}_{a q}$ " represent $U_{j}$ and $U_{j}^{i m}$ in (21), respectively, the sum of the molalities of sorbed and exchanged radionuclides, and the sum of the molalities of the radionuclide-bearing aqueous species in solution. . . . . . . . . 309

158 Retardation profiles of $\mathrm{Cs}, \mathrm{Sr}$ and $\mathrm{Pu}$ for Mineralogical Model 10d (glass surface area $5 \times 10^{-3} \mathrm{~m}^{2} / \mathrm{g}$ ) along streamline 145 at 100 years. " $\mathrm{m}_{\text {sol }}$ " and " $\mathrm{m}_{a q}$ " represent $U_{j}$ and $U_{j}^{i m}$ in $(21)$, respectively, the sum of the molalities of sorbed and exchanged radionuclides, and the sum of the molalities of the radionuclidebearing aqueous species in solution. . . . . . . . . . . . 310

159 Retardation profiles of $\mathrm{Cs}, \mathrm{Sr}$ and $\mathrm{Pu}$ for Mineralogical Model 10d (glass surface area $5 \times 10^{-3} \mathrm{~m}^{2} / \mathrm{g}$ ) along streamline 145 at 600 years. " $\mathrm{m}_{\text {sol }}$ " and " $\mathrm{m}_{a q}$ " represent $U_{j}$ and $U_{j}^{i m}$ in (21), respectively, the sum of the molalities of sorbed and exchanged radionuclides, and the sum of the molalities of the radionuclidebearing aqueous species in solution. . . . . . . . . . . . . 311

160 Retardation coefficient of $\mathrm{Pu}$ in alluvium along streamline 100 in Mineralogical Model 13a (heterogeneous distribution of reactive minerals) at 100 years. " $\mathrm{m}_{\text {sol }}$ " and " $\mathrm{m}_{a q}$ " represent $U_{j}$ and $U_{j}^{i m}$ in (21), respectively, the sum of the molalities of sorbed and exchanged radionuclides, and the sum of the molalities of the radionuclide-bearing aqueous species in solution. . . . . . . . 312

161 Simple conceptual model showing two parallel streamtubes (or streamlines) passing through a zone of melt glass and a cavity $/$ chimney rubble region. . . . . . . . . . . . . 316 
162 Radionuclide concentration profiles along two streamlines that pass through the melt glass and cavity/chimney rubble zones (located along the yellow and blue strips; Fig. 161) in the absence of decay or hydrodynamic dispersion. Glass-zone profiles (red, white, and green) shown for the general and specialized cases that are discussed in the text. Cavity/chimney profiles (yellow) are the same in each case. . . . . . . . . . . . . . . . 317 


\section{List of Tables}

1 Percentage distribution of selected radionuclides among the glass, rubble, gas, and groundwater as occurs during the condensation period following a typical underground nuclear test. Data are taken from IAEA (1998). . . . . . . . . . . . . . . .

2 Mineralogy of alluvium sampled from well RNM-1 and UE5n in the vicinity of the CAMBRIC test (after Daniels and Thompson, 1984, and Ramspott and McArthur, 1977, respectively). The range in the data account for variations in samples taken from several different depths. . . . . . . . . . . . .

3 Older (c. 1974) water composition data taken from drill-back hole RNM-1 (Hoffman et al. , 1977). Zones refer to sampling location in drillback hole (Fig. 37): I = below cavity, II = lower cavity, $\mathrm{III}=$ upper cavity, IV = chimney, and $\mathrm{V}=$ adjacent to chimney. Recent (c. 1993) water composition data taken from near the water table in RNM-1 and from the screened interval in RNM-2S (from Smith et al., 1997). . . . . . . . . . . . . . . . . .

5 Inventory of selected radionuclides at the CAMBRIC test, decay corrected to zero time on May 14, 1965 (after Hoffman et al., 1977, Hoffman, 1979, Schroeder et al., 1993, and Smith, 1995b).

6 Radionuclide concentrations measured in CAMBRIC waters from well RNM-1. Zones II through V (c. 1974) from Hoffman et al. (1977) (II = lower cavity, III = upper cavity, IV = chimney, and $\mathrm{V}=$ adjacent to chimney); Zones $\mathrm{A}, \mathrm{B}$ and $\mathrm{C}$ from Buddemeier and Isherwood (1985). Concentrations given in molality and corrected to 5/14/65. Refer also to Fig. 37. . . . . . . . . . 24

7 Some of the characteristics of radionuclides that were considered in this study. ${ }^{99} \mathrm{Tc}$ was not considered in the transport model because of its conservative (anionic) chemical behavior. ${ }^{3} \mathrm{H}$ was only considered in the analysis of the pumping experiment in RNM-2S. . . . . . . . . . . . . . .

8 Composition of rhyolitic melt glass at the CAMBRIC test (Schwartz, et al., 1984). Radioactive elements are in bold. . . . . . . . . . . 34

9 Radionuclide abundances in melt glass based upon 905 metric tons of glass. Weight $\%$ oxide refers to oxides derived from radioactive materials, natural materials, and what was used in the model, respectively. . . . . . . . . . . . . . . . 35

10 Glass dissolution rate model parameters. . . . . . . . . . . . . . 50

11 Summary of surface processes considered for radionuclides included in simulations. . . . . . . . . . . . . . . . . 54 
12 Distribution of radionuclide inventory in the modeled $18-\mathrm{m}$ radius exchange volume (see text). Calculations were made assuming a porosity of $40 \%$, yielding a total pore volume of $9.772 \times 10^{3}$ $\mathrm{m}^{3}$. Partitioning in columns 4 and 5 based upon presence of reactive minerals shown in Table 15 . When no reactive minerals are present, aqueous concentrations given in column 3 exist. . . .

13 Mole percent of total elemental concentrations of $\mathrm{Cs}$, Sr and $\mathrm{Eu}$ in GIMRT output that represent the radiogenic isotopes ${ }^{137} \mathrm{Cs}$, ${ }^{90} \mathrm{Sr}$ and ${ }^{155} \mathrm{Eu}$ (see text). . . . . . . . . . . . . . . 60

14 Ambient groundwater chemistry used in simulations (see text). . 64

15 Distribution of porous medium volume fractions used in the simulations for the alluvium/exchange volume and melt glass (see discussion in section 8.3.2). Reactive or inert medium configurations may be used to describe the alluvium/exchange volume. See Chapter 11. . . . . . . . . . . . . . . . 67

16 Kinetic parameters used in the simulations (see text). . . . . . . 69

17 Aqueous species used in simulations (see text). . . . . . . . . . . 77

18 Primary and authigenic solids and minerals considered in the simulations (see text). . . . . . . . . . . . . . . . 79

19 Hydraulic flow properties used in previous layered models of groundwater flow in the near field about the CAmBRIC test. . . . . . . . 102

20 Hydraulic and statistical flow properties used in the current model of groundwater flow, as a function of the geologic unit (see text). In all cases, isotropic (scalar) conductivities were used. . . . . . 103

21 Comparison of features in Mineralogic Models 10, 11, and 12. . . 129

22 Summary of radionuclide (RN) inventory in fluids occupying the modeled 18-m radius exchange volume. Calculations were made assuming a porosity of $40 \%$, yielding a total pore volume of $9.772 \times 10^{3} \mathrm{~m}^{3}$. Partitioning in Model 10 based upon presence of reactive minerals shown in Table 15 , where the goethite surface area is $600 \mathrm{~m}^{2} / \mathrm{g}$. Paritioning in Models 10a-d based upon a reduced goethite surface area of $50 \mathrm{~m}^{2} / \mathrm{g}$, as described in Appendix 8. When no reactive minerals are present, aqueous concentrations given under Model 11. . . . . . . . . . . . . . . . . . . . 134

23 Comparison of features in Mineralogic Models 10, 11, and 12 with those used in the sensitivity studies 10a, 10b, 10c, 10d, 13a. . . . 135

24 Comparison of predicted initial aqueous radionuclide (RN) concentrations in the exchange volume (Table 22) with measurements from RNM-1 cavity/chimney waters obtained c. 1974 (Table 6). . . . . . . . . . . . . . . . . . 
25 Comparison of predicted retardation coefficients $\left(\mathcal{R}_{j}\right)$ in uniform reactive alluvium models (as defined from data in Appendix 9 or Table 22) with equivalent values converted from distribution coefficient measurements of Wolfsberg (1978), using a porosity of $40 \%$ and a bulk density of $2.0 \mathrm{~g} / \mathrm{cm}^{3}$. . . . . . . . 151

26 Surface complexation reactions and intrinsic equilibrium constants $(K)$ used in reactive transport calculations. . . . . . . . . . . 184

27 Cation exchange energies for clinoptilolite, smectite and illite/ muscovite at $25^{\circ} \mathrm{C}$ used in the simulations (Viani and Bruton, 1992, 1996). Reactions are written in terms of one equivalent of exchanger. . . . . . . . . . . . . . . . . . 191

28 Composition of exchange sites on clinoptilolite and smectite and site I of illite/muscovite in equilibrium with CAMBRIC groundwater calculated using the one-site Vanselow model (EQ3) and exchange energies given in Viani and Bruton $(1992,1996) . . . .192$

29 Revised and updated thermodynamic data used in this study. . . 195

30 Geologic units intersected by streamlines 100 and 145, and the approximate distance along the streamline at which each unit is intersected, in meters. . . . . . . . . . . . . . . 234

31 Comparison of Mineralogic Models 10 through 10d. . . . . . . . 266 


\section{Executive Summary}

The objective of this project is to develop a modeling framework to quantitatively forecast the hydrologic source term within the near-field environment of underground nuclear tests at the Nevada Test Site. Specifically involved are the evaluation of the (1) chemical state and abundance of radionuclides that are introduced into groundwater as aqueous species or colloids and (2) the rate and extent of radionuclide migration and dilution in groundwater and radionuclide reaction with the rock surrounding the explosion point of a test.

The framework was established utilizing unclassified data from the CAMBRIC test in Frenchman Flat. We expect our approach will be used as a template to guide further hydrologic source term evaluations at other Corrective Action Units at the Nevada Test Site, as well as to plan future data acquisition activities. Results from this work will serve as the source term input for larger-scale models of contaminant migration at the Corrective Action Unit level.

The CAMBRIC test, conducted in emplacement hole U5e on May 14, 1965, was chosen because a "relatively" large amount of unclassified hydrologic and radionuclide inventory data exist, both inside and outside the blast cavity. The test has been the subject of numerous other investigations that this work could be leveraged against.

CAMBric, at a yield of $0.75 \mathrm{kt}$, was sited in alluvium about $74 \mathrm{~m}$ below the water table. A conceptual model consists of an approximately $22 \mathrm{~m}$ diameter spherical cavity centered on the working point, a collapse zone extending above the water table but not to the ground surface, and a melt glass puddle in the bottom of the cavity. An "exchange volume" consisting of the collapsed cavity, chimney, and sidewall systems that contain significant amounts of radionuclides is defined in the models. Alluvium mineralogy, groundwater chemistry, and radionuclide data were derived from previous characterization studies.

The main body of the report covers principal issues in a broad descriptive sense, while detailed technical issues are included in nine specific appendices. The technical approach used in this project is based upon several distinct characterization and modeling efforts that are ultimately linked together. Principal among these include:

- Adoption of a select group of radionuclides for formal analyses (see Chapter 5),

- Determination of the total inventory of these radionuclides and their relative partitioning among the glass and rubble zones (see Chapter 5),

- Development of a model describing radionuclide release from the melt glass (Chapter 6),

- Development of a model describing radionuclide release from and chemical interactions in the chimney and cavity regions (see Chapter 7), 
- Development of models for the aqueous complexation, surface complexation, ion exchange, precipitation and dissolution reactions that control chemical interactions among the glass, exchange volume, and alluvium (see Chapter 8),

- Development of a groundwater flow and radionuclide transport model to forecast the overall rate of radionuclide migration out of this zone as a function of groundwater flow, glass dissolution, and effective chemical retardation processes (see Chapters 9-11), and

- Assessment of model sensitivity to melt glass and reactive mineral surface area, as well as the spatial abundance and distribution of the reactive minerals in alluvium (see Chapter 12).

The radionuclides ${ }^{3} \mathrm{H},{ }^{90} \mathrm{Sr},{ }^{137} \mathrm{Cs},{ }^{155} \mathrm{Eu},{ }^{239} \mathrm{Pu}$, and ${ }^{241} \mathrm{Am}$ were chosen for this study because their inventories are unclassified and available, they have varied initial distribution in the glass, chimney, and cavity areas, and they represent a cross-section of geochemical behavior such as unrestricted flow with groundwater, sorption, ion exchange, precipitation, and dissolution.

Radionuclide retardation was evaluated for surface complexation and ion exchange. Minerals such as goethite (for $\mathrm{Pu}$ and $\mathrm{Sr}$ ), clinoptilolite (for $\mathrm{Sr}$ ), muscovite/illite (for $\mathrm{Cs}$ ), and smectite (for $\mathrm{Sr}$ ), all detected at CAMBRIC, act as sorbers. Concentrations of the selected radionuclides were never large enough to saturate available sites on reactive minerals. In addition, concentrations of selected radionuclides were not large enough to reach saturation and precipitate, except in sensitivity cases in which the glass surface area was increased by a factor of ten or more over the nominally-chosen value.

We simulated groundwater flow and tritium migration using a fully 3D model with an extremely fine mesh resolution of $2 \mathrm{~m}$. This allowed us to represent heterogeneity in material properties in a geostatistical sense. The current model representation was first used to reproduce the tritium recovery that was observed in the 16-year radionuclide migration experiment conducted at CAMBRIC.

Radionuclide migration away from the near-field environment around CAMBRIC was carried out on a large number of streamlines extracted from the threedimensional flow field. Integrated path length, coordinates, local Darcy flux and seepage velocity, time of flight away from the starting location, geologic material, geologic properties, mineralogic composition, and total flux were recorded at all points along the streamline where it crosses the grid-block boundaries in the flow model domain.

Several different reactive mineral distributions were considered in the simulations in order to to assess their overall impact on radionuclide migration and retardation. This variability was represented by the use of different spatial distributions of minerals (clays, hydrous ferric oxides, and zeolites) or through the adjustment of the specific surface area associated with each mineral. Comparison of the results indicates that even small amounts of reactive minerals, when 
evenly distributed, provide an significant retention effect for radionuclides. On a bulk or larger scale level, radionuclide mobility is increased when the same reactive minerals are only distributed in portions of the domain with lower hydraulic conductivity.

Additional sensitivity simulations focused on the effects of increased glass surface area. This has been shown to increase the rates of radionuclide transfer from the melt glass into groundwater (with increased aqueous concentrations as well), albeit with marked increases in the $\mathrm{pH}$. Further investigations are warranted in order to carefully define the specific surface areas of melt glass.

We conclude that both the melt glass and the minerals in the exchange volume release radionuclides slowly over time. Melt glass provides a steady source of radionuclides which will not be depleted for thousands of years. Radionuclide release from the exchange volume is limited by strong surface complexation onto hydrous ferric oxides and by ion exchange on clays and zeolites. Surface complexation and ion exchange can also effectively retard radionuclide migration through alluvium if reactive minerals are contacted along a flow path. Small amounts of reactive minerals significantly reduce the mobility of aqueous radionuclides. Spatial variability in reactive mineral abundance can affect the overall or bulk radionuclide mobility and flux through the system.

The high resolution 3D modeling framework provided a critically important basis to analyze coupled flow, migration, and reaction behavior. Streamline modeling proved to be an exceptionally useful and flexible tool for studying the hydrologic source term problem.

Conclusions regarding our computations of the hydrologic source term must be tempered with the recognition of the dependence of our results on the assumptions that we had to make regarding the distribution and geochemical state of radionuclides in the initial system, the geochemical processes that control radionuclide distribution, our quantitative description of these geochemical processes, and the masses and distribution of reactive minerals along the flow paths.

Review of the radionuclide inventory for Frenchman Flat has indicated that generalization of the hydrologic source term from CAMBRIC must be undertaken in a classified mode, and results from CAMBRIC are not directly scaleable.

Based on our calculational experience, we make recommendations for: acquisition of field data to better define the initial geologic and geochemical conditions at the site and to test our predictions; improvements in the geochemical process models that govern radionuclide release and retardation; measurement of single mineral surface complexation and ion exchange data; and additional activities to address issues that surfaced during the project. 



\section{Introduction}

The objectives of this project are to develop and apply a modeling framework to quantitatively evaluate the nature and extent of radionuclide migration within the immediate, near field environment about an underground nuclear test. Specifically, it will involve evaluation of

- The speciation and abundance of radionuclides that are introduced into groundwater as aqueous species or colloids, and

- The rate and extent of radionuclide movement, dilution, and reaction in groundwater surrounding the working point of a test.

To be clear, interest will only be focused on processes that have occurred well after the nuclear test, as opposed to the more dynamic processes that take place during or immediately after detonation. The meaning of "near field" in this case will loosely refer to a volume of diameter $4-8 R_{c}$, centered on the working point and chimney of the test, where $R_{c}$ is the radius of the blast cavity.

For a given nuclear test, this information will collectively comprise the test's "hydrologic source term". This work relies on and is being supported by existing data, analyses, and interpretations that have been made at the Nevada Test Site (NTS) during the American nuclear test program and previous and ongoing studies related to radionuclide migration in the subsurface (Kersting, 1996).

\subsection{The CAMBriC test}

For reasons relating to time and data constraints, the scope of this report will be limited in several ways. First, this work will concentrate on a single test in the saturated zone beneath Frenchman Flat at the NTS. This was done to simplify the development of the overall modeling process and because the alluvial environment beneath Frenchman Flat and the associated groundwater flow and transport processes are relatively simple to characterize and understand.

The test chosen for analysis was the CAMBRIC test, an underground nuclear test conducted on May 14, 1965, in Frenchman Flat. This test was chosen because there is a "relatively" large amount of unclassified hydrologic and radionuclide inventory data relating to this test, both inside and outside of the blast cavity. The test has been the subject of numerous other investigations (e.g., Bryant, 1992) that this work can be leveraged against. This kind of information is generally not available for other underground nuclear explosions.

Even though solid mineralogic samples, groundwater composition, unclassified radionuclide inventory data and additional hydrologic measurements are available at some level of detail to constrain and validate our models, more complete data are largely unavailable. As a result, the results of this study must be used and interpreted accordingly. In addition, because it was easier to work and develop the modeling process in an unclassified manner, only unclassified 
radionuclide inventory data were considered. In this sense, a carefully chosen subset of the full suite of residual radionuclides will be examined and our calculations will focus on the unclassified portion of the hydrologic source term only.

\subsection{Broader purpose for this work}

Determination of the total hydrologic source term at CAMBRIC, or any other underground nuclear test, will require classified radionuclide inventory information. With such information, the simulation approach developed in this report will be evaluated to determine how it might be generalized and used to understand more complete hydrologic source term behavior at CAMBRIC and other underground nuclear tests conducted at Frenchman Flat.

In addition, it is expected that our modeling approach can be used as a template to guide future source term evaluations at other underground testing locations outside of Frenchman Flat (classified or not), as well as a basis to plan future data acquisition activities.

In a broader context, this work will ultimately be used to support the development of larger-scale models of saturated-zone contaminant migration within a sub-regional (e.g., Frenchman Flat or Pahute Mesa) or regional (e.g., NTSwide) framework. In this sense, the relevant list of contaminants will include radionuclides associated with underground nuclear testing as well as other nonradioactive compounds used in the tests (such as lead) whose presence and migration in groundwater will be of regulatory concern. Such models are being developed to assist the Department of Energy (DOE) and other State and Federal agencies in developing a risk-based contaminant boundary that will be used for regulatory purposes, and to provide a basis for designing a network of wells for more comprehensive monitoring of the groundwater regime in the future (FFACO, 1996). 


\section{Impacts of Underground Nuclear Explosions}

In order to better describe the disturbed portions of the near field environment of underground nuclear tests, we reviewed several generic aspects of underground nuclear explosion phenomenology.

\subsection{General phenomenology}

Phenomenology describes the effects of the nuclear explosion on the surrounding geologic medium. Early-time phenomenology refers to the physical and chemical processes that occur between nuclear detonation and the time when the resulting cavity reaches its maximum size and begins to rebound. These actions are shock induced, and include shock compression followed by adiabatic expansion of gas. Late-time phenomenology refers to actions that occur after the cavity has reached its full size, and consist mainly of thermally-induced mechanisms that lead to the eventual collapse of the cavity.

The following description is derived from several papers written on phenomenology of underground nuclear explosions, including Germain and Kahn (1968), Borg et al. (1976), Butkovich and Lewis (1973), Butkovich (1976), and Office of Technology Assessment (1989). Please refer to Figure 1.

\section{$2.2 \quad$ Early-time phenomenology}

When an underground nuclear device is exploded, sufficient energy is released to instantaneously vaporize rock or alluvial media immediately surrounding the working point. Within microseconds of the detonation, initial temperatures rise to several million ${ }^{\circ} \mathrm{C}$ and pressures close to 1 megabar (Mb) are created. As a result, a compressive, outwardly moving shock wave is generated. Within milliseconds, as the shock wave expands, additional rock is crushed, melted and vaporized, creating an expanding open volume, or cavity. Within tenths of seconds the energy of the shock wave will pass elastically through the outlying geologic material to the surface.

As the geologic material surrounding the expanding cavity is melted and vaporized, pore water is also vaporized. The presence of carbonate materials in the surrounding medium is known to exacerbate the production of additional cavity gases in the form of $\mathrm{CO}_{2}$. The cavity void continues to grow radially as the expanding shock wave imparts outward momentum on the surrounding media. Cavity growth is dependent on the strength of the overlying rock. About 500 megagrams per kiloton of yield $(\mathrm{Mg} / \mathrm{kt})$ of geologic material is ultimately subjected to dynamic loading and unloading in the cavity region. Depending on the yield of the explosion, the cavity reaches its largest size within 80 to 500 milliseconds when the elastic strains within the rock attempt to recover. The material rebounds radially due to elastic unloading and tries to return to its original position. A compressive tangential hoop stress is formed when the 


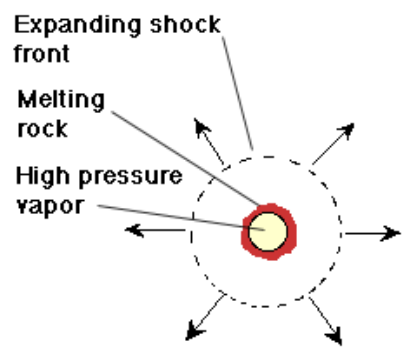

microseconds

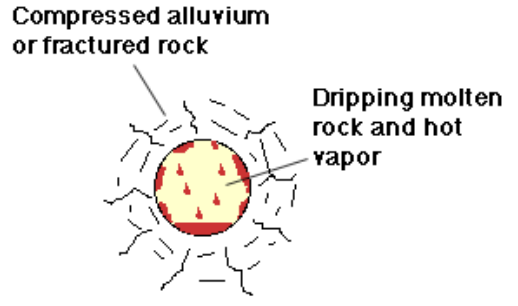

milliseconds

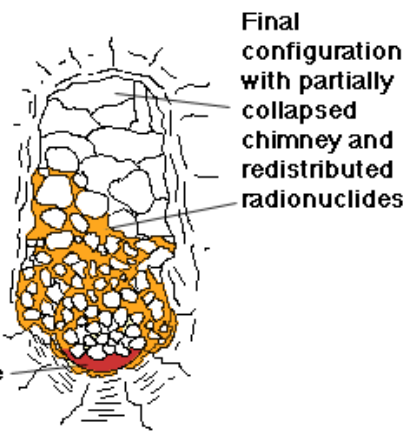

Figure 1: Conceptual illustration of early time (above) and late time (below) phenomenology of an underground nuclear explosion in competent rock showing accretion of glass puddle and redistribution of more volatile radionuclides, initially as vapor, later as condensate. Some noncondensable radionuclides may migrate further upwards. 


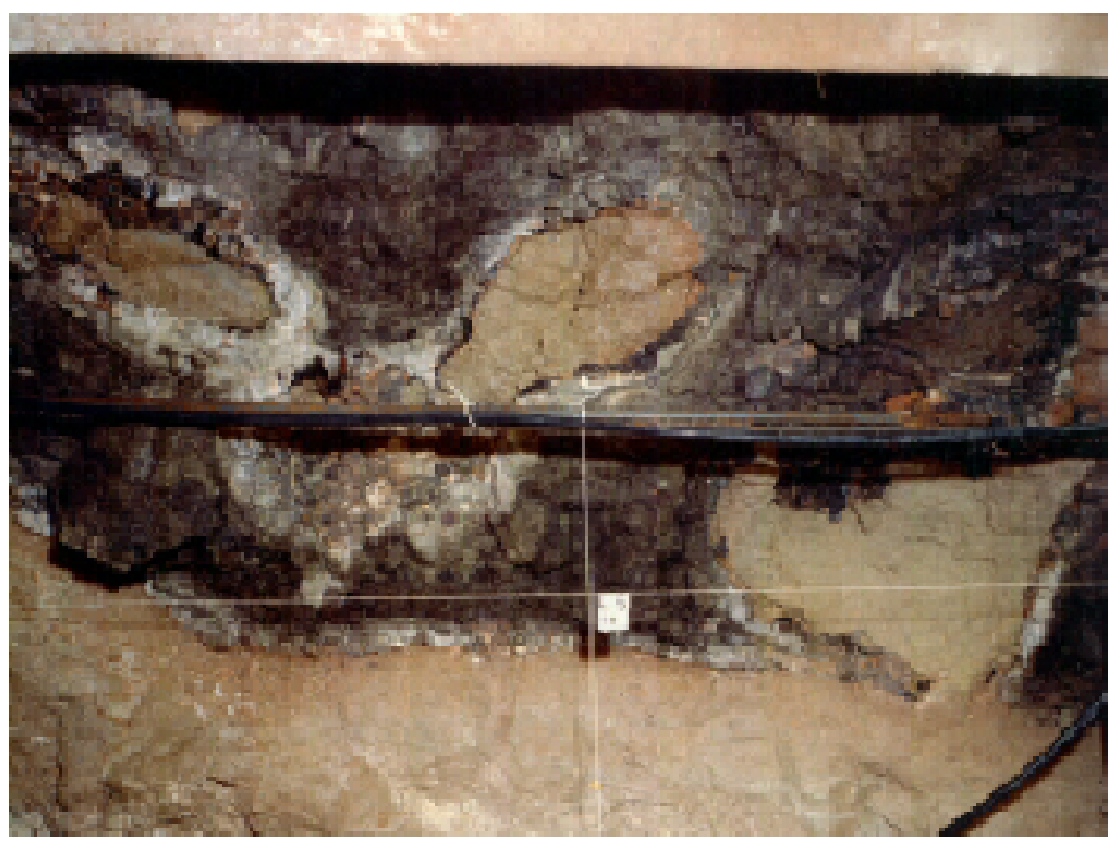

Figure 2: In situ photograph of the melt glass at the RAINIER test (Wadman and Richards, 1961). Large blocks of the host tuff can be seen inside the melted glass zone. Vesicular zones (rich in bubbles) surround some of these inclusions. The photo shows a section of the pool about 2 meters across. The zone is obviously heterogeneous in textural and hydrologic properties.

stress field in the rebounded rock is greater than the gas phase pressure in the cavity. This compressive, or residual hoop stress will close radial fractures that were opened during cavity expansion. The final size of the cavity is dependent on the yield of the explosion, the overburden stresses, and the strength of the surrounding rock.

As the shock wave moves outward, cavity growth slows. At about one third of the distance between the working point and the surface, the shock wave becomes elastic and travels at elastic speeds until it reaches the ground surface, within 100 to 500 milliseconds. Along the way, rock failure can be brittle or plastic, depending on the stress conditions and the strength properties of the geologic materials. Upward acceleration of material from the detonation point to the ground surface can cause surface bulges of about 1-3 m. A compressive wave reflected off the ground surface is known as a rarefaction. Residual stress usually forms before the rarefaction reaches the cavity region. 


\subsection{Late-time phenomenology}

After the shock and elastic waves have dissipated, the less-volatile rock vapors begin to condense and gather at the cavity bottom to form a puddle of melted material. Melt glass is produced by the condensation of vaporized rock, shock melting of the surrounding rock, and melting of the rock medium in contact with melt or vapor (Borg et al.1976). It has been estimated that between 700 and 1,300 metric tons of glass are ultimately formed per kiloton of yield (Borg et al. , 1976; Smith, 1993). Water vapor, noncondensable gases (such as $\mathrm{CO}_{2}$ and $\mathrm{H}_{2}$ ) and other noncondensed radionuclides (such as tritiated water vapor, ${ }^{85} \mathrm{Kr}$, or ${ }^{137} \mathrm{Xe}$ ) are still present in the cavity. Within minutes to hours after detonation, thermal energy in the gas is conductively transferred past the cavity walls into the surrounding geologic material, creating high thermal gradients. This induces ablation and spalling of wall material and lowers cavity temperatures so that steam condenses. Flaked wall material of various sizes enhances cooling in the cavity and mixes with puddle glass, some being incorporated in the melt and larger pieces surviving as rubble within or above the glass material. This can be seen in Figure 2 which shows an underground in situ photograph of the melt glass created at the RAINIER test of 1957.

The continuing ablation and mixing behavior reduces cavity pressures until they reach a few pounds per square inch (psi). Within minutes to hours after the explosion cavity collapse may begin and progress very quickly ${ }^{1}$. Depending on the rate or suddenness of collapse, cavity gases may migrate into the evolving void spaces in the chimney zone above the cavity. Ideally, collapse material will trap most noncondensed gases near the cavity region. Nonetheless, this could be a principal mechanism for moving high-vapor pressure (non-refractory) radionuclides outside of the cavity region. If the overlying rock is not strong enough to support the cavity roof span, collapse propagates upwards. If overlying support due to material strength is insufficient, collapse can proceed to the surface and a crater is formed.

Surface ground motion such as uplift, spall, slapdown, ground cracking, block movement, and compaction can be caused by shock wave effects or secondary mechanisms such as fault movement or collapse. Surface bulges can be caused by the acceleration of the ground surface from the outgoing shock wave. Spall occurs down to depths where rarefaction tensile stress exceeds the ascending compressive wave stress plus the overburden stress and the tensile strength of the rock. Layers of rock can separate or part along naturally occurring planes of weakness. Slapdown, also known as spall closure, occurs when the ground surface free falls after the upward traveling compressive wave accelerates the ground surface. Cracking and other explosion-caused surface effects occur on the ground surface due to radial divergence of the surface from spall motion and preferential movement along pre-existing structures (faults, joints, etc.), bulking and compaction due to collapse, and spall or rock falls at free surfaces.

\footnotetext{
${ }^{1}$ Usually within tens of minutes.
} 


\subsection{Other phenomena}

The early and late time phenomenology described above are generalized. For some tests, other phenomena have occurred, including hydrofracturing and prompt injection of radionuclides outside the cavity region, groundwater effects such as mounding and pressurization, shock reflections off of impedance layers (caused by material property differences such as rock strength or air void content, bedding planes, and faults), and movement on pre-existing structural features such as faults. These may affect cavity growth, residual stress, collapse, and crater formation. Temperartures in the cavity environment will dissipate with time as a function of the heat capacity and thermal diffusivities of the formation materials (with or without groundwater), and the groundwater motion itself. Some tests have thermal signatures that have lasted for decades, while others have returned to normal temperature conditions within years or less.

\subsection{Radionuclide distribution and behavior}

The radionuclides deposited in the subsurface as a result of an underground nuclear explosion consist of radionuclides produced from the nuclear reaction (fission products and tritium), neutron activation of surrounding material, and unreacted nuclear material. The total inventory of residual radioactivity is called the radiologic source term. The physical and chemical distribution of the radiologic source term is heterogeneous and a function of the device design, host geologic media, properties of the specific radionuclides, and the rate and character of cavity growth and collapse. As discussed in 3.3, the hydrologic source term is that portion of the radiologic source term that is or becomes available for transport in groundwater.

Previous field investigations at the NTS have yielded information regarding the initial distribution of radionuclides after a nuclear test. For more information, the reader is referred to Smith $(1993,1995 a)$ and Kersting (1996). Tritium is present as tritiated water and is an integral part of the interstitial water (Hoffman et al., 1977). In general, refractory radionuclides (e.g., $\mathrm{Pu}, \mathrm{Am}, \mathrm{Np}$, $\mathrm{Ce}, \mathrm{Eu})$ with higher boiling points and lower vapor pressures are largely incorporated in the melt glass that coalesces at the base of the cavity. The more volatile radionuclides (e.g., Sr, Cs) with lower boiling points and higher vapor pressures condense later and are heterogeneously distributed in the cavity and overlying chimney, although some fractions are incorporated in the glass. If the melt glass is still molten when rubble in the cavity/chimney area collapses, the glassy material can splash and distribute refractory material more broadly in the cavity region (Fig. 1).

The distribution of some fission products is strongly dependent on the behavior of their parental precursors. The decay chain dynamics for ${ }^{90} \mathrm{Sr}$ and ${ }^{137} \mathrm{Cs}$

are particularly important because they have noble gas precursors that can be transported away from the detonation point before decaying to their respective 
daughter products (e.g., ${ }^{137} \mathrm{Xe}$ decays to ${ }^{137} \mathrm{Cs}$ in $3.84 \mathrm{~min}$ ). Noncondensible gases such as $\mathrm{CO}_{2}$ and $\mathrm{H}_{2}$ may act as carrier gases and move fission products away from the explosion point (Thompson, 1996). In some instances, prompt injection of nuclear material along fractures or zones of weakness during the early time of a nuclear test may deposit radionuclides outside the immediate vicinity of the cavity and chimney system (Nimz and Thompson, 1992; Smith et al. , 1996).

The partitioning of a selected radionuclides among glass, rubble, water, and gas is shown in Table 1 (IAEA, 1998). This table reflects how and where the radionuclides (as components of a complex vapor mixture produced during detonation) are distributed during the cooling and condensation process following an underground nuclear explosion. Initially, radionuclides with higher boiling points condense along with other refractory materials and become preferentially incorporated within a liquid melt phase. As cooling progresses, the melt begins to quench. Lighter elements with lower boiling points subsequently condense onto exposed mineral and fracture surfaces within the cavity and the collapsed rubble. Notably, volatile radionuclides with gaseous noble gas precursors (e.g., ${ }^{137} \mathrm{Xe} \rightarrow{ }^{137} \mathrm{Cs}$ with $t_{1 / 2}=3.82$ minutes) may continuously diffuse through the cavity-chimney system for several minutes before decaying to longer-lived daughters (Borg et al.1976; Smith et al.1996; Thompson, 1996). A portion of the volatile species will also be volumetrically incorporated in any late-stage melt residual.

Among the more volatile radionuclides, tritium will condense as molecular HTO together with the large amounts of steam produced by the explosion. Fractions of volatile radionuclides with higher solubilities (e.g., ${ }^{36 C l}$ and ${ }^{129} \mathrm{I}$ ) will also be partitioned into the condensed water. Longer-lived gaseous radionuclides (e.g., HT, ${ }^{39} \mathrm{Ar},{ }^{85} \mathrm{Kr}$ ) that do not immediately condense may become trapped in the formation and also dissolve into pore waters (Guell, 1997). In tests conducted beneath the water table, these condensed waters will mix with groundwater invading from the periphery and occupy the interstitial voids of the rubble and glass matrices. This will allow for the "rubble-", "water-", as well as some of the "gas-based" fractions of the inventory to become incorporated in and mobilized by the groundwater over the short term (as aqueous-surface reactions permit), and for the "glass-bound" fractions to slowly dissolve into the groundwater over the long term. This conceptualization of radionuclide release forms the basis of the modeling approach used in this report.

The data in Table 1 originate from measurements derived from nuclear test radiochemical diagnostics (i.e., Borg, 1975) augmented by general thermodynamic properties of these elements (i.e., boiling points, vapor pressures). With the exception of ${ }^{90} \mathrm{Sr}$ and ${ }^{137} \mathrm{Cs}$, the data apply to the general experience of radionuclide distributions residual from underground nuclear testing. The partitioning behavior of ${ }^{90} \mathrm{Sr}$ and ${ }^{137} \mathrm{Cs}$ between rubble and melt glass is strongly dependent of cooling time of the glass as well as the presence of volatile, noncondensible gases (i.e., $\mathrm{CO}_{2}, \mathrm{H}_{2}$ ) in cavity and chimney. Due to the low yield 
of the CAMBRIC test (and implied faster quenching of the melt glass) as well as presence of carbonate in the firing media ( 0 - 10 volume $\%$ calcite), the proportions of ${ }^{90} \mathrm{Sr}$ and ${ }^{137} \mathrm{Cs}$ are assumed to be enriched in the CAMBRIC rubble fraction.

Table 1: Percentage distribution of selected radionuclides among the glass, rubble, gas, and groundwater as occurs during the condensation period following a typical underground nuclear test. Data are taken from IAEA (1998).

\begin{tabular}{lcccc}
\hline \hline Radionuclide & Glass & Rubble & Gas & Water \\
\hline${ }^{3} \mathrm{H}$ & & & 2 & $98^{a}$ \\
${ }^{36} \mathrm{Cl}$ & 50 & 40 & & 10 \\
${ }^{60} \mathrm{Co}$ & 90 & 10 & & \\
${ }^{90} \mathrm{Sr}$ & 25 & 75 & & 10 \\
${ }^{129} \mathrm{I}$ & 50 & 40 & & \\
${ }^{137} \mathrm{Cs}$ & 10 & 90 & & \\
${ }^{155} \mathrm{Eu}$ & 95 & 5 & & \\
${ }^{239} \mathrm{Pu}$ & 95 & 5 & & \\
${ }^{241} \mathrm{Am}$ & 95 & 5 & & \\
\hline $\bar{a}$ & & & & \\
\hline e.g., tritiated water, HTO.
\end{tabular}




\section{Physical and Chemical Setting}

\subsection{Structural and geologic setting of Frenchman Flat}

Frenchman Flat is located in the southeast corner of the Nevada Test Site (Fig. 3). It is an intermountain basin formed by Tertiary-age faulting typical of the Basin and Range physiographic province. To the north and west, the basin is rimmed by Tertiary volcanic rocks derived from volcanic centers west and northwest of Frenchman Flat. Highlands to the south and east, as well as the underlying basement rock, are composed of Paleozoic carbonate rocks. The basement is covered in most, if not all, areas by Tertiary-aged volcanic rocks and volcanic-derived sedimentary rocks. The central part of the Frenchman Flat basin is filled with Quaternary/Tertiary alluvium (Fig. 4).

Ten underground nuclear tests have been conducted in Frenchman Flat. Seven of these were located in the northern portion of the basin, while three others were situated in the central portion. Nine of the tests were conducted in the alluvium; one test was detonated in the Tertiary volcanic rocks below the alluvium located in the northern portion of Frenchman Flat. Several of the tests were conducted in the saturated zone below the water table, while the others were conducted above (yet within $100 \mathrm{~m}$ ) of the water table. Although it would seem likely that those conducted beneath the water table have already contaminated nearby groundwater, it is not clear whether any of the remaining underground tests have led to any detectable groundwater contamination (DOE, 1997a).

\subsection{The near field environment at CAMBRIC}

The CAmBric test was conducted in the central portion of Frenchman Flat, as shown in Figure 5. The device was deployed in emplacement hole U5e. As described in Hoffman et al. (1977) and Bryant (1992), CAMBRIC had a yield of $0.75 \mathrm{kt}$ with the working point located in alluvium about $662 \mathrm{~m}$ above sea level, or about $294 \mathrm{~m}$ below the ground surface and $74 \mathrm{~m}$ below the ambient water table.

The CAMBRIC test produced a blast cavity whose diameter was calculated to be $22 \mathrm{~m}$. The collapse zone, or chimney above the cavity, extends above the water table, but not to the ground surface, as there is no surface crater. The calculated volume of melt glass produced at the bottom of the cavity is between 525 and 975 metric tons. Outside the cavity and chimney region lies relatively undisturbed alluvium. The composition of the melt glass, chimney, and cavity rubble reflects the composition of the original and undisturbed alluvium.

At ground zero, groundwater is found approximately $220 \mathrm{~m}$ beneath the surface. Both the topographical and regional hydraulic gradients dip toward Frenchman Lake to the east-southeast (Figs. 5, 6). The topographical dip is considered to be consistent with the basic alluvial depositional patterns in the 


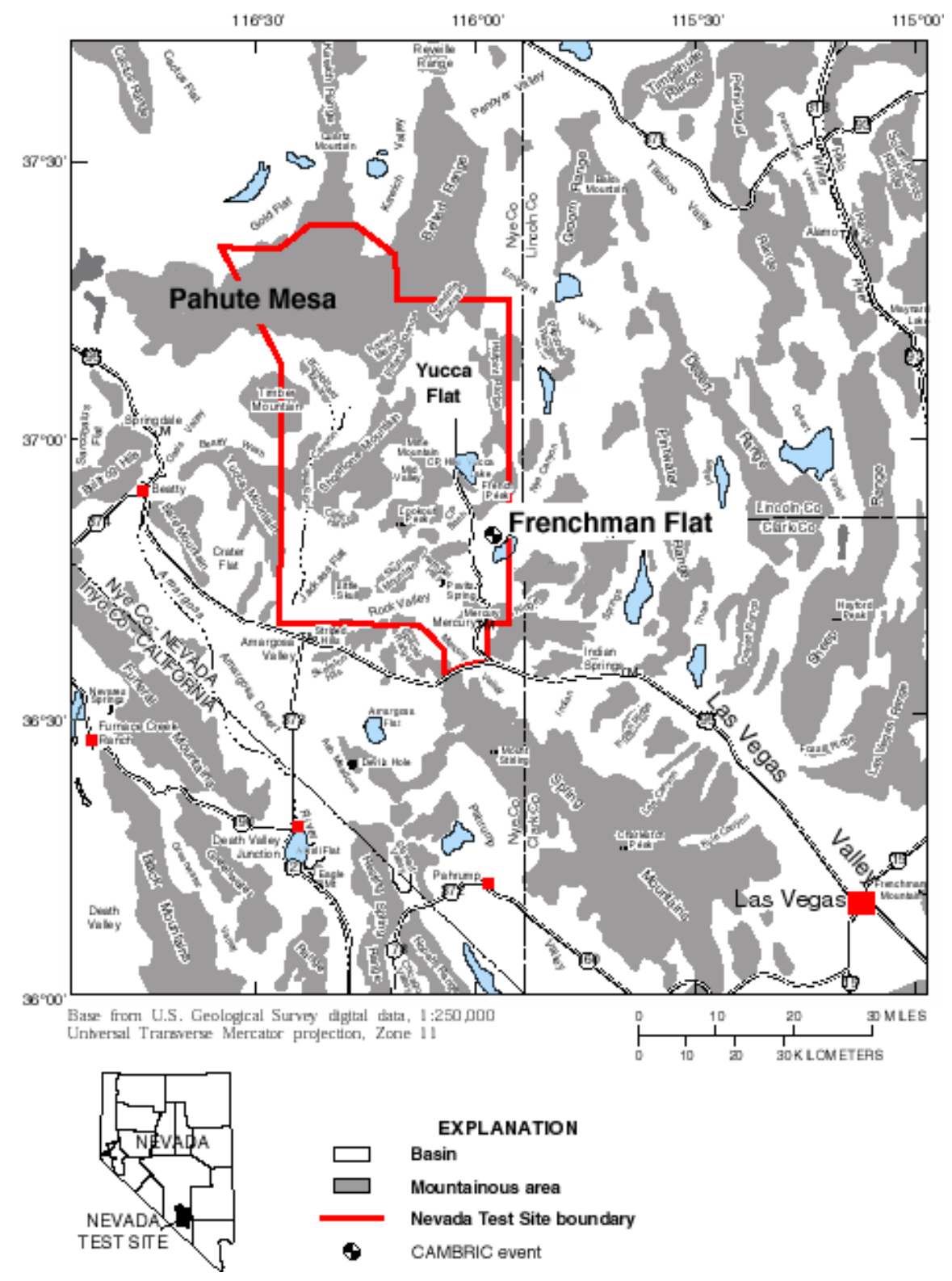

Figure 3: Schematic map of the Nevada Test Site and surrounding areas. 


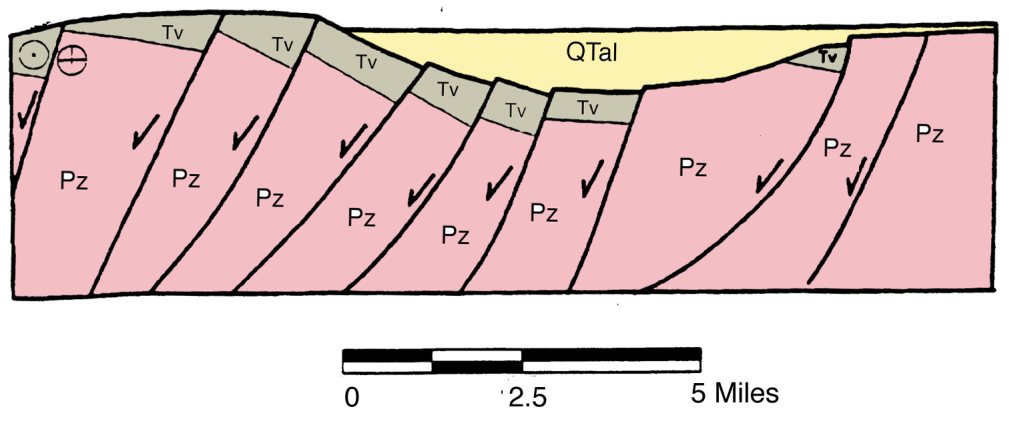

Figure 4: Conceptual structural model cross-section (W-E) for Frenchman Flat, after Grauch and Hudson (1995). Symbols: Tv $=$ Tertiary volcanic rocks; Pz $=$ Paleozoic carbonate rock; QTal = Quaternary/Tertiary alluvium.

area, although some historical shifting of these directions may have occurred during deposition. The magnitide of the horizontal hydraulic gradient lies approximately between 0.001 and 0.002 . Figure 6 also indicates that a small vertical gradient exists between the alluvial and lower carbonate aquifer systems, consistent with the fact that Frenchman Lake represents a groundwater sink or low point in the larger valley-fill setting (Hoffman et al., 1977).

\subsection{1- Nearby boreholes}

The CAmBric emplacement hole (U5e) is shown in plan view in Figure 8 and in the cross section in Figure 7. The first $140 \mathrm{~m}$ of the slanted (RNM-1) re-entry hole was drilled after the test for collection of post-test solid samples and other diagnostic information. (An enlarged view of this well is also shown in Figure 37 ). In the early 1970s, it was extended for collection of water samples from the cavity region. Just prior to this extension, a satellite pumping well (RNM$2 \mathrm{~S}$ ) was installed approximately $90 \mathrm{~m}$ south of U5e and screened between 16 and $41 \mathrm{~m}$ below the bottom elevation of the CAMBric cavity (Fig. 7). This well was used for a radionuclide migration experiment that is discussed later. Borehole UE5n was constructed about $500 \mathrm{~m}$ southeast of U5e and was used for groundwater monitoring and sampling purposes.

\subsection{2- Alluvium composition}

The alluvium in the vicinity of the CAMBrIC test consists of interbedded silts, clays, sands, and gravels. Table 2 shows the approximate mineralogic composition of the alluvium analyzed from several core samples taken over a depth interval spanning the working point of CAMBRIC in RNM-1 (Daniels and Thompson, 


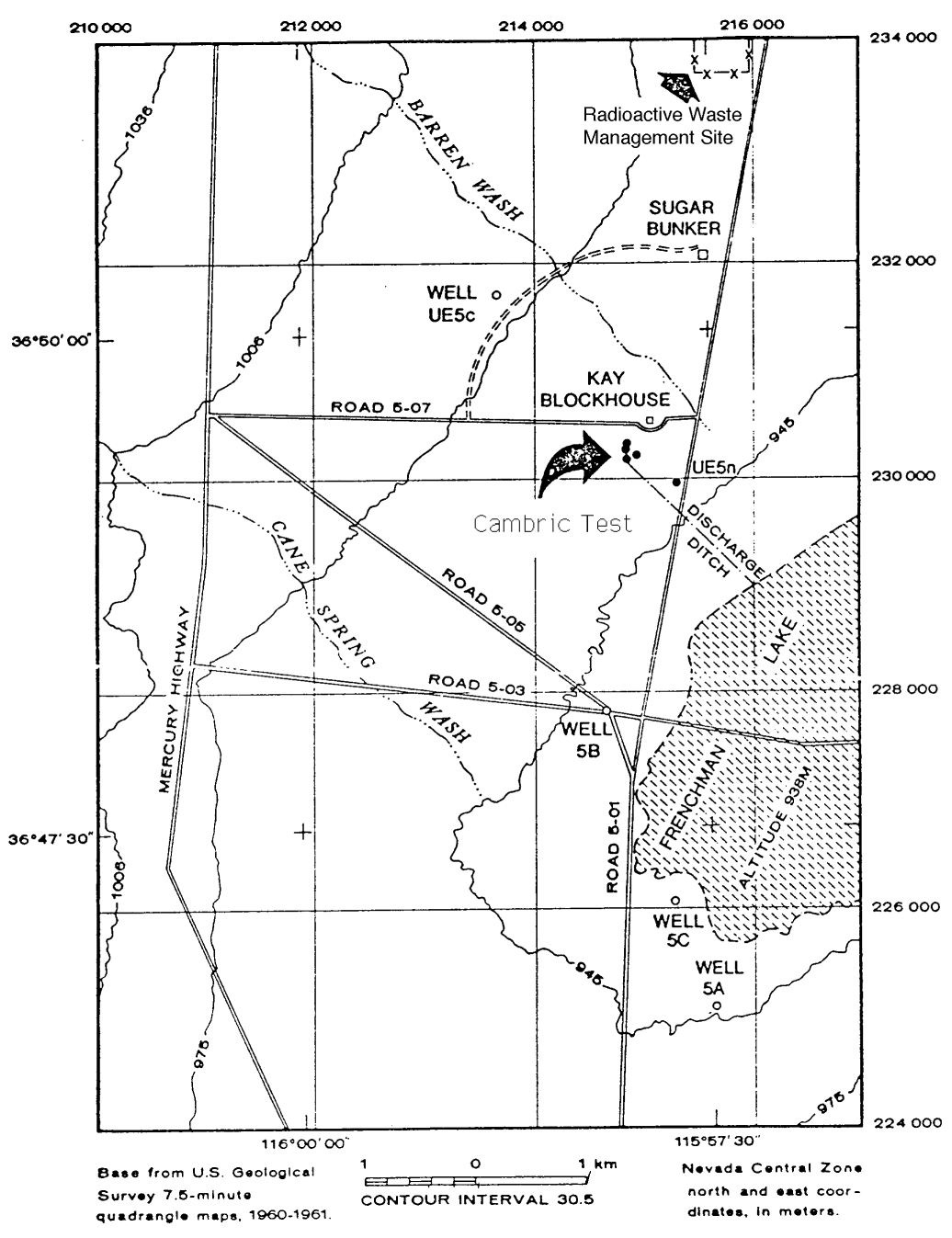

Figure 5: Location of CAmBric test in Frenchman Flat, Nevada Test Site, Nevada (after Hoffman et al., 1977). Topographic gradients are indicative of principal alluvial depositional direction southeasterly toward Frenchman Lake. 


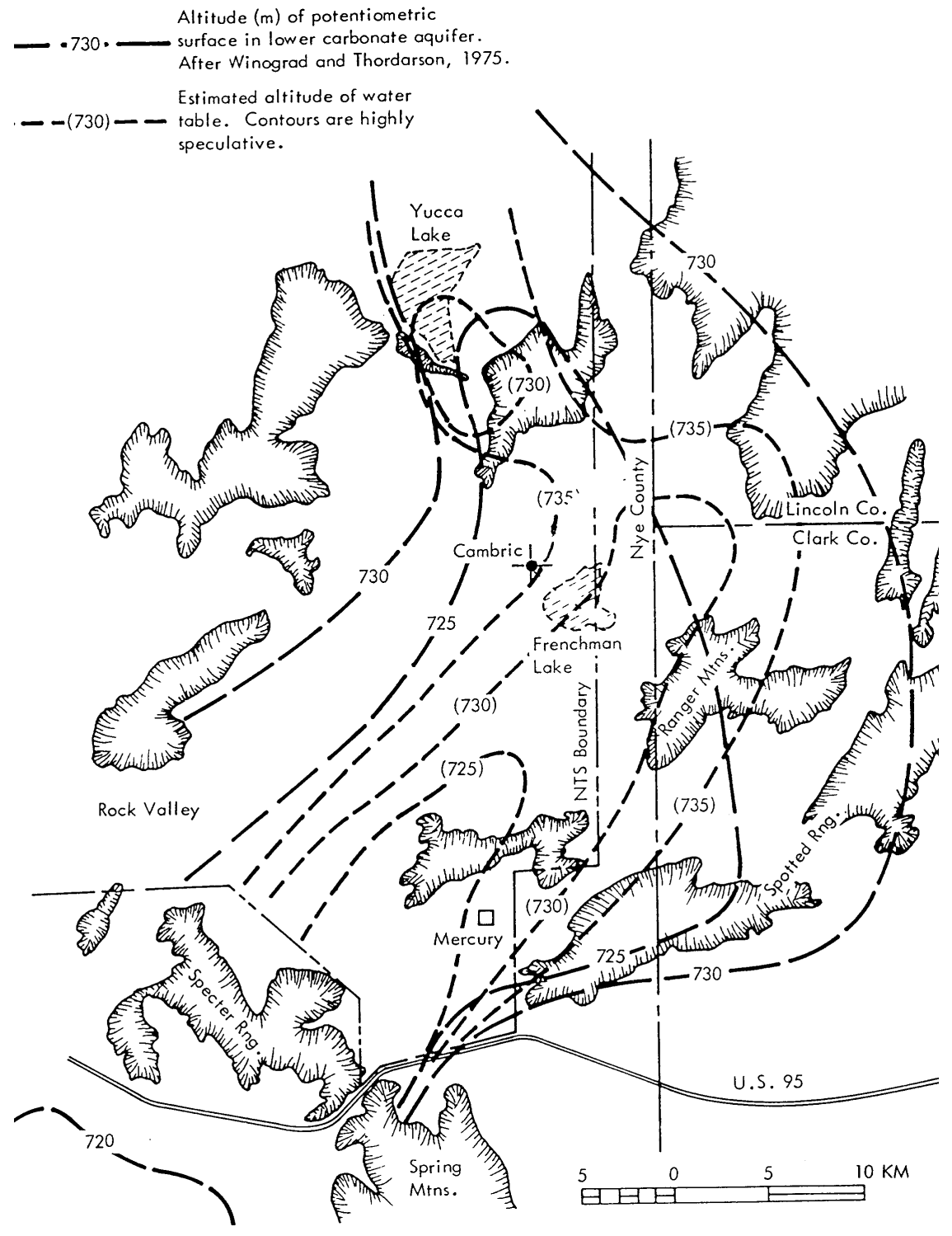

Figure 6: Regional groundwater gradients in the alluvial and deeper carbonate aquifers in Frenchman Flat (after Hoffman et al., 1977). At the CAmBRIC site, flow in the alluvial system moves slowly in an approximately east-southeast direction due to a horizontal hydraulic gradient of 0.002 or less. 


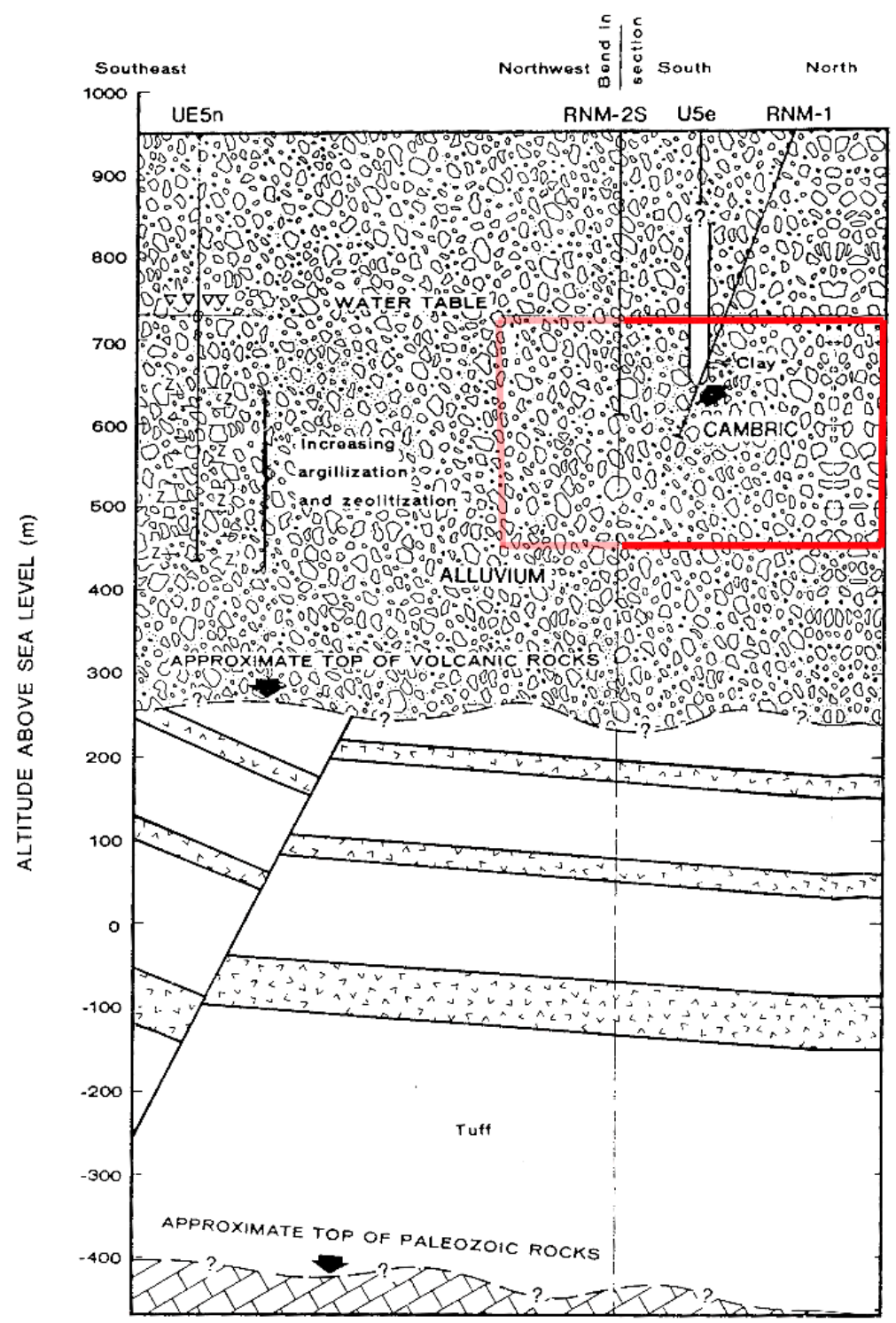

Figure 7: Conceptual cross-section through the CAMBRIC test in Frenchman Flat showing the working point, cavity, chimney, and water table (after Hoffman et al., 1977). The section transect is shown in Fig. 8. 
1984) and UE5n (Ramspott and McArthur, 1977). In general, these data show a dominance of feldspar and lesser amounts of quartz, calcite, amphibole, zeolites (clinoptilolite), clays (smectite, kaolinite, montmorillonite) and iron-oxides (goethite).

Clinoptilolite, a zeolite, ranges in abundance from 0 to $10 \%$, except in the interval between 220 and $340 \mathrm{~m}$ depth (Fig. 7). Here it has been observed in amounts between 40 and $50 \%$ volumetric abundance along with a corresponding decrease in the amounts of feldspar and other minerals. Several authors have attributed this variation to an apparent "lithologic break" that may exist over this depth range (e.g., Hoffman et al., 1977 and Ramspott and McArthur, 1977), and it has also been associated with lower hydraulic conductivities. It has been suggested that the existence of lower permeability materials at this depth may be related to a depositional lacustrine unit correlating to earlier boundaries of the Frenchman Playa (Burbey and Wheatcraft, 1986).

Table 2: Mineralogy of alluvium sampled from well RNM-1 and UE5n in the vicinity of the CAMBRIC test (after Daniels and Thompson, 1984, and Ramspott and McArthur, 1977, respectively). The range in the data account for variations in samples taken from several different depths.

\begin{tabular}{lcc}
\hline \hline & $\begin{array}{c}\text { Percent } \\
\text { Mineral }\end{array}$ & RNM-1 \\
RNic abundance and & Upproximate range \\
Feldspar & $30-90^{a}$ & $30-60^{a}$ \\
Quartz & $5-10$ & $5-10$ \\
Smectite & $3-15$ & \\
Clinoptilolite & $6-40^{a}$ & $0-50^{a}$ \\
Kaolinite & $0-1$ & \\
Biotite & $0-3$ & \\
Mica & $0-2$ & $0-5$ \\
Hornblende & $0-2$ & \\
Calcite & $0-5$ & $0-10$ \\
Muscovite & $0-2$ & $0-5$ \\
Goethite & & $5-9$ \\
Montmorillonite & & $0-10$ \\
Cristobalite-opaline silica & & \\
\end{tabular}

$\overline{\bar{a} \text { Outside the depth interval between } 290 \text { and } 350 \mathrm{~m} \text {, the abundances of clinoptilolite }}$ and feldspar are generally in the range of $5-10 \%$ and $50-90 \%$, respectively.

Figure 9 shows the relative abundance of silts, sands, and gravels as a function of depth beneath the water table at well UE5n. There is clearly a marked 


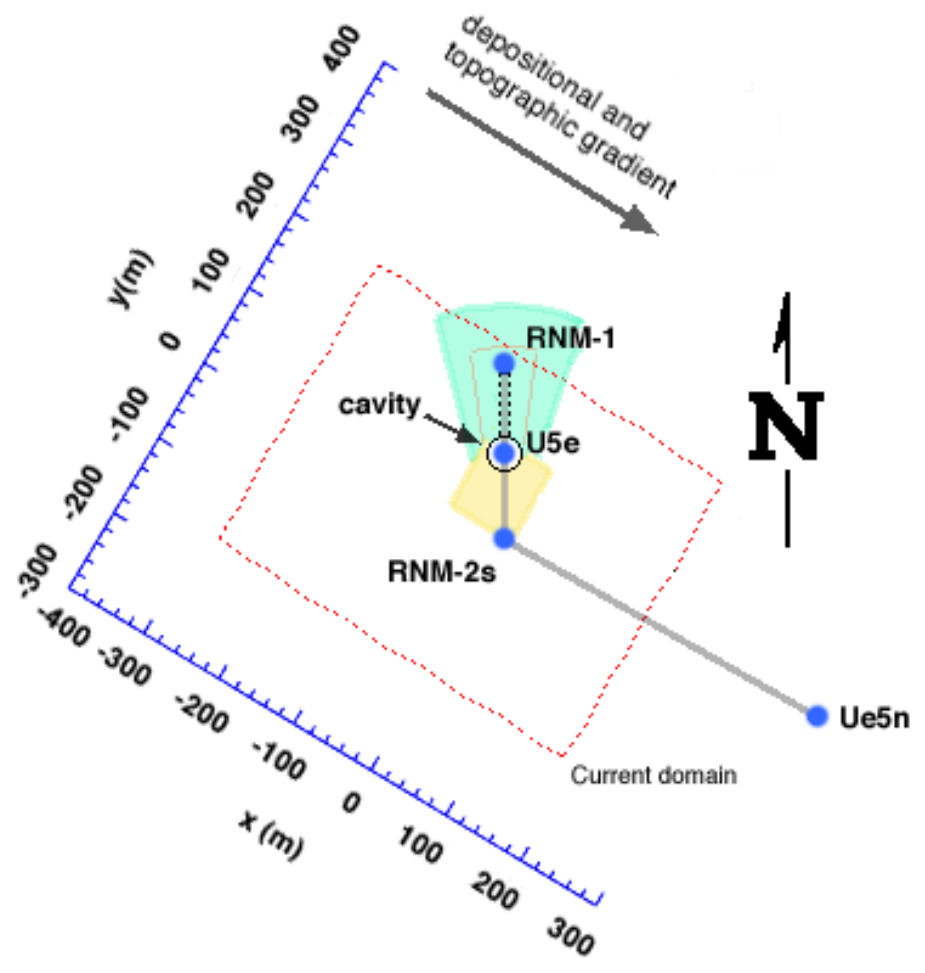

Figure 8: Plan view of the CAMBRIC site showing nearby boreholes and transect of cross-section shown in the previous figure. Large (blue) and small (pink outline) pie-shaped areas represent the areal extent of the LATA and LANL model domains, respectively. Small yellow square represents the domain of the Burbey and Wheatcraft (1986) model, while the dotted rectangle represents the model domain in this report. 


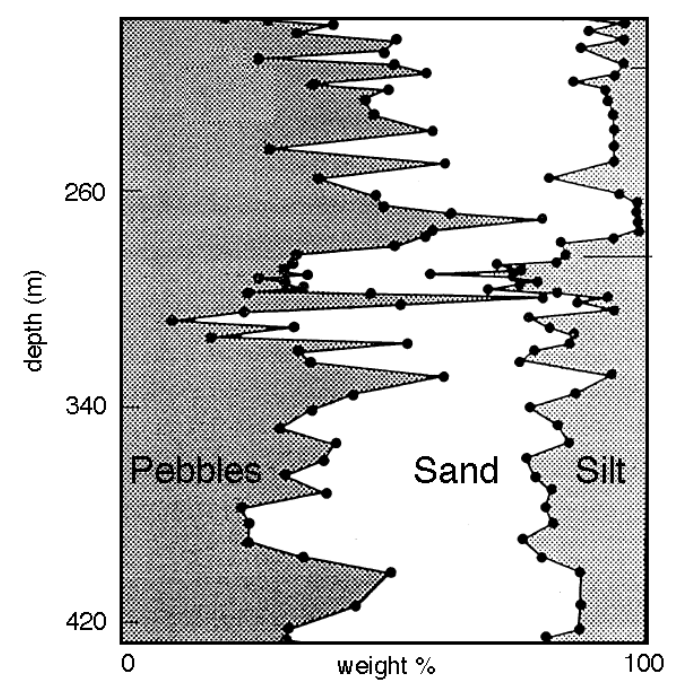

Figure 9: Variation of size fraction of alluvium with depth sampled from well UE5n using sieve and hydrometer analyses (after Ramspott and McArthur, 1977). Notice that the apparent lithologic break may be visible between 280 and $300 \mathrm{~m}$ depth beneath the ground surface.

degree of spatial variability in the physical character of the alluvium. This kind of variability can give rise to variations in physical properties such as the hydraulic conductivity. Figure 10 shows the vertical distribution of hydraulic conductivity values obtained from core and well-test analyses in RNM-1 and RNM-2S from Hoffman et al. (1977), Stone (1975), and Ramspott and McArthur (1977), as reinterpreted by Burbey and Wheatcraft (1986). The apparent lithologic break may be visible in some of this data between depths of 280 and $300 \mathrm{~m}$.

\subsubsection{Groundwater composition}

The best available analyses for major, minor and trace elements in groundwaters collected in the immediate vicinity of the CAMBRIC test have been compiled in Tables 3 and 4 . Water analyses are presented from samples taken from both RNM-1 and RNM-2s in 1974, 1975, and 1993 (Hoffman et al., 1977; Smith et al., 1997). Interestingly, no appreciable thermal signatures remaining from the test have been reported in these surveys. 


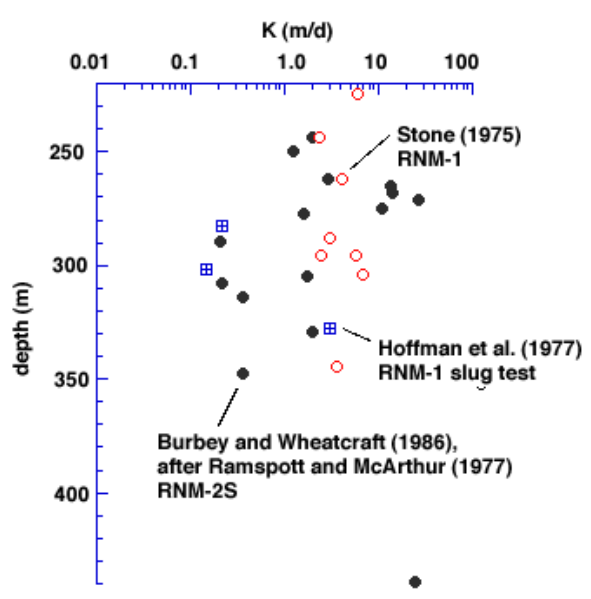

Figure 10: Vertical distribution of hydraulic conductivity beneath the water table, as measured from core and well-test analyses in RNM-1 and RNM-2S (from Hoffman et al., 1977; Stone, 1975; and Ramspott and McArthur, 1977; as reinterpreted by Burbey and Wheatcraft, 1986). Depth refers to distance beneath ground surface.

\subsubsection{Radionuclide inventory}

Portions of the post-test radionuclide inventory at CAMBRIC are tabulated in Table 5. Although the unclassified inventories for ${ }^{3} \mathrm{H},{ }^{85} \mathrm{Kr},{ }^{90} \mathrm{Sr}$, and ${ }^{137} \mathrm{Cs}$ were first derived by Hoffman (1979), our estimates were derived by Smith (1995b). The data for ${ }^{106} \mathrm{Ru},{ }^{125} \mathrm{Sb},{ }^{144} \mathrm{Ce},{ }^{147} \mathrm{Pm},{ }^{155} \mathrm{Eu},{ }^{239} \mathrm{Pu}$, and ${ }^{241} \mathrm{Am}$ are based on a calculation of source term values reported for unclassified post-test atom and activity ratios derived for CAMBRIC (Hoffman et al., 1977). The radionuclide inventory for ${ }^{99} \mathrm{Tc}$ was derived by Schroeder et al. (1993). While not released as part of the unclassified inventory, the predicted value was calculated with knowledge of the CAMBRIC fission yield $\left(10^{23}\right.$ fissions) and the specific ${ }^{99} \mathrm{Tc}$ fission yield (cumulative yield of $6.0 \%$ ).

These radionuclides will be distributed among the glass, collapsed alluvium, and water, similar to what is shown in Table 1 . As this is a fairly uniform, non-fractured environment without any significant juxtaposition of strong and weak materials, prompt injection of radionuclides beyond the cavity/chimney system is not considered likely.

\subsubsection{Radionuclide data from groundwater and alluvium samples}

Several solid samples of melt glass and rubble were collected from re-entry hole RNM-1 during its construction (Hoffman et al., 1977). Radionuclides detected 
Table 3: Older (c. 1974) water composition data taken from drill-back hole RNM-1 (Hoffman et al., 1977). Zones refer to sampling location in drillback hole (Fig. 37): I = below cavity, II = lower cavity, III = upper cavity, IV = chimney, and $\mathrm{V}=$ adjacent to chimney.

\begin{tabular}{lccccc}
\hline \hline & \multicolumn{5}{c}{ RNM-1 concentration, c. $1974(\mathrm{mg} / \mathrm{l})$} \\
Constituent & Zone I & Zone II & Zone III & Zone IV & Zone V \\
\hline $\mathrm{pH}$ & 8.1 & 8.3 & 7.2 & 7.1 & 7.4 \\
$\mathrm{Na}$ & 63 & 124 & 129 & 94 & 64 \\
$\mathrm{~K}$ & 8 & 19 & 19 & 19 & 12 \\
$\mathrm{Li}$ & 0.02 & 0.38 & 0.22 & 1.6 & 0.39 \\
$\mathrm{Ca}$ & 16 & 52 & 72 & 93 & 50 \\
$\mathrm{Mg}$ & 4 & 6 & 24 & 39 & 20 \\
$\mathrm{Sr}$ & 0.3 & 4 & 1.1 & 0.8 & 0.6 \\
$\mathrm{HCO}$ & 177 & 137 & 471 & 582 & 345 \\
$\mathrm{Cl}_{3}$ & 16 & 100 & 41 & 33 & 16 \\
$\mathrm{SO}_{4}$ & 32 & 200 & 110 & 110 & 63 \\
$\mathrm{~F}$ & 0.6 & 1.9 & 0.4 & 0.2 & 0.3 \\
& & & & & \\
\hline \hline
\end{tabular}

in the glass and rubble included the fission products ${ }^{106} \mathrm{Ru},{ }^{125} \mathrm{Sb},{ }^{137} \mathrm{Cs},{ }^{144} \mathrm{Ce}$, ${ }^{155} \mathrm{Eu}$, neutron activation products ${ }^{54} \mathrm{Mn},{ }^{60} \mathrm{Co},{ }^{134} \mathrm{Cs},{ }^{152} \mathrm{Eu},{ }^{154} \mathrm{Eu}$, as well as ${ }^{239} \mathrm{Pu}$ and ${ }^{241} \mathrm{Am}$. This material was graded between glass and non-glassy fraction and re-analyzed. The highest activities for all the specific radionuclides were found in the glassy fraction, although significant levels of ${ }^{90} \mathrm{Sr},{ }^{137} \mathrm{Cs}$, and ${ }^{144} \mathrm{Ce}$ were found in the unfused fraction. The refractory elements ${ }^{147} \mathrm{Pm},{ }^{155} \mathrm{Eu}$, ${ }^{239} \mathrm{Pu}$ and ${ }^{241} \mathrm{Am}$ were highly enriched in the melt glass.

The more volatile elements such as ${ }^{125} \mathrm{Sb}$ and fission products with gaseous precursors (e.g. ${ }^{90} \mathrm{Sr},{ }^{137} \mathrm{Cs}$ ) were depleted in the melt glass relative to highly refractory elements. Only about $23 \%$ of the ${ }^{90} \mathrm{Sr}$ and $7 \%$ of the ${ }^{137} \mathrm{Cs}$ relative to ${ }^{239} \mathrm{Pu}$ remain in the melt. These data are consistent with previous investigations of groundwater and solid samples analyzed from other underground nuclear tests at the NTS (see section Radionuclide distribution and behavior).

Over time, several radionuclides have been identified in water samples collected from wells RNM-1 and RNM-2S. In RNM-1, detectable amounts of ${ }^{3} \mathrm{H}$, ${ }^{36} \mathrm{Cl},{ }^{60} \mathrm{Co},{ }^{85} \mathrm{Kr},{ }^{90} \mathrm{Sr},{ }^{99} \mathrm{Tc},{ }^{106} \mathrm{Ru},{ }^{125} \mathrm{Sb},{ }^{129} \mathrm{I},{ }^{137} \mathrm{Cs}$, and ${ }^{239} \mathrm{Pu}$ were found in sampled waters believed to be most representative of the cavity fluids. Some of these measurements (as obtained in Hoffman et al., 1977, and Buddemeier and Isherwood, 1985) are shown in Table 6. In a 16-year pumping experiment conducted at well RNM-2S (see below in Chapter 9), ${ }^{3} \mathrm{H},{ }^{36} \mathrm{Cl},{ }^{85} \mathrm{Kr},{ }^{99} \mathrm{Tc},{ }^{106} \mathrm{Ru}$, 
Table 4: Recent (c. 1993) water composition data taken from near the water table in RNM-1 and from the screened interval in RNM-2S (from Smith et al., 1997).

\begin{tabular}{lcc}
\hline \hline & & \\
Constituent & RNM-1 (mg/l) & RNM-2S (mg/l) \\
\hline $\mathrm{Na}$ & 43.0 & 49 \\
$\mathrm{~K}$ & 8.0 & 8.9 \\
$\mathrm{Ca}$ & 26.1 & 20.9 \\
$\mathrm{Mg}$ & 9.97 & 8.13 \\
$\mathrm{SO}_{4}$ & 41.8 & 35.7 \\
$\mathrm{~B}$ & 0.2 & 0.2 \\
& & \\
& $\mathrm{RNM}-1(\mathrm{ng} / \mathrm{l})$ & $\mathrm{RNM}-2 \mathrm{~S}(\mathrm{ng} / \mathrm{l})$ \\
\cline { 2 - 3 } $\mathrm{Mn}$ & & \\
$\mathrm{Cu}$ & 0.4 & 22.5 \\
$\mathrm{Zn}$ & 1.1 & 1.0 \\
$\mathrm{As}$ & 8.0 & 2.0 \\
$\mathrm{Se}$ & 7.0 & 5.0 \\
$\mathrm{Sr}$ & 8.4 & 9.5 \\
$\mathrm{Mo}$ & 2 & 120 \\
$\mathrm{Ba}$ & 3.7 & 4.1 \\
$\mathrm{Hg}$ & 14.8 & 24.1 \\
$\mathrm{~Pb}$ & 1.1 & 1.0 \\
$\mathrm{U}$ & 0.8 & 1.4 \\
& 3.9 & 3.5 \\
\hline \hline
\end{tabular}

${ }^{125} \mathrm{Sb}$, and ${ }^{129} \mathrm{I}$ were detected. Concentrations of these radionuclides were significantly below those collected from RNM-1. Bryant (1992) also reports that a single assay for ${ }^{239} \mathrm{Pu}$ and ${ }^{241} \mathrm{Am}$ made in RMN-2S coincident the tritium peak revealed concentrations less than the detection limits of $10^{6}$ and $10^{5}$ atoms $/ \mathrm{ml}$ (or $1.66 \times 10^{-15}$ and $1.66 \times 10^{-14} \mathrm{~mol} / \mathrm{kg}-\mathrm{H}_{2} \mathrm{O}$ ), respectively.

\subsection{Definition of the hydrologic source term}

As discussed above, the hydrologic source term at CAMBRIC will generally be defined in terms of the aqueous speciation and abundance of a selected set of radionuclides that are introduced into groundwater as aqueous species or colloids, and by the rate and extent of radionuclide migration away from the near field environment. The hydrologic source term is the portion of the radiologic source 
Table 5: Inventory of selected radionuclides at the CAMBRIC test, decay corrected to zero time on May 14, 1965 (after Hoffman et al. , 1977, Hoffman, 1979, Schroeder et al. , 1993, and Smith, 1995b).

\begin{tabular}{lccc}
\hline \hline Radionuclide & Half life $(\mathrm{y})$ & Abundance $(\mathrm{Ci})$ & Abundance $($ moles $)$ \\
\hline${ }^{3} \mathrm{H}$ & 12.26 & $5.94 \times 10^{4}$ & 2.04 \\
${ }^{85} \mathrm{Kr}$ & 10.72 & 8.55 & $2.56 \times 10^{-4}$ \\
${ }^{90} \mathrm{Sr}$ & 28.78 & 42.3 & $3.44 \times 10^{-3}$ \\
${ }^{99} \mathrm{Tc}{ }^{a}$ & $2.11 \times 10^{5}$ & .017 & $1.01 \times 10^{-2}$ \\
${ }^{106} \mathrm{Ru}$ & 1.02 & $2.50 \times 10^{3}$ & $7.13 \times 10^{-3}$ \\
${ }^{125} \mathrm{Sb}$ & 2.76 & 39.4 & $3.04 \times 10^{-4}$ \\
${ }^{137} \mathrm{Cs}$ & 30.17 & $1.26 \times 10^{2}$ & $1.07 \times 10^{-2}$ \\
${ }^{144} \mathrm{Ce}$ & 0.78 & $2.89 \times 10^{3}$ & $6.30 \times 10^{-3}$ \\
${ }^{147} \mathrm{Pm}$ & 2.62 & $4.65 \times 10^{2}$ & $3.40 \times 10^{-3}$ \\
${ }^{155} \mathrm{Eu}$ & 4.73 & 6.40 & $8.46 \times 10^{-5}$ \\
${ }^{238} \mathrm{U}$ & $4.47 \times 10^{9}$ & $2.94 \times 10^{-2}$ & $3.69 \times 10^{2}$ \\
${ }^{239} \mathrm{Pu}$ & $2.41 \times 10^{4}$ & $1.91 \times 10^{2}$ & 13.0 \\
${ }^{241} \mathrm{Am}$ & 432.2 & 44.2 & $5.19 \times 10^{-2}$ \\
& & & \\
\hline \hline
\end{tabular}

$\overline{\bar{a} \text { Parent chain includes }{ }^{99} \mathrm{Zr},{ }^{99} \mathrm{Nb} \text {, and }{ }^{99} \mathrm{Mo} \text {, which are all relatively refractory. }}$ Schroeder et al. (1993) put the ${ }^{3} \mathrm{H} /{ }^{99} \mathrm{Tc}$ ratio for CAMBRIC waters at $2.8 \times 10^{-7}$, which further implies most of the ${ }^{99} \mathrm{Tc}$ is contained in the glass.

term that is available for transport in groundwater. The hydrologic source term will evolve chemically in response to interactions among the groundwater, host rock and melt glass in the cavity, chimney and alluvium. In this report, we specifically do not address the possibility of radionuclides being transported as colloidal material ( $<1 \mu \mathrm{m}$ particles) in the groundwater.

\subsubsection{Radionuclide migration and speciation}

Migration of radionuclides away from the CAMBRIC test area is assumed to occur via aqueous species transport in groundwater. Some species that are immediately introduced into groundwater, such as tritium which occurs largely as HTO, are very mobile, and are readily moved away from the test area by ambient groundwater motion ${ }^{2}$.

Other radionuclide species, specifically those in the cavity and chimney areas, may partake in surface complexation, ion-exchange or sorption reactions, par-

\footnotetext{
${ }^{2}$ In the case of the CAMBRIC test, the groundwater motion was largely forced as a result of a nearby pumping experiment that was carried out for 16 years (Bryant, 1992).
} 
Table 6: Radionuclide concentrations measured in CAMBRIC waters from well RNM-1. Zones II through V (c. 1974) from Hoffman et al. (1977) (II = lower cavity, III = upper cavity, IV = chimney, and V = adjacent to chimney); Zones A, B and C from Buddemeier and Isherwood (1985). Concentrations given in molality and corrected to 5/14/65. Refer also to Fig. 37.

\begin{tabular}{|c|c|c|c|c|}
\hline \multirow[b]{2}{*}{ Radionuclide } & \multicolumn{4}{|c|}{ RNM-1 concentration $\left(\mathrm{mol} / \mathrm{kg}-\mathrm{H}_{2} \mathrm{O}\right)$} \\
\hline & Zone II & Zone III & Zone IV & Zone $\mathrm{V}$ \\
\hline${ }^{3} \mathrm{H}$ & $1.29 \times 10^{-10}$ & $8.08 \times 10^{-11}$ & $1.74 \times 10^{-12}$ & $5.88 \times 10^{-13}$ \\
\hline${ }^{90} \mathrm{Sr}$ & $3.68 \times 10^{-13}$ & $2.47 \times 10^{-13}$ & $2.14 \times 10^{-13}$ & $9.31 \times 10^{-15}$ \\
\hline${ }^{106} \mathrm{Ru}$ & $1.25 \times 10^{-11}$ & $4.36 \times 10^{-12}$ & & \\
\hline${ }^{137} \mathrm{Cs}$ & $7.56 \times 10^{-14}$ & $6.46 \times 10^{-14}$ & $3.78 \times 10^{-14}$ & $7.65 \times 10^{-15}$ \\
\hline \multirow[t]{2}{*}{${ }^{239,240} \mathrm{Pu}^{a}$} & $5.33 \times 10^{-14}$ & $4.78 \times 10^{-14}$ & & \\
\hline & $\mathrm{A}$ & $\mathrm{B}$ & $\mathrm{C}$ & \\
\hline${ }^{3} \mathrm{H}$ & $4.77 \times 10^{-11}$ & & $4.67 \times 10^{-12}$ & \\
\hline${ }^{60} \mathrm{Co}$ & $<8.37 \times 10^{-20}$ & & $<8.37 \times 10^{-20}$ & \\
\hline${ }^{90} \mathrm{Sr}$ & & $1.63 \times 10^{-15}$ & & \\
\hline${ }^{106} \mathrm{Ru}$ & $1.63 \times 10^{-15}$ & & $<4.87 \times 10^{-15}$ & \\
\hline${ }^{137} \mathrm{Cs}$ & $4.43 \times 10^{-15}$ & & $1.96 \times 10^{-15}$ & \\
\hline${ }^{155} \mathrm{Eu}$ & $<1.85 \times 10^{-19}$ & & $<1.85 \times 10^{-19}$ & \\
\hline
\end{tabular}

$\overline{\bar{a} \text { In this report, we assume that the plutonium used in the CAMBRIC device was }}$ "weapons grade" such that the majority of the ${ }^{239,240} \mathrm{Pu}$ is ${ }^{239} \mathrm{Pu}$ (DOE,1999).

ticularly with clays, zeolites, or iron-oxide minerals in the cavity, chimney and undisturbed alluvium. As a result, they will have some mobility in groundwater, although their migration rates may be strongly retarded. Migration may also be retarded if radionuclides precpitate from solution. A disparity in migration rates may, in part, be evidenced by the recovery of more mobile radionuclides in the RNM-2S pumping experiment, with a corresponding apparent lack of the potentially more immobile radionuclides, as illustrated in various elution curves shown in the Bryant (1992) report and related references.

Radionuclides incorporated in the cavity glass will be released slowly into the groundwater as the glass dissolves naturally. Released radionuclides will interact with dissolved constituents in local groundwater to form mobile species that may be affected by precipitation, ion exchange and sorption processes in the cavity, chimney and undisturbed alluvium. The bulk rate of glass dissolution is controlled by the available surface area of the melt glass, the water chemistry, 
glass composition and temperature. The bulk dissolution rate may be decreased by clays that form along the glass surfaces. This will tend to armor the glass, clog flow pathways, and reduce glass contact area with groundwater.

Some radionuclide species (e.g., $\mathrm{Pu}$ ) may form colloids or sorb onto naturallyoccurring colloids that will facilitate or enhance radionuclide migration away from the test cavity or chimney (Ryan and Elimelech, 1996; Kersting et al., 1998). This will depend on the abundance of radionuclides, the availability of natural colloidal material, and geochemical conditions that promote colloid stability and radionuclide attachment. We do not specifically address colloidfacilitated transport in our calculations.

It is possible that some gaseous radionuclides may be injected vertically into zones that are unsaturated and above the current water table. Some of these (or, possibly, their daughter products) may ultimately become dissolved in residual moisture and migrate slowly back to the saturated regime. Although this scenario will not be considered here in the context of CAMBRIC, the reader is referred to Guell (1997) for an expanded discussion of this topic.

Many of these processes, such as the glass dissolution rates, will be dependent on temperature and may fluctuate in their intensity or magnitude if there is a lasting thermal signature in the cavity environment. Due to the small size of the CAMBRIC test, lasting thermal signatures are not expected.

\subsubsection{Exchange volume and melt glass source regions}

To simplify the discussion throughout this paper, we will define the volumetric portions of the collapsed cavity, chimney, and sidewall systems that contain significant amounts of radionuclides as the "exchange volume". The radionuclides in this volume will include many of the more volatile (non-refractory) species that have been exchanged or moved around as gases prior to recondensation. The exchange volume is considered to be distinct from the "melt glass", although, together, both will comprise the initial region of radionuclide contamination that the simulations must be based upon.

The size and geometry of the exchange volume can be difficult, in general, to fully ascertain using the kind of data that is typically available. The LLNL CAMBRIC simulations adopted a simple $18-\mathrm{m}$ radius spherical model that is compatible, in part, with approximate measures of the post-test tritium distribution used by Hoffman et al. (1977) and Burbey and Wheatcraft (1986) (Fig. 11). However, this should only be regarded as a provisional estimate at this time. Related discussions may be found in Chapters $6,7,10$, and 11, as well as Appendix 5 .

\subsubsection{Radionuclide decay}

Radioactive decay of residual actinide nuclear weapons fuels breed radioactive daughter products which in turn contribute to the post-test radiologic source 


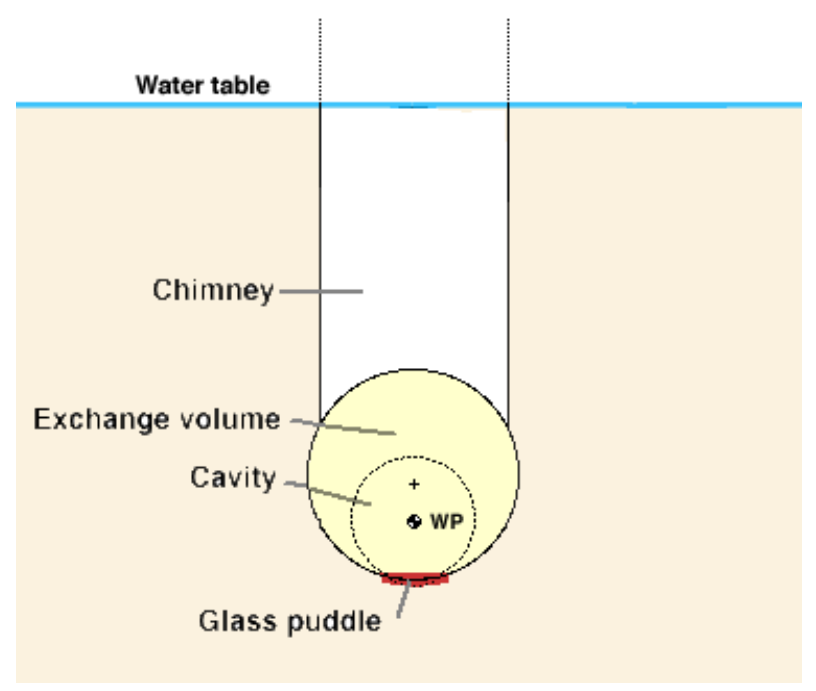

Figure 11: Generic illustration of geologic units that comprise the cavity/chimney system in a saturated environment (see text).

term. The decay of the actinide parents and the in-growth of their daughters emphasizes the dynamic nature of the weapons source term.

Radioactive daughter products may be important because they pose similar risks as the parents, and thus may be of continued concern from a regulatory perspective. In other cases, daughter products may chemically interfere and affect the migration rates of radionuclides, and require specific consideration in order to completely model the system. In still other cases, daughter products may be unimportant, but the time scales of parental decay may limit the times and spatial locations over which parental radionuclide migration are of interest.

In general, actinide decay chains are long; the ${ }^{238} \mathrm{U}$ chain has in excess of 16 daughter radionuclides. Significant decay schemes are listed in Appendix 1. Inclusion of every member of every actinide decay chain for the purposes of source term modeling is not warranted; in most cases substantial in-growth of daughters occurs on time-scales in excess of 1000 years. For this reason, the CAMBRIC actinide source term does not incorporate the evolving inventory of daughter products. In addition, as shown in Appendix 1, most of the non-actinide radionuclides considered here decay through short chains to stable daughters.

For simplicity, all simulations reviewed in this report were originally made in the absence of decay. Predicted spatial distributions or breakthrough profiles for the radionuclide species considered were later corrected ex post facto to show losses arising from decay, but not to generate secondary inventories for 
additional source term calculations. Nevertheless, ${ }^{241} \mathrm{Pu}$ has a half-life of 14.4 years $\left({ }^{241} \mathrm{Pu} \rightarrow{ }^{241} \mathrm{Am} \rightarrow{ }^{237} \mathrm{~Np} \rightarrow{ }^{233} \mathrm{U}\right)$. This decay results in increasing activities of ${ }^{241} \mathrm{Am}$ (and decreasing activities of ${ }^{241} \mathrm{Pu}$ ) on times scales of $<1000$ years and might be reasonably included in future calculations. 
Chapter 3: Physical and Chemical Setting 


\section{Modeling Approach}

The technical approach used in this project is based upon several distinct characterization and modeling efforts that are ultimately linked together. Principal among these include:

- Selection of a representative subset of radionuclides for consideration, based on data availability, classification, risk to human health, half-life, abundance, and their expected reactivity and mobility in groundwater.

- Development of a glass dissolution model to predict the rate at which glass-bound radionuclides are introduced into groundwater. Although a temperature-dependent model was developed, an ambient temperature of $25^{\circ} \mathrm{C}$ was assumed for simplicity. This is supported by the fact that no distinct elevated temperatures have been reported in groundwater or soil samples taken 10 years after CAMBRIC was detonated.

- Development of geochemical models to describe the relevant aqueous complexation, surface complexation, ion exchange, precipitation and dissolution, and other reactions that control radionuclide retardation and migration. An ambient temperature of $25^{\circ} \mathrm{C}$ was assumed to exist.

- Integration of this chemical behavior into a simple one-dimensional transport model to forecast the chemical behavior and migration rate of radionuclides along a single streamline or flow path that passes through a nonuniform regime of melt glass, cavity and chimney rubble and/or undisturbed alluvium.

- Development of a representative three-dimensional groundwater flow model within the near field environment surrounding the CAMBRIC test, incorporating, as necessary, ambient or pumping well auxiliary conditions and calibration steps that relate to existing data and flow models.

- Subsequent application of a multiple-streamline model to the near field CAMBRIC system using available radionuclide inventory and chemical partitioning data to describe and constrain the initial distribution and form of radionuclides.

- Combination of multiple-streamline simulation results to forecast the threedimensional chemical nature and migration rate of radionuclides in the near field and estimate the rate of radionuclide flux out of the near field.

- Sensitivity analyses that address effects of melt glass and reactive mineral surface area, as well as the spatial abundance and distribution of the reactive minerals in alluvium. 


\section{Selection of Radionuclides for Analysis}

Selection criteria for the radionuclides investigated in this study were mainly based on

- The unclassified radiologic source term inventory,

- The general availability of thermodynamic data for radionuclides associated with nuclear tests,

- A desire to consider radionuclides emanating from different source environments such as the glass or chimney and cavity systems, and

- Those radionuclides known to be in relative abundance, toxic to human and environmental health, and potentially mobile in the subsurface.

Although a portion of the inventory at the CAMBRIC site is unclassified, radionuclide inventories associated with most nuclear tests are generally classified. Specifics about the partitioning and abundance of these radionuclides are included in Tables 1 and 5 .

Table 7: Some of the characteristics of radionuclides that were considered in this study. ${ }^{99} \mathrm{Tc}$ was not considered in the transport model because of its conservative (anionic) chemical behavior. ${ }^{3} \mathrm{H}$ was only considered in the analysis of the pumping experiment in RNM-2S.

\begin{tabular}{|c|c|c|c|}
\hline Radionuclide & $\begin{array}{l}\text { Principal } \\
\text { source(s) }\end{array}$ & $\begin{array}{l}\text { Dominant } \\
\text { aqueous species }\end{array}$ & $\begin{array}{l}\text { Processes } \\
\text { affecting transport }\end{array}$ \\
\hline${ }^{3} \mathrm{H}$ & $\begin{array}{l}\text { chimney, } \\
\text { cavity }\end{array}$ & water (HTO) & flow \\
\hline${ }^{90} \mathrm{Sr}$ & $\begin{array}{l}\text { chimney, } \\
\text { cavity }\end{array}$ & cation & $\begin{array}{l}\text { flow, co-precipitation, } \\
\text { sorption }\end{array}$ \\
\hline${ }^{99} \mathrm{Tc}$ & glass & anion & flow \\
\hline${ }^{137} \mathrm{Cs}$ & $\begin{array}{l}\text { chimney, } \\
\text { cavity }\end{array}$ & cation & flow, ion exchange \\
\hline${ }^{155} \mathrm{Eu}$ & glass & neutral hydroxycarbonate & $\begin{array}{l}\text { flow, precipitation, } \\
\text { sorption, colloids }\end{array}$ \\
\hline${ }^{239} \mathrm{Pu}$ & glass & carbonate anion & $\begin{array}{l}\text { flow, precipitation, } \\
\text { sorption, colloids }\end{array}$ \\
\hline${ }^{241} \mathrm{Am}$ & glass & neutral hydroxycarbonate & $\begin{array}{l}\text { flow, precipitation, } \\
\text { sorption, colloids }\end{array}$ \\
\hline
\end{tabular}


The most important criterion for selection of radionuclides in this study is whether their abundances (inventories) are unclassified and available. The radionuclides that comprise this list include ${ }^{3} \mathrm{H},{ }^{85} \mathrm{Kr},{ }^{90} \mathrm{Sr},{ }^{106} \mathrm{Ru},{ }^{125} \mathrm{Sb},{ }^{137} \mathrm{Cs}$, ${ }^{144} \mathrm{Ce},{ }^{147} \mathrm{Pm},{ }^{155} \mathrm{Eu},{ }^{238} \mathrm{U},{ }^{239} \mathrm{Pu}$, and ${ }^{241} \mathrm{Am}$. The work of Schroeder et al. (1993) allowed the abundance of ${ }^{99} \mathrm{Tc}$ to be estimated as well. Nevertheless, there were additional considerations that compelled us to shorten the list of radionuclides included in the transport model. First of all, radionuclides that had very short half-lives, say less than 5 years $\left(e . g .,{ }^{106} \mathrm{Ru},{ }^{125} \mathrm{Sb},{ }^{144} \mathrm{Ce}\right.$, and ${ }^{147} \mathrm{Pm}$ ), were excluded from the list. Secondly, gases that do not react geochemically with the surrounding geologic media $\left(e . g .,{ }^{85} \mathrm{Kr}\right)$ were eliminated. Thirdly, ${ }^{238} \mathrm{U}$ was eliminated because the natural $\mathrm{U}$ concentration in the host rock is high and masks any signature of bomb-pulse ${ }^{238} \mathrm{U}$.

The list of radionuclides chosen according to the above process is shown in Table 7. Because ${ }^{3} \mathrm{H}$ and ${ }^{99} \mathrm{Tc}$ are known to migrate with groundwater and not interact with the surrounding geologic media (Borg et al., 1976), they were not considered in the geochemical modeling process, and not included in the final transport simulations ${ }^{3}$. The remaining subset of radionuclides chosen for this study has a varied initial distribution in the glass, chimney, and cavity areas, and represent a cross-section of geochemical behavior relating to sorption and ion exchange, precipitation and dissolution. In addition, the subset of radionuclides includes both fission products and activation products, short- and long-lived species, and highly to moderately hazardous species.

\footnotetext{
${ }^{3}$ Nevertheless, some theromdynamic data associated with specifc Tc species is included in Appendix 3 , and ${ }^{3} \mathrm{H}$ was used to aid calibration of the flow model.
} 


\section{Modeling Radionuclide Release from the Melt Glass}

The melt glass contains a significant fraction of the radionuclide inventory associated with the test. For this reason, it provides a source of radionuclides and must be considered in the radionuclide migration assessment. In order to predict the rates of release of radionuclides from the melt glass, we need to know the rate with which the glass reacts with typical ground waters, and how changes in parameters such as temperature, $\mathrm{pH}$ and other fluid compositional variables affect that rate. This chapter describes the glass dissolution rate model we use to model radionuclide release from the melt glass.

\subsection{Glass composition}

The melt glass has a composition very close to that of the host rocks of the test, with the exception of added trace amounts of radionuclides generated in the test. For the bulk melt glass composition at the CAMBRIC test, we use a typical rhyolitic rock composition with 75 weight \% silica, similar to the alluvium which hosts the test, with composition given in Table 8 (Schwartz et al. , 1984). The masses of radionuclides generated are given in Table 9, along with the distribution factors used to partition them into the melt glass, and their natural abundances in the rock.

Because the glass composition is so similar to natural glasses, we can use previous experimental studies of natural silicate glasses to estimate the dissolution rate of the radioactive melt glass. The effects of small amounts of contaminants, including radioactive ones with their associated radiation fields, have been shown to have negligible effects on glass dissolution rates (Bibler and Jantzen, 1987).

\subsection{Glass dissolution model}

\subsubsection{General features}

Glasses are thermodynamically unstable materials and tend to transform with time into more stable crystalline phases. The rate of this transformation provides an upper limit to the release rates of radioactive elements contained within the glass. Diffusion rates of ions through silicate glasses are too small to allow any appreciable release of any radionuclide through diffusion processes. Water acts as a flux to allow this process of transformation from glass to crystalline material to proceed at a significant rate.

When water first contacts alkali aluminosilicate glass, a rapid ion exchange process takes place which depletes or removes the alkalis in the outermost few microns of glass. With time, this outer alkali-depleted hydrous surface layer thickens until a steady-state is reached. The thickness of the layer then remains 
Table 8: Composition of rhyolitic melt glass at the CAMBRIC test (Schwartz, et al., 1984). Radioactive elements are in bold.

\begin{tabular}{|c|c|c|c|c|c|c|}
\hline Oxide & weight \% & $\begin{array}{c}\text { Oxide } \\
\text { mole } \%\end{array}$ & $\mathrm{~mol} / 100 \mathrm{~g}$ & weight $\%$ & $\begin{array}{c}\text { Element } \\
\text { mole } \%\end{array}$ & $\mathrm{~mol} / 100 \mathrm{~g}$ \\
\hline $\mathrm{O}$ & & & & 49.6 & 64.2 & 3.1 \\
\hline $\mathrm{SiO}_{2}$ & 75.9 & 82.5 & 1.3 & 35.5 & 26.1 & 1.3 \\
\hline $\mathrm{Al}_{2} \mathrm{O}_{3}$ & 13.7 & 8.8 & 0.13 & 7.3 & 5.6 & 0.27 \\
\hline $\mathrm{Fe}_{2} \mathrm{O}_{3}$ & 3.1 & 1.3 & $1.9 \times 10^{-2}$ & 2.2 & 0.8 & $3.9 \times 10^{-2}$ \\
\hline $\mathrm{Na}_{2} \mathrm{O}$ & 1.1 & 1.2 & $1.8 \times 10^{-2}$ & 0.9 & 0.8 & $3.7 \times 10^{-2}$ \\
\hline $\mathrm{K}_{2} \mathrm{O}$ & 2.9 & 2.0 & $3.0 \times 10^{-2}$ & 2.4 & 1.3 & $6.1 \times 10^{-2}$ \\
\hline $\mathrm{P}_{2} \mathrm{O}_{5}$ & 0.1 & 0.05 & $8.1 \times 10^{-4}$ & 0.05 & 0.03 & $1.6 \times 10^{-3}$ \\
\hline $\mathrm{CaO}$ & 2.3 & 2.7 & $4.1 \times 10^{-2}$ & 1.6 & 0.8 & $4.1 \times 10^{-2}$ \\
\hline $\mathrm{MgO}$ & 0.9 & 1.5 & $2.3 \times 10^{-2}$ & 0.6 & 0.5 & $2.3 \times 10^{-2}$ \\
\hline $\mathrm{SrO}$ & 0.04 & 0.03 & $4.4 \times 10^{-4}$ & $3.9 \times 10^{-2}$ & 0.01 & $4.4 \times 10^{-4}$ \\
\hline $\mathbf{P u O}_{2}$ & $4 \times 10^{-4}$ & $1.1 \times 10^{-4}$ & $1.6 \times 10^{-6}$ & $4.0 \times 10^{-4}$ & $3.4 \times 10^{-5}$ & $1.6 \times 10^{-6}$ \\
\hline $\mathrm{Am}_{2} \mathrm{O}_{3}$ & $3 \times 10^{-6}$ & $2.1 \times 10^{-7}$ & $5.9 \times 10^{-9}$ & $1.5 \times 10^{-6}$ & $1.3 \times 10^{-7}$ & $1.2 \times 10^{-8}$ \\
\hline $\mathbf{E u}_{2} \mathbf{O}_{3}$ & $1 \times 10^{-4}$ & $2.2 \times 10^{-5}$ & $3.3 \times 10^{-7}$ & $9.9 \times 10^{-5}$ & $1.4 \times 10^{-5}$ & $6.5 \times 10^{-7}$ \\
\hline $\mathrm{Cs}_{2} \mathrm{O}$ & $2 \times 10^{-4}$ & $4.9 \times 10^{-5}$ & $8.1 \times 10^{-7}$ & $2.2 \times 10^{-4}$ & $3.1 \times 10^{-5}$ & $1.6 \times 10^{-2}$ \\
\hline Totals & 100 & 100 & 1.5 & 100 & 100 & 4.8 \\
\hline
\end{tabular}

approximately constant as it migrates into the glass (Bourcier, 1994). At steady state, release of elements from the glass is essentially stoichiometric. However, most of the elements are quickly incorporated into alteration phases. For a silicate glass such as that generated at the CAMBRIC site, the glass will react with groundwater to form mainly clay and zeolite minerals. There is usually a volume increase associated with this process, which tends to restrict further fluid contact with the glass.

Alkali aluminosilicate glasses, such as rhyolite and dacite glasses, typically show a $\mathrm{pH}$ dependence to their dissolution rates which has a minimum at near neutral pHs (see Fig. 12). The test results shown in Figure 12 (from Mazer, 1987) are from flow-through experiments where the solutions are buffered at a constant $\mathrm{pH}$ and dissolving glass species are not allowed to build up in solution. These rates are therefore the fastest at which the glass will dissolve at the given $\mathrm{pH}$ (excepting any catalytic effects). The rates also show a progressive increase in durability (decrease in dissolution rate) as the silica content goes up. Rhyolitic 
Table 9: Radionuclide abundances in melt glass based upon 905 metric tons of glass. Weight \% oxide refers to oxides derived from radioactive materials, natural materials, and what was used in the model, respectively.

\begin{tabular}{lccccccc}
\hline \hline & & \multicolumn{1}{c}{ Abundance } & \multicolumn{2}{c}{ Amount in glass } & \multicolumn{4}{c}{ Weight \% oxide } \\
Element & $\begin{array}{c}\text { moles }) \\
\%\end{array}$ & moles & rad. & natural & model & Oxide \\
\hline${ }^{90} \mathrm{Sr}$ & $3.4 \times 10^{-3}$ & 25 & $8.6 \times 10^{-4}$ & $9.4 \times 10^{-9}$ & 0.04 & $4.0 \times 10^{-2}$ & $\mathrm{SrO}$ \\
${ }^{137} \mathrm{Cs}$ & $1.1 \times 10^{-2}$ & 10 & $1.1 \times 10^{-3}$ & $3.2 \times 10^{-8}$ & 0.0002 & $2.0 \times 10^{-4}$ & $\mathrm{Cs}_{2} \mathrm{O}$ \\
${ }^{155} \mathrm{Eu}$ & $8.5 \times 10^{-5}$ & 95 & $8.0 \times 10^{-5}$ & $3.0 \times 10^{-9}$ & 0.0001 & $1.0 \times 10^{-4}$ & $\mathrm{Eu}_{2} \mathrm{O}_{3}$ \\
${ }^{239} \mathrm{Pu}$ & 13. & 95 & 12. & $3.9 \times 10^{-4}$ & 0 & $3.9 \times 10^{-4}$ & $\mathrm{PuO}_{2}$ \\
${ }^{241} \mathrm{Am}$ & $5.2 \times 10^{-2}$ & 95 & $4.9 \times 10^{-2}$ & $2.8 \times 10^{-6}$ & 0 & $2.8 \times 10^{-6}$ & $\mathrm{Am}_{2} \mathrm{O}_{3}$ \\
& & & & & & & \\
\hline \hline
\end{tabular}

glass dissolve more slowly than basaltic ones. The dissolution experiments of Mazer were performed on 6-component synthetic volcanic glasses.

Glasses exhibit a saturation effect similar to crystalline solids. In closed system dissolution rate measurements where species build up in solution, we see a saturation effect which causes the dissolution rate to slow down. The decrease in rate can be several orders of magnitude. For silicate glasses, the effect is due mainly to dissolved silica. Most other aqueous species have a much less important effect, particularly at neutral to alkaline pHs. This saturation effect which slows the reaction rate is likely to be important for the slowly flowing groundwaters interacting with the melt glass at the CAMBRIC site.

\subsubsection{Rate equation}

For the purposes of our flow and transport simulations, the melt glass will be considered as a water-saturated porous medium whose matrix is completely composed of fractured (or cracked) melt-glass material. The effective rate of radionuclide transfer from the glass into the interstitial waters will be controlled by the intrinsic rate of glass dissolution. At the macroscopic level, this can be described at a point in a static (nonflowing) system by (Appendix 2)

$$
\phi \frac{d c_{j}}{d t}=\nu_{j} r_{g}=\nu_{j} A_{s} k(T) \cdot f\left(a_{i}\right) \cdot g\left(\Delta G_{r}\right) .
$$

where $c_{j}$ is the aqueous concentration of radionuclide $j$ in the pore water (moles$j / \mathrm{m}^{3}$-fluid), $\phi$ is the melt-glass porosity, $r_{g}$ is the bulk rate of intrinsic glass dissolution per unit volume of bulk medium (moles-glass $/ \mathrm{m}^{3}$-medium $/ \mathrm{s}$ ), and $\nu_{j}$ is a stoichiometric coefficient that describes the fraction of radionuclide $j$ contained within the glass (see below). The bulk rate of glass dissolution is 


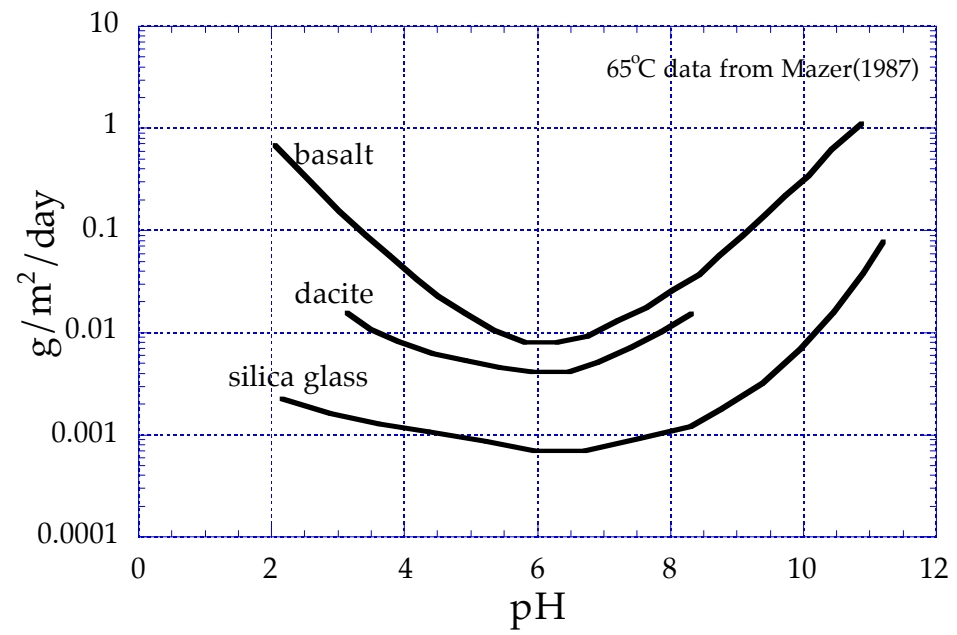

Figure 12: Dissolution rates for synthetic volcanic glasses measured at $65^{\circ} \mathrm{C}$. 
dependent on the specific surface area of the melt-glass, $A_{s}\left(\mathrm{~m}^{2}\right.$-glass $/ \mathrm{m}^{3}$ medium), a temperature-dependent rate coefficient, $k$ (moles-glass $/ \mathrm{m}^{2}$-glass $/ \mathrm{s}$ ), a dimensionless factor $(f)$ dependent on the activities $\left(a_{i}\right)$ of $N$ catalytic or inhibitive aqueous species, and another dimensionless factor $(g)$ dependent on free energy $\left(\Delta G_{r}\right)$ of the dissolution reaction. In turn, (1) may be reexpressed as (Aagaard and Helgeson, 1982)

$$
\phi \frac{d c_{j}}{d t}=\nu_{j} r_{g}=\nu_{j} A_{s} k\left(\prod_{i}^{N} a_{i}^{p_{i}}\right)\left(1-\frac{Q}{K}\right),
$$

where the $p_{i}$ are determined empirically, and $Q$ and $K$ are the activity product and equilibrium constant for the glass dissolution reaction, respectively. The quantity $(1-Q / K)$ is called the affinity term and provides for a slow-down in the rate resulting from saturation effects. Commonly, for glass dissolution processes, only the effect of $\mathrm{pH}\left(a_{H^{+}}\right)$is included in the product term.

\subsubsection{Rate equation parameters}

For the CAmbric glass, the data in Figure 12 (from Mazer, 1987) was used to regress the value of the rate coefficient as a function of glass silica content. The $65^{\circ} \mathrm{C}$ data for dacite glass was first fit to a 3rd order polynomial (Fig. 13). Based on the data shown in Figure 13, the dissolution rate was then assumed to decrease by about $0.03 \log$ units for each $1 \%$ increase in $\mathrm{SiO}_{2}$ content. Thus, the $\mathrm{pH}$ dependence of the glass dissolution rate was assumed to parallel the measured data for dacite, but is offset to higher or lower rates depending on the glass silica concentration relative to the dacite (which has about 63 weight $\left.\% \mathrm{SiO}_{2}\right)$. This regression covers silica concentrations in the glass of 50 to 75 weight $\%$.

To account for temperature changes, the rate coefficient $k$ was adjusted in terms of an activation energy $\left(E_{a}\right)$ and a reference rate $\left(k_{r}\right)$ determined at a reference temperature $\left(T_{r}\right)$ :

$$
\ln \frac{k}{k_{r}}=-\frac{E_{a}}{R}\left(\frac{1}{T}-\frac{1}{T_{r}}\right),
$$

where $R$ is the gas constant. Activation energies for dissolution of silicate glasses in water of around $20 \mathrm{kcal} /$ mole are typical (Knauss et al., 1990).

Dissolving glasses exhibit a saturation effect. As species originally present in the glass build up in solution, the dissolution rate of the glass gets smaller. Previous studies of silicate glasses have shown that the primary cause of this slowing is the increasing concentration of dissolved silica. Although other species have some effect, we will limit the model to the effect of silica only because of the lack of more detailed information. This implies that the value of $Q$ in the saturation or affinity term $(1-Q / K)$ in $(2)$, is simply the activity (or concentration) of $\mathrm{SiO}_{2}(\mathrm{aq})$. 


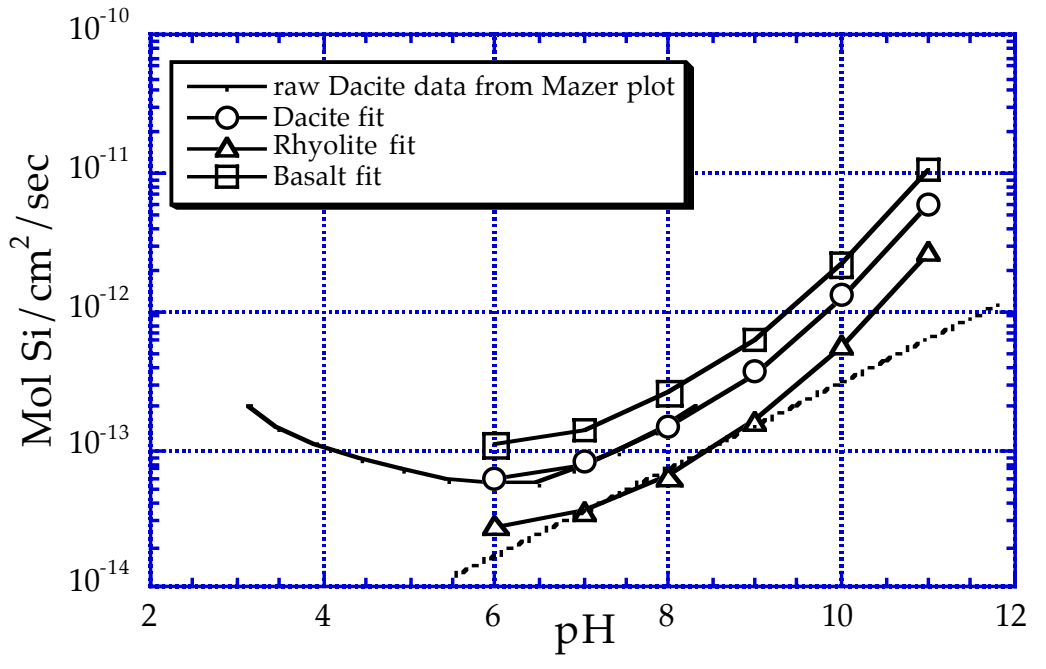

Figure 13: Regression fits to experimental data at $65{ }^{\circ} \mathrm{C}$ for synthetic volcanic glasses. Curves show 3rd order polynomial fits to data. Data for dacite shown as dark curve; line with circles shows fit to dacite data. Dotted line shows estimated $\mathrm{pH}$ dependence of log rate for rhyolite glass used as input for reactive transport codes. 


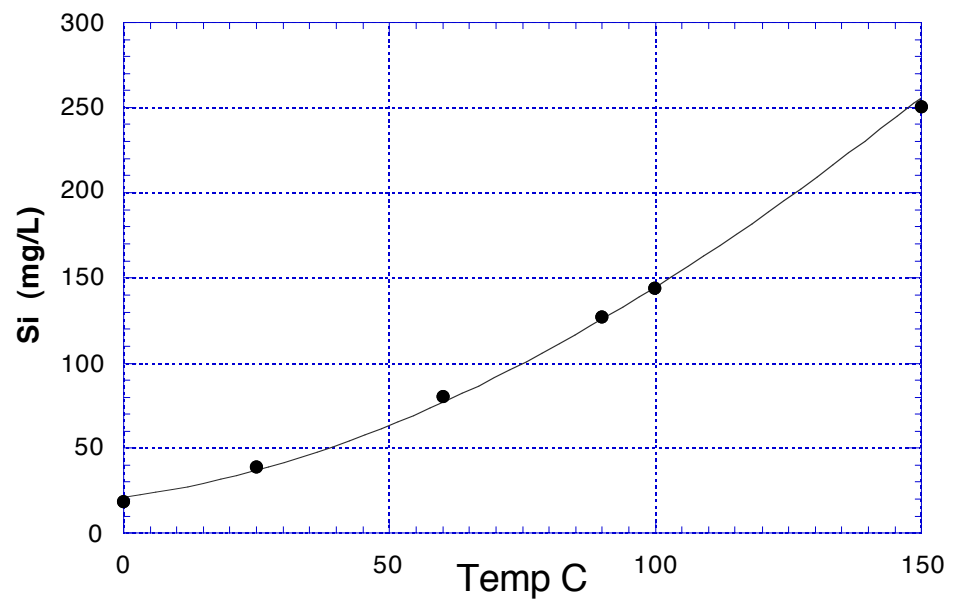

Figure 14: Silica saturation value for CAMBRIC melt glass. If groundwater leachate has higher concentration than this value, glass dissolves at minimum "silica saturation" rate which is $2.4 \times 10^{-7} \mathrm{~g} / \mathrm{m}^{2} /$ day at $25^{\circ} \mathrm{C}$ (see text).

The value of $K$ (the "silica saturation" value for the glass) is usually determined experimentally. For silica-rich glasses such as the CAMBRIC melt glass, values of $K$ are usually similar to the $K$ values for relatively soluble silica polymorphs such as cristobalite and amorphous silica. Due to the lack of available experimental data on the CAMBRIC glass, we will make the conservative assumption that the $K$ for the glass is the same as that for amorphous silica. This provides a maximum value for $K$, and therefore a maximum and conservative value for the affinity term. The values of $K$ for the puddle glass are shown in Figure 14.

The form of the affinity term in (2) predicts that if silica concentrations are higher than the silica saturation level for the glass, the term becomes negative and the rate law implies that glass would precipitate, an impossible physical phenomena. In nature, the reaction rates of glasses slow to very small, barely measurable values in high-silica concentration solutions. To account for this, we replace the rate term $\left(r_{g}\right)$ in (1) or (2) by a default, long-term rate (denoted by $\left.r_{g, l}\right)$ when the affinity term is computed to be less than or equal to zero. Under these conditions, the long-term rate equals the rate of dissolution under silica saturated conditions. Because there are no appropriate rate data for the actual 
CAMBRIC melt glass under these high silica conditions, we use data measured on silicate waste glasses at $90^{\circ} \mathrm{C}$ for this number, and the same activation energy as used to predict temperature effects on the intrinsic rate coefficient. With those assumptions, we get values for $r_{g, l}$ of $4.0 \times 10^{-8} \mathrm{~g} / \mathrm{m}^{2} /$ day at $10^{\circ} \mathrm{C}, 2.4 \times 10^{-7}$ $\mathrm{g} / \mathrm{m}^{2} /$ day at $25^{\circ} \mathrm{C}, 3.2 \times 10^{-6} \mathrm{~g} / \mathrm{m}^{2} /$ day at $50^{\circ} \mathrm{C}$, and of $4.0 \times 10^{-4} \mathrm{~g} / \mathrm{m}^{2} /$ day at $90^{\circ} \mathrm{C}$.

\subsubsection{Glass surface area}

One of the most critical and poorly defined parameters necessary to predict radionuclide release rates from the melt glass is the bulk specific surface area of the puddle. It is important because the reaction rate of the glass is proportional to the reactive surface area (eq. 2). There are several aspects to estimating the surface area which need to be considered:

1. When glasses cool from the outside, thermal gradients normal to the cooling surface produce differential thermal stress which cracks the glass. Even slowly cooled meter-sized glass masses end up as composites of fist-sized glass pieces along with finer material along a 3-D mosaic of cracks. A similar cracking process probably takes place as the melt glass cools.

2. Volatiles included in the cooling silicate liquid will tend to exsolve during vitrification and result in high porosity zones of bubbles, analogous to pumice in natural glasses (Fig. 15). These zones will have very high effective surface areas. However, it is unknown whether the high porosity will translate into a zone of high permeability.

3. As mentioned above, reactions between the melt glass and water will give rise to hydrous alteration products. This reaction has a positive molar volume change and will therefore have a tendency to decrease the permeability in the zones which contain the hydrous phases.

All three aspects are difficult to quantify without more detailed field examination of the actual CAMBRIC melt glass. Therefore we will use available data from other studies of glasses and make conservative assumptions to estimate the reactive surface area.

To estimate the extent of glass cracking, we will use experimental data for cracking in high-level waste glass. When large cans $(2 \mathrm{ft}$ in diameter $\times 10$ $\mathrm{ft}$ long) of borosilicate waste glass are cooled in air, leach testing shows that they have increased in leachable surface area relative to their geometric area by up to a factor of 25 times. The specific surface area $\left(A_{s}\right)$ created by the cooling process, based upon the entire volume of a can, is approximately $(25 \times$ outer cylinder area)/(bulk cylinder volume) $\approx 30 \mathrm{ft}^{2} / \mathrm{ft}^{3}$, or $98 \mathrm{~m}^{2} / \mathrm{m}^{3}$. These leach tests are of full-scale heated containers of glass. The test results empirically

account for the presence of restricted surface area at which diffusion-limited glass dissolution takes place. 


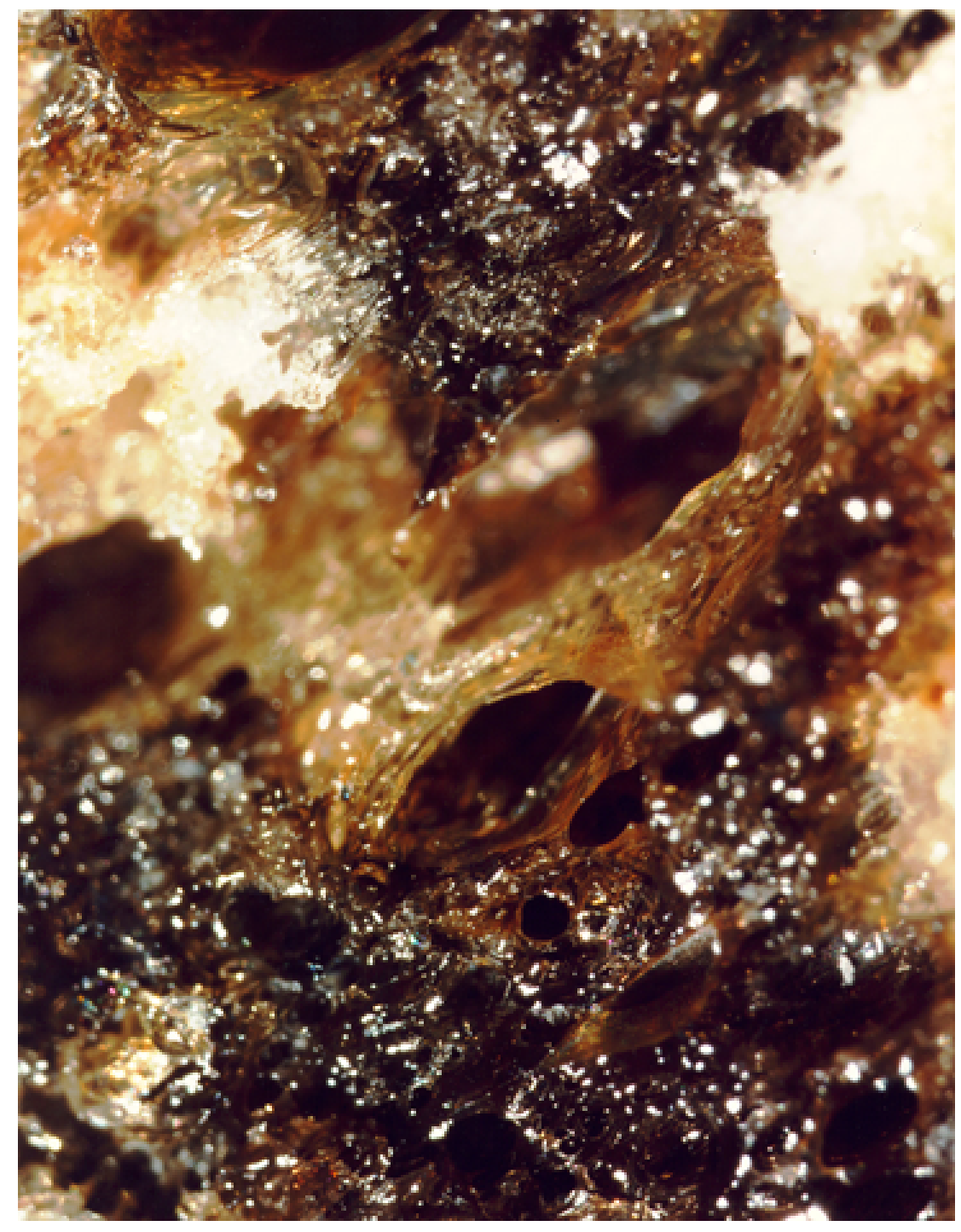

Figure 15: Detail of a melt glass specimen about 2 centimeters across from the BILBY test (U3cn, September 13, 1963), showing cracks, abundant vesicles and flow textures. The permeability and available surface area of this type of glassy material is difficult to estimate without measurements. 
As discussed in later chapters, the melt puddle at CAMBRIC will be represented by an approximately 8 -m radius, $2-\mathrm{m}$ thick glass cylinder sited at the bottom of the cavity. We will assume that the glass is fractured into a series of $4.58 \mathrm{~cm}$ cubes that are separated by $3.2 \mathrm{~mm}$ cracks, which is consistent with an overall porosity $(\phi)$ of 0.1 and a specific surface area $\left(A_{s}\right)$ of $118 \mathrm{~m}^{2}$-glass $/ \mathrm{m}^{3}$ medium. This surface area is therefore $20 \%$ larger than the maximum value measured from the high level waste glass containers. The bulk volume of the glass medium is approximately $402 \mathrm{~m}^{3}$, which, for $\phi=0.1$, yields $362 \mathrm{~m}^{3}$ of pure glass, or close to 905 metric tons using a glass density $\left(\rho_{g}\right)$ of $2.5 \mathrm{~g} / \mathrm{cm}^{3}$. This value is in the upper part of the predicted range of melt glass abundance for an 0.75 kt-yield test (Smith, 1993). Notice that the mass-based specific surface area, defined by $A_{s, m}=A_{s} /\left(\rho_{g}(1-\phi)\right)$ is approximately $0.52 \mathrm{~cm}^{2} / \mathrm{g}$-dry medium.

When the cylindrical geometry of the entire puddle is considered, the internally exposed area along the cracks is just under 100 times the outer cylindrical area of the puddle, almost 4 times as high as observed in the waste glass experiments. We will retain this higher factor to conservatively account for potentially higher areas created by pumice formation at CAMBRIC. It is also important to recognize that armoring or permeability decreases created by the formation of alteration minerals will not be accounted for here.

In trying to estimate reactive surface area for a melt glass, an important distinction must be made between the conditions of the kinetics experiments from which rate parameters were derived, and the field conditions we are trying to model. The experiments are designed to keep each particle of glass in full contact with the leachate. Under the test conditions, the glass particles are suspended in moving water, either due to flow or stirring, to insure complete contact between glass particle and fluid, with no diffusion (transport-limited) release. In the melt glass, water is flowing slowly through the fractured glass. Glass puddle-water contact is restricted to permeable zones. Water imbibed into cracks in less permeable zones will be less able to mix with bulk water. Reaction rates in these cracks will be slower due to saturation effects. Mass transfer out of the cracks may be diffusion-limited. Alteration minerals will precipitate along flow paths and restrict further water contact. These effects all tend to slow the overall dissolution rate of the glass, and therefore tend to decrease the value for effective surface area of the puddle used in the model. Therefore it is necessary to use as the value for reactive surface area, some value less than the total measured or estimated surface area in order to account for these effects. This is consistent with other measurements of reactive surface areas in field investigations where the measured rates are 1 to 3 orders of magnitude slower than rates measured on the same materials in stirred reactors (White and Peterson, 1990).

In the kinetic model for glass dissolution (eqs. 1 or 2), the surface area parameter is implicitly understood to account for glass surfaces that are in regular contact with flowing water, as opposed to isolated surfaces in restricted areas that are removed from the major flow-paths, as in fine cracks or vesicular zones. 
Because we do not have a measured surface area, and no detailed information on the permeability characteristics of the puddle, we have used the effective surface area measured for high-level waste glasses described in 5.2.4 as an approximation. In this way, we account somewhat for the existence of restricted surface area and alteration mineral formation, as both of those processes take place in the high level waste glass experiment from which we obtain our value for reactive surface area. Without more detailed information on the hydrologic characteristics, it is felt that this provides the best available estimate of reactive surface area for the CAMBRIC puddle ${ }^{4}$.

\subsection{Comparison with experimental data}

There are some available dissolution rate measurements of the actual CAMBRIC puddle glass and natural glasses of similar bulk composition with which to compare and validate our estimated rate data. Note that we have chosen not to use the CAMBRIC melt glass experimental rate data directly in our model because of problems identifying which reported elemental release rates are solubility vs. reaction rate controlled. Plus, these experimental data are all at a single temperature and fluid composition, and so they cannot be reliably extrapolated to the evolving conditions of our reactive transport model.

There are two reports which provide the rate of release of elements from the CAMBRIC melt glass in flow-through dissolution tests. Coles et al. (1978) report release rate data at $25^{\circ} \mathrm{C}$ for $\mathrm{Na}, \mathrm{Mn}, \mathrm{Co}, \mathrm{Cs}$, and $\mathrm{Sb}$ from CAmBric melt glass dissolving in NTS well water $5 \mathrm{~B}$. The glass was presumably rhyolitic (composition not given). The water had a $\mathrm{pH}$ of 8.5 and $28 \mathrm{ppm}$ dissolved Si. Figure 16 shows the reported dissolution rates for each element vs. our calculated value. One of the difficulties in interpreting experimental data of this type is knowing whether the elemental concentrations are fixed by their release rates from the glass, or are solubility controlled by alteration phases precipitating in the test. Of the elements listed, $\mathrm{Na}$ is probably the best indicator of overall glass dissolution rate, both because of its relatively higher release rate, and its known geochemical behavior. However, it is released from the glass in the ion exchange process mentioned above, so that early high release rate values shown in Figure 16 are probably indicative of the ion exchange process, not

\footnotetext{
${ }^{4}$ In a recent study of radionuclide release from the SHOAL test (Pohll et al., 1998), the mass-based reactive surface area $\left(A_{s, m}\right)$ of the SHOAL melt glass was estimated from BET measurements (Essington and Sharp, 1968) to be $A_{s, m} \approx 0.05 \mathrm{~m}^{2} / \mathrm{g}$, about a factor of 1,000 greater than our CAMBRIC value. The SHOAL area corresponds to an average grain size of about 100 microns, which, if used in the reaction model, would be equivalent to defining the melt glass as a reactive volume filled with a 100-micron glass powder and groundwater. The system would be similar to a stirred reactor composed of 100 micron grains suspended in solution. This could be viewed as an overly optimistic estimate of reactive surface area for a melt glass, even if it is highly fractured and vesicular. It is interesting to note, however, that the intrinsic glass dissolution rate parameter ( $k$ in eqs. 1 or 2$)$ used in SHOAL study $\left(10^{-9.3}\right.$ $\left.\mathrm{g} / \mathrm{m}^{2} / \mathrm{sec}\right)$ is remarkably close to our CAMBric value $\left(10^{-9.4} \mathrm{~g} / \mathrm{m}^{2} / \mathrm{sec}\right)$, despite the fact that they were arrived at independently.
} 


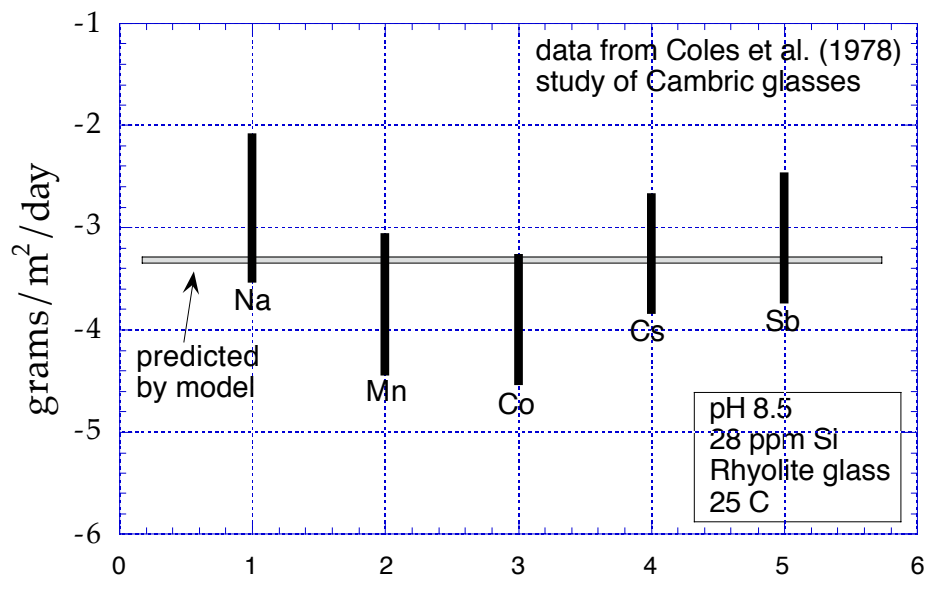

Figure 16: Measured release rates of elements from CAMBRIC melt glass in single pass flow-through tests at $25^{\circ} \mathrm{C}$. Bars show range of measured values. Horizontal line is predicted glass dissolution rate from model.

matrix dissolution (most of the $\mathrm{Na}$ data greater than $10^{-3}$ are for times earlier than 5 days). Therefore our predicted value of $10^{-3.3}$ is in fair agreement with long-term glass dissolution rates based on Coles et al. (1978).

Failor et al. (1983) did further flow-through tests on the CAMBRIC glass under similar conditions, but included longer test durations. Their results are compared with our calculated glass dissolution rates in Figure 17. Again the agreement between our estimated dissolution rates extrapolated from $65^{\circ} \mathrm{C}$ tests on synthetic glasses is good. The highest values for $\mathrm{Na}$ are again probably due to early ion exchange of the glass surface.

Note that in both the Coles et al. (1978) and Failor et al. (1983) reports, the material tested was hand-picked glass grains, crushed and sieved to a 40-150 micron size fraction. Powder x-ray analysis showed that from $65-100 \%$ of the material was glassy, the rest being various proportions of silica and feldspar phases. The bulk composition of this material is not given.

White (1983) reports dissolution rates of silica-rich natural glasses measured in static tests. For a 76 weight $\% \mathrm{SiO}_{2}$ obsidian dissolving in distilled water, he reports a dissolution rate of $0.87 \times 10^{-15} \mathrm{moles} / \mathrm{cm}^{2} / \mathrm{sec}$ (equivalent to $4.5 \times 10^{-5}$ $\mathrm{g} / \mathrm{m}^{2} /$ day). For the same conditions $\left(\mathrm{pH} 6.3,25^{\circ} \mathrm{C}, 0.03 \mathrm{mmol} \mathrm{Si}\right)$, we predict 


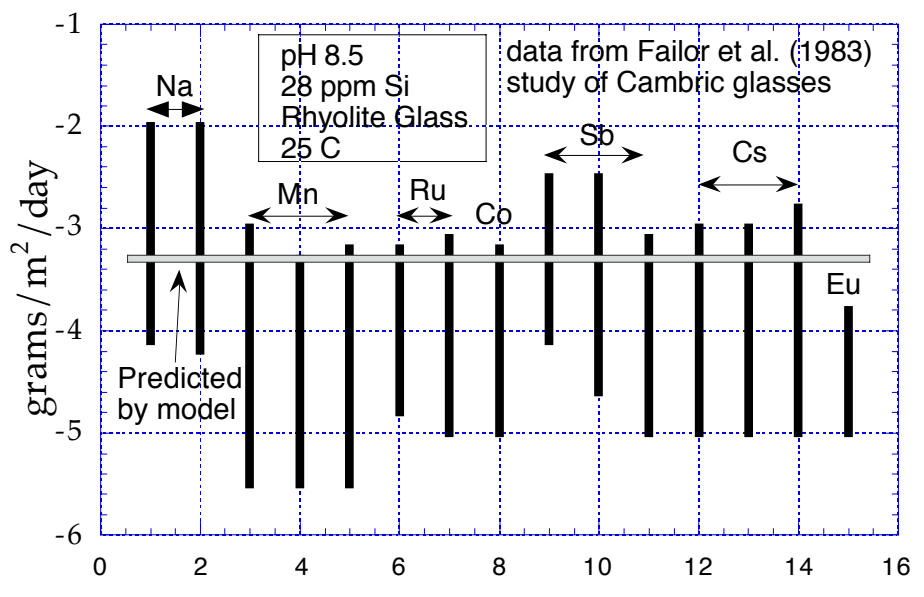

Figure 17: Measured release rates of elements from CAMBRIC melt glasses in single pass flow-through tests at $25^{\circ} \mathrm{C}$. Bars show range of measured values for tests of three glass samples. Horizontal line is predicted glass dissolution rate from model. 


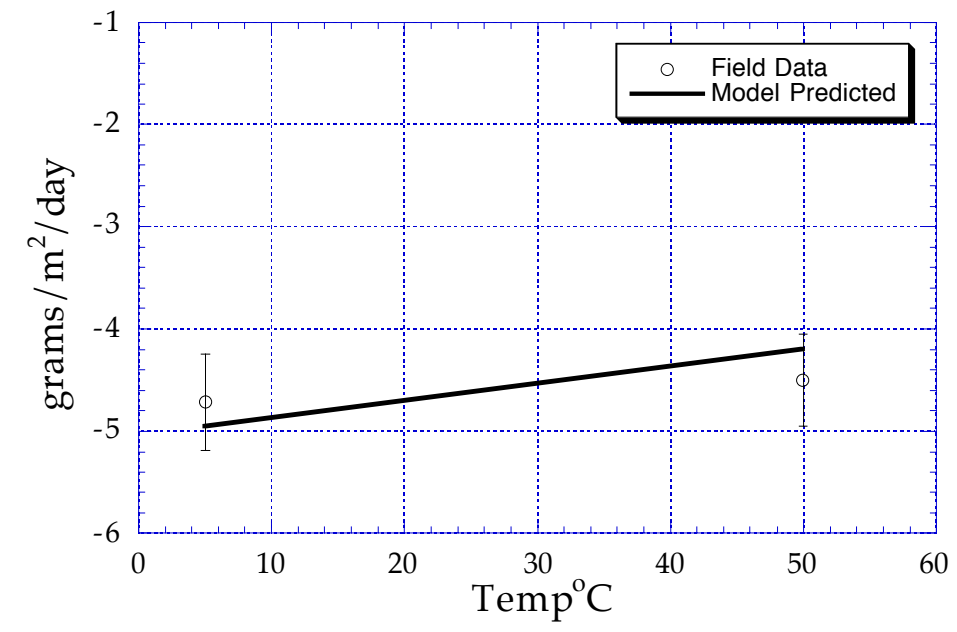

Figure 18: Comparison of field measured palagonitization rates of basaltic glasses in seawater with dissolution rates estimated from glass reaction model.

a value of $3.4 \times 10^{-5} \mathrm{~g} / \mathrm{m}^{2} /$ day, in good agreement with the measured value.

One additional comparison can be made between field data on glass dissolution rates and our model predictions. This has to do with rates of alteration of basalt by sea water, termed palagonitization. Smith (1998) uses data from Jercinovic and Ewing (1987) to estimate palagonitization rates of 2.6 to $4.3 \mathrm{mi}-$ crons per year at temperatures from 5 to $50^{\circ} \mathrm{C}$. These rates are compared with our model calculated values shown in Figure 18. Again, our predicted values lie in the range of values measured in natural environments.

The analysis of the experimental data of the flow tests and static tests above does not constitute a validation of the reactive surface area chosen for the melt glass. The analysis of these test results is based on reported BET-measured surface areas of the glass powders used in the tests. To model these tests, these measured surface areas are used along with a rate constant for glass which is also determined from kinetic experiments where surface areas were measured using the BET method. The agreement between model and experiments therefore validates the choice of rate constant, but not the choice of surface area. 


\subsection{Other factors affecting glass durability}

The dissolution rate of a silicate glass depends fairly strongly on glass composition, but also depends on the annealing history of the glass. The faster a glass is quenched, the more strain energy remains which causes the glass to dissolve more quickly. We assume here the relative cooling rates of extrusive rocks and the melt glass are both relatively slow and therefore there is no significant difference in annealing characteristics. We therefore do not attempt to account for any dissolution rate differences which could arise from variable cooling histories.

As mentioned above, the radiation field associated with radionuclides incorporated into the glass is likely to have a minimal effect on glass dissolution rates. The most significant effect is likely to be due to alpha emission from decaying actinides such as ${ }^{239} \mathrm{Pu}$. But at the low concentrations of $\mathrm{Pu}$ in the glass pool, this effect will probably be negligible (Weber et al., 1997).

\subsection{Incorporation of glass dissolution in reaction path mod- els}

In order to use the glass dissolution model described above in reactive transport calculations, we need to provide a data block for the glass reactant in the appropriate thermodynamic data file, and we need to provide the rate law in a form suitable for input to the reactive transport code.

\subsubsection{Glass data block}

The following balanced chemical reaction describes the dissolution of one mole of CAMBRIC melt glass:

$$
\begin{aligned}
\text { Melt glass }+110.62 \mathrm{H}^{+} \longrightarrow & 55.228 \mathrm{H}_{2} \mathrm{O}+0.965 \mathrm{O}_{2}(\mathrm{aq})+ \\
& 126 \mathrm{SiO}_{2}(\mathrm{aq})+26.90 \mathrm{Al}^{3+}+ \\
& 6.5 \times 10^{-5} \mathrm{Eu}^{3+}+3.6915 \mathrm{Na}^{+}+ \\
& 6.06 \mathrm{~K}^{+}+1.6 \times 10^{-4} \mathrm{Pu}^{4+}+ \\
& 2.27 \mathrm{Mg}^{2+}+1.62 \times 10^{-4} \mathrm{Cs}^{+}+ \\
& 4.41 \times 10^{-2} \mathrm{Sr}^{2+}+3.86 \mathrm{Fe}^{2+}+ \\
& 4.07 \mathrm{Ca}^{2+}+1.2 \times 10^{-6} \mathrm{Am}^{3+}+ \\
& 0.16 \mathrm{HPO}_{4}^{2-}
\end{aligned}
$$

The stoichiometric coefficients of the radionuclides on the right hand side correspond to the $\nu_{j}$ parameters used in the rate equations (1) and (2).

The glass has a molar volume of $3994.32 \mathrm{~cm}^{3} /$ mole and a molecular weight of 9985.782 grams. The molecular weight is arbitrary and was made to approximate 10,000 grams in order to increase the magnitude of the stoichiometric coefficients of the trace components in the glass. The glass has a silica content 
of 75 weight $\%$. The radionuclide contents in the glass were calculated using the data provided in Table 8 . Table 9 shows these values and the relative proportions in weight percent of radioactive and non-radioactive elements in the glass. The concentrations of $\mathrm{Cs}, \mathrm{Sr}$, and Eu are essentially their natural abundances. The contributions of radioactive $\mathrm{Cs}$, Sr, and $\mathrm{Eu}$ are much smaller than their natural abundances. The $\mathrm{Pu}$ and Am concentrations are all from the test. The natural abundances must be included with the radioactive additions in order to correctly partition these elements into ion exchange and surface complexation sites on minerals during the reactive transport calculation.

\subsubsection{Rate law}

As discussed above, the rate coefficient $k$ in (2) is a function of the silica content of the glass, the $\mathrm{pH}$, and the temperature. For experimental purposes, the Arrhenius relationship in (3) is usually expressed as

$$
k=A_{p} e^{-E_{a} / R T}
$$

where the activation energy $E_{a}$ is assumed constant at $20 \mathrm{kcal} / \mathrm{mole}$ under all conditions. The value of the pre-exponential factor $A_{p}$ (moles-glass $/ \mathrm{m}^{2} / \mathrm{s}$ ) is related to glass composition and the value regressed from the data of (Mazer, 1987 ) is given in Figure 19, along with the regression equation. Thus the effects of both temperature and glass composition on the rate coefficient are combined in this expression.

The effect of $\mathrm{pH}$ is accounted for in the rate equation (2) through the inclusion of a single $\left(\mathrm{H}^{+}\right)$species in product function. Here, $N=1, a_{1}=a_{H^{+}}$ and $p_{1}$ is the slope of the rate on a plot of log rate vs $\mathrm{pH}$. Although this form of rate equation shows a linear dependence between $\mathrm{pH}$ and $\log$ rate, our experimental data shows some curvature on such a plot. We have ignored this curvature here and have best fit a line through the data to provide the stoichiometric coefficient $\left(p_{H^{+}}\right)$. This line (dotted line in Fig. 13) has a slope of 0.33. Future work could include allowing for more complex relationships in the rate laws programmed into the reactive transport code if appropriate. For our CAMBRIC modeling calculations, the $\mathrm{pH}$ changes predicted for the fluid are so small that such refinements are thought not to be necessary.

The surface area of the glass based on the geometry and glass fracturing estimates provided above is $118 \mathrm{~m}^{2}$-glass $/ \mathrm{m}^{3}$-medium (or $0.52 \mathrm{~cm}^{2} / \mathrm{g}$-dry medium).

The values of the appropriate parameters needed to model the dissolution of a 75 weight \% rhyolite glass over a $\mathrm{pH}$ range of 6 to 10 are provided in Table 10 . These 4 parameters allow the rate coefficient for this glass to be calculated as a function of temperature and $\mathrm{pH}$ throughout the reaction progress calculation.

Finally, the affinity term $(1-Q / K)$ in reaction path codes is assumed to be expressed in terms of all the species participating in the dissolution reaction i.e., all the species present in the glass data block listed above. However, we 


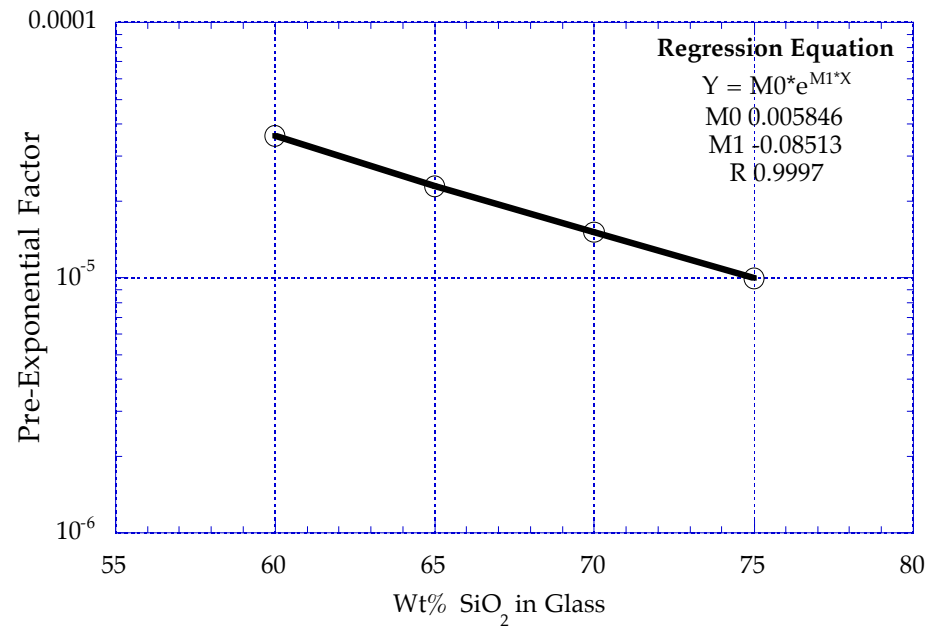

Figure 19: Pre-exponential factor in rate equation vs. glass silica content. 
Table 10: Glass dissolution rate model parameters.

\begin{tabular}{|c|c|}
\hline $\begin{array}{l}\text { Pre-exponential factor }{ }^{a}, A_{p}\left(\mathrm{~g} / \mathrm{m}^{2} \text {-glass } / \text { day }\right) \\
\text { Activation energy }^{b}, E_{a}(\mathrm{~J} / \mathrm{mole}) \\
\text { pH dependance }{ }^{c}, p_{H^{+}} \\
\text {Specific surface area }{ }^{d}, A_{s}\left(\mathrm{~m}^{2} \text {-glass } / \mathrm{m}^{3} \text {-medium }\right)\end{array}$ & $\begin{array}{l}9.94 \times 10^{-6} \\
83,680 \\
-0.33 \\
118\end{array}$ \\
\hline $\begin{array}{l}\bar{a} \text { From Figure } 19 . \\
b \text { } 20 \mathrm{kcal} / \text { mole. } \\
{ }^{c} \text { Exponent of } a_{H^{+}} \text {appearing in the rate law (2). } \\
d \text { Corresponds to } 0.52 \mathrm{~cm}^{2} / \mathrm{g} \text {-dry medium when } \rho_{g} \\
\phi=0.1 .\end{array}$ & $\mathrm{m} / \mathrm{cm}^{2}$ \\
\hline
\end{tabular}

have already determined that for melt glass dissolution, it is mainly the activity of $\mathrm{Si}$, and not the other species in the reaction, that affect the glass dissolution rate. Therefore, we want to calculate the value of the term $(1-Q / K)$ where $Q$ is now dissolved silica activity and $K$ is the "silica saturation" value for the glass, and substitute that value into the $(1-Q / K)$ term in the rate equation.

In general, geochemical modeling codes will not do this by default. However, both EQ3/6 (Wolery, 1992a,b) and Geochemist's Workbench (GwB) (Bethke, 1994, 1996) have mechanisms coded that allow for this substitution. GwB uses a "cross-affinity" option to allow the user to put in any desired affinity term into the rate expression. EQ3/6 can do the appropriate calculation by making use of its "special reactant" feature. However, the GIMRT and Os3D codes (Steefel and Yabusaki, 1996) used below do not yet have this capability.

Because the GIMRT and Os3D codes do not explicitly provide for the crossaffinity term, it was necessary to incorporate this term into the rate constant. In doing so, we essentially fixed the cross affinity term $(1-Q / K)$ at one value, rather than allowing it to change during the course of the simulation. Preliminary 1D simulations (described below) suggested that the $(1-Q / K)$ term remained constant throughout the simulations because the groundwater maintained silica concentration equivalent to that in equilibrium with $\beta$ cristobalite (discussed below). Therefore we based the $(1-Q / K)$ term on $Q$ for $\beta$-cristobalite and $K$ for amorphous silica. Because the $\mathrm{pH}$ of the groundwater was also maintained at 8 during the preliminary 1D simulations, we also used the rate constant appropriate for a $\mathrm{pH}$ of 8 in our reactive transport simulations. Given these assumptions, the rate constant of glass dissolution used in the reactive transport simulations was equal to $10^{-13.36} \mathrm{~mol} / \mathrm{m}^{2} / \mathrm{sec}$, where a mole of glass is defined for convenience to approximate 10,000 grams of glass. 


\subsection{Reaction rate of the melt glass}

The lifetime of the melt glass dissolving in groundwaters at various temperatures can be estimated by making some simple assumptions. First we assume the glass reacts with groundwaters which have silica concentrations that are at one half the glass silica saturation value. At 10,25 , and $50^{\circ} \mathrm{C}$ the silica concentration values are 18,26 , and $43 \mathrm{ppm} \mathrm{Si}$, respectively. These values are in the range of measured silica concentrations for groundwaters at NTS (Smith et al., 1997, Essington and Sharp, 1968). We also assume the fluid reacts slowly enough that the silica concentration of a water packet does not change significantly while it flows through the melt glass. Finally, we account for the decrease in surface area of the melt glass as it dissolves away in a manner consistent with our assumption of the matrix of $5 \mathrm{~cm}$ cubes described above. The results of this calculation are shown in Figure 20. Temperature has a fairly significant role in determining the lifetime of the melt glass. For anticipated temperatures of $25^{\circ} \mathrm{C}$ or less, the lifetime of the melt is greater than one million years.

How reasonable are these extrapolations of glass durability to long periods of time? The only knowledge available upon which to base an answer comes from studies of natural glasses. It is known from the geological record that natural glasses such as obsidians and glassy volcanic rocks are abundant in volcanic terrain. However, their relative amounts decrease with time until they are fairly rare in rocks greater than 30 million years old (Marshall, 1961). In the current simulations, aggressive leaching of a melt glass with undersaturated groundwaters gives a glass lifetime of one million years, which is consistent with the age range observed for natural glasses of similar composition. Most natural glasses probably experienced less aggressive conditions than the conservative values that have been chosen here (in terms of flow rates, reactive surface area, and solution saturation state). Also, if the rates of glass dissolution due to groundwater were significantly faster at the Nevada Test Site, we would see evidence in the form of dissolution features in the existing rhyolite glasses. No such dissolution features appear to exist. 


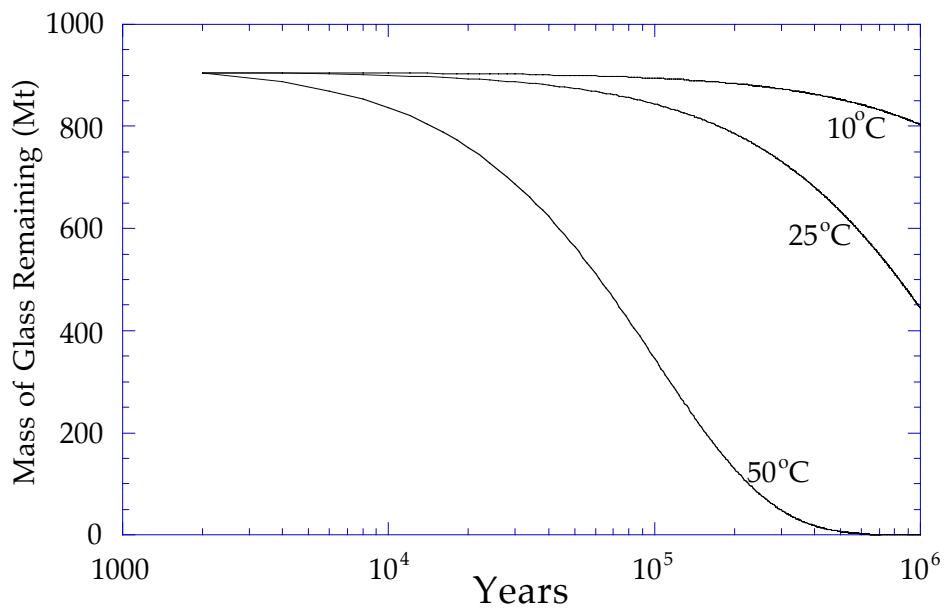

Figure 20: Estimate of mass of remaining CAMBRIC melt glass as a function of time calculated assuming a constant affinity term of 0.5 (half of saturation) at three different temperatures. The puddle surface area and geometry used are described in text. 


\section{Modeling Radionuclide Release and Chemical Interactions in the Cavity, Chimney, and Al- luvium}

The cavity and chimney contain significant quantities of radionuclides such as $\mathrm{Sr}$ and $\mathrm{Cs}$ (Table 1). The distribution and state of these radionuclides and the processes controlling their release must be considered in addition to glass dissolution when evaluating the hydrologic source term.

Very little is known about the physical and chemical state of radionuclides in the cavity/chimney region. Radionuclides may exist as discrete solid phases or as components of solid solutions, or as sorbed species on the surfaces of reactive minerals. The state of a radionuclide controls its partitioning between groundwater and alluvium in the cavity/chimney region. Whether sorbed or precipitated as solids, radionuclides can be released into groundwater via desorption, ion exchange or dissolution to contribute to the hydrologic source term.

Given the current lack of data, only the processes of dissolution, surface complexation and ion exchange were considered to impact radionuclide release from the cavity/chimney region. Precipitation, dissolution, surface complexation and ion exchange were assumed to control chemical retardation in the alluvium.

Table 11 summarizes the restricted set of radionuclides, surface processes and minerals that were considered to affect release and chemical retardation in the initial CAMBrIC study. Table 11 is by no means a comprehensive list of the radionuclides and solids that should be considered with regard to surface complexation and ion exchange. Given the scope and timeline of this project, it was necessary to use single mineral complexation and exchange data that were readily available in the literature. For example, single mineral sorption and exchange data were only readily available for $\mathrm{Pu}$ on hydrous iron oxides, although Kersting et al. (1998) demonstrated that $\mathrm{Pu}$ is associated with smectite and clinoptilolite colloids at NTS. Similarly, no retarding mechanisms for Eu and Am were considered in the simulations because of the absence of readily available single mineral sorption and exchange data. Eu and Am were therefore associated solely with the fluid phase in the exchange volume.

Although the potential existence of discrete radionuclide-bearing solids in the cavity/chimney region was considered, calculations showed that such solids were initially undersaturated in the cavity/chimney waters. The radionuclide inventory of the cavity/chimney region was distributed among the groundwaters filling the $40 \%$ porosity of the exchange volume. Geochemical calculations (described below in section 7.3), using the radionuclide concentrations obtained in this manner, revealed that the initial cavity/chimney waters were undersaturated with respect to potential radionuclide-bearing solids. It was therefore assumed that such solids do not exist initially in the cavity/chimney region, and do not contribute directly to the hydrologic source term.

Precipitation and dissolution of radionuclide-bearing solids were explicitly 
considered during the reactive transport simulations. Radionuclide-bearing solids were allowed to precipitate as a result of radionuclide release from the melt glass and cavity/chimney region, and re-dissolve if conditions warranted. The precipitation and dissolution of authigenic minerals (alteration minerals already present in the rock) were also explicitly considered. Whereas surface complexation and ion exchange were assumed to be controlled by equilibrium (i.e., reactions are instantaneous and reversible), the precipitation and dissolution of solids were controlled by kinetic rate laws (see Chapter 8). In general, surface complexation and ion exchange reactions occur much more quickly than solid precipitation/dissolution reactions.

Table 11: Summary of surface processes considered for radionuclides included in simulations.

\begin{tabular}{lllll}
\hline \hline & Surface complexation: & Ion exchange: & & \\
& $\begin{array}{l}\text { goethite } \\
\text { Radionuclide }\end{array}$ & $\begin{array}{l}\text { muscovite, } \\
\text { (hydrous ferric oxides) } \\
\text { (zeolite) }\end{array}$ & $\begin{array}{l}\text { (clay) } \\
\text { (clitectite }\end{array}$ & (clay) \\
\hline & & & yes & \\
$\mathrm{Pu}$ & yes & yes & yes \\
$\mathrm{Sr}$ & yes & & & \\
\hline \hline
\end{tabular}

The geochemical treatment of solid precipitation and dissolution is discussed in Chapter 8. The treatments of surface complexation and ion exchange processes in GIMRT are described initially in the following two sections, and in more detail in Appendix 3. The treatment of the nature and distribution of radionuclides in the cavity/chimney region is then discussed. The initial distribution of radionuclides and the processes that captured them in the cavity/chimney region will control the subsequent release of the radionuclides. Finally, provisions for the presence of both radiogenic and non-radiogenic (i.e., natural) isotopes in the melt glass and chimney/cavity region are reviewed.

\subsection{Surface complexation}

Variably charged solids such as oxyhydroxides of Fe, sometimes called hydrous ferric oxides (HFOs), can serve as $\mathrm{pH}$-sensitive sources and sinks of anions and cations through surface complexation (Dzombak and Morel, 1990; Sposito, 1984). Surface complexation refers to chemical reactions between reactive functional groups exposed on a solid surface and aqueous species in an adjacent 
fluid. The reactive functional groups at the solid surface (referred to as "sites") derive from unsatisfied bonds created by the discontinuity of a three-dimensional structure.

The reactive sites on the surfaces of oxide minerals may be negative, neutral or positive in charge depending on the extent of their protonation. Hence, the net charge on the surface may be positive or negative, depending on the $\mathrm{pH}$ of the solution. Oxide surfaces can therefore sorb anions as well as cations. Hydrous ferric oxides with large specific surface areas on the order of $600 \mathrm{~m}^{2} / \mathrm{g}$ have a sorptive capacity roughly equivalent to that of smectite when compared on a per mole of sorbent basis.

Some surface complexation and ion exchange models account for the presence of multiple types or classes of reactive sites. Each type of site is characterized by a unique binding constant (surface complexation) or exchange energy (ion exchange). The types of sites may be defined by detection with spectroscopic techniques, by crystallographic considerations, and/or because they are required to match experimental sorption data. One-, two- and three-site models are considered in this report.

Both surface complexation and ion exchange reactions vary as a function of aqueous complexation in the fluid phase, ionic strength, and the solid-fluid ratio. Surface complexation varies as a function of electrostatic effects, whereas ion exchange is sensitive to steric constraints imposed by the structure of the ion exchanger. Because the charge of reactive sites in oxides is controlled by $\mathrm{pH}$, surface complexation reactions are much more sensitive to $\mathrm{pH}$ than ion exchange. The extent of ion sorption can change drastically within a few $\mathrm{pH}$ units.

In the CAMBRIC simulations, surface complexation of $\mathrm{Pu}$ and $\mathrm{Sr}$ onto the hydrous iron oxide mineral called goethite $(\mathrm{FeOOH})$ was considered. Goethite was chosen to represent the forms of hydrous iron oxides that occur in alluvium at CAMBric. Surface complexation is described in GIMRT as a one-site nonelectrostatic model. As discussed in detail in Appendix 3, the current version of GIMRT lacks an electrostatic term which is common to many surface complexation models (for example, Dzombak and Morel, 1990). However, the impact of the electrostatic term is reduced by the low ionic strengths of the CAMBRIC waters, the water $\mathrm{pH}$ of 8 at which the electrostatic correction for goethite is a minimum, and the expected low density of sorbed radionuclides owing to the relatively small radionuclide inventory at CAMBRIC.

Binding constants for $\mathrm{Sr}$ and $\mathrm{Pu}$ on goethite using the one-site non-electrostatic model were calculated from experimental sorption data for Sr (Kinniburgh et al., 1975) and $\mathrm{Pu}$ (Sanchez et al., 1985). Data for Co was also obtained from data from Duval and Kurbatov (1952) although Co was not considered in the final simulations. Surface protonation and deprotonation constants were taken from Turner (1995). Surface complexation reactions and binding constants that were obtained in the manner described above for use in GIMRT are listed in Table 26 in Appendix 3 along with the consistent set of protonation/deprotonation 
constants from Turner (1995). The ")" symbol represents a surface species.

\subsection{Ion exchange}

Ion exchange minerals possess fixed amounts of charge imbalance which are often imposed by the substitution of $\mathrm{Al}$ for $\mathrm{Si}$ in the mineral structure. The negative charge imbalance in cation exchangers restricts their exchange to cations. Ion exchange reactions, like surface complexation reactions, vary as a function of aqueous complexation in the fluid phase, ionic strength, and the solid-fluid ratio. However, ion exchange is also sensitive to steric constraints imposed by the structure of the ion exchanger. Ion exchange is not as strongly affected by $\mathrm{pH}$ as is surface complexation.

Based upon the work of Viani (Viani and Bruton, 1992, 1996), a one-site ideal Vanselow exchange model was used in this study to model $\mathrm{Cs}$ and $\mathrm{Sr}$ exchange onto clinoptilolite, smectite and illite. The exchange properties of mica and muscovite are assumed equivalent to those of illite because of the structural and chemical similarities among the minerals. Exchange energies were obtained from the literature (Viani and Bruton, 1992, 1996). Exchange was considered between $\mathrm{Ca}$ and $\mathrm{Sr}$ on clinoptilolite, $\mathrm{Ca}, \mathrm{Mg}$ and $\mathrm{Sr}$ on smectite, and $\mathrm{Cs}, \mathrm{Na}$ and $\mathrm{K}$ on illite/muscovite.

Although GimRT does not provide explicitly for ion exchange at the present time, we were able to model homovalent exchange by utilizing GIMRT's nonelectrostatic treatment of surface complexation. We were restricted to homovalent exchange because of the stoichiometry of the exchange reaction between monovalent and divalent cations (heterovalent exchange) in the Vanselow model, and because we were using existing coding in GIMRT intended to model sorption rather than ion exchange. We verified our GIMRT calculations with explicit treatments of Vanselow exchange in a version of geochemical modeling code EQ3/6 (Wolery, 1992a,b; Wolery and Daveler, 1992). EQ3/6 simulations using the ideal Vanselow model suggested that the partitioning of strontium onto smectite and clinoptilolite and Cs onto mica, muscovite or illite in CAMBRIC groundwater is dominated by homovalent exchange.

Although illite has three sites that are defined by its crystal structure, Cs exchange is thoroughly dominated by one of the edge sites, which is the only site that is explicitly considered in the models. The planar sites were not considered because they behave similarly to planar sites in smectite, which occur in greater quantities than illite in the alluvium. The quantity of smectite in the simulations can therefore reflect the sum of the smectite and illite planar sites.

Values for the cation exchange capacities (CEC) of smectite and clinoptilolite were taken from Viani and Bruton (1992).Viani calculated cation exchange capacities of 0.85 and 2.12 mequiv/g for smectite and clinoptilolite, respectively, in samples of Yucca Mt. tuff. The CEC of illite/muscovite was assumed to equal 0.2 mequiv/g (Viani and Bruton, 1996), but exchange was limited to type I sites with a site fraction of 0.005 . 
Given our specification of the chemical system outlined above, the exchange energies and cation exchange capacities (CEC) of the exchangers used in the simulations are summarized in Table 27 in Appendix 3.

\subsection{Nature and distribution of radionuclides in the cav- ity/chimney region}

As discussed in Section 3.3.2, the portions of the chimney and cavity that contain significant amounts of radionuclides are defined as the exchange volume. At CAMBRIC, this volume has been idealized by an 18-m radius sphere, as suggested by limited tritium distribution data. The masses of $\mathrm{Pu}, \mathrm{Am}, \mathrm{Eu}, \mathrm{Cs}$ and $\mathrm{Sr}$ in the exchange volume can be obtained by multiplying the total inventory of each radionuclide (Table 5) by the percentage of the radionuclide in the exchange volume (Table 1). However, extremely little is known regarding the state of radionuclides in the exchange volume. For example, do the radionuclides initially exist as discrete pure solid phases, or as components of solid solutions? Are they sorbed or exchanged onto the surfaces of minerals in the exchange volume? If so, what minerals?

Lacking this data, it was assumed that the same processes that bind radionuclides to solids will attract the radionuclides that are suddenly introduced by a nuclear test. Thus, the partitioning of radionuclides between the water and solids in the exchange volume is assumed to be controlled by sorption and ion exchange. The radionuclides are also assumed to be distributed homogeneously throughout the exchange volume. There is some evidence that the distribution of radionclides in the chimney is a function of the half-lives of the nuclides and their volatility (e.g., Wolfsberg, 1978). However, additional work and field study are required to better constrain the heterogeneous distribution of radionuclides for use in the simulations.

The mass of each radionuclide per kilogram of $\mathrm{H}_{2} \mathrm{O}$ in the exchange volume was obtained by dividing by the exchange cavity pore volume of about $10^{4} \mathrm{~m}^{3}$, as defined in the groundwater flow model. The resulting masses were then added to the starting fluid composition in GIMRT, and the code automatically partitioned the radionuclides among the fluid phase, goethite, smectite, clinoptilolite and illite/muscovite according to the sorption and ion exchange reactions discussed earlier and the volume fraction of the sorbents and ion exchangers in the exchange volume (reactive mineral column in Table 15). Table 12 and Figure 21 summarize these calculations. Note that if no reactive minerals were present, the molalities of the radionuclides in the fluid would be given by column 3 of this table and correspond to the right side of the figure. The concentrations of radionuclides in solution did not exceed solubility limits with respect to the radionuclide-bearing solids listed in Table 18.

Further information regarding the nature and distribution of radionuclides in the chimney/cavity region is required to better constrain the hydrologic source term. Calculated releases and migration of radionuclides are controlled by the 

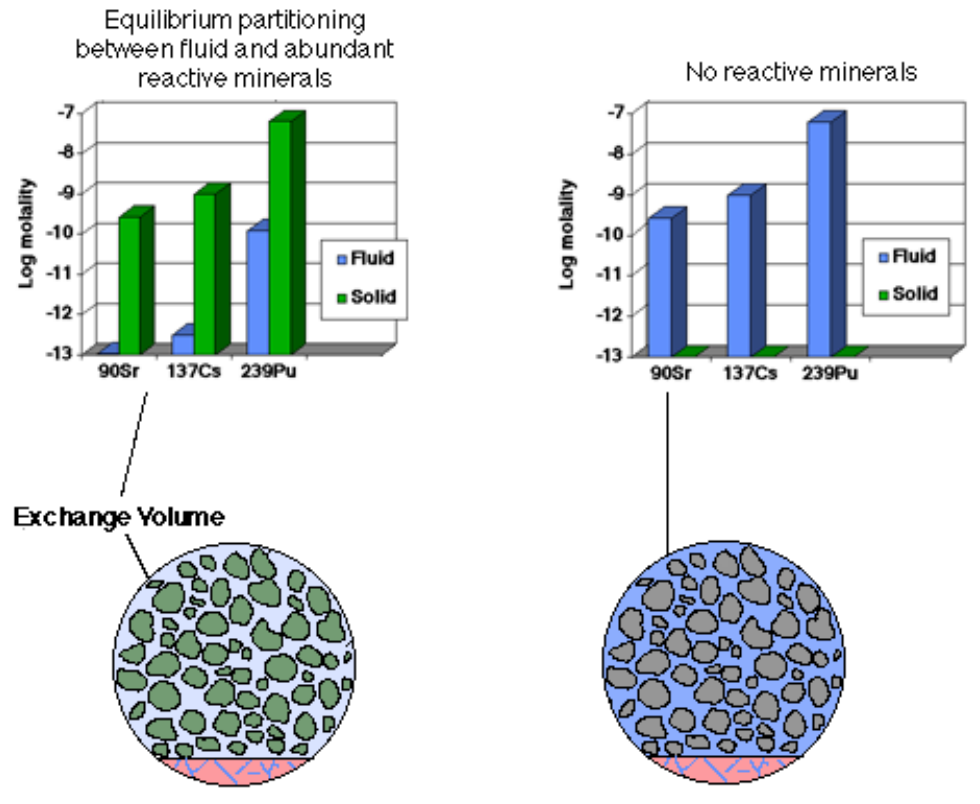

Figure 21: Conceptual illustration of the partitioning of radionuclides among the reactive minerals (green) and fluids (blue) in the exchange volume (see Table 12). Right side corresponds to lack of any reactive minerals, in which case all radionuclides are distributed as aqueous species. 
Table 12: Distribution of radionuclide inventory in the modeled 18-m radius exchange volume (see text). Calculations were made assuming a porosity of $40 \%$, yielding a total pore volume of $9.772 \times 10^{3} \mathrm{~m}^{3}$. Partitioning in columns 4 and 5 based upon presence of reactive minerals shown in Table 15. When no reactive minerals are present, aqueous concentrations given in column 3 exist.

\begin{tabular}{lcccc}
\hline \hline & $\begin{array}{c}\text { Rubble } \\
\text { inventory } \\
\text { Radionuclide }\end{array}$ & $\begin{array}{c}\text { Moles RN } \\
(\text { per kg H} \mathrm{O})\end{array}$ & $\begin{array}{c}\text { Molality } \\
(\text { RN in fluid) }\end{array}$ & $\begin{array}{c}\text { Molality } \\
(\mathrm{RN} \text { in solids })\end{array}$ \\
\hline${ }^{90} \mathrm{Sr}$ & $2.58 \times 10^{-3}$ & $2.64 \times 10^{-10}$ & $1.07 \times 10^{-13}$ & $2.64 \times 10^{-10}$ \\
${ }^{137} \mathrm{Cs}$ & $9.59 \times 10^{-3}$ & $9.81 \times 10^{-10}$ & $3.09 \times 10^{-13}$ & $9.81 \times 10^{-10}$ \\
${ }^{155} \mathrm{Eu}$ & $4.23 \times 10^{-6}$ & $4.33 \times 10^{-13}$ & $4.33 \times 10^{-13}$ & 0 \\
${ }^{239} \mathrm{Pu}$ & 0.651 & $6.66 \times 10^{-8}$ & $1.23 \times 10^{-10}$ & $6.65 \times 10^{-8}$ \\
${ }^{241} \mathrm{Am}$ & $2.59 \times 10^{-3}$ & $2.65 \times 10^{-10}$ & $2.65 \times 10^{-10}$ & 0 \\
& & & & \\
\hline \hline
\end{tabular}

assumptions regarding their state in the exchange volume. Radionuclides that are preferentially bound to minerals will be released more gradually than radionuclides that exist solely in the fluid phase. If radionuclides form discrete minerals (e.g., solid $\mathrm{PuO}_{2}$ ), radionuclide release will be controlled by the dissolution rate of the solid. The sequestration of radionuclides in the form of discrete minerals was not considered at CAMBRIC because the exchange volume fluids (Table 12) were initially undersaturated with respect to the radionuclide-bearing solids listed in Table 18.

\subsection{Radiogenic versus non-radiogenic isotopes}

GIMRT does not differentiate among isotopes of a given element. This is not an issue if the only source of the element is the nuclear test, as it is for $\mathrm{Pu}$ and Am. However, non-radiogenic sources of Sr, Cs and Eu are present in the groundwater and host alluvium prior to the nuclear test. We must therefore be able to differentiate between the radiogenic and non-radiogenic isotopes in our calculations.

Non-radiogenic Sr has been measured in CAMBRIC groundwaters (Table 14), and $\mathrm{Cs}$ is commonly contained in waters in contact with siliceous rocks. The total concentrations of $\mathrm{Sr}, \mathrm{Cs}$ and $\mathrm{Eu}$ in melt glass includes their natural abundance in the tuff from which the glass formed, as well as the radioactive isotopes produced during the test (Table 9). We assumed that the distribution between radioactive and non-radioactive isotopes of $\mathrm{Sr}$, $\mathrm{Cs}$ and $\mathrm{Eu}$ in the exchange volume is equal to that in the glass. We also assumed that the initial concentrations 
of $\mathrm{Sr}$ and $\mathrm{Cs}$ in the groundwaters equaled zero, and that all isotopes of a given element had similar geochemical behavior. The radiogenic components of the total $\mathrm{Sr}$, Cs and Eu released from the melt glass and exchange volume were thus obtained by multiplying GIMRT's prediction of an element's total concentration in the water by the ratio of its radiogenic to nonradiogenic concentrations in the glass. The correction factors used to adjust GIMRT output are given in Table 13.

Table 13: Mole percent of total elemental concentrations of $\mathrm{Cs}$, $\mathrm{Sr}$ and Eu in GIMRT output that represent the radiogenic isotopes ${ }^{137} \mathrm{Cs},{ }^{90} \mathrm{Sr}$ and ${ }^{155} \mathrm{Eu}$ (see text).

\begin{tabular}{lc}
\hline \hline & \\
Element & Mole percent radiogenic isotope \\
\hline & \\
$\mathrm{Cs}$ & $7.82 \times 10^{-3}$ \\
$\mathrm{Sr}$ & $2.08 \times 10^{-5}$ \\
$\mathrm{Eu}$ & $1.35 \times 10^{-3}$ \\
& \\
\hline \hline
\end{tabular}

Neglecting the background $\mathrm{Sr}$ and $\mathrm{Cs}$ in solution will have no effect on our calculations of radionuclide transport or retardation if there is a linear relationship between the sorbed and dissolved concentrations. Viani found that such a linear relationship existed for ion exchange of Cs on clinoptilolite-rich samples of the Bedded Tuff of Calico Hills. Sr exchange exhibited a change of slope at Sr concentrations greater than about $1 \times 10^{-7} \mathrm{M}$ (Viani and Bruton, 1996). For sorption, a slope of unity is observed at low sorbate-sorbent ratios. Further code development work is required to allow the geochemical modeling codes to explicitly track both the natural (nonradiogenic) and radiogenic components of elements. 


\section{Geochemical Modeling of Radionuclide Mi- gration}

Once radionuclides are released into groundwater from the melt glass and cavity and chimney system (or exchange volume), they have the potential to be retarded by a number of processes such as precipitation, surface complexation and ion exchange. The extent to which released radionuclides are affected by these processes depend on the nature of the radionuclide, the chemistry of the fluid, and the minerals that the fluid contacts along the flow path. We used the reactive transport modeling code GIMRT (Steefel and Yabusaki, 1996) to calculate the chemical changes in groundwater as it flows through the glass, cavity and chimney (e.g., exchange volume) regions, and alluvium, picking up radionuclides and sometimes re-depositing them farther along the flow path.

One-dimensional (1D) reactive transport simulations of radionuclide migration through simplified sequences of the glass, exchange volume and alluvium were made using GIMRT to evaluate the efficacy and controls of migration and retardation. Using these simulations as a guide, we then distilled the geochemical systems and process descriptions as much as possible in order to expedite the next phase of computations in three dimensions. The geochemical models obtained in this manner were then integrated with the groundwater flow models using the streamline approach to calculate radionuclide migration in three dimensions.

Production of detailed 1D simulations prior to making the streamline calculations for more complicated 3D analyses is a critical component of our study. Given the complexity of the chemical reactions affecting radionuclide migration, our analyses of the 1D simulations allow us to better understand the controls, timing and extent of radionuclide breakthrough predicted by the more complex $3 \mathrm{D}$ models.

The time-consuming nature of geochemical calculations, especially when coupled with groundwater flow, usually requires that the chemistry of the system be simplified wherever possible to facilitate larger-scale coupled reactive transport modeling. Understanding the controls of radionuclide migration and their relation to the host rock allows us to reduce the geochemical models to the essentials required for describing radionuclide transport. This approach will also allow us to judge the adequacy of simplified representations of the chemical system. For example, some migration studies use partition coefficients to describe the partitioning of radionuclides between water and solids. However, experimentally determined partition coefficients are strictly applicable only to the specific rock sample and fluid-rock ratio used in the experiment. In our approach, we use process-based descriptions for sorption and ion exchange to calculate the partitioning of radionuclides based on the mineralogy of the rock. We can then calculate partition coefficients from our output and evaluate the adequacy of the partition coefficient approach. By starting with the process- 
based descriptions, we hope to find scientifically defensible ways of simplifying the process descriptions for higher level hydrogeochemical computations.

In the geochemical simulations of radionuclide migration presented in this paper, we take explicit consideration of aqueous speciation in the fluid phase, dissolution and precipitation of solids according to kinetic rate laws, ion exchange, and surface complexation. All processes except dissolution/precipitation are assumed to occur instantaneously and reversibly. There are many different ways to treat each of these processes, each with various degrees of rigor with regard to our current understanding of the process mechanisms. We describe the quantification of these processes in the following sections and Appendix 2.

\subsection{Geochemical modeling codes}

A number of geochemical modeling codes have been used in this study. The principal reactive transport simulations were made with the GIMRT code, and they were duplicated at times with the related Os3D code (Steefel and Lasaga, 1994; Steefel and Yabusaki, 1996).

Both GIMRT and Os3D can account for advective, diffusive and dispersive transport processes, and can simulate multicomponent mass transport in porous and/or fractured media under isothermal or fixed temperature gradient conditions. GIMRT can make calculations in 1 or 2 spatial dimensions (D), and Os3D can address problems posed in 0 (batch), 1, 2 or $3 \mathrm{D}$. The user can specify a number of zones which vary in mineralogy and initial fluid chemistry.

GIMRT and Os3D can treat chemical equilibria associated with aqueous speciation reactions, kinetically-controlled mineral dissolution and precipitation reactions, and surface complexation reactions based upon a non-electrostatic model. As will be discussed below, we utilized the coding for surface complexation to enable the code to simulate homovalent ion exchange as well.

Both GIMRT and Os3D use finite difference techniques to discretize the nonlinear balance equations associated with mass transport and reaction in porous media. The governing equations and underlying geochemical conceptualization used in these models are reviewed briefly in Appendix 2 for a one-dimensional formulation. As its name implies, GimRT (Global Implicit Multicomponent Reactive Transport) is based upon a one-step or global implicit solution approach. In this technique, the advection, diffusion, and reaction processes occurring over a single time step are treated in a coupled and implicit manner. In contrast, Os3D (Operator Splitting 3D Reactive Transport) is based upon an operator splitting approach in which the same processes are accounted for using individual numerical treatments that are performed in a sequential manner.

Although Os3D better minimizes well-known numerical dispersion errors, it is subject to Courant Number constraints that rendered its use in our streamline approach impractical. This constraint indirectly imposes a limit of the allowable time step (as a function of the velocity and grid scale), which could turn out to be unpredictably small depending on the grid block segments intersected by 
any given streamline. Instead, GIMRT was used throughout this study because larger time steps could be used, despite the fact that numerical dispersion errors would be more prevalent.

Supporting geochemical calculations were made using codes in The Geochemist's Workbench package, version 2.4 (Bethke, 1994). The code package includes REACT, which calculates aqueous species distributions and traces reaction paths among fluids, gases and solids, ACT2, which creates stability diagrams, and GTPLOT, which is a plotting routine for REACT.

\subsection{Thermodynamic data}

Thermodynamic data for aqueous species, gases and solids were obtained from the Gembochs thermodynamic data base version data.com.V8.R6 (Johnson and Lundeen, $1997^{5}$ ). A survey of the literature was made to determine if additional or updated data were available for $\mathrm{Pu}, \mathrm{Am}, \mathrm{Eu}, \mathrm{Sr}, \mathrm{Cs}, \mathrm{Co}$ and Tc. Appendix 4 lists the aqueous species and minerals whose data have been updated or added for this $\mathrm{study}^{6}$. Data for $\mathrm{Pu}$ aqueous species, solids, and gases were also updated based on data from a draft Nuclear Energy Agency (NEA) report (R. J. Lemire, private communication). However, these data are not presented in this paper at the request of the NEA. We received permission from them to use the data and publish results using the data, but not to publish the data itself. Calculations in this paper were restricted to $25^{\circ} \mathrm{C}$, so no effort was made to acquire data at elevated temperature.

The extended Debye-Hückel formulation (also known as the B-DOT model) was used for activity coefficients (Bethke, 1996; Helgeson, 1969). This formulation is well suited to handle the CAMBRIC groundwater used in this study which has an ionic strength of about 0.0046. Values of the ion size parameter (Bethke, 1996; Helgeson, 1969) for aqueous species added to the data base were estimated by analogy to aqueous species of similar valence and ligand.

\subsection{The ambient environment}

\subsubsection{Groundwater chemistry}

The fluid chemistry of the CAMBRIC groundwater used as the starting point in the calculations is shown in Table 14. The basic chemistry is similar to that of

\footnotetext{
${ }^{5}$ Available via anonymous ftp to s122.es.llnl.gov:/users/johnson.

${ }^{6}$ During the course of the simulations, it was found necessary to convert data in Gembochs for a Ca-clinoptilolite which contained a trace amount of $\mathrm{Fe}$ to an Fe-free form. The $\mathrm{Fe}_{2} \mathrm{O}_{3}$ component was substituted by $\mathrm{Al}_{2} \mathrm{O}_{3}$ and the appropriate changes were made in the thermodynamic properties and hydrolysis reaction stoichiometry. GIMRT also seemed to converge more readily when the properties of Ca-clinoptilolite in GEмвоснs (e.g., molar volume, free energy, molecular weight and stoichiometric coefficients in the hydrolysis reaction) were reduced by a factor of 10 . This has the effect of redefining 1 mole of clinoptilolite as 10 moles of clinoptilolite. These changes have no effect on the simulation output because of the uniform scaling of parameters.
} 
Zone I water (Table 3), which was sampled from just below the cavity (Fig. 37). Concentrations of $\mathrm{SiO}_{2}$ and $\mathrm{HPO}_{4}$ were obtained from Smith et al. (1997). The groundwater is a dilute $\mathrm{Na}-\mathrm{HCO}_{3}$ type water; its ionic strength equals 0.0046.

The initial redox state of the groundwater was set by assuming equilibrium with respect to atmospheric oxygen with fugacity of $\mathrm{O}_{2}(\mathrm{~g})=0.2$ bars. Plutonium is the only radionuclide in this study that is redox-sensitive. The redox state of $\mathrm{Pu}$ in CAMBRIC groundwaters is unknown. Equilibrium with atmospheric oxygen was assumed to set an upper limit to the redox state of $\mathrm{Pu}$ in solution (approximately $700 \mathrm{mV}$ ). Preliminary calculations indicated that redox potentials as low as $100 \mathrm{mV}$ will significantly alter the aqueous speciation of $\mathrm{Pu}$, and may affect $\mathrm{Pu}$ concentrations in solution and the extent of $\mathrm{Pu}$ migration. The impact of lower redox potentials will be explored more fully in future calculations.

The fluid was assumed to have a fluid density of $1 \mathrm{~g} / \mathrm{cm}^{3}$ in recognition of the dilute nature of the groundwater and the restriction of the simulations to $25^{\circ} \mathrm{C}$.

Table 14: Ambient groundwater chemistry used in simulations (see text).

\begin{tabular}{lc}
\hline \hline & \\
Constituent & Concentration $(\mathrm{mg} / \mathrm{l})$ \\
\hline $\mathrm{pH}$ & 8.0 \\
$\mathrm{Na}$ & 63 \\
$\mathrm{~K}$ & 8 \\
$\mathrm{Ca}$ & 16 \\
$\mathrm{Mg}$ & 4 \\
$\mathrm{Sr}$ & .24 \\
$\mathrm{HCO}$ & 177 \\
$\mathrm{Cl}_{3}$ & 16 \\
$\mathrm{SO}_{4}$ & 32 \\
$\mathrm{HPO}_{4}$ & .31 \\
$\mathrm{SiO}_{2}$ & 65 \\
& \\
\hline \hline
\end{tabular}

The starting groundwater is approximately saturated with respect to calcite, so the initial Ca concentration was fixed at calcite equilibrium. The resulting $\mathrm{Ca}$ concentration is essentially equal to that given in Table 14 . The silica concentration of the groundwater is equivalent to the concentration defined by equilibrium with respect to a silica polymorph referred to as $\beta$-cristobalite in the thermodynamic data base. The data for $\beta$-cristobalite was obtained from a sample of natural siliceous sinter which was probably cryptocrystalline (Walther and 
Helgeson, 1977). Elevated $\mathrm{SiO}_{2}(\mathrm{aq})$ concentrations are common in low temperature, near-surface waters in contact with tuff (e.g., Yucca Mountain waters).

$\mathrm{Al}$ and $\mathrm{Fe}$ analyses were not available for the CAMBRIC groundwaters. We therefore used mineral equilibrium to define their concentrations. Fe was set by fixing equilibrium with respect to goethite $(\mathrm{FeOOH})$ which acted as a sorbent for radionuclides in the simulations. Aluminum concentration was assumed to be controlled by equilibrium with the zeolite clinoptilolite which is homoionic with respect to $\mathrm{Ca}\left(\mathrm{Ca}_{1.7335} \mathrm{Al}_{3.467} \mathrm{Si}_{14.533} \mathrm{O}_{36}: 10.922 \mathrm{H}_{2} \mathrm{O}\right)$. There were many potential choices for minerals that could fix initial $\mathrm{Al}$ concentrations. Ca-clinoptilolite was chosen because it is present in the alluvium, and it maintains low $\mathrm{Al}$ concentrations in solution and minimizes saturation with respect to aluminosilicate minerals. The choice of a mineral other than Ca-clinoptilolite would have no significant effect on the simulations.

In general, results of the simulations will not be affected significantly if moderately different elemental concentrations (excluding $\mathrm{pH}$ and the redox state) are chosen. Geochemical calculations are largely based on the logarithm of the concentrations, which tends to minimize the impact of compositional variability.

Initial concentrations of $\mathrm{Pu}, \mathrm{Am}, \mathrm{Eu}, \mathrm{Cs}$ and $\mathrm{Sr}$ in CAMBRIC groundwater were assumed to equal $10^{-15}$ molal, in lieu of zero, because finite concentrations were required to initialize GIMRT. The implications of this assumption with regard to $\mathrm{Sr}$ are discussed below; Sr concentrations of a few $\mathrm{mg} / \mathrm{L}$ have been measured in CAMBRIC groundwater (Table 14). GIMRT does not differentiate among isotopes of a given element, and assumes that all isotopes of a given element have similar geochemical behavior. Because both radiogenic and natural non-radiogenic isotopes of $\mathrm{Sr}, \mathrm{Cs}$ and $\mathrm{Eu}$ are present in the melt glass and exchange volume, GIMRT's predicted concentrations of total $\mathrm{Sr}$, Cs and $\mathrm{Eu}$ must be adjusted to isolate the concentrations of ${ }^{137} \mathrm{Cs}{ }^{90} \mathrm{Sr}$ and ${ }^{155} \mathrm{Eu}$. The adjustment will be discussed in detail later in this report.

\subsubsection{Mineralogy}

The initial mineralogy and mineral volume fractions of the rock types encountered along the flow path, as well as potential secondary precipitates (authigenic minerals) will affect radionuclide migration. The mineralogy of the chimney, exchange volume, lower crush zone and alluvium outside the cavity/chimney system (Figure 36, below) is assumed to be the same in the simulations, and is equivalent to that defined for the alluvium.

Alluvium mineralogy. The first GIMRT simulations were made using a full mineralogic and kinetic description of the alluvium, excluding the ferromagnesium minerals (Table 2). A combination of albite, anorthite and K-feldspar was used to represent the feldspar. Quartz, a smectite (montmorillonite), clinoptilolite, kaolinite, muscovite and calcite were also specified in proportions within the 
ranges given in Table 2 . However, it became clear that the full mineralogic description was not only time-consuming in terms of computational resources, but also unnecessary for the needs of this project. We therefore combined our simulation results with "common-sense geologic reasoning" to focus the simulations on the authigenic minerals and minerals in the alluvium that will significantly affect radionuclide migration on the time scale of tens of years to thousands of years. For example, the dissolution kinetics of quartz and feldspars at $25^{\circ} \mathrm{C}$ are extremely slow, and they are not expected to react significantly over the time spans of hundreds to thousands of years. They were therefore omitted from the simulations and replaced with a fictive, non-reactive solid referred to as "matrix" in the thermodynamic data base.

In contrast to the matrix, zeolites, smectites and sheet silicates such as illite are known to participate in ion exchange reactions that occur over time scales ranging from minutes to hours. Surface complexation rates of ions on hydrous iron oxides are similarly fast. The alluvium was therefore described as a combination of the non-reactive inert matrix, and the "reactive" minerals such as zeolites (clinoptilolite), clays (beidellite, which is a smectite, and muscovite), hydrous iron oxides (goethite), and calcite.

We assume in this report that the surfaces of muscovite, mica and illite interact similarly with groundwater because of their structural and chemical similarities. Muscovite and muscovite/illite therefore refer to the sum of muscovite, mica and illite, and the ion exchange properties of mica and muscovite are assumed to be equivalent to those of illite.

The spatial distribution of minerals in the vicinity of CAMBRIC is poorly known, and probably heterogeneous. The streamline calculations were run assuming both homogeneous and heterogeneous distributions of reactive minerals (see later discussions in Chapter 11). However, the 1D calculations were made assuming a uniform distribution of the reactive minerals shown Table 15 in the alluvial and exchange volume environments. The purpose of the initial 1D calculations was not so much to fully represent the diversity of the geologic environment, but to evaluate in detail the relations among the mineralogy, fluid chemistry and the processes that affect radionuclide migration.

Table 15 summarizes the volume percent of the solids chosen to comprise the alluvium, exchange volume and melt glass in the simulations. Two columns are shown for the alluvium and exchange volume, corresponding to either a reactive or inert specification (used later in Chapter 11). Although Table 2 was used as a guide in constructing the reactive medium column in Table 15, strong consideration was given to using low percentages in order not to over-estimate the capacity for radionuclide retardation, and to better represent the mode of the mineralogy rather than the extremes of mineralogic content. The selection was also made to facilitate comparison of the impact of various minerals on retardation.

The matrix in Table 15 represents the slow-reacting sum of the feldspar and quartz. Trace quantities of calcite and goethite represent near surface sec- 
Table 15: Distribution of porous medium volume fractions used in the simulations for the alluvium/exchange volume and melt glass (see discussion in section 8.3.2). Reactive or inert medium configurations may be used to describe the alluvium/exchange volume. See Chapter 11.

\begin{tabular}{lccc}
\hline \hline \multirow{2}{*}{$\begin{array}{l}\text { Solid, mineral, } \\
\text { or pore volume }\end{array}$} & \multicolumn{2}{c}{$\begin{array}{c}\text { Alluvium and exchange volume } \% \\
\text { Reactive medium }\end{array}$} & $\begin{array}{c}\text { Inert medium } \\
\text { volume } \%\end{array}$ \\
\hline Glass & 0 & 0 & 90 \\
Inert matrix & 47 & 60 & 0 \\
Clinoptilolite-Ca & 5 & 0 & 0 \\
Beidellite-Ca & 5 & 0 & 0 \\
Calcite & 1 & 0 & 0 \\
Muscovite & 1 & 0 & 0 \\
Goethite & 1 & 0 & 0 \\
Porosity & 40 & 40 & 10 \\
Total & & & \\
\hline \hline
\end{tabular}

ondary minerals. Alluvium sampled from wells RNM-1 and UE5n (Table 2) contain from 0 to $5 \%$ goethite or other iron oxyhydroxide(s) and 0-10\% calcite. The abundances of micas range from $0-2 \%$ and $0-5 \%$, respectively. Micas are represented by muscovite in the simulations. The $\mathrm{Ca}$ end member of a clinoptilolite solid solution (Ca-clinoptilolite) represents the zeolite which can comprise up to $50 \%$ of the alluvium. Ca-rich beidellite (Ca-beidellite), a compositional end-member of a smectite solid solution, represents the smectite and montmorillonite clays which have been observed in amounts of $3-15 \%$. Cristobalite, opaline silica, and the ferromagnesium mineral hornblende were not considered as primary minerals in the simulations.

The porosity of the alluvium and melt glass was assumed to equal $40 \%$ and $10 \%$ respectively, in accordance with the specifications of the groundwater flow model used to develop the streamlines.

Authigenic mineralogy. In addition to the primary mineralogy, one must specify in GIMRT what minerals may precipitate as authigenic minerals during fluid-rock interaction if their solubility is exceeded. The minerals most likely to precipitate in the alluvium are those authigenic minerals that are already found in the alluvium (e.g., clays, calcite, goethite). Therefore, calcite, smectite (beidellite-Ca), goethite and muscovite (a proxy for illite) were allowed to precipitate and re-dissolve in the simulations. The same phases are also potential 
precipitates in the melt glass.

Additional precipitates must be considered to accommodate chemical components released into solution owing to glass dissolution, especially if glass dissolution is fast relative to fluid flow rates. These precipitates were allowed to form in both the melt glass and alluvium if they became saturated. Am-, $\mathrm{Pu}-$ and Eu-bearing solids were considered as potential precipitates, as discussed later. $\beta$-cristobalite was also allowed to precipitate. The ambient groundwater is near equilibrium with a silica polymorph with solubility similar to $\beta$-cristobalite. $\beta$ cristobalite was to allowed to precipitate to allow the silica released by glass dissolution to re-precipitate and maintain the silica concentration at $\beta$-cristobalite saturation. As discussed in more detail in Chapter 6, the dissolution rate of the melt glass is assumed to be controlled by the difference in solubility between amorphous silica (melt glass) and $\beta$-cristobalite, a silica precipitate.

The zeolite clinoptilolite was not allowed to precipitate in the simulations. Zeolites found in the alluvium were probably formed in a previous hydrothermal event at elevated temperature (analogous to zeolite occurrences at Yucca Mountain), and our simulations are restricted to ambient low temperatures.

\subsubsection{Kinetic parameters of minerals}

Published dissolution rate constants for silicate minerals tend to vary significantly, even for a specific mineral. Our current state of knowledge regarding the rates and mechanisms of mineral precipitation is very limited. Therefore, GIMRT uses the same rate law to describe precipitation as well as dissolution (see Appendix 2, equation 25).

In this study, groups of related minerals were assigned the same rate constant (Table 16) in recognition of the variability of published rate constants and to facilitate comparison of dissolution and precipitation rates. The rate constants of the sheet silicates smectite and muscovite were assumed to equal $1 \times 10^{-13}$ $\mathrm{mol} /\left(\mathrm{m}^{2}\right.$-sec) (Nagy, 1995) in general accordance with available experimental data. Calcite, goethite, $\mathrm{EuOHCO}_{3}, \mathrm{AmOHCO}_{3}$ and $\mathrm{PuO}_{2}(\mathrm{OH})_{2} \cdot \mathrm{H}_{2} \mathrm{O}$ were assigned rate constants of $1 \times 10^{-10} \mathrm{~mol} /\left(\mathrm{m}^{2}\right.$-sec $)$ to represent minerals with comparatively fast kinetics, rather than to explicitly reproduce published rate data. The rate constant for $\beta$-cristobalite was set at $1 \times 10^{-8}$ in order to ensure that it precipitates fast enough to maintain $\mathrm{Si}$ concentrations at $\beta$-cristobalite saturation within the melt glass during glass dissolution (see Chapter 6 ). The rate constant for glass dissolution was obtained as previously described in Chapter 6. The rate constant for clinoptilolite dissolution was selected as a lower limit of data for heulendite from Ragnarsdottir (1989) and for laumontite from Savage et al. (1993).

The rates of mineral dissolution and precipitation are dependent on the reactive surface area of the mineral as well as the rate constant (Appendix 2, equation 25). The user also has the option in GIMRT to specify a saturation or nucleation threshold which must be exceeded before precipitation can occur. 
Table 16: Kinetic parameters used in the simulations (see text).

\begin{tabular}{|c|c|c|c|c|}
\hline \multirow[b]{2}{*}{ Solid } & \multirow{2}{*}{$\begin{array}{c}\text { Rate } \\
\text { constant, } k \\
\left(\mathrm{~mol} / \mathrm{m}^{2} / \mathrm{sec}\right)\end{array}$} & \multicolumn{2}{|c|}{$\begin{array}{l}\text { Specific surface area, } A_{s} \\
\left(\mathrm{~m}^{2} / \mathrm{m}^{3}-\text { medium }\right)\end{array}$} & \multirow{2}{*}{$\begin{array}{c}\text { Saturation } \\
\text { threshold } \\
(\mathrm{kcal} / \mathrm{mol}) \\
\end{array}$} \\
\hline & & glass & alluvium/rubble & \\
\hline Melt glass ${ }^{a}$ & $4.4 \times 10^{-14}$ & 117.59 & 0. & 0 \\
\hline$\beta$-Cristobalite & $1 \times 10^{-8}$ & 117.59 & 10. & 0 \\
\hline Calcite & $1 \times 10^{-10}$ & 10. & 10. & 0 \\
\hline Muscovite & $1 \times 10^{-13}$ & 10. & 0.001 & 0 \\
\hline Ca-Clinoptilolite & $1 \times 10^{-13}$ & 0.001 & 0.001 & 10. \\
\hline Ca-Beidellite & $1 \times 10^{-13}$ & 10. & 10. & 0 \\
\hline Goethite & $1 \times 10^{-10}$ & 10. & 10. & 0 \\
\hline $\mathrm{EuOHCO}_{3}$ & $1 \times 10^{-10}$ & 10. & 10. & 0 \\
\hline $\mathrm{PuO}_{2}(\mathrm{OH})_{2}: \mathrm{H}_{2} \mathrm{O}$ & $1 \times 10^{-10}$ & 10. & 10 & 0 \\
\hline $\mathrm{AmOHCO}_{3}$ & $1 \times 10^{-10}$ & 10. & 10. & 0 \\
\hline Inert matrix & $1 \times 10^{-16}$ & 0. & 0.001 & 4. \\
\hline
\end{tabular}

$\overline{\bar{a}}$ One mole of melt glass is defined as 9986 grams of glass

Table 16 summarizes the specific surface areas and saturation thresholds used in our initial studies. For authigenic minerals, the specific surface area represents the surface area available as a substrate for precipitation. The surface area of the melt glass was obtained as described in Chapter 6 . $\beta$-cristobalite in the melt glass was assigned the same specific surface area as the glass to maintain equilibrium with $\beta$-cristobalite.

Most of the surface areas of the other minerals in both the melt glass and alluvium are assumed to equal $10 \mathrm{~m}^{2} / \mathrm{m}^{3}$ bulk volume. Analogous to the assignment of rate constants, this value was chosen to facilitate identification of important processes for the initial calculations rather than to represent true estimates of the reactive surface area of the minerals as determined by BET analysis, for example. Exceptions include Ca-clinoptilolite and muscovite, which are assigned surface areas of 0.001 to prevent their precipitation. The thermodynamic data for these minerals tends to overestimate their stability at earth surface temperatures, and the reduction in surface area is a means of correcting for this. A saturation threshold is also established for Ca-clinoptilolite to ensure that it does not precipitate at $25^{\circ} \mathrm{C}$ in the CAMBRIC groundwater. Zeolites are observed to form at low temperatures, but only under conditions of high $\mathrm{pH}$ or high alkalinity. The fictive, non-reactive "Matrix" is assigned an extremely small rate constant, a small surface area, a high saturation threshold and large equilibrium constant to prevent it from dissolving or precipitating during the 
simulations.

Future simulations should continue to explore variations in the kinetic parameters. We are especially interested in the growth of surface-active solids such as clays and hydrous ferric oxides that can change the capacity of the rock to retard radionuclides. However, our extremely limited quantitative understanding of precipitation and dissolution mechanisms, rates, and reactive surface areas at $25^{\circ} \mathrm{C}$ in a natural porous medium necessitates our simplified approach for the time being.

\subsection{Aqueous complexation and solubility limits for ra- dionuclides}

Radionuclides released into solution will undergo aqueous complexation and may precipitate as part of a radionuclide-bearing solid. Both aqueous complexation and the solubility of radionuclide-bearing solids depend on the solution composition, $\mathrm{pH}$, and redox potential. GIMRT requires the user to specify the aqueous species, minerals and gases to be considered in the simulation. The selection of aqueous species should reflect the impact on speciation of variations in fluid composition, $\mathrm{pH}$, and redox potential that may occur during glassalluvium-water interactions. The REACT geochemical modeling code in The Geochemist's Workbench software package (Bethke, 1996) was used to select the dominant aqueous species and solids that were considered in the GIMRT simulations. REACT simultaneously considers all known aqueous species, minerals and gases when calculating the equilibrium distribution of aqueous species in a fluid. In this section, we summarize the equilibrium calculations which were made to support the selection of aqueous species and solids containing Cs, Sr, $\mathrm{Eu}, \mathrm{Pu}$ and $\mathrm{Am}$.

\subsubsection{Calculational method}

Starting with the CAMBRIC groundwater composition shown in Table 14 and adding trace masses of $\mathrm{Cs}, \mathrm{Sr}, \mathrm{Eu}, \mathrm{Pu}$ and $\mathrm{Am}$, we increased the $\mathrm{pH}$ in REACT from 5 to 10 and continuously monitored the aqueous speciation. Charge balance was maintained by varying either $\mathrm{Na}^{+}$or $\mathrm{Cl}^{-}$. The aqueous complexes accounting for over $90 \mathrm{~mol} \%$ of the radionuclide in solution were included in the GimRT simulations.

Inspection of the REACT output also revealed the saturation state of the fluid with respect to various radionuclide-bearing solids as a function of $\mathrm{pH}$. This information was used to identify potential solubility-limiting solids. The solubility-limiting solid was then used to fix the radionuclide concentration in the next set of REACT runs in which $\mathrm{pH}$ was again increased from 5 to 10 . In this manner, we defined the lower limit of solid solubility (e.g., the least soluble minerals), or inversely, the upper limits of radionuclide concentration in solution imposed by the precipitation of radionuclide-bearing solids. One 
solubility-limiting phase was considered for each radionuclide. Exceptions were made when no reasonable precipitate could be expected to form (see below).

Aqueous complexation of radionuclides by phosphate ligands and the precipitation of radionuclide-bearing phosphates were not considered in the simulations. Available thermodynamic data suggest that phosphate can dominate radionuclide complexation, and phosphate is known to be an effective complexer of radionuclides under some geochemical conditions. However, little has been done to establish the quality of existing thermodynamic data, especially in the neutral $\mathrm{pH}$ range. Phosphate complexes should be considered explicitly in future studies.

The possibility that a radionuclide could co-precipitate with another cation to form a solid solution (e.g., ${ }^{90} \mathrm{Sr}$ in a calcite solid solution of the form $\mathrm{Ca}_{x} \mathrm{Sr}_{1-x} \mathrm{CO}_{3}$ ) was not considered because GIMRT does not currently provide for solid solutions. Future work should address the sequestration of radionuclides by coprecipitation.

\subsubsection{Cesium (Cs)}

Calculations showed that the aqueous species $\mathrm{Cs}^{+}$dominated the CAmBrIC groundwaters at all values of $\mathrm{pH}$. Cs-bearing solids were found to be extremely soluble. Therefore, only the $\mathrm{Cs}^{+}$aqueous species was considered in the GIMRT simulations, and no Cs-bearing solid was considered as a potential precipitate.

\subsubsection{Strontium $(\mathrm{Sr})$}

$\mathrm{Sr}^{2+}$ comprises over 90 mole \% of the Sr-bearing aqueous species up to a $\mathrm{pH}$ of 9 (Fig. 22). Strontianite and celestite set the lower solubility limits of $\mathrm{Sr}$ concentration in solution (Fig. 23). However, preliminary reactive transport calculations using GIMRT showed that $\mathrm{Sr}$ concentrations in solution during glass dissolution were far below strontianite and celestite solubility. Thus, a Sr-bearing precipitate was not specifically included in the 1D or streamline calculations. This simplification reflects our effort to simplify the time-consuming geochemical calculations by omitting species whenever possible. The adequacy of such simplifications in the geochemical model must always be checked by examining calculated $\mathrm{Sr}$ concentrations to make sure they do not exceed the solubility limits shown in Figure 23. If so, Sr-bearing solids should be explicitly considered as potential precipitates. Simulations must be tailored to the specific application. Simplifications that work for CAMBRIC may be invalid at other test sites. It may also be true that simplifications that are valid for one streamline may be invalid for another owing to differences in rock types encountered, residence times, and so on. 


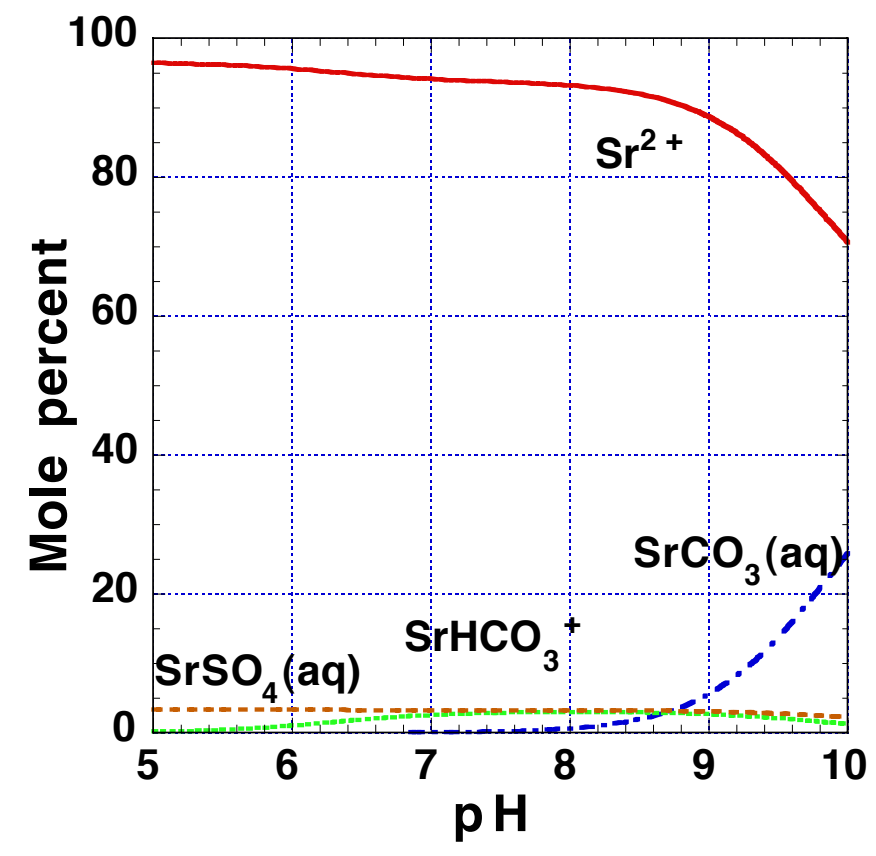

Figure 22: Aqueous speciation of strontium ( $\mathrm{Sr})$ as a function of $\mathrm{pH}$ in representative CAMBRIC groundwater (Table 14). 


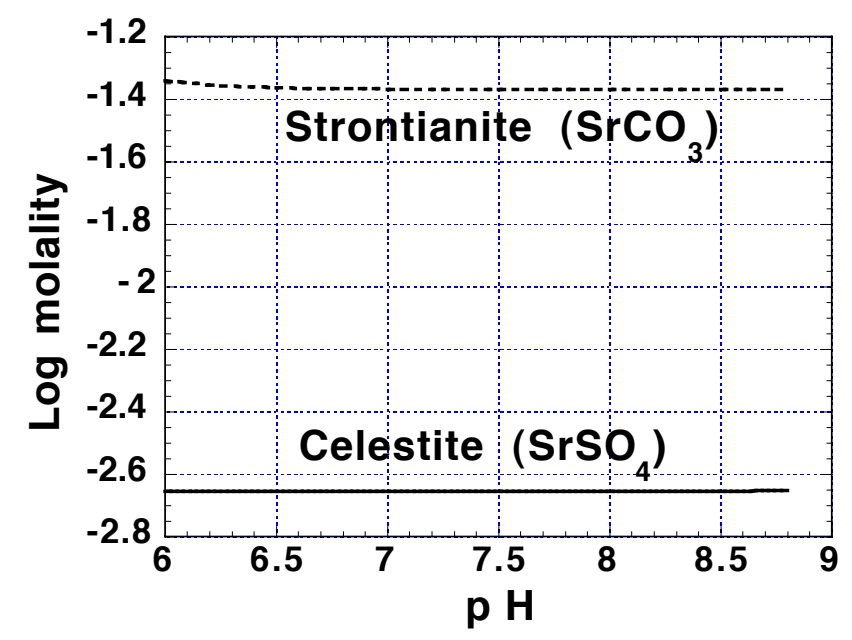

Figure 23: Calculated solubility of strontium (Sr)-bearing solid phases as a function of $\mathrm{pH}$ in representative CAMBRIC groundwater (Table 14).

\subsubsection{Europium (Eu)}

Carbonate complexes, especially $\mathrm{EuOHCO}_{3}(\mathrm{aq})$, dominate Eu speciation (Fig. 24). The three Eu species selected, $\mathrm{EuOH}\left(\mathrm{CO}_{3}\right)_{2}^{2-}, \mathrm{Eu}(\mathrm{OH})_{2}\left(\mathrm{CO}_{3}\right)^{-}$and $\mathrm{EuOHCO}_{3}$ (aq) comprise nearly $100 \%$ of the $\mathrm{Eu}$ at $\mathrm{pH}=8$. The solid $\mathrm{EuOHCO}_{3}$ sets the lower solubility limit for Eu over the $\mathrm{pH}$ range of 6 to 9 (Figure 25).

\subsubsection{Plutonium $(\mathrm{Pu})$}

$\mathrm{PuO}_{2}\left(\mathrm{CO}_{3}\right)_{2}^{2-}$ dominates the aqueous speciation of $\mathrm{Pu}$ at $\mathrm{pH}$ values from 7 to 9 (Fig. 26). Carbonate species are again dominant; $\mathrm{PuO}_{2}\left(\mathrm{CO}_{3}\right)_{3}^{4-}, \mathrm{PuO}_{2} \mathrm{CO}_{3}^{-}$ and $\mathrm{PuO}_{2}\left(\mathrm{CO}_{3}\right)_{2}^{2-}$ were considered in GimRT. $\mathrm{PuO}_{2}(\mathrm{OH})_{2}(\mathrm{aq})$ was included although limited in mass because of its relation to the sorbed species of $\mathrm{Pu}$ (see Table 26). $\mathrm{PuO}_{2}^{+}$and $\mathrm{PuO}_{2}^{2+}$ were required by the code to provide for variations in the redox state of $\mathrm{Pu}$ in solution.

The selection of a solubility-limiting phase for $\mathrm{Pu}$ is rather problematic. Crystalline $\mathrm{PuO}_{2}$ has the lowest solubility by many orders of magnitude (Fig. 27). However, the crystalline form of $\mathrm{PuO}_{2}$ is not expected to be the first $\mathrm{Pu}$ precipitate to form at ambient temperatures in the field, nor is it the first precipitate in laboratory experiments. A poorly crystalline, hydrated phase tends to precipitate which gradually transforms to a more crystalline phase over time. The poorly crystalline, hydrated phase is represented in our data base by 


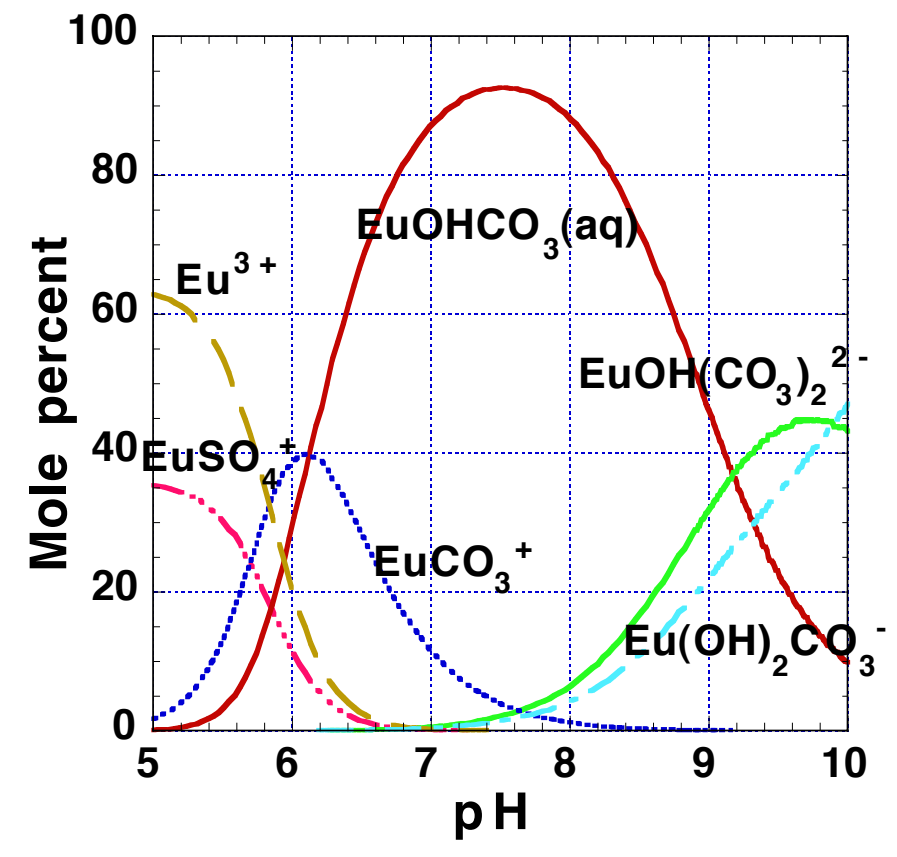

Figure 24: Aqueous speciation of europium $(\mathrm{Eu})$ as a function of $\mathrm{pH}$ in representative CAMBRIC groundwater (Table 14). 


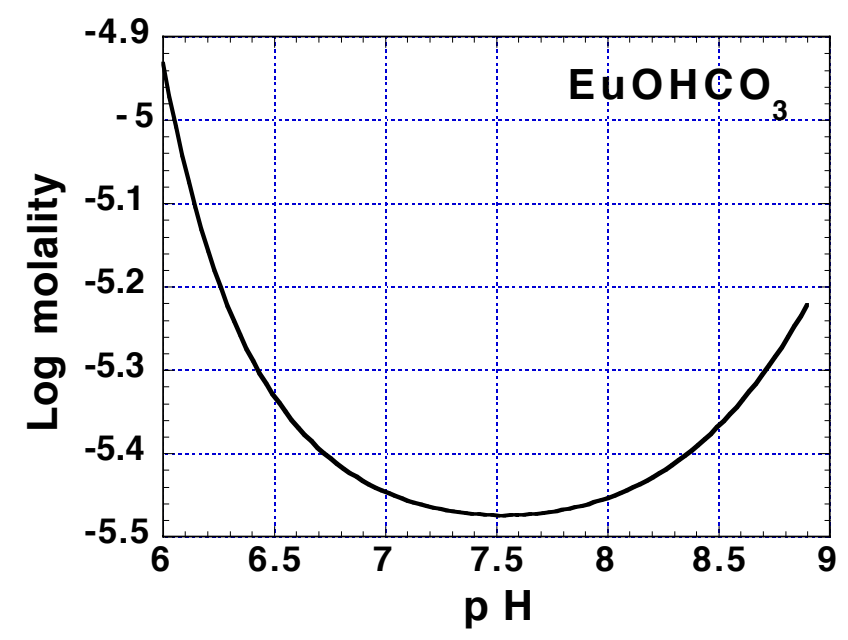

Figure 25: Calculated solubility of europium (Eu)-bearing solid phases as a function of $\mathrm{pH}$ in representative CAMBRIC groundwater (Table 14).

$\mathrm{PuO}_{2}$ (s, hydrated) where s refers to solid. However, $\mathrm{PuO}_{2}$ (s, hydrated) tends to precipitate from supersaturated solutions, whereas at CAMBRIC, the solubility limit will be approached from a state of undersaturation. Rather than choosing one of these solubility end-members, the hydrated oxyhydroxide $\mathrm{PuO}_{2}(\mathrm{OH})_{2}$. $\mathrm{H}_{2} \mathrm{O}$ was chosen as an intermediate solubility-limiting phase.

\subsubsection{Americium (Am)}

The carbonate species $\mathrm{AmCO}_{3}^{+}$and $\mathrm{Am}\left(\mathrm{CO}_{3}\right)_{2}^{-}$together with $\mathrm{AmOH}^{2+}$ at higher $\mathrm{pH}$ account for the majority of $\mathrm{Am}$ in solution (Fig. 28). $\mathrm{AmOHCO}_{3}$ is the solubility limiting phase up to a $\mathrm{pH}$ of about 8.7 (Fig. 29), and was used in the GIMRT simulations.

Table 17 summarizes the radionuclide-bearing aqueous species and the aqueous species representing the major components of the groundwater that were used in the GIMRT simulations. Table 18 lists the radionuclide-bearing solids and the primary and authigenic minerals considered in the simulations. 


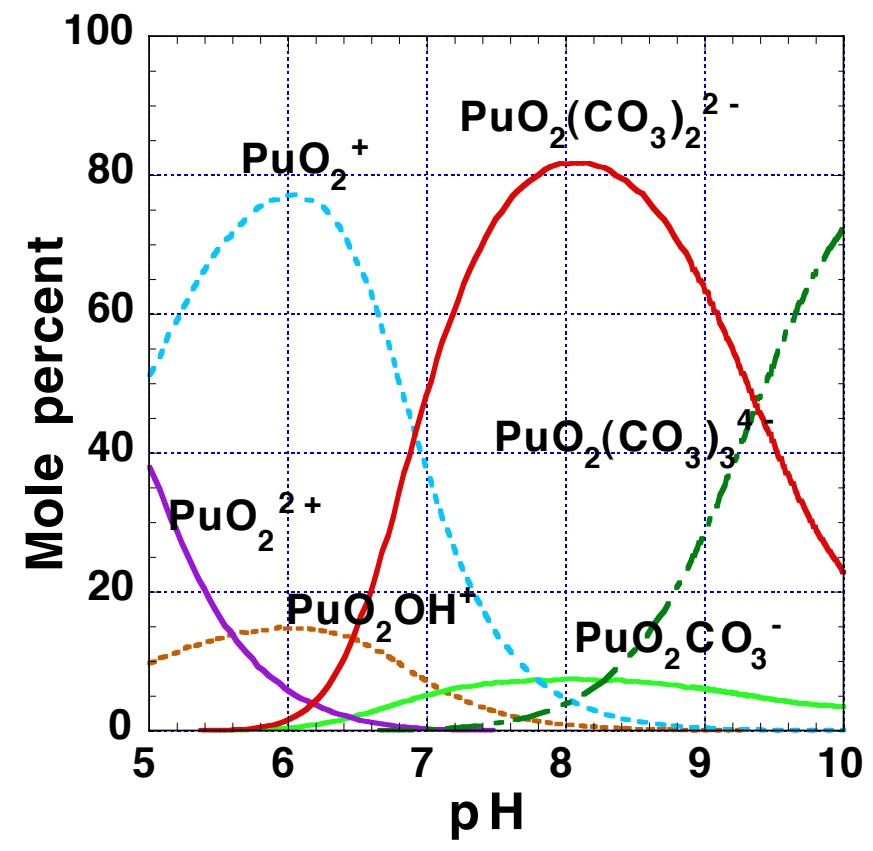

Figure 26: Aqueous speciation of plutonium $(\mathrm{Pu})$ as a function of $\mathrm{pH}$ in representative CAMBRIC groundwater (Table 14). 


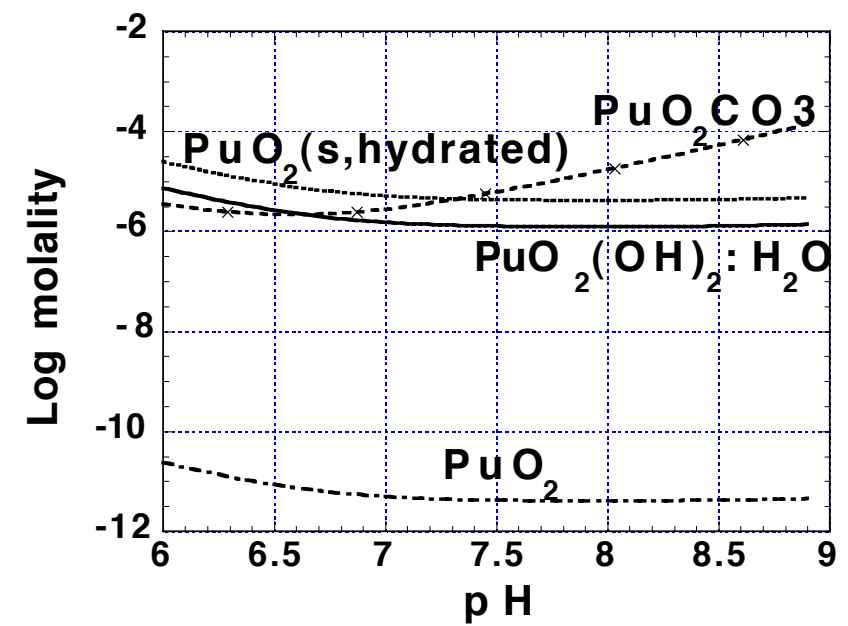

Figure 27: Calculated solubility of plutonium $(\mathrm{Pu})$-bearing solid phases as a function of $\mathrm{pH}$ in representative CAMBRIC groundwater (Table 14).

Table 17: Aqueous species used in simulations (see text).

\begin{tabular}{lll}
\hline \hline & & \\
$\mathrm{H}^{+}$ & $\mathrm{OH}^{-}$ & $\mathrm{Na}^{+}$ \\
$\mathrm{Ca}^{2+}$ & $\mathrm{K}^{+}$ & $\mathrm{Mg}^{2+}$ \\
$\mathrm{O}_{2}(\mathrm{aq})$ & $\mathrm{Cs}^{+}$ & $\mathrm{Sr}^{2+}$ \\
$\mathrm{Fe}^{2+}$ & $\mathrm{Fe}^{3+}$ & $\mathrm{Fe}(\mathrm{OH})_{3}(\mathrm{aq})$ \\
$\mathrm{Fe}(\mathrm{OH})_{4}^{-}$ & $\mathrm{Fe}(\mathrm{OH})_{2}^{+}$ & $\mathrm{Al}^{3+}$ \\
$\mathrm{AlO}_{2}^{-}$ & $\mathrm{SiO}_{2}(\mathrm{aq})$ & $\mathrm{HSiO}_{3}^{2-}$ \\
$\mathrm{HPO}_{4}^{2-}$ & $\mathrm{H}_{2} \mathrm{PO}_{4}^{-}$ & $\mathrm{HCO}_{3}^{-}$ \\
$\mathrm{CO}_{3}^{2-}$ & $\mathrm{SO}_{4}^{2-}$ & $\mathrm{Cl}^{-}$ \\
$\mathrm{Eu}^{3+}$ & $\mathrm{EuOHCO}_{3}(\mathrm{aq})$ & $\mathrm{Eu}(\mathrm{OH})_{2} \mathrm{CO}_{3}^{-}$ \\
$\mathrm{EuOH}\left(\mathrm{CO}_{3}\right)_{2}^{2-}$ & $\mathrm{Am}^{3+}$ & $\mathrm{AmCO}{ }_{3}^{+}$ \\
$\left.\mathrm{Am}_{(\mathrm{CO}}\right)_{2}^{-}$ & $\mathrm{Am}_{2}(\mathrm{OH})_{2}^{+}$ & $\mathrm{Pu}^{4+}$ \\
$\mathrm{PuO}_{2}\left(\mathrm{CO}_{3}\right)_{2}^{2-}$ & $\mathrm{PuO}_{2}\left(\mathrm{CO}_{3}\right)_{3}^{4-}$ & $\mathrm{PuO}_{2} \mathrm{CO}_{3}^{-}$ \\
$\mathrm{PuO}_{2}(\mathrm{OH})_{2}(\mathrm{aq})$ & $\mathrm{PuO}_{2}^{2+}$ & $\mathrm{PuO}_{2}^{+}$ \\
& & \\
\hline \hline
\end{tabular}




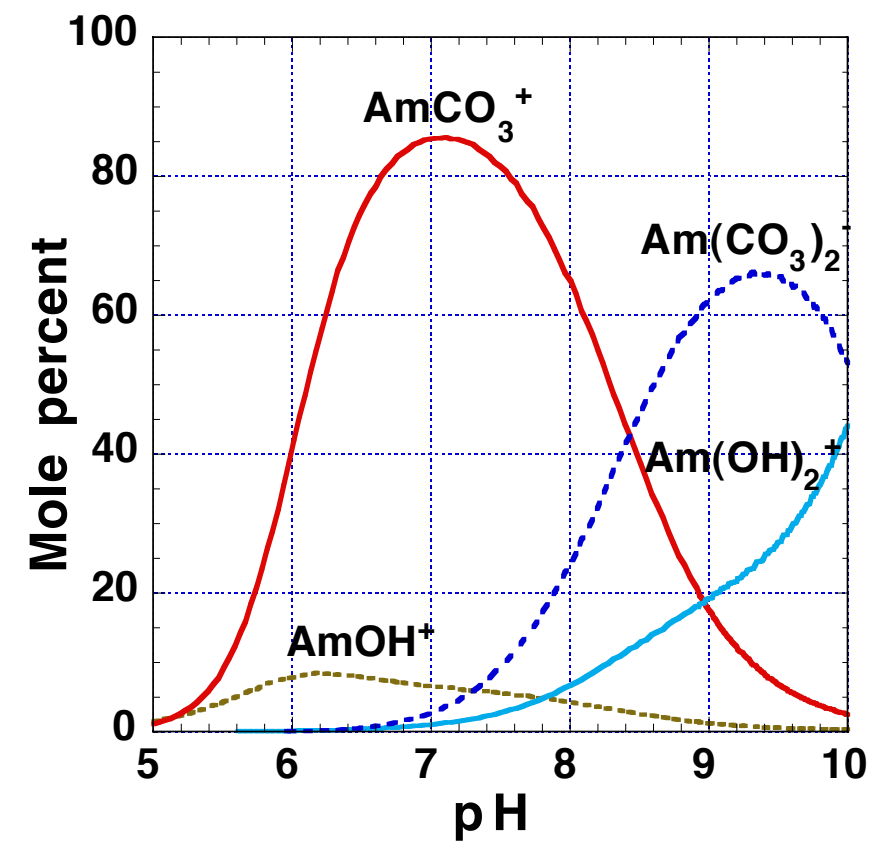

Figure 28: Aqueous speciation of americium (Am) as a function of $\mathrm{pH}$ in representative CAMBRIC groundwater (Table 14). 


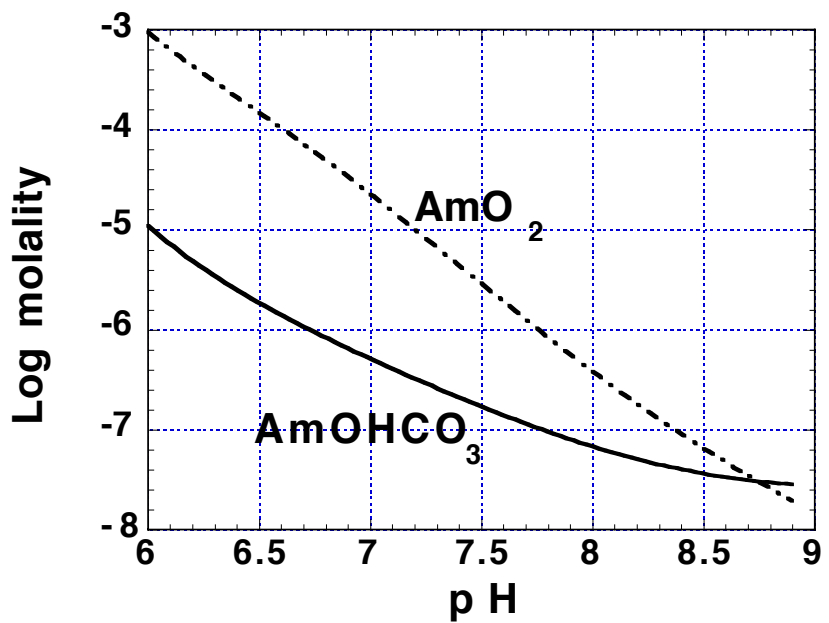

Figure 29: Calculated solubility of americium (Am)-bearing solid phases as a function of $\mathrm{pH}$ in representative CAMBRIC groundwater (Table 14).

Table 18: Primary and authigenic solids and minerals considered in the simulations (see text).

Melt glass

$\beta$-cristobalite $\left(\mathrm{SiO}_{2}\right)$

Calcite $\left(\mathrm{CaCO}_{3}\right)$

Muscovite $\left(\mathrm{KAl}_{2} \mathrm{AlSi}_{3} \mathrm{O}_{10}(\mathrm{OH})_{2}\right)$

Clinoptilolite-Ca $\left(\mathrm{Ca}_{1.7335} \mathrm{Al}_{3.467} \mathrm{Si}_{14.533} \mathrm{O}_{36} \cdot 10.922 \mathrm{H}_{2} \mathrm{O}\right)$

Beidellite-Ca $\left(\mathrm{Ca}_{0.165} \mathrm{Al}_{2.33} \mathrm{Si}_{3.67} \mathrm{O}_{10}(\mathrm{OH})_{2}\right)$

Goethite (FeOOH)

$\mathrm{EuOHCO}_{3}$

$\mathrm{AmOHCO}_{3}$

$\mathrm{PuO}_{2}(\mathrm{OH})_{2}: \mathrm{H}_{2} \mathrm{O}$ 


\section{One-Dimensional Reactive Transport Simula- tions using GIMRT}

Given the potential complexity of the reactive transport simulations along the streamlines, it is instructive to simulate radionuclide release, migration and attenuation along one dimensional flow paths of constant Darcy flux that intersect a simplified sequence of rock types of the type encountered in the CAMBRIC system. With the aid of these heuristic $1 \mathrm{D}$ simulations, we can readily evaluate the processes that will impact radionuclide migration, and we will be better prepared to interpret the geochemical profiles produced by the streamline calculations. The simulations will also help us to identify the model parameters that have the most effect on predictions of radionuclide migration.

Although the 1D simulations are based upon an arbitrary geometrical configuration of material and a typical fluid flux, the radionuclide concentrations assigned to the exchange volume and composition of the melt glass are consistent with what is used in the final simulations. Hence, the exchange volume concentrations will be based on the model 18-m radius exchange volume discussed earlier in Chapter 1 (as well as in Chapters 10, 11, and Appendix 5 below). Please note that the exploratory $1 D$ simulations introduced here and discussed in greater detail in Appendix 5 should not be confused with the $i n$ dividual streamline simulations that are discussed in Chapter 11 and Appendix 7. The individual streamline simulations are based upon the proper material configurations and fluid fluxes and are part of the final suite of 3D simulations.

\subsection{Four basic simulations}

Four 1D simulations were made of groundwater flowing at a constant Darcy flux of $1 \mathrm{~m} / \mathrm{yr}$ through sequences of melt glass, exchange volume and alluvium given by:

- alluvium-melt glass-alluvium

- alluvium-exchange volume-alluvium

- alluvium-melt glass-exchange volume-alluvium

- alluvium-exchange volume-melt glass-alluvium

Schematic illustrations of the flow paths are given in Figures 30 through 33. The path length through each rock type was assumed to equal $10 \mathrm{~m}$. Grid cells were assigned a constant spacing of $1 \mathrm{~m}$. The fluid chemistry and mineralogy of the rock types used in the simulations are listed in Tables 14 through 18. Simulations were carried out at $25^{\circ} \mathrm{C}$. Diffusion and hydrodynamic dispersion in the aqueous phase were assumed to be absent in order to simplify analysis of

code output. Radioactive decay was also not included at this stage. Assigned concentration data are discussed in Appendix 5. 


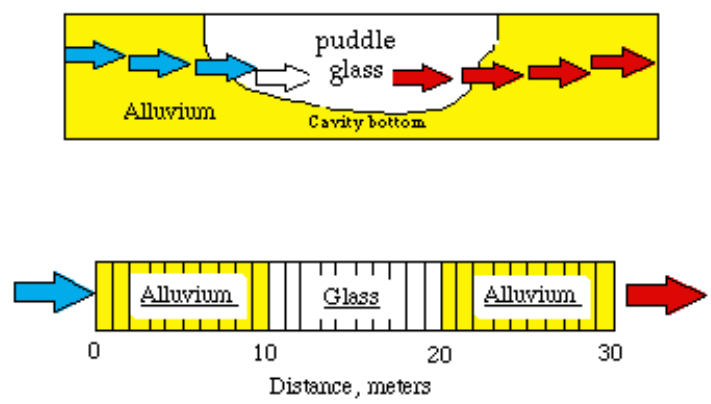

Figure 30: (a, top) Conceptual model of fluid flow through the sequence of rock types alluvium, glass, and alluvium. (b, bottom) Grid and zones of rock type used in 1D GIMRT simulations of model in (a).

The simulations were run over a span of 5000 years. The 1D simulations covered a longer period of time than the streamline calculations in order to better evaluate reactions over extended time periods, which is especially relevant when considering processes as slow as glass dissolution.

Simulations were made using a nonreactive fictive aqueous species named "Tracer" to use as a reference in comparing radionuclide migration with movement of a nonreactive chemical component in the aqueous phase. The tracer was initially present in the groundwater in the melt glass at a concentration of $1 \times 10^{-6}$ molal. The tracer concentration was fixed at $1 \times 10^{-12}$ molal outside the melt glass. As discussed previously, groundwaters were assumed to contain an initial concentration of $1 \times 10^{-15}$ molal $\mathrm{Pu}, \mathrm{Am}, \mathrm{Eu}$, Cs and $\mathrm{Sr}$ because finite concentrations are required by GIMRT. The concentrations of $\mathrm{Cs}, \mathrm{Sr}$ and $\mathrm{Eu}$ in the 1D simulations contain not only the radiogenic isotopes ${ }^{137} \mathrm{Cs},{ }^{90} \mathrm{Sr}$ and ${ }^{155} \mathrm{Eu}$, respectively, but also their natural, non-radiogenic counterparts. Calculation of the radionuclide source term requires multiplying the total concentrations by the correction factor listed in Table 13.

The 1D simulations results are presented in Appendix 5 because of the specialized and detailed geochemical analysis of the effects on radionuclide migration of glass dissolution, release from the exchange volume, aqueous complexation, surface complexation and ion exchange. A summary of the 1D simulation results follows.

The 1D simulation results demonstrate that the homogeneous distribution of 1 volume $\%$ goethite and muscovite/illite and 5 volume $\%$ clinoptilolite and smectite in contact with pore fluid can significantly retard radionuclide migration. Both the exchange volume mineralogy and the glass acted as long-term sources of radionuclide release. As expected, the glass dissolved slowly, releasing small quantities of radionuclides continuously over time. The results for the 


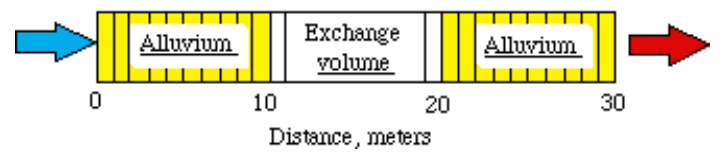

Figure 31: Grid and zones of rock type used in 1D GIMRT simulations of fluid flow through the sequence of rock types alluvium, exchange volume, and alluvium.

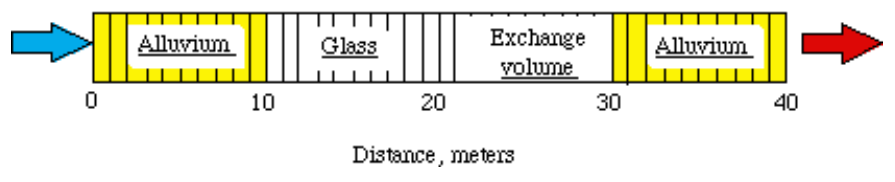

Figure 32: Grid and zones of rock type used in 1D GIMRT simulations of fluid flow through the sequence of rock types alluvium, glass, exchange volume and alluvium.

exchange volume were rather unexpected, as it was expected that radionuclidefree groundwater would flush out the radionuclides fairly effectively. However, the concentrations of radionuclides associated with the solid phases in the exchange volume exceed the concentrations in the pore fluid by several orders of magnitude. Thus as the incoming fluid flushed out the radionuclides in the fluid, the solids released enough radionuclide to maintain equilibrium with the solution, yet still maintained a significant percentage of their original radionuclide content.

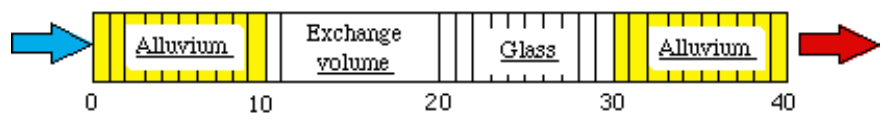

Figure 33: Grid and zones of rock type used in 1D GIMRT simulations of fluid flow through the sequence of rock types alluvium, exchange volume, glass and alluvium. 
Chapter 9: One-Dimensional Transport Simulations 


\section{Near-Field Groundwater Flow at CAMBRIC}

We have developed a three-dimensional numerical model of steady groundwater flow in a portion of the saturated alluvium surrounding the CAMBRIC cavity and chimney system. This model will be used as a basis to integrate the reactive transport and glass dissolution models outlined above and forecast the elution and total flux of selected radionuclides out of the near field environment under ambient flow conditions.

\subsection{Model domain}

The model domain is comprised of a $450 \mathrm{~m}$-long by $360 \mathrm{~m}$-wide by $210 \mathrm{~m}$ deep prismatic block carved out of the alluvium, as shown in Figures 8 and 34 . The top of the domain has been aligned with the existing water table, located approximately $220 \mathrm{~m}$ beneath the ground surface. The domain encompasses the cavity, chimney, and emplacement hole (Ue5) features of the CAMBRIC test, as well as the slanted drill-back hole (RNM-1) and the radionuclide migration experiment pumping well (RNM-2S).

The domain was oriented such that its longer $(450 \mathrm{~m})$ side is collinear with the topographical gradient and principal direction of geologic deposition (Fig. 5 ), as well as the ambient horizontal hydraulic gradient (Fig.6) ${ }^{7}$. This ensures that the ambient motion of groundwater enters and exits the smaller ends of the domain (Fig. 34) and simplifies setting up the model to look at transport under natural gradient conditions.

Ultimately, nonuniform distributions of hydraulic conductivity are to be specified in this domain, as chosen from an idealized Gaussian random field model of conductivity variability (Tompson, et al., 1989). This particular configuration allows the principal directions of spatial correlation in the permeability distribution to be aligned with the main axes of the domain, and, thus, the assumed main axes of deposition.

\subsection{Previous models and the radionuclide migration ex- periment}

Between October 1975 and August 1991, a long term radionuclide migration experiment was conducted to monitor the distribution and movement of tritium and other radionuclides associated with the CAMBRIC test (Buddemeier, 1988; Daniels, 1982; Bryant, 1992). A large part of the experiment involved the continuous pumping of nearby well RMN-2S to obtain elution profiles of various radionuclides. This well was drilled $90 \mathrm{~m}$ south of the device emplacement hole (Ue5) and was screened over an approximate $25 \mathrm{~m}$ interval between depths of 318 and $343 \mathrm{~m}$ (below the CAMBRIC cavity), or, equivalently, between 615 and $640 \mathrm{~m}$ above sea level (Figs. 7 and 34 ).

\footnotetext{
${ }^{7}$ This domain differs from an earlier version that was oriented in a North-South direction
} 


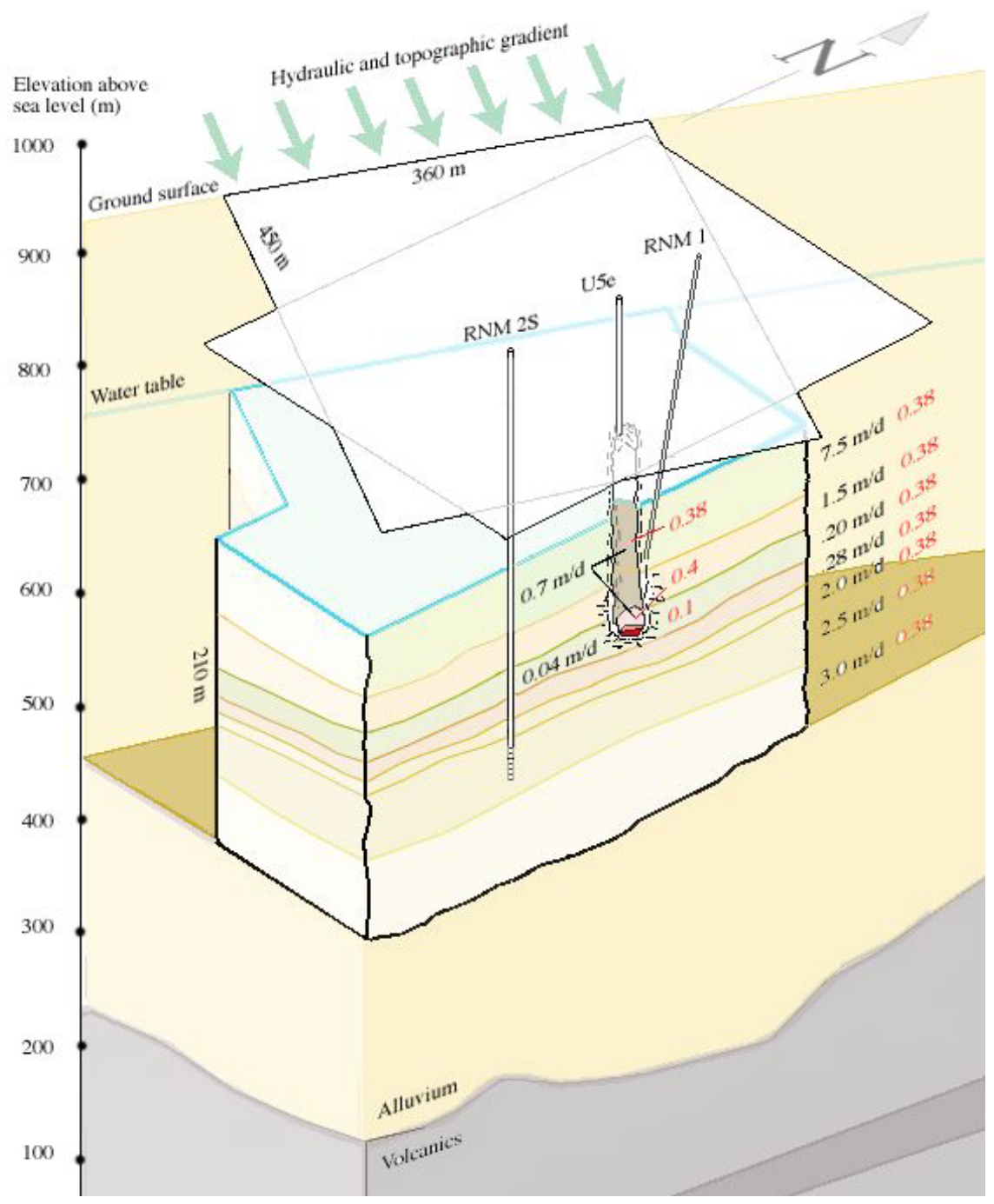

Figure 34: Localized perspective of the hydrogeologic flow region around CAMBRIC. The modeling domain in the current model lies beneath the white rectangle oriented in a NW-SE direction that is aligned with the hydraulic and topographic gradient. It extends from the water table to a final depth of 210 $\mathrm{m}$ below the water table and is composed of the same alluvial layers used in the Burbey and Wheatcraft (1986) model. Numbers represent porosities and geometric-mean conductivities used in the current model. 
The well was initially pumped at a rate of $300 \mathrm{gal} / \mathrm{min}$ for 700 days. The rate was increased to $600 \mathrm{gal} / \mathrm{min}$ thereafter, with a few short shutdowns in between (Bryant, 1992). The first amounts of tritium were observed in the well after 900 days of pumping. Altogether, over $90 \%$ of the $5.9 \times 10^{4} \mathrm{Ci}$ of tritium produced in the test (Table 5) was recovered during the 16 years of pumping (Fig. 35). As mentioned earlier, various amounts of ${ }^{36} \mathrm{Cl},{ }^{85} \mathrm{Kr},{ }^{99} \mathrm{Tc},{ }^{106} \mathrm{Ru},{ }^{125} \mathrm{Sb}$, and

${ }^{129} \mathrm{I}$ were also detected in the well over the same 16 year period. Because of this, these elements have been considered to be the more mobile ones of the inventory in the CAMBRIC alluvial environment, even though differences the arrival profiles have been attributed to many factors related to, for example, ion-exclusion effects $\left(e . g .,{ }^{36} \mathrm{Cl}\right)$, low-level sorption (e.g., HTO), or longer-term reentrainment of volatile components $\left(e . g .{ }^{85} \mathrm{Kr}\right)$.

This experiment has been the focus of several recent modeling efforts, and will serve as the starting point for our current modeling work. Several of these related studies will be reviewed briefly below. Our own work will initially focus on modeling the elution of the tritium during the 16-year migration experiment, but will then shift towards analyzing the transport of the target radionuclides (Table 7) under natural hydraulic gradients (no pumping whatsoever) over long periods of time.

\subsubsection{LATA model}

The numerical model applied by Los Alamos Technical Associates (1982) (or, "LATA") was based upon a simplified layered conceptualization of the alluvium around the pumping well and cavity-chimney system. A two-dimensional, axisymmetric $19^{\circ}$ pie-shaped modeling domain (Fig. 8) centered on the pumping well (RNM-2S) was designed and used to look at vertical and radial flow components converging toward the well screen in the absence of any background hydraulic gradient. The top of the domain was aligned with the water table and considered to be a no-flow boundary. The domain extended $200 \mathrm{~m}$ below the water table and $304 \mathrm{~m}$ radially away from the well. The volume was discretized into a coarse $38 \times 8$ (304 block) grid with radial and vertical spacings of $8 \mathrm{~m}$ and $25 \mathrm{~m}$, respectively.

The flow model was characterized using several pump and slug test results, and was calibrated against drawdown curves obtained in well tests conducted in RNM-2S and RNM-1. A uniformly layered system composed of 3 principal horizontal flow units was assumed, as summarized in Table 19. Separate parameter specifications were also made in the cavity volume.

Simulations of tritium transport and recovery in the pumping well RNM2S between 1975 and 1991 were also conducted using this model. Tritium was initially distributed in groundwater occupying a $75 \mathrm{~m}$-high, wedge-shaped volume spanning the cavity-chimney system. This volume was approximately 32 $\mathrm{m}$ long in the radial direction and $32 \mathrm{~m}$ wide in the angular direction. Initial concentrations ranged between 0.6 and $6 \mu \mathrm{Ci} / \mathrm{ml}$. The apparent total HTO in- 


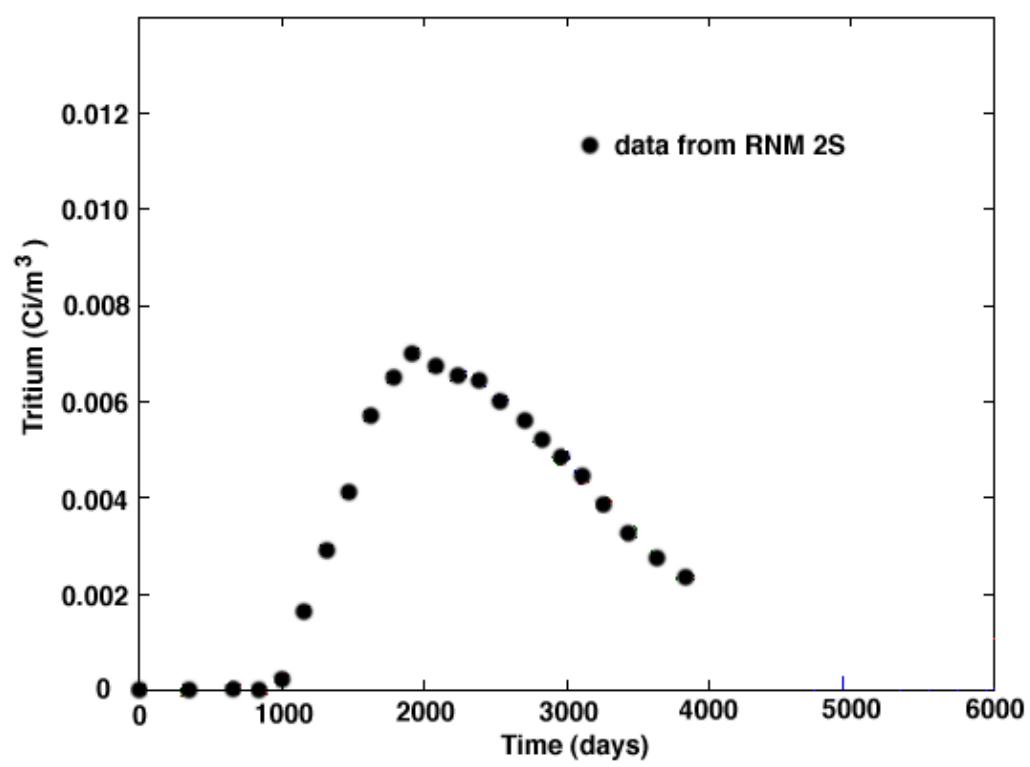

Figure 35: Decay-corrected tritium elution profiles obtained at the RNM-2S well. Times correspond to the number of days since pumping began in October 1975 . 


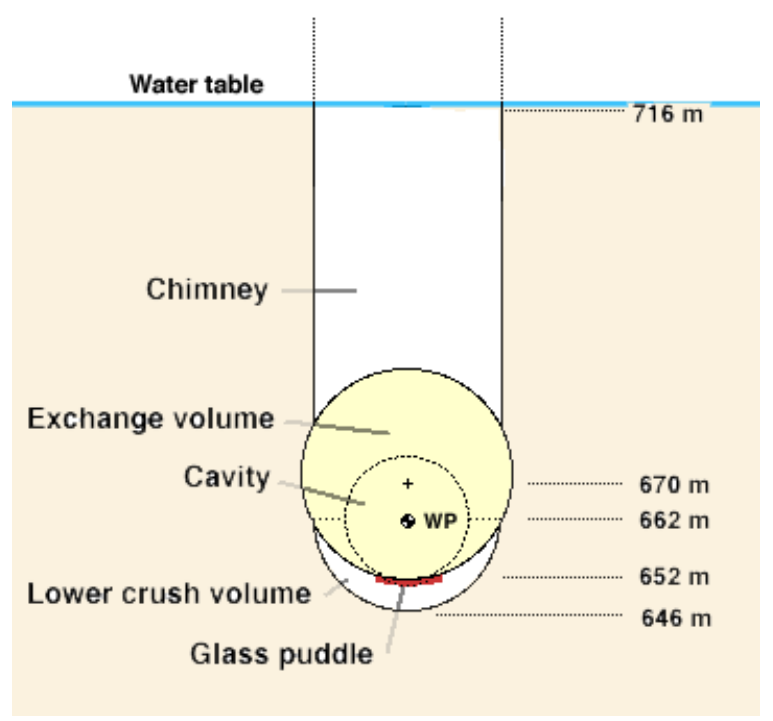

Figure 36: Generic illustration of geologic units that comprise the cavity/chimney system in the simulation models (see text). Numbers represent elevation above sea level.

ventory specified in this volume ${ }^{8}$ was approximately $5.2 \times 10^{4} \mathrm{Ci}$, as corrected to zero-time. This is slightly smaller than the real amount shown in Table 5.

Altogether, most of the transport model results showed tritium breakthrough behavior that was premature and overly spread-out over time. Some additional calibration was achieved at this stage by uniformly decreasing the assigned hydraulic conductivities or the vertical-to-horizontal conductivity ratio, or by specifically modifying the hydraulic properties specified in the cavity and chimney (these are reflected in three columns in Table 19). The magnitude of the hydrodynamic dispersion coefficients used in the model was not discussed, and it was not clear to what extent numerical diffusion errors in the model led to smearing in the simulated elution profiles. It also seems that the initial amount of tritium specified in the model may underestimate the actual amount in the system. Although not addressed in detail, the report did stress the importance of three dimensional flow in this system as well as the potential relevance of material heterogeneity in controlling the migration of radionuclides on the scale of this problem.

\footnotetext{
${ }^{8}$ As determined from integrating the specified concentrations over the pore volume in the specified source region.
} 


\subsubsection{LANL model}

As described by Daniels (1982), a two-dimensional, axisymmetric model of flow and transport was also developed to analyze the CAMBRIC experiment by Los Alamos National Laboratory. In this case, a $13.5^{\circ}$ wedge domain centered on RNM-2S was used, extending $220 \mathrm{~m}$ radially outwards towards the cavity (Fig. 8 ). The wedge was $300 \mathrm{~m}$ high and was also bounded on the top by the water table. Hydraulic properties were assumed to be completely uniform throughout the domain except for some properties in the cavity, a 5 -m thick low permeability "crush-up" zone lying underneath the cavity (Table 19 and Fig. 36), and a small gravel pack about the well screen of RNM-2S. Simulations were made in the absence of any background hydraulic gradient, and were focused on predicting the elution of tritium and ${ }^{36} \mathrm{Cl}$ that was observed in RNM-2S.

Tritium was initially distributed in a $16-\mathrm{m}$ diameter spherical volume surrounding the working point at concentrations of 3.8 and $6.1 \mu \mathrm{Ci} / \mathrm{ml}$ in the upper and lower halves of the volume, respectively. Because of the axisymmetric grid configuration, the "spherical" volume is more closely represented by a "torroidal wedge". The apparent "modeled" HTO inventory specified in this wedge was approximately $3.7 \times 10^{4} \mathrm{Ci}$, as corrected to zero-time. This is much smaller than the real amount shown in Table 5 . Some additional studies of ${ }^{36} \mathrm{Cl}$ migration were also presented.

Premature breakthrough of tritium (distributed initially uniformly throughout the cavity volume) was simulated, just as in the LATA model, although the temporal profile was more sharp, or less damped. As above, it again seems that the initial amount of tritium specified in the model may underestimate the actual amount in the system. Very few additional calibrations were made in order to improve the results. Few details were given about the numerical model grid used. Additional work with ${ }^{36} \mathrm{Cl}$ simulations attempted to reproduce its earlier arrival profile (relative to tritium). This was attributed to an anion exclusion effect in which ${ }^{36} \mathrm{Cl}$ ions are perceived to remain in the central portions of the pore volumes, moving with faster-than-average velocities through the porous system.

\subsubsection{Burbey and Wheatcraft model}

A more recent model of hydrologic flow and transport was presented by Burbey and Wheatcraft (1986) ("BW"). Although the model was three-dimensional, it

was also based upon a horizontally stratified model of the alluvium structure with no background hydraulic gradient. A prismatic quarter-element domain was used, with one vertical edge coincident with the pumping well (RNM-2S) and the diagonally-opposite vertical edge lying just beyond the cavity-chimney system (Fig. 8). The domain was roughly $100 \mathrm{~m}$ thick, with its top located $39 \mathrm{~m}$ below the water table. Both the top and bottom were considered noflow boundaries. This simulation volume was discretized into an $11 \times 11 \times 7$ 
(847) grid of irregularly sized block elements. Outside of the cavity zone, a uniformly layered system composed of seven distinct hydraulic units was used, as summarized in Table 19.

In this model, both tritium and ${ }^{36} \mathrm{Cl}$ migration were considered. Initial concentrations of HTO were determined by assuming the zero-time inventory shown in Table 5 was completely and uniformly dissolved within the pore water in an $18 \mathrm{~m}$-radius spherical exchange volume centered $7 \mathrm{~m}$ above the working point (Fig. 36). As discussed elsewhere, this volume was meant to encapsulate the condensed tritium that may have moved beyond the cavity-proper during the cool-down and collapse of the cavity-chimney system (Fig. 1). At an assumed porosity of 0.32 , this was consistent with an average HTO concentration of 6.9 $\mu \mathrm{Ci} / \mathrm{ml}$ estimated from drillback hole data.

In the numerical model, the 18-m sphere was represented as an approximate ${ }^{9}$ rectilinear block that is $34 \mathrm{~m}$ long, $34 \mathrm{~m}$ wide, and $30 \mathrm{~m}$ deep. Knowing that the tritium concentration is to be fixed at $6.9 \mu \mathrm{Ci} / \mathrm{ml}$, this implies a slightly larger modeled inventory of $7.7 \times 10^{4} \mathrm{Ci}$ at the assumed porosity of 0.32 . On the other hand, given that the "best fit" model $(\mathrm{BW}, \mathrm{p} 72)$ is found with a cavity porosity of 0.15 , the initial modeled inventory would then be reduced to $3.6 \times 10^{4} \mathrm{Ci}$, substantially lower than the recognized value shown in Table 5 .

In spite of these mismatched inventories, the tritium recovery profiles were better than the previous results. The improvements were largely obtained through the specification of a continuous low-permeability layer located between the bottom of the cavity and the top of the screen in RMN-2S (Fig. 34), the inclusion of solute dispersion processes, and a specific assumption of chemical retardation in the basic tritium transport processes, although there is again some concern about the initial amount of tritium specified in the model. The lower conductivity unit was meant to represent the lithologic break discussed previously. Additional simulations also indicated a particular sensitivity to the cavity porosity.

The longitudinal dispersivity $\left(\alpha_{L}\right)$ used in this model was estimated to be 2 $\mathrm{m}$. It was determined by fitting the elution records to an idealized representation developed by Sauty (1980). A similar approach pursued by Ogard et al. (1988) yielded larger dispersivity estimates between 9 and $15 \mathrm{~m}$. Additional simulations were made to judge the sensitivity of the results of the vertical-to-horizontal conductivity ratio, cavity-zone porosity, and transverse dispersivity.

Additional transport simulations focused on matching ${ }^{36} \mathrm{Cl}$ elution profiles were also discussed. These involved use of a modified initial chlorine-36 distribution to account for differences in its formation, and an assumption of a tritium retardation effect to account for the fact that the ${ }^{36} \mathrm{Cl}$ recovery preceded that of the tritium. Interestingly, this is a distinctly different assumption from the ${ }^{36} \mathrm{Cl}$ ion exclusion effect proposed in the LANL model.

\footnotetext{
${ }^{9}$ No specific dimensions were given.
} 


\subsubsection{Guell model}

More recently, an updated version of the LANL model has been developed by Guell (1997). It was based on a slightly longer radial domain and a more layered formation structure, as motivated by the formulation of the Burbey and Wheatcraft (1986) model. Recovery of tritium was markedly improved. Importantly, the model also focused on recovery of ${ }^{85} \mathrm{Kr}$ which was envisioned to have been generated as a gas, spatially redistributed within the chimney region, and later recaptured into the saturated regime. The importance of the initial phenomenological response of the system, spatial redistribution of radionuclide gases, and the timing of their ultimate recondensation or reintroduction into groundwater were clearly documented and emphasized.

\subsection{Current model}

The current groundwater flow model was developed to allow a larger and more highly resolved flow domain to be considered. Initial simulations have also been used to examine the RNM-2S pumping experiment, while later simulations focus on longer term radionuclide release and migration under ambient hydraulic conditions.

The domain shown in Figures 7, 8, and 34 encompasses most of the steady state drawdown behavior associated with the experimental pumping in RNM-2S and reduces the influence of specified conditions along the boundary. It has been discritized by a grid of $235 \times 180 \times 105$ (or $4.483 \times 10^{6}$ ) cubic finite difference blocks of length $2 \mathrm{~m}$. Both the top and bottom surfaces of the domain are considered confined, and no percolation recharge is specified. Specificed head conditions were used along all vertical faces of the domain.

Unlike the previous models, the size and orientation of this domain does not require any a priori assumptions of symmetry or uniformity in the geology or hydraulic behavior to be made. Increased spatial resolution allows smaller-scale variabilities in material properties such as the hydraulic conductivity, porosity, or mineralogic abundance to be considered, as well as a more refined representation of radionuclide inventories or other chemical distributions. This kind of spatial resolution allows for numerical dispersion effects produced by coarser grids in the previous models to be minimized, and permits more defensible simulations and interpretations of real processes to be made. Flow simulations have been made with the PARFLOw model at LLNL (Ashby, et al., 1994; Ashby, 1996).

\subsubsection{Geometry and features of the disturbed zone}

The geometry of the disturbed zone used in our flow model is shown in Figure 36 . The $10.9-\mathrm{m}$ radius spherical cavity is centered on the working point, and is surrounded by an approximate, $18-\mathrm{m}$ radius exchange volume similar to that 
used in the Burbey and Wheatcraft (1986) model. The centers of these volumes are offset about $8 \mathrm{~m}$ in the vertical such that their bottoms lie approximately at the same point. We have also specified a cylindrical, $16 \mathrm{~m}$ radius chimneyrubble zone above the exchange volume, a 5-m thick crescent-shaped crush-up zone beneath the exchange volume, and a thin melt melt glass at the bottom of the cavity and exchange volumes.

As defined earlier, the exchange volume is usually considered to envelope the portions of the collapsed cavity, chimney, and sidewall systems that contain significant amounts of radionuclides redistributed during collapse. These radionuclides include many of the more volatile (non-refractory) species that have been exchanged as vapors prior to recondensation. Some noncondensable species such as ${ }^{85} \mathrm{Kr}$ or ${ }^{137} \mathrm{Xe}$ may actually migrate further upwards into the unsaturated portions of the chimney system (Guell, 1997). Smith et al. (1997) have also documented this phenomena on a field scale at the site of the HyRAX (U-3bh) test in carbonate-rich alluvium (Area 3) of Yucca Flat.

Although the size of the CAMBRIC exchange volume has not been explicitly measured, it has been approximated by a 16 - to 18 -m radius sphere as a means to describe the distribution of condensed HTO (Hoffman et al., 1977; Burbey and Wheatcraft, 1986). The size of an exchange volume can often be estimated from correlations that have been developed from drillback hole data (Borg et $a l ., 1976)$. Burbey and Wheatcraft's estimate is based upon the size of a sphere necessary to house the entire HTO inventory at the measured mean aqueous concentration of $6.93 \mu \mathrm{Ci} / \mathrm{ml}$ and a $32 \%$ porosity.

Figure 37 shows the distribution of HTO measured in water samples taken from RNM-1, as well as the concentrations measured in alluvium samples taken during the well's construction. In addition, the gamma log intensity measured down the hole is also shown. Overall, these data suggest that an 18-m radius exchange volume may be a reasonable choice at CAMBRIC, but that radionuclide concentrations may not be uniformly distributed within this volume.

The lower crush-up zone shown in Figure 36 is meant to represent a region of lower permeability and porosity produced by the compressive forces of the test. We have included it to match similar features included in the LANL (Daniels, 1982) and Guell (1997) models.

The melt-glass puddle is represented by a $2-\mathrm{m}$ thick, 8 -m radius cylindrical volume that is draped over the bottom of the cavity and exchange volumes. The bulk volume of glass is approximately $402 \mathrm{~m}^{3}$, which at an approximate porosity of 0.1 yields $362 \mathrm{~m}^{3}$ of pure glass, or close to 905 metric tons using a glass density of $2.5 \mathrm{~g} / \mathrm{cm}^{3}$. This value is in the upper part of the predicted range of melt glass abundance for an 0.75 kt-yield test (Smith, 1993).

\subsubsection{Specification of flow properties}

We have chosen to honor the basic layering apparent in the undisturbed alluvium by identifying 8 fundamental lithologic layers that are consistent with those used 


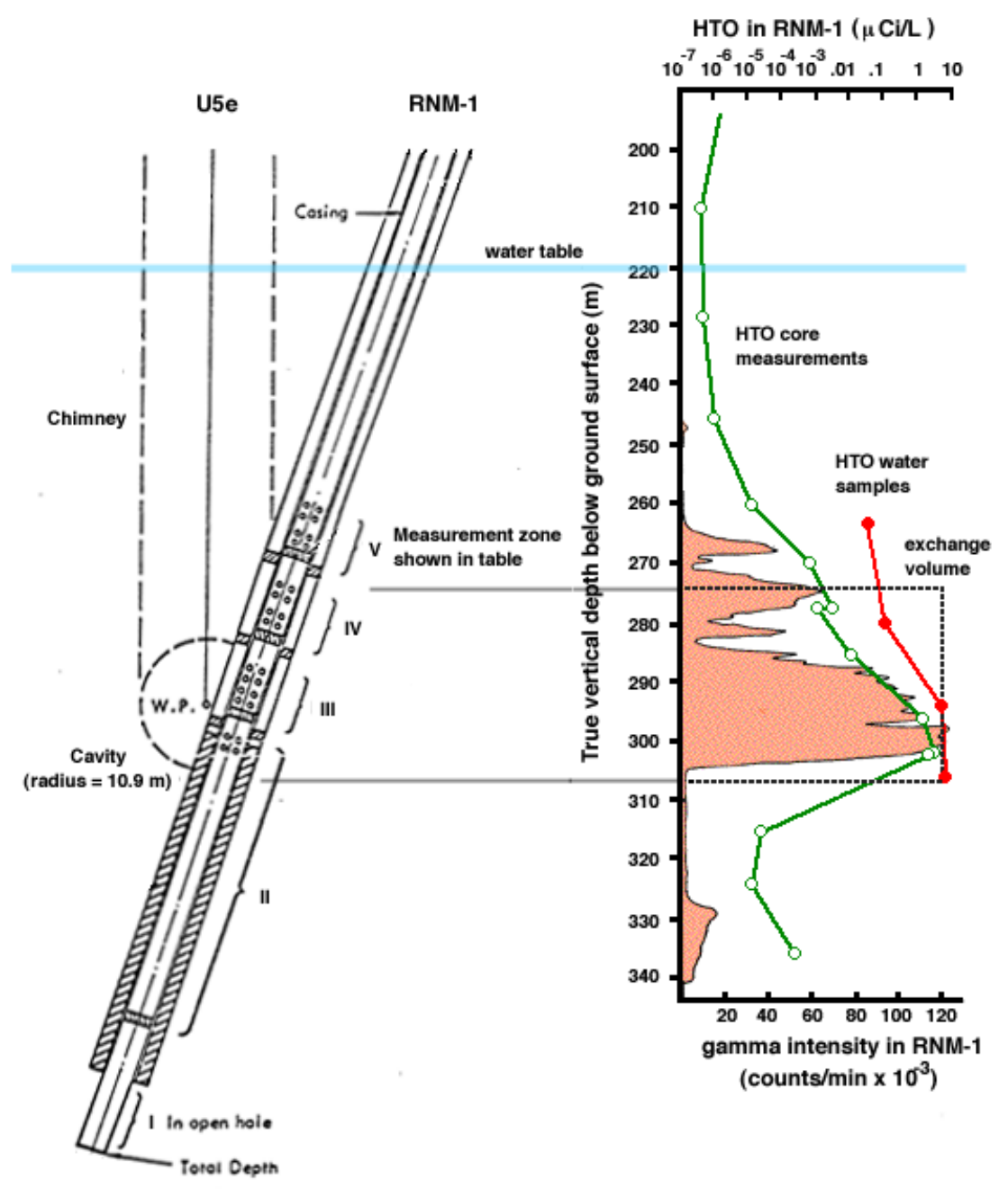

Figure 37: Schematic of slanted RNM-1 monitoring hole (purposely expanded in the radial direction), measured gamma intensity profile, and measured tritium concentration profiles from water samples taken in ports I-V and from borehole cores taken during construction (after Hoffman et al., 1977, and Burbey and Wheatcraft, 1986). The intersection with assumed 18-m radius exchange volume is also shown. 


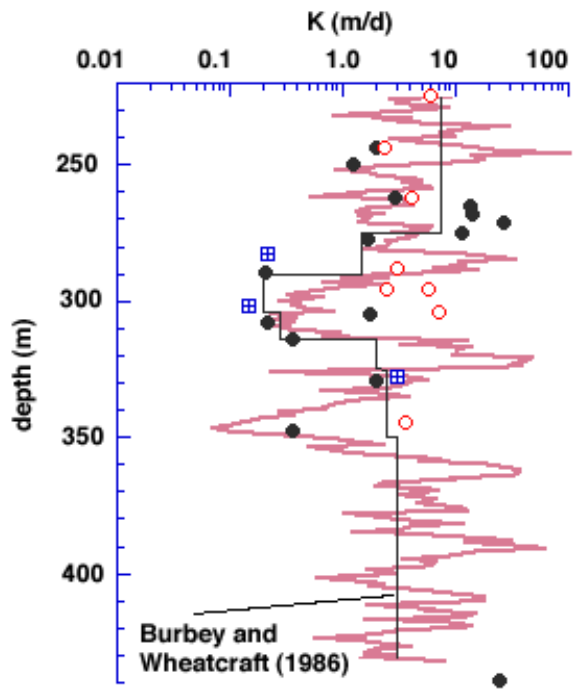

Figure 38: Measured hydraulic conductivity data superposed on the layered distribution used by Burbey and Wheatcraft (1986) and a typical realization of the correlated Gaussian distribution of conductivity referred to in the text.

by Burbey and Wheatcraft (1986). As shown in Figure 34 and Table 20, the top and bottom layer have been extended to fit the larger vertical extent of our domain.

Within each layer, hydraulic conductivities were specified to reproduce a finer-scale variability that is approximately consistent in a statistical sense with what is shown in Figures 9 and 10, while still retaining distinct trends in their overall mean values. Specifically, heterogeneity will be specified in terms of a simple and approximate Gaussian random field model (Dagan, 1989; Gelhar, 1993) in which the spatial distribution of hydraulic conductivity $K$ in each layer is described by

$$
\ln K_{j}(\mathbf{x}) \approx F_{j}+f_{j}(\mathbf{x}) .
$$

Here, $F_{j}$ is the mean of the $\ln K$ distribution in layer $j$ and $f_{j}(\mathbf{x})$ is a spatially fluctuating component with standard deviation $\sigma_{f j}$.

The conductivity was regarded as an isotropic, scalar valued parameter. Anisotropic behavior typically modeled by tensorial conductivities will be represented here in terms of an anisotropic model of spatial correlation (or spatial persistence) in the distribution of $K(\mathbf{x})$. Here, we have used an anisotropic exponential correlation of model of the form

$$
C_{j}(\mathbf{r})=\sigma_{f j}^{2} e^{\left\{-\left[\left(r_{1} / \lambda_{j 1}\right)^{2}+\left(r_{2} / \lambda_{j 2}\right)^{2}+\left(r_{3} / \lambda_{j 3}\right)^{2}\right]\right\}^{1 / 2}}
$$


where $\mathbf{r}$ is a separation, or lag vector, and $\lambda_{j i}$ is a correlation length scale for direction $i$ in layer $j$. Horizontal stratification that is present in most natural settings is represented by smaller correlation lengths in the vertical $\left(\lambda_{z}\right)$ than in the horizontal $\left(\lambda_{x}, \lambda_{y}\right)$.

For simplicity, the geometric mean conductivity, $K_{G j}=e^{F_{j}}$ was set to the layer-specific horizontal conductivity value used in the Burbey and Wheatcraft (1986) model (compare Tables 19 and 20). The principal axes of the correlation structure were assumed to be aligned with the $x, y$, and $z$ axes of the model domain (Figs. 8 and 34), as discussed earlier.

Although available data such as those shown in Figures 9 and 10 are really insufficient to determine the variance and correlation length scales reliably, provisional values of $\sigma_{f j}=1.5$ and $\lambda_{j i}=25,12$, and $6 \mathrm{~m}$, respectively, have been estimated from some of this data, additional interpretations in Hoffman et al. (1977), Ramspott and McArthur (1977), Stone (1975), Los Alamos Technical Associates (1982), and Burbey and Wheatcraft (1986), analog information from other similar sites (e.g., Gelhar, 1993, p291), and some preliminary calibration simulations.

The vertical variation of conductivity obtained in a realization of the layered Gaussian representation is shown in Figure 38, along with the constant values adopted by Burbey and Wheatcraft (1986) and several of the measured data. It is important to recognize that this distribution is a single realization derived from a larger family of equally-probable realizations that preserve the statistical characteristics specified in each layer (Table 20).

Values of the hydraulic conductivity in the chimney, cavity, and lower crush zones were also chosen from random Gaussian representations, albeit with different statistical parameters (Table 20). Relatively low values of conductivity were specified in the cavity and chimney system, and extremely low values were used in the lower crush zone. These were all motivated, in one sense or another, by various "compaction" arguments in the Borg, et al. (1976), LATA (1982), Daniels (1982), Burbey and Wheatcraft (1986), and Guell (1997) reports, although there is no general unanimity on these issues. Indeed, the reliable determination of the physical and chemical medium properties within a post-test cavity and chimney system continues to be a challenging research problem.

Although not pertinent to the flow problem itself, medium porosities ranging between 0.1 and 0.38 were generally specified throughout the domain (Table 20). The smaller value was prescribed in the lower crush zone, in keeping with the specification used in the Daniels (1982) and Guell (1997) reports.

One of the main reasons for pursuing a heterogeneous approach was to facilitate a more fundamental representation of flow variability, as derived from geologic heterogeneity, at the 2 to $20-\mathrm{m}$ length scale. Variability in hydraulic conductivity and alluvial composition over relatively short distances across the vertical horizon in the model region is obvious in the data and has been widely recognized in related CAMBRIC literature. This directly generates the dispersive effect that is otherwise parameterized with larger-scale "dispersivity" terms 
and produce more accurate levels of dilution that could affect concentrationdependent radionuclide interactions.

A complete single realization of the three-dimensional layered hydraulic conductivity distribution developed from this approach is shown in Figure 39 (compare also with Fig. 34). The numerical technique of Tompson et al. (1989) was used in this process. The cavity and chimney system can be seen in the cut-away portion of the figure. The distinctly low-permeability layer associated with the lithologic break just below the cavity can clearly be seen.

\subsubsection{Steady flow fields and tritium recovery}

To simulate the radionuclide migration experiment, steady, saturated flow in this system was determined by the PARFLow model (Ashby, et al., 1994; Ashby, 1996) in accordance with the flow equation

$$
\boldsymbol{\nabla} \cdot(K \nabla h)=\sum_{w} Q_{w} \delta\left(\mathbf{x}-\mathbf{x}_{w}\right) .
$$

Here, $h(\mathbf{x})$ is the hydraulic head $[\mathrm{L}], K(\mathbf{x})$ is the medium hydraulic conductivity $[\mathrm{L} / \mathrm{T}]$, and $Q_{w}>0\left[\mathrm{~L}^{3} / \mathrm{T}\right]$ represents a loss of fluid due to extraction pumping at location $\mathbf{x}_{w}$. The average groundwater seepage velocity $\mathbf{v}(\mathbf{x})[\mathrm{L} / \mathrm{T}]$ can subsequently be determined from

$$
\phi \mathbf{v}=-K \nabla h,
$$

where $\phi$ is the medium porosity.

Constant, fixed head boundary conditions consistent with the water level elevations and an ambient hydraulic gradient of $-0.001 \mathbf{i}^{10}$ were specified on the smaller, vertical faces of the domain. Fixed-head conditions were also specified on the longer, vertical faces of the domain in such a way that $h$ was constant over the vertical (hydrostatic) yet linearly-varying in the $x$ direction. This allowed flow to enter or exit the model domain along all vertical faces. No-flow conditions were specified on the bottom and top faces of the domain (assuming that the top was approximately confined).

For a given realization of the hydraulic conductivity field, such as that shown in Figure 39, three steady flow fields were determined using the boundary conditions above. The first field corresponds to the ambient flow that occurs under the natural hydraulic gradient, in the absence of any pumping in well RNM-2S (i.e., $Q_{w} \equiv 0$ ). This type of flow field can be used to forecast radionuclide migration over long periods (as discussed in the next chapter), but it is not that pertinent to simulating tritium recovery in the radionuclide experiment. The second and third flow fields correspond to the RNM-2S well operating at total pumping rates of 300 and $600 \mathrm{gal} / \mathrm{min}$, respectively. In these cases, the total rate was distributed evenly over the $25 \mathrm{~m}$ vertical extent of the screened interval

\footnotetext{
${ }^{10} \mathbf{i}$ being a unit vector in the $x$ direction
} 


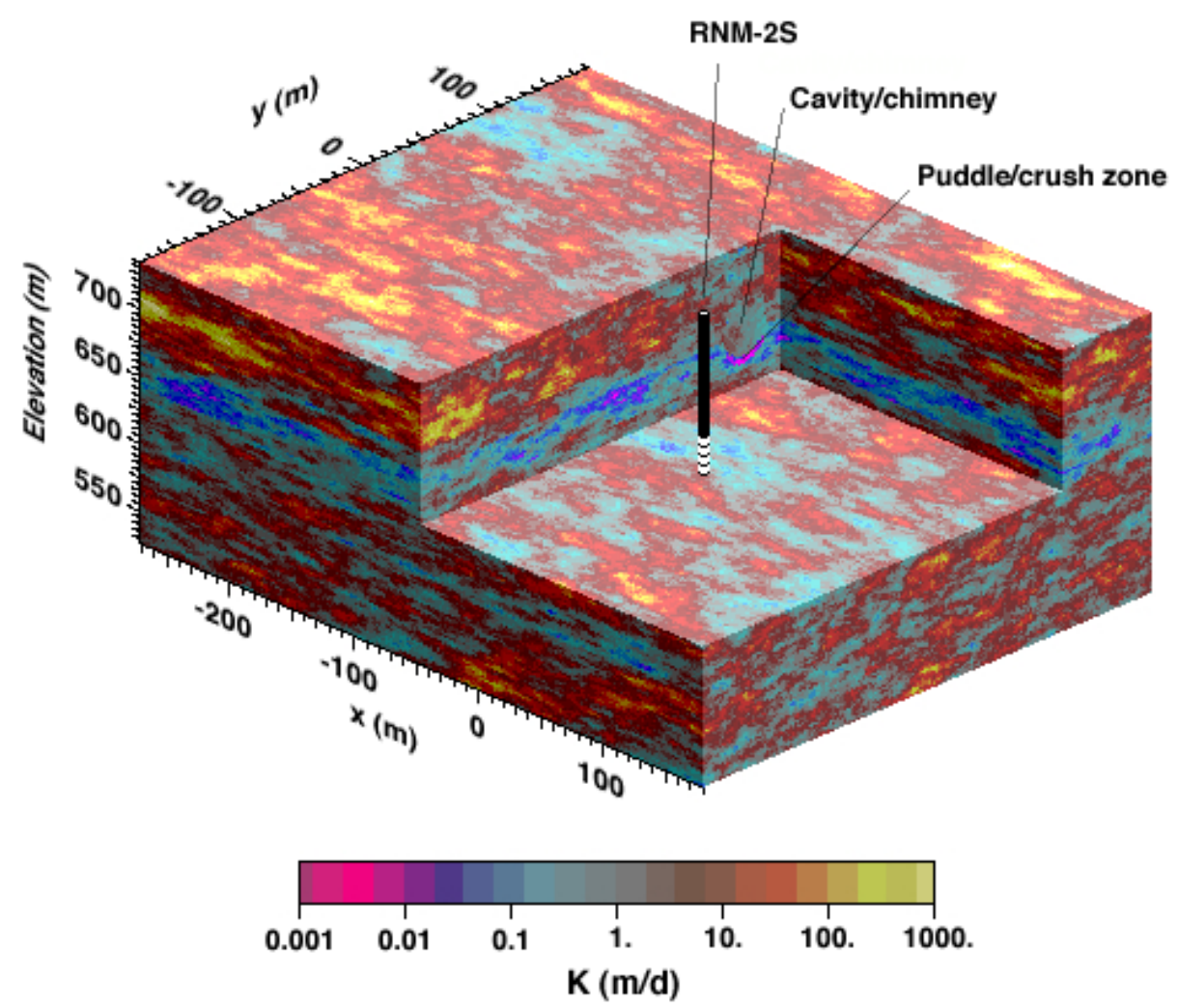

Figure 39: A single realization of the three-dimensional, layered hydraulic conductivity distribution at the CAMBRIC model domain, looking to the North. This was developed from the statistical approach outlined in the text. Background hydraulic gradients induce flow from the Northwest (upper left) to the Southeast (lower left). 
of the well (such that $Q_{w} \approx 25$ or 50 gpm in each of the 12 grid blocks spanning the well screen in the model $)^{11}$.

The use of a background hydraulic gradient in the pumping configurations will have virtually no visible impact on the results, and this is why previous investigators neglected it altogether. Its use in the ambient simulation will control the effective flow rate through the system. The magnitude of the gradient (0.001) is very small and, as mentioned earlier, was estimated from Figure 6. Other sources of information, such as the regional groundwater model for NTS (DOE, 1997b), do not provide sufficient resolution in this area in order to confirm the value used. Although a vertical gradient is also apparent in this area (Fig. 6 , none was specified in the model because of its relatively small size.

Tritium recovery was based upon an initial post-test radionuclide distribution that corresponded to uniformly distributing the $5.9 \times 10^{4} \mathrm{Ci}$ of tritium as HTO within the saturated pore spaces of the 18-m exchange volume. Again, outside of the nonuniform profiles shown in Figure 37, there were no other ways to reliably specify the initial tritium distribution. Tritium migration under the ambient flow conditions between the time of the test (May 1965) and the beginning of the remedial pumping (October 1975) was negligible and not explicitly simulated. Instead, tritium migration was simulated under pumping conditions using the second steady flow field for the first 700 days after October 1975, and then using the third steady flow field for all times thereafter.

Trituim migration was simulated according to

$$
\frac{\partial c}{\partial t}+\mathbf{v} \cdot \nabla c=0
$$

in the absence of local dispersion and diffusion processes. An advection-only particle tracking algorithm was used (Tompson and Gelhar, 1990). In this approach, elemental particles are used to represent the spatial distribution of tritium and are assigned a fraction of the total initial HTO mass. The spatial density of particles in some neighborhood thus corresponds to the HTO concentration in that neighborhood. As more particles are used to represent the same total mass, the individual particle mass becomes smaller, and the representation of the spatial mass distribution becomes more resolved.

Over 24,000 particles of equal mass were uniformly distributed within the exchange volume and used to represent the initial tritium inventory. When the flow field is steady, each particle can be associated with a streamline (or pathline trajectory) passing through its location (see Pollock, 1988, and Appendix 5). For the first 700 days, particles were moved along streamlines that were extracted from the second velocity field. After 700 days, particles were "frozen", associated with a new set of streamlines derived from the third flow field, and allowed to continue migrating toward the well. Near the well, particles are captured and removed from the system.

\footnotetext{
${ }^{11}$ This was an approximantion that was not believed to be too significant.
} 


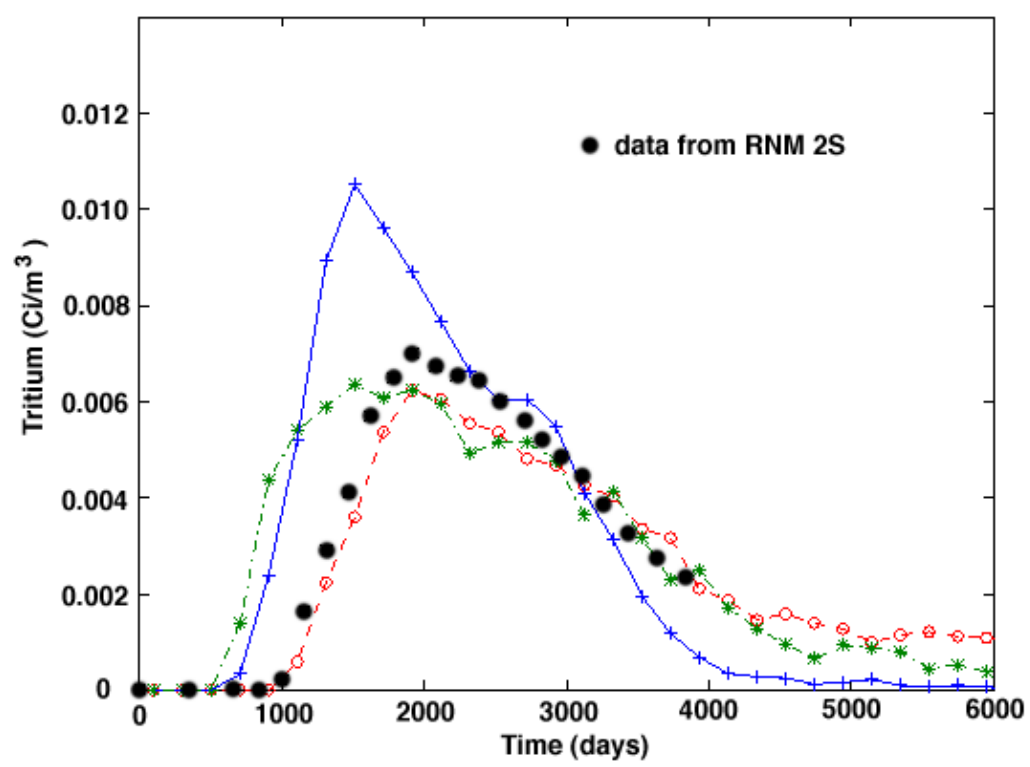

Figure 40: Decay-corrected tritium elution profiles at the RNM-2S well obtained from current simulations based upon three equally-likely conductivity realizations. Black dots represent the measured well concentrations. Times correspond to the number of days since pumping began in October 1975.

The decay-corrected recovery profile of HTO at well RMN-2S obtained in this simulation is shown in Figure 40 as the open circle curve. The dispersed shape of the recovery curve is largely due to the influence of the heterogeneity, and seems to be more reflective of the true system behavior ${ }^{12}$. The decayed value can be obtained by multiplying a concentration value by $e^{-\lambda t}$, where $\lambda$ and $t$ are the decay rate and time since detonation ${ }^{13}$, respectively (Appendix 1). All particles were eventually captured in the well.

\subsubsection{Additional observations}

The entire simulation procedure was repeated two more times using two additional realizations of the medium properties corresponding to the statistical

\footnotetext{
${ }^{12}$ As opposed to numerical artifacts, etc.

${ }^{13}$ Expressed in the same time units, of course
} 
data in Table 20. The recovery results are also shown in Figure 40 and show some slight variation about the measured values and previous simulation. This represents a measure of the uncertainty associated with any given statistical realization of the medium.

As mentioned before, the results in Figure 40 were obtained after some calibration was performed with respect to the correlation scales used. An earlier set of runs based upon larger correlation legths $\left(\lambda_{j i}=50,20\right.$, and $10 \mathrm{~m}$ in each layer $j$, respectively) produced much more dispersed profiles with smaller peak values. Another sequence of simulations based upon of smaller $\ln K$ standard deviations $\left(\sigma_{f}<1.5\right)$ produced less dispersed profiles with higher peak values. Although the current results look reasonably good, it is difficult to exhaustively and systematically test other configurations in the absence of new data, as this would constitute more of a "search" analysis, and would be beyond the scope of this report. In addition, it is generally difficult to use a measured recovery curve to drive a more complete calibration process, as the recovery curve represents an integrated result. Nevertheless, the authors feel the current model representation is in reasonable agreement with the CAMBRIC system (as far as the available data would indicate) and certainly can be used to represent typical alluvium flow and transport behavior in Frenchman Flat. 
Table 19: Hydraulic flow properties used in previous layered models of groundwater flow in the near field about the CAMBRIC test.

\begin{tabular}{rccccccc}
\hline \hline Zone & \multicolumn{9}{c}{ LATA (1982) } & Daniels $(1982)^{a}$ & BW (1986) \\
\hline Alluvium depth (m) & \multicolumn{3}{c}{$K_{h}(\mathrm{~m} / \mathrm{d})$} & depth & $K_{h}$ & depth & $K_{h}$ \\
$221-321$ & 3.4 & 3.4 & 0.85 & $221-521$ & 1.0 & $260-275$ & 7.5 \\
$321-346$ & 1.4 & 1.4 & 0.35 & & & $275-290$ & 1.5 \\
$346-241$ & 0.7 & 0.7 & 0.18 & & & $290-304$ & 0.20 \\
& & & & & $304-314$ & 0.28 \\
& & & & & $314-325$ & 2.0 \\
& & & & & $325-350$ & 2.5 \\
$K_{v} / K_{h}$ & 0.1 & 0.1 & 0.5 & 1.0 & $350-360$ & 3.0 \\
$\phi$ & 0.25 & 0.25 & 0.25 & 0.38 & 0.2 & 0.32 \\
\end{tabular}

Cavity volume

$\begin{array}{rccccc}K_{h}(\mathrm{~m} / \mathrm{d}) & 3.4 & 0.034 & 0.0085 & 1.0 & 0.25 \\ K_{v} / K_{h} & 0.1 & 0.1 & 0.5 & 1.0 & 0.2 \\ \phi & 0.25 & 0.25 & 0.25 & 0.45 & 0.15^{b}\end{array}$

Lower crush volume

$\begin{array}{rc}K_{h}(\mathrm{~m} / \mathrm{d}) & 0.05 \\ K_{v} / K_{h} & 1.0 \\ \phi & 0.1\end{array}$

$\overline{\bar{a} \text { Specifications here do not show a small gravel pack about the well screen of RNM-2S, }}$, as referred to in Daniels (1982).

${ }^{b}$ Best fit in model (BW, p72), yet 0.32 used to calculate exchange radius (BW, p54). 
Table 20: Hydraulic and statistical flow properties used in the current model of groundwater flow, as a function of the geologic unit (see text). In all cases, isotropic (scalar) conductivities were used.

\begin{tabular}{|c|c|c|c|c|c|c|}
\hline Zone & $K_{G}(\mathrm{~m} / \mathrm{d})$ & $\sigma_{f}$ & $\lambda_{1}(\mathrm{~m})$ & $\lambda_{2}(\mathrm{~m})$ & $\lambda_{3}(\mathrm{~m})$ & $\phi$ \\
\hline \multicolumn{7}{|l|}{ Alluvium depth (m) } \\
\hline $220-275$ & 7.5 & 1.5 & 25 & 12 & 6 & 0.38 \\
\hline $275-290$ & 1.5 & 1.5 & 25 & 12 & 6 & 0.38 \\
\hline $290-304$ & 0.2 & 1.5 & 25 & 12 & 6 & 0.38 \\
\hline $304-314$ & 0.28 & 1.5 & 25 & 12 & 6 & 0.38 \\
\hline $314-325$ & 2.0 & 1.5 & 25 & 12 & 6 & 0.38 \\
\hline $325-350$ & 2.5 & 1.5 & 25 & 12 & 6 & 0.38 \\
\hline $350-431$ & 3.0 & 1.5 & 25 & 12 & 6 & 0.38 \\
\hline Chimney volume & 0.73 & 1.5 & 25 & 12 & 6 & 0.38 \\
\hline Lower crush volume & 0.04 & 1.5 & 25 & 12 & 6 & 0.10 \\
\hline $\begin{array}{l}\text { Exchange }+ \text { cavity } \\
\text { volume }\end{array}$ & 0.73 & 1.0 & 6 & 6 & 6 & 0.38 \\
\hline
\end{tabular}


Chapter 10: Near-Field Groundwater Flow 


\section{Integrated Radionuclide Migration away from CAMBRIC}

Three-dimensional simulation of radionuclide migration away from the near field environment around the CAMBRIC test will be carried out with a streamline transport model (Thiele, et al., 1996; Batycky, 1997). The basic concept in such a model is simple: carry out a large number of independent one-dimensional reactive transport simulations (e.g., with GIMRT) that correspond in a one-toone fashion to a large number of streamlines that have been extracted from a simulated three-dimensional flow field. In this way, the transport and reaction simulations can carried out in a fully (or partially) Lagrangian framework.

A short synopsis of the streamline method used here is provided in Appendix 6. The reader may also consult other references such as Thiele et al.(1996), Batycky (1997), and King and Datta-Gupta (1998).

In what follows, we will describe how the streamlines were extracted, review the development of three distinct models of the mineralogic composition of the alluvial system surrounding CAMBRIC, and refer the reader to Appendix 7 where the results of several GIMRT simulations along two selected streamlines in each mineralogic representation are discussed. Simulations along these streamlines are typical of the those made along all streamlines, the results of which are combined to produce the fully three-dimensional simulation. Following this discussion, we review the fully integrated radionuclide breakthrough behavior obtained in this fashion.

\subsection{Streamline generation}

The transport simulations considered here will be based upon dissolution and migration processes associated with ambient groundwater flow through the CAMBRIC region, as induced by natural hydraulic gradients (Chapter 10). For brevity, we will only report on transport simulations based upon the first flow simulation in the first realization of hydraulic properties, as reported in Section 10.3.3 and shown in Figure 39.

For this flow field, a total of 809 streamlines were generated in which the integrated path length $(s)$, coordinates $(x(s), y(s)$, and $z(s))$, local Darcy flux and seepage velocity $(q(s)$ and $V(s))$, time off flight $(\tau(s))$ away from the starting location $\left(x_{0}, y_{0}\right.$, and $\left.z_{0}\right)$ of the streamline, geologic material (alluvium, glass, exchange volume), and geologic properties $(K(s), \phi(s)$, mineralogic composition) were recorded at all points along the streamline where it crosses grid-block boundaries in the flow model domain. In addition, a streamline flux, $Q_{i}$, was determined and assigned to each streamline $i$, as discussed more below and in Appendix 6. The total flux among all streamlines considered was computyed to be $\sum_{i} Q_{i}=615.5 \mathrm{~m}^{3} / \mathrm{yr}$. 


\subsubsection{Streamline mapping procedure}

The streamline mapping procedure is, in some sense, a regridding process tailored specifically for the transport simulations. The procedure used to select the streamlines was constrained by two important issues:

- A desire to use streamlines passing through the initially-contaminated regions (exchange volume and melt glass) only, as opposed to the entire domain, so as to focus all computational effort on the migrating radionuclides, and

- A desire to have at least one streamline passing through each grid block inside of the contaminated zone, so as to provide a numerical basis to "pick up" all of the mass comprising the initial inventory as it is introduced into the aqueous regime.

This particular approach did not ensure that all grid-blocks in the downgradient "shadow" zone (beyond the initially contaminated region) had streamlines passing through them. However, such grid blocks, should they exist, would likely be associated with very low conductivities and a lack of streamline resolution in these regions would less important from an overall migration perspective.

The final family of streamlines was chosen according to the following procedure:

1. The center of each gridblock in the exchange volume and melt glass was chosen as a starting point for a streamline, and the streamline was mapped out, both in a forward (with the flow, positive time of flight) and a backward manner (reversed flow direction with a negative time of flight), to the ends of the flow domain. The geometric and geologic attributes associated with each point along each streamline were recorded.

2. Left alone, the process described in step one generates many more lines that are desired or necessary. Hence, the number of streamlines obtained in the first step was thinned out. This was achieved by sequentially (and randomly) looping through the full streamline list generated in step 1 and deleting individual streamlines whose presence in all grid blocks belonging to the exchange volume and melt glass was duplicated by the existence of other streamlines in the same blocks. In other words, if a candidate streamline was the only streamline passing through one (or more) exchange volume or melt glass grid blocks, it was retained. In this fashion, the onestreamline-per-grid-block constraint was met.

3. Once step 2 was finished, inflow conditions along each streamline were examined in order to assign a total flux $Q$ to each streamline, as reviewed in Appendix 6. Briefly, the inflow face of the domain was examined to ascertain a correspondence between individual streamlines and the gridblocks 
through which they enter the domain. The total flux, $Q^{\text {block }}$, moving into a given gridblock on the inflow face is determined in terms of the local Darcy flux and cross-sectional area of the block. This flux is then equally distributed among all streamlines entering the domain through this block.

Altogether, 809 streamlines were generated in this process. Many grid blocks in the exchange volume and melt glass have more than one streamline, but none have fewer than one. A selected number are shown in a three-dimensional sense in Figure 41. Figure 42 shows a close up view of a thin $x-z$ cross-section passing through the exchange volume and puddle area in which all streamlines are shown. The streamlines in both figures are color-coded to indicate time of flight. Because there is no formal order in the final list of streamlines, the starting locations are arbitrary, and so are the relative locations where $\tau=0$ along each line. The absolute values of $\tau$ along a streamline are not as important as the incremental changes in $\tau$.

In Figure 43, the path length, $s$, is plotted against the time of flight, $\tau$, for two particular lines selected from the full set of 809. These are illustrative of the coordinate transformation issues associated with the streamline approach (Appendix 5), and will be used to review a series of isolated, yet representative GIMRT simulations that comprise the family of simulations used for the full 3D results. In Figure 43, "line 100" passes from the alluvium through the exchange volume and back into the alluvium. Transport is relatively faster here that on "line 145 ", which passes from the alluvium via a weaving path into the exchange volume and melt glass. Line 145 later emerges into the low conductivity zones adjacent to the bottom of the cavity region.

\subsection{Models of the mineralogic distribution}

Once released from the melt glass and exchange volume, the rates of radionuclide migration will be controlled by the flow rates and subsequent retardation effects produced by reactive minerals such as clays, hydrous iron oxides and zeolites. Although the simplified 1D simulations reported on in Chapter 9 and Appendix 5 involved uniformly distributed reactive minerals, we know for a fact that the spatial abundance of reactive minerals in the field system is nonuniform and heterogeneous (e.g., Chapter 2, Table 2), and that the reasons for this heterogeneity may be related to the same depositional processes giving rise to heterogeneity in the hydraulic conductivity (Fig. 39) or possibly other postdepositional processes (Tompson and Jackson, 1996).

The importance of nonuniformly distributed reactive minerals is related to their potential collective effect on the mobility of relatively dilute contaminant mixtures (Appendix 9). If, in a one-dimensional framework, the mobility of a particular species is negligible, owing to a significant retardation effect produced by a uniformly distributed reactive mineral, then the species will be similarly immobile in a three-dimensional environment if the reactive mineral is distributed 


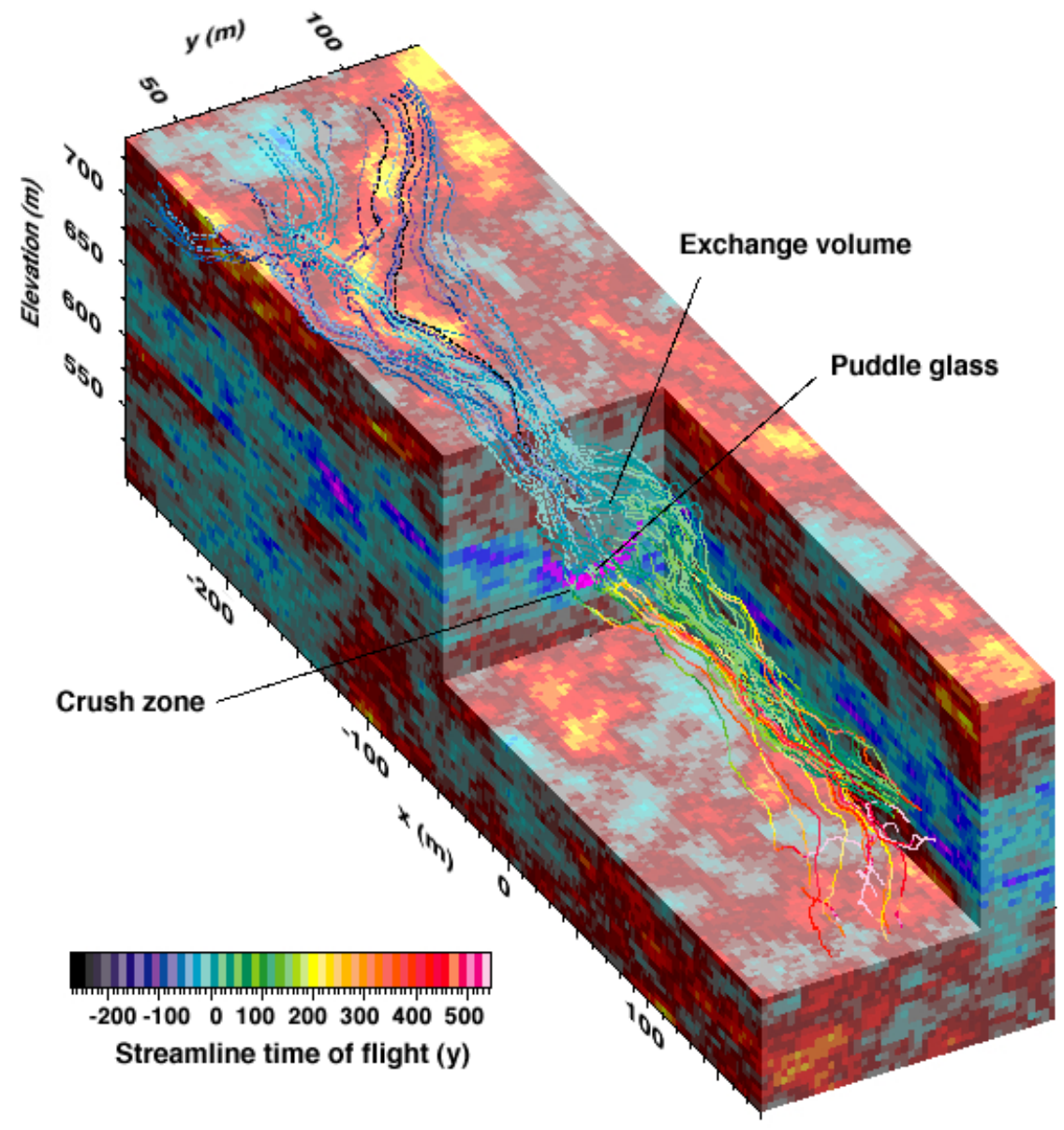

Figure 41: Expanded three dimensional view of the model domain showing selected streamlines moving through the exchange volume and melt glass areas. Flow proceeds from the upper left to the lower right. Streamline colors refers to time of flight relative to an initial point along the streamline (see text). Hydraulic conductivity scale is the same as that in Fig. 39. 


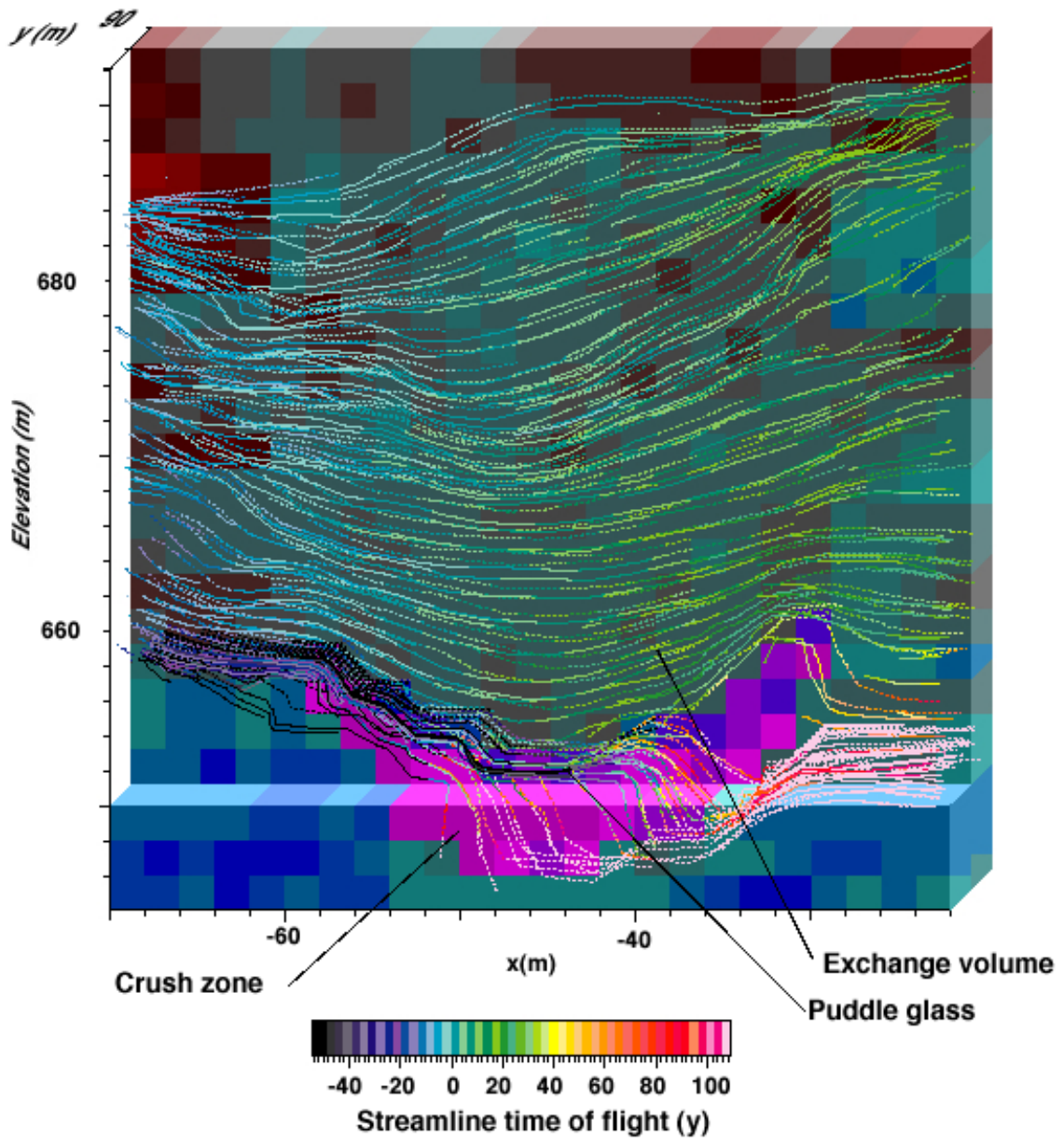

Figure 42: Close-up cross-sectional view of the model domain showing all streamlines in the section that move through the exchange volume and melt glass areas. Streamline colors refers to time of flight relative to an initial point along the streamline (see text). Hydraulic conductivity scale is the same as that in Fig. 39. 


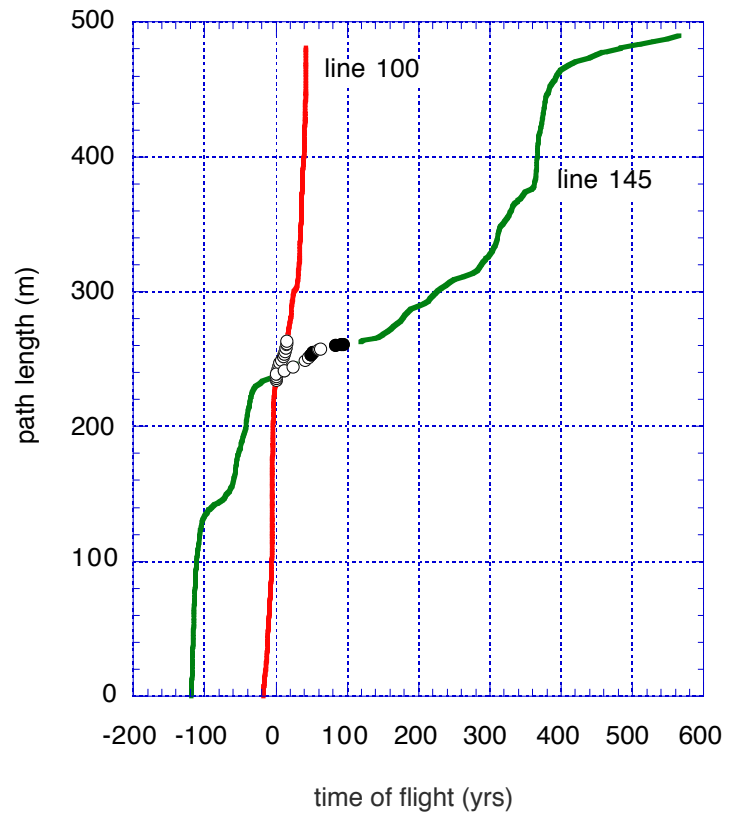

Figure 43: Path length, $s(\mathrm{~m})$, versus time-of-flight, $\tau$ (yr), for lines 100 (red) and 145 (green) extracted out of the ambient flow simulation at CAMBRIC. Notice that the rate of travel is much faster along line 100 than line 145, indicating the influence of conductivity variability. Symbols correspond to the geologic unit traversed by the streamline (Table 30 ); line = alluvium, open circles $=$ exchange volume, solid dots $=$ melt glass. 
uniformly and in the same abundance. If little is known about the true distribution of a reactive mineral in situ, then an assumption of uniformity, as guided or suggested by a few measurements, could potentially lead to an inordinate amount of retardation being predicted with respect to the migration rate of a spatially distributed plume. It has been shown that nonuniform distributions of reactive minerals (e.g., inclusion of zones where the minerals are present or not) can strongly increase the migration rates of plumes that are otherwise strongly retarded (Tompson et al., 1996).

Hence, this issue of chemical heterogeneity, although really not describable in any quantitative sense at the CAMBRIC site with the current data, may be considered to be an important element that will affect the bulk migration rates and fluxes of reactive radionuclide mixtures out of the near field environment. It is potentially similar in importance to the effects of colloidal facilitated transport in moving contaminants significant distances (when they were otherwise considered immobile, e.g., Ryan and Elimelech, 1996; Kersting et al., 1998), or to the enhanced mobility of specific components in contaminant mixtures achieved, possibly, as a result of strongly competitive chemical interactions, as may be the case beneath a leaking tank at the DOE Hanford facility ${ }^{14}$.

As a result, we chose to consider three different models of the mineralogic distribution in our 3D simulations. In each case, the geologic materials were considered to be physically heterogeneous in terms of their conductivity distribution (as covered in Chapter 10 and Fig. 39) and the abundance or distribution of the reactive minerals (clays, hydrous iron oxides and zeolites).

In the first model, (called Mineralogic Model 10) ${ }^{15}$, the alluvial and exchange volume materials were considered to include a spatially uniform distribution of reactive minerals, consistent in abundance with the reactive column in Table 15 and the $1 \mathrm{D}$ simulations in Appendix 5.

In the second model (designated Mineralogic Model 11), the alluvial and exchange volume materials were considered to be uniformly free of reactive minerals, in accordance with inert column in Table 15, such that no retardation effects would be present. Although Model 11 is not considered to be a plausible configuration, the pair of models (10 and 11) are considered to form two endmembers of the mineralogic specification.

The third model (designated Mineralogic Model 12) was meant to represent a simple intermediate case. In this configuration, the reactive specification was only used in alluvium or exchange volume grid cells whose log hydraulic conductivity $(\ln K$ ) belongs to the lowest $20 \%$ of the entire $\ln K$ range. This would correspond to values of $\ln K<-5$, or $K<.007 \mathrm{~m} / \mathrm{d}$ (Fig. 39). The concept here is that the reactive minerals may be preferentially distributed with the lower permeability materials (Tompson and Jackson, 1996; Tompson et al. , 1996), as suggested by the predominance of the reactive minerals in the vicinity

\footnotetext{
${ }^{14}$ e.g., see www.hanford.gov/press/1996/96-116.htm

${ }^{15}$ We use the same labels here for consistency with the local computer files generated.
} 
of the low permeability lithologic break beneath the cavity (see Tables 2, 19, and 20 and the surrounding discussions).

In the absence of more complete characterization data, other intermediate specifications could be made, of course, to more fully explore the potential impacts of chemical heterogeneity. Clearly, different $\ln K$ cutoffs could be used to develop an increasingly more uniform reactive medium. Alternatively, the abundances of reactive minerals could be more directly adjusted to be consistent, in some sense, with what is portrayed in Table 15. Certainly, we have no compelling reason to know whether all reactive minerals (e.g., goethite vs. clinoptilolite) are distributed in the same way. At this stage, it was felt that additional consideration would be required to make these specifications after having reviewed the results of simulations based upon the first three mineralogic configurations.

\subsection{Geochemical analyses of single streamline simulations}

In Appendix 7, we present several detailed analyses of reactive transport GIMRT simulations along streamlines 100 and 145 that correspond to the three different mineralogic configurations (10, 11, and 12) discussed above. These two lines exemplify the kinds of behavior that will occur on lines passing from alluvium to exchange volume and back to alluvium (line 100), as well as lines passing through the melt glass as well (line 145). They are somewhat different from the $1 \mathrm{D}$ simulations presented in Appendix 5 in that the appropriate flow rates and geologic configuration corresponding to the real problem are used. Similar simulations along all other lines will be used and integrated to develop the full three-dimensional results.

These streamline simulations (as well as all that comprise the entire set of 809) were made with a modified version of GIMRT that accounts for the slightlydifferent time of flight formulation of the transport equations, as described in Appendix 6. The results are, nevertheless, reinterpreted and presented in terms of the original path length coordinate, $s$.

Each streamline is conceptualized as a one-dimensional pathway moving through the domain, everywhere parallel with the local velocity vector. Streamlines 100 and 145, for example, extend over 481 and 490 meters, respectively (Fig. 43). Initial flow, path length, time of flight and mineralogic conditions along each line are determined from the original flow simulation and the particular mineralogic configuration in use.

Initial aqueous or surface complex concentrations for the radionuclides along each line are determined in terms of where the line passes in three-dimensional space. In the glass puddle and alluvium outside of the exchange volume, the concentrations are set to zero. In the exchange volume, concentrations are specified in accordance with the total radionuclide inventory allotted to the exchange volume and the local mineralogic conditions that constrain the partitioning between aqueous and surface complexation species, as discussed in Appendix 5. 


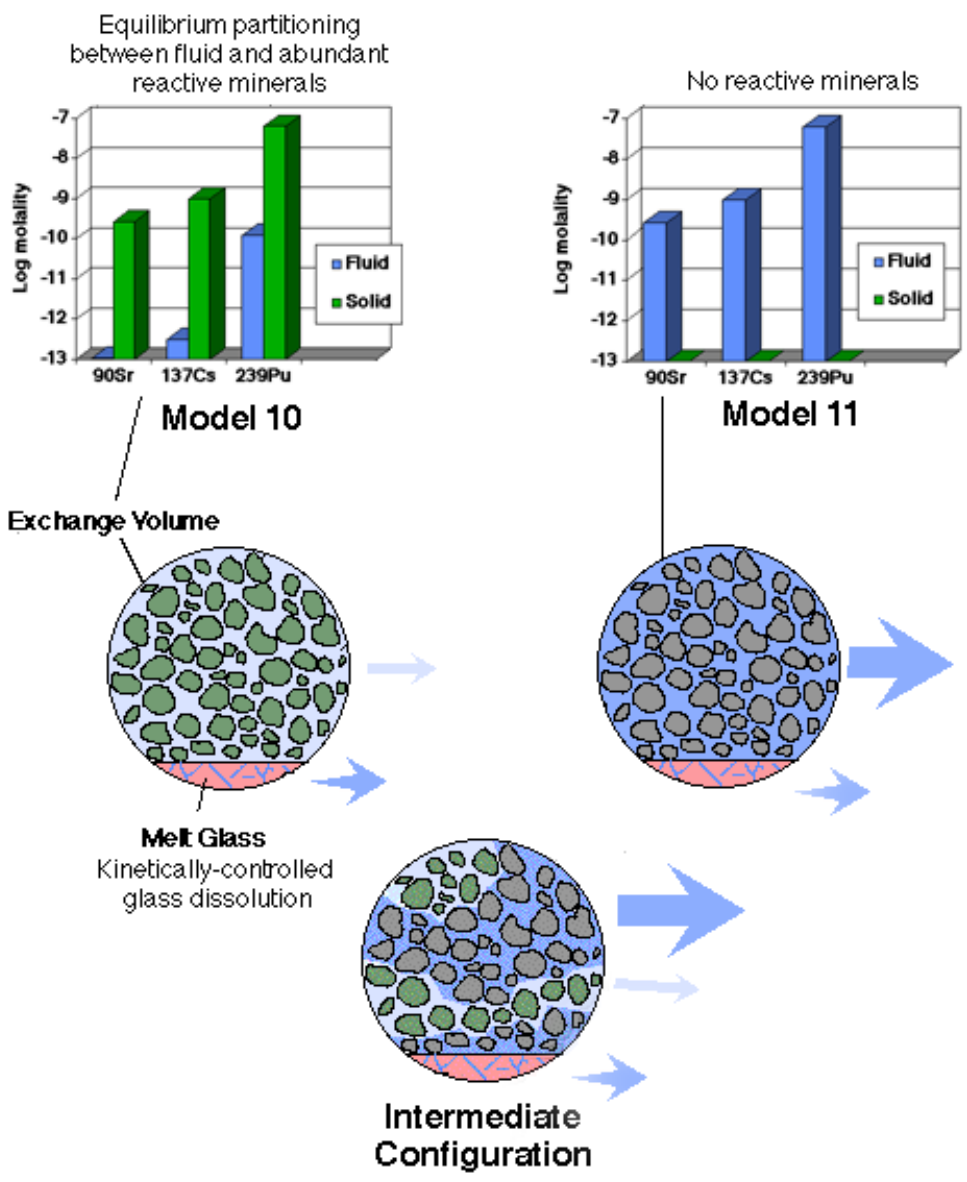

Figure 44: Radionuclide release out of the exchange volume is controlled by groundwater transport and retardation effects associated with equilibrium partitioning of the exchange volume radionuclide inventory among fluids and reactive solids. A greater abundance of reactive solids (green, left) promotes increased partitioning and retardation and an effectively slower release. No reactive minerals (gray, right) eliminates retardation such that release is maximized and controlled by the groundwater flow alone. A spatially mixed distribution (below) will lead to intermediate degrees of release in an integrated sense. Radionuclide release out of the melt glass is controlled by groundwater transport and kinetically-controlled glass dissolution. 
The background geochemistry and the aqueous composition at the inflow point along each line are as specified in Appendix 5. As discussed in Chapter 11 and elsewhere, local longitudinal dispersion and diffusion processes along each line are not included, even though macroscopic dispersion processes will be produced in the integrated results presented below. Note that radionuclide decay was not incorporated as an ongoing kinetic loss term within the transient "time-loop" portion of these simulations. Rather, it is included only in a postprocessing stage as an approximation. The potential limitations of this approach are discussed in Section 3.3.3.

Importantly, simulations based upon Model 10 show a lack of flux in total $\mathrm{Sr}, \mathrm{Cs}$, and $\mathrm{Pu}$, as a result of sorption and ion exchange processes. The lack of mobility can be expressed in terms of a significant retardation effect, as estimated from partitioning ratios (Appendix 9) determined from (moles sorbed or exchanged + moles in solution $) /($ moles in solution). This is not the case in the end member problem based upon Model 11, where all radionuclides are unretarded, and only to a small extent in the intermediate problem based upon Model 12.

\subsection{Integrated 3D simulations}

For each mineralogic configuration, streamline simulations based upon GIMRT were carried out on each of the 809 streamlines for a period up to 600 years. The time steps were restricted to be no larger than 10 years, but could be regulated to be smaller within GimRT for numerical convergence purposes.

Periodically, at times near 100, 200, 300, 400, 500, and 600 years after detonation, the one-dimensional spatial concentration profiles produced by GIMRT were collected and integrated to develop three-dimensional spatial profiles (on the orthogonal, regular flow grid) from which three-dimensional plume images could be constructed. The effects of radionuclide decay are accounted for (approximately) at this stage in a post-processing procedure. The procedure for mapping information from the streamline to the regular grid is outlined in Appendix 6. Selected (decayed) profiles will be shown below for specific radionuclides in specific problems.

More importantly, the integrated species flux across the entire downstream face of the model domain was also computed for all radionuclides. For species $j$, this flux is represented by

$$
J_{j}(t)=\int_{A} \mathbf{J}_{j}\left(x_{d}, y, z, t\right) \cdot \mathbf{n} d A=\int_{A} \phi \mathbf{v}\left(x_{d}, y, z\right) c_{j}\left(x_{d}, y, z, t\right) \cdot \mathbf{n} d A
$$

where $\mathbf{J}_{j}$ is the local species flux at a point on the downstream boundary face, $A$ is the area of the face, and $\mathbf{n}$ is the outward normal vector on the face. The $x$-coordinate of the face is defined by $x_{d}$, and $\mathbf{v}$ and $c_{j}\left(x_{d}, y, z, t\right)$ are the outflow velocity $(\mathrm{m} / \mathrm{yr})$ and radionuclide concentration $\left(\mathrm{mol} / \mathrm{m}^{3}\right)$ at location $\left(x_{d}, y, z\right)$ on the face and time $t$, respectively. Importantly, this process only includes 
the advective flux in the integrand, owing to the fact that local dispersion and diffusion processes were not considered. Macroscale dispersion will appear in the integrated profiles as a result of the local flux variation along the outflow face.

In terms of the streamline results, the flux may simply be estimated from

$$
J_{j}(t) \approx \sum_{i} \mathbf{J}_{i, j}\left(s_{i, d}, t\right) \cdot \mathbf{n} d A=\sum_{i} Q_{i} c_{i, j}\left(s_{i, d}, t\right)
$$

where $\mathbf{J}_{i, j}\left(s_{i, d}, t\right)$ is the total streamline species flux past its endpoint at $s_{i, d}, Q_{i}$ is the total fluid flux $\left(\mathrm{m}^{3} / \mathrm{yr}\right)$ along line $i$, and $c_{i, j}\left(s_{i, d}, t\right)$ is the molar concentration $\left(\mathrm{mol} / \mathrm{m}^{3}\right)$ of radionuclide $j$ at the outflow location, $s_{i, d}$. It is assumed here that the streamlines exit the domain normal to the boundary so that $Q_{i}$ can be construed as the normal fluid flux contributed by streamline $i$.

If the concentrations were uncorrected for simple decay, then the decaycorrected flux, $J_{j}^{d}(t)$, may be determined from

$$
J_{j}^{d}(t)=J_{j}(t) \cdot e^{-\lambda_{j} t}
$$

where $\lambda_{j}$ is the decay rate for radionuclide $j$ and the time $t$ is assumed to be the time since detonation. Additional daughter products may be computed from the information in Appendix 1.

\subsubsection{Results for Mineralogic Model 10}

Figures 45 and 46 portray the spatial distribution of total americium (as summed over all species) after 100 and 600 years of dissolution and migration. Notice that the portion of total americium associated with the exchange volume has largely been removed at 600 years, even though it continues to dissolve out of the melt glass.

Figure 47 shows the spatial distribution of total europium (as summed over all species) after 100 years. Much of the europium in the exchange volume has decayed or been flushed out by this time, while there is still a significant amount being eluted from the melt glass. At 600 years (not shown), most of the europium has decayed, owing to its short half life.

Figures 48 and 49 show plots of the flux of individual Eu and Am species out of the domain, uncorrected for decay, corresponding to Mineralogic Model 10. Fluxes of the individual species of $\mathrm{Pu}, \mathrm{Sr}$, and $\mathrm{Cs}$ were essentially nonexistent because of the reactivity of the species and retarding nature of the medium. In Figures 48 and 49, the principal species coming out are $\mathrm{EuOHCO}_{3}$ (aq) and $\mathrm{AmCO}_{3}^{+}$, consistent with earlier analyses. The initial "bump" in each of these figures corresponds to elution of the radionuclides originally distributed in the exchange volume, while the subsequent flux corresponds to the longer term elution of radionuclides originally contained in the glass. Figures 50 and 51 show the total flux of the total $\mathrm{Eu}, \mathrm{Am}, \mathrm{Pu}, \mathrm{Sr}$, and $\mathrm{Cs}$ species out of 


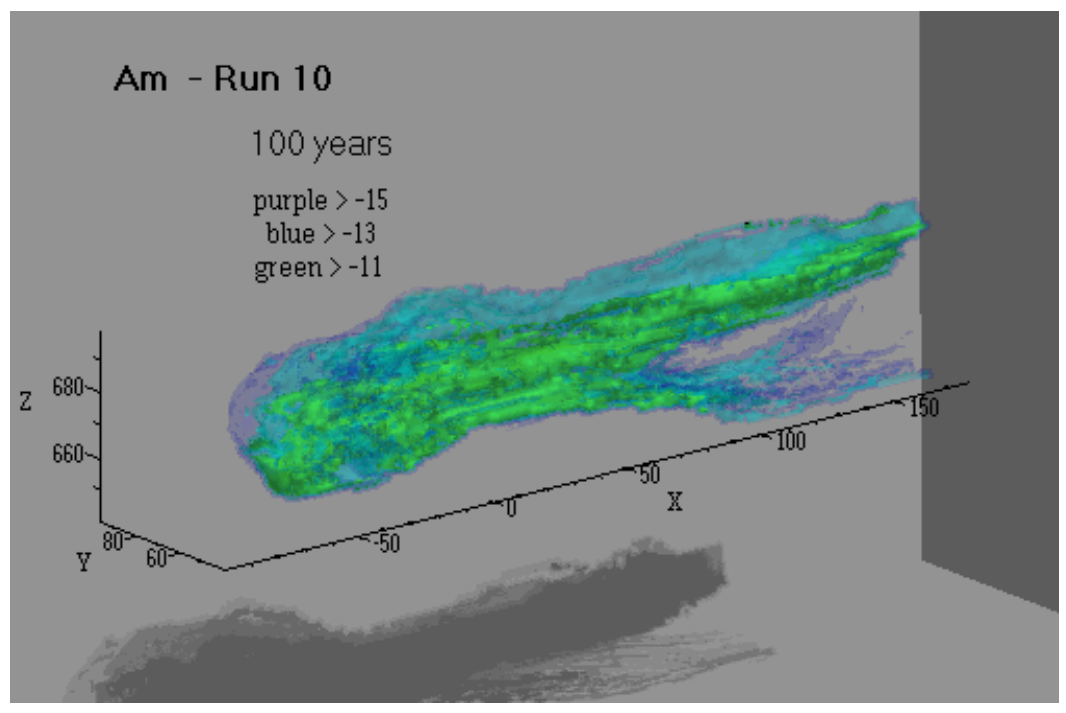

Figure 45: 3D perspective of decay-corrected total-americium plume at 100 years in Mineralogic Model 10. Molar concentrations $>10^{-15}$ are in purple; $>10^{-13}$, in blue, and $>10^{-11}$ in green. Portions originating in the exchange volume and melt glass are both evident.

the domain under conditions corresponding to no-decay and decay, respectively. Specifically, the species included in the totals are:

- Total $\mathrm{Eu}=\mathrm{EuOHCO}_{3}(\mathrm{aq})$ (predominant species), $\mathrm{EuOH}\left(\mathrm{CO}_{3}\right)_{2}^{2-}, \mathrm{Eu}(\mathrm{OH})_{2} \mathrm{CO}_{3}^{-}$, and $\mathrm{Eu}^{3+}$,

- Total $\mathrm{Am}=\mathrm{AmCO}_{3}^{+}$(predominant species), $\mathrm{Am}\left(\mathrm{CO}_{3}\right)_{2}^{-}, \mathrm{Am}(\mathrm{OH})_{2}^{+}$, and $\mathrm{Am}^{3+}$

- Total $\mathrm{Pu}=\mathrm{PuO}_{2}\left(\mathrm{CO}_{3}\right)_{2}^{2-}$ (predominant species), $\mathrm{PuO}_{2}\left(\mathrm{CO}_{3}\right)_{3}^{3-}, \mathrm{PuO}_{2} \mathrm{CO}_{3}^{-}$, $\mathrm{PuO}_{2}(\mathrm{OH})_{2}(\mathrm{aq}), \mathrm{PuO}_{2}^{2-}, \mathrm{PuO}_{2}^{-}$, and $\mathrm{Pu}^{4+}$,

- Total $\mathrm{Sr}=\mathrm{Sr}^{2+}$, and

- Total $\mathrm{Cs}=\mathrm{Cs}^{+}$

Because these results correspond to Mineralogic Model 10, the elution of $\mathrm{Pu}$, $\mathrm{Sr}$, and Cs are essentially zero (even they show up at constant or decayed background "0" levels used in the simulations).

Under the conditions adopted in this simulation, the only radionuclide that appears to move out of the near field in appreciably relative amounts is Am. Remaining radionuclides are lost to radioactive decay or are reactively retained in the system. 


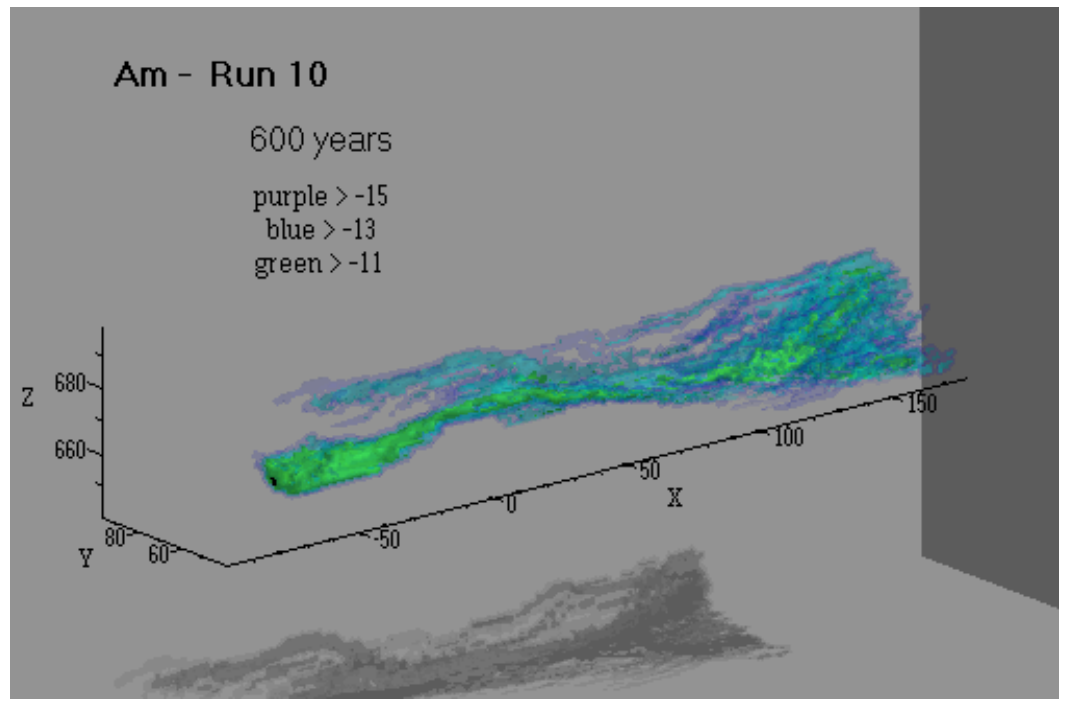

Figure 46: 3D perspective of decay-corrected total-americium plume at 600 years in mineralogic Model 10. Molar concentrations $>10^{-15}$ are in purple; $>10^{-13}$, in blue, and $>10^{-11}$ in green. Portions originating in the exchange volume have largely been flushed out of the domain or have decayed; other portions contained in the melt glass are still entering the domain, despite the effects of decay. 


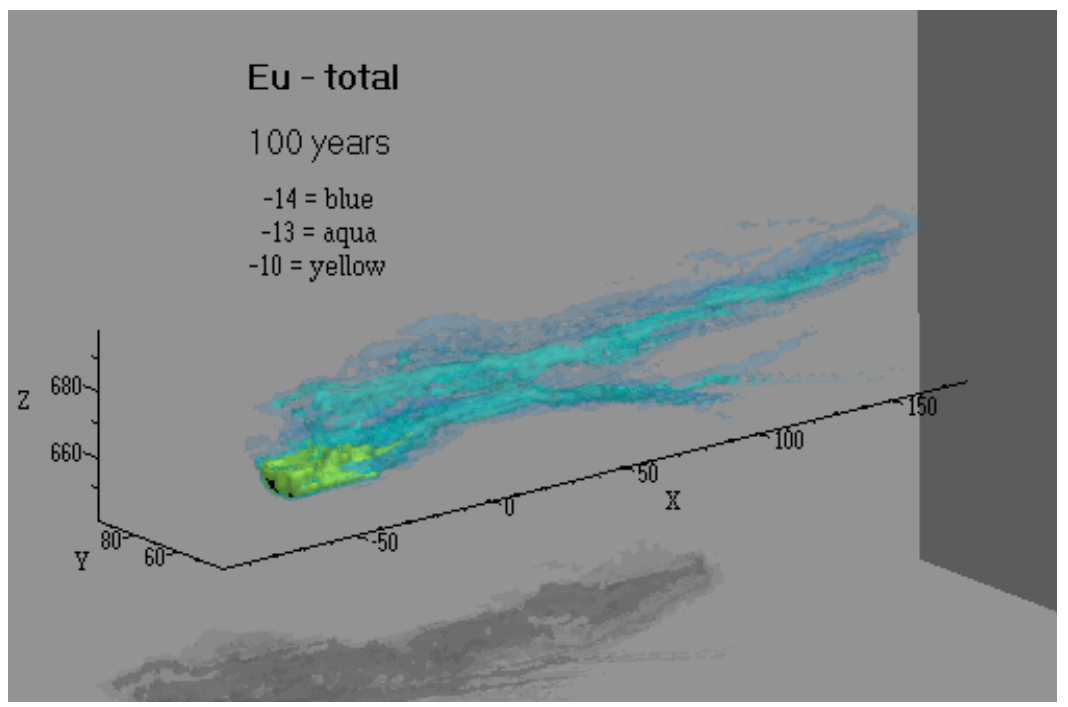

Figure 47: 3D perspective of decay-corrected total-europium plume at 600 years in Mineralogic Model 10. Molar concentrations $>10^{-14}$ are in blue; $>10^{-13}$, in aqua, and $>10^{-10}$ in yellow. Portions originally in the exchange volume have been flushed out and have decayed; other portions contained in the melt glass are still entering the domain, despite the effects of decay. 


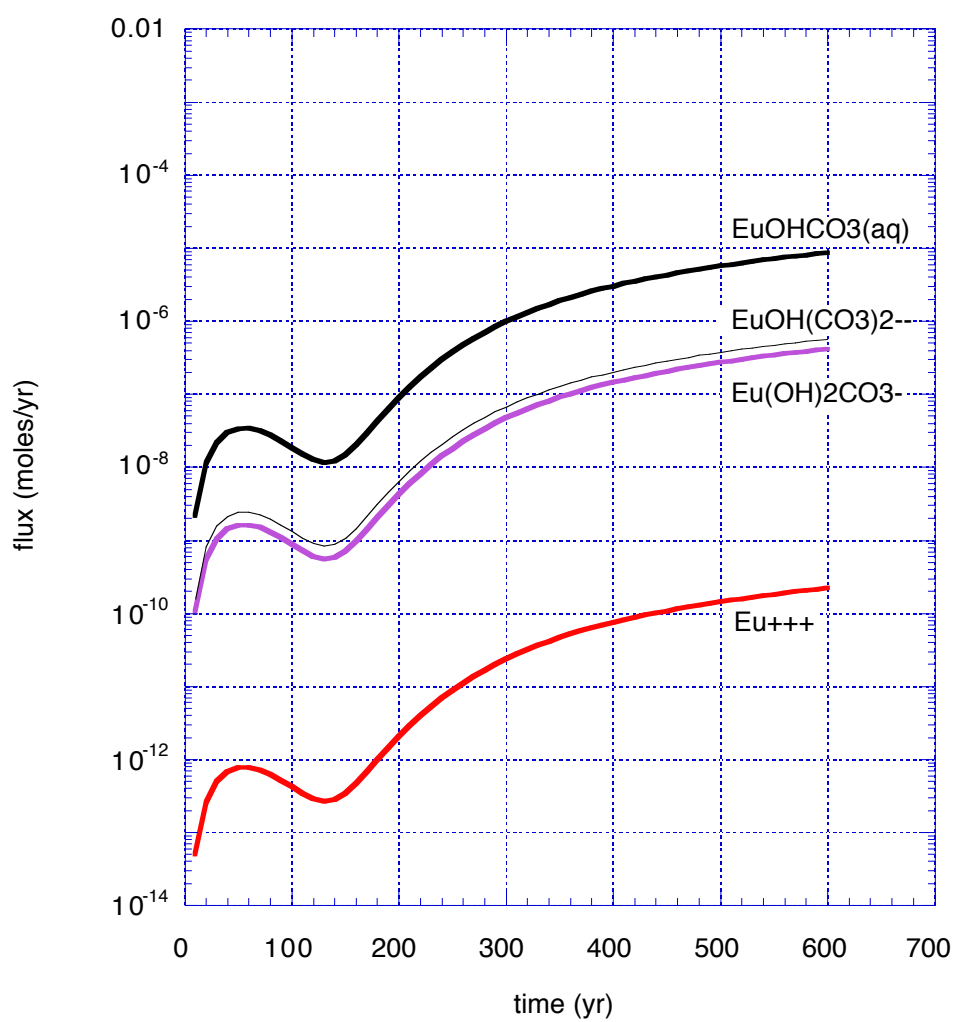

Figure 48: Integrated flux of individual Eu species out of the domain, uncorrected for decay, corresponding to Mineralogic Model 10. 


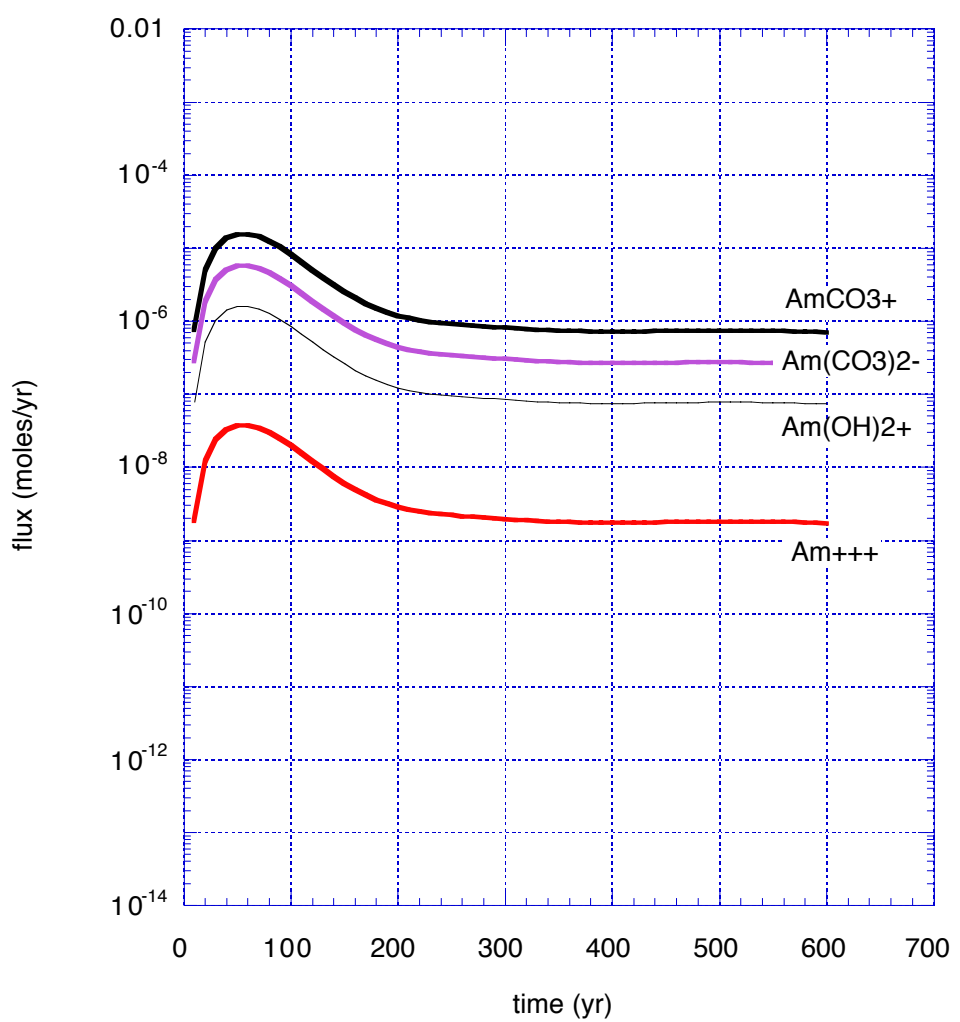

Figure 49: Integrated flux of individual Am species out of the domain, uncorrected for decay, corresponding to Mineralogic Model 10. 


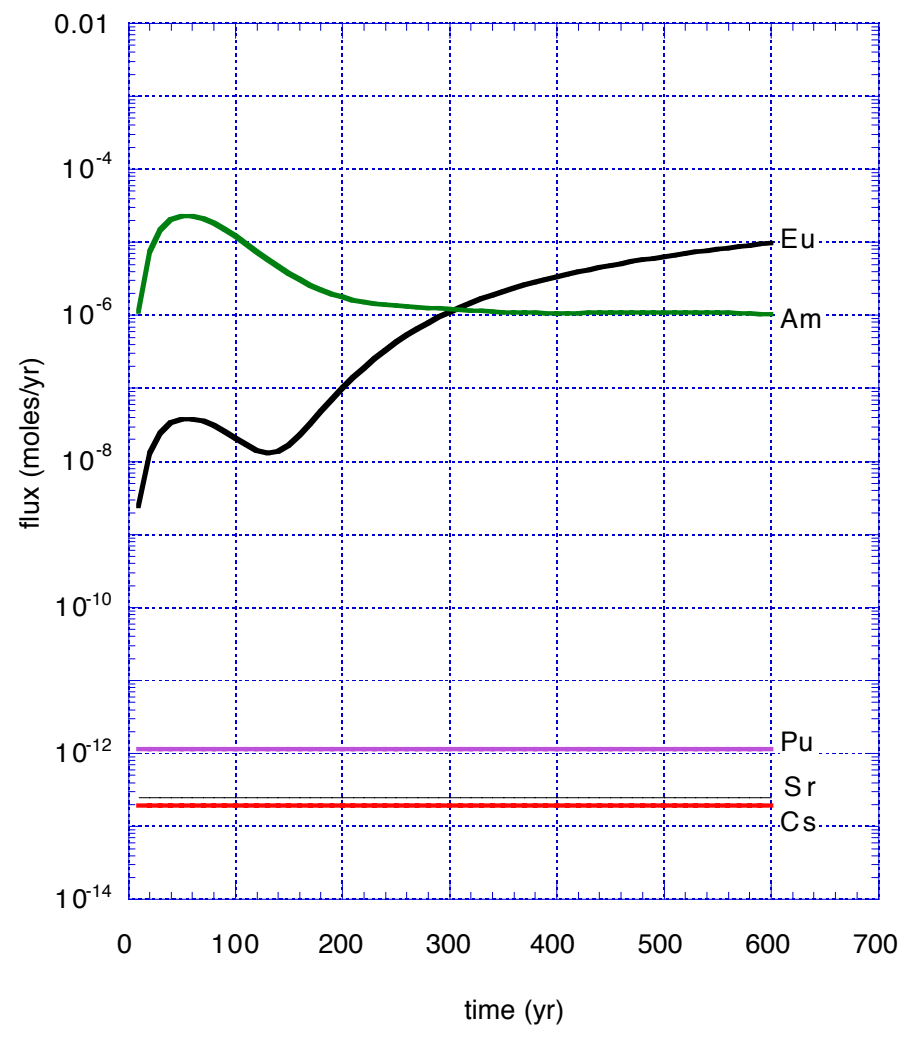

Figure 50: Integrated flux of the total $\mathrm{Eu}, \mathrm{Am}, \mathrm{Pu}, \mathrm{Sr}$, and $\mathrm{Cs}$ species out of the domain under no-decay conditions. These results correspond to Mineralogic Model 10. The fluxes of $\mathrm{Pu}, \mathrm{Sr}$, and $\mathrm{Cs}$ flux should be considered zero, as they correspond to decayed "0" background values used in the model. 


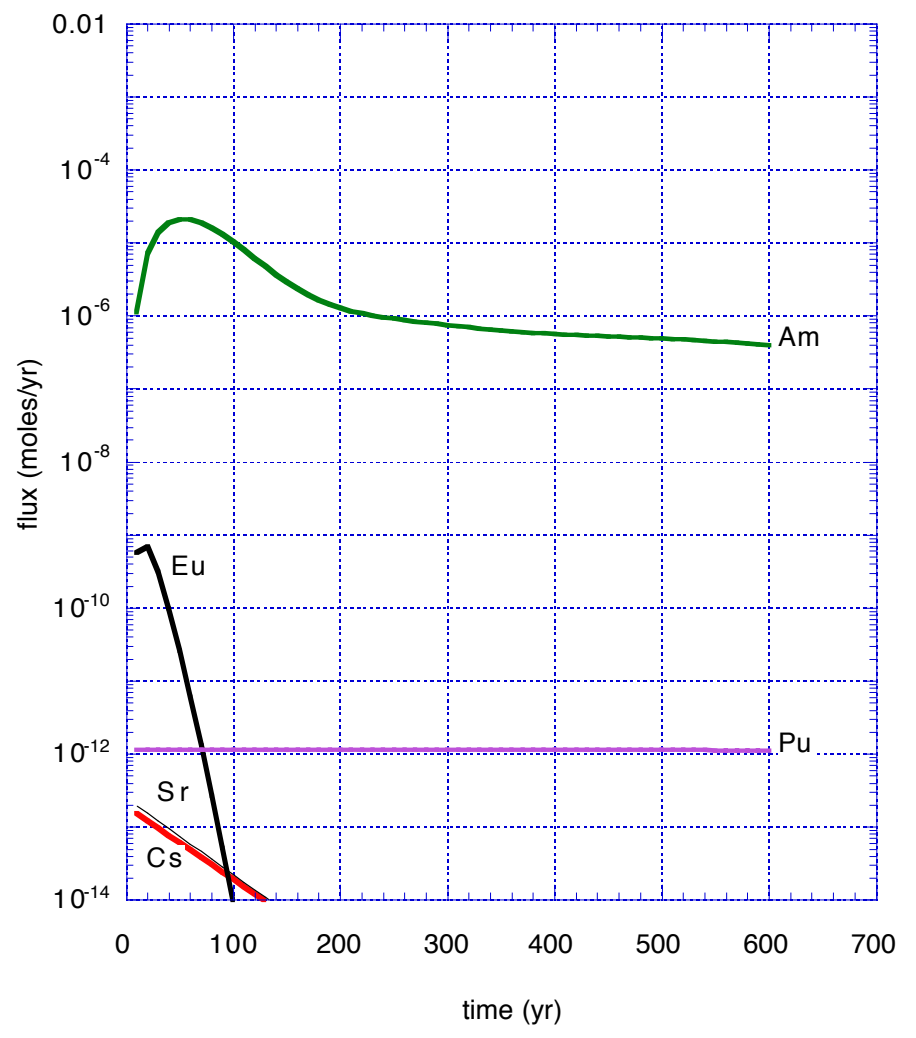

Figure 51: Integrated flux of the total $\mathrm{Eu}, \mathrm{Am}, \mathrm{Pu}, \mathrm{Sr}$, and $\mathrm{Cs}$ species out of the domain under decay conditions corresponding to Mineralogic Model 10. 


\subsubsection{Results for Mineralogic Model 11}

Figure 52 shows the total flux of the total $\mathrm{Eu}, \mathrm{Am}, \mathrm{Pu}, \mathrm{Sr}$, and $\mathrm{Cs}$ species out of the domain under decay conditions corresponding to Mineralogic Model 11. In this case, the medium is completely nonreactive and more of the $\mathrm{Pu}, \mathrm{Sr}$, and Cs species escape the confines of the near field.

The total $\mathrm{Pu}$ flux in this case might conservatively be associated with an upper bound estimate for colloid-facilitated $\mathrm{Pu}$ migration in other model configurations (especially in Model 10). According to this assumption, all released $\mathrm{Pu}$ is loaded upon colloidal material, whence it becomes completely mobile. It does not, however, account for the potentially enhanced mobility of colloidal particles, nor does it account for the interactions of colloidal material with the minerals in the system.

\subsubsection{Results for Mineralogic Model 12}

Figures 53 and 54 show the spatial distribution of cesium, both uncorrected for decay and corrected, obtained after 600 years based upon simulations from Mineralogic Model 12 . Over $90 \%$ of the cesium was initially located in the exchange volume, which is clearly evident in Figure 53. The effects of decay are quite significant for this short-lived radionuclide.

Figures 55 through 57 show the spatial distribution of decay-corrected totalplutonium at 100, 300, and 600 years from simulations based upon Mineralogic Model 12. Plutonium is strongly retarded in the presence of the reactive minerals in Model 12, and the effects can be clearly be seen in these figures. Between the first and last figures, the small amounts of $\mathrm{Pu}$ distributed in the exchange volume begin to migrate out, while after 600 years, most of the remaining $\mathrm{Pu}$ is emanating from the melt glass. Interestingly, from a larger scale perspective, there is a significant degree of $\mathrm{Pu}$ mobility allowed by the nonuniform distribution of reactive minerals.

Figure 58 shows the total flux of the total $\mathrm{Eu}, \mathrm{Am}, \mathrm{Pu}, \mathrm{Sr}$, and Cs species out of the domain under decay conditions corresponding to Mineralogic Model 12. In this case, the medium is only partially reactive, but the results are largely similar to the previous case where no reactive minerals were present. Only slight reductions in the flux of $\mathrm{Pu}, \mathrm{Sr}$, and $\mathrm{Cs}$ can be observed. These are more easily seen in Figs. 68-70 in the next chapter. Thus, although reactive minerals are present, the mobility of the reactive radionuclides is hardly reduced from the unreactive case. This arises, of course, because the reactive minerals in this case were purposely sequestered in low permeability areas through which little flow and radionuclide transport occurs.

As will be illustrated in the next chapter, other configurations of the reactive minerals may impart increasingly stronger retardation effects on the elution fluxes. Nevertheless, very small levels of the minerals, when uniformly distributed as in Mineralogic Model 10, were sufficient to provide a significant 


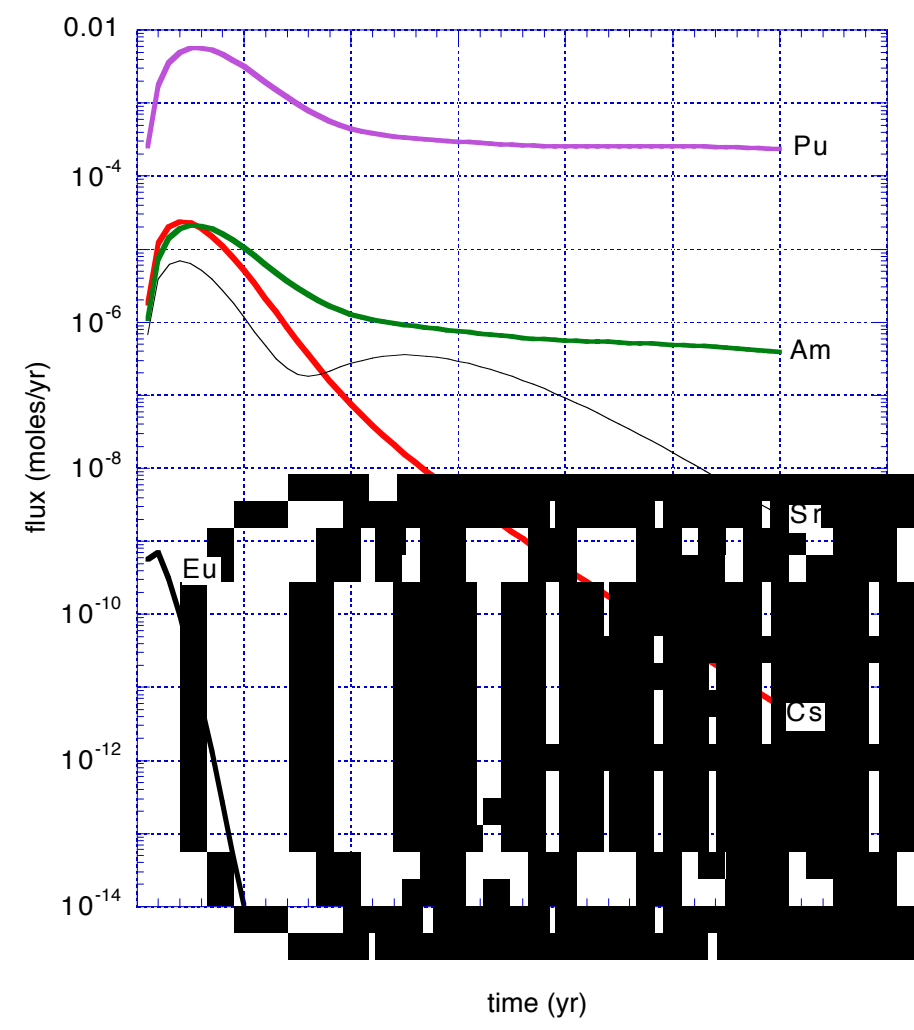

Figure 52: Integrated flux of the total $\mathrm{Eu}, \mathrm{Am}, \mathrm{Pu}, \mathrm{Sr}$, and $\mathrm{Cs}$ species out of the domain under decay conditions corresponding to Mineralogic Model 11. 


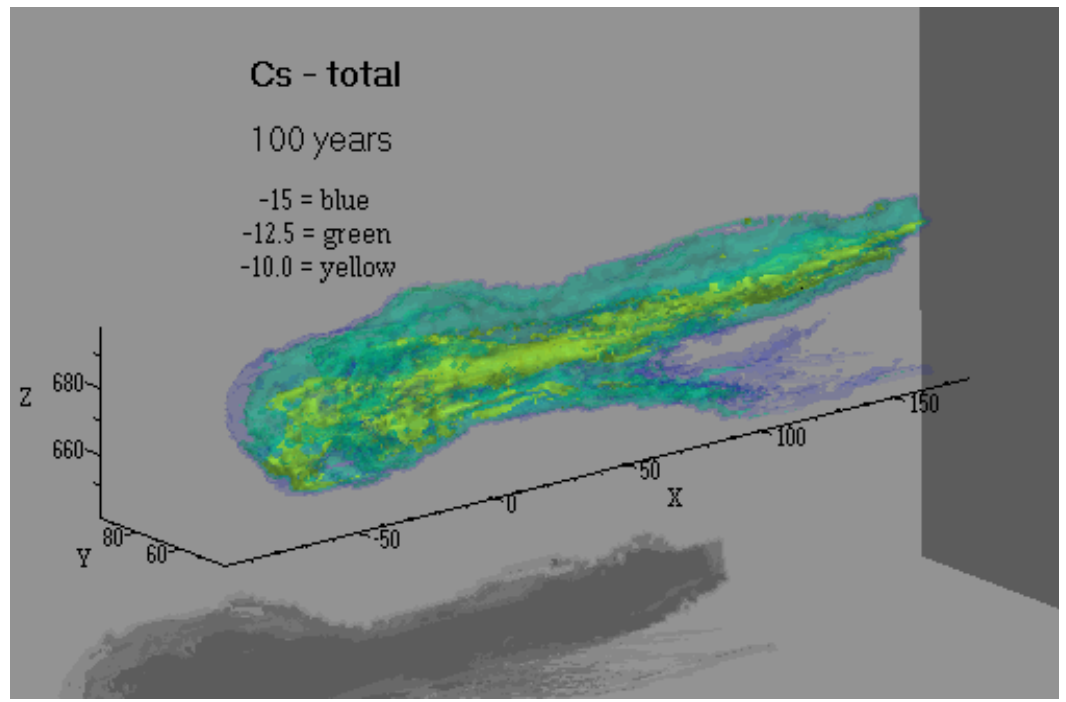

Figure 53: 3D perspective of cesium plume at 100 years in mineralogic Model 12 in the absence of decay correction. Molar concentrations $>10^{-15}$ are in blue; $>10^{-12.5}$, in green, and $>10^{-10}$ in yellow. Most portions of the cesium were originally in the exchange volume, and can be seen moving well out into the domain. Smaller portions contained in the melt glass are slowly entering the domain as well. 


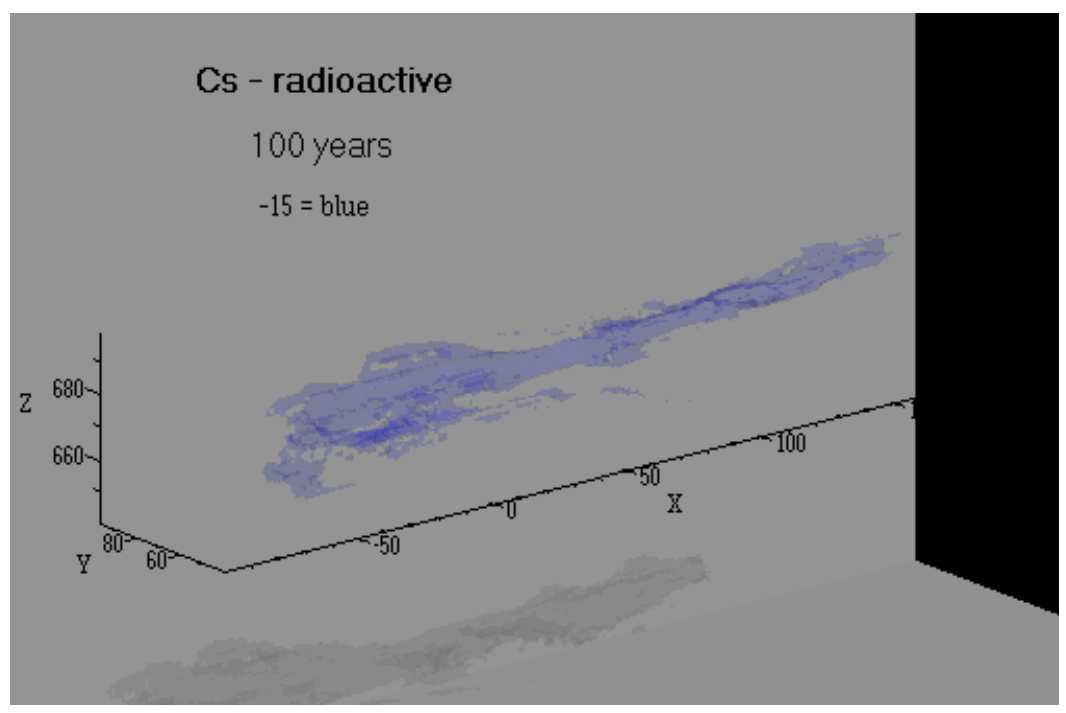

Figure 54: 3D perspective of decay-corrected cesium plume at 100 years in mineralogic Model 12. Molar concentrations $>10^{-15}$ are in blue. This image shows the strong effect of decay when the half life of a radionuclide is short.

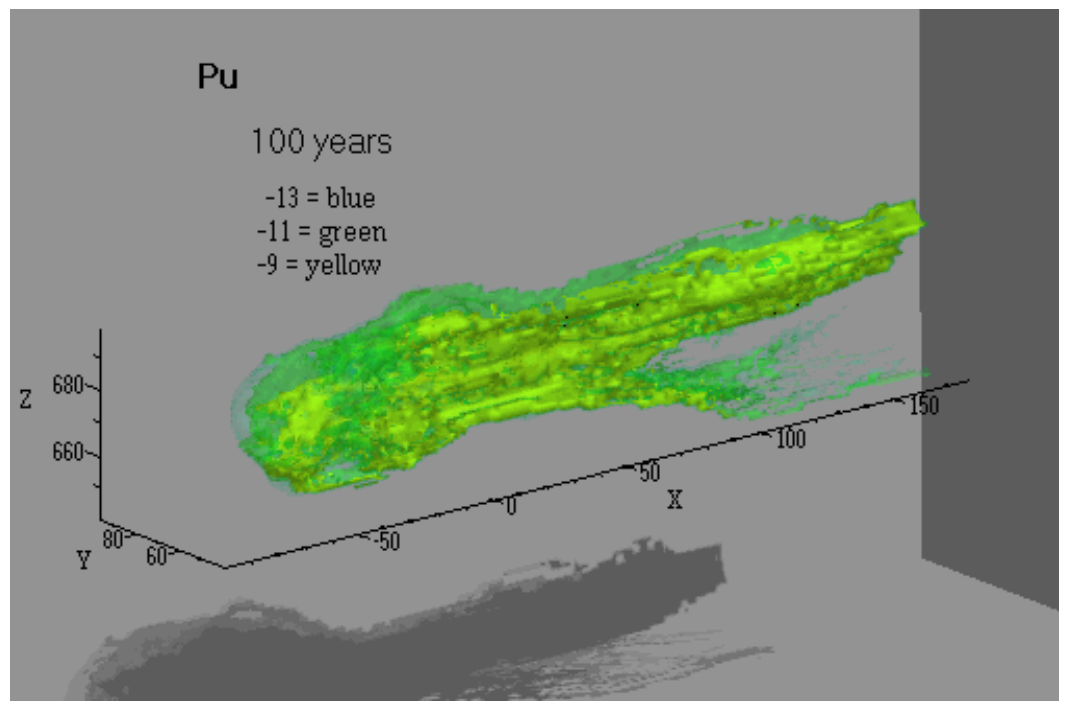

Figure 55: 3D perspective of decay-corrected total-plutonium plume at 100 years based upon Mineralogic Model 12. Molar concentrations $>10^{-13}$ are in blue; $>10^{-11}$, in green, and $>10^{-9}$ in yellow. 


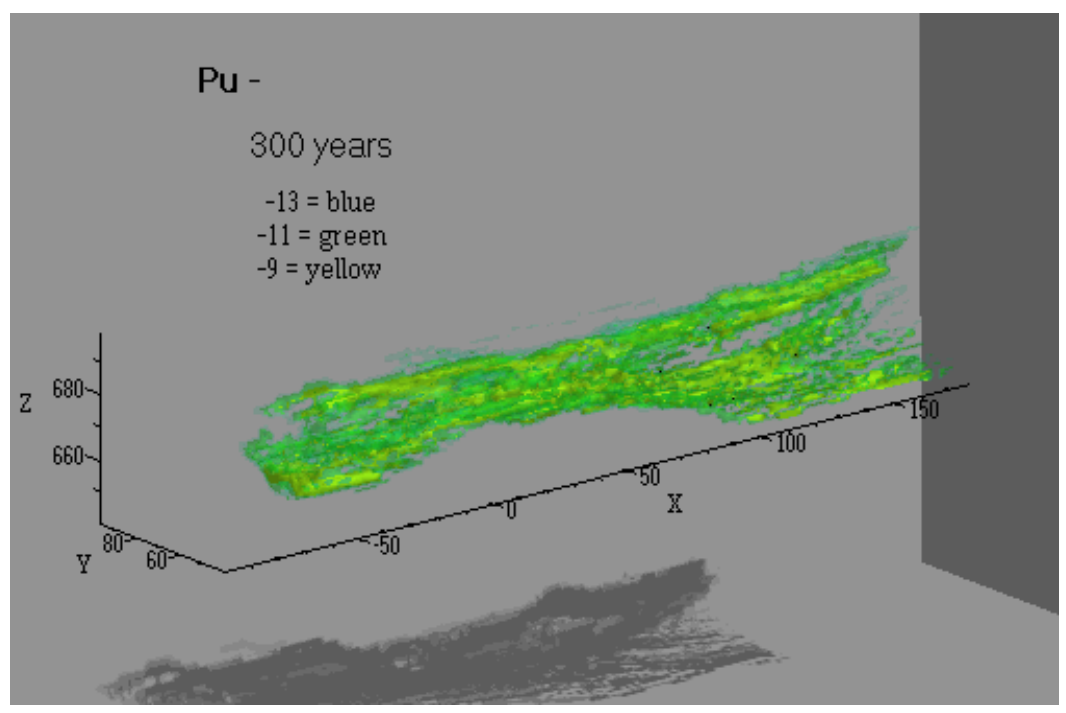

Figure 56: 3D perspective of decay-corrected total-plutonium plume at 300 years based upon Mineralogic Model 12. Molar concentrations $>10^{-13}$ are in blue; $>10^{-11}$, in green, and $>10^{-9}$ in yellow.

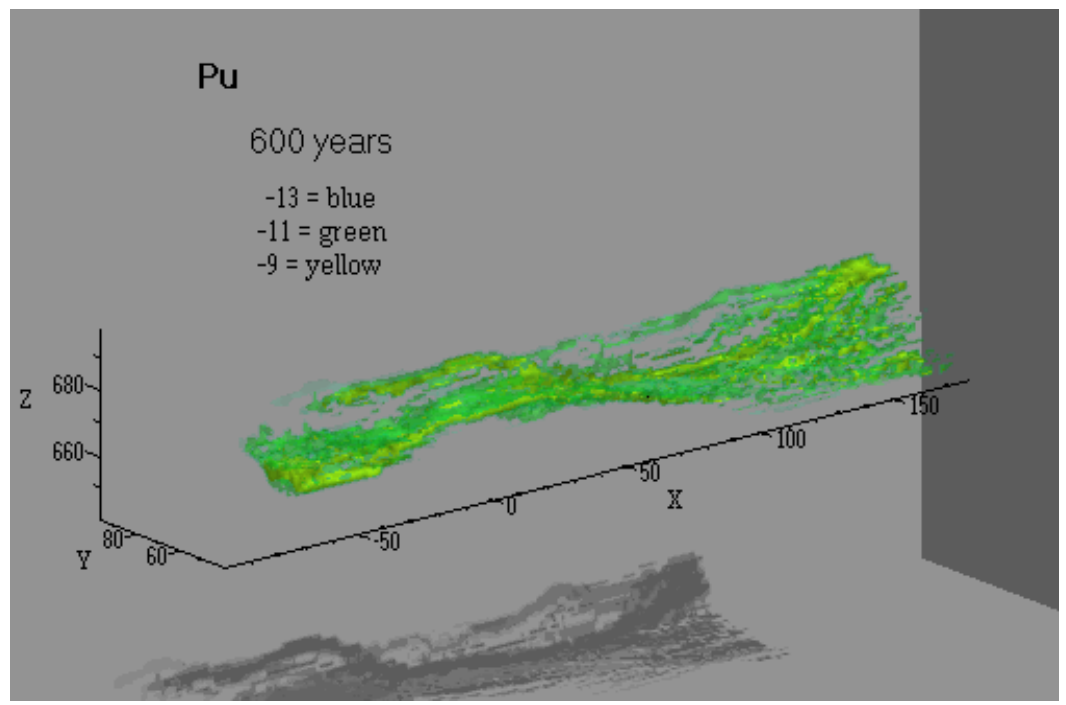

Figure 57: 3D perspective of decay-corrected total-plutonium plume at 600 years based upon Mineralogic Model 12. Molar concentrations $>10^{-13}$ are in blue; $>10^{-11}$, in green, and $>10^{-9}$ in yellow. 


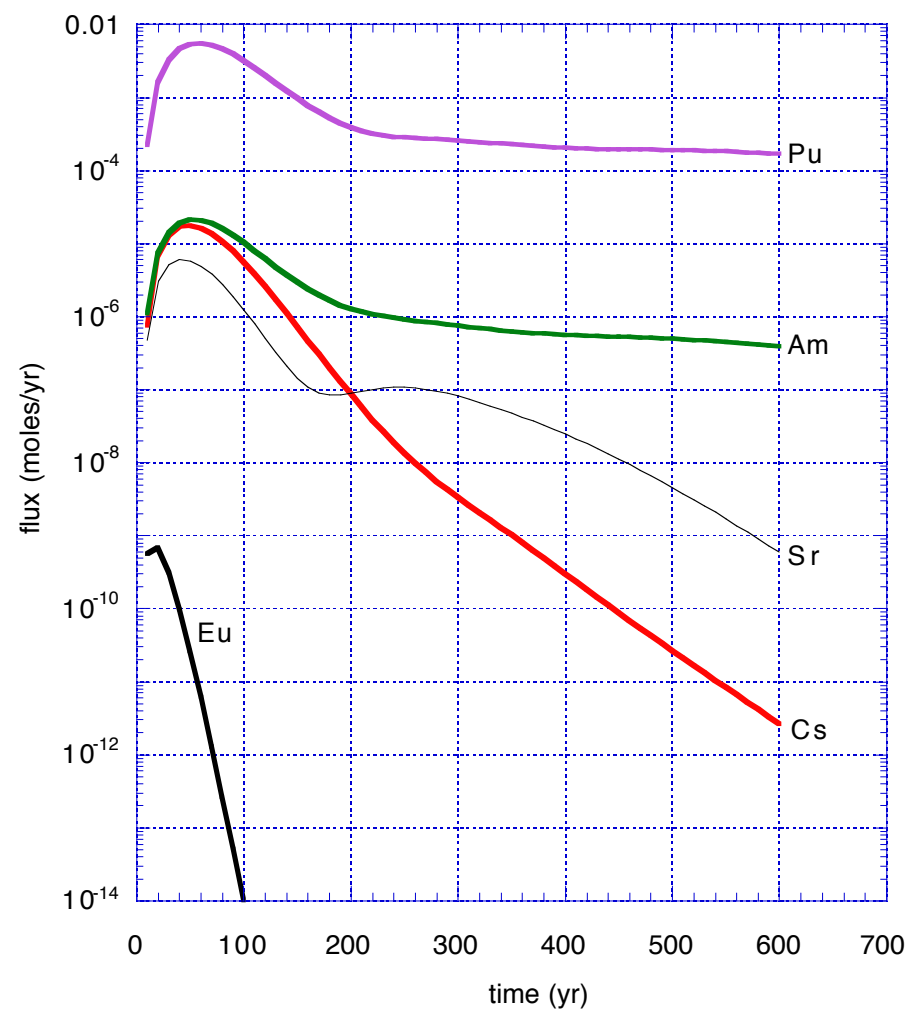

Figure 58: Integrated flux of the total $\mathrm{Eu}, \mathrm{Am}, \mathrm{Pu}, \mathrm{Sr}$, and $\mathrm{Cs}$ species out of the domain under decay conditions corresponding to Mineralogic Model 12. 
retention effect for the radionuclides considered. All things remaining equal (and outside of inventory constraints), larger concentrations of the reactive radionuclides will tend to more readily saturate the available surface complexation sites, and, as a result, achieve a greater overall mobility. Conversely, specification of greater amounts of the minerals (in a uniform way) will have no meaningful effect on the results from Model 10. Thus it is apparent that the abundance and configuration of the reactive minerals in the system may be very important indeed.

Table 21: Comparison of features in Mineralogic Models 10, 11, and 12.

\begin{tabular}{lcc}
\hline \hline Model & $\begin{array}{c}3 \mathrm{D} \\
\text { result }\end{array}$ & $\begin{array}{c}\text { Reactive mineral } \\
\text { distribution }^{a}\end{array}$ \\
\hline 10 & $\S 11.4 .1$ & uniform \\
11 & $\S 11.4 .2$ & none \\
12 & $\S 11.4 .3$ & zones comprising lowest \\
& & $20 \%$ of $\ln K$ range \\
\hline \hline
\end{tabular}

${ }^{\bar{a} \text { Goethite, smectitie, illite/muscovite, and clinoptilolite }}$

\subsection{4 pH distribution evolved from each model}

As an ancillary result, Figures 59 through 61 show several three-dimensional perspectives of the above-background $\mathrm{pH}$ distribution after 600 years determined from the results of each mineralogic model. Above-background values result from the influence of melt glass dissolution and a lack of subsequent buffering interactions with goethite minerals in the system. Hence, increased levels of $\mathrm{pH}$ accompany steadily decreasing amounts of goethite in the system, as seen sequentially in Figures 60 (Model 11), 60 (Model 12), and 59 (Model 10). These results are not significantly affected by the presence of the radionuclides (at their respective concentrations). 


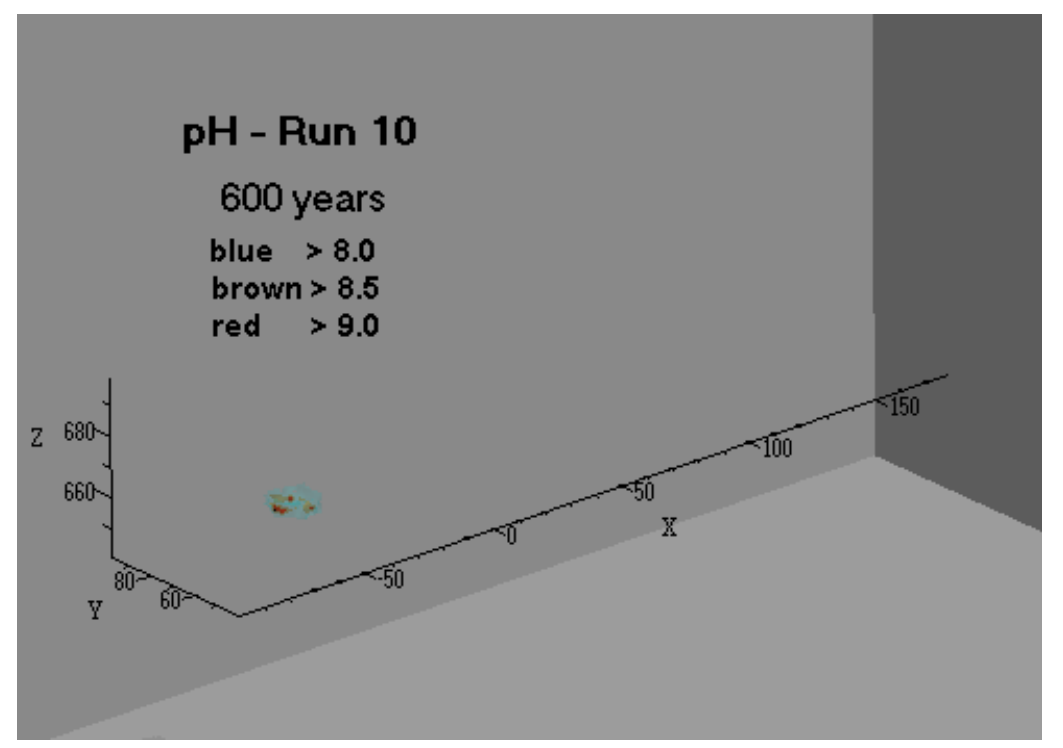

Figure 59: 3D perspective of the above-background $\mathrm{pH}$ distribution after 600 years determined from the results using Mineralogic Model 10. Values above $8,8.5$, and 9 are shown in blue, brown, and red, respectively, and result from the influence of melt glass dissolution in the puddle area. The background $\mathrm{pH}$ is slightly below 8 and is not rendered. Buffering interactions with iron oxide (goethite) minerals in the system tend to reduce the $\mathrm{pH}$ of fluids leaving the glass to background levels. 


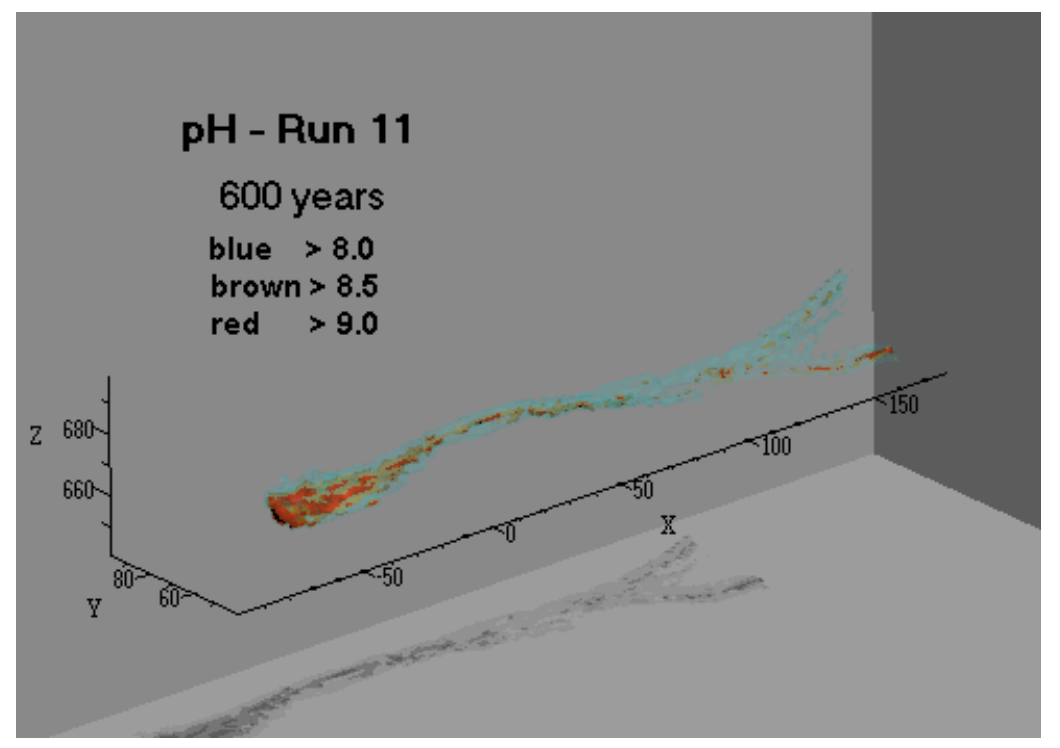

Figure 60: 3D perspective of the above-background $\mathrm{pH}$ distribution after 600 years determined from the results using Mineralogic Model 11. Values above 8, 8.5 , and 9 are shown in blue, brown, and red, respectively, and result from the influence of melt glass dissolution and the subsequent lack of buffering interactions with iron oxide (goethite) minerals in the system. The background $\mathrm{pH}$ is slightly below 8 and is not rendered. 


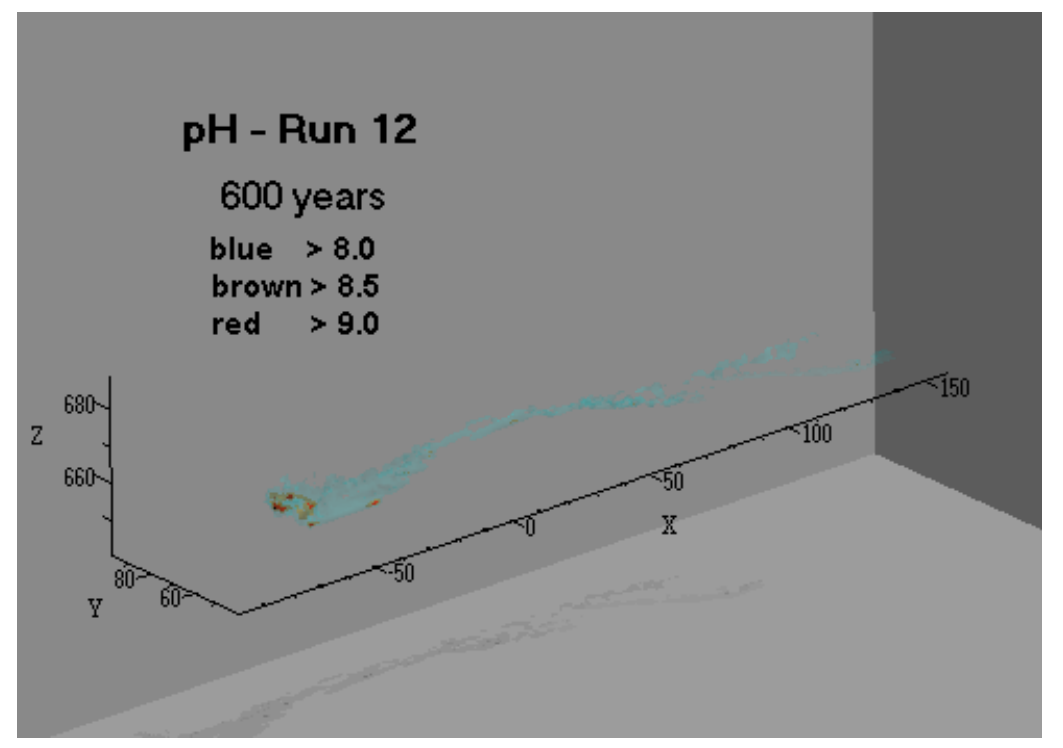

Figure 61: 3D perspective of the above-background $\mathrm{pH}$ distribution after 600 years determined from the results using Mineralogic Model 12. Values above 8, 8.5 , and 9 are shown in blue, brown, and red, respectively, and result from the influence of melt glass dissolution and the subsequent lack of buffering interactions with iron oxide (goethite) minerals in the system. The background $\mathrm{pH}$ is slightly below 8 and is not rendered. 


\section{Sensitivity Studies}

Some additional simulations have been performed in order to assess the sensitivities of the hydrologic source term model to the reactive surface areas of melt glass and goethite and to the reactive mineral distributions. These will be introduced below and discussed in more detail in the context of two specific streamlines in Appendix 8 (similar to the analyses if Models 10, 11, and 12 in Appendix 7). The model results have also been reviewed with respect to their simplification for use in larger scale ("upscaled") models and to facilitate the execution of other sensitivity studies. This is discussed in Appendix 9.

\subsection{Modified models of the mineralogic distribution}

\subsubsection{Retardation by reactive minerals - Goethite surface area}

In the sensitivity model designated Mineralogic Model 10a, the alluvium and exchange volume were characterized by a spatially uniform distribution of reactive minerals, equivalent to the specification in Model 10, albeit with a reduced specific goethite surface area. The reduced surface area was selected to reflect potential variability in the reactivity of natural iron oxides. The net effect of this change is to reduce the overall retardation of $\mathrm{Sr}$ and $\mathrm{Pu}$ species which react with goethite, while the behavior of the other radionuclides is unchanged. The initial concentrations of radionuclides in the fluids occupying the exchange volume also increased, as reviewed in Table 22.

\subsubsection{Melt glass surface area}

In the sensitivity models designated Mineralogic Models 10b, c, and d, the uniform mineralogic conditions of Model 10a were retained (Table 23), while the specific surface area of the melt glass was increased by factors of 1000, 10, and 100, respectively. The effect of increased glass surface area was pursued as a result of the work of Pohll et al. (1998), who analyzed the source term behavior at the SHOAL site using a much larger glass surface area, abeit with a less complex chemical analysis. Streamline results from these models generally show increased release of glass-bound radionuclides into solution and increased $\mathrm{pH}$. Model 10b did not run to completion, owing to convergence problems caused by an increased $\mathrm{pH}$ in excess of 12 . Models $10 \mathrm{c}$ and $10 \mathrm{~d}$ converged and produced incipient $\mathrm{Pu}$ precipitation in the glass.

\subsubsection{Spatial distribution of reactive minerals.}

Mineralogic Model 13a was meant to represent an alternative case in which the reactive minerals were distributed nonuniformly. In this particular configuration, the reactive specification of Model 10a was used in alluvium or exchange 
Table 22: Summary of radionuclide $(\mathrm{RN})$ inventory in fluids occupying the modeled $18-\mathrm{m}$ radius exchange volume. Calculations were made assuming a porosity of $40 \%$, yielding a total pore volume of $9.772 \times 10^{3} \mathrm{~m}^{3}$. Partitioning in Model 10 based upon presence of reactive minerals shown in Table 15, where the goethite surface area is $600 \mathrm{~m}^{2} / \mathrm{g}$. Paritioning in Models 10a-d based upon a reduced goethite surface area of $50 \mathrm{~m}^{2} / \mathrm{g}$, as described in Appendix 8. When no reactive minerals are present, aqueous concentrations given under Model 11.

\begin{tabular}{|c|c|c|c|c|c|}
\hline \multirow[b]{2}{*}{$\mathrm{RN}$} & \multirow{2}{*}{$\begin{array}{c}\text { Rubble } \\
\text { inventory } \\
\text { (moles) }\end{array}$} & \multirow{2}{*}{$\begin{array}{c}\text { Moles } \mathrm{RN} \\
\left.\text { (per kg } \mathrm{H}_{2} \mathrm{O}\right)\end{array}$} & \multicolumn{3}{|c|}{$\mathrm{RN}$ in fluid $\left(\mathrm{mol} / \mathrm{kg} \mathrm{H} \mathrm{H}_{2} \mathrm{O}\right)$} \\
\hline & & & Model 11 & Model 10 & Models 10a-d \\
\hline${ }^{90} \mathrm{Sr}$ & $2.58 \times 10^{-3}$ & $2.64 \times 10^{-10}$ & $2.64 \times 10^{-10}$ & $1.07 \times 10^{-13}$ & $1.83 \times 10^{-13}$ \\
\hline${ }^{137} \mathrm{Cs}$ & $9.59 \times 10^{-3}$ & $9.81 \times 10^{-10}$ & $9.81 \times 10^{-10}$ & $3.09 \times 10^{-13}$ & $3.09 \times 10^{-13}$ \\
\hline${ }^{155} \mathrm{Eu}$ & $4.23 \times 10^{-6}$ & $4.33 \times 10^{-13}$ & $4.33 \times 10^{-13}$ & $4.33 \times 10^{-13}$ & $4.33 \times 10^{-13}$ \\
\hline${ }^{239} \mathrm{Pu}$ & 0.651 & $6.66 \times 10^{-8}$ & $6.66 \times 10^{-8}$ & $1.23 \times 10^{-10}$ & $1.43 \times 10^{-9}$ \\
\hline${ }^{241} \mathrm{Am}$ & $2.59 \times 10^{-3}$ & $2.65 \times 10^{-10}$ & $2.65 \times 10^{-10}$ & $2.65 \times 10^{-10}$ & $2.65 \times 10^{-10}$ \\
\hline
\end{tabular}

volume grid cells whose log hydraulic conductivity $(\ln K)$ belongs to the lowest $80 \%$ of the entire $\ln K$ distribution. This would correspond to values of $\ln K<2.5$, or $K<12 \mathrm{~m} / \mathrm{d}$ (Fig. 39). Nonreactive minerals were distributed in all other cells (Table 22).

The concept in Model 13a is that the reactive minerals will be preferentially located in lower permeability zones as they were in Model 12, but throughout a much larger portion of the modeling volume. In Model 12, these minerals were only located in small fraction of the modeling volume, so that most of the surface-reactive radionuclides $(\mathrm{Pu}, \mathrm{Cs}, \mathrm{Sr})$ were generally quite mobile. Despite this, there is some minimal evidence to suggest that reactive species, such as $\mathrm{Pu}$ and even Am (which was not considered reactive here) have been effectively retained or rendered immobile in the cavity, chimney, and alluvium.

As described in Section 3.2.5, Bryant (1992) reported that the only attempt to measure $\mathrm{Pu}$ or Am at a point away from the cavity occurred when a sample from RNM-2S was taken at time that coincided with the observed peak of the tritium profile in Figure 35. Concentrations of $\mathrm{Pu}$ and $\mathrm{Am}$ were both less than the detection limits of $1.66 \times 10^{-15}$ and $1.66 \times 10^{-14} \mathrm{~mol} / \mathrm{kg}-\mathrm{H}_{2} \mathrm{O}$, respectively. If there were no reactive minerals in the system (as in Model 11), we would expect the $\mathrm{Pu}$ and $\mathrm{Am}$ in the exchange volume to be as mobile as the tritium, and thus show up at the well with a peak concentration coincident (approximately) with the tritium peak. What would the peak concentrations of $\mathrm{Pu}$ and $\mathrm{Am}$ be if 
Table 23: Comparison of features in Mineralogic Models 10, 11, and 12 with those used in the sensitivity studies 10a, 10b, 10c, 10d, 13a.

\begin{tabular}{|c|c|c|c|c|}
\hline Model & $\begin{array}{l}\text { Goethite surface } \\
\text { area }\left(\mathrm{m}^{2} / \mathrm{g}\right)\end{array}$ & $\begin{array}{c}\text { Glass surface } \\
\text { area }\left(\mathrm{m}^{2} / \mathrm{g}\right)\end{array}$ & $\begin{array}{l}3 \mathrm{D} \\
\text { result }\end{array}$ & $\begin{array}{l}\text { Reactive mineral } \\
\text { distribution }^{b}\end{array}$ \\
\hline 10 & 600 & ${ }^{a} 5 \times 10^{-5}$ & $\S 11.4 .1$ & uniform \\
\hline $10 \mathrm{a}$ & 50 & $5 \times 10^{-5}$ & $\S 12.2 .1$ & uniform \\
\hline $10 \mathrm{~b}$ & 50 & $5 \times 10^{-2}$ & $c$ & uniform \\
\hline $10 \mathrm{c}$ & 50 & $5 \times 10^{-4}$ & $c$ & uniform \\
\hline $10 \mathrm{~d}$ & 50 & $5 \times 10^{-3}$ & $\S 12.2 .3$ & uniform \\
\hline 11 & 600 & $5 \times 10^{-5}$ & $\S 11.4 .2$ & none \\
\hline 12 & 600 & $5 \times 10^{-5}$ & $\S 11.4 .3$ & $\begin{array}{c}\text { zones comprising lowest } \\
20 \% \text { of } \ln K \text { range }\end{array}$ \\
\hline $13 \mathrm{a}$ & 50 & $5 \times 10^{-5}$ & $\S 12.2 .2$ & $\begin{array}{l}\text { zones comprising lowest } \\
80 \% \text { of } \ln K \text { distribution }\end{array}$ \\
\hline
\end{tabular}

$\overline{\bar{a} \text { Equivalent to } 118 \mathrm{~m}^{2} / \mathrm{m}^{3} \text { bulk volume }}$

${ }^{b}$ Goethite, smectite, illite/muscovite, and clinoptilolite specified as in Table 15, column 2

${ }^{c}$ Only single streamline simulations (100 and 145) considered, as reviewed in Appendix 8

this were the case? In the absence of reactive minerals, initial concentrations of $\mathrm{Pu}$ and Am would be approximately $6.66 \times 10^{-8}$ and $2.65 \times 10^{-10} \mathrm{~mol} / \mathrm{kg}$ $\mathrm{H}_{2} \mathrm{O}$, respectively (Table 12 ). In comparing the initial tritium concentration in the exchange volume with the peak value observed at the well, we see a dilution factor close to 1000. If this were applied to $\mathrm{Pu}$ and $\mathrm{Am}$ (assuming mobile conditions and similar volumetric distributions), we would expect to see peak concentrations of $6.66 \times 10^{-11}$ and $2.65 \times 10^{-13} \mathrm{~mol} / \mathrm{kg}-\mathrm{H}_{2} \mathrm{O}$ at the well, which are above the detection limits. Since this was not the case, it would be incorrect to neglect the presence of reactive minerals altogether. Rather, it would seem that their abundance is sufficient and appreciably widespread to produce significant retardation effects in the near field.

The choice of the reactive mineral distribution in Model 13a was not, unfortunately, based upon actual mineralogic data, as it does not appear to be available. Hence, the results of this configuration and, possibly that of Model 10 and $10 \mathrm{a}$, can only be considered the more plausible of the four distributional models (10, 10a, 11, 12, 13a) examined. 


\subsection{Results of integrated 3D simulations}

Figures 62, 65, and 63 show the integrated flux of the total Eu, Am, Pu, Sr, and Cs species out of the domain under decay conditions for Mineralogic Models 10a, 10d, and 13a.

\subsubsection{Results for Mineralogic Model 10a}

Under Mineralogic Model 10a, the reduction in goethite surface area from that used in Model 10 (Appendix 8) promotes greater $\mathrm{Pu}$ mobility which is manifested in an observable breakthrough after $250 \mathrm{yr}$. Both the Cs and Sr fluxes (as well as the $\mathrm{Pu}$ flux for $t<250 \mathrm{yr}$ ) correspond to the background "0" levels specified in the model, as modified by decay ${ }^{16}$.

\subsubsection{Results for Mineralogic Model 13a}

Under Mineralogic Model 13a (Fig. 63), the most notable behavior relative to Model 10a is an accelerated breakthrough of $\mathrm{Pu}$ owing to the changed distribution of reactive minerals in this system. This is consistent with the existence of a few fast pathways through high permeability areas where the abundance of reactive minerals has been minimized. A $3 \mathrm{D}$ snapshot of the $\mathrm{Pu}$ distribution at 600 years is shown in Figure 64. When present, the goethite specified in this system has a reduced surface area, similar to what was used in Model 10a. Observable fluxes of $\mathrm{Cs}$ and $\mathrm{Sr}\left(>10^{-12}\right.$ moles/yr) are now also seen in the early years as a result.

\subsubsection{Results for Mineralogic Model 10d}

Under Mineralogic Model 10d (Fig. 65), a 100-fold increase in the melt glass surface area was specified relative to that used in all other models; other specifications remain as in Model 10a. The most notable behavior is an increased flux of $\mathrm{Pu}$ and Am species from the melt glass, as evidenced in the higher latetime profiles. The dramatic rise and flattening out of the $\mathrm{Pu}$ flux stems from the faster release of $\mathrm{Pu}$ and the subsequent achievement of saturation with respect to the solid $\mathrm{PuO}_{2}(\mathrm{OK})_{2} \cdot \mathrm{H}_{2} \mathrm{O}$ in the glass zone. Precipitation constrains eluting $\mathrm{Pu}$ concentrations to the equilibrium saturation state concentration of $10^{-7.7}$ molal (Appendix 8). Figure 66 shows this effect in a 3D perspective of the aqueous $\mathrm{Pu}$ distribution at 600 years. Notice that there is a distinct, high concentration plume of $\mathrm{Pu}$ eminating from the melt glass zone that is not visible in the Model 13a configuration (Fig. 64).

Figure 67 shows the distribution of above-background $\mathrm{pH}$ at 600 years for Model 10d. In contrast to Mineralogic Model 10 (Fig. 59), the high pH plume

\footnotetext{
${ }^{16}$ The "0" levels for $\mathrm{Pu}$ and $\mathrm{Sr}$ are "larger" than those shown in Fig. 51 because the reduced goethite abundance promotes greater partitioning of the " 0 " value into the aqueous phase.
} 


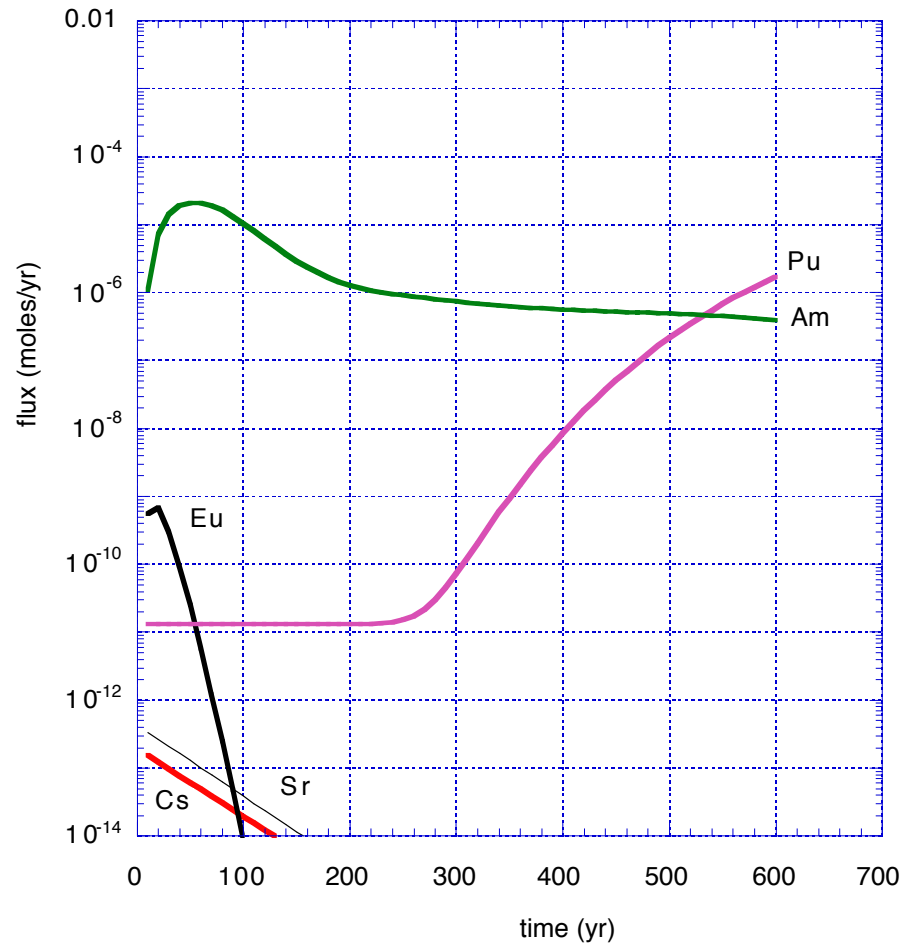

Figure 62: Integrated flux of the total $\mathrm{Eu}, \mathrm{Am}, \mathrm{Pu}, \mathrm{Sr}$, and $\mathrm{Cs}$ species out of the domain under decay conditions corresponding to Mineralogic Model 10a. The fluxes of $\mathrm{Pu}$ (for $t<250 \mathrm{yr}$ ), and $\mathrm{Sr}$ and $\mathrm{Cs}$ (for all $t$ ) should be considered zero, as they correspond to decayed " 0 " background values used in the model. 


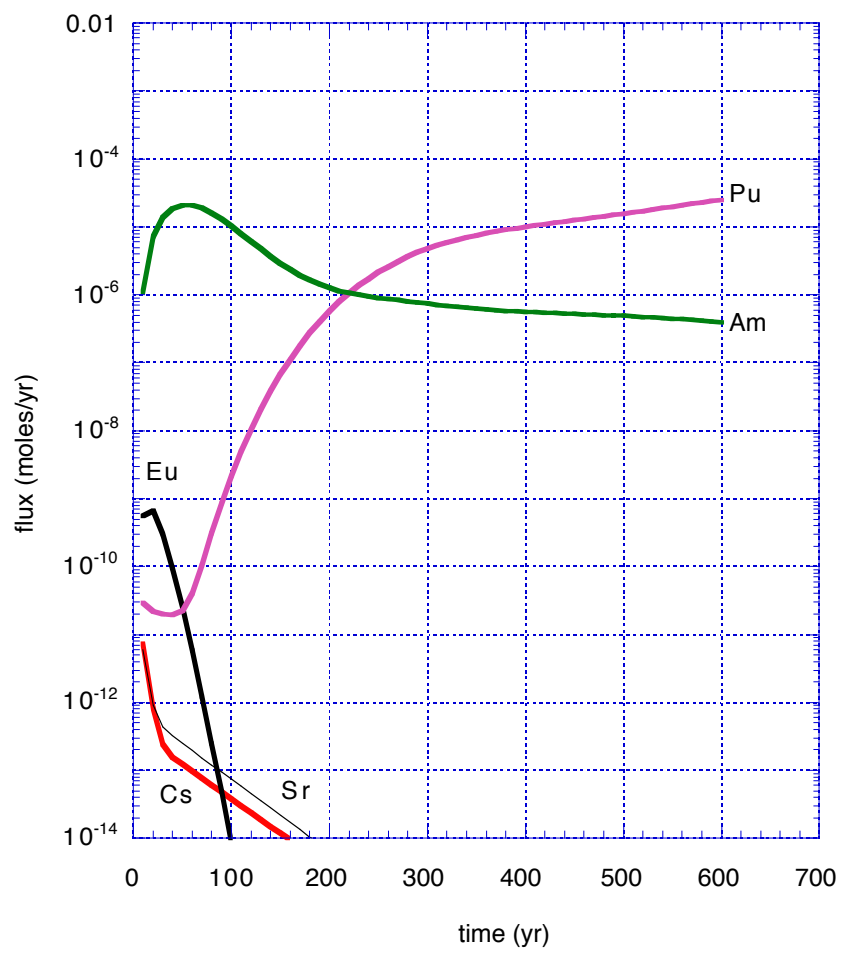

Figure 63: Integrated flux of the total $\mathrm{Eu}, \mathrm{Am}, \mathrm{Pu}, \mathrm{Sr}$, and $\mathrm{Cs}$ species out of the domain under decay conditions corresponding to Mineralogic Model 13a. The fluxes of $\mathrm{Pu}$ (for $t<50 \mathrm{yr}$ ), and $\mathrm{Sr}$ and Cs (for $t>20 \mathrm{yr}$ ) should be considered zero, as they correspond to decayed " 0 " background values used in the model. 


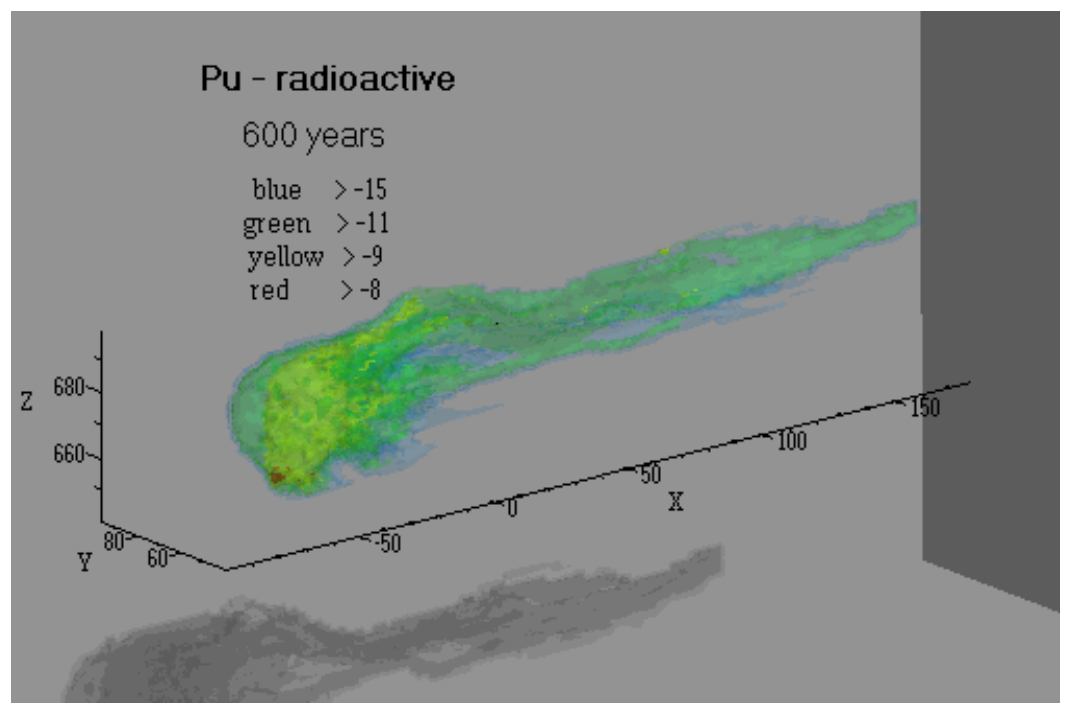

Figure 64: 3D perspective of decay-corrected total-plutonium plume at 600 years based upon Mineralogic Model 13a. Molar concentrations $>10^{-15}$ are in blue; $>10^{-11}$, in green, $>10^{-9}$ in yellow, and $>10^{-8}$ in orange/red.

is caused by a combination of high glass dissolution rate and reduced goethite surface area.

\subsubsection{Comparisons among all model results}

Figure 68 compares the integrated $\mathrm{Pu}$ flux obtained under decay conditions based upon Mineralogic Models 10, 10a, 10d, 11, 12, and 13a. The Pu flux should be considered zero for all time in Model 10, before $t=250$ years in Models $10 \mathrm{a}$ and $10 \mathrm{~d}$, and before $t=50$ years in model 13a. When reactive minerals are largely absent (Models 11 and 12), the flux profiles have larger magnitudes and show distinct signatures corresponding to the exchange volume (early) and melt glass (late) releases. These signatures are blurred and not obvious in the Model 10a and 13a profiles, although the effect of a larger glass dissolution rate is obvious in the Model 10d result. The slight differences between the Model 11 and 12 profiles correspond to the small amount of reactive (retarding) minerals present in the Model 12 configuration.

Figures 69 and 70 compare the total $\mathrm{Sr}$ and $\mathrm{Cs}$ fluxes for all mineralogic models considered. These fluxes should be considered zero for all time in Models 10 and 10a, and zero beyond the earlier years in Model 13a. As in Figure 68, the exchange volume and melt glass breakthrough signatures are quite distinct in the Model 11 and 12 results. The differences in the profiles at larger times, corresponding to melt glass releases, reflect the greater abundance of slow flow 


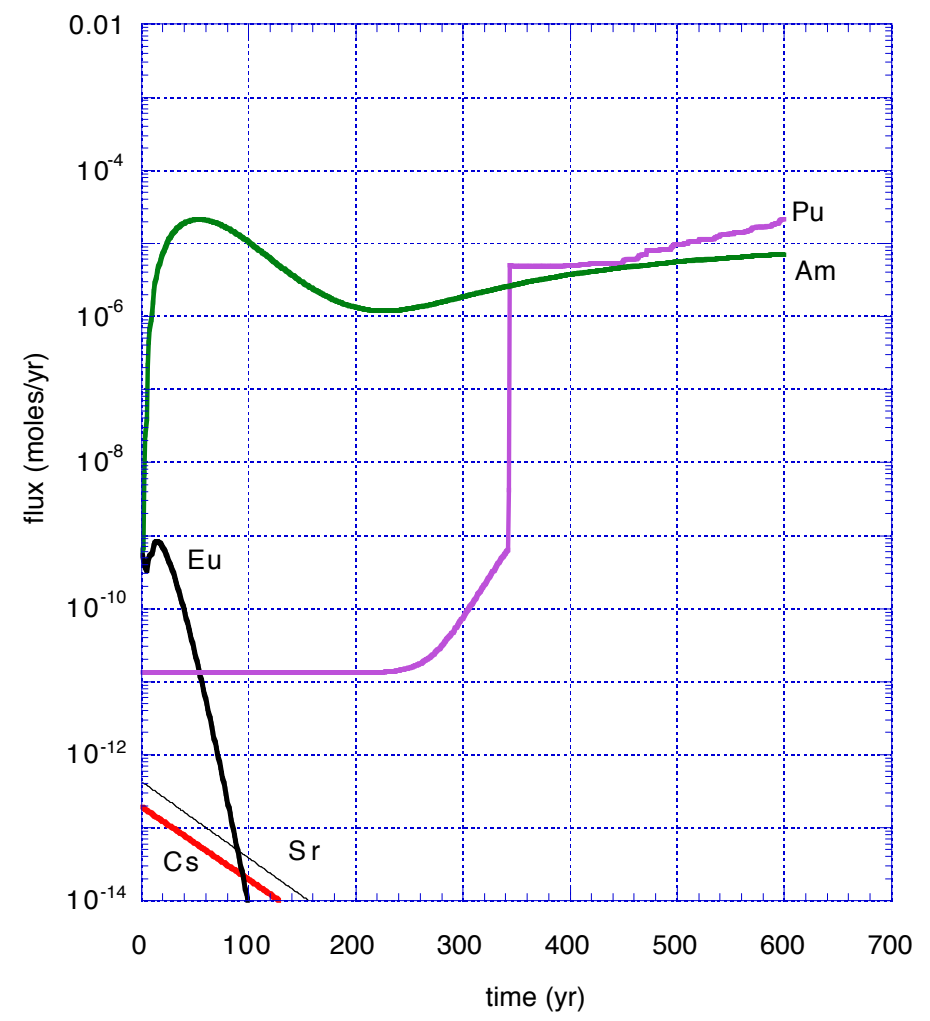

Figure 65: Integrated flux of the total $\mathrm{Eu}, \mathrm{Am}, \mathrm{Pu}, \mathrm{Sr}$, and $\mathrm{Cs}$ species out of the domain under decay conditions corresponding to Mineralogic Model 10d. The fluxes of $\mathrm{Pu}$ (for $t<250 \mathrm{yr}$ ), and $\mathrm{Sr}$ and $\mathrm{Cs}$ (for allt) should be considered zero, as they correspond to decayed "0" background values used in the model. 


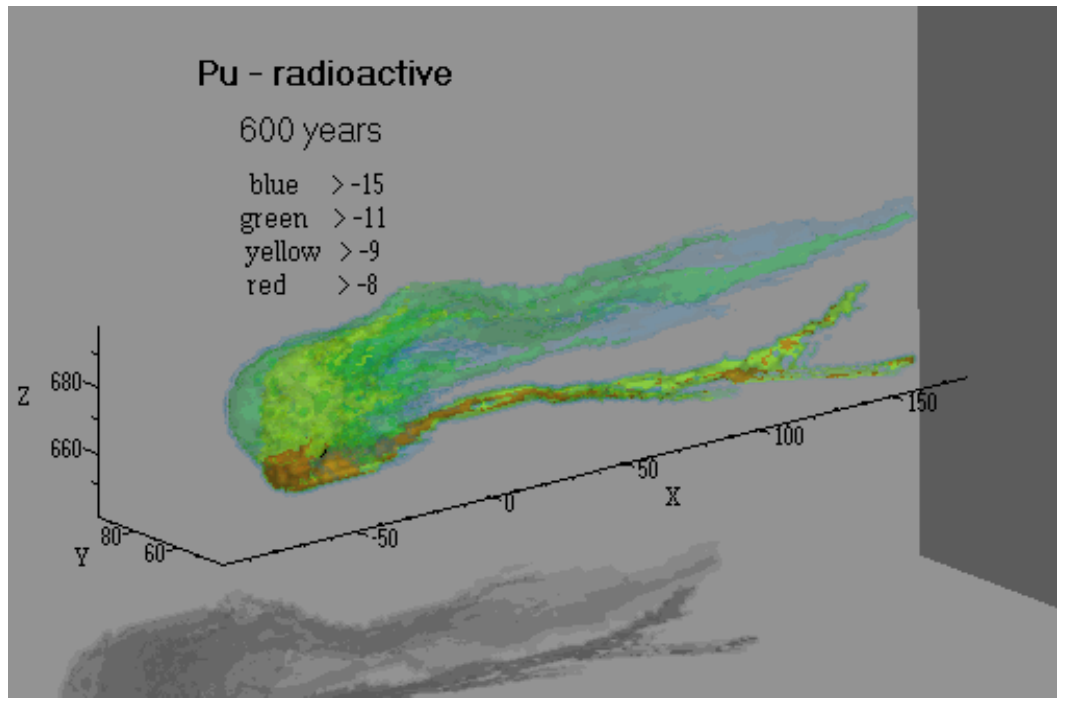

Figure 66: 3D perspective of decay-corrected total-plutonium plume at 600 years based upon Mineralogic Model 10d. Molar concentrations $>10^{-15}$ are in blue; $>10^{-11}$, in green, $>10^{-9}$ in yellow, and $>10^{-8}$ in orange $/$ red.

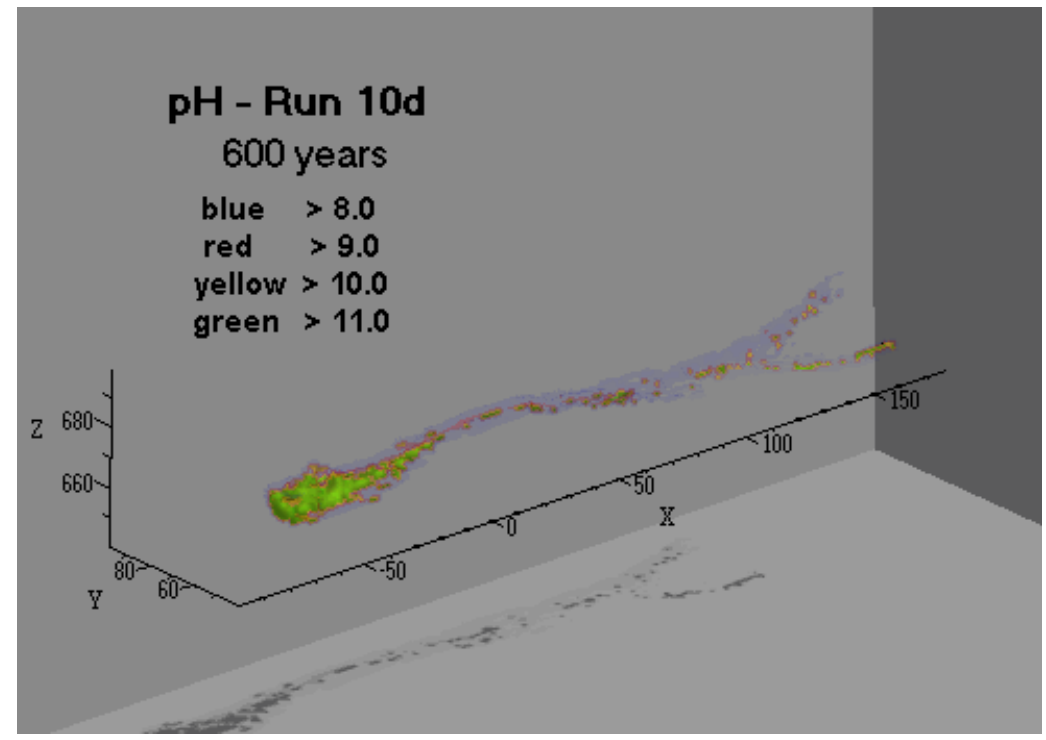

Figure 67: 3D perspective of the above-background $\mathrm{pH}$ distribution after 600 years determined from the Mineralogic Model 10d simulation. Values above 8, 9, 10, and 11 are shown in blue, red, yellow, and green, respectively. 


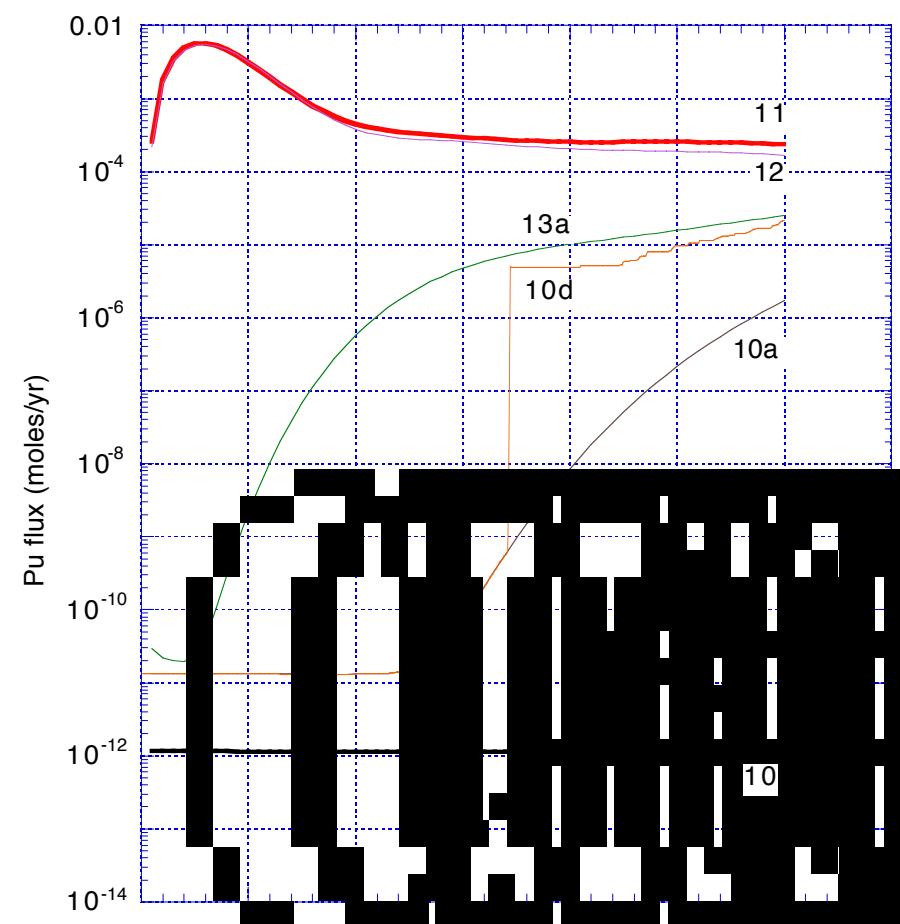

time (yr)

Figure 68: Integrated flux of the total $\mathrm{Pu}$ species out of the domain under decay conditions corresponding to Mineralogic Models 10, 10a, 10d, 11, 12, and 13a. 
pathways and retarding minerals along streamlines passing through the melt glass.

Figure 71 shows the same comparisons for the total Am species in each model run. As Am was not assumed to partake in ion exchange or sorption reactions, the only noticable effect occurs with the faster melt glass dissolution rates used in Model 10d.

No comparable figure is provided for the Eu fluxes. As with the Am results, the Eu profiles from all models identical with the exception of Model 10d. However, this effect would not be visible on the graphs because radioactive decay reduces Eu concentrations to values off the lower scale used in the graphs. 


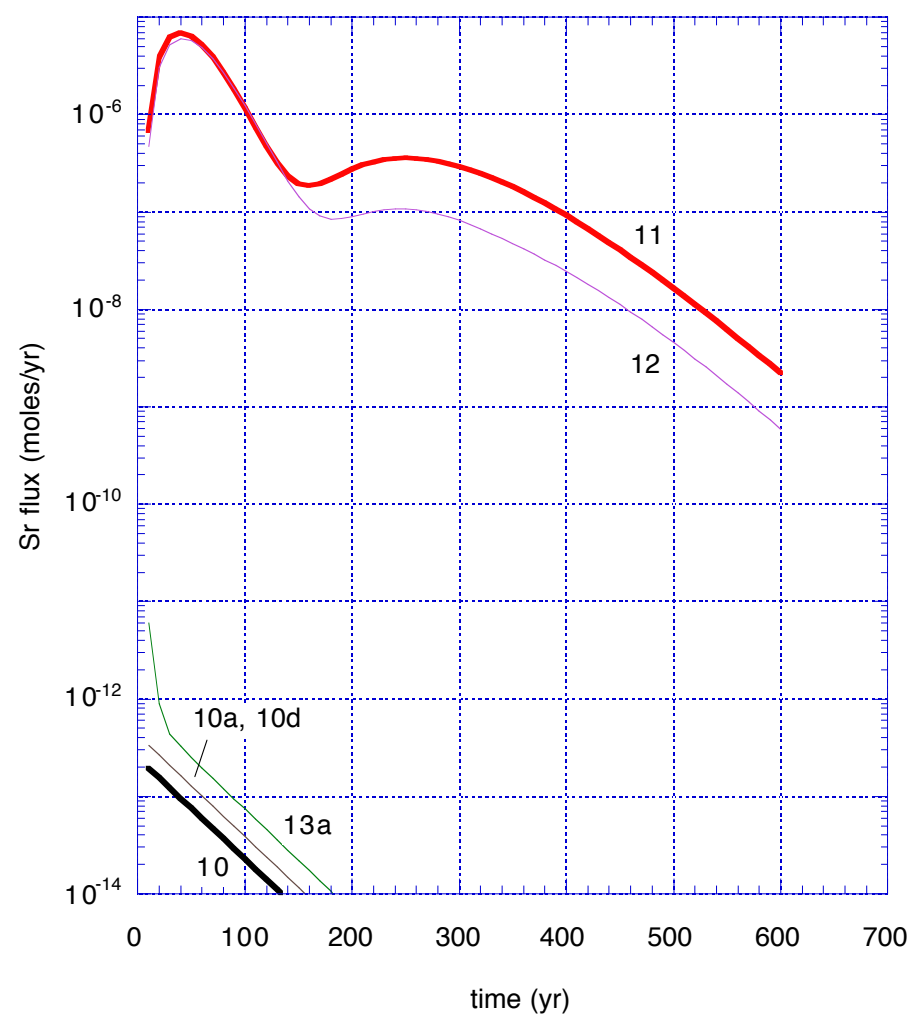

Figure 69: Integrated flux of the total Sr species out of the domain under decay conditions corresponding to Mineralogic Models 10, 10a, 10d, 11, 12, and 13a. 


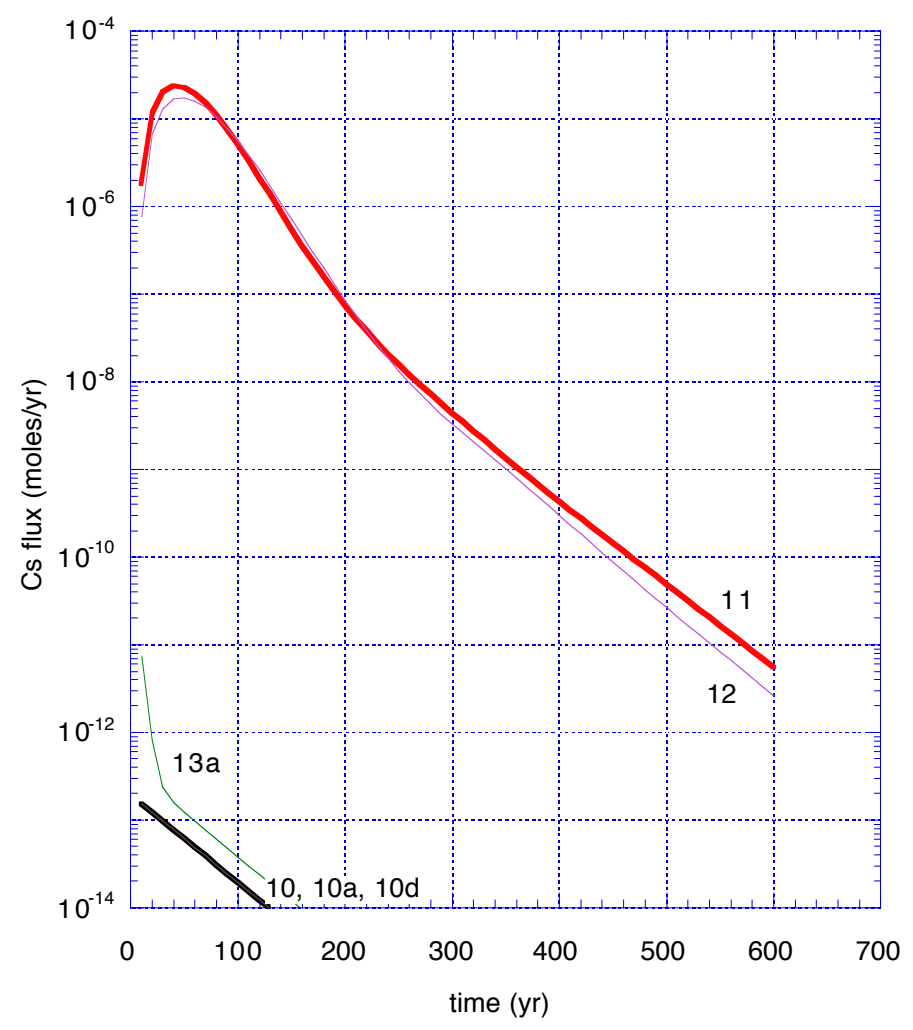

Figure 70: Integrated flux of the total Cs species out of the domain under decay conditions corresponding to Mineralogic Models 10, 10a, 10d, 11, 12, and 13a. 


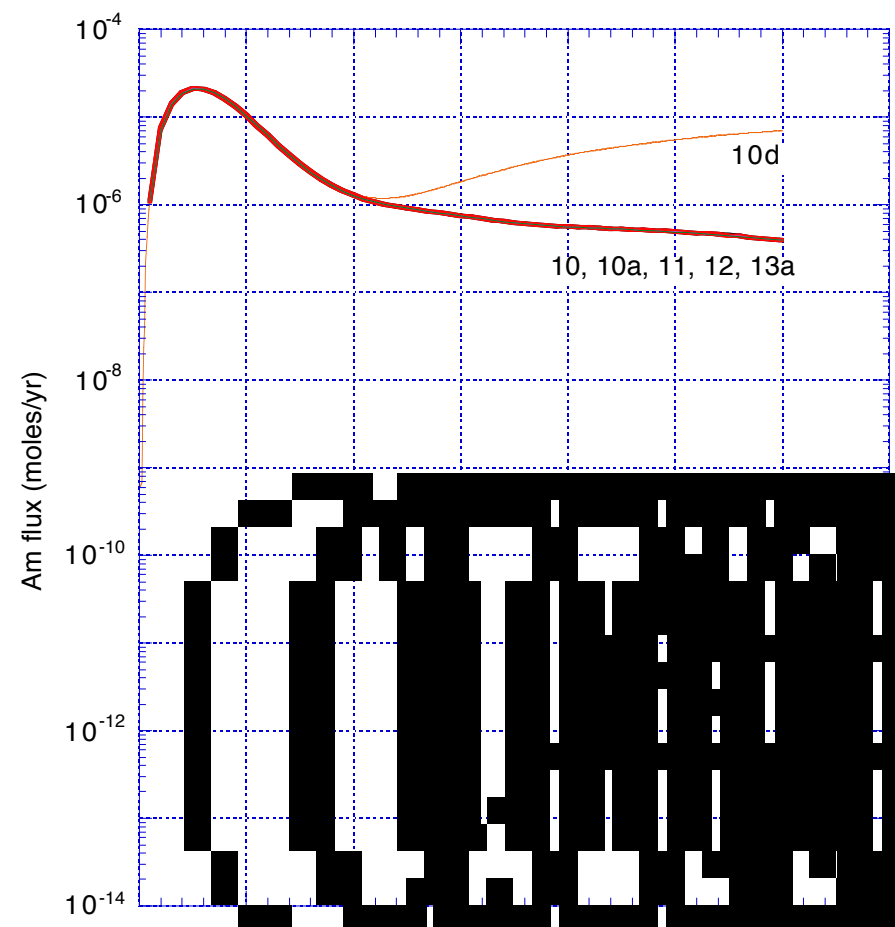

time (yr)

Figure 71: Integrated flux of the total Am species out of the domain under decay conditions corresponding to Mineralogic Models 10, 10a, 10d, 11, 12, and 13a. 


\section{Extrapolating Results to Larger Scale Simu- lations}

From a larger scale perspective in which the migration of radionuclides over larger distances is of interest, say through the entire aquifer underlying Frenchman Flat, the principal results of interest in this report are:

- The prediction of the principal aqueous species of $\mathrm{Sr}, \mathrm{Cs}, \mathrm{Eu}, \mathrm{Pu}$, and $\mathrm{Am}$ that migrate out of the cavity, chimney, and melt glass system, and

- The prediction of the integrated flux (moles/yr) of the total $\mathrm{Sr}, \mathrm{Cs}, \mathrm{Eu}$, $\mathrm{Pu}$, and Am eluting from the near-field system.

What may also be needed at this stage, but was not explicitly extracted from the results, is some simplified or bulk estimate of the overall species mobilities in the system. In short, can radionuclide mobilities in the far field, relative to water, be described by simple retardation processes? Rather than carrying out the same type of reactive transport simulations throughout all of Frenchman Flat, simpler representations are of interest, if they can be identified. This will be discussed in the first part of Appendix 9.

A second issue that arises, and one that is discussed from a different perspective below, is whether the hydrologic source term results from one test (like CAMBRIC) can be "scaled" or "moved" to represent the source term of another test. There are several reasons why this may not be possible, mostly relating to classification issues, differing inventories, dissimilar flow environments, and the fact that many key chemical and flow processes are mathematically nonlinear and do not scale with inventory. Nevertheless, it may be possible to use the current results to represent a "hypothetically similar" test in another part of the Frenchman Flat saturated zone. The key issue in this case will be the effect of the groundwater flow velocity, because the elution of radionuclides out of the melt glass will be sensitive to the groundwater flux.

An analytic solution is presented in Appendix 9 for a simple case involving radionuclide elution out of a melt glass into a $1 \mathrm{D}$ flow system. It is easily seen how the dependence of aqueous concentration on velocity is inversely related to its dependence the melt glass surface area. Although the result may be used ultimately to find a simpler representation of the hydrologic source term, it also provides a quick way to gauge sensitivities of the simulations to the size of the melt glass regime, the specific surface area of melt glass, and the groundwater flow velocity. 
Chapter 13: Larger Scale Simulations 


\section{Comparison of Simulations with Observations: A Summary}

Many of the predictions and simulation results reviewed in this document cannot be independently verified with observations or field measurements. This is largely due to:

- The long term nature of the simulations themselves, e.g., $600 \mathrm{yr}$.

- A lack of historical observations, such as continual monitoring of radionuclide concentrations in RNM-1 or RNM-2S.

- Limited characterization data describing, for example, hydraulic conductivity or reactive mineral distributions, and initial radionuclide distributions in the cavity.

- The fact that ambient migration behavior was simulated at CAMBRIC, as opposed to the disturbed events associated with the 16-year migration study. Should new measurements be taken, for example, they may not be comparable with the simulations.

Nevertheless, it is pertinent to review and discuss the more important comparisons that can be made; this information is summarized below.

\subsection{Predicted breakthrough of tritium at RNM-2S vs. the migration test observations}

Reasonable predictions of the tritium breakthrough measured in the radionuclide migration experiment were obtained with the flow model, as shown in Figure 40. Nevertheless, it should be noted that the simulations were not obtained independently - rather, the tritium extraction observations were used to support the development and calibration of the flow model.

\subsection{Initial exchange volume concentrations vs. RNM-1 measurements}

Table 24 compares available radionuclide concentrations measured in cavity and chimney waters c. 1974 with the initial aqueous concentrations used in our simulations (these have been reported elsewhere in Tables 6 and 22). Because the measurement date occurred before the 16 -yr radionuclide migration experiment and because little migration is expected to have occurred in the 10 prior years, these data should be appropriate to compare with our predictions. The predicted values presented are for initial configurations corresponding to Mineralogic Models 10 and 10a; predicted values under Model 11 (Table 22) are considered to be much too large. 
The predicted values were obtained independently from the measurements, and were subject to a series of assumptions relating to:

- The proper degree of radionuclide segregation between the melt glass and exchange volume areas.

- The proper definition of the exchange volume size for specific radionuclides, as well as the uniformity (or lack thereof) of their spatial distribution inside of the exchange volume.

- The proper degree of chemical partitioning between reactive minerals and the fluids in the exchange volume, as a function of the distribution of reactive minerals and the specific ion-exchange and sorption models considered.

In light of these assumptions, the results are reasonable. It should be noted that the high degree of partitioning generally leaves 0.1 to 10 parts-per-thousand mass fractions in the fluids, which can be subject to a wide amount of interpretational errors in terms of experimental data and theoretical assessment. The disagreement in the $\mathrm{Pu}$ results could be due to lack of an electrostatic model for sorption in GIMRT, which would decrease the predicted aqueous $\mathrm{Pu}$ concentrations, as described below and in Appendix 3. Errors in the other assumptions relative to $\mathrm{Pu}$ could also exist.

Table 24: Comparison of predicted initial aqueous radionuclide (RN) concentrations in the exchange volume (Table 22) with measurements from RNM-1 cavity/chimney waters obtained c. 1974 (Table 6).

\begin{tabular}{lccccc}
\hline \hline & \multicolumn{3}{c}{ Molality (moles/kg fluid) } & \multicolumn{2}{c}{ Ratio (model/RNM1) } \\
& \multicolumn{2}{c}{ Model 10a } & RNM-1 & Model 10 & Model 10a \\
$\mathrm{RN}$ & Model 10 & & & & \\
& & & & \\
${ }^{90} \mathrm{Sr}$ & $1.07 \times 10^{-13}$ & $1.83 \times 10^{-13}$ & $2.14-3.68 \times 10^{-13}$ & $0.3-0.5$ & $0.5-0.9$ \\
${ }^{137} \mathrm{Cs}$ & $3.09 \times 10^{-13}$ & $3.09 \times 10^{-13}$ & $3.78-7.56 \times 10^{-14}$ & $4-8$ & $4-8$ \\
${ }^{239} \mathrm{Pu}$ & $1.23 \times 10^{-10}$ & $1.43 \times 10^{-9}$ & $\sim 5 \times 10^{-14, a}$ & 2,460 & 28,600 \\
& & & & & \\
\hline
\end{tabular}

$\overline{\bar{a} \text { This represents the total of }{ }^{239} \mathrm{Pu} \text { and }{ }^{240} \mathrm{Pu} \text {. The majority of the total }}$ can be assumed to be ${ }^{239} \mathrm{Pu}$ (LLNL, 1996).

\subsection{Predicted retardation behavior in alluvium vs. batch test measurements}

Table 25 compares the predicted retardation behavior of $\mathrm{Sr}, \mathrm{Cs}$, and $\mathrm{Pu}$ in alluvium (in the absence of melt glass effects) to retardation coefficients predicted 
from a series of batch sorption tests. The predicted retardation behavior (as reviewed in Appendix 9) corresponds to migration along streamlines passing through the exchange volume only in uniformly reactive alluvium configured according to Mineralogic Models 10 and 10a. In this sense, the predicted behavior shown in Appendix 9 corresponds to a constant level of partitioning. The measured retardation values were converted from distribution coefficients reported by Wolfsberg (1978) using a porosity of $40 \%$ and a bulk density of 2.0 $\mathrm{g} / \mathrm{cm}^{3}$.

The predicted values were obtained independently of the measured values, and they are subject to the same series of assumptions and limitations discussed in the previous paragraph. Reasonable agreements are found, despite the same concerns about errors associated in working with parts-per-thousand mass fractions in partitioning calculations. A distribution coefficient for $\mathrm{Pu}$ was not reported by Wolfsberg (1978) because precipitation apparently occurred during the experiment. Notice that the ratios of predicted and measured values for $\mathrm{Sr}$ and $\mathrm{Cs}$ are somewhat similar between tables 24 and 25. The sorption experiments, however, used crushed samples of alluvium which may not be representative (in terms of reactive surface area) of the intact porous medium.

Table 25: Comparison of predicted retardation coefficients $\left(\mathcal{R}_{j}\right)$ in uniform reactive alluvium models (as defined from data in Appendix 9 or Table 22) with equivalent values converted from distribution coefficient measurements of Wolfsberg (1978), using a porosity of $40 \%$ and a bulk density of $2.0 \mathrm{~g} / \mathrm{cm}^{3}$.

\begin{tabular}{|c|c|c|c|c|c|}
\hline \multirow[b]{2}{*}{$\mathrm{RN}(j)$} & \multirow[b]{2}{*}{ Model 10} & \multirow{2}{*}{$\begin{array}{c}\mathcal{R}_{j} \\
\text { Model 10a } \\
\end{array}$} & \multirow[b]{2}{*}{ Measurement } & \multicolumn{2}{|c|}{ Ratio (model/measurement } \\
\hline & & & & Model 10 & Model 10a \\
\hline${ }^{90} \mathrm{Sr}$ & 2,460 & 1,446 & 1,100 & 0.5 & 0.8 \\
\hline${ }^{137} \mathrm{Cs}$ & 3,200 & 3,200 & 38,500 & 12 & 12 \\
\hline${ }^{239} \mathrm{Pu}$ & 537 & 47 & precipitation & - & - \\
\hline
\end{tabular}

\subsection{Expected breakthrough of $\mathrm{Pu}$ and $\mathrm{Am}$ at RNM-2S vs. the migration test observations}

As reported in Sections 3.2.5 and 12.1.3, the single attempt to measure $\mathrm{Pu}$ and $\mathrm{Am}$ in the RNM-2S well water during the 16-yr radionuclide migration experiment (Bryant, 1992) yielded values that were below detection at a point in time coincident with the arrival of the peak tritium concentration. If their initial aqueous concentrations in the exchange volume were as predicted in Tables 
12,22 , or 24, this result could be used (as in Section 12.1.3) to argue that $\mathrm{Pu}$ and Am are significantly retarded by the alluvium.

Notably this argument could not be made in the case of $\mathrm{Pu}$ if the measured cavity concentrations (in Tables 6 or 24) were used instead of the predicted initial value. In this case, assuming perfectly mobile conditions, the expected peak elution value of $\mathrm{Pu}$ in $\mathrm{RMN}-2 \mathrm{~S}$ would also fall below the $\mathrm{Pu}$ detection limit and preventing any comparisons or inferences to be made about its real mobility. 


\section{Summary, Conclusions, and Recommenda- tions}

\subsection{Summary}

The objectives of this project were to develop a modeling framework to quantitatively evaluate the nature and extent of radionuclide contamination within the near field groundwater environment of the CAMBRIC underground nuclear test, and to generalize the approach to other tests in Frenchman Flat.

We only considerd processes that occur well after the nuclear test under relatively ambient temperature and hydraulic conditions. We did not consider prompt injection processes, or migration of noncondensable or precursor gases (e.g., Guell, 1997) into or out of the unsaturated zone. We also did not consider colloid transport.

Most of the work in this report has been focused on analyzing behavior at the CAMBRIC test under ambient flow conditions. This choice was motivated by the relative abundance and availability of hydrologic, chemical, and radionuclide data connected with this test.

\subsubsection{Modeling framework}

Our framework was designed to allow the chemical nature and abundance of radionuclides introduced into groundwater as aqueous species or colloids to be estimated, together with the rate and extent of radionuclide migration, dilution, and reaction in groundwater surrounding the working point of a test. Specifically, it involved:

- Adoption of a select group of radionuclides for formal analyses,

- Determination of the total inventory of these radionuclides and their relative partitioning among the glass and rubble zones,

- Development of a glass phase dissolution model,

- Development of models for the aqueous complexation, surface complexation, ion exchange, precipitation and dissolution reactions that control chemical interactions among the glass, exchange volume, and alluvium,

- Development of a groundwater flow and radionuclide transport model to forecast the overall rate of radionuclide migration out of this zone as a function of groundwater flow, glass dissolution, and effective chemical retardation processes, and

- Sensitivity analyses that address effects of melt glass and reactive mineral surface area, as well as the total abundance and spatial distribution of the reactive minerals in alluvium. 


\subsubsection{Radionuclide selection, distribution, and release}

The radionuclides ${ }^{3} \mathrm{H},{ }^{90} \mathrm{Sr},{ }^{137} \mathrm{Cs},{ }^{155} \mathrm{Eu},{ }^{239} \mathrm{Pu}$, and ${ }^{241} \mathrm{Am}$ were chosen for this study because their inventories are unclassified and available, they have varied initial distribution in the glass, chimney, and cavity areas, and they represent a cross-section of geochemical behavior such as unrestricted flow with groundwater, sorption, ion exchange, precipitation, and dissolution.

At CAMBric, we developed a glass dissolution model to forecast the rate at which glass-bound radionuclides are released into the aqueous regime. The model was based upon an idealized approximation of the melt glass volume, and surface area, and an estimate of the total glass-bound radionuclide inventory. The intrinsic glass dissolution rates and specific glass surface areas are critical in controlling the total amounts of radionuclides released over time. Although intrinsic rates have been measured from CAMBRIC glass samples, the reactive surface area of the melt glass is not well known. Modified glass porosity and permeability created over long dissolution times were also not considered.

The principal aqueous species in ambient CAMBRIC groundwaters associated with the target radionuclides were $\mathrm{Sr}^{2+}, \mathrm{Cs}^{+}, \mathrm{EuOHCO}_{3}(\mathrm{aq}), \mathrm{PuO}_{2}\left(\mathrm{CO}_{3}\right)_{2}^{2-}$, and $\mathrm{AmCO}_{3}^{+}$. The initial distribution of radionuclides outside of the melt glass was confined to an idealized $18-\mathrm{m}$ radius spherical exchange volume centered on top of the cavity bottom. The definition of the exchange volume was based upon data from a down hole gamma log in RNM-1, approximate correlations between yield and extent of radionuclide contamination reviewed by Borg et al. (1976), and similar regions defined and used in previous tritium migration simulations. Radionuclides were assumed to be distributed uniformly inside of this volume.

Both the exchange volume and the glass acted as long-term sources of radionuclides over time. The glass dissolved slowly, continuously releasing small quantities of radionuclides over time. The concentrations of radionuclides associated with solid reactive minerals in the exchange volume exceeded the concentrations in the pore fluid by several orders of magnitude. Thus, the solids were able to continuously release enough radionuclides to maintain equilibrium with the solution to replace the radionuclides flushed out by the incoming water.

\subsubsection{Radionuclide mobility at CAMBRIC}

Relative to groundwater, the mobility of dissolved radiounuclide species will be affected by precipitation and by sorption and ion exchange processes associated with reactive minerals such as goethite, clinoptilolite, muscovite/illite, and smectite, all of which have been detected in the alluvial sediments near CAMBRIC. The possibility for colloidal facilitated transport of $\mathrm{Pu}$ was not accounted for, although little data exists that would suggest the presence, or lack thereof, of colloid material at CAMBRIC. Nevertheless, the results of $\mathrm{Pu}$ migration in a problem without reactive minerals might be used as a first-order approximation 
of facilitated transport under the assumption that all $\mathrm{Pu}$ is loaded onto colloids.

In terms of mineral reactions, we considered equilibrium sorption of $\mathrm{Sr}$ and $\mathrm{Pu}$ onto goethite and equilibrium ion exchange of $\mathrm{Cs}$ and $\mathrm{Sr}$ onto clinoptilolite, muscovite/illite and smectite. Simulations suggest $\mathrm{Sr}$ sorption onto goethite dominates ion exchange of $\mathrm{Sr}$, while Cs exchanges primarily with muscovite/illite. Eu and Am were assumed to be unretarded by these minerals because sorption and exchange models were not readily available. HTO was assumed to move with the bulk water phase, as opposed to being retarded as suggested by Burbey and Wheatcraft (1986).

Concentrations of the radionuclides were never large enough to saturate available surface complexation or exchange sites on reactive minerals that were present in a spatially uniform sense, even in only very small amounts. Competitive effects were minimized as a result. At these concentrations, analyses of partitioning ratios (moles sorbed or exchanged + moles in solution) $/($ moles in solution) suggest that the associated retardation coefficients are extremely large, and hence the mobility of the participating species is extremely small (Appendix 9). Nevertheless, this conclusion may not be appropriate in a larger scale sense where the abundance of reactive minerals is not spatially uniform (see below). In addition, concentrations of all species were never large enough to reach solubility limitations and induce precipitation.

\subsubsection{Radionuclide flux at CAMBRIC}

Groundwater flow was first simulated within a domain surrounding the CAMBRIC cavity and chimney system in order to simulate HTO migration and reproduce a measured elution in the RNM-2S well, as observed in the 16-year pumping and migration experiment. This allowed us to duplicate earlier HTO migration and capture simulations while using a fully three-dimensional model based upon an extremely fine mesh resolution (2-m spacings). This kind of detail was used to represent heterogeneity in the material properties and characteristics in a geostatistical sense. Important hydraulic properties specified in the cavity chimney system included a low permeability and porosity crush zone beneath the cavity, specific inclusion of the melt glass phase, and approximately variable cavity and exchange volume properties.

Heterogeneity in the CAMBRIC alluvium is reflected in terms of textural variability (sand, clay, etc.), physical properties (hydraulic conductivity and porosity) and mineralogic composition (e.g., mass and surface area of goethite, clinoptilolite, muscovite/illite and and smectite). Our modeling efforts incorporated heterogeneity directly. In terms of the HTO migration, the influence of conductivity heterogeneity was largely realized in the dispersed elution profile observed at the well.

Simulations of the migration of other radionuclide species were performed under ambient (non pumping) conditions, beginning with an inventory that was decay corrected to 1965. Radioactive decay was incorporated ex post facto as 
a post-processing step. A unique streamline approach was adopted in which a 3D transport simulation was broken into a series of independent 1D simulations along a dense collection of flow lines passing through the cavity and glass areas. This was used to predict the migration of radionuclides through the model domain and evaluate the integrated radionuclide elution flux through the downgradient boundary. Using the same groundwater flow field obtained previously, several different 3D transport simulations were made to assess the impacts of the spatial distribution of reactive minerals and their specific surface area.

In one approach (Model 10), reactive minerals were distributed uniformly, and the results showed strongly retarded migration behavior. Another configuration (designated Model 11) involved specification of no reactive minerals, promoting greater species mobility, larger fluxes over longer times, and larger species concentrations. Although Model 10 certainly represents a plausible configuration (based upon the sparse data in hand), Model 11 is not plausible and serves mainly to illustrate end-member behavior.

A third configuration (designated Model 12) was used to illustrate a case where reactive minerals were present, albeit sparsely, in a heterogeneous sense where they were preferentially located with materials of the lowest permeability. In the specific case examined, radionuclide fluxes were not strongly changed from the Model 11 results, although the results lead us to conclude that other intermediate cases could generate intermediate degrees of mobility (e.g., flux rate out of the system), which, in turn could provide an intermediate degree of effective retardation.

Comparisons of models 10, 11, and 12 indicate that even small amounts of reactive minerals, when uniformly distributed, provide a significant retention effect for radionuclides. The abundance and configuration of reactive minerals in the system is very important.

Sensitivity studies focused on reduced reactive surface area for goethite in the system indicated greater mobilities and fluxes of $\mathrm{Pu}$, as would also be achieved if goethite were removed in bulk from the system. As expected, sensitivity studies focused on larger melt glass surface areas produced faster release of glass-bound radionuclides. This was generally accompanied by $\mathrm{Pu}$ precipitation in the glass, and by increased $\mathrm{pH}$ values that, depending on the surface area used, exceed typical field and experimental observations.

Because of the uncertainty in what is really known about the mineral distribution and medium reactivity, it is difficult to evaluate whether Model 10, 11, 12 , or any other intermediate configuration is most appropriate. Although different configurations can be developed and used to predict effective retardation behavior, it is felt that additional discussion is necessary before undertaking additional simulations.

An approach for scaling the results for use in larger scale applications was outlined and will be pursued more carefully in future publications. 


\subsection{Conclusions}

1. The cavity, chimney, and melt glass environments act as distinct and long term sources of radionuclide introduction into groundwater. Important processes controlling the rates of radionuclide introduction into groundwater include melt glass dissolution and chemical retention effects associated with ion exchange and sorption processes on reactive minerals in the alluvium and cavity/chimney regions. Colloid facilitated transport was not considered in this study. Albeit approximate in many respects, the current simulations indicate that these environments can act as significant sources of radionuclides for hundreds (from the cavity and chimney) to thousands (from the melt glass) of years, or more.

2. The rates of radionuclide release from melt glass were particularly sensitive to the specific surface area of the glass. Higher surface areas can (i) dramatically increase the aqueous concentrations of radionuclides in the melt glass and at locations downstream of the glass zone, (ii) lead to precipitation of radionuclides in the glass zone, and (iii) increase the $\mathrm{pH}$ (which may, subsequently, affect other $\mathrm{pH}$-sensitive processes). Melt glass surface areas beyond a factor of 10 larger than our nominal value of $5 \times 10^{-5}$ $\mathrm{m}^{2} / \mathrm{g}\left(118 \mathrm{~m}^{2} / \mathrm{m}^{3}\right)$ do not seem reasonable because the $\mathrm{pH}$ values produced are not typically associated with glasses in natural environments.

3. Although not examined in depth in this study, analytic results suggest that results (i) - (iii) in (2) will also be produced by higher glass dissolution rate constants (e.g., at higher temperatures), larger volumes of melt glass or longer travel pathways through the glass (e.g., found in larger-yield tests), and smaller groundwater flow velocities through the glass (e.g., owing to lower permeabilities in the glass or, by extrapolation, immobile or slowly moving water in unsaturated environments).

4. Small amounts of reactive minerals identified in alluvium near CAMBRIC, such as goethite, clinoptilolite, muscovite/illite, and smectite, significantly impacted the mobility and aqueous concentrations of $\mathrm{Pu}, \mathrm{Sr}$, and Cs. Retention effects associated with Am and Eu likely exist, but were not considered in this report. When present, reactive minerals retain all but the smallest amounts of $\mathrm{Pu}, \mathrm{Sr}$, and $\mathrm{Cs}$, such that only 1 part in 50 to 1 part in 3,200 resides in the aqueous phase. From a different perspective, this also means that the mobilities of these radionuclides, relative to groundwater, can be reduced by factors ranging between 50 and 3,200.

5. The mobilities of radionuclides in alluvium can be more variable if they originated in the melt glass. Retardation behavior in or near the glass and at downstream locations will be more complicated as a result of chemical effects associated with glass dissolution. 
6. When viewed from a larger scale perspective, radionuclide mobility and flux through the entire system will be affected by the spatial uniformity or variability in reactive mineral abundance. If reactive minerals are exclusively distributed within specific parts of the domain, then retardation processes will be absent in the other parts of the domain, allowing for increased radionuclide mobilities in these locations. The effective or bulk retardation in the system as a whole will therefore be reduced from the "local" values in effect at specific locations where reactive minerals are present. The magnitude of the effective retardation will be affected, in part, by the way in which the reactive minerals are distributed spatially. The overall distribution and degree of spatial variability of reactive minerals in the CAMBRIC alluvium could not be determined and remains an important question.

7. Six mineralogic models used in our 3D simulations (Models 10, 10a, 10d, 11,12 , and 13a) produced a wide range of effective radionuclide mobilities and flux rates out of the near-field environment. With the exception of Model 10d (magnified glass dissolution rate), Models 10 and 11 might be considered to produce end-member behavior in the sense they they produce bounding upper and lower limits of the integrated radionuclide flux or mobility at 600 yrs. Model 10 has a uniform distribution of reactive minerals at the nominal abundances, and produces strong retardation effects. Model 11 has no reactive minerals and allows for all radionuclides to move with groundwater. Each of these models was based upon the nominal glass dissolution rate.

Model 12 was similar to Model 10, except that reactive minerals were only placed in a very small fraction of the domain whose hydraulic conductivity is in the lowest $20 \%$ of the range of the $\ln K$ distribution. Therefore, radionuclide mobilities in Model 12 were only slightly less than those in Model 11.

Model 10a is similar to Model 10, in that it is also based upon a uniform distribution of reactive minerals. However, the goethite in this model was assumed to have a reduced specific surface area, which led to increased flux rates and mobilities of the radionuclides that interact with goethite.

Model 13a is the same as Model 10a, except that the reactive minerals were preferentially distributed into zones whose hydraulic conductivity is in the lowest the $80 \%$ of the $\ln K$ (log-hydraulic conductivity) distribution (e.g., the $20 \%$ of the volume with the highest conductivities has no reactive minerals). Mobilities and fluxes of the surface-reactive radionuclides increased markedly.

Model 10d was similar to Model 10a, except that the glass surface area was increased by a factor of 100 . This allowed for a faster rate of radionuclide introduction into groundwater, and led to increased fluxes of radionuclides 
Chapter 15: Summary, Conclusions, and Recommendations-

preferentially separated into the melt glass. This was the case for $\mathrm{Pu}$, although concentrations and fluxes were eventually limited because $\mathrm{Pu}$ precipitated in the glass zone. The $\mathrm{Pu}$ flux in Models 10d and 13a at 600 yrs were very close, albeit for different physical reasons. The Am flux increased markedly as a result of the higher glass dissolution rates. Because it was not considered surface-reactive, its mobility parallels that of the groundwater, and its flux is even higher than the Am flux in Model 11.

It is difficult to choose the mineralogic configuration most likely to apply at CAMBric. Of the models considered, it reasonable to conclude that Models 11 and 10a represent upper and lower bounds for the mobilities of the radionuclides considered. Models 10 and 10d were excluded because their goethite and melt glass surface areas, respectively, are believed to be too large.

8. The high resolution 3D modeling framework provided a critically important basis from which to analyze the coupled flow, migration, and reaction behavior in the $3 \mathrm{D}$ cavity, chimney, and melt glass environments, explore the potential impacts of physical and chemical heterogeneity in the surrounding alluvium, and develop defensible ways to simplify the results for larger scale models.

For example, radionuclide plumes emanating from the melt glass region were shown to move along small, narrow channels in the alluvium as opposed to the more dispersed patterns typically predicted by coarselyresolved models. This insight shows that the plume would be almost impossible to pinpoint or strike with a borehole from the surface. Although a nearby pumping well might capture portions of the plume, it could also capture a large volume of uncontaminated water such that radionuclide concentrations in the well effluent become diluted and misrepresentive of the local in situ concentrations. In addition, the existence of locally high velocity flow pathways could promote the fast migration of some radionuclides (like $\mathrm{Eu}, \mathrm{Cs}$, or $\mathrm{Sr}$ ) that might otherwise be ignored because of their short half lives.

9. The streamline modeling approach employed in this study proved to be an exceptionally useful and flexible technique for studying the hydrologic source term problem. First and foremost, it allowed a highly resolved 3D reactive transport problem to be decomposed into a large, yet tractable, number of $1 \mathrm{D}$ reactive transport problems, whose results could later be recombined into a 3D solution. In particular, this approach allowed:

- Attention to be focused only on the fraction of the 3D domain encompassing the radionuclides, as opposed to the entire volume. 
- A series of simpler computational problems to be solved for each streamline, as opposed to one large simulation for the entire domain. This allowed the solution to be assembled in a steady, piecemeal fashion using less computer time and allowing for problematic aspects of the solution to be solved more quickly. When convergence or other problems occurred, for example, single line simulations could be quickly reworked instead of a complete $3 \mathrm{D}$ problem being analyzed and restarted.

- Provisional simulations for testing specific geochemical specifications and mineral configurations, which typically outnumber the real number of final 3D simulations, could be done in a $1 \mathrm{D}$ framework using single line simulations. This allowed for faster benchmarking and analysis of specific sensitivity and design issues, as well as for diagnosis and interpretation of particular transport and reaction behavior before the more time-consuming 3D simulations were performed.

10. Although the 3D simulations can be complicated and detailed, two approaches for simplifying the results for use in larger scale models were proposed. These involve a procedure for defining the integrated retardation effect associated with radionuclide migration into the far-field, and an analytic procedure that may be used to simplify the glass dissolution process in cases where precipitation and other complicating factors are not considered. Future implementation of these approaches will require reconciliation of the conceptual models of aquifer structure and mineralogic distribution in the near- and far-field environments.

\subsection{Radionuclide migration away from other tests in French- man Flat}

One of our objectives was to generalize the approach and hydrologic source term calculated for CAMBRIC to other tests in Frenchman Flat. Investigation of radionuclide inventory data showed that this would not be possible in an unclassified mode. Thus, classified simulations are needed to provide an evaluation of the generalized Frenchman Flat source term for corrective action unit-level contaminant modeling.

Topics that must be evaluated include:

- We recognize that radionuclide inventory abundance will affect mobilities in a similar hydrogeologic environment. Increased radionuclide mobilities may result at larger concentrations. However, precipitation thresholds for certain reactions that were not met here may be met elsewhere.

- Differences in groundwater chemistry will affect speciation of radionuclides. We need to understand the variance in groundwater chemistry in Frenchman Flat. 
Chapter 15: Summary, Conclusions, and Recommendations

- The volume of melt glass and associated radionuclide inventories must be estimated from test-specific yield information which are generally classified.

- The hydrogeologic properties and reactive mineralogic abundances will affect the mobilities, regardless of radionuclide abundance. Radionuclide concentrations in groundwater passing out of melt glass zones will differ as a function of the overall groundwater flow rates in the test region.

\subsection{Recommendations for future work}

Recommendations for future work involve acquisition of additional experimental and field data, improvement of geochemical process models, expansion of simulations to provide for additional radionuclides and geochemical processes, and developing specific refinements in the hydrologic modeling approach.

Acquisition of experimental and field data is required to better describe chemical reactions involving radionuclides, to better define the initial geological and geochemical state of the CAMBric site, and to test, calibrate, refine, and validate our simulations. For example:

- Measure relevant data for surface complexation, ion exchange and coprecipitation reactions involving radionuclides. Batch and flow-through tests should be conducted with single minerals and with intact samples of bulk alluvium.

Limited data is available from the viewpoint of process-oriented geochemical models (as opposed to distribution coefficients).

- Determine the composition and surface area of CAMBric melt glass.

We do not have an actual composition of the CAMBRIC melt glass, nor a measure of its reactive surface area. The effective surface area of melt glass is the most critical, yet poorly defined, parameter necessary to model glass dissolution. Cracking and vesicles developed in melt glass can significantly affect its surface area. Precipitation of alteration products may decrease glass permeability. Detailed field examination of the CAMBRIC melt glass is required to address these issues.

- Determine the spatial distribution of radionuclides outside the glass puddle.

This is necessary to correctly partition radionuclides between the reactive minerals and groundwater at different points in the exchange volume.

- Validate our models with new field data.

Outside of the radionuclides extracted from RNM-1 and in the RNM-2S experiment, there are few measurements indicative of radionuclide con- 
centrations at varying distances from the working point. Acquisition of new data would permit us to validate our models and assumptions.

Our ability to evaluate the hydrologic source term at CAMBRIC will be enhanced when additional field data is complemented by improvements in our geochemical process models for radionuclide release and retardation. For example:

- Straight-forward modifications that would add efficiency to operations and evaluations include: specification of long-term glass dissolution rates under saturated conditions; tailoring of the affinity term $(1-Q / K)$ for the specific needs of the glass dissolution model; implementation of a surface complexation model with an electrostatic term; and implementation of the Vanselow and Gapon ion exchange models to fully account for both homovalent and heterovalent exchange.

For both the surface complexation and ion exchange models, it is important to better define the masses and distributions of the mineral sorbents and exchangers in the CAMBRIC host rock. The masses and distributions of minerals which are relatively minor components of the rock can greatly affect predicted radionuclide concentrations and migration.

- Modifications that would require more effort but still be valuable include: implementation of a solid solution model that would provide for co-precipitation of radionuclides; implementation of colloid transport of radionuclides; and implementation of radioactive decay.

At the present time, we can use GIMRT and its thermodynamic data base to model the formation of a chemically inert $\mathrm{Pu}$ colloid from $\mathrm{Pu}$ released from glass and/or the exchange volume. Future simulations should provide explicitly for the re-equilibration of the $\mathrm{Pu}$-colloid with its surroundings along the flow path, with attendant $\mathrm{Pu}$ loss or gain from solution.

The effect of continuous radioactive decay of radionuclides should be added to GimRT, rather than applied as a post-simulation adjustment. The production of relevant daughter products should also be accounted for, if significant. It would be useful as well to enable the geochemical code to keep track of the radiogenic and nonradiogenic isotopes of elements of interest, rather than applying a post-simulation adjustment to code output.

An evaluation of the total hydrologic source term at CAMBRIC will require expansion of the geochemical models to a greater variety of radionuclides. Application of the streamline approach to transport in a heterogeneous medium should also be evaluated further. For example:

- The potential for radionuclide retardation by carbonates should be considered. 
- Potential retardation mechanisms for $\mathrm{Eu}, \mathrm{Am}$, and other radionuclides must be considered in future simulations.

- The potential for colloid facilitated migration of $\mathrm{Pu}$ and other radionuclides should be considered. The importance of phosphate as a ligand for radionuclides in the fluid phase and for sequestering radionuclides as phosphate minerals must also be evaluated.

- The potential for nonuniform distributions of reactive minerals (at the small scale) to produce intermediate (e.g., smaller) degrees of retardation (e.g., greater mobility) at a larger scale (as might be required in basin or regional scale simulations) should be more carefully investigated and reconciled.

- The effects of cross-streamline diffusion should be evaluated. Although not included in the current simulations, inclusion of cross-streamline diffusion behavior may promote a small degree of additional physical mixing. This, in turn, could affect how radionuclides move into or out of low permeability or highly reactive zones, and ultimately affect the elution fluxes.

- Additional sensitivity simulations designed to examine the effects of larger or smaller permeabilities and porosities in the cavity, exchange volume, and crush-up zonses are warranted. 


\section{References}

[1] Aagaard, P., and H.C. Helgeson (1982), Thermodynamic and kinetic constraints on reaction rates among minerals and aqueous solutions I. Theoretical considerations. American Journal of Science, 282, 237-285.

[2] Abrajano, T. A., J. K. Bates, A. B. Woodland, J. P. Bradley, and W. L. Bourcier (1990), Secondary phase formation during nuclear waste-glass dissolution: Clays and Clay Minerals, 38, 537-548.

[3] Ashby, S. F. (1996): ParFlow home page: www.llnl.gov/CASC/ParFlow/

[4] Ashby, S. F., W. J. Bosl, R. D. Falgout, S. G. Smith, A. F. B. Tompson, and T. J. Williams (1994): A numerical simulation of groundwater flow and contaminant transport the CRAY T3D and C90 supercomputers, Proceedings, 34th Cray User Group Conference, October 10-14, 1994, Tours, France; also Livermore National Laboratory, Livermore CA, UCRL-JC118635 .

[5] Batycky, R. (1997), A three-dimensional two-phase field scale streamline simulator, Ph.D Thesis, Department of Petroleum Engineering, Stanford University, Stanford, CA.

[6] Bethke, C. M. (1994), The Geochemist's Workbench (Version 2.0): A user's guide to Rxn, ACt2, TACt, React, and GtPlot: Hydrogeology Program, University of Illinois.

[7] Bethke, C. M. (1996), Geochemical Reaction Modeling: Oxford Univ. Press, New York, 397 p.

[8] Bibler, N. E., and J. C. Jantzen (1987), Materials interactions relating to long-term geologic disposal of nuclear waste glass. Materials Research Society Symposium Proceedings, 84, 47-66.

[9] Borg, I. Y. (1975), Radioactivity trapped in melt produced by a nuclear explosion, Nuclear Technology, 26, p. 88-100.

[10] Borg, I. Y., Stone, R., Levy, H. B., and Ramspott, L. D. (1976), Information pertinent to the migration of radionuclides in ground water at the Nevada Test Site. Part 1: Review and analysis of existing information. Lawrence Livermore National Laboratory, Livermore CA, UCRL-52078.

[11] Bourcier, W. L. (1994), Waste glass corrosion modeling: comparison with experimental results. Materials Research Society Symposium Proceedings, vol 333, p. 69-82.

[12] Buffle, J. (1988) Complexation Reactions in Aquatic Aystems: An Analytical Approach, Ellis Horwood, Chichester. 
[13] Bryant, E. A. (1992), The CAmbRIC migration experiment. A summary report, Los Alamos National Laboratory, Los Alamos, NM, LA-12335-MS.

[14] Buddemeier, R. W., ed. (1988), Hydrology and radionuclide migration program 1985-1986 progress report, Lawrence Livermore National Laboratory, Livermore CA, UCRL-53779.

[15] Buddemeier, R. W., and D. Isherwood (1985), Radionuclide migration program 1984 progress report, Lawrence Livermore National Laboratory, Livermore CA, UCRL-53628.

[16] Burbey, T. J. and S. W. Wheatcraft (1986), Tritium and chlorine-36 migration from a nuclear explosion cavity, Desert Research Institute, University of Nevada System, Reno, NV, Water Resources Center Publication 45050, DOE/NV/10384-09.

[17] Butkovich, T. R. (1976), Cavities produced by Underground Nuclear Explosions: Lawrence Livermore National Laboratory, Livermore, CA, UCRL52097.

[18] Butkovich, T. R. and A. E. Lewis (1973), Aids for Estimating Effects of Underground Nuclear Explosions: Lawrence Livermore National Laboratory, Livermore, CA, UCRL-50929 Rev. 1.

[19] Coles, D. G., H. C. Weed, D. D. Jackson, D.D., and J. S. Schweiger (1978), Single-pass leaching of nuclear melt glass by groundwater. Lawrence Livermore National Laboratory, Livermore, CA, UCRL-81617.

[20] Dagan, G. (1989), Flow and Transport in Porous Formations, Springer Verlag, Berlin.

[21] Daniels, W. R., ed. (1982), Laboratory and field studies related to the radionuclide migration project, October 1, 1981-September 30, 1982, Los Alamos National Laboratory, Los Alamos, NM, LA-9691-PR.

[22] Daniels, W. R. and J. L. Thompson, eds. (1984), Laboratory and field studies related to the radionuclide migration project, October 1, 1982September 30, 1983, Los Alamos National Laboratory, Los Alamos, NM, LA-10121-PR.

[23] DOE (1997a), Shaft and tunnel nuclear detonation at the Nevada Test Site: Development of a primary database for the estimation of potential interactions with the regional groundwater system, U. S. Department of Energy, Nevada Operations Office, Environmental Restoration Division, Las Vegas, NV: DOE/NV-464. 
[24] DOE (1997b), Regional groundwater flow and tritium transport modeling and risk assessment of the underground test area, Nevada Test Site, Nevada, U. S. Department of Energy, Nevada Operations Office, Environmental Restoration Division, Las Vegas, NV: DOE/NV-477.

[25] DOE (1999), "Drawing Back the Curtain of Secrecy", Restricted data declassification decisions 1946 to the present (RDD-5), January 1, 1999, U. S. Department of Energy, Office of Declassification, Washington DC.

[26] Drever, J. I. (1982), The Geochemistry of natural waters, Prentice-Hall, Englewood Cliffs, N.J.

[27] Duval, J. E. and M. H. Kurbatov (1952), The adsorption of cobalt and barium ions by hydrous ferric oxide at equilibrium: Journal of Physical Chemistry, 56, 982-984.

[28] Dzombak, D. A. and F. M. M. Morel (1990), Surface Complexation Modeling: Hydrous Ferric Oxide: J. Wiley and Sons, New York, 393 p.

[29] Essington, E. H., and J. V. A. Sharp (1968), Some aspects of groundwater solution chemistry, Underground nuclear explosion zones, Nevada Test Site, in Nevada Test Site, Eckel, E. B., ed., Geological Society of America Memoir 110, Geological Society of America, 263-273

[30] Failor, R. A., D. G. Coles, and J. H. Rego (1983), A leaching study of nuclear melt glass: Part 1. Lawrence Livermore National Laboratory, Livermore, CA, UCID-19729.

[31] FFACO (1996), Federal Facilities Agreement and Consent Order. Agreed to by the U.S. Department of Energy, the U.S. Department of Defense, and the state of Nevada, Las Vegas, NV.

[32] Gelhar, L. W. (1993), Stochastic Subsurface Hydrology, Prentice Hall.

[33] Germain, L. S. and J. S. Kahn (1968), Phenomenology and Containment of Underground Nuclear Explosions: Lawrence Livermore National Laboratory, Livermore, CA, UCRL-50482.

[34] Grauch, V. J. S. and M. R. Hudson (1995), Preliminary analysis of major structures and lithologic boundaries for the Frenchman Flat model area, U. S. Geological Survey, Denver, CO.

[35] Guell, M. A. (1997), Subsurface transport of radionuclides at the Nevada Test Site, PhD thesis, Department of Civil and Environmental Engineering, University of California, Berkeley, CA.

[36] Helgeson, H. C. (1969), Thermodynamics of hydrothermal systems at elevated temperatures and pressures: American Journal of Science, 267, 729804. 
[37] Hoffman, D. C., R. Stone, W. W. Dudley, Jr. (1977), Radioactivity in the underground environment of the CAMBRIC nuclear explosion at the Nevada Test Site, Los Alamos National Laboratory, Los Alamos, NM, Informal Report LA-6877-MS.

[38] Hoffman, D. C. (1979), A field study of radionuclide migration, in Radioactive Waste in Geologic Storage, S. Fried, ed., American Chemical Society Symposium Series, 100, 149-166, American Chemical Society, Washington, DC.

[39] IAEA (1998), The radiological situation at the atolls of Mururoa and Fangataufa. Inventory of radionuclides underground at the atolls. Interim version, Vol. 3, International Atomic Energy Agency, Vienna, in preparation.

[40] Jercinovic, M. J., and R. C.Ewing (1987), Basaltic glasses from Iceland and the deep sea: natural analogues to borosilicate nuclear waste-form glass. JSS Project, 88-01.

[41] Johnson, J. W., and S. R. Lundeen (1997), Gembochs thermodynamic datafiles for use with the EQ3/6 modeling package: Lawrence Livermore National Laboratory internal report, also available via anonymous ftp to s122.es.llnl.gov:/users/johnson.

[42] Johnson, J. W., K. G. Knauss, W. E. Glassley, L. D. DeLoach, and A. F. B. Tompson (1998), Reactive transport modeling of plug-flow reactor experiments: Quartz and tuff dissolution at $240{ }^{\circ} \mathrm{C}$, Journal of Hydrology, in press.

[43] Kersting, A. B. (1996), The state of the hydrologic source term, Lawrence Livermore National Laboratory, Livermore, CA, UCRL-ID-126557.

[44] Kersting, A. B., D. W. Efurd, D. L. Finnegan, D. J. Rokop, D. K. Smith, and J. L. Thompson (1998), Migration of plutonium in groundwater at the Nevada Test Site, Nature, in press.

[45] King, M. J. and A. Datta-Gupta (1998), Streamline simulation: A current perspective, In Situ 22, 91-140.

[46] Kinniburgh, D.G., J. K. Syers, and M. L. Jackson (1975), Specific adsorption of trace amounts of calcium and strontium by hydrous oxides of iron and aluminum: Soil Science Society of America Journal, 39, 464-470.

[47] Knauss, K. G., W. L. Bourcier, K. D. McKeegan, C. I. Merzbacher, S. N. Nguyen, F. J. Ryerson, D. K. Smith, H. C. Weed, and L. Newton (1990), Dissolution kinetics of a simple nuclear waste glass as a function of $\mathrm{pH}$, time, and temperature. Materials Research Society Symposium Proceedings, 176, 371-381. 
[48] Landström, O. and E.-L. Tullborg (1994), Lithology, mineralogy and geochemistry of Äspö bedrock and fracture fillings: in S. Banwart, ed., Proc. Äspö International Geochemistry Workshop, June 2-3, 1994, Äspö Hard Rock Laboratory, A26-A40.

[49] Los Alamos Technical Associates (LATA) (1982), Selection of a simulation model for analysis of radionuclide migration at the RNM experiment site Nevada Test Site, Nevada, Los Alamos Technical Associates, Inc., Los Alamos, NM, LATA-LSL-29-01.

[50] Marshall, Royal R. (1961), Devitrification of natural glass. Geololgic Society of America, Bulletin, 72, 1493-1520.

[51] Mazer, J. J. (1987), Kinetics of glass dissolution as a function of temperature, glass composition, and solution pHs. Ph.D. thesis, Northwestern University.

[52] Nagy, K. L (1995), Dissolution and precipitation kinetics of sheet silicates: in Chemical Weathering Rates of Silicate Minerals, A. F. White and S.L. Brantley, eds., Reviews in Mineralogy, 31, Mineralogical Society of America, Washington, DC.

[53] Nimz, G. J. and J. L. Thompson (1992), Underground radionuclide migration at the Nevada Test Site, U. S. Department of Energy, Nevada Field Office, report DOE/NV-246, UC-703.

[54] Office of Technology Assessment (1989), The Containment of underground explosions, Unites States Congress, Office of Technology Assessment, Report OTA-ISC-414.

[55] Ogard, A. E., J. L. Thompson, R. S. Rundberg, K. Wolfsberg, P. W. Kubic, D. Elmore, and H. W. Bentley (1988), Migration of chlorine-36 and tritium from an underground nuclear test, Radiochimica Acta, 44/45, 213-217.

[56] Pohll, G., J. Chapman, A. Hassan, L. Papelis, R. Andricevic, and C. Shirley (1998), Evaluation of groundwater flow and transport at the SHOAL underground Nuclear Test: An interim report, Desert Research Institute, University of Nevada System, Reno, NV, Water Resources Center Publication 45162, DOE/NV/11508-35.

[57] Pollock, D. W. (1988), Semianalytical computation of path lines for finitedifference models, Groundwater, 26(6), 743-750.

[58] Ragnarsdottir, K. V. (1989), Kinetics of dissolution of heulandite at 25C: in Miles, D. L., ed., Proc. of Water-Rock Interaction WRI-6, Aug. 3-8, 1989, Malvern, England, 567-568. 
[59] Ramspott, L. D., and R. D. McArthur (1977), Results of the exploratory drill hole UE5n, Frenchman Flat, Nevada Test Site, Lawrence Livermore National Laboratory, Livermore, CA, UCID-17392.

[60] Ryan, J. N. and M. Elimelech (1996), Colloid mobilization and transport in groundwater, Colloids and Surfaces A, 107, 1-56.

[61] Sanchez, A. L., J. W. Murray, and T. H. Sibley (1985), The adsorption of plutonium IV and V on goethite: Geochimica et Cosmochimica Acta, 49, $2297-2307$.

[62] Sauty, J.-P. (1980), An analysis of hydrodispersive transfer in aquifers, Water Resources Research, 16, 145-158.

[63] Savage, D., M. R. Cave, D. Haigh, A. E. Milodowski, and M. E. Young (1993): The reaction kinetics of laumontite under hydrothermal conditions, European Journal of Mineralogy, 5, 523-535.

[64] Schroeder, N. C., D. Morgan, D. J. Rokop, and J. Fabryka-Martin (1993), Migration of Technetium-99 in the alluvial aquifer at the Nevada Test Site, Nevada, Radiochmica Acta, 60, 203-209.

[65] Schwartz, L., A. Piwinski, F. Ryerson, H. Tewes, and W. Beiringer (1984), Glass produced by underground nuclear explosions. In P. L. D., J. A. O'Keefe, and V. D. Frechette (eds.), Natural Glasses, p. 559-598. North Holland, Amsterdam.

[66] Smith, D. K. (1993), A review of literature pertaining to the leaching and sorption of radionuclides associated with nuclear explosive melt glasses, Livermore National Laboratory, Livermore, CA, UCRL-ID-113370.

[67] Smith, D. K. (1995a), Characterization of nuclear explosive melt debris, Radiochemica Acta, 69, 157-167.

[68] Smith, D. K., R. J. Nagle, and J. M. Kenneally (1996), Transport of gaseous fission products adjacent to an underground nuclear test cavity, Radiochimica Acta, 73, 177-183.

[69] Smith, D. K. (1995b), 1994 Cambric Source Term, Letter to J. Hunt, U.C. Berkeley.

[70] Smith, D. K., Kersting, A. B., Kenneally, J. M., Rego, J. H., Thompson, J. L. (1997), Hydrologic Resources Management Program FY 1996 Progress Report, Lawrence Livermore National Laboratory, Livermore, CA, UCRLID-126886.

[71] Smith, D. K. (1998), Insight to the release of radionuclides from nuclear explosive melt glasses using natural analogs. Lawrence Livermore National Laboratory, Livermore CA, unpublished report. 
[72] Sposito, G. (1984). The surface chemistry of soils, Oxford University Press, New York.

[73] Steefel, C.I., and A. C. Lasaga (1994), A coupled model for transport of multiple chemical species and kinetic precipitation/dissolution reactions with application to reactive flow in single phase hydrothermal systems, American Journal of Science, 294, 529-592.

[74] Steefel, C. I., and S. B. Yabusaki (1996), OS3D/GImRT, Software for modeling multicomponent and multidimensional reactive transport, User manual and programmer's guide, Version 1.0, Pacific Northwest National Laboratory, Richland, WA, PNL-11166.

[75] Stone, R. (1975), Lithologic description and particle size distribution of sidewall samples of valley fill material from RNM\#1, K-division internal memorandum UOPKB 75-46, April 1, Lawrence Livermore National Laboratory, Livermore, CA

[76] Thiele, M. R., R. P. Batycky, M. J. Blunt, and F. M. Orr (1996), Simulating flow in heterogeneous systems using streamtubes and streamlines, SPR Reservoir Engineering, February, 5-12.

[77] Thompson, J. L. (1996) Radionuclide distribution in a nuclear test cavity: the sc Baseball event, Radiochimica Acta, 72, 157-162.

[78] Tompson, A. F. B., R. Ababou, and L. W. Gelhar (1989), Implementation of the three dimensional turning bands random field generator, Water Resources Research, 25, 2227-2243.

[79] Tompson, A. F. B., and L. W. Gelhar (1990), Numerical simulation of solute transport in three-dimensional, randomly heterogeneous porous media, Water Resources Research, 26(10), 2541-2562.

[80] Tompson, A. F. B. (1993), Numerical simulation of chemical migration in physically and chemically heterogeneous porous media, Water Resources Research, 29(11), 3709-3726

[81] Tompson, A. F. B., A. L. Schafer, and R. W. Smith (1996), Impacts of physical and chemical heterogeneity on co-contaminant transport in a sandy porous medium, Water Resources Research, 32(4), 801-818.

[82] Tompson, A. F. B., and K. J. Jackson (1996), Reactive transport in heterogeneous systems: An overview, Reviews in Mineralogy, 34, Mineralogical Society of America, Washington, DC.

[83] Triay, I. R., C. R. Cotter, M. H. Huddleston, D. E. Leonard, S. C. Weaver, S. J. Chipera, D. L. Bish, A. Meijer, and J. A. Canepa (1996a), Batch sorption results for neptunium transport through Yucca Mountain tuffs: Los Alamos National Laboratory, Los Alamos, NM, LA-12961-MS. 
[84] Triay, I. R., C. R. Cotter, S. M. Kraus, M. H. Huddleston, S. J. Chipera, and D. L. Bish (1996b), Radionuclide sorption in Yucca Mountain tuffs with J-13 well water: Neptunium, uranium, and plutonium: Los Alamos National Laboratory, Los Alamos, NM, LA-12956-MS.

[85] Turner, D. R. (1995), A uniform approach to surface complexation modeling of radionuclide sorption, Center for Nuclear Waste Regulatory Analyses, San Antonio, TX, CNWRA 95-001.

[86] Viani, B. E. and C. J. Bruton (1992), Modeling fluid-rock interaction at Yucca Mountain, Nevada: A Progress Report: Lawrence Livermore National Laboratory, Livermore, CA, UCRL-ID-109921.

[87] Viani, B. E. and C. J. Bruton (1996), Assessing the role of cation exchange in controlling groundwater chemistry during fluid mixing in fractured granite at Äspö, Sweden: Lawrence Livermore National Laboratory, Livermore, CA, UCRL-JC-121527.

[88] Wadman R. E. and D. Richards D. (1961), Posthot geologic studies of excavations below RAINIER Ground Zero, Lawrence Livermore National Laboratory, Livermore, CA, UCRL 6586.

[89] Walther, J. V., and H. C. Helgeson (1977), Calculation of the thermodynamic properties of aqueous silica and the solubility of quartz and its polymorphs at high pressures and temperatures: American Journal of Science, $277,1315-1351$.

[90] Weber, W., R. Ewing, C. Angell, G. Arnold, A. Cormack, J. Delaye, D. Griscom, L. Hobbs, A. Navrotsky, D. Price, A. Stoneham, and M. Weinberg (1997), Radiation effects in glasses used for immobilization of high-level waste and plutonium disposition, Journal of Materials Research, in press.

[91] Westall, J. C. (1982), FiteQL: Aprogram for the determination of chemical equilibrium constants from experimental data: Technical report, Chemistry Department, Oregon Stat University, Corvallis, OR.

[92] White, A. F. (1983), Surface chemistry and dissolution kinetics of glassy rocks at 25 C. Geochimica et Cosmochimica Acta, 47, 805-815.

[93] White, A. F., and M. L. Peterson (1990), Role of reactive-surface-area characterization in geochemical kinetic models, in Chemical modeling of aqueoues systems II, D. C. Melchior and R. L. Bassett, eds., ACS symposium series 416, American Chemical Society, Washington DC, 461-475.

[94] Winograd, I. J. and W. Thordarson (1975), Hydrogeologic and hydrochemical framework, South-Central Great Basin, Nevada-California, with special reference to the Nevada Test Site, U. S. Geological Survey Professional Paper 712-C. 
[95] Wolery, T. W. (1992a) EQ3/6, a software package for geochemical modeling of aqueous systems: Package overview and installation guide (Version 7.0), Lawrence Livermore National Laboratory, Livermore, CA, UCRLMA-110662 PT I.

[96] Wolery, T. J., (1992b) EQ3NR, a computer program for geochemical aqueous speciation-solubility calculations: Theoretical manual, user's guide and related documentation (version 7.0): Lawrence Livermore National Laboratory, Livermore, CA, UCRL-MA-110662 Pt III

[97] Wolery, T. J. and S. A. Daveler (1992), EQ6, a computer program for reaction path modeling of aqueous geochemical systems: Theoretical manual, user's guide and related documentation (version 7.0): Lawrence Livermore National Laboratory, Livermore, CA, UCRL-MA-110662 Pt IV.

[98] Wolfsberg, K. (1978), Sorption-desorption studies of Nevada Test Site alluvium and leaching studies of nuclear test debris: Los Alamos National Laboratory, Los Alamos, NM, LA-7216-MS. 
References 


\section{Appendix 1: Selected Radionuclide Decay Chains}

The decay chains for radionuclides pertinent to this report are shown below ${ }^{17}$. The half life and mode of decay are indicated. The end products are stable.

In these expressions, 'My' denotes millions of years, 'y', years, 'h', hours, 'd', days, 's', seconds, 'ms', milliseconds, and $\mu \mathrm{s}$, microseconds. An asterisk denotes the principal decay branch when more than one is present.

\begin{tabular}{|c|c|c|c|}
\hline${ }^{3} \mathrm{H}$ & $\underset{\beta}{\stackrel{12.3 \mathrm{y}}{\longrightarrow}}$ & ${ }^{3} \mathrm{He}$ & \\
\hline${ }^{60} \mathrm{Co}$ & $\underset{\beta}{\stackrel{5.27}{\longrightarrow}}$ & ${ }^{60} \mathrm{Ni}$ & \\
\hline${ }^{90} \mathrm{Sr}$ & $\underset{\beta}{28.8 \mathrm{y}}$ & ${ }^{90} \mathrm{Y}$ & $\underset{\beta}{\stackrel{64 \mathrm{~h}}{\longrightarrow}}$ \\
\hline${ }^{99} \mathrm{Tc}$ & $\underset{\beta}{0.21 \mathrm{M}} \mathrm{y}$ & ${ }^{99} \mathrm{Ru}$ & \\
\hline${ }^{137} \mathrm{Cs}$ & $\underset{\beta}{\stackrel{30.1}{\mathrm{y}}}$ & ${ }^{137} \mathrm{Ba}$ & \\
\hline${ }^{155} \mathrm{Eu}$ & $\underset{\beta}{\stackrel{4.76 \mathrm{y}}{\longrightarrow}}$ & ${ }^{155} \mathrm{Gd}$ & \\
\hline
\end{tabular}

${ }^{17}$ Source: Table of the nuclides, www.dne.bnl.gov/CoN/ 


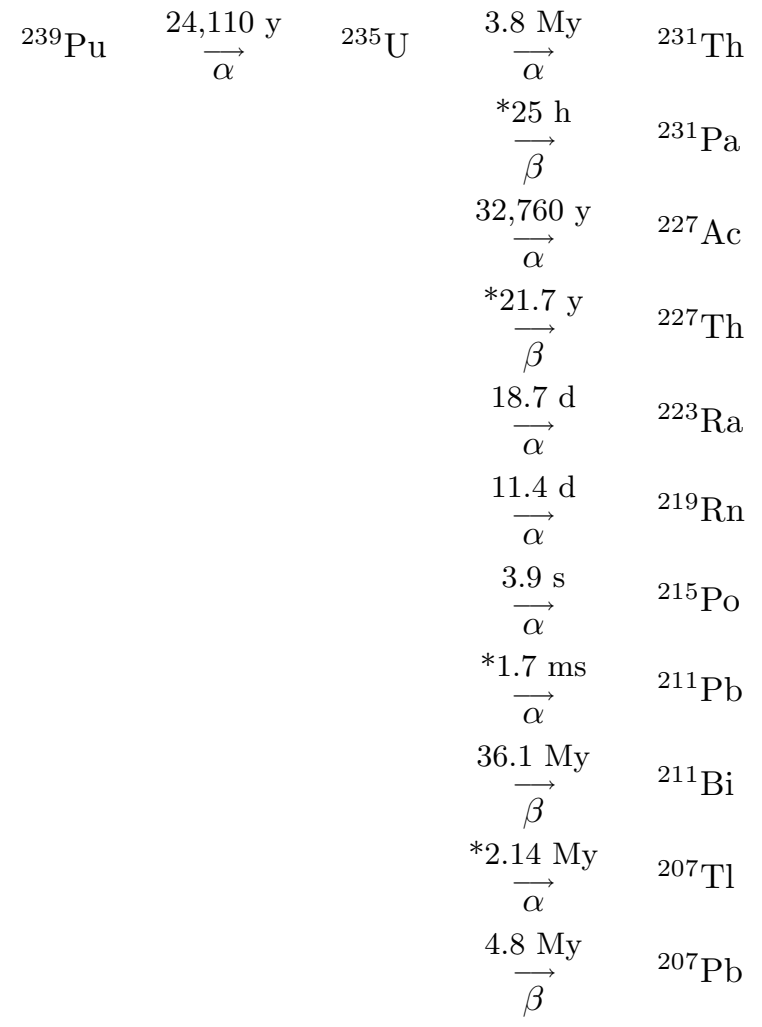




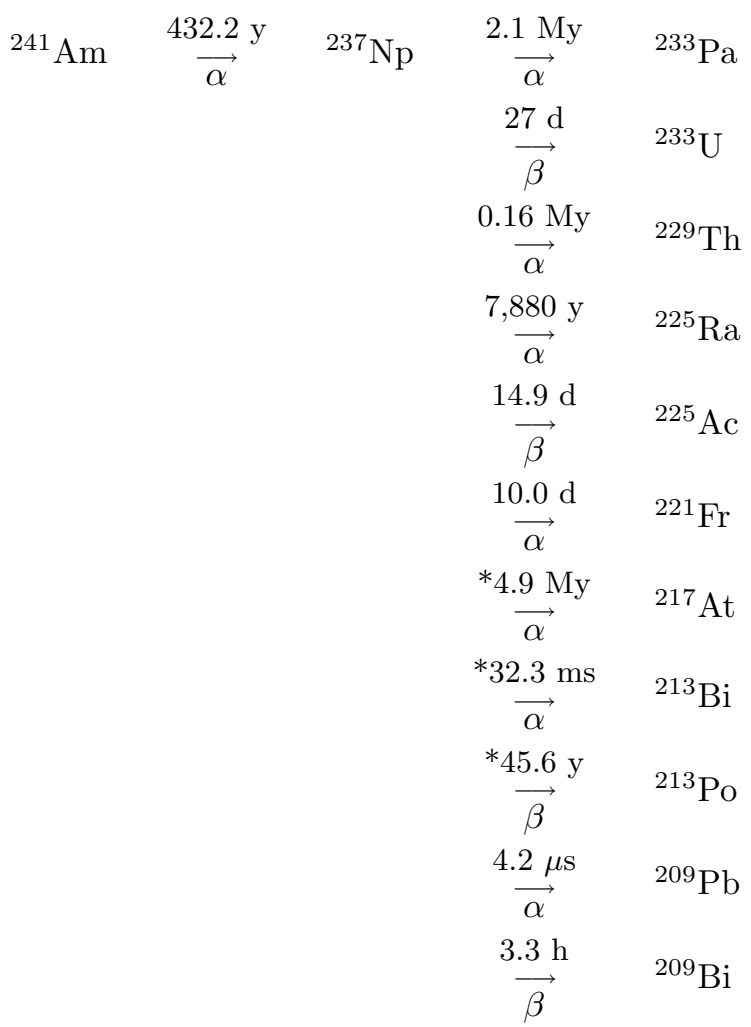

Consider a general radionuclide decay chain of the form

$$
R_{1} \longrightarrow R_{2} \longrightarrow R_{3} \longrightarrow \ldots R_{N}
$$

where $R_{i}$ denotes the $i$ th radionuclide in the chain. If the abundance (concentration or mass) of each radionuclide is denoted by $C_{i}(t)$, then their future concentrations are determined by

$$
\begin{aligned}
\frac{d C_{1}}{d t} & =-\lambda_{1} C_{1} \\
\frac{d C_{i}}{d t} & =\lambda_{i-1} C_{i-1}-\lambda_{i} C_{i}
\end{aligned}
$$

where $\lambda_{i}$ and $t_{1 / 2, i}=\ln 2 / \lambda_{i}$ are the decay rate and half life of the $i$ th radionuclide, respectively. If $C_{1}(0)=C_{1}^{0}$ and the daughter product concentrations are all initially zero such that $C_{i}(0)=0$ for $i>1$, then it is easily shown that

$$
C_{1}(t)=C_{1}^{0} e^{-\lambda_{1} t}
$$


and, for $i>1$,

$$
C_{i}(t)=\sum_{j=1}^{i-1} E_{j}^{i} e^{-\lambda_{j} t}+E_{i}^{i} e^{-\lambda_{i} t}
$$

where

$$
E_{1}^{1}=C_{1}^{0}, \quad E_{j}^{i}=\frac{E_{j}^{i-1} \lambda_{i}}{\lambda_{i+1}-\lambda_{i}}, \quad \text { and } \quad E_{i}^{i}=-\sum_{j=1}^{i-1} \frac{E_{j}^{i-1} \lambda_{i}}{\lambda_{i+1}-\lambda_{i}}=-\sum_{j=1}^{i-1} E_{j}^{i} .
$$

Hence, $C_{2}(t)$ is given by

$$
C_{2}(t)=\frac{C_{1}^{0} \lambda_{1}}{\lambda_{2}-\lambda_{1}} e^{-\lambda_{1} t}-\frac{C_{1}^{0} \lambda_{1}}{\lambda_{2}-\lambda_{1}} e^{-\lambda_{2} t}
$$

and so forth. 


\section{Appendix 2: 1D Reactive Transport Equations in GIMRT and Os3D}

GIMRT and Os3D are based upon an assumption that the chemical species in solution or sorbed or exchanged as surface complexes on the solid matrix are all in chemical equlibrium ${ }^{18}$. In this sense, mass action expressions can then be defined and used to relate the concentrations of these species.

In general, we consider a primary series of $N_{c}$ basis species whose concentrations are denoted by $C_{j}$ (molal, or moles $j$ per $\mathrm{kg}-\mathrm{H}_{2} \mathrm{O}$ ), and a secondary set of $N_{x}$ species whose concentrations are denoted by $X_{i}$ (molal), where $N_{c}+N_{x}=N$ is the total number of species considered. The number of secondary species $\left(N_{x}\right)$ is equal to the number of mass action expressions that can be written from the known equilibria. These equilibria allow for the secondary concentrations $\left(X_{i}\right)$ to be determined from the primary concentrations $\left(C_{j}\right)$. The particular species chosen to be "primary" or "secondary" is arbitrary in some sense, but is often guided by accuracy and numerical convergence issues that arise in the computer codes, and can be modified during the course of a simulation (Steefel and Yabusaki, 1996).

The transport equations in GIMRT and Os3D are written in terms of a series of $N_{c}$ total concentrations given by

$$
U_{j}=C_{j}+\sum_{i=1}^{N_{x}} \nu_{i j} X_{i}
$$

and

$$
U_{j}^{i m}=C_{j}^{i m}+\sum_{i=1}^{N_{x}} \nu_{i j} X_{i}^{i m} .
$$

In these expressions, $U_{j}^{i m}, C_{j}^{i m}$ and $X_{i}^{i m}$ represent the molal (moles $j$ per kg$\mathrm{H}_{2} \mathrm{O}$ ) concentrations of the immobile surface complexes, where $j=1, \ldots, N_{c}$, and the $\nu_{i j}$ are the stoichiometric coefficients that appear in the equilibrium relationships.

In the absence of any pumping well sources or sinks, the one-dimensional transport equation for the $j$-th total concentration may be written as

$$
\begin{aligned}
\frac{\partial}{\partial t}\left(\phi \rho M_{H_{2} O}\left(U_{j}+U_{j}^{i m}\right)\right)+ & \frac{\partial}{\partial x}\left(\phi V \rho M_{H_{2} O} U_{j}\right)- \\
\frac{\partial}{\partial x}\left(\phi D_{L} \frac{\partial}{\partial x}\left(\rho M_{H_{2} O} U_{j}\right)\right) & =R_{j}^{\text {min }}
\end{aligned}
$$

where $\phi$ is the medium porosity, $\rho$ is the fluid density (e.g., kg-solution/l-solution), $M_{\mathrm{H}_{2} \mathrm{O}}$ is the mass fraction of water in the solution (e.g., $\mathrm{kg}$-water $/ \mathrm{kg}$-solution),

\footnotetext{
${ }^{18}$ This is not meant to imply that species involved in mineral precipitation or dissolution reactions are controlled by equilibrium; these will be considered separately.
} 
and $V$ is the mean pore velocity (e.g., $\mathrm{m} / \mathrm{yr})$. The longitudinal hydrodynamic dispersion coefficient is typically defined by

$$
D_{L}(x)=\alpha_{L} V(x)+\mathcal{D}_{e},
$$

where $\alpha_{L}$ is the longitudinal medium dispersivity (e.g., m) and $\mathcal{D}_{e}$ is an effective molecular diffusivity $\left(e . g ., \mathrm{m}^{2} / \mathrm{s}\right)$ for the porous medium. The rate of species production (e.g., moles-j $/ \mathrm{m}^{3} / \mathrm{s}$ ) via dissolution or precipitation of mineral phase $m$ is defined by

$$
R_{j}^{\text {min }}=-\sum_{m=1}^{N_{m}} \nu_{j m} r_{m}
$$

where $\nu_{j m}$ is the number of moles of $j$ per mole of mineral $m, r_{m}$ is the rate of precipitation or dissolution of mineral $m$ per bulk volume of the medium (e.g., moles-mineral $/ \mathrm{m}^{3} / \mathrm{s}$ ), and $N_{m}$ is the number of separate mineral phases considered.

During the solution process, the $U_{j}$ and $U_{j}^{i m}$ are generally decomposed according to equations (19) and (20) such that the mass action phenomena in the aqueous speciation or surface complexation reactions can be explicitly incorporated. In this sense, the abundance of surface complexation sites on the minerals can be specified and used to control the overall partitioning of species between the aqueous and solid phases.

In GIMRT and Os3D, precipitation and dissolution rates are generally written in terms of an expression of the form

$$
r_{m}=A_{s, m} k_{m}(T) \cdot f_{m}\left(a_{i}\right) \cdot g_{m}\left(\Delta G_{r}\right),
$$

where $A_{s, m}$ is the specific surface area of mineral $m$ in the medium $\left(e . g ., \mathrm{m}^{2} / \mathrm{m}^{3}\right.$ medium), $k_{m}$ is a temperature-dependent rate coefficient associated with mineral $m$ (e.g., moles $/ \mathrm{m}^{2}-$ mineral $\left./ \mathrm{s}\right)$, and $f_{m}$ and $g_{m}$ are, respectively, dimensionless factors that are dependent on the activities $\left(a_{i}\right)$ of up to $N$ catalytic or inhibitive aqueous species and the free energy $\left(\Delta G_{r}\right)$ of the dissolution or precipitation reaction. Because neither GIMRT nor Os3D explicitly accounts for the transfer of heat or energy, thermal effects cannot be generally incorporated, except for an allowance to specify a fixed and steady temperature gradient throughout the domain.

Aagaard and Helgeson (1982) have formalized this rate law as

$$
r_{m}=S_{m} \cdot A_{s, m} k_{m}\left(\prod_{i}^{N} a_{i}^{p_{i}}\right)\left|\left(\frac{Q_{m}}{K_{m}}\right)^{\mathcal{M}}-1\right|^{n},
$$

where the $p_{i}$ are determined empirically, $Q_{m}$ and $K_{m}$ are the activity product and equilibrium constant for the dissolution or precipitation reaction, respectively, $S_{m}$ is equal to the $\operatorname{sign}$ of $\log \left(Q_{m} / K_{m}\right)$, and $\mathcal{M}$ and $n$ are additional (positive) experimental parameters. Application of this rate law to melt glass 
dissolution is discussed in greater detail in Chapter 6, and to other precipitation reactions in Chapter 8. In general, both $\mathcal{M}$ and $n$ have been set to 1.0 in the problems considered in this study. The effect of inhibiting or catalyzing species, as manifested in the product term, has only been considered and included in the puddle glass dissolution rate, specifically in terms of a direct dependence on $\mathrm{pH}\left(\right.$ or $\left.a_{H^{+}}\right)$.

For dilute solutions, $\rho \approx 1 \mathrm{~kg} / 1, M_{H_{2} O} \approx 1$, and the value of $U_{j}$ will be equal in magnitude to the molar concentration, $u_{j}$ (moles- $j$ per liter solution), defined by $u_{j}=\rho M_{H_{2} O} U_{j}$. Furthermore, if the fluid density is considered to be constant and the porosity is not considered to change significantly over time, then (21) may be simplified to

$$
\phi \frac{\partial}{\partial t}\left(u_{j}+u_{j}^{i m}\right)+\phi V \frac{\partial u_{j}}{\partial x}-\frac{\partial}{\partial x}\left(\phi D_{L} \frac{\partial u_{j}}{\partial x}\right)=-\sum_{m=1}^{N_{m}} \nu_{j m} r_{m}
$$

where the balance of fluid mass,

$$
\frac{\partial(\phi V)}{\partial x}=0
$$

has been employed. 


\section{Appendix 3. Implementing Surface Complexa- tion and Ion Exchange in GIMRT}

\section{Surface complexation}

\section{Model and binding constants}

GIMRT includes provision for surface complexation using a one-site model. However, the existing model does not have an electrostatic or coulombic term that is commonly used to describe the effect of the electrostatic field on the sorption of ions (Dzombak and Morel, 1990). Such a term could be coded into GimRT, but given the time limitations of this project, the decision was made to describe surface complexation using the existing non-electrostatic model. This approach required taking available experimental data for adsorption of radionuclides of interest onto HFOs and determining the surface complexation reactions and binding constants that best fit the data using a non-electrostatic model. However, an additional complication arose in that we did not have a non-electrostatic surface complexation model in any of the geochemical modeling codes to be used for deriving the binding constants.

The coulombic correction factor varies as a function of ionic strength and pH. Preliminary 1D simulations of fluid-glass-alluvium interactions at CAMBRIC suggested that the ionic strength does not change significantly with reaction, nor does the $\mathrm{pH}$ deviate significantly from the initial groundwater $\mathrm{pH}$ of about 8. The coulombic correction factor is near zero at a $\mathrm{pH}$ of 8 when the cation sorption density is low (Dzombak and Morel, 1990). Cation densities are expected to be low in our simulations because of the relatively small inventory of radionuclides at CAMBRIC, and the slow dissolution rate of the glass. It was therefore possible to use the React geochemical modeling code to estimate binding constants even though the surface complexation model implemented in it includes an electrostatic term. Consequently, GIMRT simulations using these binding constants will be reliable at $\mathrm{pH}$ values of about 8 , but progressively more inaccurate as the $\mathrm{pH}$ deviates from 8 .

Experimental sorption data for Sr are available from Kinniburgh et al. (1975), $\mathrm{Pu}$ from Sanchez et al. (1985), and Co from Duval and Kurbatov (1952) as summarized in Dzombak and Morel (1990). All experiments were conducted on hydrous ferric oxides. Turner (1995) took the Sanchez et al. (1985) sorption data for $\mathrm{Pu}$ on goethite, and fit binding constants to the data for the diffuse layer model (with a coulombic term) using the iterative nonlinear least squares optimization program FITEQL. To simplify sorption modeling for performance assessment, Turner restricted his sorption model to one surface complexation reaction written in terms of one radionuclide-bearing surface species and one radionuclide-bearing aqueous species that best fit the data.

Rather than using FITEQL (Westall, 1982) to identify complexation reactions and determine binding constants for $\mathrm{Sr}, \mathrm{Pu}$ and $\mathrm{Co}$, an expedient approach was 
taken by running REACT repeatedly with different possible values and combinations of surface binding reactions and constants to find the best fit to the experimental data. Conditions of the experiment, including sorbent surface area, site density, mass of water, and moles of metal, were reproduced in the simulations to obtain the binding constants. Turner's reaction stoichiometries and complexation constants were used as a starting point. The surface protonation/deprotonation constants were taken from Turner's one-site treatment. In the absence of surface area or site density from Kinniburgh et al. (1975) and Duval and Kurbatov (1952), a specific surface area of $600 \mathrm{~m}^{2} / \mathrm{g}$ and site density of 2.31 sites $/ \mathrm{nm}^{2}$ (0.2 mol/mol-Fe) were assumed (Dzombak and Morel, 1990).

Surface complexation reactions and binding constants that were obtained in the manner described above for use in GIMRT are listed in Table 26 along with the consistent set of protonation/deprotonation constants from Turner (1995). The "〉" symbol represents a surface species. Figures 72-74 compare

Table 26: Surface complexation reactions and intrinsic equilibrium constants $(K)$ used in reactive transport calculations.

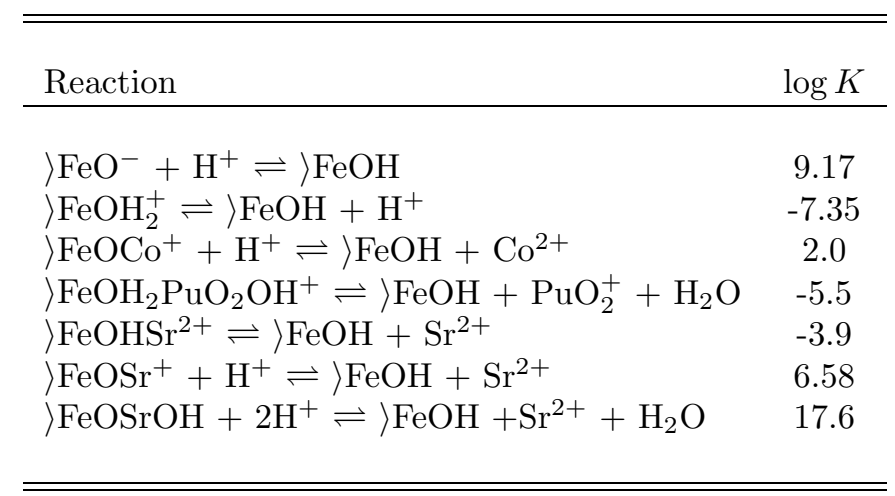

the calculated fit of the sorption curves with the experimentally determined sorption data for $\mathrm{Sr}, \mathrm{Pu}$ and $\mathrm{Co}$. The fit of the sorption data using the diffuse double layer two-site model obtained by Dzombak and Morel (1990) for Sr and Co is shown for comparison.

A two-site electrostatic double layer model should be implemented in GIMRT and Os3D to better correspond to sorption models commonly in use today and to better describe radionuclide migration. Viani's (private communication, 1998) computer simulations of laboratory experiments involving plug flow through a mixture of hematite $\left(\mathrm{Fe}_{2} \mathrm{O}_{3}\right)$ and quartz showed that in a two-site model, the strong sites controlled uranium migration while the weak sites determined the maximum percent sorbed and the filling of all available sites. Viani used the Dzombak and Morel diffuse double layer model and carried out his simulations 


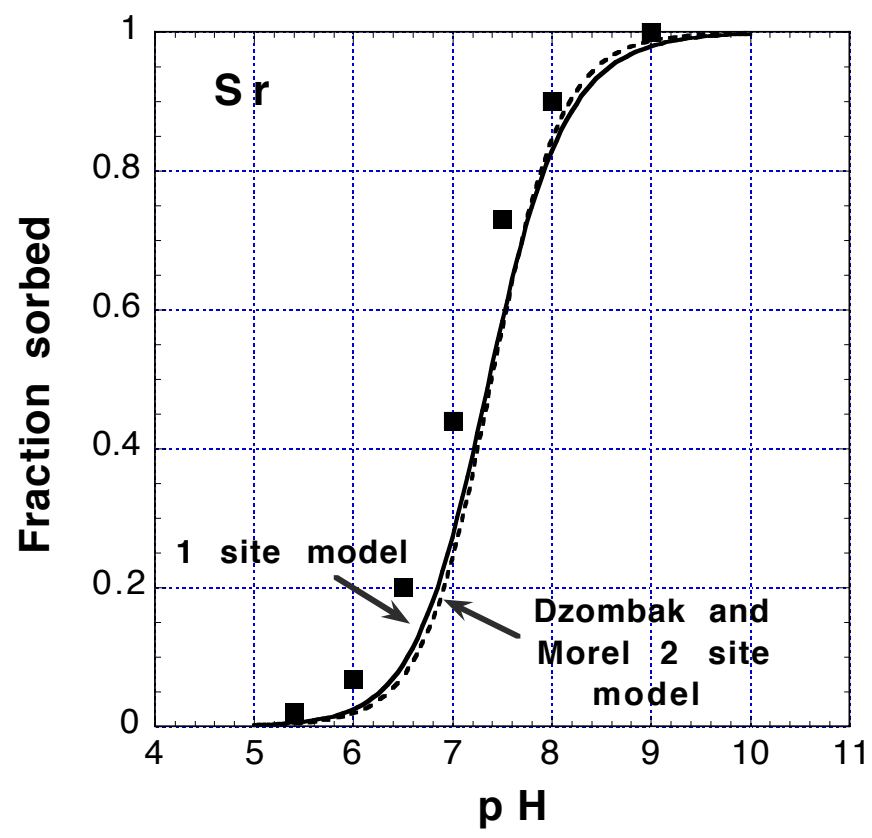

Figure 72: Comparison among the calculated sorption curve for $\mathrm{Sr}$ on goethite obtained using a 1-site non-electrostatic model (solid line), the sorption curve calculated with data from Dzombak and Morel (1990) using a 2-site diffuse double layer model (dashed line), and experimental data from Kinniburgh, Syers and Jackson (1975) (symbols). Experimental data represent Sr sorption onto hydrous ferric oxide in $1.0 \mathrm{M} \mathrm{NaNO}$ at $2 \times 10^{-6} \mathrm{M} \mathrm{Sr}$ and a sorbate-sorbent ratio of $2.6 \times 10^{-5} \mathrm{~mol} / \mathrm{mol}$. 


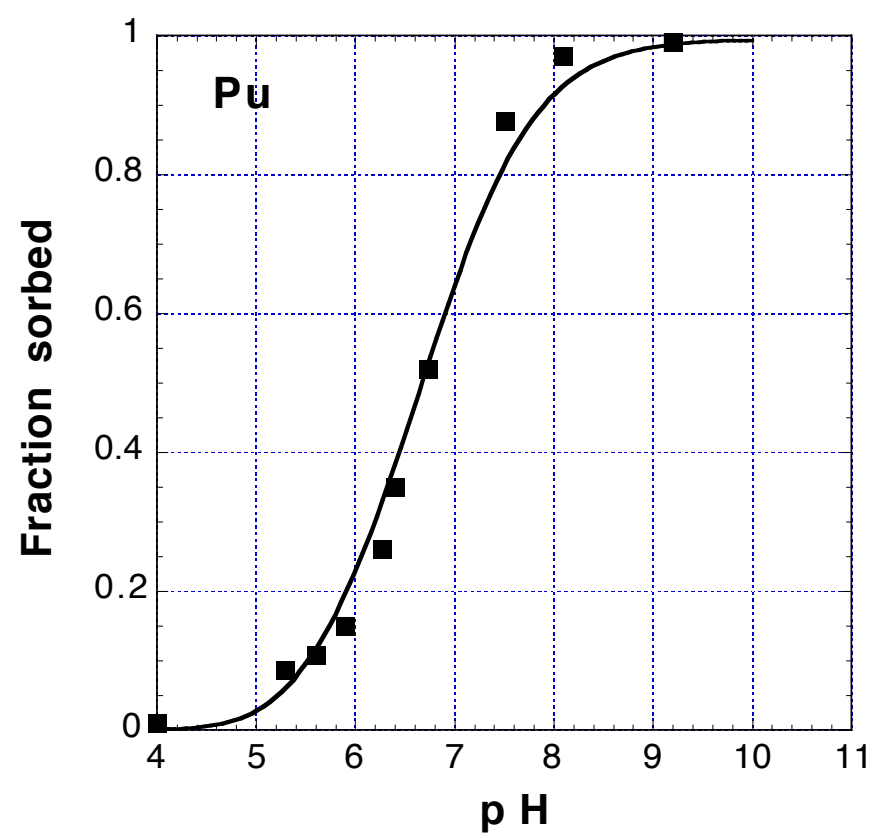

Figure 73: Comparison between the calculated sorption curve for $\mathrm{Pu}(\mathrm{V})$ on goethite obtained using a one-site non-electrostatic model (solid line) and experimental data from Sanchez, Murray and Sibley (1985) (symbols) for adsorption of $\mathrm{Pu}(\mathrm{V})$ on goethite in $0.1 \mathrm{M} \mathrm{NaNO}_{3}$ solution at $10^{-11} \mathrm{M} \mathrm{Pu}$ and $28.5 \mathrm{~m}^{2}$ $\alpha-\mathrm{FeOOH} / \mathrm{l}$-solution. 


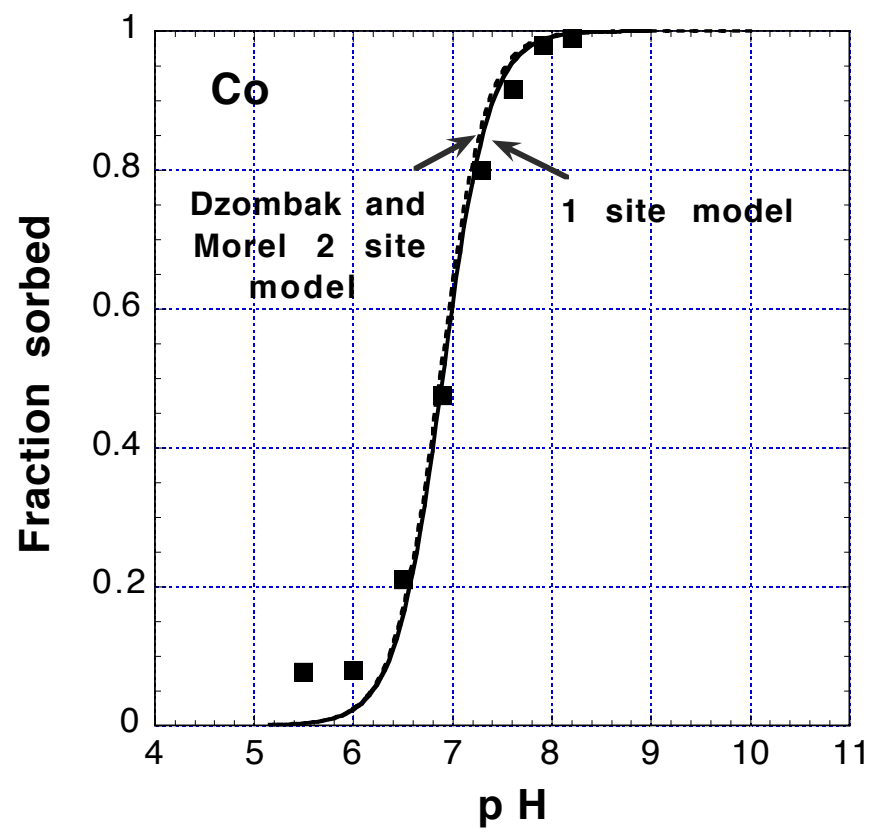

Figure 74: Comparison among the calculated sorption curve for Co on goethite obtained in this paper using a 1-site non-electrostatic model (solid line), the sorption curve calculated with data from Dzombak and Morel (1990) using a diffuse double layer 2-site model (dashed line), and experimental data from Duval and Kurbatov (1952) (symbols) as presented by Dzombak and Morel (1990). Experimental data represent adsorption of Co on hydrous ferric oxide in $0.0087 \mathrm{~N} \mathrm{NH}_{4} \mathrm{Cl}$ solution at $10^{-11} \mathrm{M}$ Co with a sorbate-sorbent ratio of $7.0 \times 10^{-4}$ $\mathrm{mol} / \mathrm{mol}$. 
with reactive transport code X1T (Bethke, 1996).

\section{Goethite as sorbent}

For the calculations, goethite $(\mathrm{FeOOH})$ was used as a proxy for a variety of hydrous ferric oxides and oxyhydroxides such as ferrihydrite and hematite that act as sorbents. Hydrous ferric oxides can vary significantly in terms of their surface area and corresponding total number of surface sites per mole of Fe. However, by relating our calculations to the number of surface sites available for reaction, a common frame of reference for all forms of hydrous ferric oxides is obtained.

In our simulations, the surface areas and site density of goethite were assumed to equal either $600 \mathrm{~m}^{2} / \mathrm{g}$ (Mineralogic Models 10 and 12) or $50 \mathrm{~m}^{2} / \mathrm{g}$ (Mineralogic Models 10a-10d and 13a), with 2.31 sites $/ \mathrm{nm}^{2}$, respectively.

\section{Additional model assumptions}

The possibility of carbonate adsorption on goethite has not been considered in our initial simulations. However, carbonate in solution affects indirectly radionuclide sorption in the simulations by complexing radionuclides in solution. Turner found that sorption of carbonate was not necessary to describe radionuclide sorption at low carbonate concentrations, and avoids the potential to overestimate radionuclide sorption at elevated carbonate concentrations. Turner stressed, however, that the adequacy of the assumption must be reexamined at high carbonate concentrations.

The simulations described in this report did not provide explicitly for competition of ions other than $\mathrm{Pu}$ and $\mathrm{Sr}$ for goethite surface sites. REACT calculations suggest that other ions from the CAMBRIC groundwater (e.g., $\mathrm{Ca}, \mathrm{SO}_{4}, \mathrm{PO}_{4}$ ) also sorb onto goethite, but that the surface sites are not "filled" by complexed ions. Given the low radionuclide inventory for CAMBRIC, it was assumed that the availability of goethite surface sites far exceeds the concentrations of $\mathrm{Pu}$ and Sr delivered to the sites by groundwater flow. Thus there should be no significant limitation on radionuclide sorption caused by competition by other species for a limited number of surface sites.

\section{Ion exchange}

\section{Exchange models}

Ion exchange models for clinoptilolite, smectite and muscovite used in this paper are based on the work of Viani. Viani developed models for Cs and Sr exchange on clinoptilolite, smectite and illite in order to describe radionuclide behavior at Yucca Mt., NV (Viani and Bruton, 1992) and to simulate fluid mixing at the Äspö Hard Rock Laboratory in Sweden (Viani and Bruton, 1996). The 
exchange properties of mica and muscovite are assumed equivalent to those of illite because of the structural and chemical similarities among the minerals.

Viani modified a version of the computer modeling code EQ3/6 (Wolery, 1992a,b; Wolery and Daveler, 1992) to include both the Vanselow and Gapon exchange models by treating the exchanger as an aqueous ligand. The activity coefficient expressions of the aqueous exchanger/cation complexes were then written to conform with the definitions of the exchanger component activities. Exchange was assumed to be ideal on each site. For the Vanselow model, the activity of the exchange component is equal to the mole fraction of the cation on the exchange site (Viani and Bruton, 1992).

Viani found that the one-site ideal Vanselow exchange model using exchange energies from the literature reproduced closely experimental sorption measurements of Cs and Sr onto Yucca Mt. tuffs. In fact, he found it possible to reproduce measured partition coefficients for $\mathrm{Sr}$ and Cs onto Yucca Mt. tuffs by taking explicit account of the weight percent of the smectite and clinoptilolite exchangers in the tuffs. This suggests that ion exchange models can be used to provide a scientific basis for the use of partition coefficients in hydrologic models, and be used to estimate partition coefficients for particular rock types when no experimental data is available but the mineralogy is known.

\section{Incorporating homovalent exchange models in GIMRT}

GimRT does not provide explicitly for ion exchange at the present time. However, it was possible to use the existing version of the code to model homovalent exchange using an approach similar to that of Viani by utilizing GIMRT's nonelectrostatic model for surface complexation. The model is restricted to homovalent exchange because of the stoichiometry of the exchange reaction between monovalent and divalent cations (heterovalent exchange) in the Vanselow model, and because existing coding in GIMRT was intended to model sorption rather than ion exchange.

According to the Vanselow convention, the heterovalent exchange of $\mathrm{Na}$ and $\mathrm{Ca}$ on an exchanger $(\mathrm{Z})$ can be expressed as

$$
\mathrm{NaZ}+0.5 \mathrm{Ca}^{2+} \rightleftharpoons 0.5 \mathrm{CaZ}_{2}+\mathrm{Na}^{+} .
$$

The corresponding equilibrium constant for (160) for ideal exchange is given by

$$
\mathrm{K}_{v}=\frac{\left(x_{\mathrm{Ca}}\right)^{0.5} a_{\mathrm{Na}^{+}}}{x_{\mathrm{Na}}\left(a_{\mathrm{Ca}^{2+}}\right)^{0.5}}
$$

where $x$ and $a$ denote mole fraction on the exchange site and activity, respectively.

In contrast, for homovalent exchange of $\mathrm{Sr}$ and $\mathrm{Ca}$ on an exchanger,

$$
\mathrm{SrZ}+\mathrm{Ca}^{2+} \rightleftharpoons \mathrm{CaZ}+\mathrm{Sr}^{2+}
$$


where the corresponding equilibrium constant is

$$
\mathrm{K}_{v}=\frac{x_{\mathrm{Ca}} a_{\mathrm{Sr}^{2+}}}{x_{\mathrm{Sr}} a_{\mathrm{Ca}^{2+}}} .
$$

The ratio of the mole fractions of $\mathrm{Ca}$ and $\mathrm{Sr}$ on the exchange site in (31) is equal to the ratio of their molalities when they are treated as fictive aqueous species. As neutral species, their activity coefficients are equal to one. However, such a relationship does not hold for heterovalent exchange because of the exponent of 0.5 which modifies the mole fraction of $\mathrm{Ca}$ on the exchange site in (161). Viani accounted for this in EQ3/6 by modifying the activity coefficients for these exchanger/cation complexes, which we have not done in GIMRT or Os3D. However, the problem disappears for homovalent exchange. In addition, EQ3/6 simulations using the ideal Vanselow model suggested that the partitioning of strontium onto smectite and clinoptilolite and Cs onto mica, muscovite or illite in CAMBRIC groundwater is dominated by homovalent exchange. Homovalent reactions were therefore focused on in the initial GIMRT simulations. The following cations and exchangers were considered:

- $\mathrm{Ca}, \mathrm{Sr}$ on clinoptilolite

- $\mathrm{Ca}, \mathrm{Mg}, \mathrm{Sr}$ on smectite

- Cs, Na, K on illite/muscovite

${ }^{90} \mathrm{Sr}$ in solution may therefore exchange onto clinoptilolite and smectite, and ${ }^{137}$ Cs may exchange onto illite/muscovite.

Fictive aqueous species were created that correspond to the ions on the exchanger, and new basis species to represent the exchange sites on clinoptilolite, smectite and illite/muscovite, and added them to the GIMRT thermodynamic data base. Reactions were then written between the fictive aqueous species to correspond to the exchange energies of the ions of the exchanger of interest.

Viani (Viani and Bruton, 1992, 1996) described clinoptilolite and smectite using one exchange site. However, illite has three sites that are defined by its crystal structure. $96.5 \%$ of the sites are planar sites whose exchange energies are similar to those of smectite. Sites I and II are associated with the frayed edges of the illite crystallites and comprise 0.5 and $3 \%$ of the total number of sites, respectively. Viani (Viani and Bruton, 1996) showed that Cs exchange on illite is dominated by site I, even though it only comprises $0.5 \%$ of the total sites of illite. The model was therefore restricted to site I because it will have the greatest impact on Cs migration in the alluvium. Exchange on the planar site of illite was not considered explicitly in the initial simulations because the planar sites behave similarly to those in smectite, which occurs in greater quantities than illite in the alluvium. The quantity of smectite in the simulations can therefore reflect the sum of the smectite and illite planar sites. Exchange of Cs was also restricted to illite because of the overwhelming preference of Cs for illite site I rather than smectite. 
The implementation of ion exchange in GIMRT was checked by incorporating the GimRT exchange model in REACT and its data base, and then ensuring that the same results were obtained by REACT and EQ3/6.

\section{Exchange energies and cation exchange capacities}

Given the specification of the chemical system outlined above, the exchange energies and cation exchange capacities (CEC) of the exchangers used in the simulations are summarized in Table 27. Divalent cations are favored equally

Table 27: Cation exchange energies for clinoptilolite, smectite and illite/ muscovite at $25^{\circ} \mathrm{C}$ used in the simulations (Viani and Bruton, 1992, 1996). Reactions are written in terms of one equivalent of exchanger.

\begin{tabular}{|c|c|c|c|}
\hline Exchanger & Exchange reaction & $\begin{array}{c}\text { Exchange } \\
\text { energy } \\
\text { (kcal/equiv) }\end{array}$ & $\begin{array}{c}\text { Cation } \\
\text { exchange capacity } \\
\text { (mequiv/g) }\end{array}$ \\
\hline Clinoptilolite & $\mathrm{Sr} \Longrightarrow \mathrm{Ca}$ & 0.10 & 2.12 \\
\hline Smectite & $\mathrm{Mg} \Longrightarrow \mathrm{Ca}$ & 0.00 & 0.85 \\
\hline & $\mathrm{Sr} \Longrightarrow \mathrm{Ca}$ & 0.00 & \\
\hline Illite, muscovite & $\mathrm{Cs} \Longrightarrow \mathrm{K}$ & 5.6 & $0.2^{a}$ \\
\hline
\end{tabular}

$\overline{\bar{a} \text { total } 3 \text { sites; } \text { site } \mathrm{I}=1 \times 10^{-3}}$

on smectite. The preference for Cs on illite site I is reflected by its exchange energy. The exchange energies for smectite are those for a Wyoming-type montmorillonite.

Viani calculated CECs of 0.85 and 2.12 mequiv/g for smectite and clinoptilolite, respectively, in samples of Yucca Mt. tuff (Viani and Bruton, 1992). The CEC of illite/muscovite was assumed to equal 0.2 mequiv/g (Viani and Bruton, 1996), but exchange was limited to type I sites with a site fraction of 0.005 .

\section{Adequacy of restriction to homovalent exchange}

The impact of neglecting heterovalent exchange, or alternately, the adequacy of considering only homovalent exchange, was tested by running EQ3 with the full implementation of the Vanselow model for clinoptilolite, smectite and illite/muscovite (Viani and Bruton, 1992, 1996). Table 28 shows the predicted 
compositions of the exchange site on each mineral in equilibrium with the CAMBRIC groundwater whose composition is given in Table 14 .

Table 28: Composition of exchange sites on clinoptilolite and smectite and site I of illite/muscovite in equilibrium with CAMBRIC groundwater calculated using the one-site Vanselow model (EQ3) and exchange energies given in Viani and Bruton (1992, 1996).

\begin{tabular}{lcccc}
\hline \hline Exchanger & $\begin{array}{c}\mathrm{Na} \\
(\mathrm{mol} \%)\end{array}$ & $\begin{array}{c}\mathrm{K} \\
(\mathrm{mol} \%)\end{array}$ & $\begin{array}{c}\mathrm{Ca} \\
(\mathrm{mol} \%)\end{array}$ & $\begin{array}{c}\mathrm{Mg} \\
(\mathrm{mol} \%)\end{array}$ \\
\hline Clinoptilolite & 14 & 13 & 72 & - \\
Smectite & 6 & 4 & 63 & 26 \\
Illite (site I) & 23 & 71 & 4 & 2 \\
& & & & \\
\hline \hline
\end{tabular}

Ca was predicted to occupy about $72 \mathrm{~mol} \%$ of the exchange sites in clinoptilolite (Table 28). Figure 75 shows the Na-Ca binary exchange isotherm calculated using the one site Vanselow model in EQ3 at $0.01 \mathrm{~N}$ for clinoptilolite. The equivalent fraction of $\mathrm{Na}$ in CAMBRIC groundwater is about 0.73 , which yields an equivalent fraction of $\mathrm{Na}$ in clinoptilolite of less than 0.2. Given the dominance of divalent cations on the exchange site, the restriction of exchange on clinoptilolite to divalent ions seems a reasonable first approximation.

The exchange site of smectite in equilibrium with CAMBRIC groundwater is predicted to be dominated by the divalent ions $\mathrm{Ca}$ and $\mathrm{Mg}$ (Table 28). Thus exchange among $\mathrm{Ca}, \mathrm{Mg}$ and $\mathrm{Sr}$ was considered for smectite. The composition of exchange site I in illite/muscovite, which dominates Cs exchange, is predicted to be dominated by the monovalent cations Na and K (Table 28). Therefore, exchange among $\mathrm{Cs}, \mathrm{Na}$ and $\mathrm{K}$ ions was considered in the case of illite/muscovite.

Although these approximations are expected to represent the dominant exchange reactions affecting the migration and retardation of $\mathrm{Sr}$ and $\mathrm{Cs}$, future work should be directed at implementing the full Vanselow model into GIMRT and Os3D.

\section{Representing exchangers in GIMRT}

Implementation of ion exchange in GIMRT required that the exchange properties of smectite and clinoptilolite be assigned to minerals in the thermodynamic data base. Smectite is represented by three sets of homoionic end-member minerals (Na-, K-, H-, Ca- and Mg-beidellite, Na-, K-, H-, Ca- and Mg-nontronite and Na-, K-, Ca- and Mg-montmorillonite) which are used in EQ3/6 in a solidsolution model which provides for the compositional variability of smectite in 


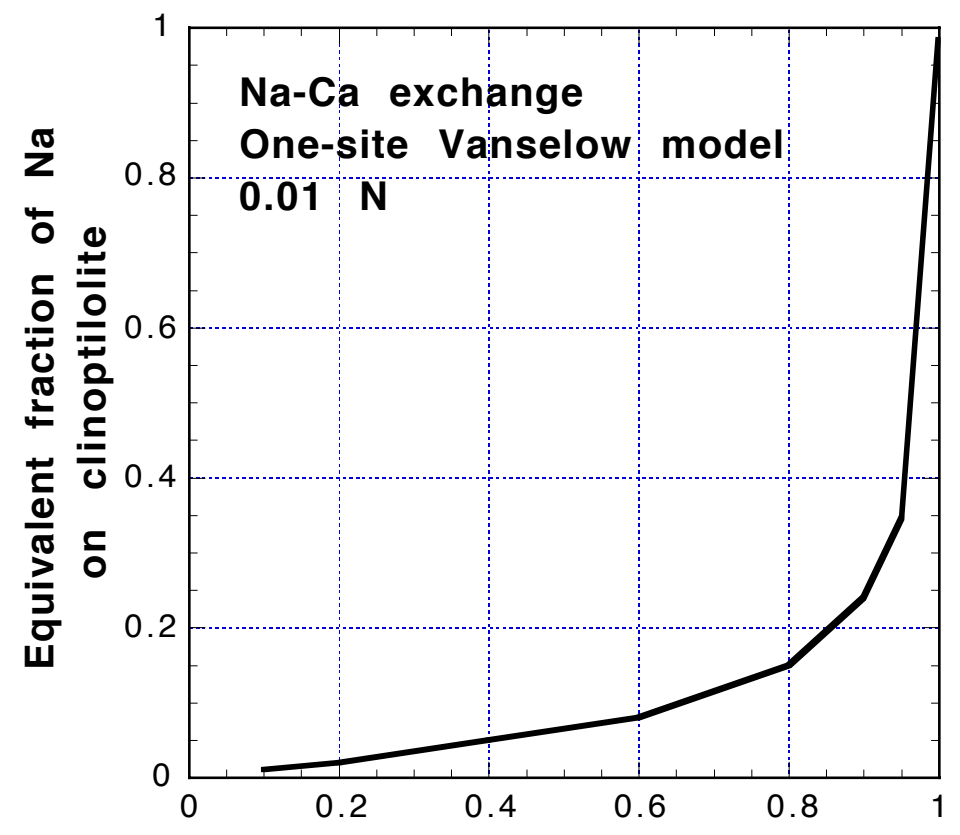

Equivalent fraction of $\mathrm{Na}$ in solution

Figure 75: Binary Na-Ca exchange isotherm for clinoptilolite calculated using a one-site Vanselow model at $0.01 \mathrm{~N}$ and $25^{\circ} \mathrm{C}$. 
the interlayer and tetrahedral and octahedral sites. GIMRT does not have solid solution capabilities. Ca-beidellite was selected to represent smectite because it reflects the dominance of divalent cations in the exchange layer of the smectite predicted by EQ3 to be in equilibrium with CAMBRIC groundwater (Table 28), and because it can also be considered as a potential precipitate which incorporates $\mathrm{Ca}, \mathrm{Al}$ and $\mathrm{Si}$ released from the melt glass over time. Clinoptilolite is represented by the homoionic end member Ca-clinoptilolite in the simulations because $\mathrm{Ca}$ is predicted to dominate the exchange site in the presence of CAMBRIC groundwaters (Table 28). 


\section{Appendix 4: Thermodynamic data}

Revised and updated thermodynamic data used in this study are shown below.

Table 29: Revised and updated thermodynamic data used in this study.

\begin{tabular}{|c|c|c|c|}
\hline Compound or element & $\log K_{\mathrm{rxn}}$ & $\begin{array}{c}\Delta G_{f}^{\circ} \\
(\mathrm{kJ} / \mathrm{mol})\end{array}$ & Reaction \\
\hline $\mathrm{Eu}_{2} \mathrm{O}_{3}($ monoclinic $)$ & & -1555.2 & \\
\hline $\mathrm{Eu}_{2} \mathrm{O}_{3}($ cubic $)$ & & -1565.9 & \\
\hline $\mathrm{EuPO}_{4}$ & -25.96 & & $\mathrm{EuPO}_{4} \rightleftharpoons \mathrm{Eu}^{3+}+\mathrm{PO}_{4}^{3-}$ \\
\hline $\mathrm{EuH}_{2} \mathrm{PO}_{4}^{2+}$ & -2.21 & & $\mathrm{EuH}_{2} \mathrm{PO}_{4}^{2+} \rightleftharpoons \mathrm{Eu}{ }^{3+}+\mathrm{H}_{2} \mathrm{PO}_{4}^{-}$ \\
\hline $\mathrm{EuHPO}_{4}^{+}$ & -5.42 & & $\mathrm{EuHPO}_{4}^{+} \rightleftharpoons \mathrm{Eu}{ }^{3+}+\mathrm{HPO}_{4}^{2-}$ \\
\hline $\mathrm{EuPO}_{4}(\mathrm{aq})$ & -12 & & $\mathrm{EuPO}_{4}(\mathrm{aq}) \rightleftharpoons \mathrm{Eu}{ }^{3+}+\mathrm{PO}_{4}^{3-}$ \\
\hline $\mathrm{Eu}_{2}\left(\mathrm{CO}_{3}\right)^{3}: 3 \mathrm{H}_{2} \mathrm{O}$ & -31.5 & & $\mathrm{Eu}_{2}\left(\mathrm{CO}_{3}\right)^{3}: 3 \mathrm{H}_{2} \mathrm{O} \rightleftharpoons 2 \mathrm{Eu}^{3+}+3 \mathrm{CO}_{3}^{2-}+3 \mathrm{H}_{2} \mathrm{O}(\mathrm{l})$ \\
\hline $\mathrm{Eu}(\mathrm{OH}) \mathrm{CO}_{3}$ & -21.34 & & $\mathrm{Eu}(\mathrm{OH}) \mathrm{CO}_{3} \rightleftharpoons \mathrm{Eu}^{3+}+\mathrm{CO}_{3}^{2-}+\mathrm{OH}-$ \\
\hline $\mathrm{Eu}_{2}\left(\mathrm{SO}_{4}\right)^{3}: 8 \mathrm{H}_{2} \mathrm{O}$ & -11.64 & & $\mathrm{Eu}_{2}\left(\mathrm{SO}_{4}\right)^{3}: 8 \mathrm{H}_{2} \mathrm{O} \rightleftharpoons 2 \mathrm{Eu}^{3+}+3 \mathrm{SO}_{4}^{2-}+8 \mathrm{H}_{2} \mathrm{O}(\mathrm{l})$ \\
\hline $\mathrm{Tc}$ & & 0 & $\mathrm{Tc}+\frac{7}{4} \mathrm{O}_{2}(\mathrm{aq})+\frac{1}{2} \mathrm{H}_{2} \mathrm{O}(\mathrm{l}) \rightleftharpoons \mathrm{TcO}_{4}^{-}+\mathrm{H}^{+}$ \\
\hline $\mathrm{TcO}_{4}^{-}$ & & -637.4 & \\
\hline $\operatorname{Tc}(\mathrm{g})$ & & 630.7 & $\mathrm{Tc}(\mathrm{g})+\frac{7}{4} \mathrm{O}_{2}(\mathrm{aq})+\frac{1}{2} \mathrm{H}_{2} \mathrm{O}(\mathrm{l}) \rightleftharpoons \mathrm{TcO}_{4}^{-}+\mathrm{H}^{+}$ \\
\hline $\mathrm{TcO}(\mathrm{g})$ & & 357.5 & $\mathrm{TcO}(\mathrm{g})+\frac{5}{4} \mathrm{O}_{2}(\mathrm{aq})+\frac{1}{2} \mathrm{H}_{2} \mathrm{O}(\mathrm{l}) \rightleftharpoons \mathrm{TcO}_{4}^{-}+\mathrm{H}^{+}$ \\
\hline $\mathrm{NaTcO}_{4}: 4 \mathrm{H}_{2} \mathrm{O}$ & & -1843.4 & $\mathrm{NaTcO}_{4}: 4 \mathrm{H}_{2} \mathrm{O} \rightleftharpoons \mathrm{Na}^{+}+\mathrm{TcO}_{4}^{-}+4 \mathrm{H}_{2} \mathrm{O}$ \\
\hline $\mathrm{KTcO}_{4}$ & & -932.9 & $\mathrm{KTcO}_{4} \rightleftharpoons \mathrm{K}^{+}+\mathrm{TcO}_{4}^{-}$ \\
\hline $\mathrm{CsTcO}_{4}$ & & -949.7 & $\mathrm{CsTcO}_{4} \rightleftharpoons \mathrm{Cs}^{+}+\mathrm{TcO}_{4}^{-}$ \\
\hline $\mathrm{AgTcO}_{4}$ & & -579 & $\mathrm{AgTcO}_{4} \rightleftharpoons \mathrm{Ag}^{+}+\mathrm{TcO}_{4}^{-}$ \\
\hline $\mathrm{TlTcO}_{4}$ & & -700.1 & $\mathrm{TlTcO}_{4} \rightleftharpoons \mathrm{Tl}^{+}+\mathrm{TcO}_{4}^{-}$ \\
\hline $\mathrm{NH}_{4} \mathrm{TcO}_{4}$ & & -722 & $\mathrm{NH}_{4} \mathrm{TcO}_{4} \rightleftharpoons \mathrm{NH}^{3}(\mathrm{aq})+\mathrm{H}^{+}+\mathrm{TcO}_{4}^{-}$ \\
\hline $\mathrm{TcO}_{2}$ & & -401.8 & $\mathrm{TcO}_{2}+\frac{3}{4} \mathrm{O}_{2}(\mathrm{aq})+\frac{1}{2} \mathrm{H}_{2} \mathrm{O}(\mathrm{l}) \rightleftharpoons \mathrm{TcO}_{4}^{-}+\mathrm{H}^{+}$ \\
\hline $\mathrm{TcO}_{2}: 1.6 \mathrm{H}_{2} \mathrm{O}$ & & -758.3 & $\mathrm{TcO}_{2}: 1.6 \mathrm{H}_{2} \mathrm{O}+\frac{3}{4} \mathrm{O}_{2}(\mathrm{aq}) \rightleftharpoons \mathrm{TcO}_{4}^{-}+\mathrm{H}^{+}+1.1 \mathrm{H}_{2} \mathrm{O}$ \\
\hline $\mathrm{Tc}_{2} \mathrm{O}_{7}$ & & -950.3 & $\mathrm{Tc}_{2} \mathrm{O}_{7}+\mathrm{H}_{2} \mathrm{O}(\mathrm{l}) \rightleftharpoons 2 \mathrm{TcO}_{4}^{-}+2 \mathrm{H}^{+}$ \\
\hline
\end{tabular}


Table 29, continued.

\begin{tabular}{|c|c|c|c|}
\hline Compound or element & $\log K_{\mathrm{rxn}}$ & $\begin{array}{c}\Delta G_{f}^{\circ} \\
(\mathrm{kJ} / \mathrm{mol}) \\
\end{array}$ & Reaction \\
\hline $\mathrm{Tc}_{2} \mathrm{O}_{7}(\mathrm{~g})$ & & -904.8 & $\mathrm{Tc}_{2} \mathrm{O}_{7}(\mathrm{~g})+\mathrm{H}_{2} \mathrm{O}(\mathrm{l}) \rightleftharpoons 2 \mathrm{TcO}_{4}^{-}+2 \mathrm{H}^{+}$ \\
\hline $\mathrm{Tc}_{2} \mathrm{O}_{7}: \mathrm{H}_{2} \mathrm{O}$ & & -1194.3 & $\mathrm{Tc}_{2} \mathrm{O}_{7}: \mathrm{H}_{2} \mathrm{O} \rightleftharpoons 2 \mathrm{TcO}_{4}^{-}+2 \mathrm{H}^{+}$ \\
\hline $\mathrm{TcO}(\mathrm{OH})_{2}(\mathrm{aq})$ & & -567.5 & $\mathrm{TcO}(\mathrm{OH})_{2}(\mathrm{aq})+\frac{3}{4} \mathrm{O}_{2}(\mathrm{aq}) \rightleftharpoons \mathrm{TcO}_{4}^{-}+\frac{1}{2} \mathrm{H}_{2} \mathrm{O}(\mathrm{l})+\mathrm{H}$ \\
\hline $\mathrm{TcO}(\mathrm{OH})^{+}$ & & -344.6 & $\mathrm{TcO}(\mathrm{OH})^{+}+\frac{3}{4} \mathrm{O}_{2}(\mathrm{aq})+\frac{1}{2} \mathrm{H}_{2} \mathrm{O}(\mathrm{l}) \rightleftharpoons \mathrm{TcO}_{4}^{-}+2 \mathrm{H}^{+}$ \\
\hline $\mathrm{TcO}(\mathrm{OH})_{3}^{-}$ & & -742.4 & $\mathrm{TcO}(\mathrm{OH})_{3}^{-}+\frac{3}{4} \mathrm{O}_{2}(\mathrm{aq}) \rightleftharpoons \mathrm{TcO}_{4}^{-}+\frac{3}{2} \mathrm{H}_{2} \mathrm{O}(\mathrm{l})$ \\
\hline $\mathrm{Tc}^{3+}$ & & 105.8 & $\mathrm{Tc}^{3+}+\mathrm{O}_{2}(\mathrm{aq})+2 \mathrm{H}_{2} \mathrm{O}(\mathrm{l}) \rightleftharpoons \mathrm{TcO}_{4}^{-}+4 \mathrm{H}^{+}$ \\
\hline $\mathrm{Sr}(\mathrm{OH})_{2}$ & & -875.89 & \\
\hline Celestite $\left(\mathrm{SrSO}_{4}\right)$ & -6.613 & & $\mathrm{SrSO}_{4} \rightleftharpoons \mathrm{Sr}^{2+}+\mathrm{SO}_{4}^{2-}$ \\
\hline Strontianite $\left(\mathrm{SrCO}_{3}\right)$ & -9.271 & -1144.73 & $\mathrm{SrCO}_{3} \rightleftharpoons \mathrm{Sr}^{2+}+\mathrm{CO}_{3}^{2-}$ \\
\hline $\mathrm{SrHCO}_{3}^{-}$ & -1.18 & & $\mathrm{SrHCO}_{3}^{+} \rightleftharpoons \mathrm{Sr}^{2+}+\mathrm{HCO}_{3}^{-}$ \\
\hline $\mathrm{UO}_{2}(\mathrm{OH})_{2}($ alpha $)$ & & -1398.8 & $\mathrm{UO}_{2}(\mathrm{OH})_{2}($ alpha $)+2 \mathrm{H}^{+} \rightleftharpoons \mathrm{UO}_{2}^{2+}+2 \mathrm{H}_{2} \mathrm{O}$ \\
\hline $\mathrm{CsSO}_{4}^{-}$ & -0.33 & & $\mathrm{CsSO}_{4}^{-} \rightleftharpoons \mathrm{Cs}^{+}+\mathrm{SO}_{4}^{2-}$ \\
\hline $\mathrm{CsCl}$ & 1.529 & & $\mathrm{CsCl} \rightleftharpoons \mathrm{Cs}^{+}+\mathrm{Cl}^{-}$ \\
\hline $\mathrm{Cs}_{2} \mathrm{SO}_{4}$ & & -1322.3 & $\mathrm{Cs}_{2} \mathrm{SO}_{4} \rightleftharpoons 2 \mathrm{Cs}^{+}+\mathrm{SO}_{4}^{2-}$ \\
\hline $\mathrm{CsOH}$ & & -371.8 & $\mathrm{CsOH}+\mathrm{H}^{+} \rightleftharpoons \mathrm{Cs}^{+}+\mathrm{H}_{2} \mathrm{O}$ \\
\hline $\mathrm{CsF}$ & & -527.95 & $\mathrm{CsF} \rightleftharpoons \mathrm{Cs}^{+}+\mathrm{F}^{-}$ \\
\hline $\mathrm{RbSO}_{4}^{-}$ & -0.6 & & $\mathrm{RbSO}_{4}^{-} \rightleftharpoons \mathrm{Rb}++\mathrm{SO}_{4}^{2-}$ \\
\hline $\mathrm{CoOH}^{+}$ & -9.695 & & $\mathrm{Co}^{2+}+\mathrm{H}_{2} \mathrm{O} \rightleftharpoons \mathrm{CoOH}^{+}+\mathrm{H}^{+}$ \\
\hline
\end{tabular}




\section{Appendix 5: Analyses of 1D Reactive Transport Simulations}

\section{Alluvium-melt glass-alluvium}

The first 1D simulation involved Darcy flow of $1 \mathrm{~m} / \mathrm{yr}$ through the following sequence of rock types: $10 \mathrm{~m}$ of alluvium, $10 \mathrm{~m}$ of melt glass, and $10 \mathrm{~m}$ of alluvium (Figs 30a and b). Glass dissolution releases radionuclides into the groundwater from 10 to $20 \mathrm{~m}$. Subsequent transport of $\mathrm{Pu}, \mathrm{Sr}$ and $\mathrm{Cs}$ through the alluvium downstream from the glass (from 20 to $30 \mathrm{~m}$ ) is affected by surface complexation of $\mathrm{Pu}$ and $\mathrm{Sr}$ onto goethite, ion exchange of $\mathrm{Sr}$ onto smectite and clinoptilolite, and ion exchange of Cs onto illite/muscovite. All radionuclides except Cs have the potential for precipitating as authigenic minerals if the minerals become supersaturated.

\section{Major element chemistry}

During the entire simulation, the $\mathrm{pH}$ remained about 8 , which is equal to that of the incoming groundwater. The major element chemistry (e.g., $\mathrm{SiO}_{2}, \mathrm{Na}$, $\mathrm{K}, \mathrm{Ca}, \mathrm{Mg}$ ) remained constant as well. The constancy of the $\mathrm{pH}$ and major element chemistry reflects the slow dissolution rate of the glass relative to the rate of fluid flux. In contrast, the concentrations of radionuclides show the effects of even slow glass dissolution rates because the radionuclides exist initially in infinitesimal concentrations in the groundwater. Even negligible amounts of glass dissolution will release small, but finite amounts of radionuclides. The masses of major elements released (e.g., Si, Na) tend to be masked by the high concentrations of the same elements that are already in solution. $\mathrm{pH}$ is expected to be a sensitive indicator of glass dissolution rates vs. fluid flow fluxes, as will be shown later during the analysis of the streamline calculations.

\section{Radionuclide concentrations}

Figures 76 through 78 illustrate the spatial distribution of the total masses of $\mathrm{Sr}, \mathrm{Cs}, \mathrm{Eu}, \mathrm{Pu}$ and Am in solution at 1, 134 and 5034 years $^{19}$. Multiple aqueous species of $\mathrm{Eu}, \mathrm{Pu}$ and Am exist, and their concentrations are summed to obtain the total mass in solution. The aqueous speciation of $\mathrm{Pu}, \mathrm{Eu}$ and $\mathrm{Am}$ at 1 year are shown in Figures 79 through 81. The relative distribution of the aqueous complexes varies negligibly with time in the simulation owing to the general constancy of fluid chemistry. In fact, the relative distribution of the radionuclide-bearing aqueous complexes are similar in all the $1 \mathrm{D}$ simulations

\footnotetext{
${ }^{19}$ Version 1.0 of GIMRT selects it own time steps during the simulations. The user specifies the times at which output should be written, and GIMRT then generates the files when that time has been exceeded by the previous time step.
} 


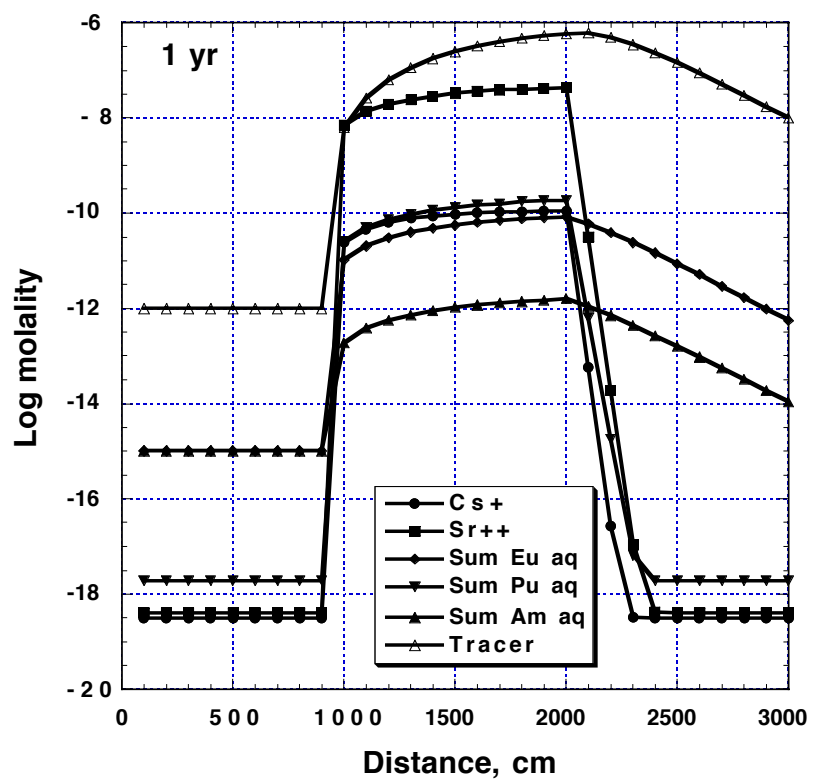

Figure 76: Spatial distribution of total $\mathrm{Cs}, \mathrm{Sr}, \mathrm{Eu}, \mathrm{Pu}$ and Am molalities in solution at 1 year in alluvium-glass-alluvium 1D GIMRT simulation. Non-reactive tracer concentration shown for reference. 


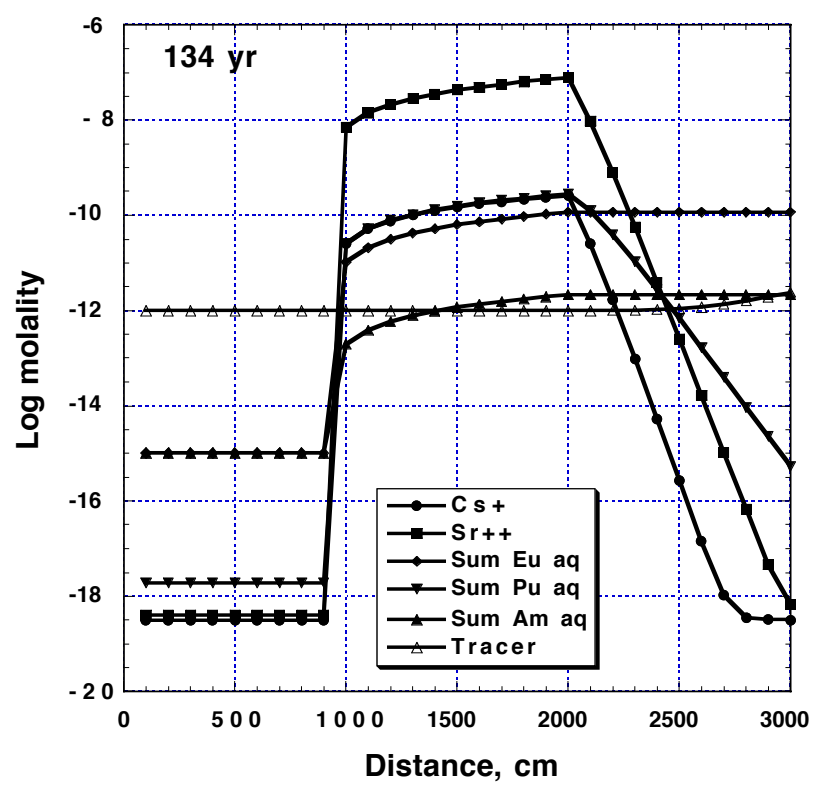

Figure 77: Spatial distribution of total $\mathrm{Cs}, \mathrm{Sr}, \mathrm{Eu}, \mathrm{Pu}$ and $\mathrm{Am}$ molalities in solution at 134 years in alluvium-glass-alluvium 1D GIMRT simulation. Nonreactive tracer concentration shown for reference. $\mathrm{Pu}$ and $\mathrm{Cs}$ concentrations are coincident from 10 to $20 \mathrm{~m}$. 


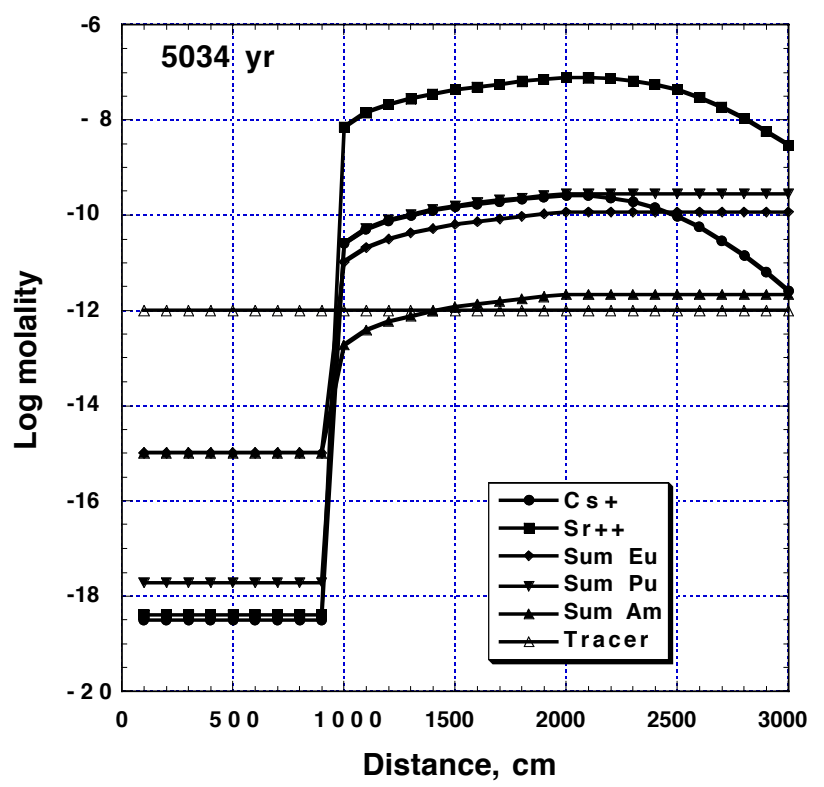

Figure 78: Spatial distribution of total $\mathrm{Cs}, \mathrm{Sr}, \mathrm{Eu}, \mathrm{Pu}$ and $\mathrm{Am}$ molalities in solution at 5034 years in alluvium-glass-alluvium 1D GIMRT simulation. Nonreactive tracer concentration shown for reference. 


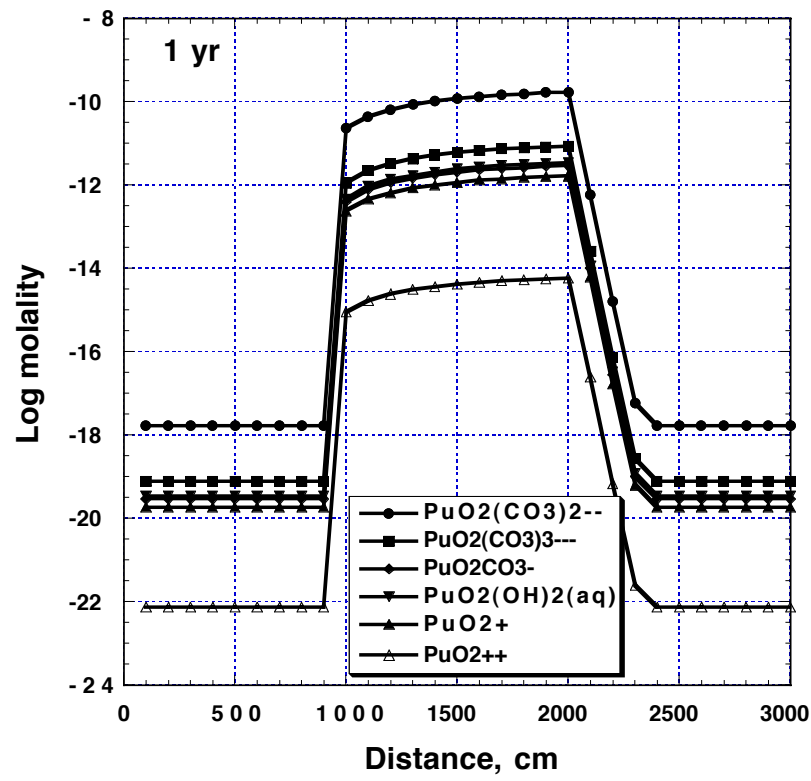

Figure 79: $\mathrm{Pu}$ aqueous speciation at 1 year in alluvium-glass-alluvium 1D GIMRT simulation.

that were made. Cs and $\mathrm{Sr}$ in solution were limited to the species $\mathrm{Cs}^{+}$and $\mathrm{Sr}^{2+}$.

Radionuclide concentrations increase steadily from 10 to $20 \mathrm{~m}$ when the fluid flows through dissolving melt glass. By 1 year (Figure 76), a pseudo-steady state has been achieved between the rate of glass dissolution and the fluid flux. The shape of the concentration profiles are similar for the radionuclides because all elements are assumed to be released congruently from the glass, and no sinks for these elements occur in the glass. The numerical dispersion produced by GIMRT can be seen in the tracer concentration distributions.

Once the fluid exits the melt glass and enters the alluvium downstream, the concentrations of $\mathrm{Pu}, \mathrm{Sr}$ and $\mathrm{Cs}$ are reduced to near background levels within a few meters (Figs. 76). With time, the concentration fronts move downstream from the glass/alluvium interface and the slopes of the fronts decrease (Figs. $77,78)$. 


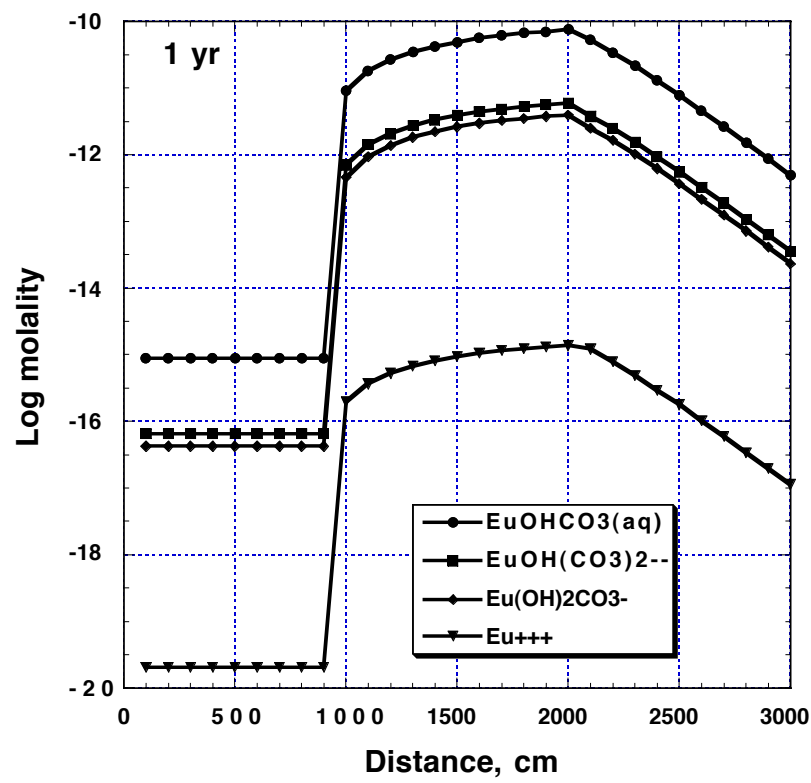

Figure 80: Eu aqueous speciation at 1 year in alluvium-glass-alluvium 1D GIMRT simulation. 


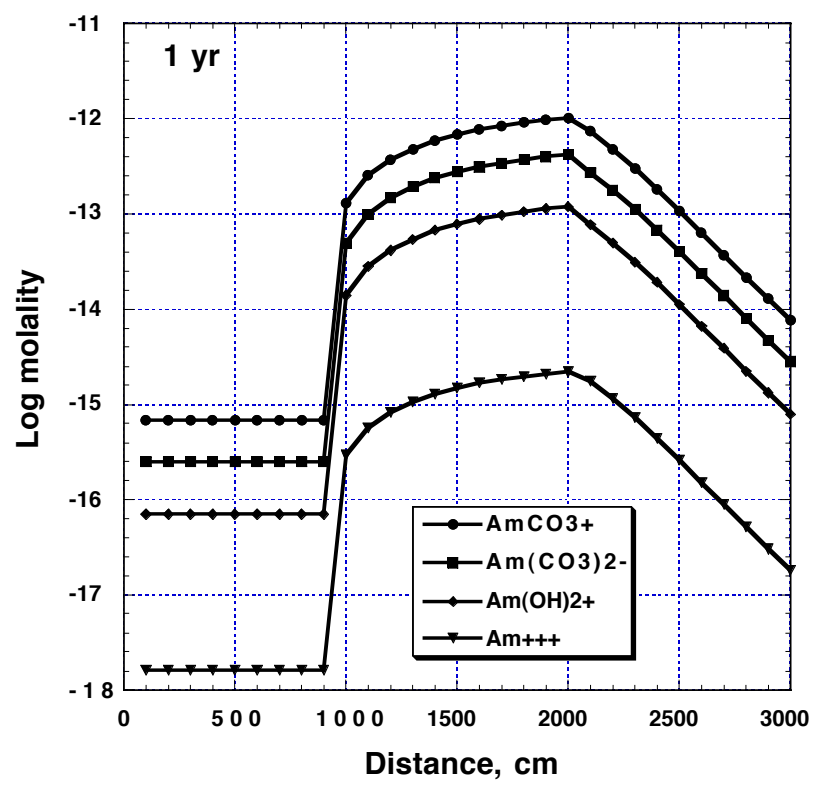

Figure 81: Am aqueous speciation at 1 year in alluvium-glass-alluvium 1D GIMRT simulation. 
By 134 years (Fig. 77), the tracer has been flushed out of the glass zones and is at near background levels throughout. From 134 years onward (Figs. 77, 78), the Am and Eu concentrations are constant throughout the alluvium downstream of the glass because no sink is considered for these elements except precipitation, and their concentrations in solution are far below saturation with respect to $\mathrm{AmOHCO}_{3}$ and $\mathrm{EuOHCO}_{3}$. In contrast, the migration of $\mathrm{Pu}, \mathrm{Sr}$ and Cs continues to be retarded at 134 years, and are only approaching constant concentration profiles downstream of the glass after 5000 years of flow and reaction.

The relative importance of sorption and ion exchange on $\mathrm{Pu}, \mathrm{Sr}$ and $\mathrm{Cs}$ retardation can be examined by plotting the compositions of the goethite surface sites and the exchange sites on clinoptilolite, smectite and illite/muscovite. Figure 82 shows the concentration of surface complexes on goethite at 1 year. From background levels in the alluvium upstream of the glass, concentrations of the $\mathrm{Pu}$ and Sr surface complexes increase monotonically in the glass zone, as glass dissolves and the radionuclides partition themselves between the goethite surface and the fluid phase. An increase in sorbed radionuclides occurs immediately downstream of the glass/alluvium interface. The increase is due to the presence of additional surface sites in the alluvium which is assumed to contain 1 volume $\%$ goethite. Only $1 \times 10^{-6}$ volume $\%$ goethite was assumed for the melt glass. Volume fractions of zero for surface species are not allowed by GIMRT, and thus $1 \times 10^{-6}$ was used as a minimal background concentration. Figure 83 shows the concentrations of the surface hydroxyl groups on goethite at 1 year in the alluvium and the glass, and the jump in concentration at $20 \mathrm{~m}$. Figure 83 also illustrates why the background concentrations of some radionuclides upstream of the glass are lower than the $1 \times 10^{-15} \mathrm{~m}$ that was input. The presence of finite amounts of sorbent and ion exchangers partitions portions of the $1 \times 10^{-15} \mathrm{~m}$ into solid phases, and reduces the molality of the radionuclide in solution.

Figure 84 illustrates distribution at 1 year of the Sr released by glass dissolution. Within the melt glass, $\mathrm{Sr}^{2+}$ comprises the largest component of $\mathrm{Sr}$, but is closely followed by the sum of the molalities of the three sorbed $\mathrm{Sr}$ surface complexes. The amount of Sr undergoing ion exchange on clinoptilolite and smectite is minor in comparison. When the fluid flows downstream into the alluvium, however, the distributions shift. The concentrations of sorbed and exchanged $\mathrm{Sr}$ suddenly increase at $21 \mathrm{~m}$ while the $\mathrm{Sr}^{2+}$ in solution decreases concomitantly. As time passes (Figs. 85 and 86), the concentrations of sorbed and exchanged $\mathrm{Sr}$ continue to increase as the alluvium continues to incorporate Sr released from the glass and retards Sr migration. Sr concentrations in alluvium pore fluids gradually increase as the concentration fronts migrate downstream. The ratios between the $\mathrm{Sr}^{2+}$ concentrations in the pore fluid and sorbed and exchanged $\mathrm{Sr}$ are controlled by the equilibrium constants of the surface complexation and exchange reactions and the mass of the sorbent and exchanger.

Cs released by glass dissolution can be carried in the aqueous phase and participate in ion exchange reactions on muscovite/illite. Cs is predicted to 


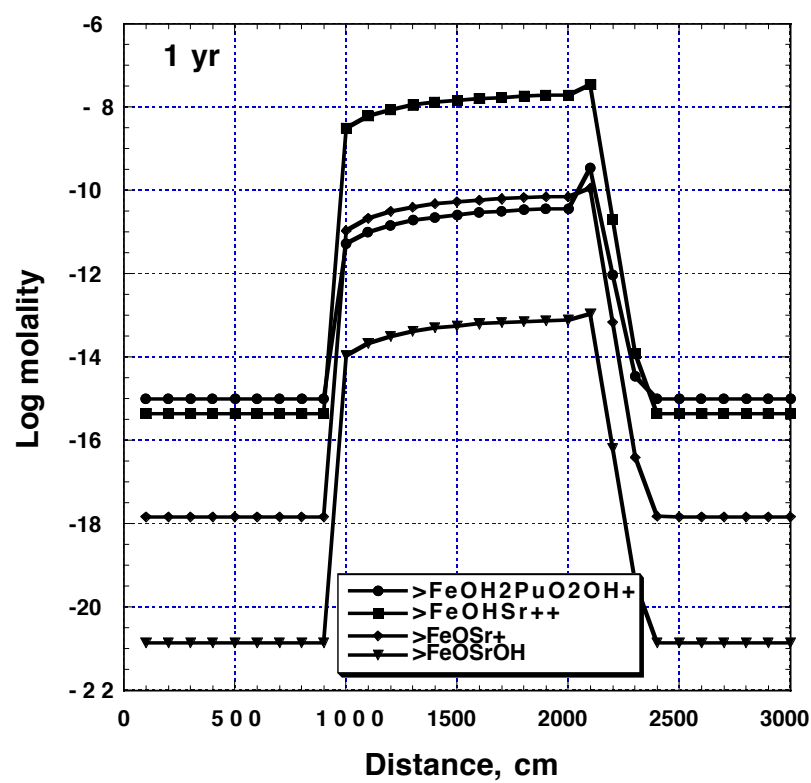

Figure 82: Log molality of surface complexes on goethite at 1 year in alluviumglass-alluvium 1D GIMRT simulation. 


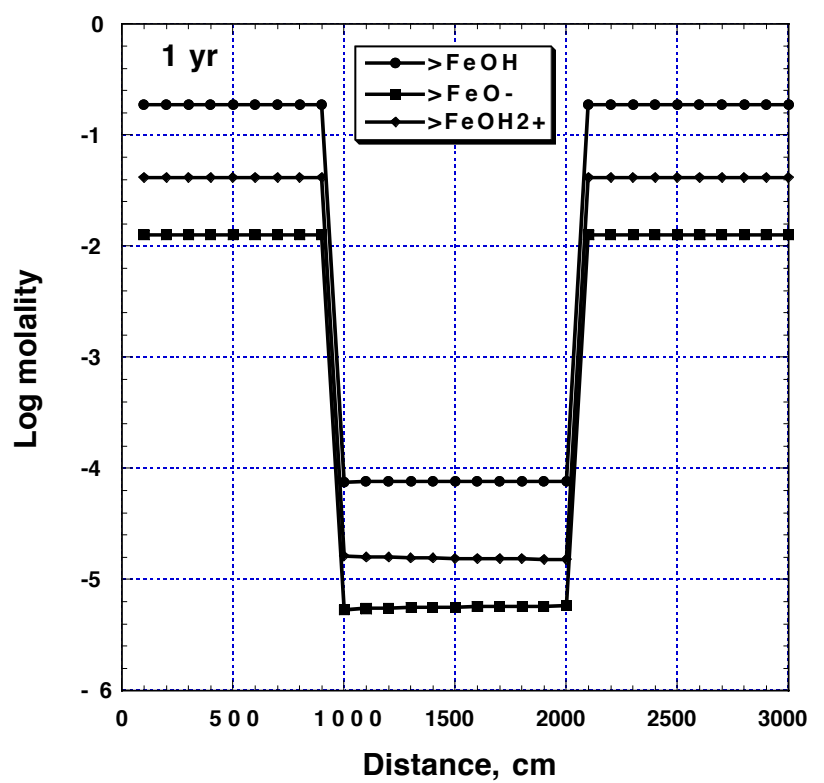

Figure 83: Log molality of surface hydroxyl groups on goethite at 1 year in alluvium-glass-alluvium 1D GIMRT simulation. 


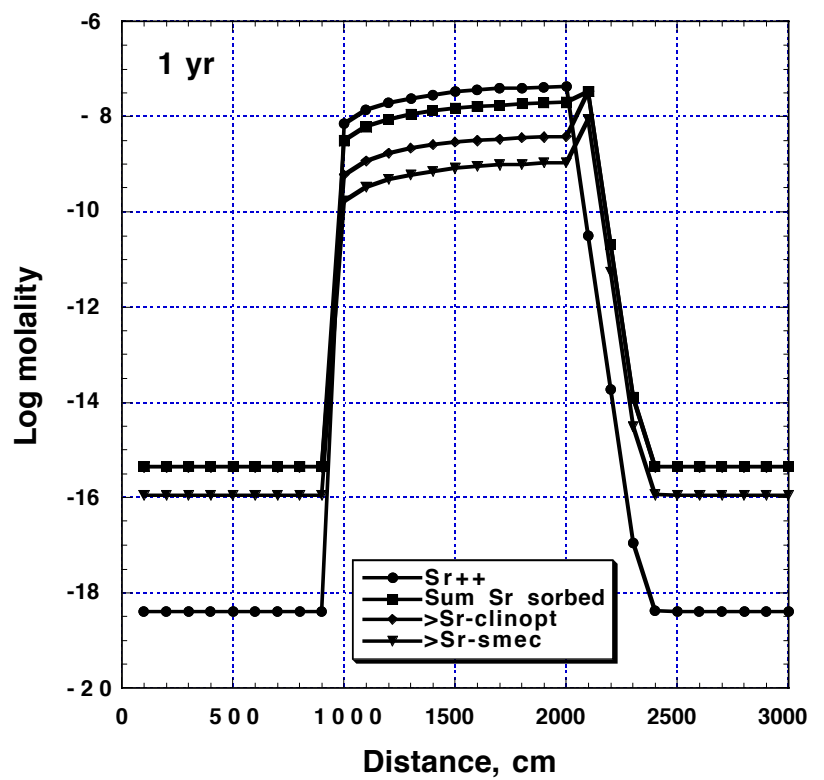

Figure 84: Comparison of molalities of various forms of Sr at 1 year in alluviumglass-alluvium 1D GimRT simulation. $\mathrm{Sr}^{++}=$aqueous $\mathrm{Sr}$, Sum $\mathrm{Sr}$ sorbed = total Sr sorbed onto goethite, $\rangle$ Sr-clinopt $=$ Sr exchanged onto clinoptilolite, \rangle Sr-smec $=$ Sr exchanged onto smectite. 


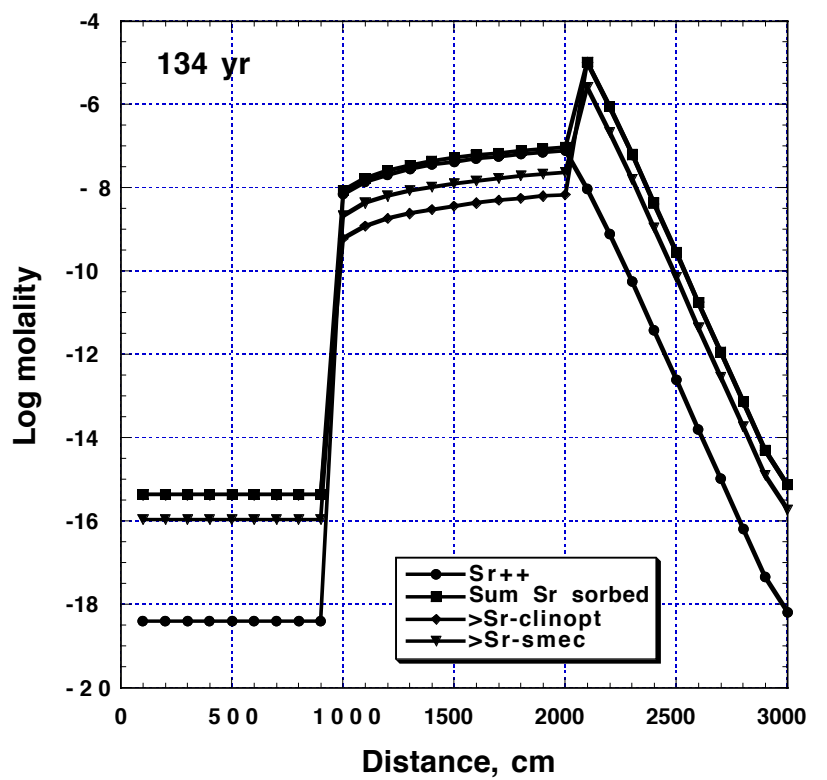

Figure 85: Comparison of molalities of various forms of $\mathrm{Sr}$ at 134 years in alluvium-glass-alluvium 1D GimRT simulation. $\mathrm{Sr}^{++}=$aqueous $\mathrm{Sr}$, Sum $\mathrm{Sr}$ sorbed $=$ total $\mathrm{Sr}$ sorbed onto goethite, $\rangle$ Sr-clinopt $=$ Sr exchanged onto clinoptilolite, $\rangle \mathrm{Sr}$-smec $=\mathrm{Sr}$ exchanged onto smectite. 


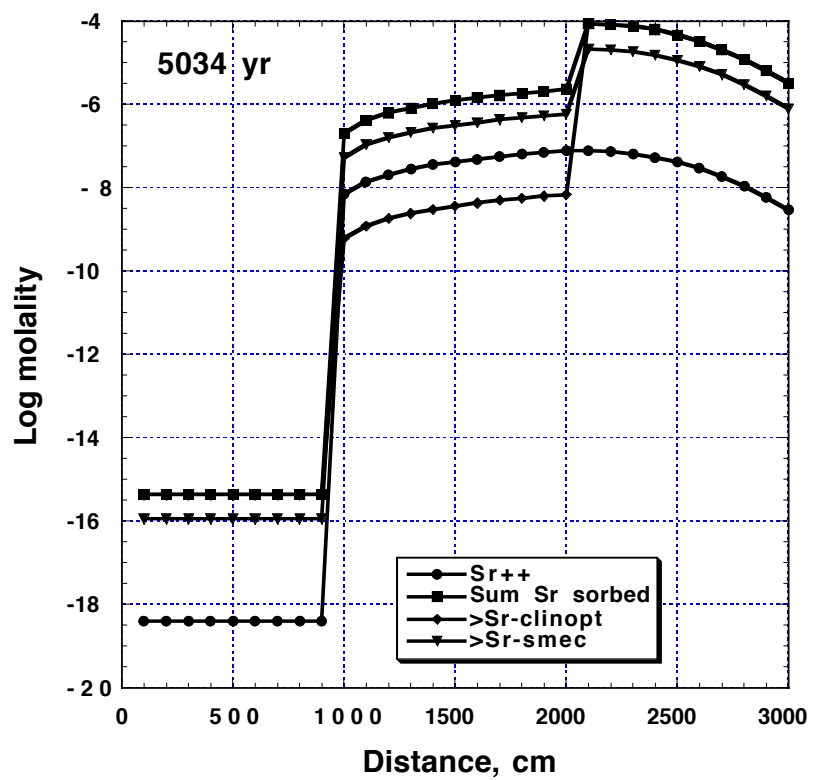

Figure 86: Comparison of molalities of various forms of $\mathrm{Sr}$ at 5034 years in alluvium-glass-alluvium 1D GimRT simulation. $\mathrm{Sr}^{++}=$aqueous $\mathrm{Sr}$, Sum $\mathrm{Sr}$ sorbed $=$ total $\mathrm{Sr}$ sorbed onto goethite, $\rangle$ Sr-clinopt $=$ Sr exchanged onto clinoptilolite, $\rangle \mathrm{Sr}$-smec $=\mathrm{Sr}$ exchanged onto smectite. 


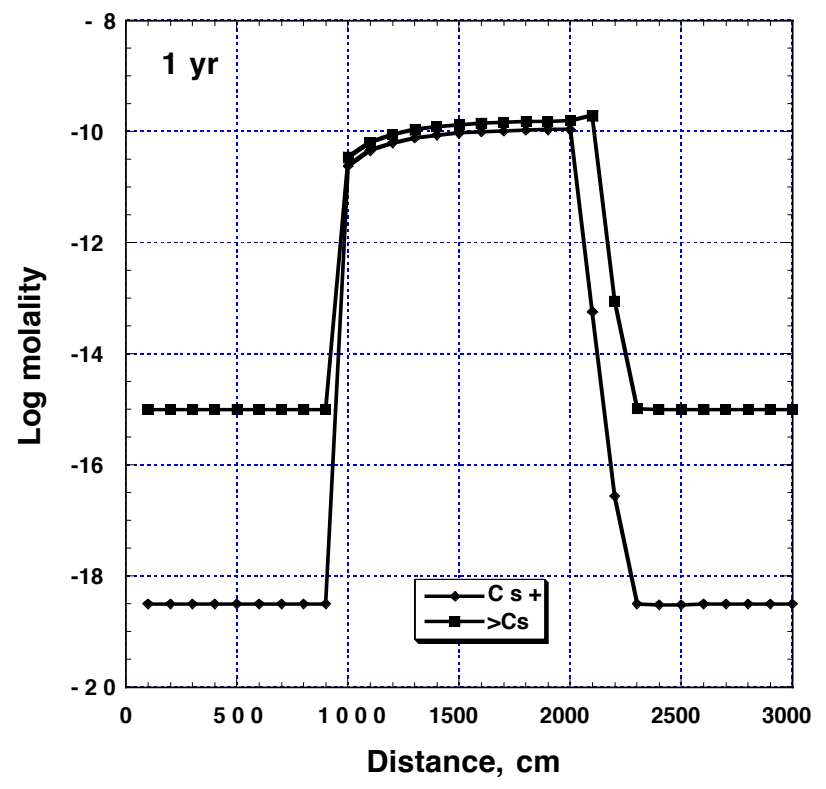

Figure 87: Comparison of molalities of various forms of Cs at 1 year in alluviumglass-alluvium 1D GIMRT simulation. $\mathrm{Cs}^{+}=$aqueous $\left.\mathrm{Cs},\right\rangle \mathrm{Cs}=\mathrm{Cs}$ exchanged onto illite/muscovite.

partition so strongly on muscovite/illite that the Cs concentration on the muscovite exchange site in the alluvium is over 3 orders of magnitude larger than the $\mathrm{Cs}^{+}$concentration in solution (Figs. $87-89$ at 1, 134 and 5034 years). Thus small masses of muscovite/illite can significantly affect Cs migration. Within the glass, the ratio of Cs in solution and Cs associated with muscovite/illite is much closer to one. This reflects the extremely small quantities of exchanger $\left(1 \times 10^{-6}\right.$ volume\%) assumed to be in the melt glass, as compared to 1 volume $\%$ in the alluvium. Even such small quantities of exchanger can serve as a significant sink for Cs.

For the remainder of the 1D simulations, the general chemical trends noted above remain the same. Therefore, a reduced number of figures will be shown. 


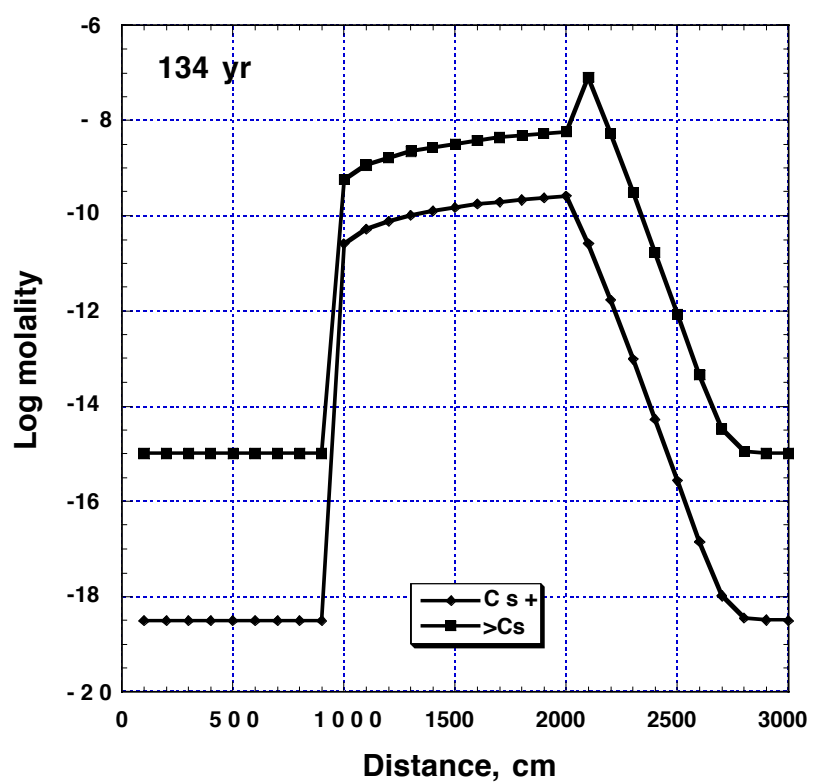

Figure 88: Comparison of molalities of various forms of Cs at 134 years in alluvium-glass-alluvium 1D GIMRT simulation. $\mathrm{Cs}^{+}=$aqueous $\left.\mathrm{Cs},\right\rangle \mathrm{Cs}=\mathrm{Cs}$ exchanged onto illite/muscovite. 


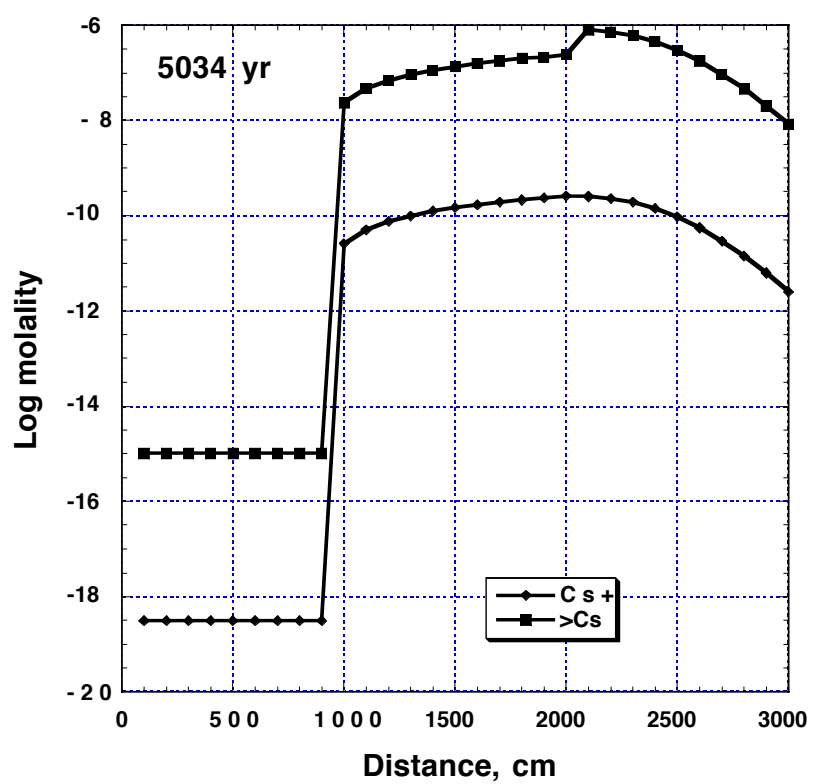

Figure 89: Comparison of molalities of various forms of Cs at 5034 years in alluvium-glass-alluvium 1D GimRT simulation. $\mathrm{Cs}^{+}=$aqueous $\left.\mathrm{Cs},\right\rangle \mathrm{Cs}=\mathrm{Cs}$ exchanged onto illite/muscovite. 


\section{Alluvium-exchange volume-alluvium}

Figure 31 shows the conceptual model and the spatial dimensions used in the alluvium-exchange volume-alluvium simulations. Simulations involving flow through the exchange volume requires specification of the masses and distribution of radionuclides in the exchange volume. The masses of $\mathrm{Pu}, \mathrm{Am}, \mathrm{Eu}$, $\mathrm{Cs}$ and $\mathrm{Sr}$ in the exchange volume were obtained by multiplying the total inventory of each radionuclide (Table 5) by the percentage of the radionuclide in the exchange volume (rubble in Table 1). As discussed in Section 7.3, the radionuclides were then partitioned among the fluids and minerals in the exchange volume according to sorption and ion exchange reactions.

Figures 90 - 92 show the predicted migration of radionuclides over 5034 years. Note the similarity of the concentration profiles for $\mathrm{Eu}, \mathrm{Am}$, and the tracer. Eu and Am essentially act as tracers because no Eu- or Am-bearing precipitates formed, and no other sink was considered for them in the initial simulations. Numerical dispersion has "smeared" the tracer and other concentrations over space, rather than defining distinct concentration fronts that can be directly related to the rate of fluid flux. By 134 years (Fig. 91), Am and Eu have been flushed entirely out of the exchange volume.

The majorities of ${ }^{90} \mathrm{Sr},{ }^{137} \mathrm{Cs}$ and ${ }^{239} \mathrm{Pu}$ in the exchange volume are associated with solid phases through sorption and ion exchange (Table 12; Figs. 93 95). Given our assumptions for the volume fractions of surface-active minerals in the exchange volume, Figures 90 through 92 suggest that it will take thousands of years to sweep $\mathrm{Pu}, \mathrm{Cs}$ and $\mathrm{Sr}$ out of the exchange volume. Cs and $\mathrm{Sr}$ are more tightly bound in the exchange volume than $\mathrm{Pu}$ (Fig. 92). Because the volume fractions of minerals in the exchange volume are estimates, the absolute rates of radionuclide transport are uncertain. The calculations do suggest, however, that goethite, clinoptilolite and smectite can effectively retard radionuclide migration if there is sufficient contact between the minerals and the pore fluid.

\section{Alluvium-melt glass-exchange volume-alluvium}

This simulation involves a path length of $40 \mathrm{~m}$ through alluvium-melt glassexchange volume-alluvium, as schematically illustrated in Figure 35. The chemical and mineralogic conditions in each zone are as described in the two 1D simulations described above. Although the radionuclide concentrations with distance in Figures 96 through 98 are complex, their geochemical behavior in each rock type is similar to that predicted in the previous two simulations. From 10 to $20 \mathrm{~m}$, radionuclides are added to solution owing to glass dissolution and a pseudo-steady-state condition is achieved (Fig. 96; compare to glass zone at 10 to $20 \mathrm{~m}$ in Fig. 76). Over the transition from glass to alluvium at 20 to 21 $\mathrm{m}$, the concentrations of $\mathrm{Pu}, \mathrm{Sr}$ and Cs change to those initially in the fluid in the exchange volume (Fig. 96; compare to exchange volume zone at 10 to $20 \mathrm{~m}$ 


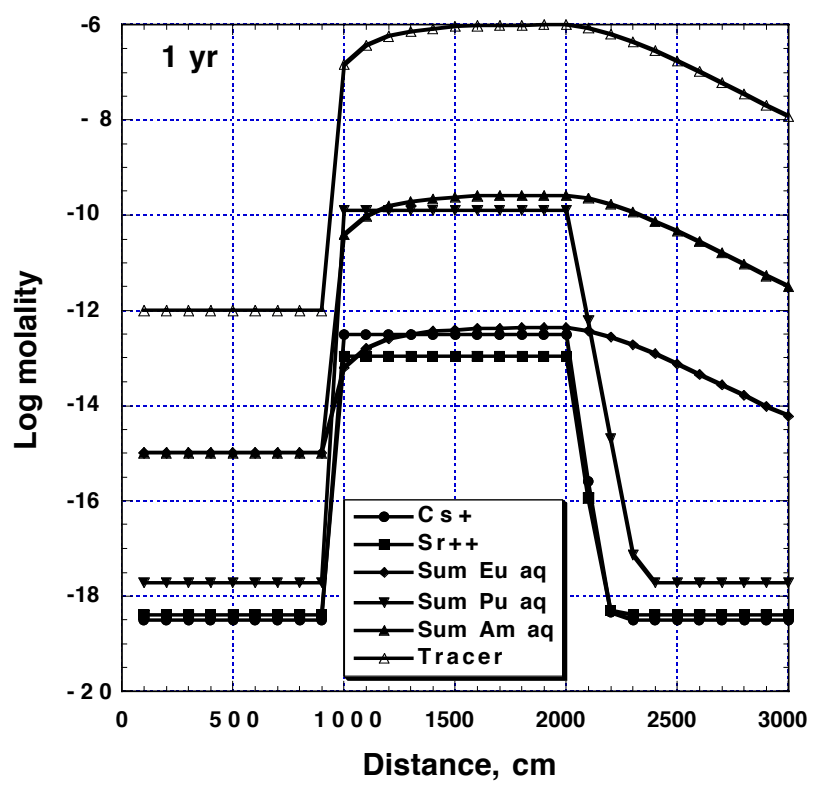

Figure 90: Spatial distribution of total $\mathrm{Cs}, \mathrm{Sr}, \mathrm{Eu}, \mathrm{Pu}$ and $\mathrm{Am}$ molalities in solution at 1 year in alluvium-exchange volume-alluvium 1D GIMRT simulation. Non-reactive tracer concentration shown for reference. 


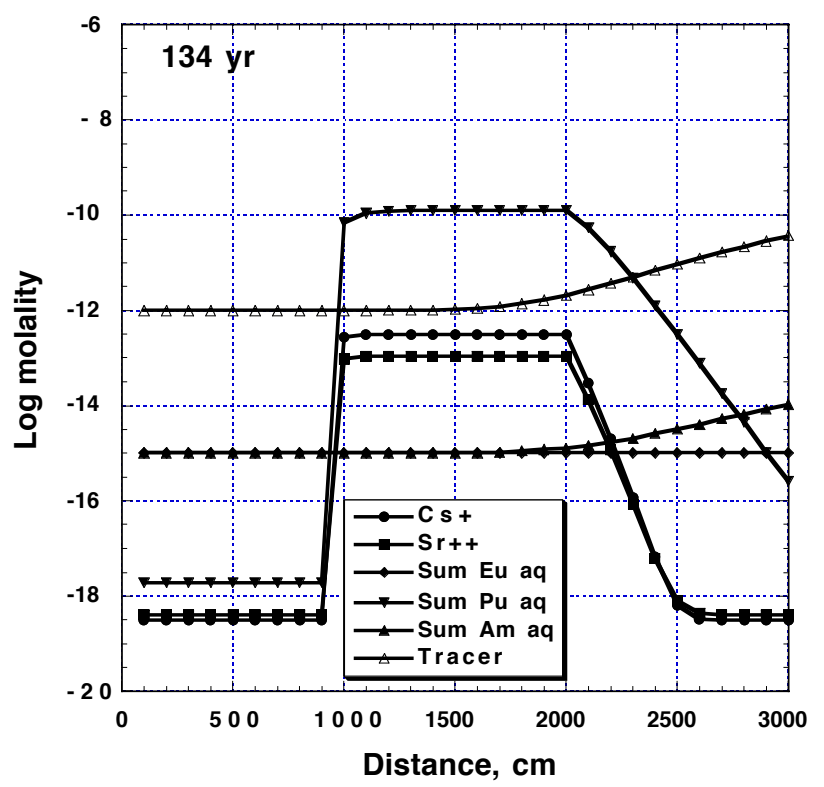

Figure 91: Spatial distribution of total $\mathrm{Cs}, \mathrm{Sr}, \mathrm{Eu}, \mathrm{Pu}$ and Am molalities in solution at 134 years in alluvium-exchange volume-alluvium 1D GIMRT simulation. Non-reactive tracer concentration shown for reference. 


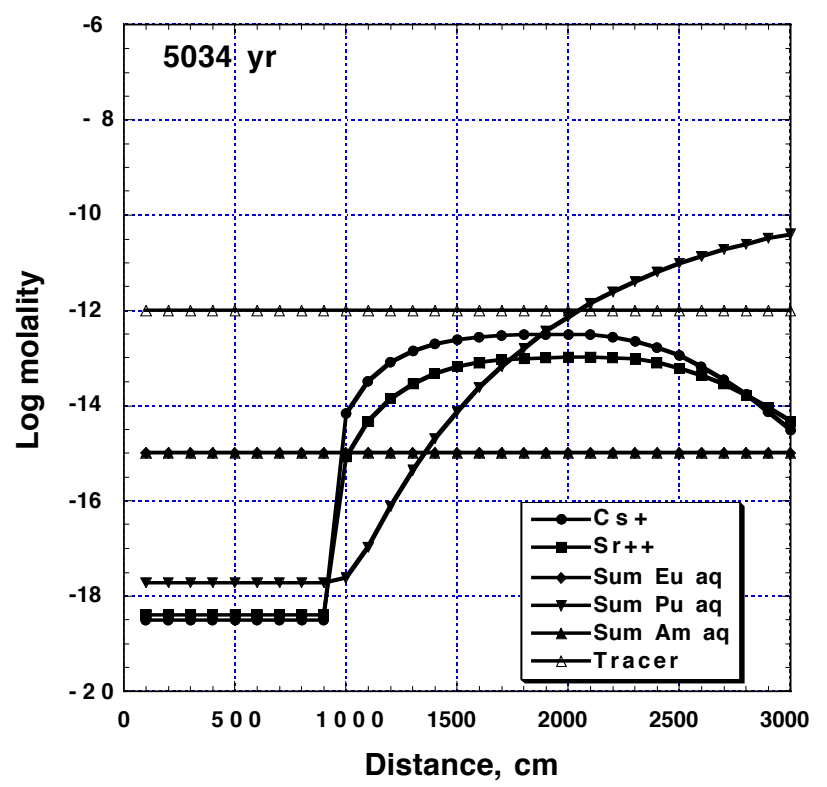

Figure 92: Spatial distribution of total $\mathrm{Cs}, \mathrm{Sr}, \mathrm{Eu}, \mathrm{Pu}$ and Am molalities in solution at 5034 years in alluvium-exchange volume-alluvium 1D GIMRT simulation. Non-reactive tracer concentration shown for reference. 


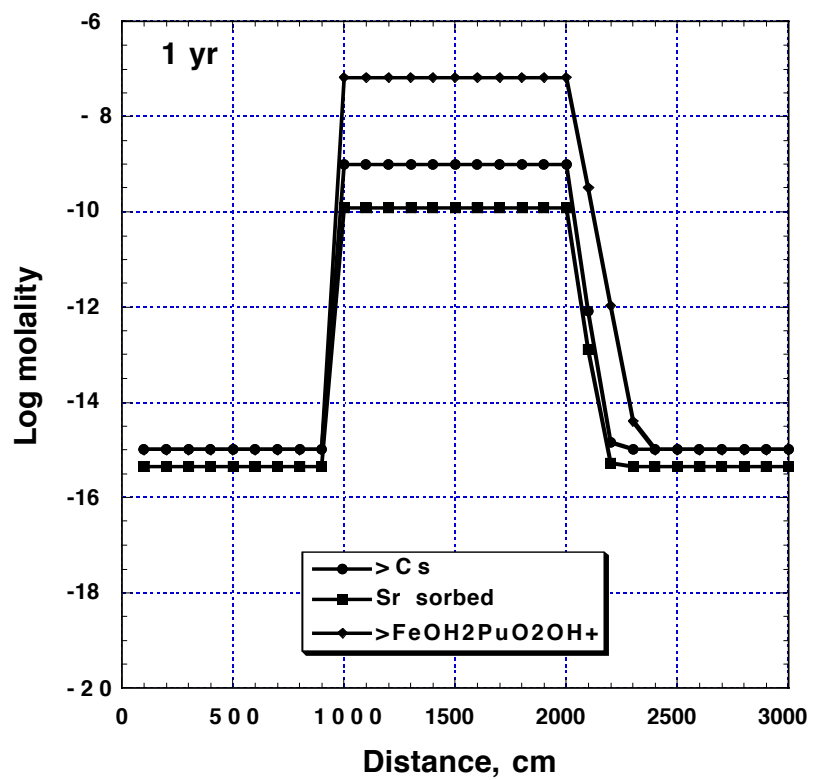

Figure 93: Molalities of $\mathrm{Cs}, \mathrm{Sr}$ and $\mathrm{Pu}$ associated with solid phases in the exchange volume at 1 year. $>\mathrm{Ca}=\mathrm{Ca}$ exchanged onto clinoptilolite, $\mathrm{Sr}$ sorbed $=$ sum of molalities of $\mathrm{Sr}$ surface complexes on goethite, $\rangle \mathrm{FeOH}_{2} \mathrm{PuO}_{2} \mathrm{OH}^{+}=$ $\mathrm{Pu}$ surface complex on goethite. 


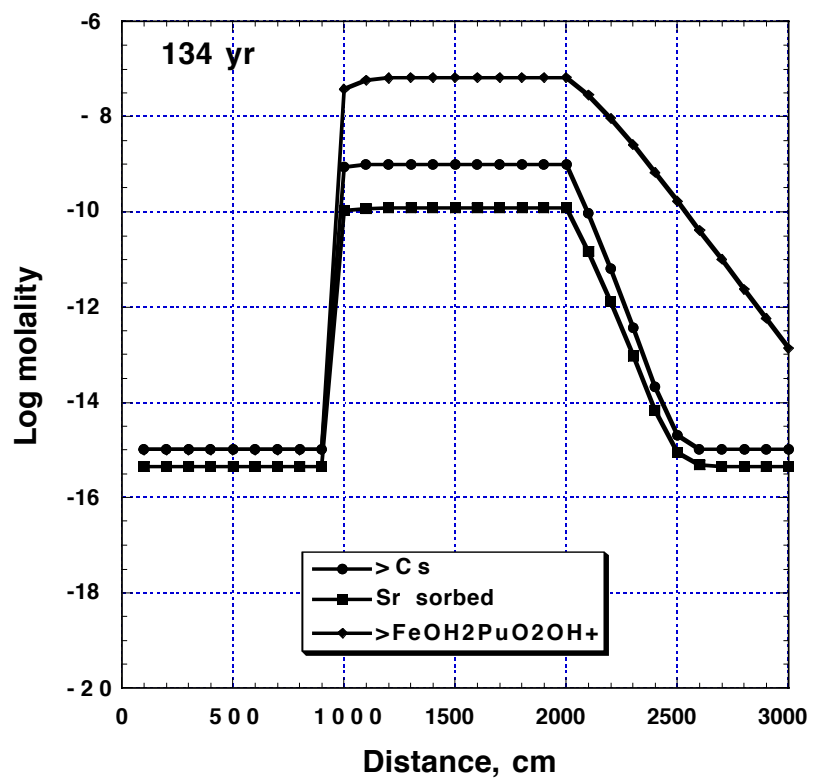

Figure 94: Molalities of $\mathrm{Cs}, \mathrm{Sr}$ and $\mathrm{Pu}$ associated with solid phases in the exchange volume at 134 years. $\rangle \mathrm{Ca}=\mathrm{Ca}$ exchanged onto clinoptilolite, $\mathrm{Sr}$ sorbed $=$ sum of molalities of $\mathrm{Sr}$ surface complexes on goethite, $\rangle \mathrm{FeOH}_{2} \mathrm{PuO}_{2} \mathrm{OH}^{+}=$ $\mathrm{Pu}$ surface complex on goethite. 


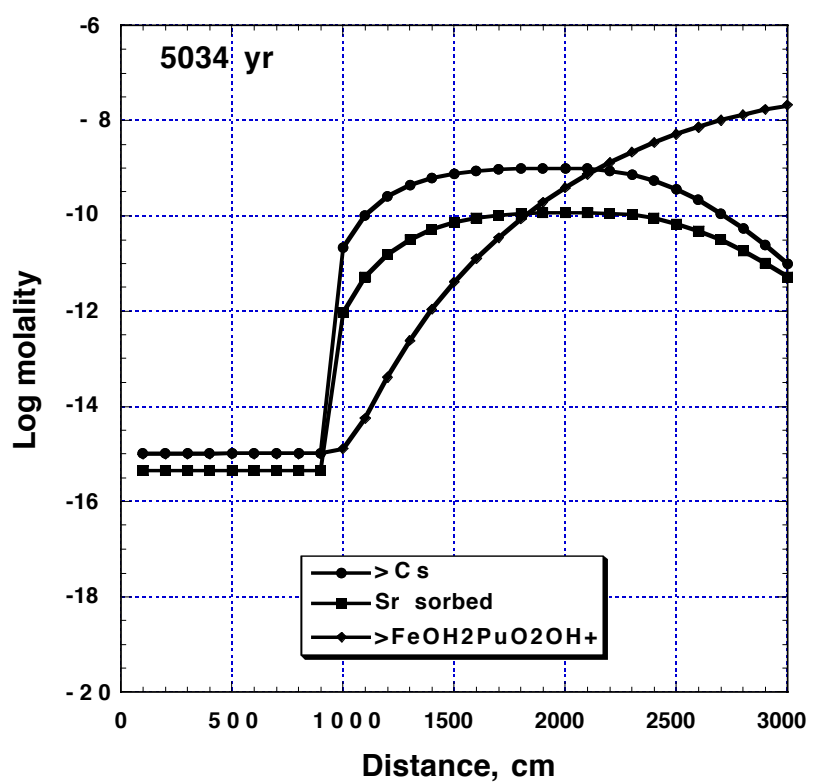

Figure 95: Molalities of $\mathrm{Cs}, \mathrm{Sr}$ and $\mathrm{Pu}$ associated with solid phases in the exchange volume at 5034 years. $>\mathrm{Ca}=\mathrm{Ca}$ exchanged onto clinoptilolite, $\mathrm{Sr}$ sorbed $=$ sum of molalities of $\mathrm{Sr}$ surface complexes on goethite, $\rangle \mathrm{FeOH}_{2} \mathrm{PuO}_{2} \mathrm{OH}^{+}=$ $\mathrm{Pu}$ surface complex on goethite. 


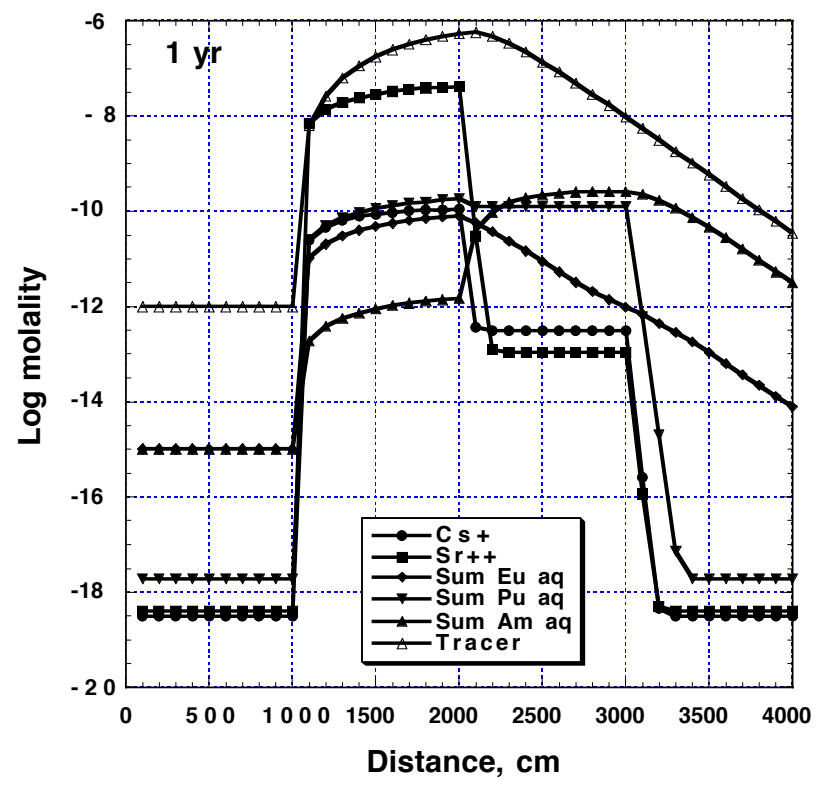

Figure 96: Spatial distribution of total $\mathrm{Cs}, \mathrm{Sr}, \mathrm{Eu}, \mathrm{Pu}$ and Am molalities in solution at 1 year in alluvium-glass-exchange volume-alluvium 1D GIMRT simulation. Non-reactive tracer concentration shown for reference.

in Fig. 90). The Pu concentration decreases slightly and the Am concentration increase greatly in the transition from glass to the exchange volume because the fluid in the exchange volume contains higher concentrations of $\mathrm{Pu}$ and $\mathrm{Am}$ than those produced by glass dissolution. Table 12 shows that the initial concentrations of $\mathrm{Pu}$ and $\mathrm{Am}$ in the exchange volume pore fluids are about 3 orders of magnitude greater than those of $\mathrm{Sr}, \mathrm{Cs}$ and $\mathrm{Eu}$. Once the radionuclides reach the initially radionuclide-free alluvium at $30 \mathrm{~m}$, the clays, zeolite and goethite act to sequester $\mathrm{Pu}, \mathrm{Sr}$ and $\mathrm{Cs}$ and retard their transport, as described in the previous 1D simulations.

Tracer was present initially at $1 \times 10^{-6} \mathrm{~m}$ in the melt glass only. Eu roughly follows the tracer concentration profile because its initial concentrations in the exchange volume fluid are much smaller than the Eu added to solution via glass dissolution. 


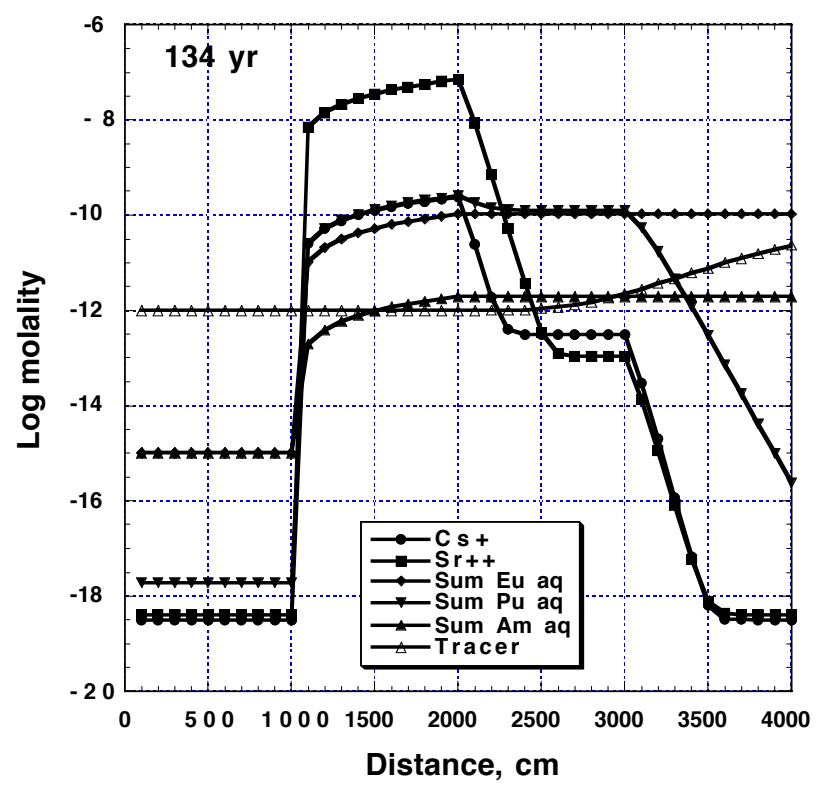

Figure 97: Spatial distribution of total $\mathrm{Cs}, \mathrm{Sr}, \mathrm{Eu}, \mathrm{Pu}$ and $\mathrm{Am}$ molalities in solution at 134 years in alluvium-glass-exchange volume-alluvium 1D GIMRT simulation. Non-reactive tracer concentration shown for reference. 


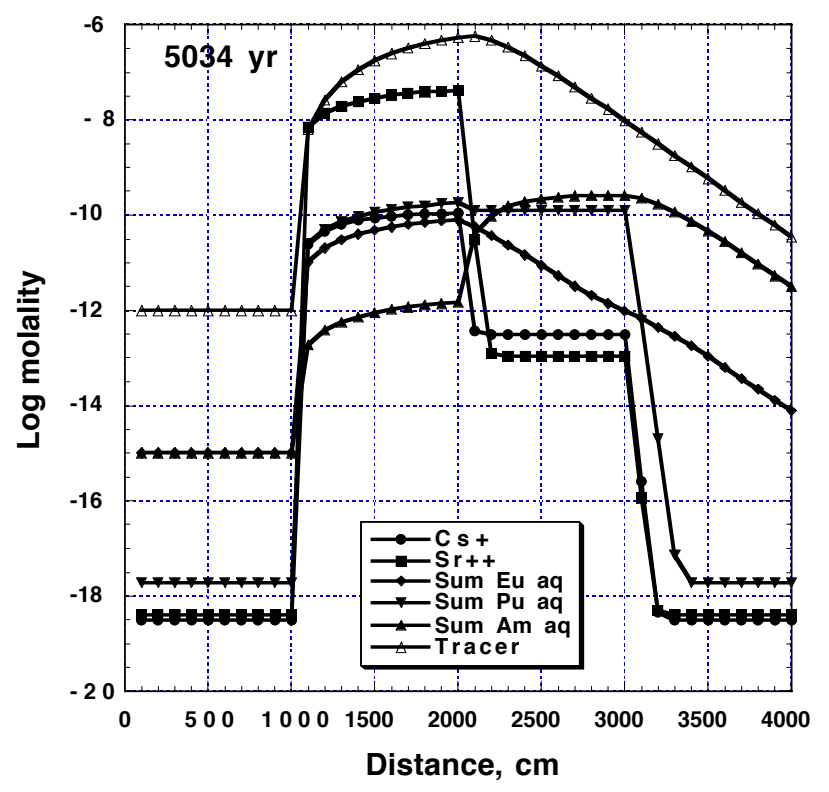

Figure 98: Spatial distribution of total $\mathrm{Cs}, \mathrm{Sr}, \mathrm{Eu}, \mathrm{Pu}$ and $\mathrm{Am}$ molalities in solution at 5034 years in alluvium-glass-exchange volume-alluvium 1D GIMRT simulation. Non-reactive tracer concentration shown for reference. 


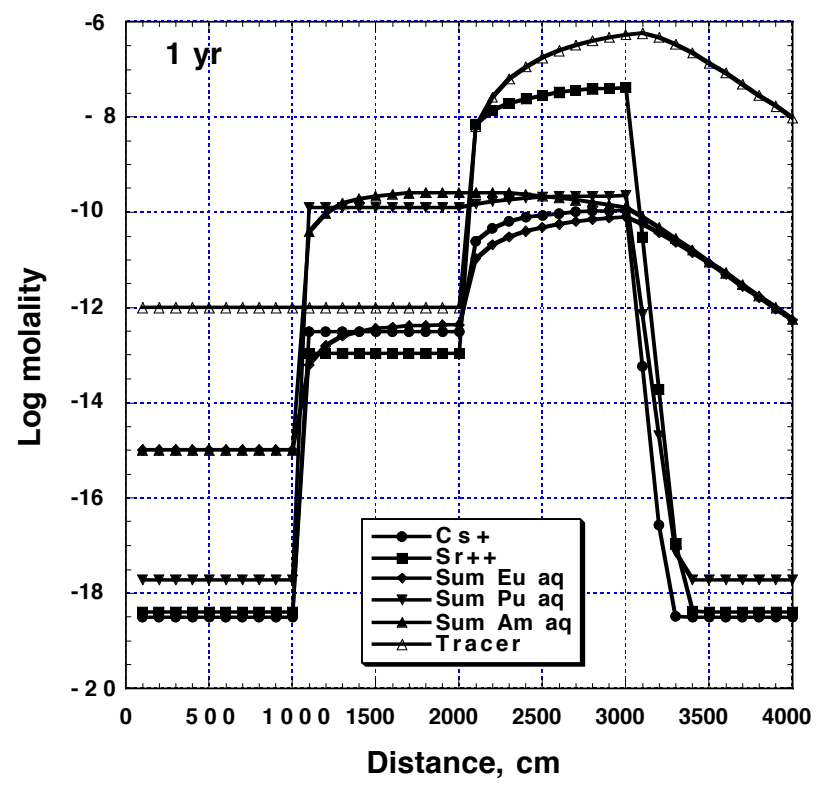

Figure 99: Spatial distribution of total $\mathrm{Cs}, \mathrm{Sr}, \mathrm{Eu}, \mathrm{Pu}$ and Am molalities in solution at 1 year in alluvium-exchange volume-glass-alluvium 1D GIMRT simulation. Non-reactive tracer concentration shown for reference.

\section{Alluvium-exchange volume-melt glass-alluvium}

Figure 33 displays the sequence of rocks types intersected in this simulation. Simulation results are summarized in Figures 99 through 101. From 10 to $20 \mathrm{~m}$, $\mathrm{Sr}, \mathrm{Cs}$ and $\mathrm{Pu}$ concentrations in solution are held constant for extended periods in the exchange volume because of the mass of sorbents present and their affinity for the radionuclides. The typical increase in radionuclide concentrations during flow through the glass from 20 to $30 \mathrm{~m}$ is observed, as is subsequent retardation of $\mathrm{Sr}, \mathrm{Cs}$ and $\mathrm{Pu}$ in the alluvium downstream from the glass. 


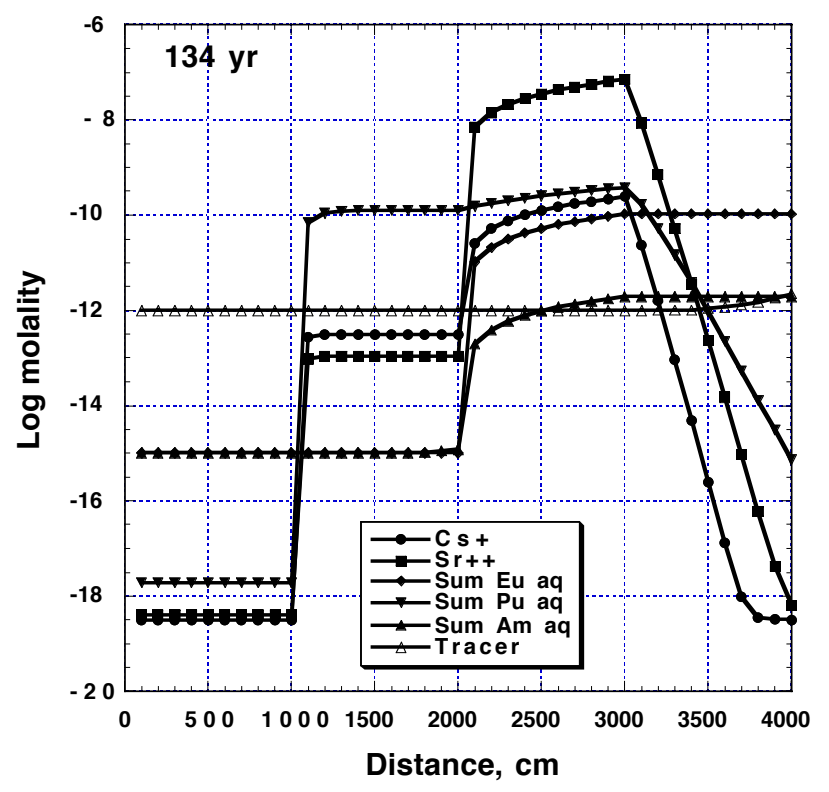

Figure 100: Spatial distribution of total $\mathrm{Cs}, \mathrm{Sr}, \mathrm{Eu}, \mathrm{Pu}$ and Am molalities in solution at 134 years in alluvium-exchange volume-glass-alluvium 1D GIMRT simulation. Non-reactive tracer concentration shown for reference. 


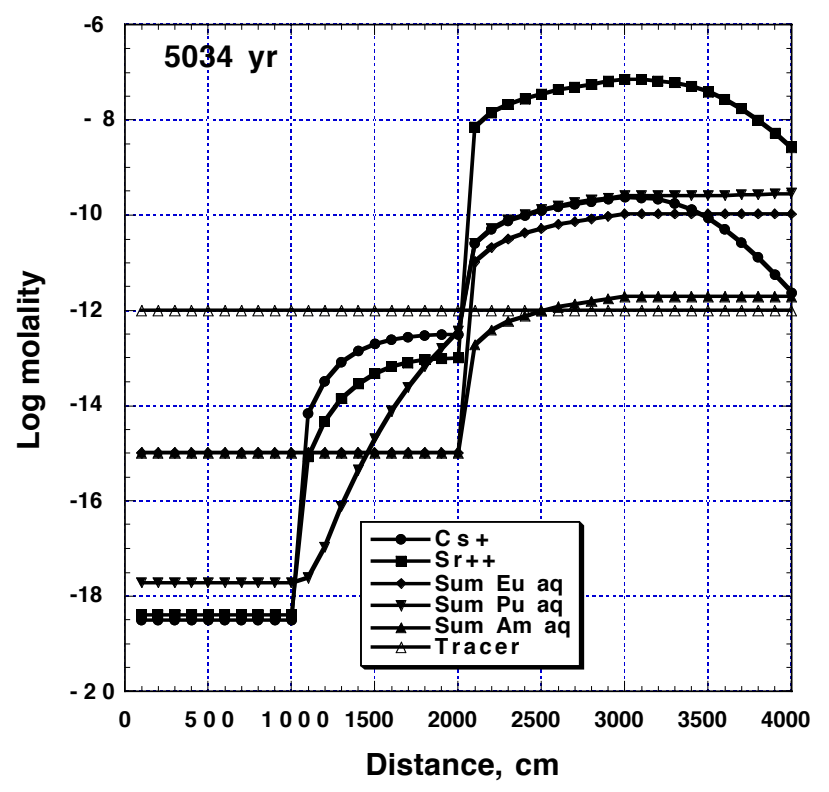

Figure 101: Spatial distribution of total $\mathrm{Cs}, \mathrm{Sr}, \mathrm{Eu}, \mathrm{Pu}$ and Am molalities in solution at 5034 years in alluvium-exchange volume-glass-alluvium 1D GIMRT simulation. Non-reactive tracer concentration shown for reference. 


\section{Appendix 6: Streamline Transport Model}

\section{Basic concepts}

Consider the transport of a dilute, conservative chemical species in a steady three-dimensional groundwater flow field in the absence of dispersion, diffusion, or reaction processes. If we assume that the fluid density is approximately constant, then the concentration $c(\mathbf{x}, t)$ will satisfy

$$
\frac{\partial c}{\partial t}+\mathbf{v} \cdot \nabla c=0
$$

or, equivalently,

$$
\frac{\partial c}{\partial t}+V \frac{\partial c}{\partial s}=0
$$

where $s$ is a curvilinear coordinate aligned with the direction of flow and $V(s) \equiv$ $|\mathbf{v}|$.

In a steady, incompressible flow field, the locus of points traced out by a particle passing through a point $\mathbf{x}$ defines a streamline whose length is described by the coordinate $s$. To each steady flow field, there exist a continuum of streamlines. This suggests that a generically three-dimensional transport problem of the form (32) might be reduced in a discrete sense to a series of one-dimensional problems of the form (33) along a finite number of streamlines extracted from the flow field ${ }^{20}$. Clearly, the number of streamlines used will control how the problem is discretized and will ultimately affect the resolution and accuracy of the solution.

How will this work? At first, it is probably easier to conceptualize each streamline as the center of an associated streamtube that envelopes a portion of the total flow moving through the domain. The boundaries of each streamtube are collinear with the flow so that fluid may only enter or leave through the ends of the streamtube. In this sense, each streamline or streamtube will occupy some volumetric fraction of the flow domain into which transport or other mass balance problems can be effectively parceled.

For example, the pore volume in a streamtube between an initial point located at $\zeta=0$ and an arbitrary intermediate point $s$ is

$$
\mathcal{V}(s)=\int_{0}^{s} \phi(\zeta) A(\zeta) d \zeta
$$

where $\phi(\zeta)$ is the porosity and $A(\zeta)$ is the cross-sectional area of the streamtube at location $\zeta$. Although the cross-sectional area and velocity may fluctuate as

\footnotetext{
${ }^{20}$ Note, also, that if the flow field is transient, then streamlines will migrate accordingly, and additional "streakline" and "pathline" concepts may be required in the solution of mass transport problems (Batycky, 1997). These will not be considered here.
} 
a result of porosity variations or converging and diverging flows, the total flow remains fixed; e.g.,

$$
Q \approx \phi(s) V(s) A(s),
$$

where the streamline velocity is used to approximate a cross-sectional average velocity.

Importantly, the choice of $Q$ or $A(s)$ at some point on a streamline will ultimately define the size or volume of the associated streamtube. A larger flux or cross-sectional area will correspond to a larger streamtube and a coarser representation of the flow behavior; a smaller flux or area will correspond to a finer representation. Thus, "better resolution" translates into a higher density of streamlines with smaller cross-sectional areas.

It is not important to explicitly map out the geometrical boundaries of streamtubes. In fact, this would be a very difficult and frustrating task that is largely unnecessary. This will be made clearer below.

\section{Mapping streamlines}

In traditional finite difference models of steady groundwater flow, streamlines may be easily mapped from initial points lying along an inflow boundary towards final points lying on an exit boundary (Pollock, 1988). They may also be mapped between injection and production wells (Thiele et al., 1996), or between arbitrary internal surfaces or points. This procedure allows streamline coordinates, velocities, and travel times to be readily identified at arbitrary space or time intervals. Streamtube fluxes and cross-sectional areas may then be defined and assigned accordingly.

For example, consider a typical finite difference model of groundwater flow through a prismatic block domain of dimensions $L_{x}, L_{y}$, and $L_{z}$ in which the flow is constrained to enter and exit the negative and positive $\mathrm{x}$-coordinate faces of the domain, respectively, with the other boundaries being impermeable. Consider, further, a particular finite difference block of dimensions $\Delta x, \Delta y$, and $\Delta z$ lying at the upstream boundary of the domain. Suppose the normal Darcy

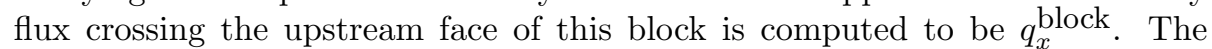
total flux entering the domain through this block can then be approximated by $Q^{\text {block }} \approx q_{x}^{\text {block }} \Delta y \Delta z$.

Suppose further that a single streamline $i$ is launched from the center of the block inflow face and mapped downstream to the exit face of the domain. All other things being equal, we could assign the total flux entering the block to a streamtube about this streamline such that $Q_{i}=Q^{\text {block }}$ and $A_{i}(0)=\Delta y \Delta z$. Thus, at any point $s$ along this streamline where the streamline velocity $V_{i}(s)$ can estimated from the flow solution, the equivalent streamtube cross-sectional area could be inferred from (35) as $Q_{i} / \phi(s) V_{i}(s)$.

Alternatively, suppose four streamlines $j=1,2,3,4$ are launched from equallyor randomly-parceled locations on the same block inflow face. In this case, the 
resolution is finer and each streamline can be associated with smaller diameter streamtubes with smaller fluxes. Because the entry flux cannot be resolved any finer than the scale of the finite difference block itself, the total flux $Q^{\text {block }}$ might, as an approximation, be parceled out equally among the four streamtubes that correspond to the four streamlines such that $Q_{j}=Q^{\mathrm{block}} / 4$ and $A_{j}(0)=\Delta y \Delta z / 4$.

Thus, streamlines and their associated streamtubes can be launched from all (or some) of the entrance face blocks in a similar fashion to effectively parcel all (or a specified fraction) of the flow in the domain to the requisite streamtubes. Accordingly, the streamline density at the inflow face can be adjusted to control the resolution of this process. Alternatively, streamlines could also be launched from specific internal cross sections that intersect the flow field.

Although streamtube boundaries cannot be explicitly recorded in this process, the variation of the streamtube cross-sectional area can be estimated as a function of the streamline coordinate. To complete the transport simulations within each streamtube, a discrete form of the one-dimensional transport equation (33), expressed in terms of cross-sectional area and cross-sectionally averaged concentrations, must be obtained to account for fluctuations in the volume or area that accompany converging or diverging flows. Although this could be readily accomplished, we will now review a simpler, alternative formulation that eliminates the need for explicitly including area in the equation altogether.

\section{Time-of-flight formulation}

Consider the motion of an infinitesimal fluid or tracer parcel along a streamline extracted from a steady, three-dimensional flow field. The time-of-flight

$$
\tau(s)=\int_{0}^{s} \frac{1}{V(\zeta)} d \zeta
$$

represents the parcel's travel time from an initial point located at $s=0$ to an arbitrary intermediate point located at $s$. Equation (36) can be used to show

$$
\frac{\partial \tau}{\partial s}=\frac{1}{V}
$$

such that (33) may be transformed into an equivalent time-of-flight form (Thiele, et al., 1996; Batycky, 1997):

$$
\frac{\partial c}{\partial t}+\frac{\partial c}{\partial \tau}=0
$$

Because of its dependence on the time-of-flight $\tau$, this equation automatically incorporates the volumetric information contained in a surrounding streamtube without explicit reference to cross-sectional area. This can be seen by associating 
a total flux $Q$ to a streamtube surrounding the streamline, using the methods discussed above, and then reexpressing the streamtube volume $\mathcal{V}(s)$ in (34) as

$$
\mathcal{V}(s)=\int_{0}^{s} \phi(\zeta) A(\zeta) d \zeta=\int_{0}^{s} \frac{Q}{V(\zeta)} d \zeta=Q \tau(s) .
$$

Thus, variations in time-of-flight will account directly for variations in streamtube volume.

Under this formulation, streamline transport simulations should be based upon (38) as opposed to (33). This approach is advantageous because streamline coordinate and travel time information is easily mapped out from threedimensional flow simulations, and provide a natural way to implement the transformation in (37). The complicated area and volumetric information embodied in (34) do not have to be calculated.

\section{Relating streamline and grid-block quantities}

Transferring streamline concentration information to an orthogonal background grid (consistent with the flow model, for example) may be required at specific times to graphically illustrate the spatial distribution of $c$ or to facilitate the solution of more complicated problems in unsteady flow fields. Conversely, grid information may have to be transferred back to the streamlines for similar purposes or to develop initial conditions for the streamline simulations.

This can generally be accomplished in a consistent manner using the approach of Batycky (1997, Section 4.3). In brief, a grid block concentration $c_{g b}$ at some time $t$ may be calculated from a weighted sum of the average concentrations $c^{s l}$ along all streamlines that pass through that grid block. That is, for a series of streamlines $i$ passing through the block,

$$
c_{g b}=\sum_{i} \omega_{i} c_{i}^{s l}
$$

where the weighting factor is made proportional to the incremental time-of-flight and total flux $Q_{i} \Delta \tau_{i}$ via

$$
\omega_{i}=\frac{Q_{i} \Delta \tau_{i}}{\sum_{i} Q_{i} \Delta \tau_{i}} .
$$

Referring to (39), this ratio can also be interpreted as a streamtube volume fraction.

\section{Adding dispersion, diffusion, and reaction processes}

The streamline approach can additionally treat longitudinal dispersion and diffusion behavior along a streamline, as well as many types of reaction processes. Unfortunately, cross-streamline mass transfer (as produced by transverse dispersion or diffusion processes) is not as easily incorporated into the method. 
Although this is a significant limitation, it is not expected to be pronounced in highly-resolved problems where advection processes are dominant (Theiele et al., 1996). Most of our applications are expected to fall into this category.

Under conditions of constant fluid density and steady porosity, an equivalent version of (33) that includes these processes and is pertinent to this work is described by equation (26) of Appendix 2,

$$
\phi \frac{\partial}{\partial t}\left(u_{j}+u_{j}^{i m}\right)+\phi V \frac{\partial u_{j}}{\partial s}-\frac{\partial}{\partial s}\left(\phi D_{L} \frac{\partial u_{j}}{\partial s}\right)=-\sum_{m=1}^{N_{m}} \nu_{j m} r_{m}
$$

where the streamline coordinate $s$ has been substituted. Recall that the $u_{j}$ represent total (molar) concentrations of the principal mobile species, the $u_{j}^{i m}$ are the corresponding (molar) concentrations of the immobile species, and the $r_{m}$ correspond to the rates of various precipitation and dissolution reactions.

An equivalent time-of-flight version of (42) will be used to perform streamline reactive transport simulations in this report. Using (37) this equation can be written as

$$
\phi \frac{\partial}{\partial t}\left(u_{j}+u_{j}^{i m}\right)+\phi \frac{\partial u_{j}}{\partial \tau}-\frac{1}{V} \frac{\partial}{\partial \tau}\left(\left(\phi \alpha_{L}+\frac{\phi \mathcal{D}_{e}}{V}\right) \frac{\partial u_{j}}{\partial \tau}\right)=-\sum_{m=1}^{N_{m}} \nu_{j m} r_{m}(43)
$$

where the definition of $D_{L}$, as described by (22) in Appendix 2, has been substituted. 


\section{Appendix 7: Analyses of single streamline simu- lations}

To illustrate the geochemical controls of radionuclide concentrations, we analyzed reactive behavior predicted by GIMRT along the streamlines 100 and 145 in each of the mineralogic model configurations $(10,11$ and 12) discussed in Chapter 11 above. These simulations (as well as all other streamline runs) were made with a version of GIMRT modified for the time of flight formulation of the transport equations, as described in Appendix 6.

Streamline 100 crosses through alluvium and the exchange volume, while streamline 145 intersects alluvium, melt glass, and exchange volume. The specific sequences of geologic units along each streamline are illustrated in Table 30 as well as Figures 102 and 105. Each streamline, although curving in 3D space, is conceptualized as a one-dimensional pathway and the geochemistry illustrated as a function of distance along the streamline. The length of streamlines 100 and 145 extend over 481 and 490 meters, respectively. In all figures below, the spatial distance coordinate refers to length along each streamline referenced from its upstream end, as opposed to the internal point that was used to define the streamline in the first place.

As described previously, the chemical processes that impact radionuclide migration in each mineralogic model are as follows. Mineralogic Model 10 considers the effects of surface complexation onto hydrous ferric oxide and ion exchange onto smectite, illite/muscovite and clinoptilolite in the alluvium and exchange volume. In Model 11, the masses of these phases have been set to zero and replaced by an equivalent volume of inert matrix. A heterogeneous distribution of sorbent and ion exchangers based on the conductivity distribution is considered in Mineralogic Model 12.

The elemental concentrations considered along the streamlines are not corrected for radioactive decay. The concentrations of $\mathrm{Eu}$, $\mathrm{Cs}$ and $\mathrm{Sr}$ represent total elemental concentrations rather than the concentrations of the radiogenic isotopes ${ }^{155} \mathrm{Eu},{ }^{137} \mathrm{Cs}$ and ${ }^{90} \mathrm{Sr}$. The concentrations of the radioactive isotopes can be calculated using the conversion factors given in Table 13.

Each streamline contains over 300 grid points. In the following figures, markers on lines are not placed at every grid point, which would obscure the lines owing to their density, but are spaced at intervals to help distinguish among the curves. The geochemical state of the system at every grid point was captured at $1 \times 10^{-5}, 100,200,300,400,500$ and 600 years. The conditions at $1 \times 10^{-5}$ years (0.00365 days) are equivalent to those of the initial state of the system, and will be used in the following discussions to represent the chemical state of the initial system.

Unlike the simplistic 1D GIMRT simulations, the Darcy flux and mean seepage velocity along the streamlines varies from grid point to grid point. Unique geochemical behavior can therefore be produced merely by allowing more or 
Table 30: Geologic units intersected by streamlines 100 and 145, and the approximate distance along the streamline at which each unit is intersected, in meters.

\begin{tabular}{cll}
\hline \hline & & \multicolumn{2}{c}{ Geologic unit } \\
Path coordinate, $s(\mathrm{~m})$ & Line 145 & Line 100 \\
& & \\
\hline & Alluvium & Alluvium \\
232 & $\vdots$ & Exchange volume \\
239 & Exchange volume & $\vdots$ \\
245 & Alluvium & $\vdots$ \\
246 & Exchange volume & $\vdots$ \\
252 & Melt glass & $\vdots$ \\
255 & Exchange volume & $\vdots$ \\
257 & Melt glass & $\vdots$ \\
261 & Alluvium & $\vdots$ \\
263 & $\vdots$ \\
490 & $\vdots$ & $\vdots$ \\
\end{tabular}

less time for reaction between rock and fluid to occur over the space of a grid block. Because of the detailed resolution used in this modeling approach, local longitudinal dispersion and diffusion processes along the lines are not included, as they would be small in magnitude and possibly overshadowed by numerical dispersion effects.

Larger scale dispersion effects will be produced by the heterogeneity in the medium properties (as discussed in Chapter 10) as observed over the larger scale associated with the entire modeling domain.

\section{Mineralogic Model 10}

Streamline 100. The initial total concentrations of $\mathrm{Cs}, \mathrm{Sr}, \mathrm{Eu}, \mathrm{Pu}$ and $\mathrm{Am}$ in the aqueous phase along streamline 100 for Mineralogic Model 10 are shown in Figure 102. The streamline runs through alluvium everywhere along its length 


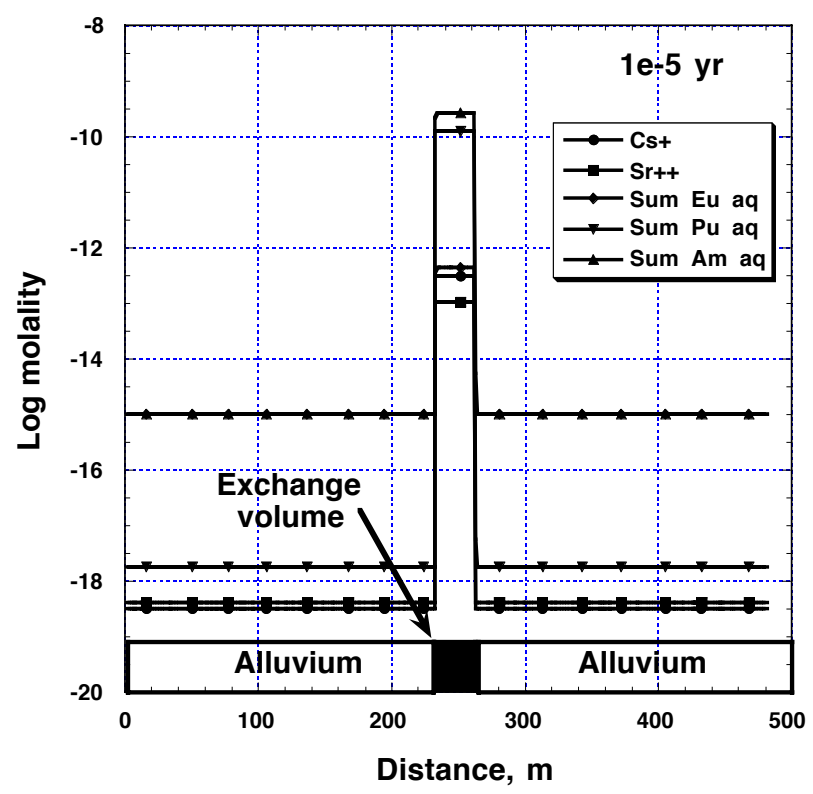

Figure 102: Spatial distribution of total $\mathrm{Cs}, \mathrm{Sr}, \mathrm{Eu}, \mathrm{Pu}$ and Am molalities in solution at $1 \times 10^{-5}$ years along streamline 100 in Mineralogic Model 10 simulation. Geologic units intersected along flow path shown at bottom of figure.

except from about 232 to 263 meters, when the exchange volume is traversed (Table 30). The linear distribution of geologic units along the flow path is shown on the bottom of Figure 102.

After 100 years (Fig. 103), the Eu and Am are largely swept out of the exchange volume. The concentrations of $\mathrm{Pu}, \mathrm{Cs}$ and $\mathrm{Sr}$, however, are comparatively unchanged, and have been transported downstream less than 13 meters to 276 meters. $\mathrm{Eu}$ and $\mathrm{Am}$ are completely swept out of the exchange volume and transported over 200 meters downstream from the exchange volume after 600 years (Fig. 104). In contrast, Cs and Sr have migrated only about 9 meters downstream, and $\mathrm{Pu}$ about 27 meters. As previously discussed, elemental concentrations equal to and less than 1e-15 molal can be considered equal to zero in the simulations.

$\mathrm{Pu}, \mathrm{Cs}$ and $\mathrm{Sr}$ are tightly bound by goethite $(\mathrm{Pu}, \mathrm{Sr})$, illite/muscovite $(\mathrm{Cs})$, 


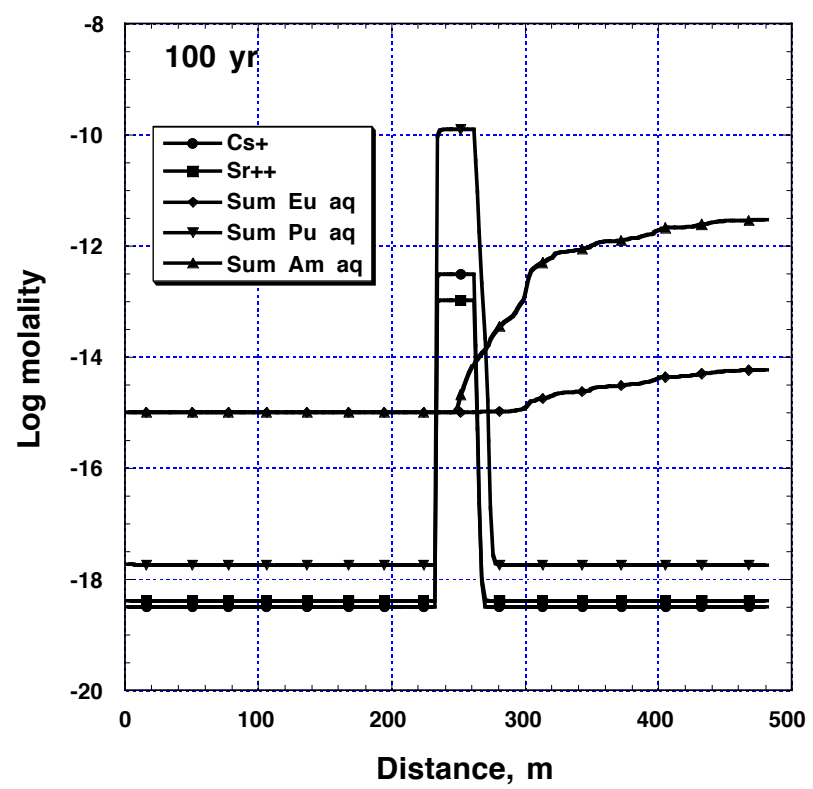

Figure 103: Spatial distribution of total $\mathrm{Cs}, \mathrm{Sr}, \mathrm{Eu}, \mathrm{Pu}$ and Am molalities in solution at 100 years along streamline 100 in Mineralogic Model 10 simulation. 


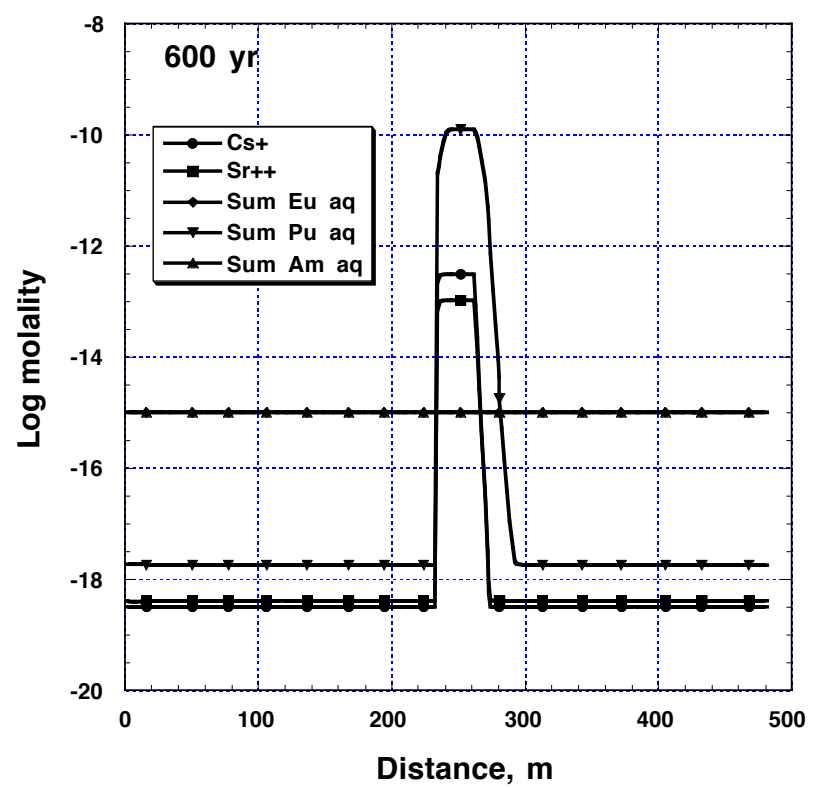

Figure 104: Spatial distribution of total $\mathrm{Cs}, \mathrm{Sr}, \mathrm{Eu}, \mathrm{Pu}$ and Am molalities in solution at 600 years along streamline 100 in Mineralogic Model 10 simulation. 
and clinoptilolite and smectite ( $\mathrm{Sr}$ ) in the exchange volume. In contrast, $\mathrm{Eu}$ and Am are contained entirely in the initial exchange volume fluid, and are not affected by sorption or ion exchange in this preliminary simulation. Lacking a mechanism for retardation and in the absence of continued release from glass or reactive minerals, $\mathrm{Eu}$ and $\mathrm{Am}$ are completely removed from the system by 600 years.

The Model 10 simulation illustrates how hydrous ferric oxides and ion exchangers such as illite/muscovite, smectite and zeolites can effectively retard radionuclide migration. However, the extent to which radionuclides are retarded suggests that we overestimated the retardation capacity of the alluvium by selecting the distribution and properties of the alluvium as we did. The extent to which the simulation forecasts radionuclide behavior in the natural system depends on how well we have characterized and described the natural system. For example, it was assumed that all minerals are distributed homogeneously through the alluvium and exchange volume, and are contacted by every volume of groundwater passing through the system. However, the heterogeneous nature of sediments and rocks and the fluid flow within them is well documented. In addition, the degree of retardation is determined by the reactive surface area specified for each mineral. A mineral's reactive surface is, in fact, a function of the physical structure of the alluvium and the contact area between mineral and fluid. These variables are largely unknown in natural systems at the present time. To compensate, we conducted simulations of Mineralogic Models 10 and 11 which represent end members of system behavior, and an intermediate case (Mineralogic Model 12).

Streamline 145. Despite the relative simplicity of the conceptual geometry of the CAMBRIC site used in this study (Figure 36), the tortuousity of streamline 145 causes the streamline to intersect a varied sequence of geologic units. The sequence is shown on the bottom of Figure 105. Table 30 lists the distances at which various geologic units are traversed along the streamline.

The initial distribution of elemental concentrations along streamline 145 is shown in Figures 105 and 106. The sequence of geologic units encountered is illustrated at the bottom of Figure 105. Note that the following figures focus on the interval from 200 to 300 meters within which most of the variations in chemistry and geologic units occur. The peaks and valleys of the concentration profiles in Figures 105 and 106 are caused by concentrations in the exchange volume and melt glass.

After 100 years of fluid flow, $\mathrm{Cs}, \mathrm{Pu}$ and $\mathrm{Sr}$ concentrations peak in the glass intervals, whereas their concentration profiles are shifted only slightly downstream in the exchange volume intervals (Figs. 107 and 108). Eu and Am have migrated downstream to a greater extent, and exhibit less prominent increases in concentration in the glass intervals. Concentration profiles change little from 100 to 600 years (Figs. 107 through 110). The concentration fronts for $\mathrm{Pu}, \mathrm{Cs}$ 


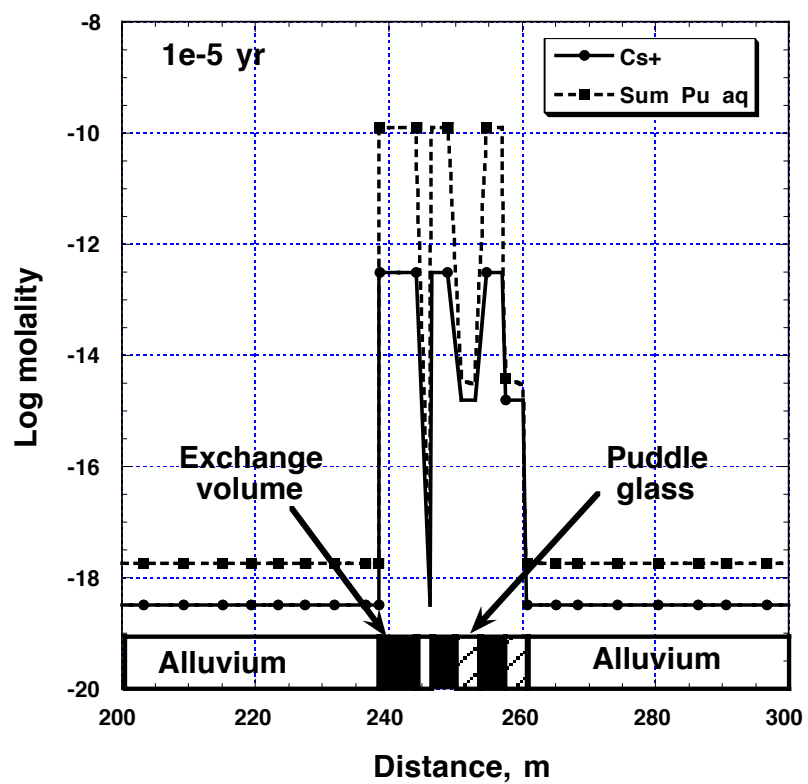

Figure 105: Spatial distribution of total $\mathrm{Cs}$ and $\mathrm{Pu}$ molalities in solution at $1 \times 10^{-5}$ years along streamline 145 in the Mineralogic Model 10 simulation. Geologic units intersected along flow path shown at bottom of figure. 


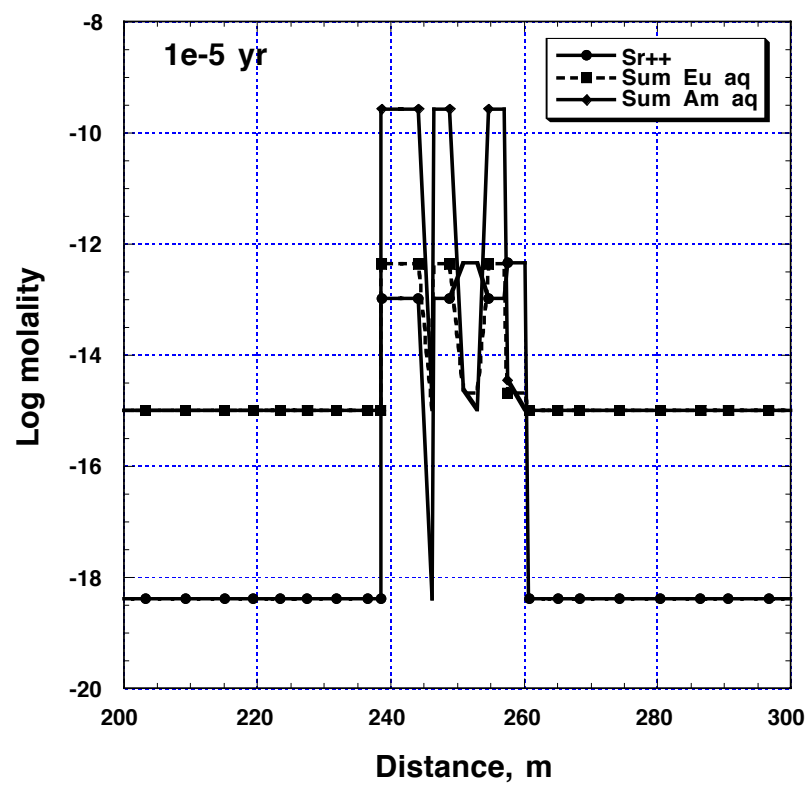

Figure 106: Spatial distribution of total $\mathrm{Sr}, \mathrm{Eu}$ and Am molalities in solution at $1 \times 10^{-5}$ years along streamline 145 in Mineralogic Model 10 simulation. 


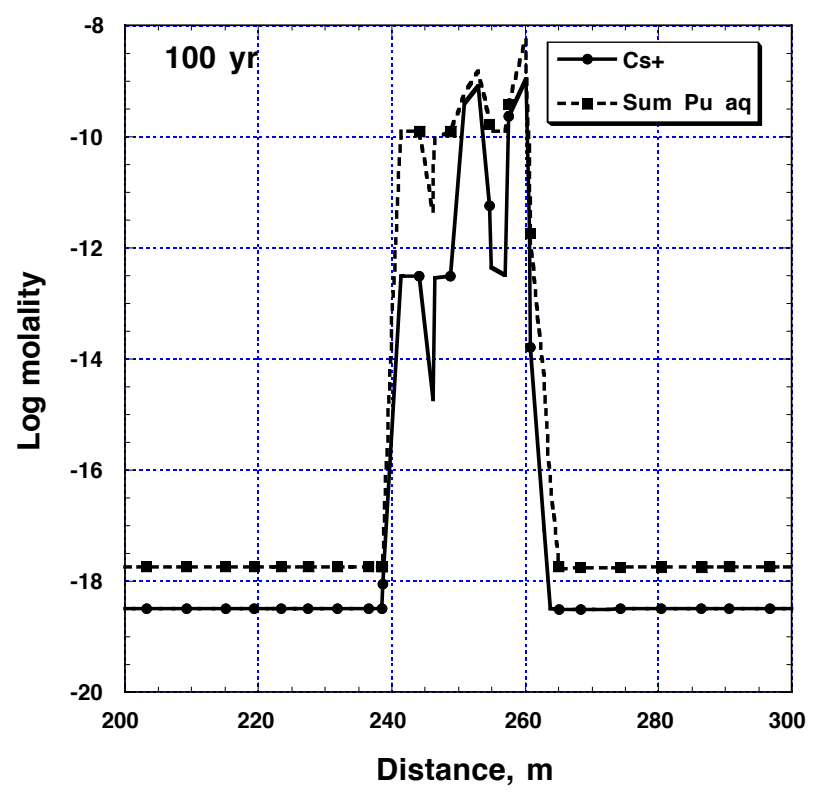

Figure 107: Spatial distribution of total Cs and Pu molalities in solution at 100 years along streamline 145 in Mineralogic Model 10 simulation.

and $\mathrm{Sr}$ have migrated less than 10 meters downstream from 100 to 600 years. Eu and Am concentrations are constant downstream of the last glass zone, fed by glass dissolution and transported by the groundwater without further reaction along the streamline.

Whereas $\mathrm{pH}$ is maintained at 8 along streamline 100 , the $\mathrm{pH}$ along streamline 145 increases to a maximum of 8.7 within the melt glass zones (Fig. 111). The increase in $\mathrm{pH}$ is caused by glass dissolution. $\mathrm{H}^{+}$ions are consumed when glass dissolves and releases an abundance of cations into solution relative to anions (see hydrolysis reaction for glass in equation 4 ). The extent of the $\mathrm{pH}$ increase depends on the path length through the glass zone and the flux of groundwater through the zone. When fluid flux is adequate, the continual influx of "fresh" pH 8 groundwater minimizes or eliminates the $\mathrm{pH}$ rise. However, fluid flux through the glass was sufficiently slow along streamline 145 that the $\mathrm{pH}$ increased in response to glass dissolution.

The 1D simulations did not show the $\mathrm{pH}$ increase because of the relatively 


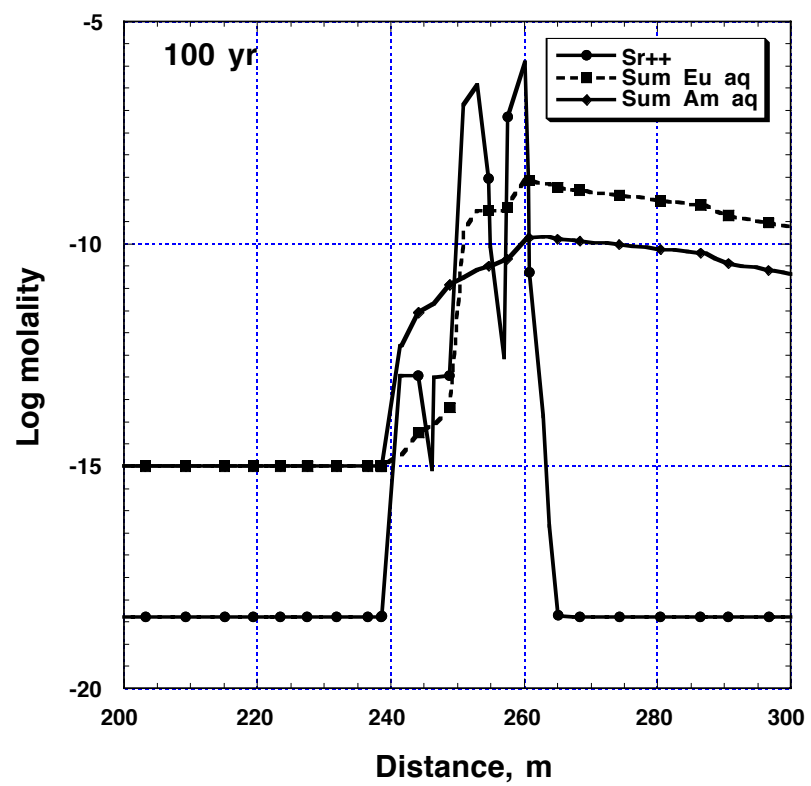

Figure 108: Spatial distribution of total Sr, Eu and Am molalities in solution at 100 years along streamline 145 in Mineralogic Model 10 simulation. 


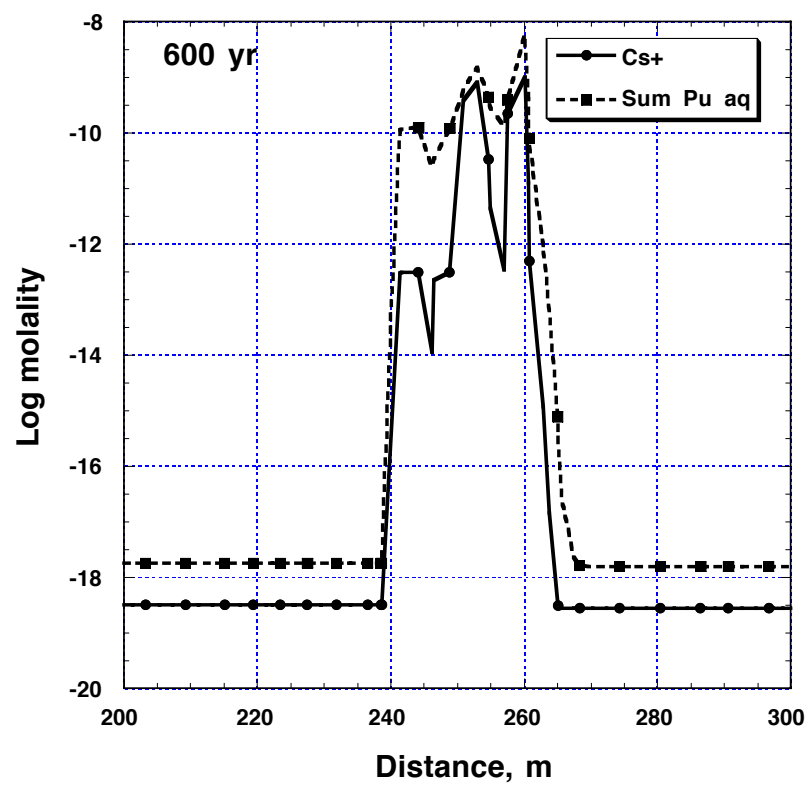

Figure 109: Spatial distribution of total $\mathrm{Cs}$ and $\mathrm{Pu}$ molalities in solution at 600 years along streamline 145 in Mineralogic Model 10 simulation. 


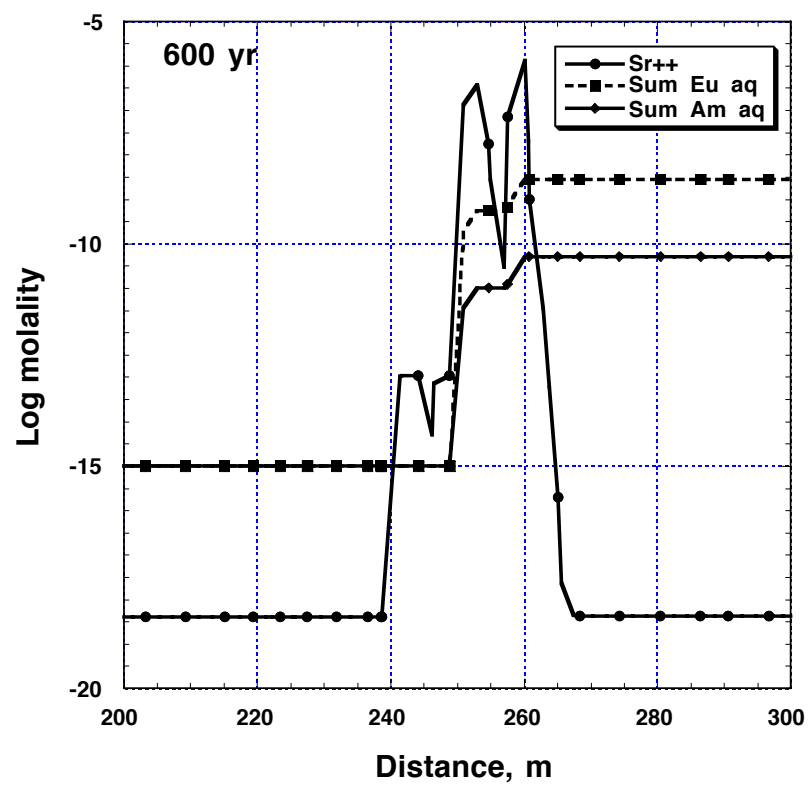

Figure 110: Spatial distribution of total Sr, Eu and Am molalities in solution at 600 years along streamline 145 in Mineralogic Model 10 simulation. 


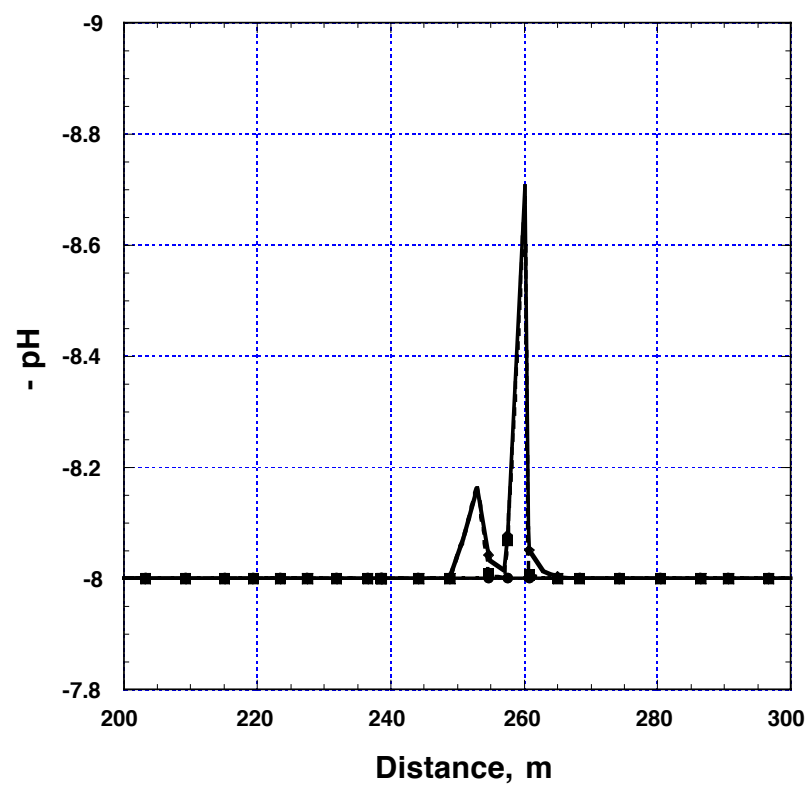

Figure 111: Values of $\mathrm{pH}$ (expressed as - $\mathrm{pH}$ ) at $1 \times 10^{-5}$ (solid with filled circle markers), 100 (dashed with filled square markers) and 600 years (solid with diamond markers) for Mineralogic Model 10, streamline 145. 
high Darcy flux $(1 \mathrm{~m} / \mathrm{yr})$ that was used. Based on the 1D simulations and the desire to simplify the geochemical system as much as possible, we used a rate constant for glass dissolution in the simulations that was relevant for $\mathrm{pH}$ $=8$ conditions. Glass dissolution rates at higher $\mathrm{pH}$ values are accelerated. According to Figure 13, glass dissolution rates will accelerate by a factor of about 2 when $\mathrm{pH}$ increases from 8 to 9 . We are thus underestimating glass dissolution rates in the melt glass by a factor of less than 2 . The $\mathrm{pH}$ dependence of the rate law for glass dissolution will be included explicitly in future GIMRT simulations.

Even though the $\mathrm{pH}$ increases within the melt glass, Figure 111 shows that the $\mathrm{pH}$ is promptly neutralized to 8 after the streamline exits the glass and enters the alluvium at about 260 meters. The goethite in the alluvium is acting as a $\mathrm{pH}$ buffer. Given the volume percent and surface properties of goethite used in the simulation, the goethite surface is an abundant source of both acid and base. The goethite surface contains both positively (\rangle $\left.\mathrm{FeOH}_{2}^{+}\right)$and negatively (\rangle $\left.\mathrm{FeO}^{-}\right)$charged surface sites. At the starting $\mathrm{pH}$ of the groundwater $(8)$ and the pristine point of zero charge (8.26) of goethite, the surface of goethite contains over 3 times as many protonated (\rangle $\left.\mathrm{FeOH}_{2}^{+}\right)$as deprotonated (\rangle $\left.\mathrm{FeO}^{-}\right)$sites. The pristine point of zero charge represents the $\mathrm{pH}$ at which the surface has zero net proton charge and zero net charge (Dzombak and Morel, 1990).

Future simulations should explore the minimum number of goethite surface sites $/ \mathrm{kg} \mathrm{H}_{2} \mathrm{O}$ at which such buffering occurs. In particular, the next set of simulations should use a smaller surface area per gram of goethite, because a high value $\left(600 \mathrm{~m}^{2} / \mathrm{g}\right)$ was used in the preliminary simulations. Additional work should also address potential neutralization processes that might occur in addition to buffering by surface-active sites on minerals such as hydrous ferric oxides. The tendency in nature is to neutralize $\mathrm{pH}$, especially once the driving force (e.g., glass dissolution) is gone.

The major element chemistry of the groundwater varies significantly within the glass puddles. The variation in major element chemistry along the entire length of the streamline at 600 years is shown in Figure 112, and the path from 250 to 262 meters which includes the glass zones $(250-254 \mathrm{~m}$ and $257-260 \mathrm{~m})$ is shown in Figure 113. $\mathrm{Ca}^{2+}, \mathrm{K}^{+}$and $\mathrm{HCO}_{3}^{-}$concentrations decrease in the glass zones, whereas $\mathrm{Na}^{+}$and $\mathrm{Mg}^{2+}$ increase. The increases in $\mathrm{Na}^{+}$and $\mathrm{Mg}^{2+}$ are due to their release from glass during dissolution. In contrast, the decreases in $\mathrm{Ca}^{2+}, \mathrm{K}^{+}$and $\mathrm{HCO}_{3}^{-}$result from mineral precipitation in the melt glass.

The volume percentages of the authigenic minerals $\beta$-cristobalite, calcite, muscovite/illite, Ca-beidellite (smectite) and goethite are shown in Figure 114 at a distance of 253 meters along the streamline within the glass zone. The linear increases in mass reflect the linear dissolution rate of the glass. Precipitation results from both the addition of elements to solution through glass dissolution and the increase in $\mathrm{pH}$ caused by glass dissolution.

The groundwater in the alluvium upstream of the glass is in equilibrium with calcite and $\beta$-cristobalite. Calcite precipitates when the $\mathrm{pH}$ increases in the glass 


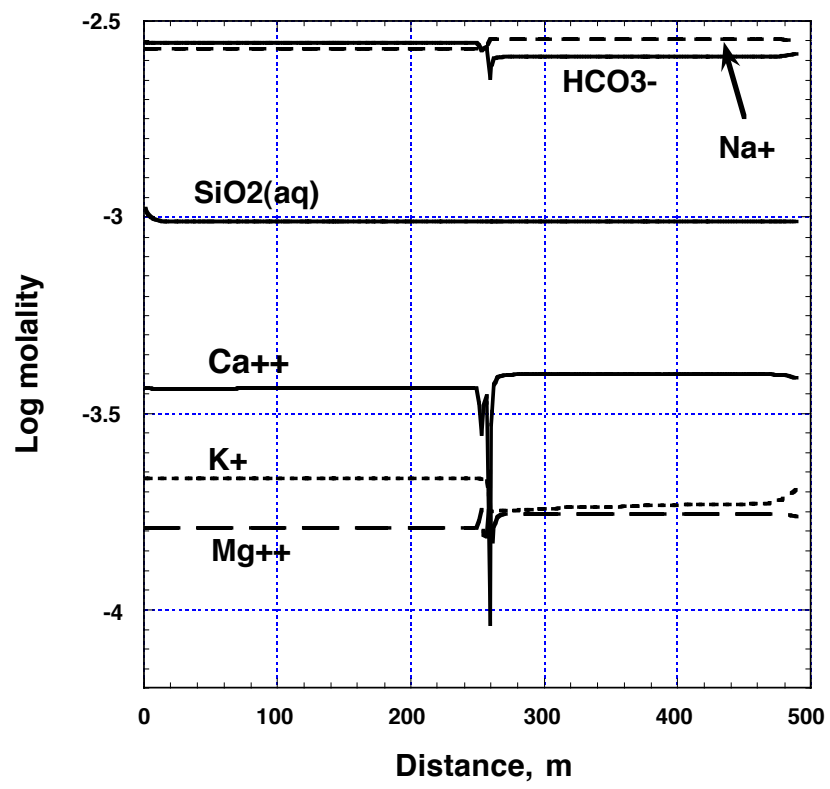

Figure 112: Major element chemistry at 600 years for Mineralogic Model 10, streamline 145 . 


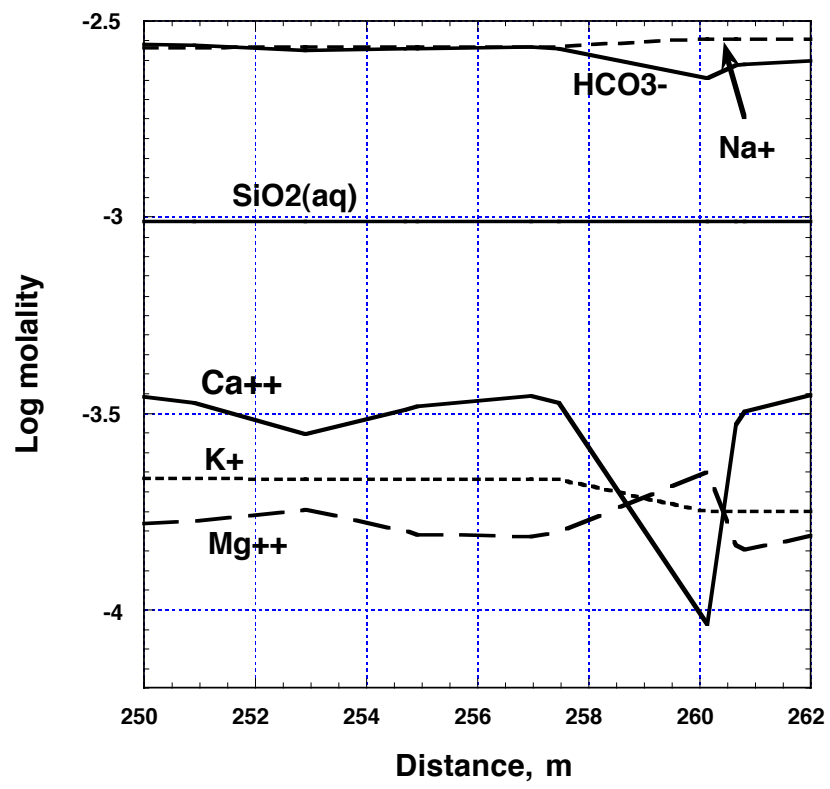

Figure 113: Major element chemistry at 600 years for Mineralogic Model 10, streamline 145 from 250 to $262 \mathrm{~m}$. 


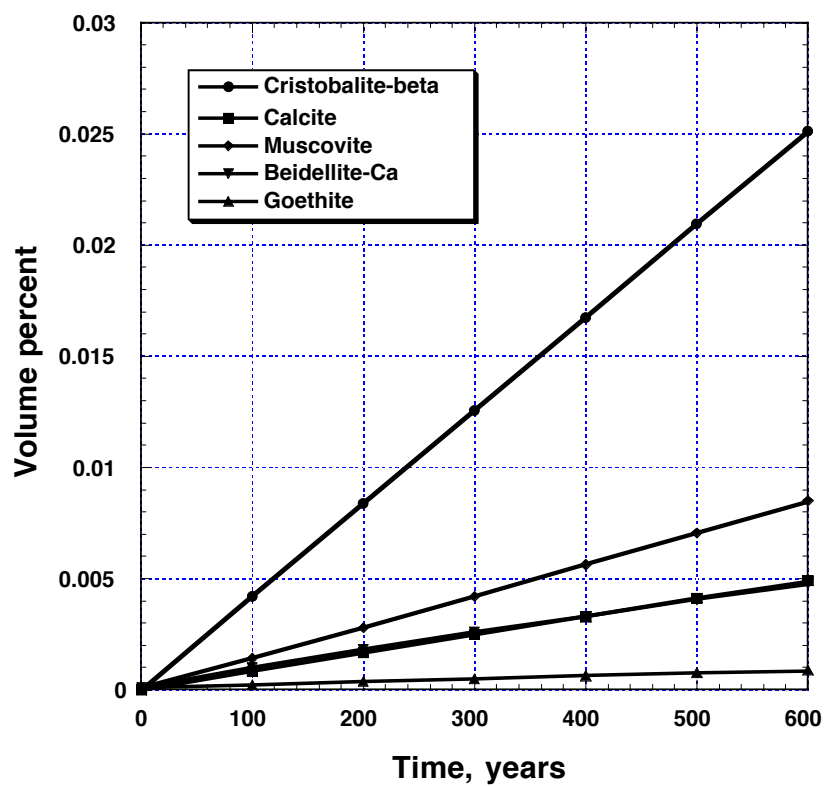

Figure 114: Volume percent of authigenic minerals precipitating in melt glass at $252.91 \mathrm{~m}$ along streamline 145 in Mineralogic Model 10. The calcite and beidellite-Ca curves are nearly coincident. 
zone. We used a rate constant for calcite dissolution/precipitation of $1 \times 10^{-10}$ $\mathrm{mol} / \mathrm{m}^{2} / \mathrm{sec}$ (Table 16) to allow calcite to precipitate readily from solution, and thus maintain near local equilibrium conditions with respect to calcite. In nature and in experiments, calcite precipitation and dissolution occurs relatively rapidly in response to changing geochemical conditions. Inspection of the calcite saturation index, which is maintained near 0 in the simulation, indicates that the kinetics of precipitation were sufficiently fast to maintain equilibrium with respect to calcite as $\mathrm{pH}$ increased.

$\beta$-cristobalite precipitation maintains silica concentrations at a constant value in the glass zones (Fig. 113) even though glass dissolution releases more moles of Si than any other element. Precipitation of muscovite/illite and Ca-smectite depletes the concentrations of $\mathrm{K}^{+}$and $\mathrm{Ca}^{2+}$ in solution. Goethite precipitates in the melt glasses as well, although not shown in Figures 112 or 113. The precipitation of goethite, smectite and muscovite/illite on the glass surface is representative of secondary minerals formed during alteration of natural and nuclear waste glasses. For example, Abrajano et al. (1990) identified surface precipitates which included iron oxyhydroxides, saponite (a trioctehedral smectite) and smectite clays during nuclear waste glass dissolution tests.

Figures 112 and 113 illustrate that $\mathrm{Ca}$ and $\mathrm{HCO}_{3}$ concentrations increase once groundwater leaves the glass and re-enters the alluvium. The fluid exiting the glass has a relatively high $\mathrm{pH}$ and is in equilibrium with calcite. When the $\mathrm{pH}$ decreases owing to reaction with the goethite in the alluvium (see above), calcite in the alluvium dissolves and $\mathrm{Ca}$ and $\mathrm{HCO}_{3}$ concentrations increase until equilibrium with the calcite in the alluvium is achieved.

Future simulations should consider the possibility that radionuclides could co-precipitate with $\mathrm{Ca}$ as part of a calcite solid solution. Trace elements such as $\mathrm{Sr}$, rare earth elements and $\mathrm{U}$ have been measured in calcites coating fractures (see, e.g., Landström and Tullborg, 1994). GIMRT does not presently provide for solid solutions. The implications with regard to radionuclide complexation of decreased bicarbonate concentrations in the groundwater that has passed through the glass must also be evaluated. As shown in Figures 24, 26, and 28, carbonate is the dominant ligand for aqueous species of $\mathrm{Pu}, \mathrm{Am}$ and $\mathrm{Eu}$.

\section{Mineralogic Model 11}

Owing to the extreme retardation of radionuclides that occurs when ion exchange and sorption are assumed to occur on minerals distributed homogeneously throughout the alluvium, the next simulation (Model 11) omitted the presence of hydrous iron oxide, muscovite/illite, smectite, clinoptilolite and calcite in the alluvium and exchange volume. The volumes of these minerals were replaced by inert matrix. Model 11 represents an end member conceptualization of the CAMBRIC system in which radionuclides are distributed between melt glass and the fluid phase in the exchange volume, and no chemical mechanisms other than precipitation are considered to retard radionuclide migration. The 
simulation also explores the implications of assumptions regarding the distribution of radionuclides between fluid and solids in the exchange volume. During the course of the simulation, radionuclide-laden groundwater will be gradually swept out of the exchange volume, and glass, when present, will continuously release radionuclides into solution. Radionuclide transport then occurs without further reaction with the host alluvium.

Streamline 100. After 100 years, radionuclides have been swept out of the first 10 meters of the exchange volume, which moves the upstream concentration front to about 250 meters from 239 meters (Figure 115). The profiles for $\mathrm{Eu}$ and Am are identical to those in Model 10 (Fig. 103) because Eu and Am are not assumed to be retarded in either model. However, in contrast to Model 10 (Fig. 103), Cs, Sr and Pu migrate significantly downstream in Model 11 because the exchange volume and alluvium lack the clays and zeolites that tend to hold radionuclides in place. By 600 years, the radionuclides have been completely flushed out of the exchange volume and transported over $200 \mathrm{~m}$ downstream (Fig. 116)

Streamline 145. The Eu and Am concentration profiles (Fig. 117) are identical to those of mineralogic Model 10 along the same streamline (Figs. 107 and 108) because no retardation mechanisms are operative for these elements in either run. Unlike Model 10, the concentration profiles for $\mathrm{Cs}, \mathrm{Sr}$ and $\mathrm{Pu}$ in Model 11 do not exhibit the abrupt decreases in concentration when the groundwater is in contact with alluvium and exchange volume between 240 and 260 meters, owing to the lack of reactive minerals (Fig. 118). Nonetheless, the Cs and $\mathrm{Sr}$ concentrations at the downstream edge of the last glass zone at about 260 meters are equal in both Mineralogic Models 10 and 11. The Pu concentration at this point is greater in Mineralogic Model 11, largely because of the relatively high concentrations of $\mathrm{Pu}$ derived from the exchange volume which was not sequestered by goethite. The exchange volume contains much more $\mathrm{Pu}$ than $\mathrm{Cs}$ and $\mathrm{Sr}$. In contrast, the glass contains more $\mathrm{Sr}$ than $\mathrm{Cs}$ and $\mathrm{Pu}$, which occur in near-equimolar proportions.

Downstream of 260 meters, the radionuclides are transported according to the groundwater flux in the absence of further chemical reactions. Cs appears to migrate slower than the rest of the elements, perhaps because even the trace mass of muscovite/illite $\left(1 \times 10^{-6}\right.$ volume percent $)$ assumed present in the alluvium has such a strong preference for Cs. By 600 years, the concentrations of the radionuclides are constant throughout the alluvium up to 200 meters downstream of the glass zones (Fig. 119) as a pseudo-steady-state is achieved between glass dissolution and fluid flow. 


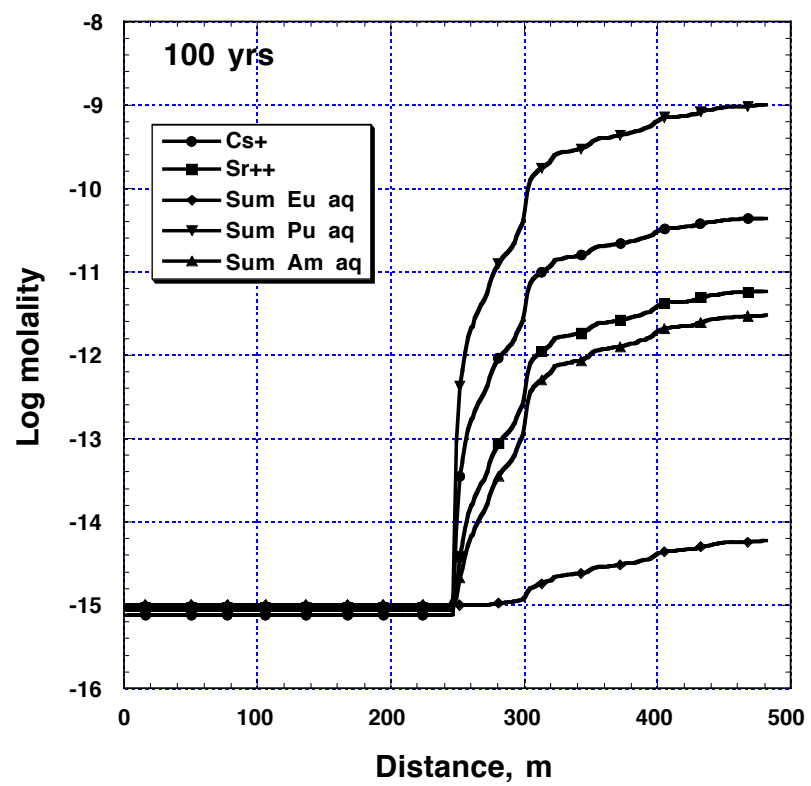

Figure 115: Spatial distribution of total Cs, Sr, Eu, Pu and Am molalities in solution at 100 years in Mineralogic Model 11 along streamline 100. 


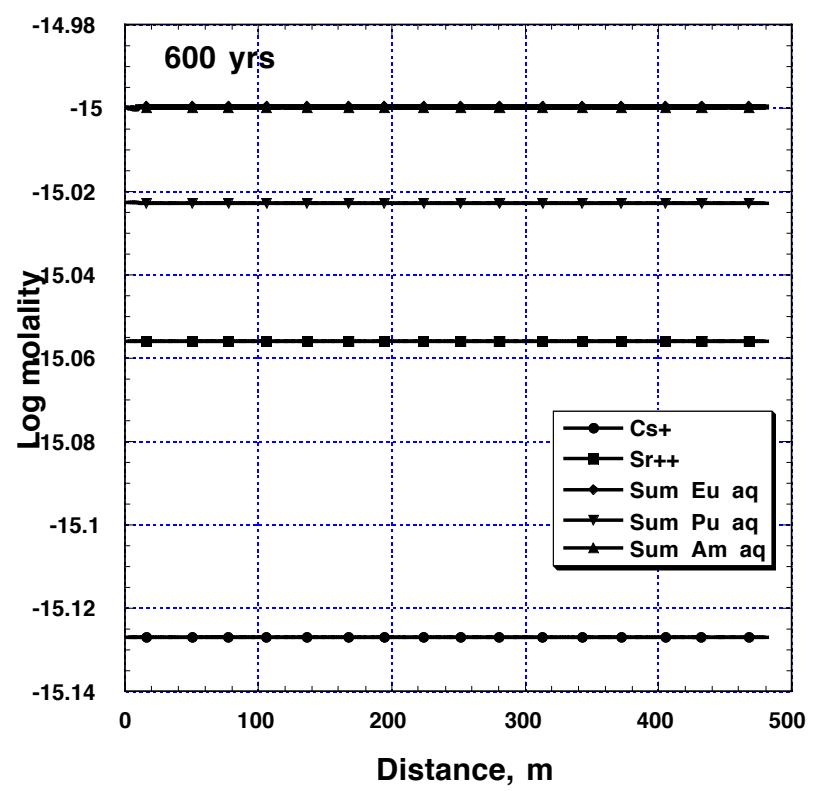

Figure 116: Spatial distribution of total Cs, Sr, Eu, Pu and Am molalities in solution at 600 years in Mineralogic Model 11 along streamline 100. 


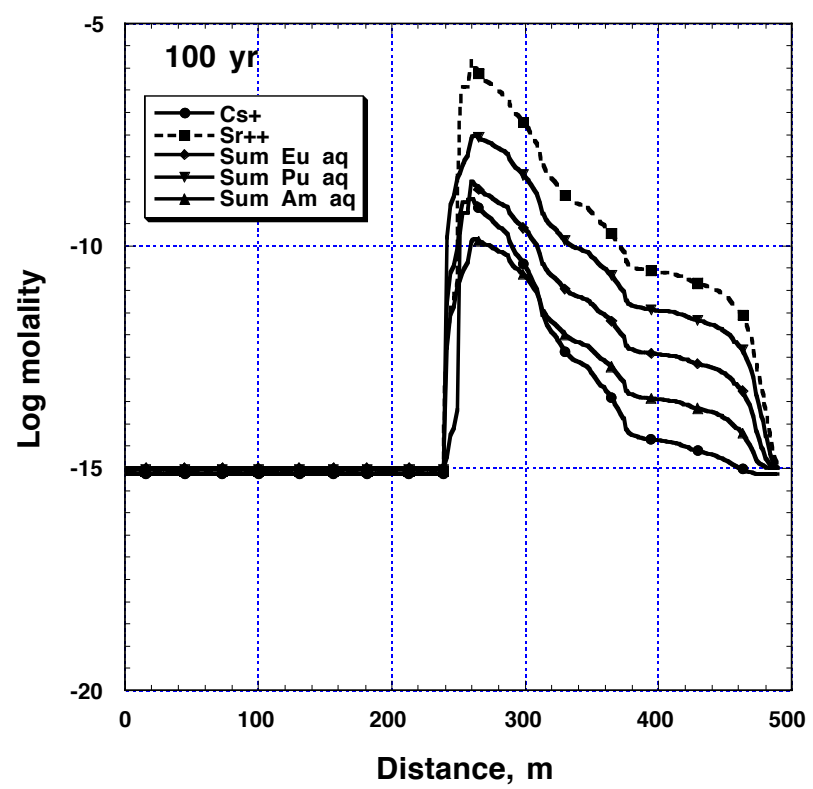

Figure 117: Spatial distribution of total $\mathrm{Cs}, \mathrm{Sr}, \mathrm{Eu}, \mathrm{Pu}$ and $\mathrm{Am}$ molalities in solution at 100 years in Mineralogic Model 11 along streamline 145. 

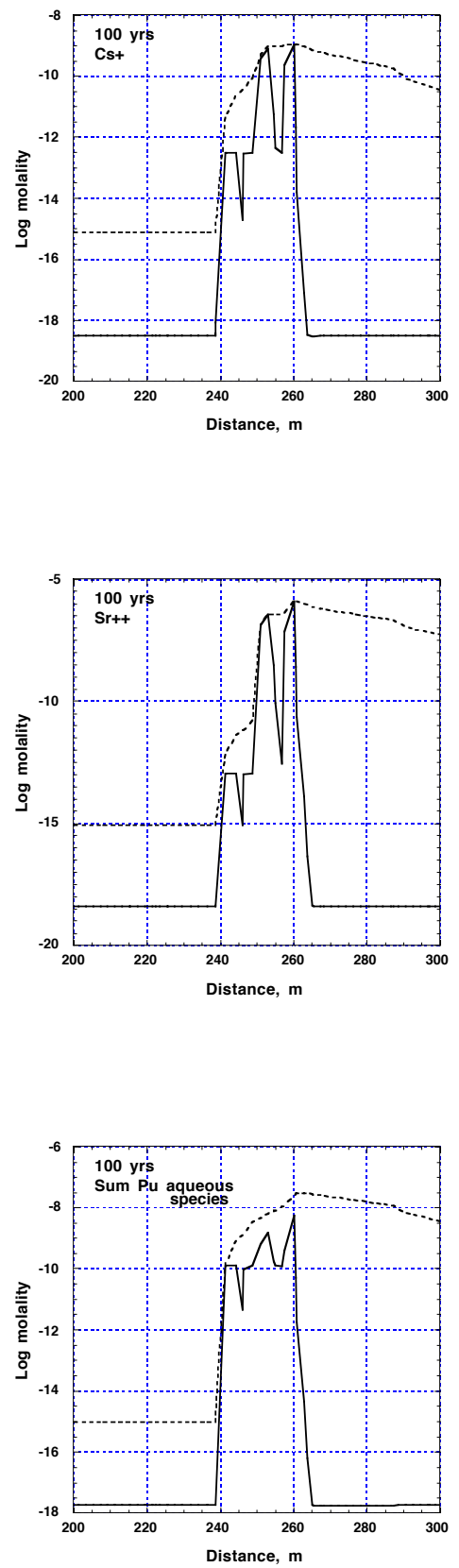

Figure 118: Concentrations of $\mathrm{Cs}, \mathrm{Sr}$ and $\mathrm{Pu}$ at 100 years along streamline 145 for Model 10 (solid curve) and Model 11 (dashed curve). 


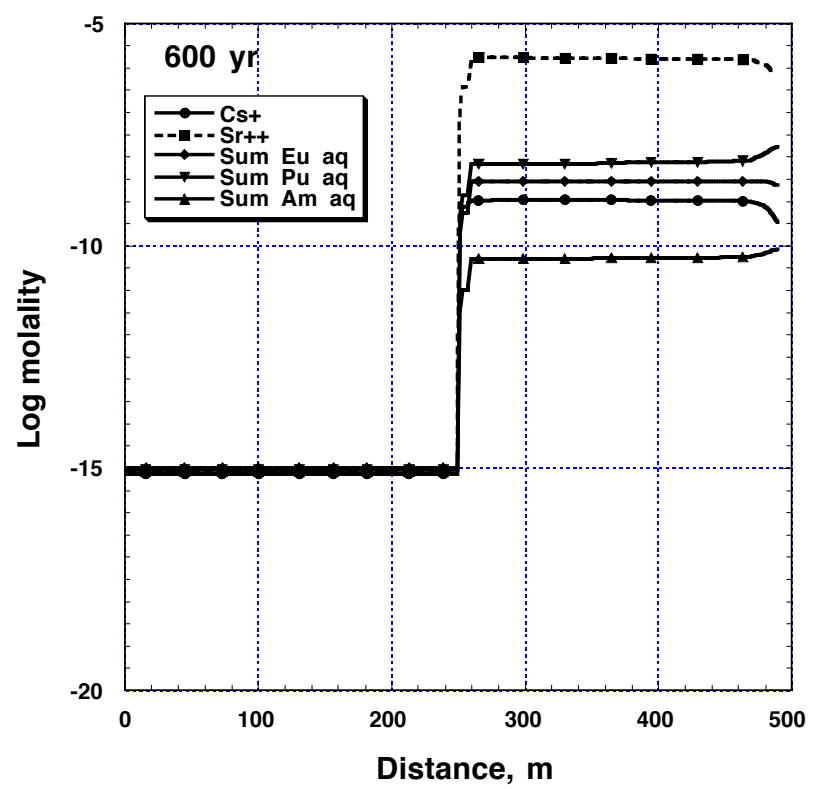

Figure 119: Spatial distribution of total $\mathrm{Cs}, \mathrm{Sr}, \mathrm{Eu}, \mathrm{Pu}$ and Am molalities in solution at 600 years in Mineralogic Model 11 along streamline 145. 


\section{Mineralogic Model 12}

The third run was considered an intermediate between the extremes of Mineralogic Models 10 and 11. Here, as mentioned at the outset, grid blocks in the hydrologic model (excluding the melt glass) with log-conductivities $(\ln K)$ in the lowest $20 \%$ of the overall $\ln K$ range were designated to contain hydrous iron oxide, muscovite/illite, smectite, clinoptilolite and calcite according to the reactive column in Table 15 . The mineralogic composition of remaining grid blocks was specified according to the inert column of Table 15.

As will be discussed below, radionuclide migration along streamline 100 is similar in Mineralogic Models 11 and 12. Streamline 145 in Model 12, however, has characteristics of both models 10 and 11 .

Streamline 100. The concentration profiles for radionuclides in Model 12 at 100 years (Fig. 120) are the same as in Model 11 (Fig. 115, taking into account the differences in distance represented on the x-axes). As in Model 11, radionuclides are flushed over 200 meters downstream after 600 years (Fig. 121).

Streamline 145. Streamline 145 contains characteristics both of Mineralogic Models 10 and 11 because of the heterogeneous distribution of reactive minerals. Figures 122 through 125 illustrate the complex trends in concentrations forecasted along streamline 145 at 100 and 600 years. The concentration profiles for $\mathrm{Sr}, \mathrm{Cs}$ and $\mathrm{Pu}$ reflect the occurrence of grid blocks with reactive minerals. Note the dip in concentrations from $1 \times 10^{-15}$ molal immediately before the first exchange volume is contacted at about 239 meters. The alluvium in this grid block contains reactive minerals, whereas the other blocks upstream did not. Similarly, the last glass zone encountered is followed by a block with reactive minerals at about 264 meters.

From about 240 meters (the transition from alluvium into exchange volume) to 255 meters, concentrations vary as they do in Model 11, that is, as if no reactive minerals were present. At 255 to 257 meters, a zone of exchange volume containing reactive minerals (i.e. clays and zeolite) is intersected, which causes sudden decreases in concentrations similar to Model 10 owing to uptake of radionuclides by reactive minerals. Immediately after the fluid exits the last glass zone at about 260 meters, alluvium containing reactive minerals is again encountered, as evidenced by a significant decrease in radionuclide concentrations. Although concentrations appear to rise from 265 meters onward, note that concentrations do not exceed 1e-15 molal, which is considered to be equivalent to zero in the simulations.

At 600 years (Figures 124 and 125), $\mathrm{Pu}$ and $\mathrm{Sr}$ concentrations downstream of the glass zones are higher than those of Model 10 but lower than those of Model 11. Cs is still retarded effectively in the alluvium immediately after the glass zone. Radionuclides have been depleted from the exchange volume from about 


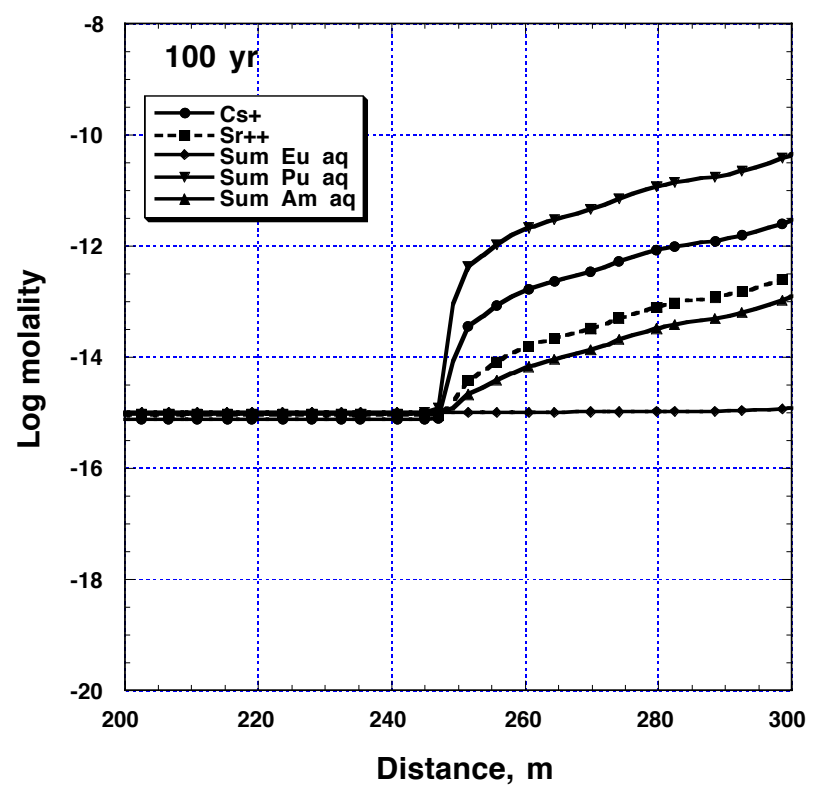

Figure 120: Spatial distribution of total Cs, Sr, Eu, Pu and Am molalities in solution at 100 years in Mineralogic Model 12 along streamline 100. 


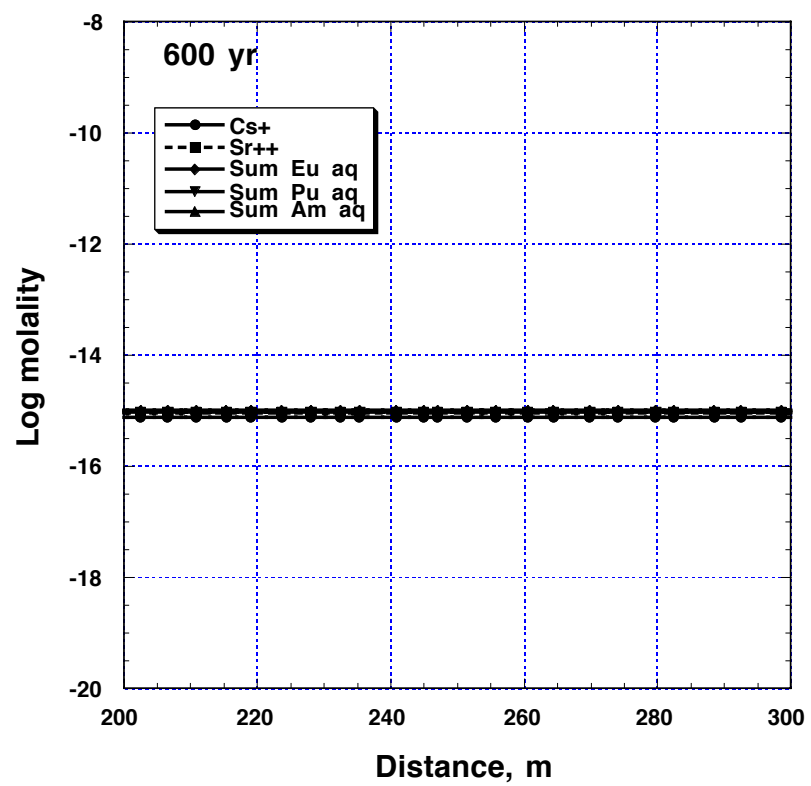

Figure 121: Spatial distribution of total $\mathrm{Cs}, \mathrm{Sr}, \mathrm{Eu}, \mathrm{Pu}$ and Am molalities in solution at 600 years in Mineralogic Model 12 along streamline 100. 


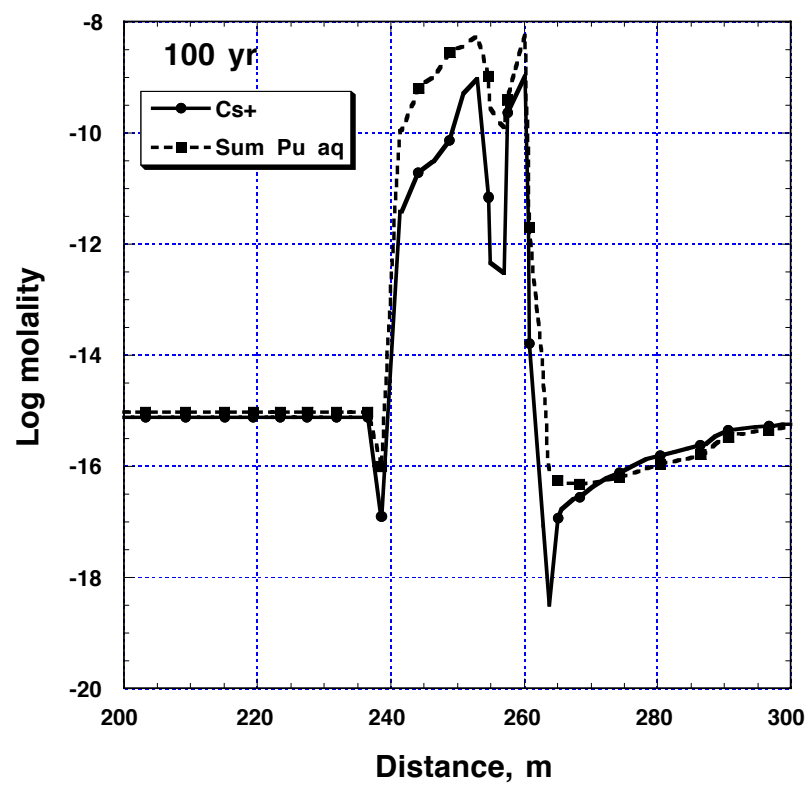

Figure 122: Spatial distribution of total $\mathrm{Cs}$ and $\mathrm{Pu}$ molalities in solution at 100 years in Mineralogic Model 12 along streamline 145. 


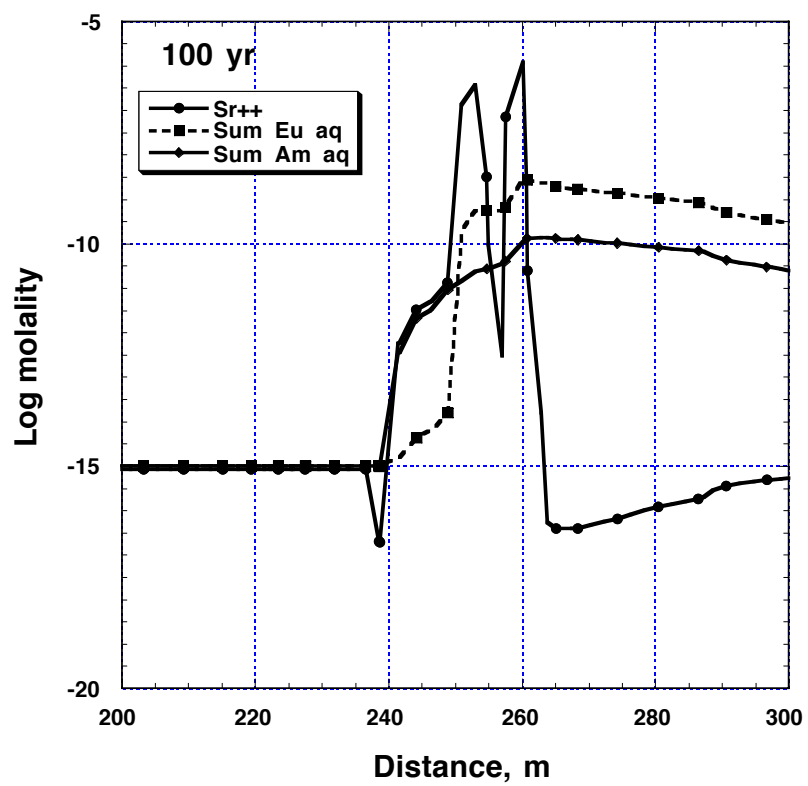

Figure 123: Spatial distribution of total $\mathrm{Sr}, \mathrm{Eu}$ and Am molalities in solution at 100 years in Mineralogic Model 12 along streamline 145. 


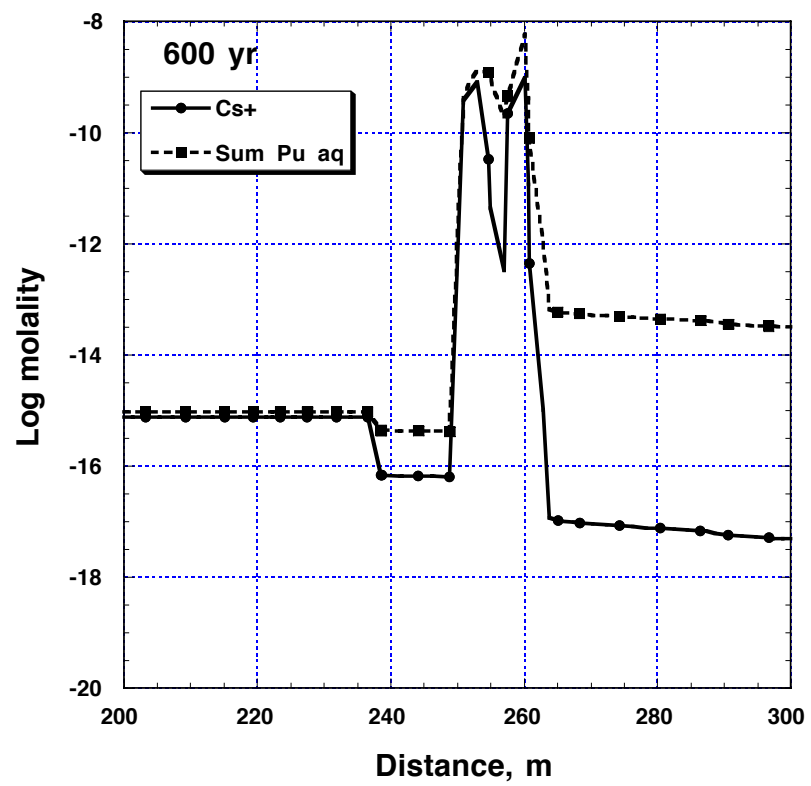

Figure 124: Spatial distribution of total $\mathrm{Cs}$ and $\mathrm{Pu}$ molalities in solution at 600 years in Mineralogic Model 12 along streamline 145.

240 to 250 meters. The exchange volume contains some reactive minerals, as evidenced by radionuclide concentrations in solution less than $1 \times 10^{-15}$ molal.

$\mathrm{Eu}$ and Am concentrations (Figs. 123 and 125) vary as they do in Mineralogic Models 10 and 11 because no retardation mechanisms were considered for these elements. 


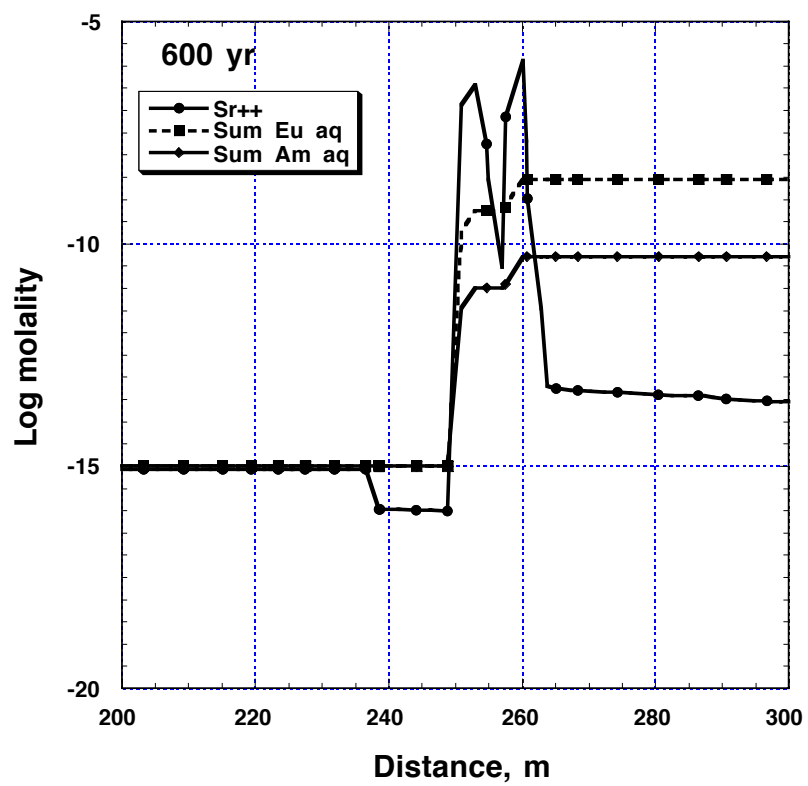

Figure 125: Spatial distribution of total Sr, Eu and Am molalities in solution at 600 years in Mineralogic Model 12 along streamline 145. 


\section{Appendix 8: Sensitivity of model results to iron oxide and melt glass surface areas}

As has been repeatedly emphasized throughout this report, the reliability of the model results is directly dependent on the reliability of the input parameters to the model. Two important parameters include the reactive surface areas of goethite (the proxy for ferric iron oxide) and the melt glass. The surface area of the glass will control the release rate of radionuclides, and the surface area of the goethite will impact the extent to which goethite retards the migration of radionuclides. In Mineralogic Models 10 through 12, goethite and glass surface areas of $600 \mathrm{~m}^{2} / \mathrm{g}$ and $5 \times 10^{-5} \mathrm{~m}^{2} / \mathrm{g}$ were used ${ }^{21}$. However, the actual surface area of the CAMBRIC melt glass and iron oxide in the alluvium may vary by orders of magnitude, and the sensitivity of model results to such variations must be examined.

To address the sensitivity of model results to surface area, a series of additional reactive transport calculations were made along streamlines 100 and 145 (see Table 30) in which the surface areas of goethite and glass were varied. Table 31 compares the conditions of these models with Mineralogic Model 10, which assumed a homogeneous distribution of surface active minerals in the alluvium and exchange volume. Input parameters for models 10a through 10d were identical to Model 10 except for the variables listed in Table 31. The choices of the surface areas employed and the results of the simulations are discussed in the following sections. Results from the individual streamlines listed in Table 31 were used to select the models for which the full 3D simulation was run, as indicated in Table 31.

\section{Goethite (ferric iron oxide) surface area}

The surface areas of iron oxides vary as a function of mineralogy (e.g., lower for magnetite, higher for goethite) and the physical nature of the solid (e.g., higher if freshly precipitated, lower if aged). Most laboratory experiments measuring sorption onto iron oxides use freshly precipitated amorphous hydrous ferric (Fe(III)) oxide, the surface area of which can range from about 160 to $700 \mathrm{~m}^{2} / \mathrm{g}$ (Buffle, 1988; Dzombak and Morel, 1990). This material is often assigned a surface area of $600 \mathrm{~m}^{2} / \mathrm{g}$ (Dzombak and Morel, 1990). $600 \mathrm{~m}^{2} / \mathrm{g}$ was used in models 10 through 12 to represent poorly crystalline iron oxides that might form as weathering products on ferromagnesium minerals in the alluvium. Such iron oxides might appear as coatings on detrital grains. In comparison, surface areas for the crystalline mineral goethite range from about 32 to $71 \mathrm{~m}^{2} / \mathrm{g}$ (Buffle, 1988). The surface area is a critical parameter because it determines the number of reactive surface sites available for sorption. It was assumed in this study

\footnotetext{
10.

${ }^{21}$ A glass surface area of $5 \times 10^{-5} \mathrm{~m}^{2} / \mathrm{g}$ is equivalent to $118 \mathrm{~m}^{2} / \mathrm{m}^{3}$ bulk volume; see Table
} 
Table 31: Comparison of Mineralogic Models 10 through 10d.

\begin{tabular}{lcccc}
\hline \hline Model & $\begin{array}{c}\text { Goethite surface } \\
\text { area }\left(\mathrm{m}^{2} / \mathrm{g}\right)\end{array}$ & $\begin{array}{c}\text { Glass surface } \\
\text { area }\left(\mathrm{m}^{2} / \mathrm{g}\right)\end{array}$ & $\begin{array}{c}3 \mathrm{D} \\
\text { result }\end{array}$ & $\begin{array}{c}\text { Reactive mineral } \\
\text { distribution }\end{array}$ \\
\hline 10 & 600 & $5 \times 10^{-5, a}$ & $\S 11.4 .1$ & uniform \\
$10 \mathrm{a}$ & 50 & $5 \times 10^{-5}$ & $\S 12.2 .1$ & uniform \\
$10 \mathrm{~b}$ & 50 & $5 \times 10^{-2}$ & $c$ & uniform \\
$10 \mathrm{c}$ & 50 & $5 \times 10^{-4}$ & $c$ & uniform \\
$10 \mathrm{~d}$ & 50 & $5 \times 10^{-3}$ & $\S 12.2 .3$ & uniform \\
& & & & \\
\hline
\end{tabular}

${ }^{a}$ Equivalent to $118 \mathrm{~m}^{2} / \mathrm{m}^{3}$ bulk volume

${ }^{b}$ Goethite, smectitie, illite/muscovite, and clinoptilolite

${ }^{c}$ Only single streamline simulations (100 and 145) considered

that the site density of ferric iron oxide equals $2.31 \mathrm{sites} / \mathrm{nm}^{2}$ (Dzombak and Morel, 1990).

The nature and reactivity of the iron oxide in the alluvium is not known. Wolfsberg (1978) described the alluvium from CAMBRIC hole U5e (RNM-1) below the water table at vertical depths ranging from 238 to 331 meters as containing an "iron-oxide-rich....matrix". He measured significant distribution coefficients for elements including $\mathrm{Sr}$ and Cs onto the alluvium, but did not focus on the minerals responsible for the uptake. In contrast, iron oxides in Yucca Mountain tuffs proved to be essentially passive in experiments conducted by the Los Alamos National Laboratory, although single phase synthetic hematite $\left(\mathrm{Fe}_{2} \mathrm{O}_{3}\right)$ experiments revealed a high affinity for radionuclides (Triay et al., $1996 \mathrm{a}, \mathrm{b})$. The cause of the iron oxide passivation has not yet been identified (Triay et al., 1996a, b), nor have the iron oxides in the Yucca Mt. tuffs and the CAMBRIC alluvium been compared to see if they are of similar nature or if they react in the same manner.

Based on the above information, the choice for the surface area of the iron oxide at the CAMBric site is problematic. Mineralogic Model 10 showed that a surface area of $600 \mathrm{~m}^{2} / \mathrm{g}$ produced an extremely high retardation of $\mathrm{Pu}$. To address the possibility that the iron oxide in the alluvium has a smaller surface area, additional simulations were made along streamlines 100 and 145 in which the surface area of goethite was assumed to equal $50 \mathrm{~m}^{2} / \mathrm{g}$. The extreme case in which the iron oxide is completely passivated (unreactive) is represented by Mineralogic Model 11. 


\section{Mineralogic Model 10a versus Model 10: Effect of reducing goethite surface area}

Input parameters for Mineralogic Model 10a were identical to those of Model 10 except that a goethite surface area of $50 \mathrm{~m}^{2} / \mathrm{g}$ was used rather than 600 $\mathrm{m}^{2} / \mathrm{g}$. Because only the goethite properties changed, the only radionuclides that should be affected in the simulation are $\mathrm{Sr}$ and $\mathrm{Pu}$, which sorb onto goethite. In summary, reduction of goethite surface area in Model 10a generated the following:

- Pu migration increased significantly along streamline 100 because of the reduction in the number of available sorption sites on goethite. $\mathrm{Pu}$ migration increased minimally along streamline 145 because of low fluid flow rates through the glass zones.

- In contrast to $\mathrm{Pu}$, migration of $\mathrm{Sr}$ was largely unchanged owing to increased exchange onto clinoptilolite. The volume percent of clinoptilolite and/or smectite must be reduced to affect Sr migration.

More detailed descriptions of the Model 10a streamline results are given below.

Streamline 100. The migration of $\mathrm{Pu}$ and $\mathrm{Sr}$ at 100 and 600 years in models 10 and 10a is compared in Figures 126 through 129. Although Sr migration is affected minimally, the impact on $\mathrm{Pu}$ is significant after 600 years. Sr has a number of potential sinks other than goethite, namely, smectite and clinoptilolite. In Model 10a, Sr exchange onto clinoptilolite (dominant) and smectite effectively sequester the $\mathrm{Sr}$ that used to sorb onto goethite. As a result, the change in the surface area of goethite has a minimal effect on Sr mobility in groundwater. $\mathrm{Pu}$ has no additional sinks other than goethite (disregarding precipitation), so reduction of the number of available surface sites for $\mathrm{Pu}$ allows it migrate further downstream.

Streamline 145. The migration of $\mathrm{Pu}$ and $\mathrm{Sr}$ is affected minimally by the decrease in goethite surface area at 100 years (Figs. 130 and 131). After 600 years, $\mathrm{Pu}$ has migrated an additional twenty or so meters downstream (Fig. 132), but the extent of Sr migration is largely unchanged (Fig. 133). Migration along streamline 145 was not affected as greatly as in streamline 100 because of the slower flow rates though the glass (Fig. 43). Whereas the alkaline $\mathrm{pH}$ of fluids exiting the glass zones were neutralized by surface exchange reactions on goethite immediately upon entering the alluvium in Model 10, elevated $\mathrm{pH}$ values migrated slightly farther downstream in Model 10a owing to the reduced number of $\mathrm{pH}$-buffering surface sites on goethite. However, the elevated $\mathrm{pH}$ values are effectively neutralized less than 5 meters downstream of the last glass zone at 600 years. 


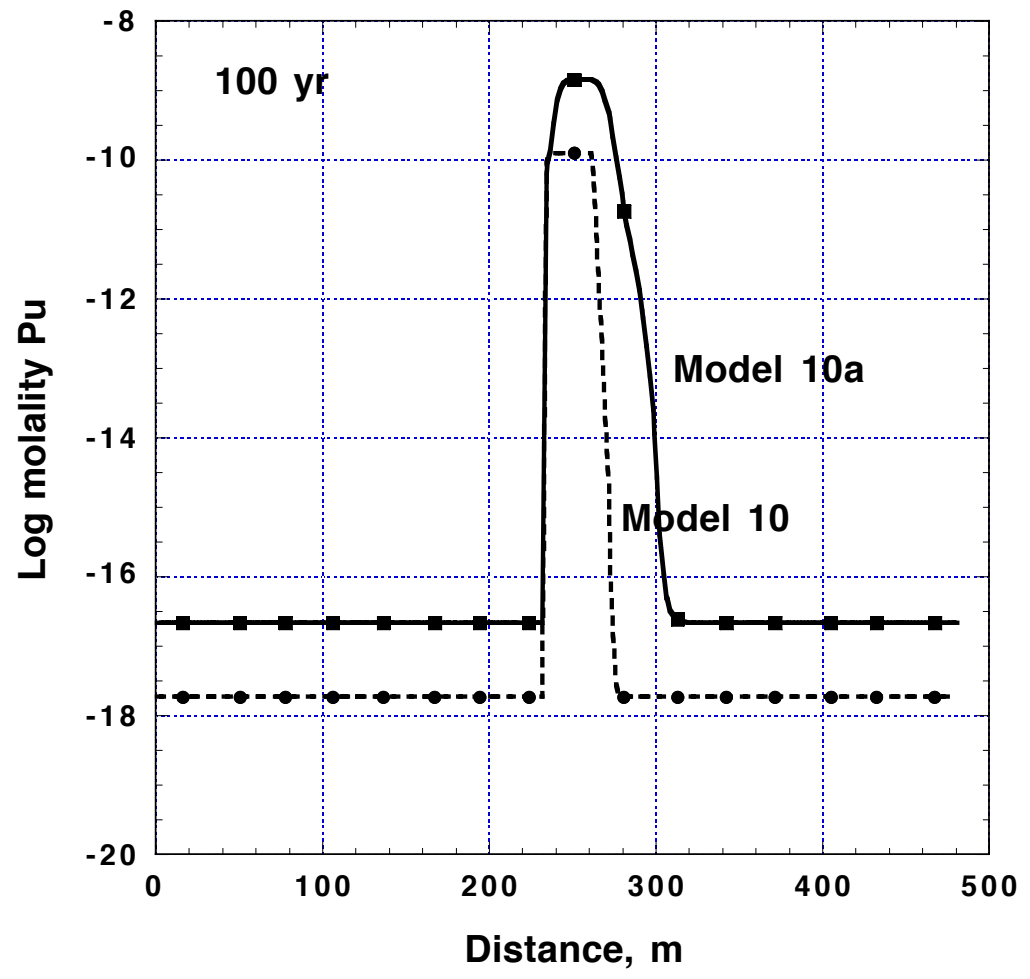

Figure 126: Comparison of spatial distribution of total $\mathrm{Pu}$ molality in solution at 100 years along streamline 100 for models 10 and 10a with goethite surface areas of 600 and $50 \mathrm{~m}^{2} / \mathrm{g}$, respectively. 


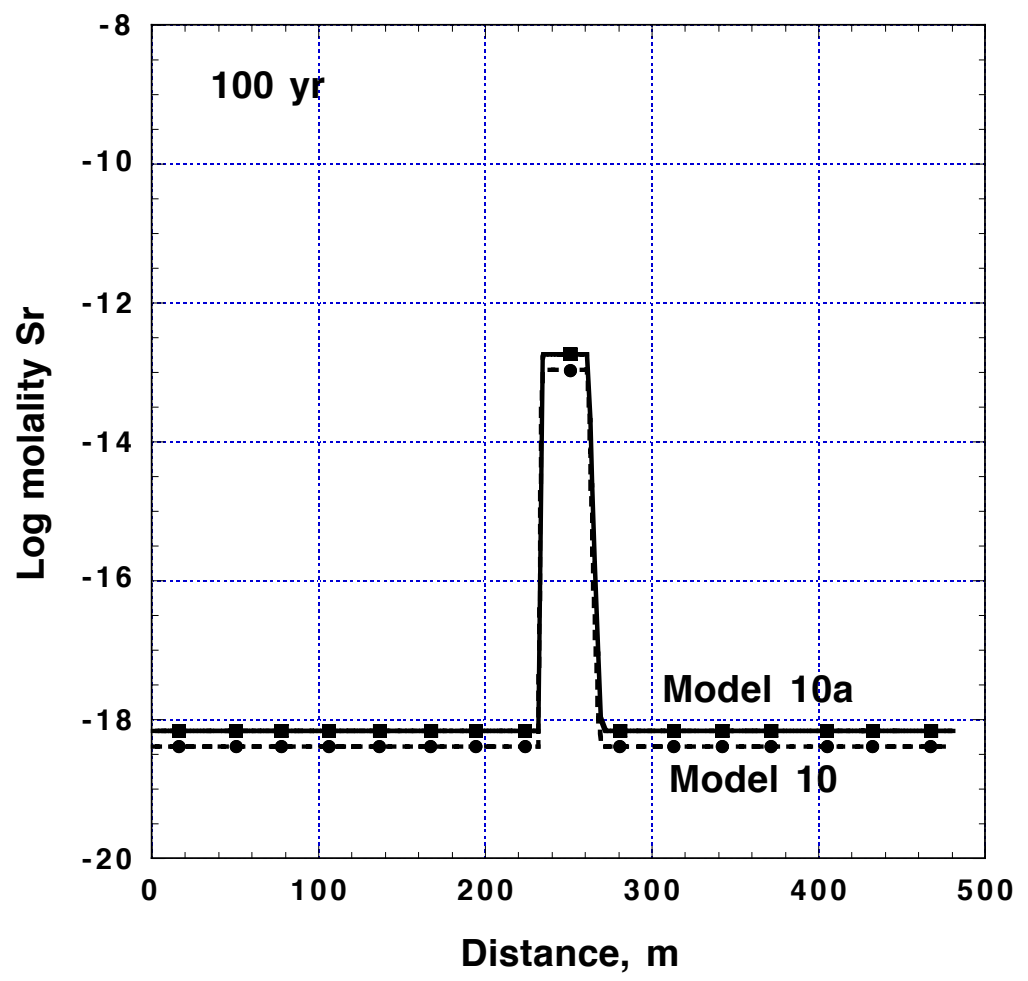

Figure 127: Comparison of spatial distribution of total Sr molality in solution at 100 years along streamline 100 for models 10 and 10a with goethite surface areas of 600 and $50 \mathrm{~m}^{2} / \mathrm{g}$, respectively. 


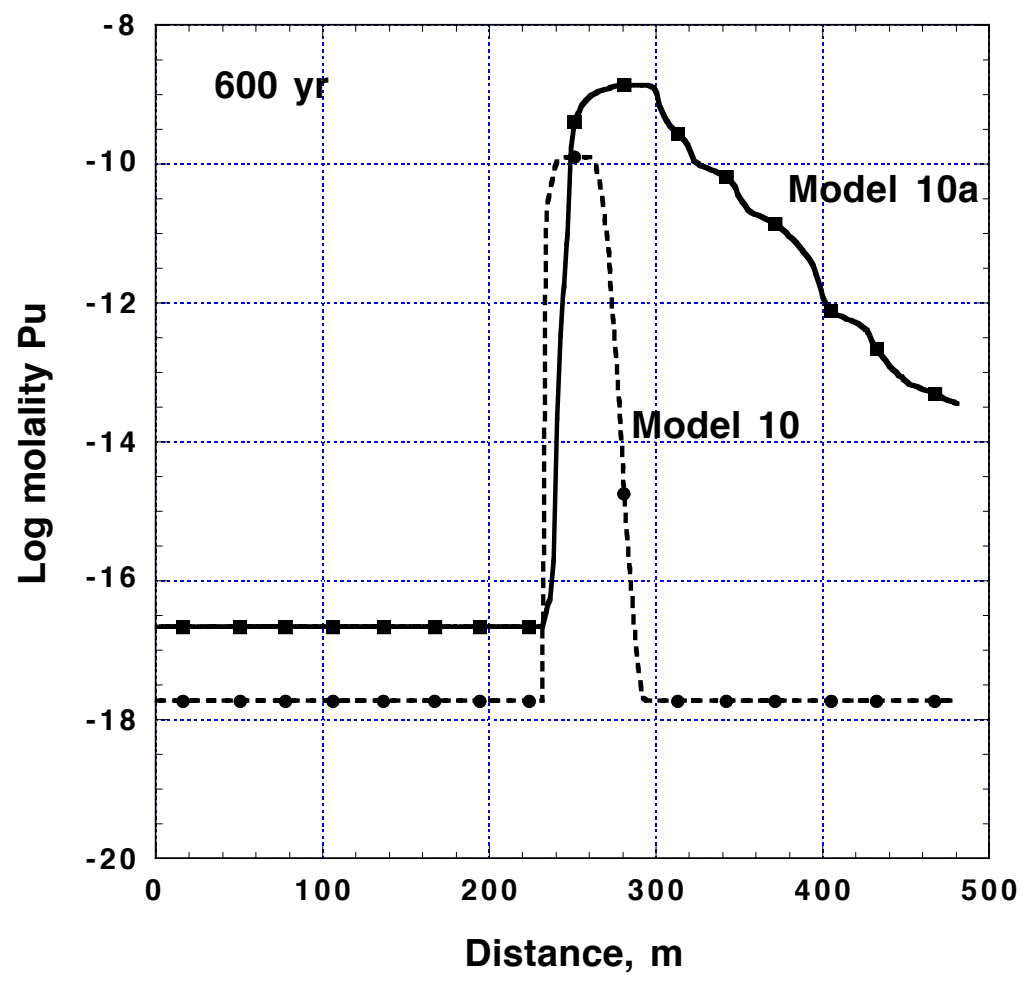

Figure 128: Comparison of spatial distribution of total $\mathrm{Pu}$ molality in solution at 600 years along streamline 100 for models 10 and 10a with goethite surface areas of 600 and $50 \mathrm{~m}^{2} / \mathrm{g}$, respectively. 


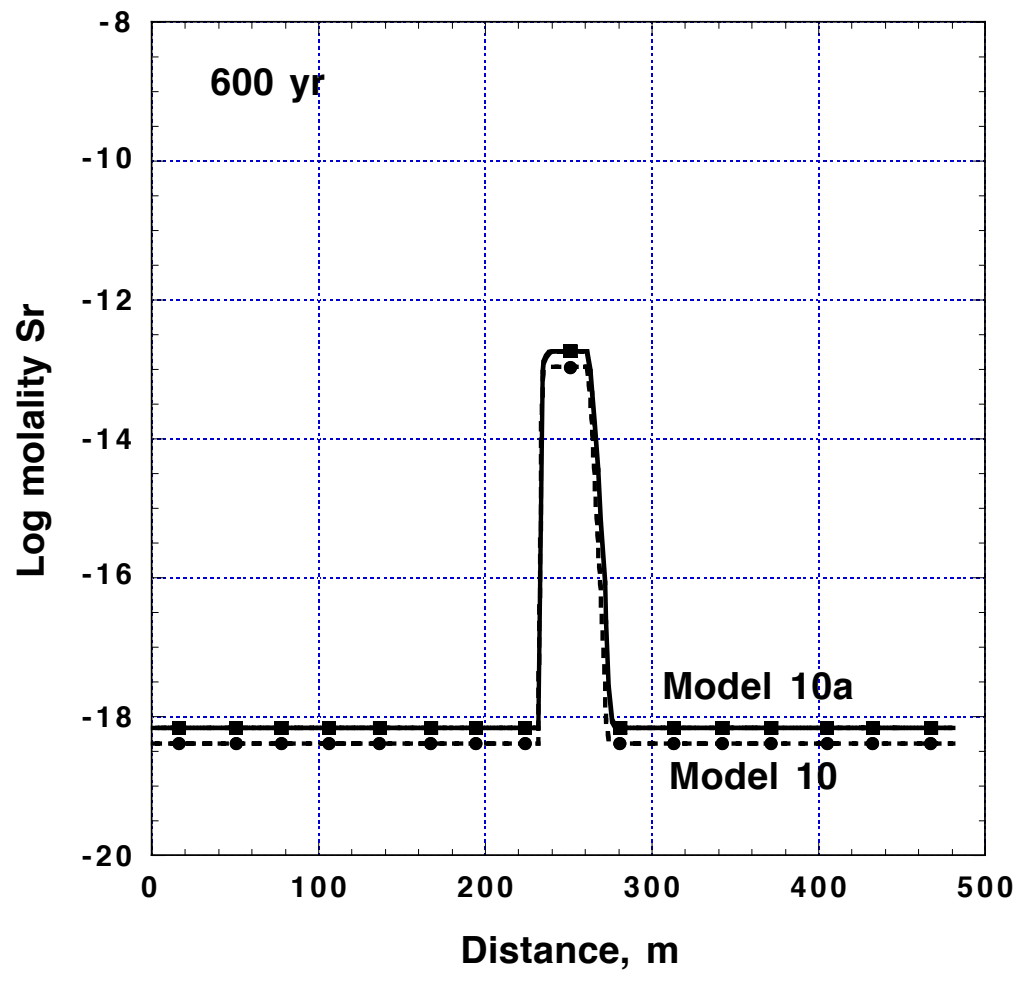

Figure 129: Comparison of spatial distribution of total Sr molality in solution at 600 years along streamline 100 for models 10 and 10a with goethite surface areas of 600 and $50 \mathrm{~m}^{2} / \mathrm{g}$, respectively. 


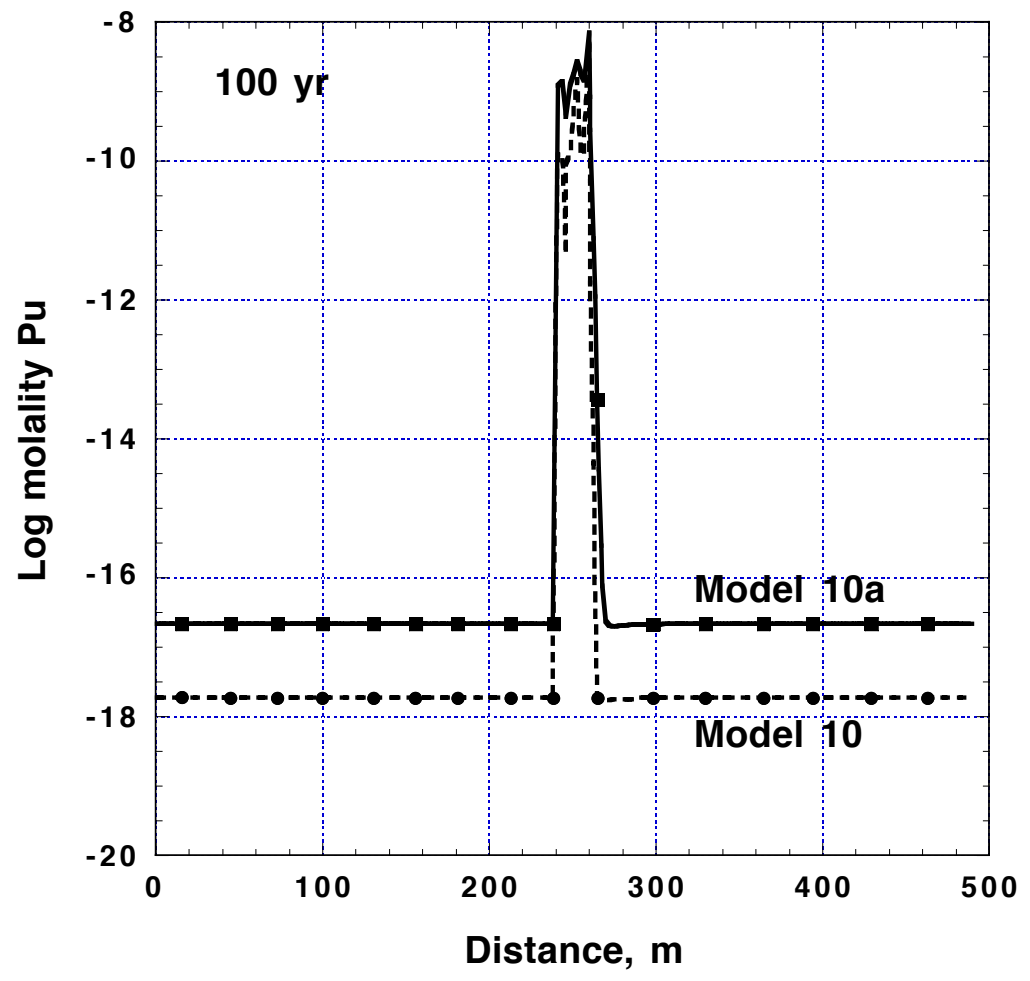

Figure 130: Comparison of spatial distribution of total $\mathrm{Pu}$ molality in solution at 100 years along streamline 145 for models 10 and 10a with goethite surface areas of 600 and $50 \mathrm{~m}^{2} / \mathrm{g}$, respectively. 


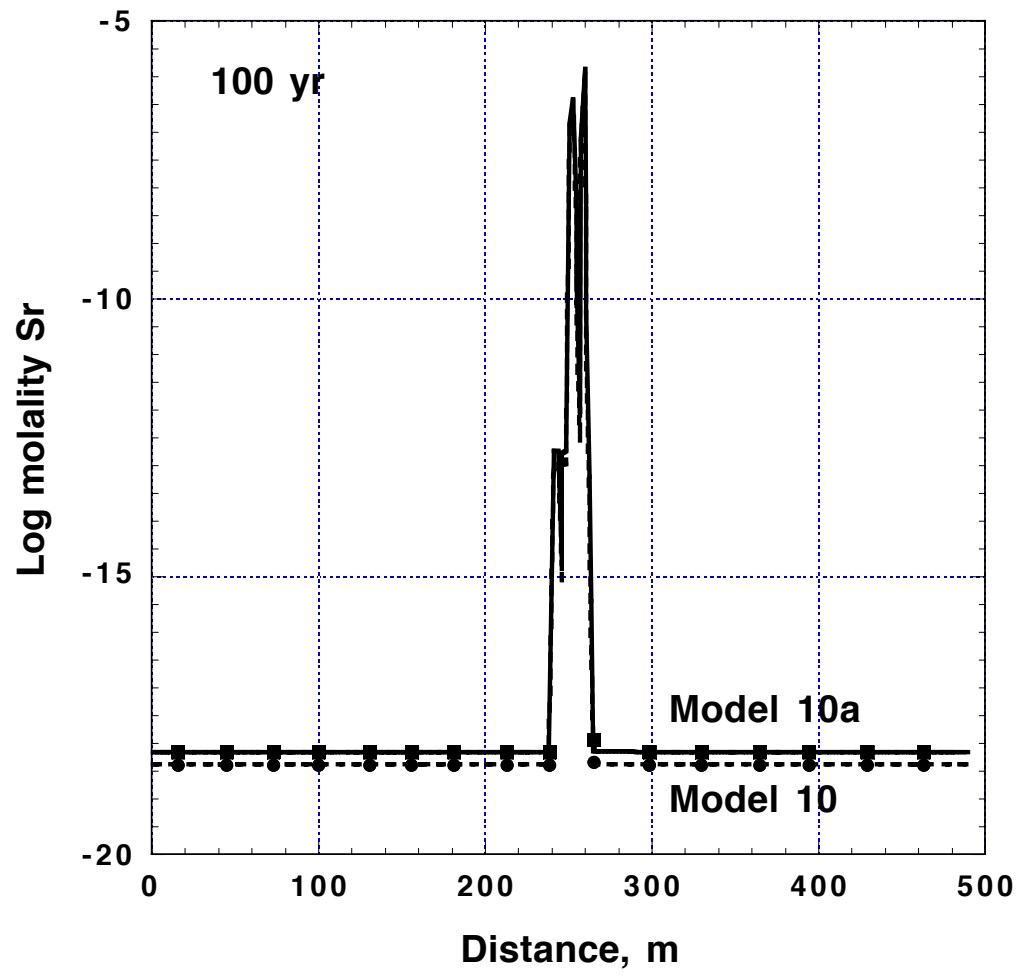

Figure 131: Comparison of spatial distribution of total Sr molality in solution at 100 years along streamline 145 for models 10 and 10a with goethite surface areas of 600 and $50 \mathrm{~m}^{2} / \mathrm{g}$, respectively. 


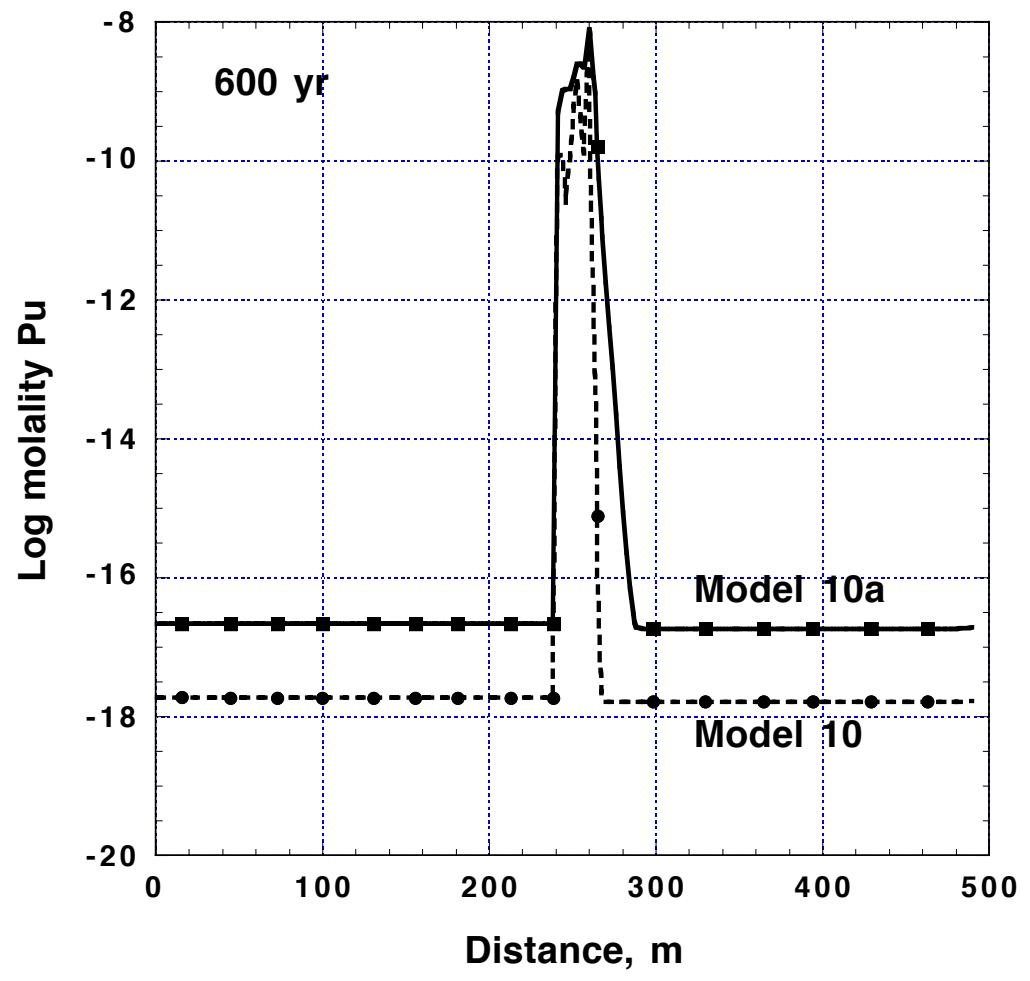

Figure 132: Comparison of spatial distribution of total $\mathrm{Pu}$ molality in solution at 600 years along streamline 145 for models 10 and 10a with goethite surface areas of 600 and $50 \mathrm{~m}^{2} / \mathrm{g}$, respectively. 


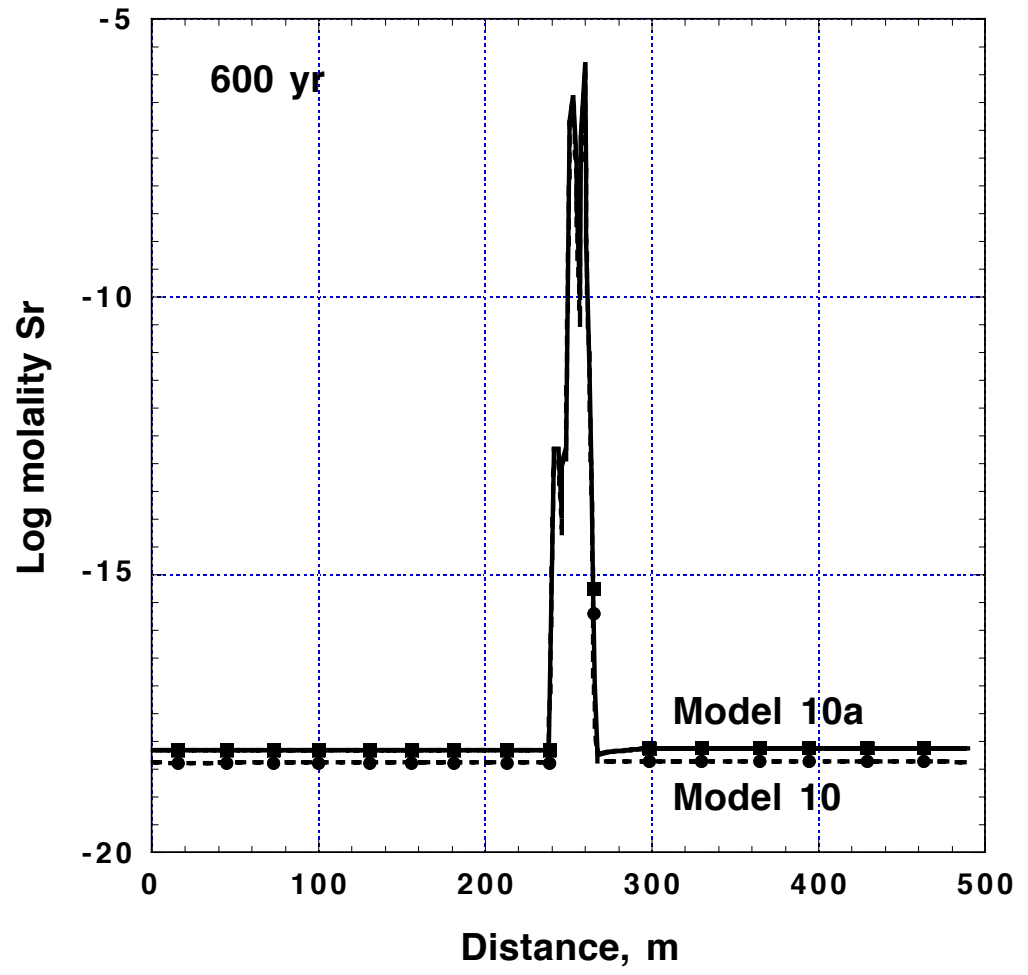

Figure 133: Comparison of spatial distribution of total Sr molality in solution at 600 years along streamline 145 for models 10 and 10a with goethite surface areas of 600 and $50 \mathrm{~m}^{2} / \mathrm{g}$, respectively. 


\section{Glass surface area}

As previously discussed (see section 6.2.4), the choice of the reactive surface area for melt glass is highly problematic. A transport model of radionuclide migration from the SHOAL test employed a glass reactive surface area of about $5 \times 10^{-2} \mathrm{~m}^{2} / \mathrm{g}$ (Pohll et al. , 1998). This value is about 3 orders of magnitude greater than the surface area used in Mineralogic Models 10 through $12\left(5 \times 10^{-5}\right.$ $\left.\mathrm{m}^{2} / \mathrm{g}\right)$. Increased glass surface areas will produce a proportional increase in total glass dissolution at near-neutral $\mathrm{pH}$, and a faster release of radionuclides from the glass. This will lead to higher radionuclide concentrations in the immediate vicinity of the glass. For nonreactive radionuclides, higher concentrations will be realized behind an advancing front moving away from the glass, but the location of the front will be unaffected by the dissolution rate and remain a function of the groundwater flow only ${ }^{22}$. For chemically reactive radionuclides, higher concentrations realized from higher dissolution rates could lead to different radionuclide mobilities (as a result of site saturation or pH-dependent effects) which may affect locations of advancing fronts.

To address the sensitivity of model results to estimated glass surface area, a series of runs was made with order of magnitude increases in glass surface area (Table 31). Mineralogic models 10b through 10d were run along streamline 145, which intersects the melt glass in two locations (see Table 30) and Fig. 105). (Streamline 100 does not intersect the melt glass.) Model 10b was run first to reproduce the surface area used in the Shoal report. Although there is inadequate evidence to support a priori the selection of a "best" surface area, it appears that the following reactive transport simulations may help to set an upper limit to glass surface area.

\section{Mineralogic Model 10b versus Model 10a: Effect of increasing glass surface area by three orders of magnitude}

Input parameters for Mineralogic Model 10b were identical to those of Model 10 a except that the glass surface area was increased to $0.05 \mathrm{~m}^{2} / \mathrm{g}$, which is equal to the surface area used to evaluate the Shoal source term (Pohll et al. , 1998). The increase in glass surface area produced a glass dissolution rate that is three orders of magnitude higher than the rate in Model 10, because the $\mathrm{pH}$ independent rate law yields a surface-area-normalized rate of $3.75 \times 10^{-5}$ grams glass $/\left(\mathrm{m}^{3}\right.$-day). The high rate of glass dissolution coupled with the low rate of groundwater flow caused the $\mathrm{pH}$ to increase to 12.6 in the glass melt zones after 100 years. The pH became alkaline because hydrogen ions are consumed during glass dissolution (see equation 4).

The increase in $\mathrm{pH}$ caused significant deviations in the aqueous speciation. Above a $\mathrm{pH}$ of 9.3 , the anionic silica complex $\mathrm{HSiO}_{3}^{-}$dominates total silica in solution, which is controlled by $\beta$-cristobalite saturation. Thus, by the time the

\footnotetext{
${ }^{22}$ This assumes the permeability in the glass remains fixed.
} 
$\mathrm{pH}$ climbed to 12.6 at 100 years, the concentration of $\mathrm{HSiO}_{3}^{-}$equalled about 0.57 molal. The ionic strength of the water at 100 years climbed to over 0.8 , versus 0.005 in the ambient groundwater, because of the high silica concentration.

Natural analogues to the behavior predicted in Model 10b are not known. The contributors to this report know of no instances in which groundwaters emanating from natural glasses are characterized by $\mathrm{pH}$ values approaching 12.5 and possess significantly elevated ionic strengths owing solely to glass dissolution.

The simulation failed to converge at simulation times greater than 100 years. The numerical problem is not believed to reflect numerical deficiencies in the code, but rather the fact that the geochemical system was evolving out of control. The high glass dissolution rate produced highly unrealistic geochemical conditions which caused the code to fail. If the $\mathrm{pH}$ dependent rate law for glass dissolution had been used, glass dissolution rates would have increased by another order of magnitude (Fig. 12) to compound the problem.

Given the unchecked rise in $\mathrm{pH}$, it is apparent that there are no processes accounted for in the GIMRT model that adequately buffer the $\mathrm{pH}$ values in the glass zones. Although precipitation of secondary minerals can sometimes buffer the $\mathrm{pH}$, their precipitation did not buffer the $\mathrm{pH}$ in Model 10b. The minerals $\beta$-cristobalite, muscovite, smectite (Ca-beidellite), goethite and calcite precipitated in the glass zones similarly to what was previously described in Model 10 (Fig. 114). However, the precipitation was insufficient to offset the rise in $\mathrm{pH}$ forced by the high rate of glass dissolution.

It is possible that the secondary silica precipitate ( $\beta$-cristobalite) could "armor" the glass surface, thus preventing glass dissolution and effectively decreasing the reactive glass surface area with time. It is also possible that the initial glass possesses variable physical characteristics (e.g., pumiceous, vesicular, blebs, massive) which result in variable reactive surface areas. In this case, the glass reactive surface area is not a constant. The glass surface area should more appropriately be represented by a distribution of values. In this scenario, the portions of glass with high surface area would dissolve first, leading to progressively lower glass surface areas with time. Regardless of whether the glass surface is armored with time or a distribution of glass surface areas exist, the net effect to is decrease reactive glass surface area with time.

Given the lack of natural or experimental analogues to the behavior predicted in model 10b and the arguments above, it is assumed that a reactive glass surface area of $0.05 \mathrm{~m}^{2} / \mathrm{g}$ for the lifetime of melt glass is unrealistically high. Further streamline and 3D simulations were not made using Model 10b parameters. Instead, additional simulations were made to explore the sensitivity of model results to glass surface areas that are one and two orders of magnitude greater than that used in Model 10a. 


\section{Mineralogic Model 10c and 10d versus 10a: Effect of increasing glass surface area by one and two orders of magnitude}

Input parameters for models $10 \mathrm{c}$ and $10 \mathrm{~d}$ were identical to those of $10 \mathrm{a}$ except for the increase in glass surface areas to $5 \times 10^{-4} \mathrm{~m}^{2} / \mathrm{g}$ and $5 \times 10^{-3} \mathrm{~m}^{2} / \mathrm{g}$, respectively (Table 31). Figures 134 through 149 illustrate the sensitivity of radionuclide migration to glass surface area. Results are only discussed for streamline 145 because streamline 100 does not intersect the glass melt.

Radionuclide concentrations. No significant changes in Cs migration occurred because released Cs was effectively removed from solution by ion exchange onto illite/muscovite regardless of the estimated glass surface area.

The extents of migration of $\mathrm{Pu}$ and $\mathrm{Sr}$ are little affected in 100 years by order of magnitude increases in glass surface area (Figs. 134 and 135). Although Am and $\mathrm{Eu}$ concentrations increase downstream relative to Model 10a (Figs. 136 and 137), the farthest extent of the concentration front is maintained at about 480 meters independent of the glass surface area. As Am and Eu are unimpeded by sorption, ion exchange and precipitation processes, the higher concentrations released from the glass migrate directly with the groundwater and produce a similar front profile albeit with a higher concentration.

$\mathrm{Pu}$ migrates to about 490 meters after 600 years when the glass surface area equals $5 \times 10^{-3} \mathrm{~m}^{2} / \mathrm{g}$ in Model 10d (Fig. 138). Migration is less extensive when lower glass surface areas are used in models 10a and 10c. Figure 139 focuses on the concentration front of $\mathrm{Pu}$ in Model 10d as a function of time. The concentration front migrates fastest, and thus travels the most distance, between 300 and 500 years. During this time period, the rate of travel along the streamline increases owing to an increase in the conductivity of the alluvium (see Fig. 43).

Sr migrates an additional thirty meters downstream in Model 10d relative to models 10a and 10c after 600 years (Fig. 140). Although the extent of migration of $\mathrm{Am}$ and $\mathrm{Eu}$ is the same in models 10a, 10c and 10d, the radionuclide concentrations differ by an order of magnitude in correspondence with the order of magnitude differences in glass surface areas, and thus total glass dissolution (Figs. 141 and 142). Whereas the maximum extent of migration of non-sorbing radionuclides such as $\mathrm{Eu}$ and $\mathrm{Am}$ is independent of glass dissolution rate, the extent of Sr migration is both a function of the glass dissolution rate and the ability of sorbing minerals to retard $\mathrm{Sr}$.

Groundwater $\mathbf{p H}$. The alkaline $\mathrm{pH}$ front resulting from an increased glass surface area, combined with reduced goethite reactivity, is shown in Figures 143 and 144 for models 10c and 10d. (The pH front associated with Model 10 is shown in Fig. 111.) The alkaline values of $\mathrm{pH}$ in models $10 \mathrm{c}$ and $10 \mathrm{~d}$ cause significant changes in the aqueous speciation and the surface speciation of goethite. For example, the dominant aqueous species of Si becomes the anion 


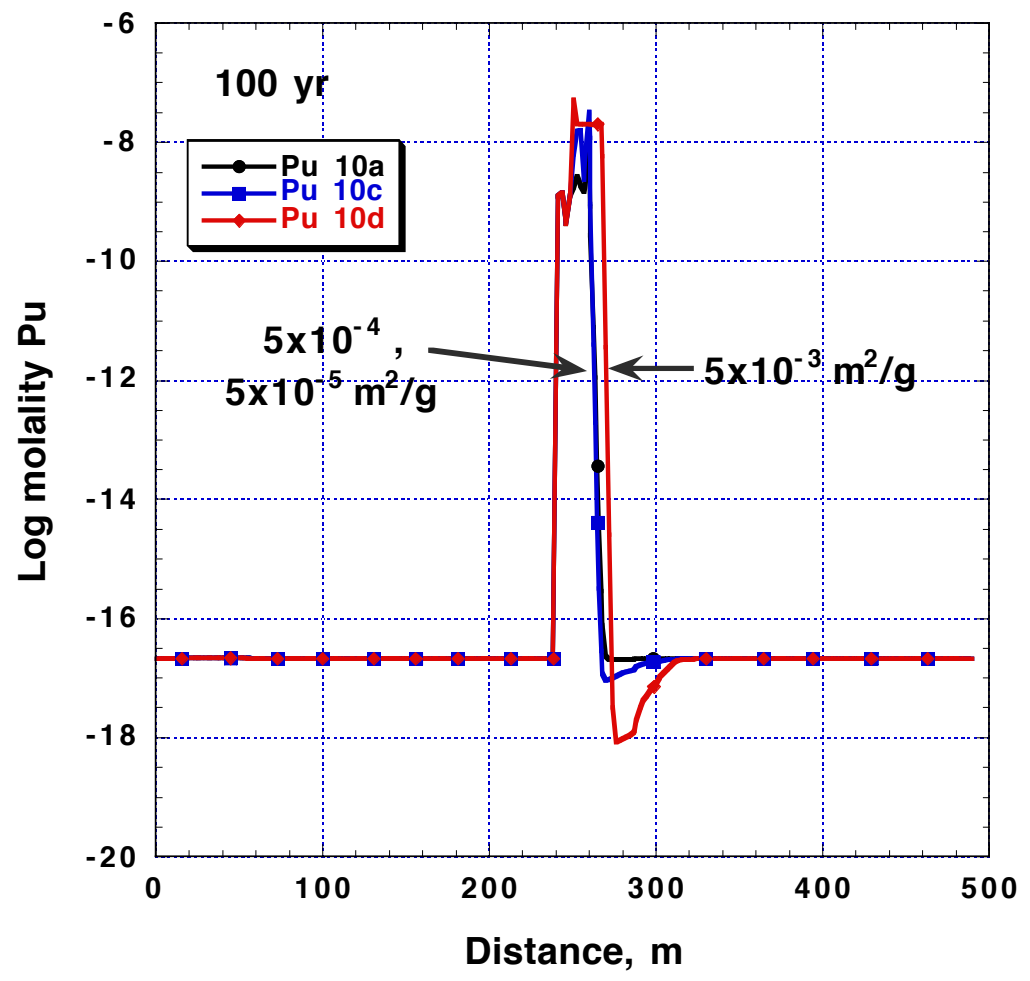

Figure 134: Comparison of spatial distribution of total $\mathrm{Pu}$ molality in solution at 100 years along streamline 145 for models $10 \mathrm{a}, 10 \mathrm{c}$ and $10 \mathrm{~d}$ with glass surface areas of $5 \times 10^{-5}, 5 \times 10^{-4}$ and $5 \times 10^{-3} \mathrm{~m}^{2} / \mathrm{g}$, respectively, and goethite surface area of $50 \mathrm{~m}^{2} / \mathrm{g}$. 


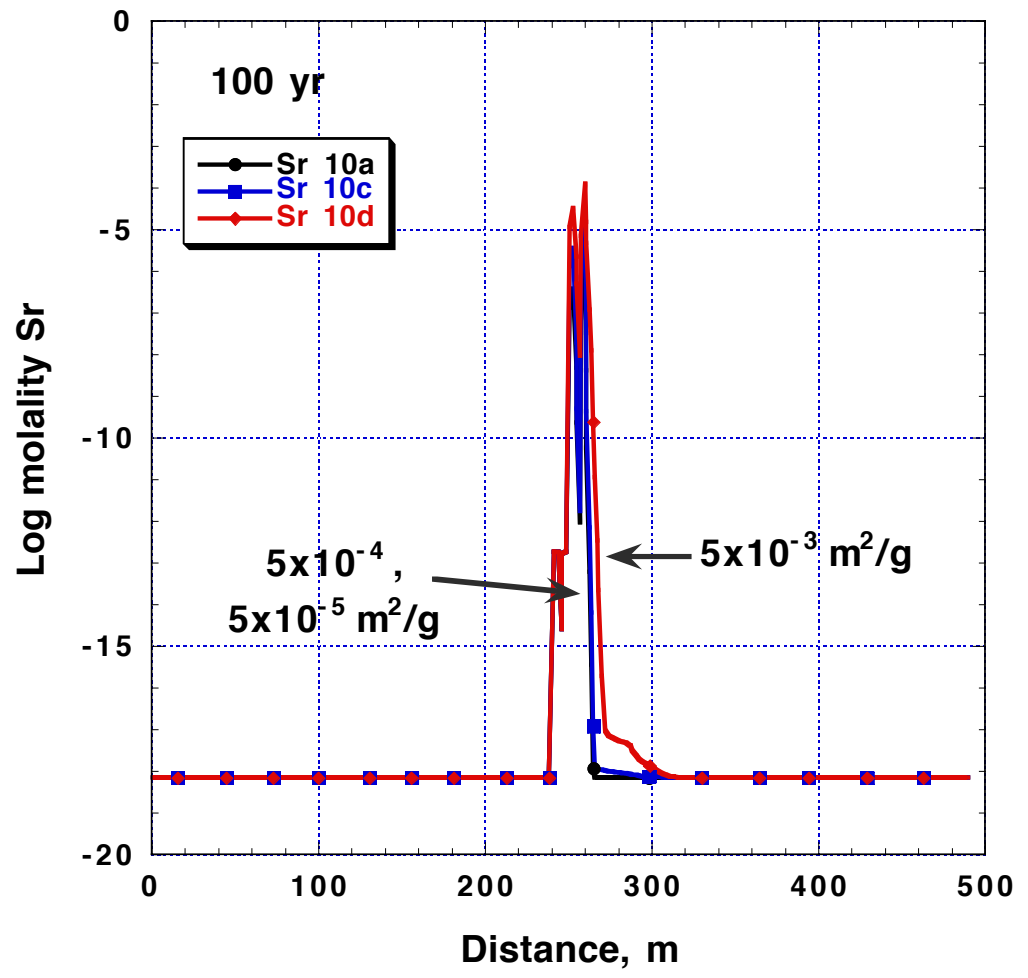

Figure 135: Comparison of spatial distribution of total Sr molality in solution at 100 years along streamline 145 for models $10 \mathrm{a}, 10 \mathrm{c}$ and $10 \mathrm{~d}$ with glass surface areas of $5 \times 10^{-5}, 5 \times 10^{-4}$ and $5 \times 10^{-3} \mathrm{~m}^{2} / \mathrm{g}$, respectively, and goethite surface area of $50 \mathrm{~m}^{2} / \mathrm{g}$. 


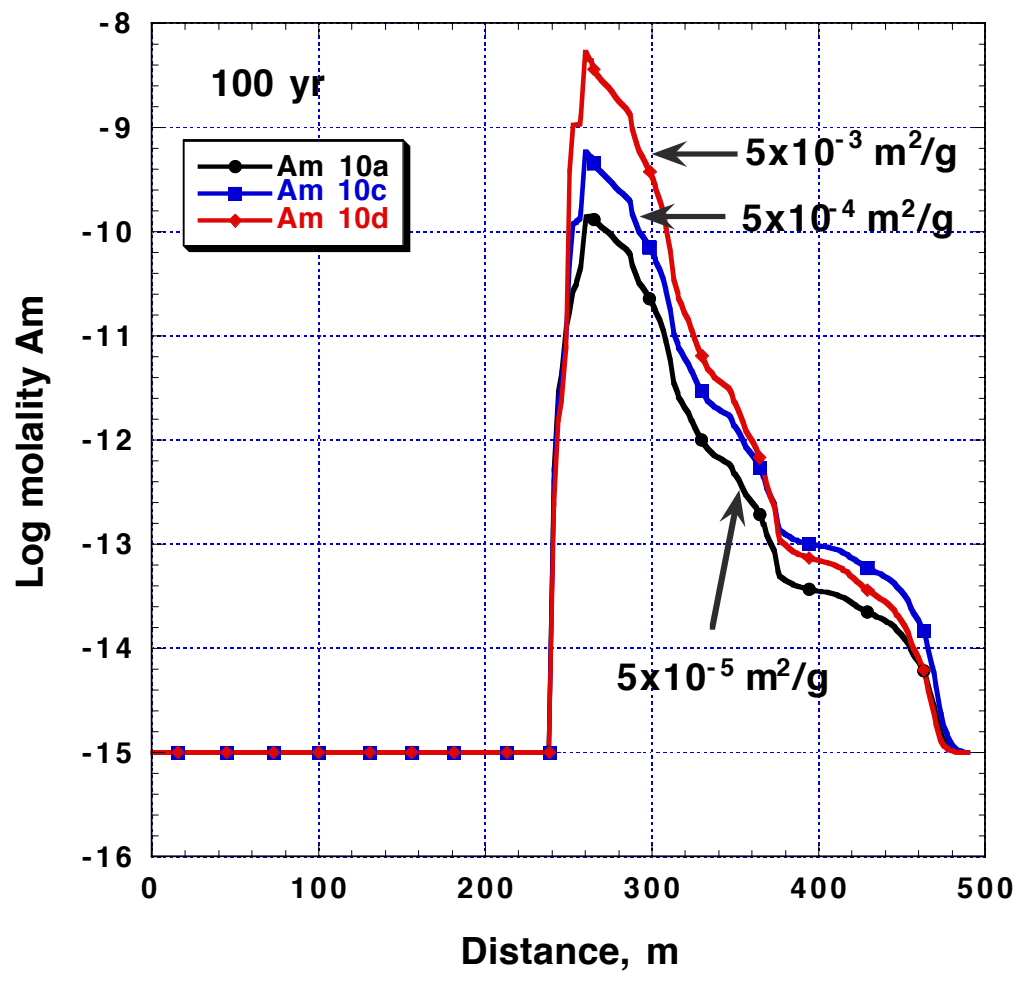

Figure 136: Comparison of spatial distribution of total Am molality in solution at 100 years along streamline 145 for models $10 \mathrm{a}, 10 \mathrm{c}$ and $10 \mathrm{~d}$ with glass surface areas of $5 \times 10^{-5}, 5 \times 10^{-4}$ and $5 \times 10^{-3} \mathrm{~m}^{2} / \mathrm{g}$, respectively, and goethite surface area of $50 \mathrm{~m}^{2} / \mathrm{g}$. 


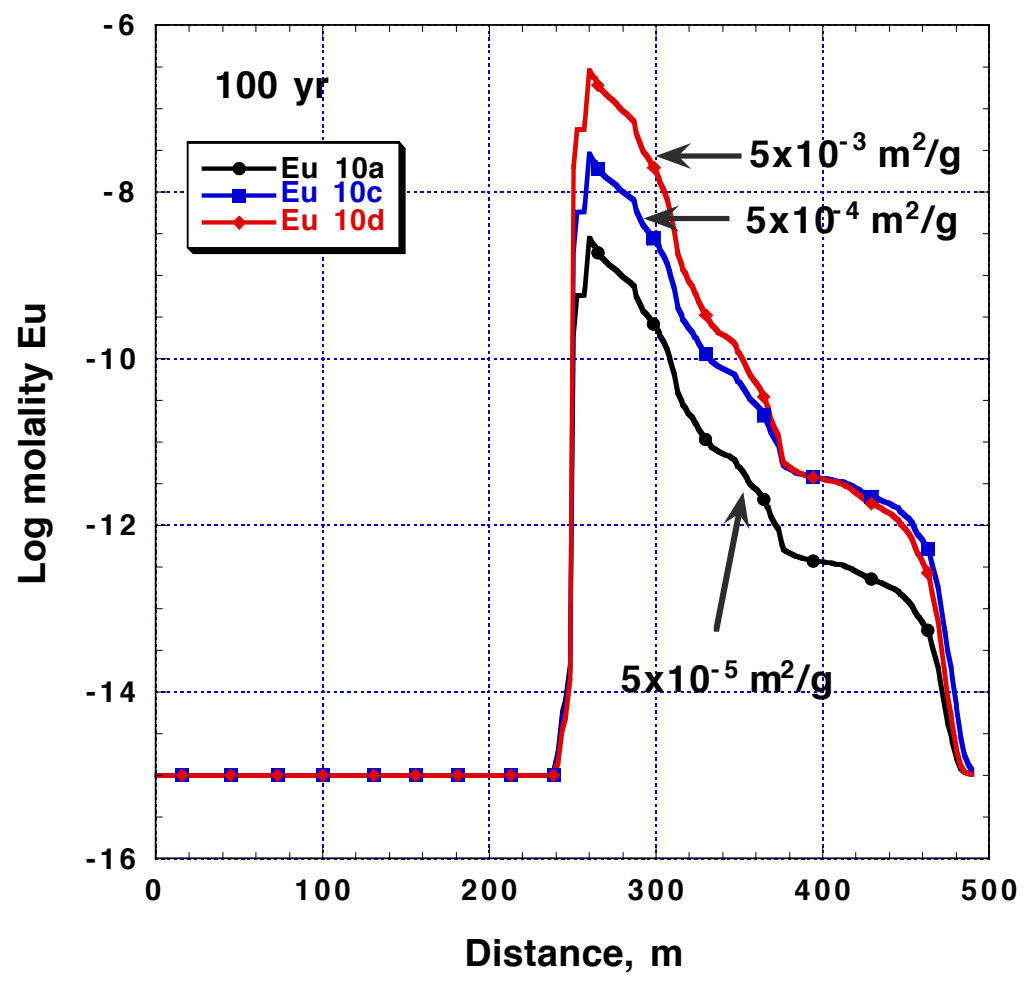

Figure 137: Comparison of spatial distribution of total Eu molality in solution at 100 years along streamline 145 for models $10 \mathrm{a}, 10 \mathrm{c}$ and $10 \mathrm{~d}$ with glass surface areas of $5 \times 10^{-5}, 5 \times 10^{-4}$ and $5 \times 10^{-3} \mathrm{~m}^{2} / \mathrm{g}$, respectively, and goethite surface area of $50 \mathrm{~m}^{2} / \mathrm{g}$. 


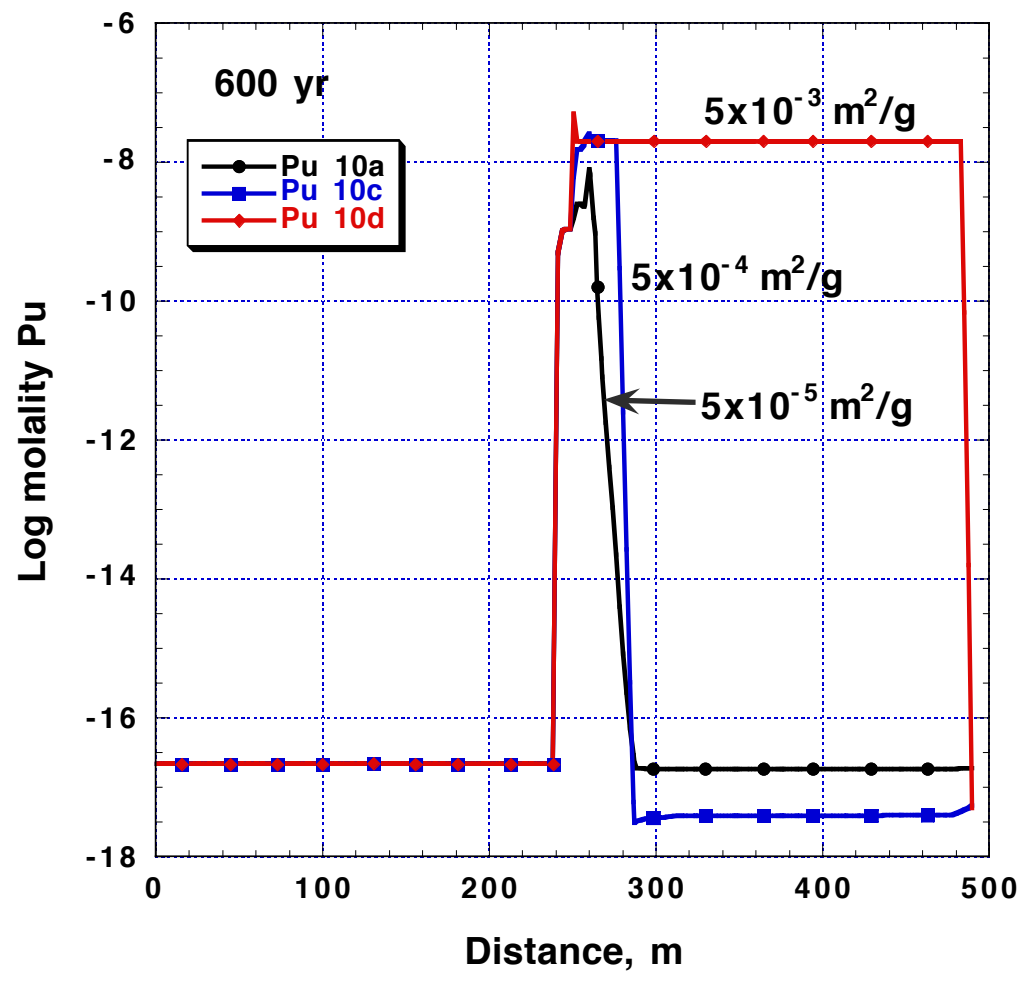

Figure 138: Comparison of spatial distribution of total $\mathrm{Pu}$ molality in solution at 600 years along streamline 145 for models $10 \mathrm{a}, 10 \mathrm{c}$ and $10 \mathrm{~d}$ with glass surface areas of $5 \times 10^{-5}, 5 \times 10^{-4}$ and $5 \times 10^{-3} \mathrm{~m}^{2} / \mathrm{g}$, respectively, and goethite surface area of $50 \mathrm{~m}^{2} / \mathrm{g}$. 


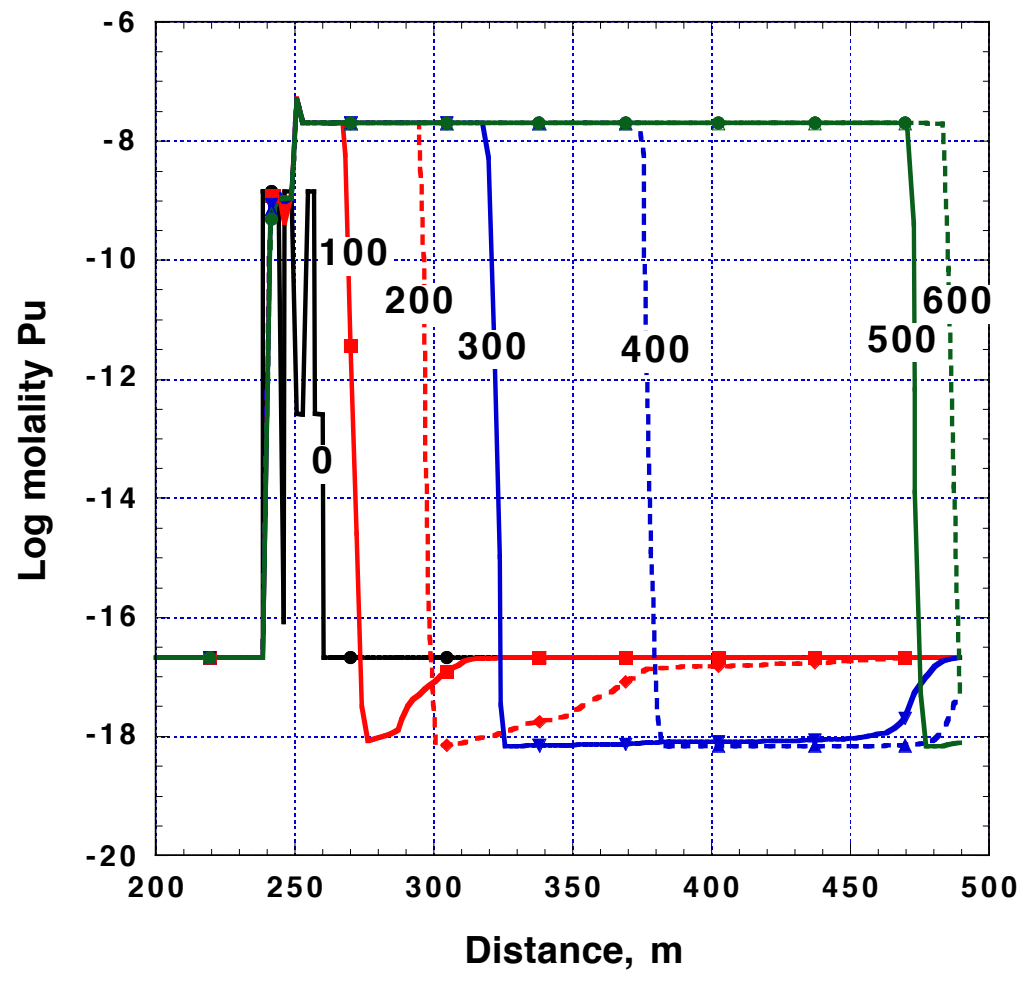

Figure 139: Downstream movement of $\mathrm{Pu}$ concentration front as a function of time (labelled in years) along streamline 145 for Model 10d with glass surface area of $5 \times 10^{-3} \mathrm{~m}^{2} / \mathrm{g}$ and goethite surface area of $50 \mathrm{~m}^{2} / \mathrm{g}$. 


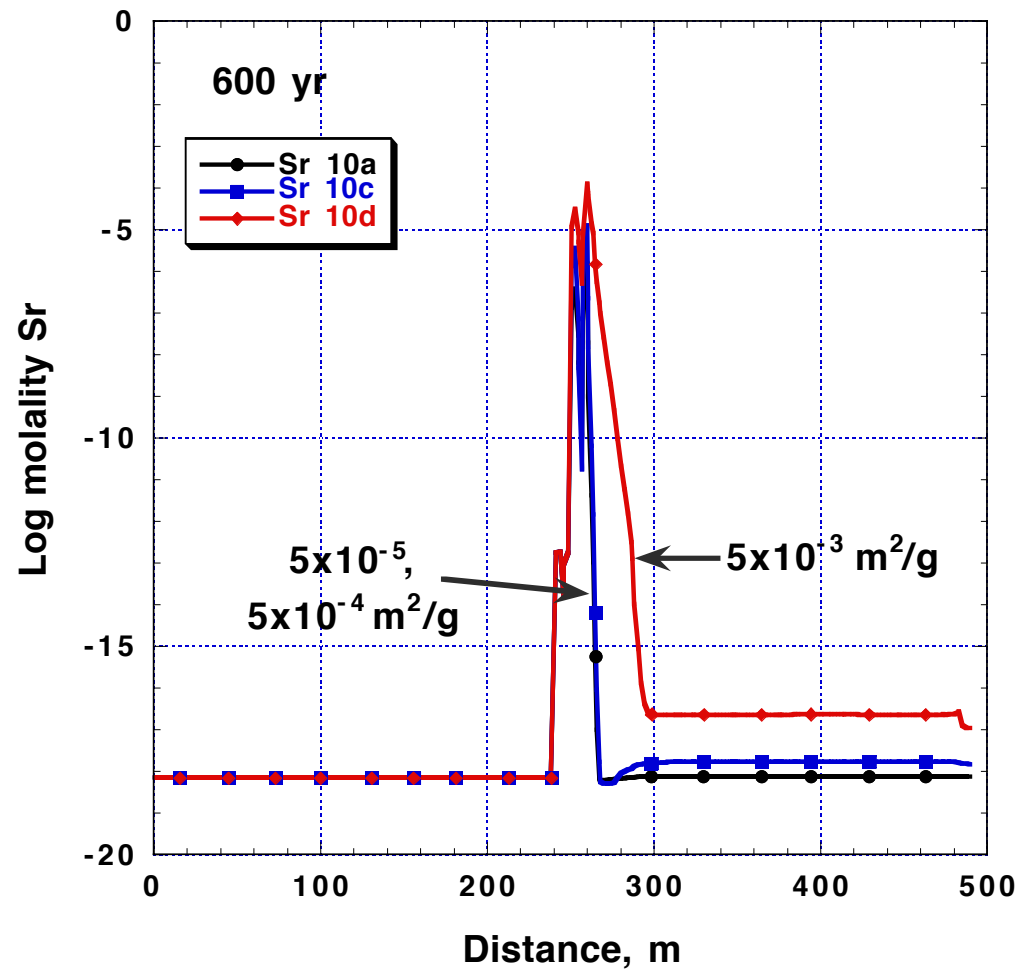

Figure 140: Comparison of spatial distribution of total Sr molality in solution at 600 years along streamline 145 for models $10 \mathrm{a}, 10 \mathrm{c}$ and $10 \mathrm{~d}$ with glass surface areas of $5 \times 10^{-5}, 5 \times 10^{-4}$ and $5 \times 10^{-3} \mathrm{~m}^{2} / \mathrm{g}$, respectively, and goethite surface area of $50 \mathrm{~m}^{2} / \mathrm{g}$. 


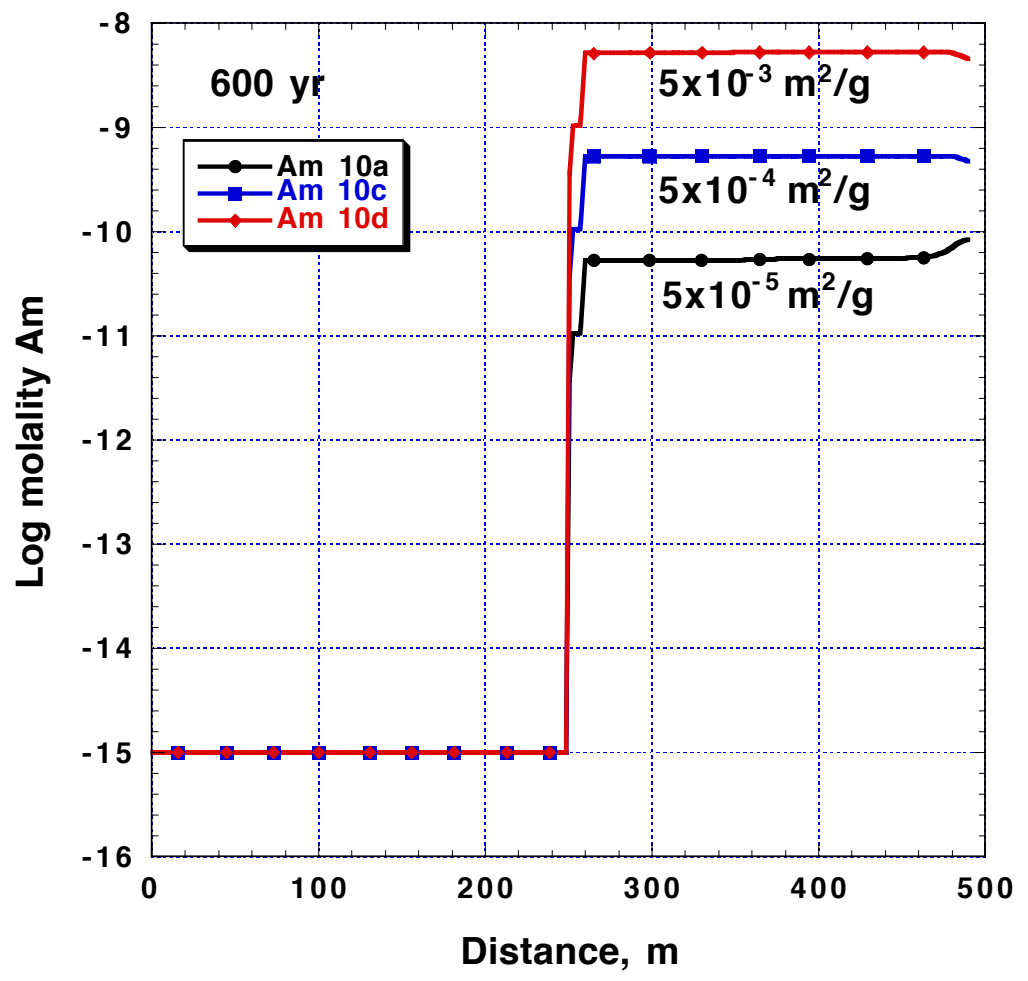

Figure 141: Comparison of spatial distribution of total Am molality in solution at 600 years along streamline 145 for models $10 \mathrm{a}, 10 \mathrm{c}$ and $10 \mathrm{~d}$ with glass surface areas of $5 \times 10^{-5}, 5 \times 10^{-4}$ and $5 \times 10^{-3} \mathrm{~m}^{2} / \mathrm{g}$, respectively, and goethite surface area of $50 \mathrm{~m}^{2} / \mathrm{g}$. 


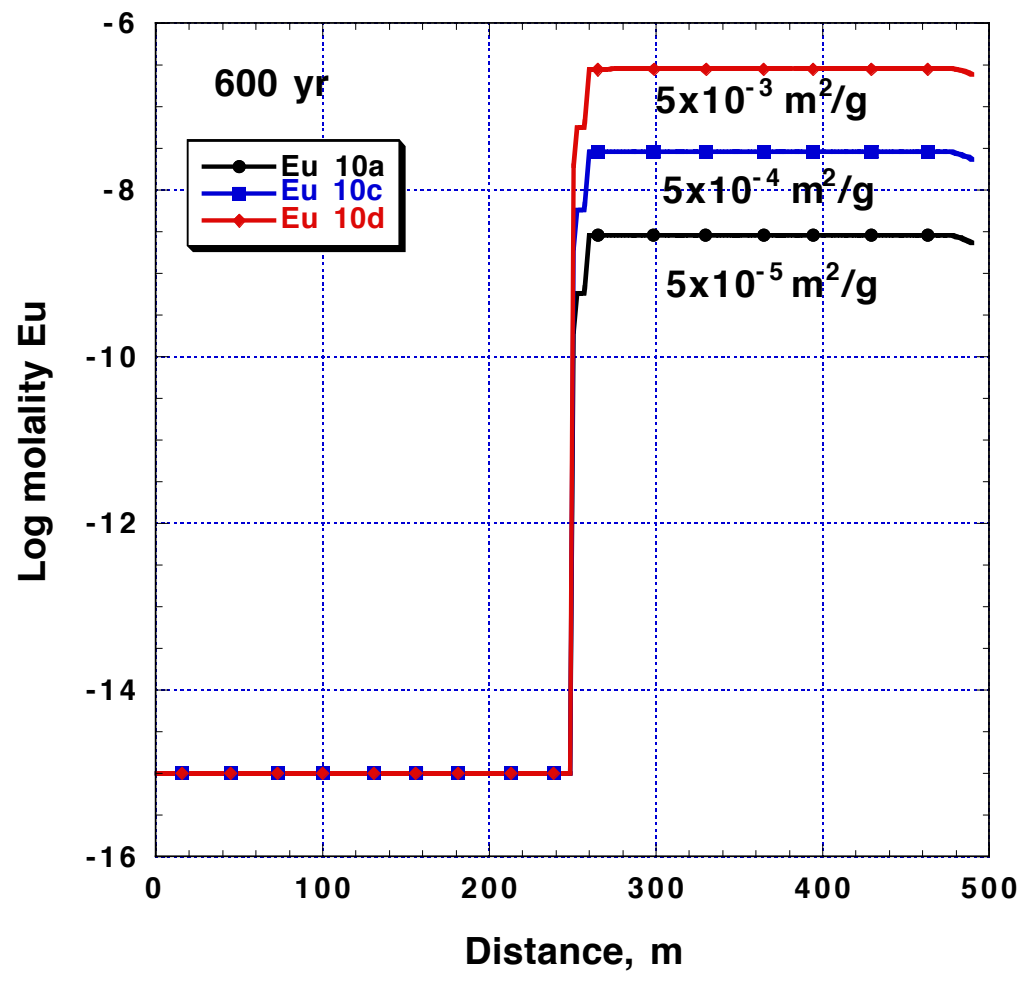

Figure 142: Comparison of spatial distribution of total Eu molality in solution at 600 years along streamline 145 for models $10 \mathrm{a}, 10 \mathrm{c}$ and $10 \mathrm{~d}$ with glass surface areas of $5 \times 10^{-5}, 5 \times 10^{-4}$ and $5 \times 10^{-3} \mathrm{~m}^{2} / \mathrm{g}$, respectively, and goethite surface area of $50 \mathrm{~m}^{2} / \mathrm{g}$. 
$\mathrm{HSiO}_{3}^{-}$(Fig. 145), and that for carbon (C) becomes $\mathrm{CO}_{3}^{-2}$. The $\mathrm{Pu}$ speciation also shifts, as shown in Figure 146. The neutral species $\mathrm{PuO}_{2}(\mathrm{OH})_{2}(\mathrm{aq})$ dominates, in contrast to the dominance of $\mathrm{PuO}_{2}\left(\mathrm{CO}_{3}\right)_{2}^{-2}$ at lower values of $\mathrm{pH}$ (Fig. 26). $\rangle \mathrm{FeO}^{-2}$ dominates the goethite surface instead of the neutral $\rangle \mathrm{FeOH}$, which decreases in concentration by 2 orders of magnitude.

The contributors to this report are not aware of any natural occurrences of a plume of alkaline $\mathrm{pH}$ emanating from natural glasses, nor of fluids with total silica concentrations exceeding that in equilibrium with amorphous silica by orders of magnitude. Skepticism therefore exists regarding the use of glass surface areas large enough to generate highly alkaline values of $\mathrm{pH}(e . g$., greater that 10). Nevertheless, models 10a through 10d illustrate the sensitivity of the hydrologic source term to the reactive surface area of the glass.

A pH independent glass dissolution rate expression was used in the initial simulations because preparatory calculations suggested that $\mathrm{pH}$ deviations from 8 would be minimal. However, models $10 \mathrm{~b}, 10 \mathrm{c}$ and $10 \mathrm{~d}$ produced significant excursions from a $\mathrm{pH}$ of 8 , reaching 10.4 and 11.5 in models $10 \mathrm{c}$ and $10 \mathrm{~d}$, respectively (Figs. 143 and 144) and at least 12.5 in Model 10b. Figure 12 shows that the rate constant for glass dissolution increases over an order of magnitude at these alkaline pHs. If the full $\mathrm{pH}$-dependent rate law had been used in these simulations, the rate of glass dissolution under alkaline conditions would be an additional 1 to 2 orders of magnitude faster that now predicted in models $10 \mathrm{~b}, 10 \mathrm{c}$ and $10 \mathrm{~d}$. Thus the realism of a reactive glass surface area as high as $0.05 \mathrm{~m}^{2} / \mathrm{g}$ is even more suspect. Future simulations will include the $\mathrm{pH}$-dependent rate law for glass dissolution.

Mineral precipitation. Although potential Am and Eu-bearing precipitates are considered in the simulation, the concentrations of $\mathrm{Am}$ and $\mathrm{Eu}$ were never sufficient to reach saturation with respect to $\mathrm{AmOHCO}_{3}$ and $\mathrm{EuOHCO}_{3}$ at any time in models 10c and 10d (Figs. 147 through 150). The saturation index is equal to the logarithm of the ratio of the activity product (Q) of the ions involved in the mineral's hydrolysis reaction, to the equilibrium constant $(\mathrm{K})$ of the mineral (Drever, 1982; Bethke, 1996). Positive, negative and zero saturation indices indicate supersaturation, undersaturation and equilibrium with respect to the mineral, respectively.

The solid $\mathrm{PuO}_{2}(\mathrm{OH})_{2} \cdot \mathrm{H}_{2} \mathrm{O}$ reaches saturation in Model 10c just before the groundwater exits the last glass zone at about 260 meters (Fig. 147). At 600 years, the equilibrium saturation index is maintained to 275 meters (Fig. 148). It is important to note that Pu precipitation occurs only in the glass zones and not in the alluvium. Within the glass zone, the dissolving glass releases a constant source of $\mathrm{Pu}$ that increases in concentration until precipitation occurs. When the groundwater leaves the glass and enters the alluvium downstream, nothing acts on the fluid to disturb its state of equilibrium with respect to $\mathrm{PuO}_{2}(\mathrm{OH})_{2} \cdot \mathrm{H}_{2} \mathrm{O}$ (such as contacting a different rock type) so the 


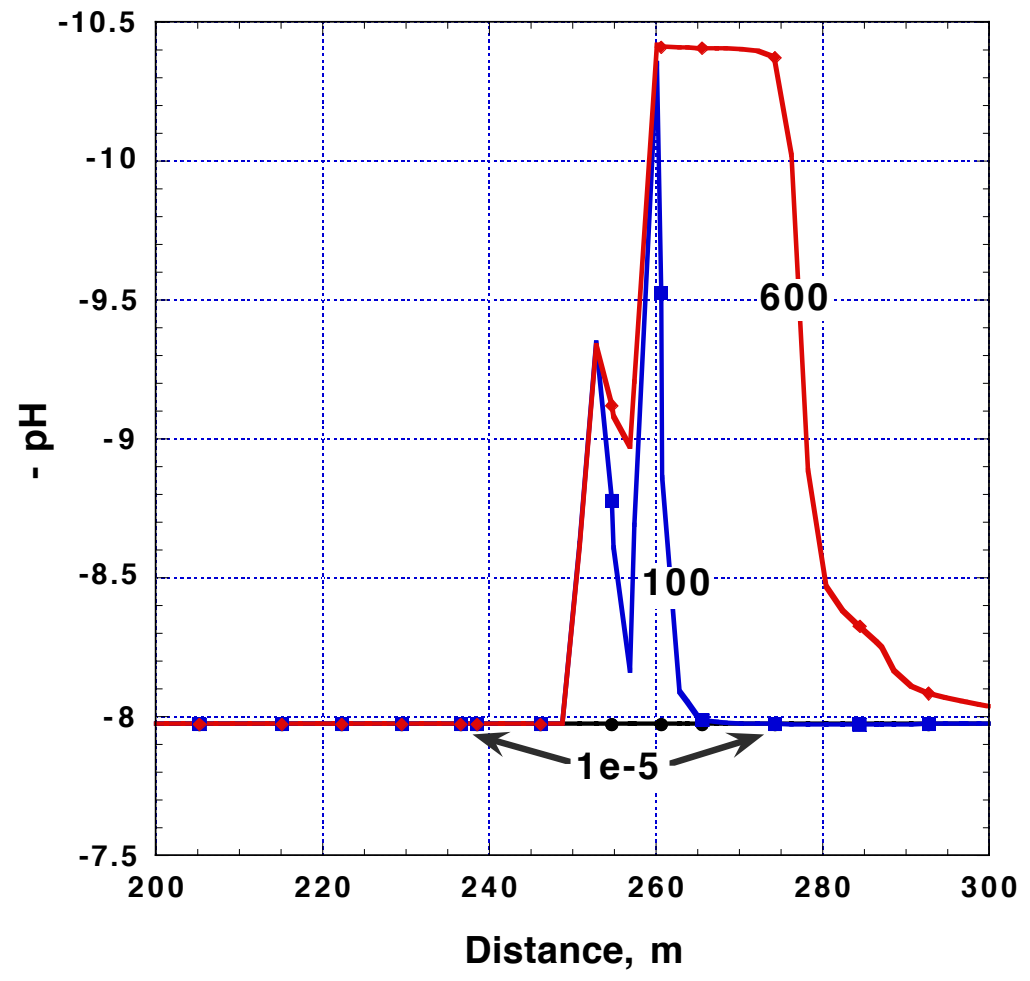

Figure 143: Comparison of spatial distribution of solution pH at 1e-5, 100 and 600 years along streamline 145 for Model $10 \mathrm{c}$ with glass surface area of $5 \times 10^{-4}$ $\mathrm{m}^{2} / \mathrm{g}$ and goethite surface area of $50 \mathrm{~m}^{2} / \mathrm{g}$. 


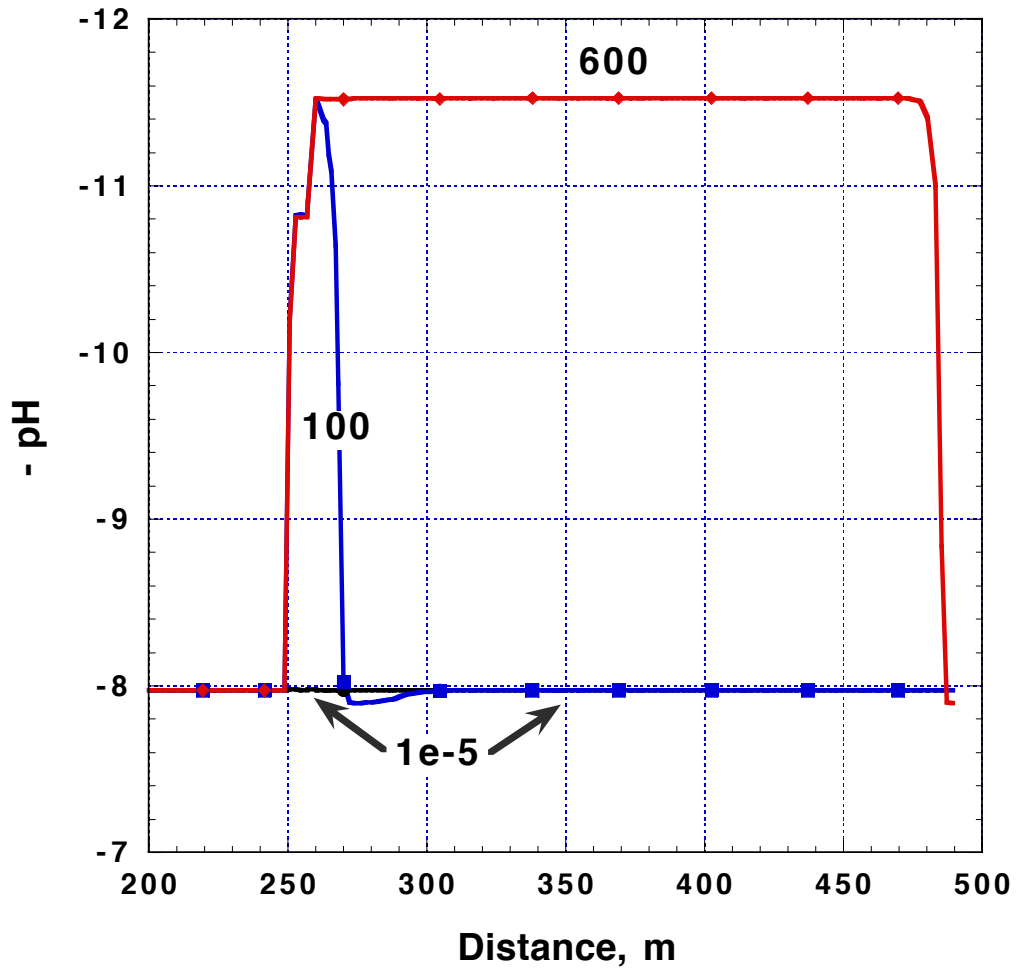

Figure 144: Comparison of spatial distribution of solution $\mathrm{pH}$ at 1e-5, 100 and 600 years along streamline 145 for Model 10d with glass surface area of $5 \times 10^{-3}$ $\mathrm{m}^{2} / \mathrm{g}$ and goethite surface area of $50 \mathrm{~m}^{2} / \mathrm{g}$. 


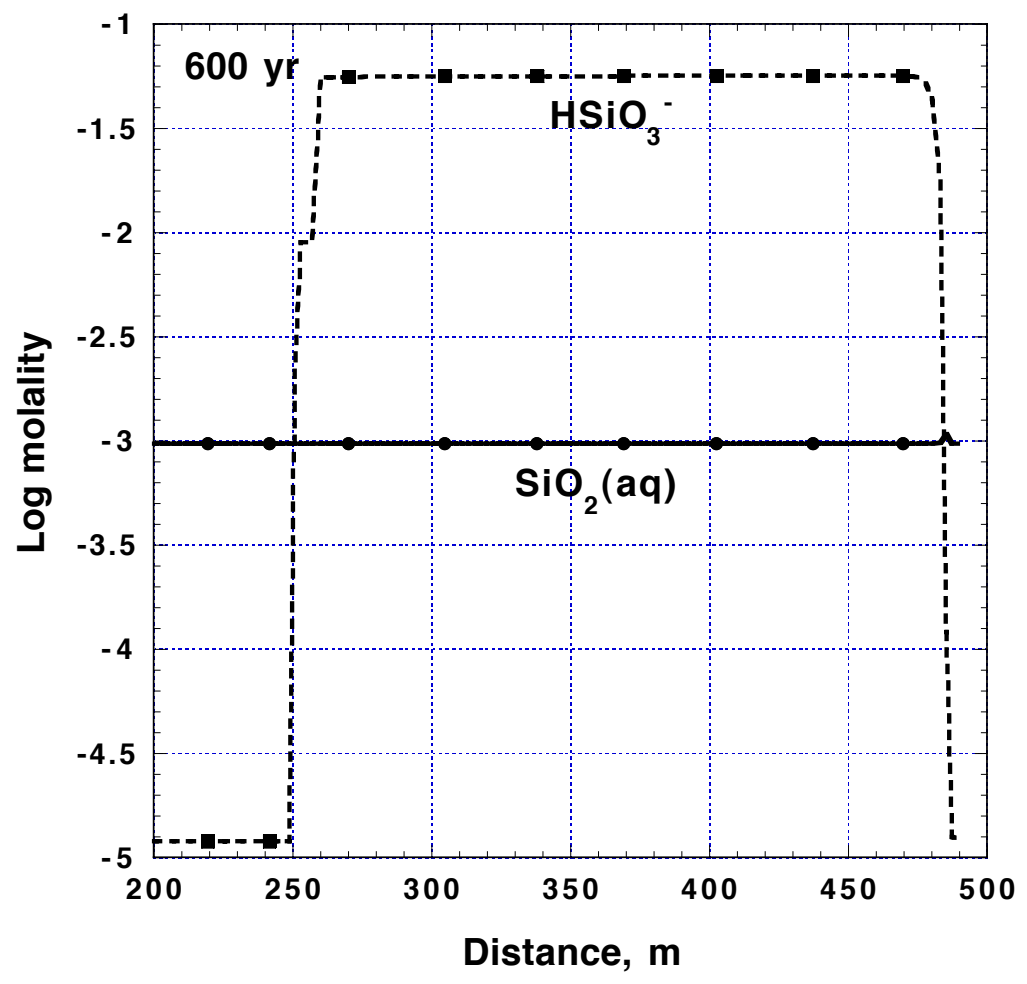

Figure 145: Silica speciation in groundwater at 600 years along streamline 145 for Model 10d with glass surface area of $5 \times 10^{-3} \mathrm{~m}^{2} / \mathrm{g}$ and goethite surface area of $50 \mathrm{~m}^{2} / \mathrm{g}$. Note the dominance of $\mathrm{HSiO}_{3}$ over $\mathrm{SiO} 2(\mathrm{aq})$ when the $\mathrm{pH}$ is greater than 10 (Fig. 144). 


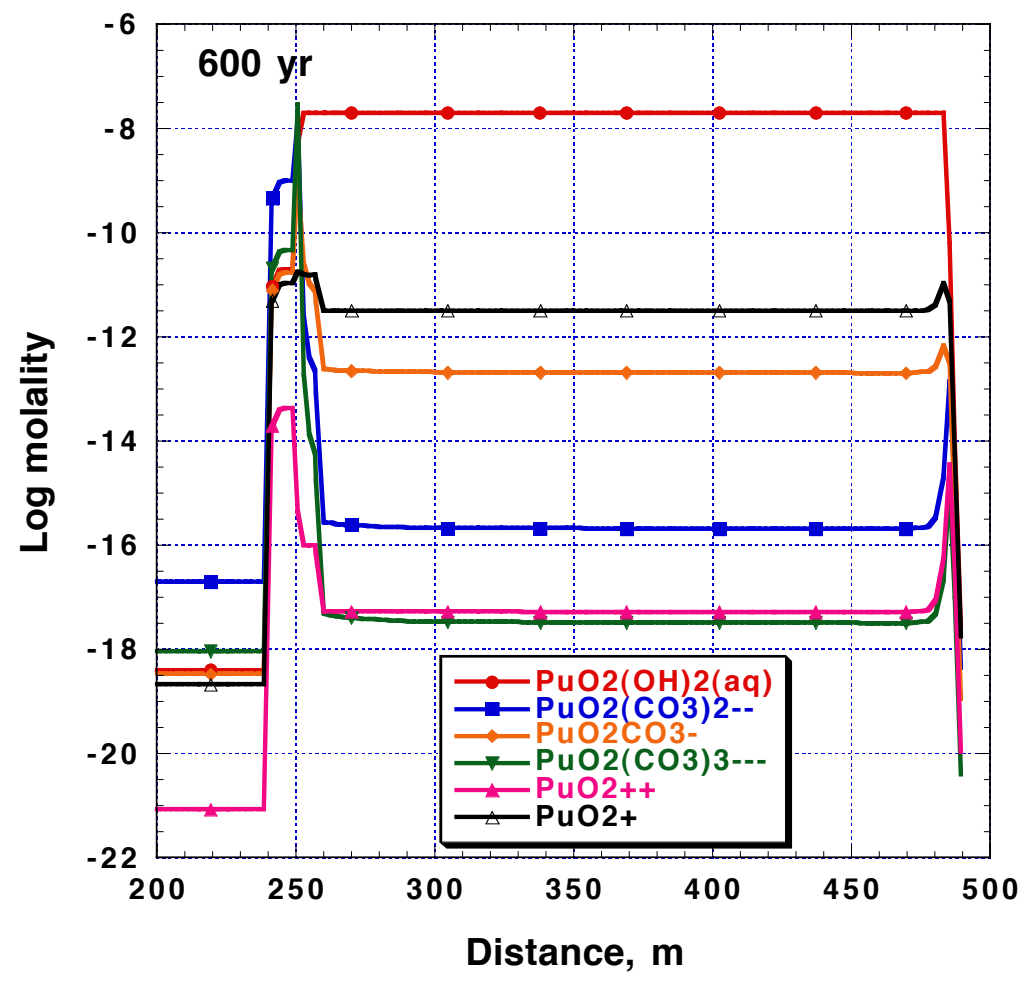

Figure 146: Plutonium speciation in groundwater at 600 years along streamline 145 for Model 10d with glass surface area of $5 \times 10^{-3} \mathrm{~m}^{2} / \mathrm{g}$ and goethite surface area of $50 \mathrm{~m}^{2} / \mathrm{g}$. Note the dominance of the neutral complex $\mathrm{PuO}_{2}(\mathrm{OH})_{2}(\mathrm{aq})$ over the anion $\mathrm{PuO}_{2}\left(\mathrm{CO}_{3}\right)^{-2}$ when the $\mathrm{pH}$ is highly alkaline (Fig. 144). 


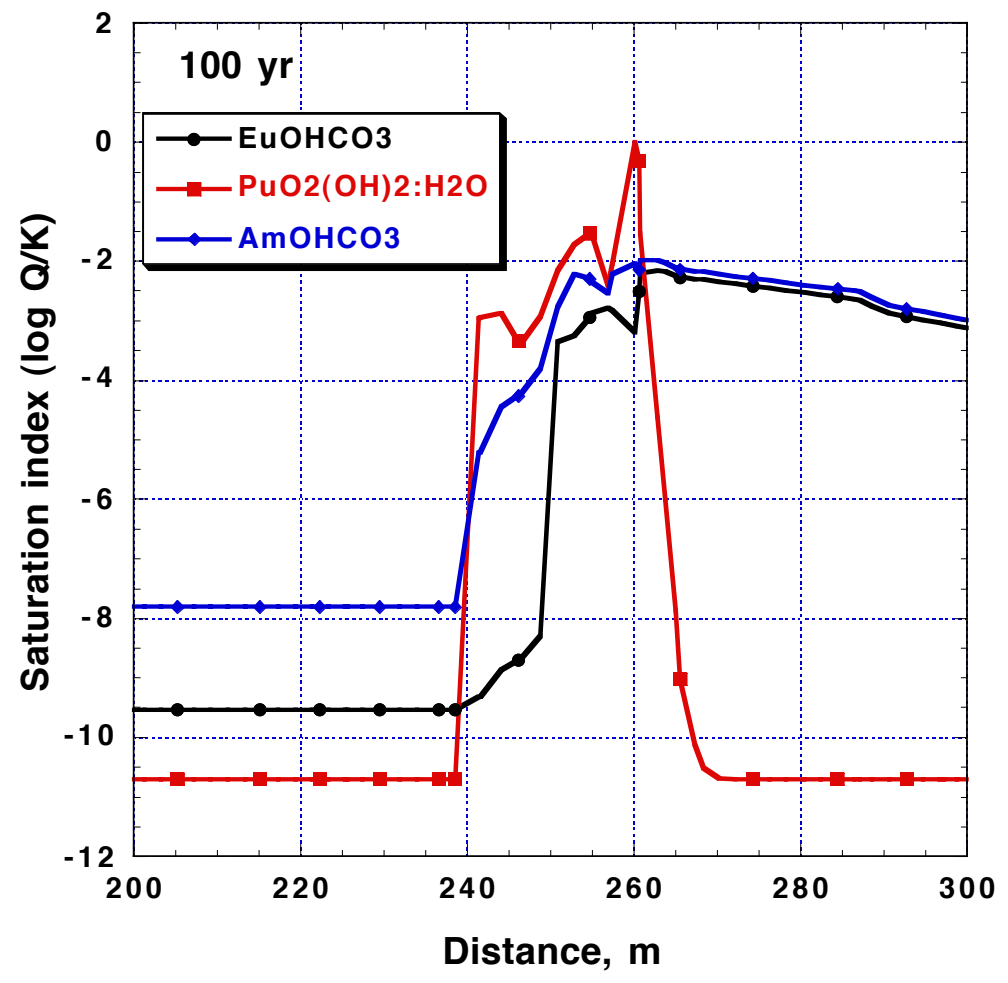

Figure 147: Saturation index, defined as $\log Q / K$ (see text), with respect to radionuclide-bearing solids at 100 years along streamline 145 for Model $10 \mathrm{c}$ with glass surface area of $5 \times 10^{-4} \mathrm{~m}^{2} / \mathrm{g}$ and goethite surface area of $50 \mathrm{~m}^{2} / \mathrm{g}$. 


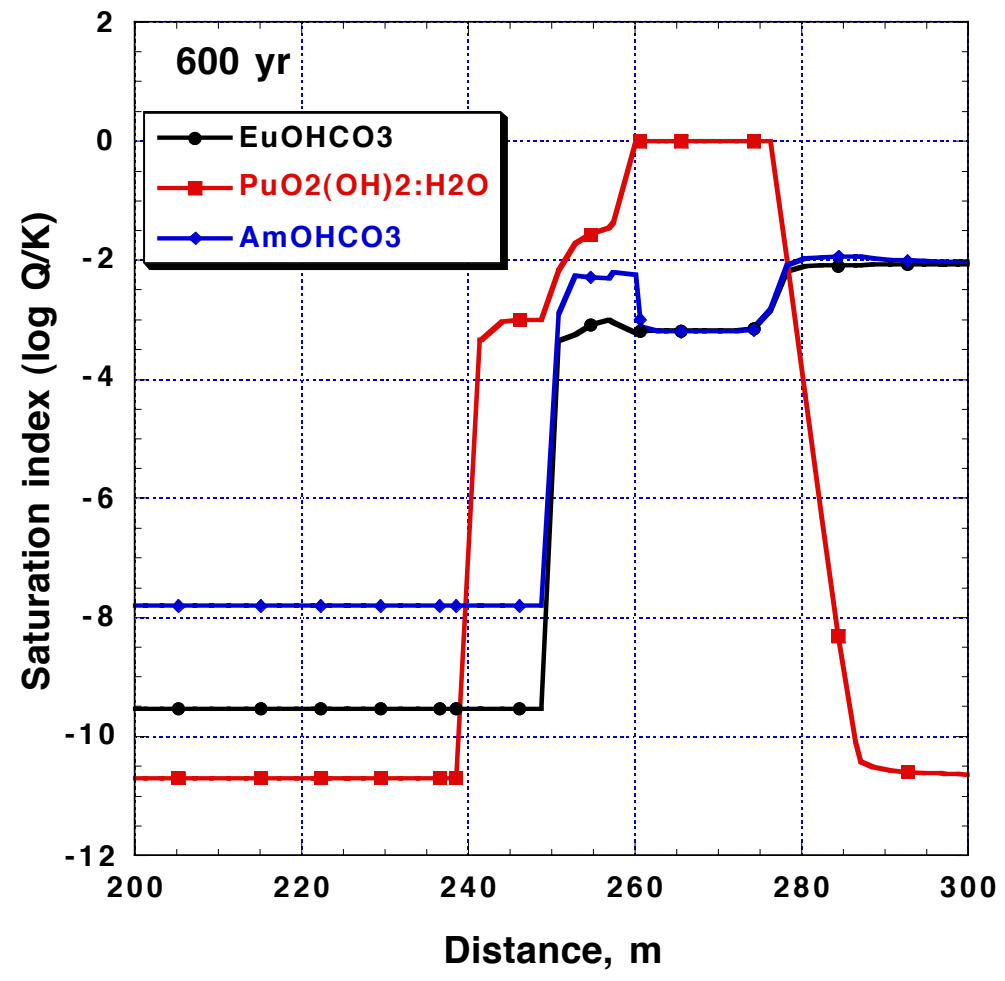

Figure 148: Saturation states with respect to radionuclide-bearing solids at 600 years along streamline 145 for Model 10c with glass surface area of $5 \times 10^{-4}$ $\mathrm{m}^{2} / \mathrm{g}$ and goethite surface area of $50 \mathrm{~m}^{2} / \mathrm{g}$. 


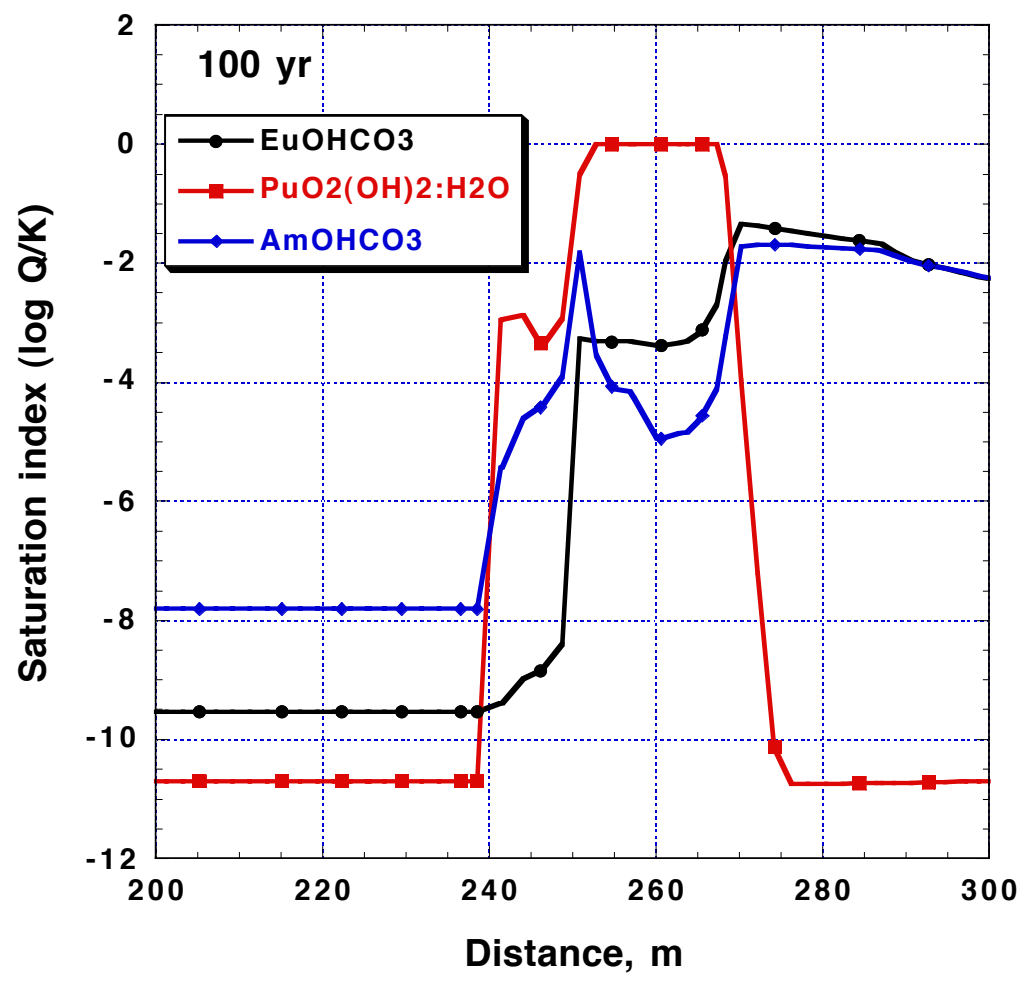

Figure 149: Saturation states with respect to radionuclide-bearing solids at 100 years along streamline 145 for Model 10d with glass surface area of $5 \times 10^{-3}$ $\mathrm{m}^{2} / \mathrm{g}$ and goethite surface area of $50 \mathrm{~m}^{2} / \mathrm{g}$. 


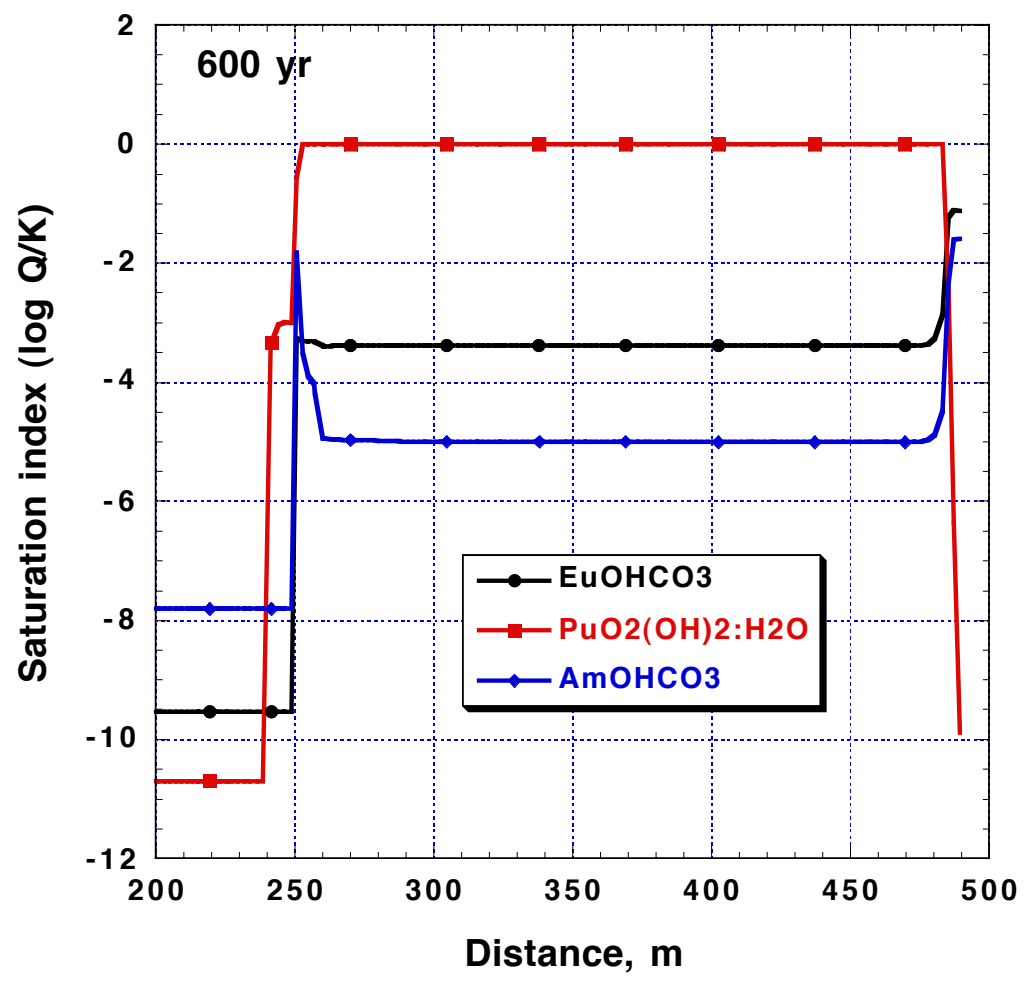

Figure 150: Saturation states with respect to radionuclide-bearing solids at 600 years along streamline 145 for Model 10d with glass surface area of $5 \times 10^{-3}$ $\mathrm{m}^{2} / \mathrm{g}$ and goethite surface area of $50 \mathrm{~m}^{2} / \mathrm{g}$. 
saturation index remains at zero. However, no precipitation occurs in the alluvium because there is no source of additional $\mathrm{Pu}$. Equilibrium with respect to $\mathrm{PuO}_{2}(\mathrm{OH})_{2} \cdot \mathrm{H}_{2} \mathrm{O}$ under pseudo-steady state conditions fixes the total concentration of $\mathrm{Pu}$ in solution at about $10^{7.7}$ molal, as shown in Figure 138.

Increasing the glass surface area to $5 \times 10^{-3} \mathrm{~m}^{2} / \mathrm{g}$ in Model $10 \mathrm{~d}$ causes precipitation of $\mathrm{PuO}_{2}(\mathrm{OH})_{2} \cdot \mathrm{H}_{2} \mathrm{O}$ in both glass zones at about 250 and 260 meters at 100 years (Fig. 149). By 600 years, the equilibrium saturation state, in the absence of precipitation, exists to about 480 meters (Fig. 150). Equilibrium with respect to $\mathrm{PuO}_{2}(\mathrm{OH})_{2} \cdot \mathrm{H}_{2} \mathrm{O}$ under pseudo-steady state conditions fixes the total concentration of $\mathrm{Pu}$ in solution at about $10^{-7.7}$ molal, as shown in Figure 139.

The occurrence of downstream equilibrium with respect to a radionuclidebearing solid in the absence of the solid has special relevance for the UGTA project. Groundwater sampling for radionuclides may reveal saturation with respect to a radionuclide-bearing solid. This does not necessarily imply that the fluid is in direct contact with the radionuclide-bearing solid at the point of sampling. It could instead imply that the groundwater has been in contact with the solid somewhere upstream of the actual sampling point. For example, groundwater sampled 100 meters from the glass melt (360 meters distance in Figure 138) 600 years after the CAMBRIC test would produce fluids in equilibrium with $\mathrm{PuO}_{2}(\mathrm{OH})_{2} \cdot \mathrm{H}_{2} \mathrm{O}$ (Fig. 150), although the mineral was last precipitated 100 meters upstream in the glass melt.

Figure 151 shows the volume percent of $\mathrm{PuO}_{2}(\mathrm{OH})_{2} \cdot \mathrm{H}_{2} \mathrm{O}$ that has precipitated at 100 and 600 years in Model 10d with $5 \times 10^{-3} \mathrm{~m}^{2} / \mathrm{g}$ glass surface area. Precipitation occurs only in the two glass zones that are intersected between 250 and 260 meters. The actual volume percent of the solid is very small, in accordance with the relatively low concentrations of $\mathrm{Pu}$ in the melt glass.

\section{Choice of glass surface area to be used in conservative source term calculations}

The glass surface area of $5 \times 10^{-3} \mathrm{~m}^{2} / \mathrm{g}$ in Model $10 \mathrm{~d}$ was selected for use in the integrated 3D Mineralogic Model 10d to illustrate the sensitivity of the source term to glass surface area. As discussed with regards to Model 10b, surface area on the order of $5 \times 10^{-2} \mathrm{~m}^{2} / \mathrm{g}$ produced an unlikely geochemical scenario. Model 10d produces glass dissolution rates that are two orders of magnitude higher than those in models 10 through 12 . The model will therefore serve as an example of the sensitivity of the source term to glass reactive surface area.

Further work is required to better estimate the actual reactive surface area(s) of melt glass. Work should also assess the reasonableness of the unique geochemical states caused by large glass surface area (e.g., alkaline $\mathrm{pH}$ ), and evaluate the merits of utilizing a distribution of glass surface areas in the dissolution model. For the time being, however, Model 10d can serve as an upper limit to glass surface area and dissolution rates. 


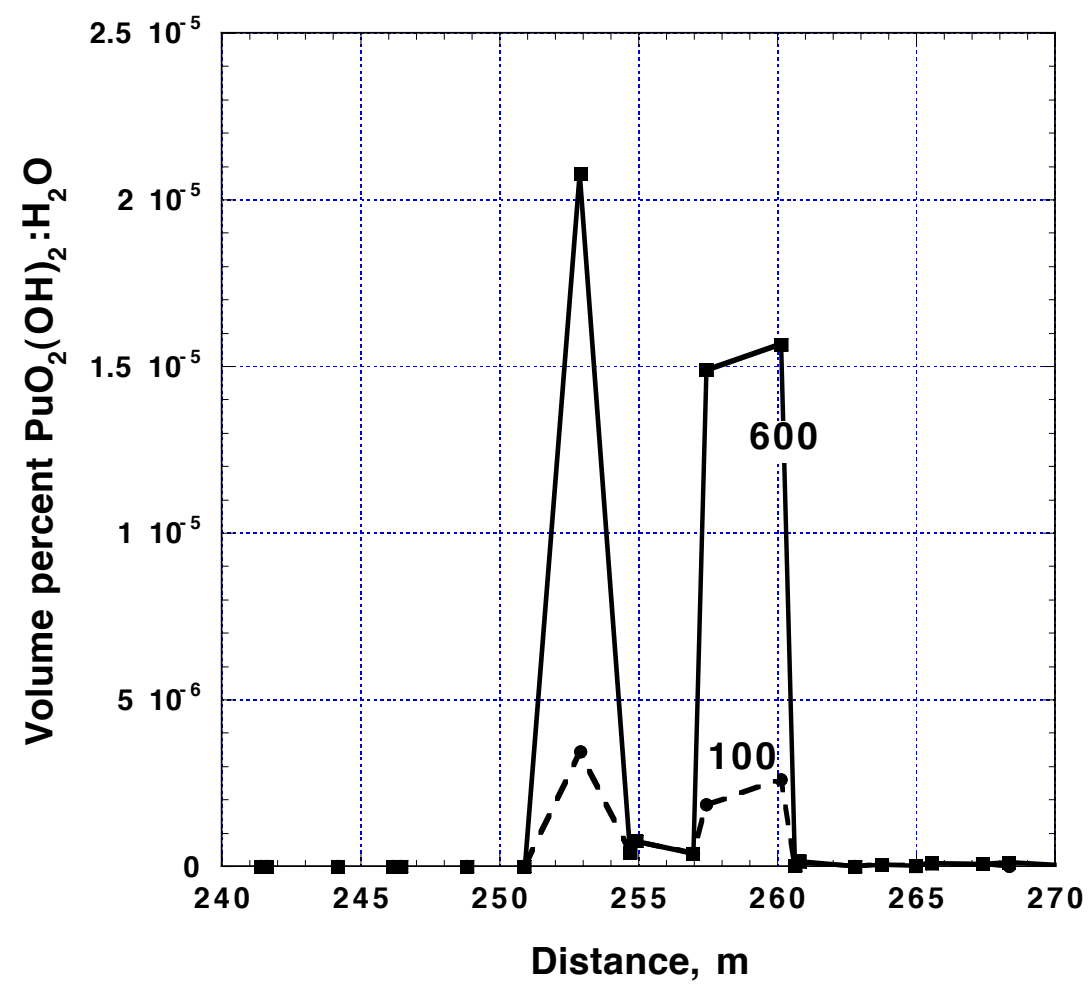

Figure 151: Volume percent of the solid $\mathrm{PuO}_{2}(\mathrm{OH})_{2} \cdot \mathrm{H}_{2} \mathrm{O}$ at 100 and 600 years along streamline 145 for Model $10 \mathrm{~d}$ with glass surface area of $5 \times 10^{-3} \mathrm{~m}^{2} / \mathrm{g}$ and goethite surface area of $50 \mathrm{~m}^{2} / \mathrm{g}$. 


\section{Summary of sensitivity of model results to iron oxide and glass surface areas}

- Changing the surface area of goethite affects mainly the migration of $\mathrm{Pu}$. An order of magnitude reduction in goethite surface area results in higher $\mathrm{Pu}$ concentrations downstream and greater distances of migration after hundreds of years. Sr migration is largely unaffected because increased exchange onto clinoptilolite and, secondarily, smectite, balance the loss of sorption sites on goethite.

- Increasing the surface area of glass results in significantly increased migration of $\mathrm{Pu}$ and slightly increased migration of Sr. The farthest extent of $\mathrm{Am}$ and Eu migration is unaffected, although $\mathrm{Am}$ and Eu concentrations at a given distance behind their concentration fronts increase. Cs migration is essentially unchanged because almost all Cs released from the glass is partitioned into illite/muscovite, regardless of the rate at which Cs is released from glass.

- Glass surface areas on the order of $5 \times 10^{-2} \mathrm{~m}^{2} / \mathrm{g}$ seem to produce increasingly unreasonable geochemical conditions which argue against the use of these surface areas in source term calculations. It is recommended that a glass surface area of $5 \times 10^{-3} \mathrm{~m}^{2} / \mathrm{g}$ be used as a conservative upper limit of glass reactive surface area.

- Increasing the surface area of the melt glass creates very alkaline values of $\mathrm{pH}(>10)$ which may migrate downstream with time. The greater the surface area of goethite in the alluvium, the greater the ability of the alluvium to neutralize the alkaline waters to a $\mathrm{pH}$ of about 8 .

- For non-sorbing radionuclides, the extent of radionuclide migration downgradient of a melt glass region is independent of the glass dissolution rate, assuming the permeability in the glass region remains fixed. Nonetheless, radionuclide concentrations behind an advancing front will increase or decrease with larger or smaller glass dissolution rates, respectively. For chemically reactive radionuclides, different concentrations realized from different dissolution rates could lead to different radionuclide mobilities (as a result of site saturation or $\mathrm{pH}$-dependent effects) which may affect locations of advancing fronts.

- Radionuclide-bearing solids will only precipitate in the glass zones unless something disturbs the geochemical state of downstream groundwaters in the alluvium.

- A geochemical analysis of a groundwater that indicates equilibrium or supersaturation with respect to a radionuclide-bearing solid solid does not necessarily imply the presence of that solid at the sampling point, but may instead reflect equilibrium with the solid upstream. 


\section{Appendix 9: Simplifying the Results for Larger Scale Applications}

Future simulations will be used to forecast the migration and fate of radionuclides released from multiple nuclear tests scattered throughout larger areas, such as all of Frenchman Flat. These simulations will require radionuclide source term information for each test in the system, both in terms of the abundance and flux of aqueous radionuclide species released into the environment, as well as their bulk migration, dilution, and reaction as they move through differing aquifer materials. How can the current results be used in this process? Two important issues must be considered:

- The level of detail and process complexity included in the current near field model may not be allowable in larger-scale models because of computational limitations and the need to focus on much larger simulation areas. Thus, it is of interest to see how the observed behavior in the current simulations can be simplified for use or easier representation in larger scale models.

- Source term configurations will differ from one test to another as a result of variable radionuclide inventories (as discussed earlier), changing geologic environments, or fluctuating regional flow conditions. From this perspective, it is of interest to see how the results of one test might be simplified or modified to reflect different flow conditions (as though the same test were "copied" into different locations), or to more easily gauge the sensitivities to uncertain parameters of the system, such as a variable hydraulic gradient.

Two types of simplifications will be presented and discussed below, although their direct application to the CAMBRIC results will be deferred for a future report. Both implicitly refer to tests conducted in the saturated zone. The first deals with the representation of radionuclide retardation in the system, as a simple means to represent the net effect of sorption and ion exchange processes. This has relevance in that, although total integrated flux results were provided in Chapter 11, nothing quantitative was said about the average mobility or "retardation" of the radionuclides as they depart the near field. The second deals with a simplified description, through an analytic solution, of glass dissolution and radionuclide release from the melt glass. This is of interest, both as an easier way to assess the sensitivities of the radionuclide fluxes to melt glass surface area and groundwater velocity, as well as a potential way to simplify the description of the fluxes themselves. 


\section{Effective retardation of radionuclide migration outside of the cavity and chimney region}

Consider again the simplified, one-dimensional mass balance equation (42) for transport along a streamline, as defined in Appendices 2 and 5 for the total mass of species $j$ :

$$
\phi \frac{\partial}{\partial t}\left(u_{j}+u_{j}^{i m}\right)+\phi V \frac{\partial u_{j}}{\partial s}-\frac{\partial}{\partial s}\left(\phi D_{L} \frac{\partial u_{j}}{\partial s}\right)=-\sum_{m=1}^{N_{m}} \nu_{j m} r_{m}
$$

This has been expressed in terms of the total mobile $\left(u_{j}\right)$ and immobile $\left(u_{j}^{i m}\right)$ species concentrations (moles- $j$ /liter-solution), which are assumed to be related by a series of equilibrium mass action relationships (Appendix 2). This equation may be expressed equivalently as

$$
\phi \frac{\partial}{\partial t}\left(u_{j} \mathcal{R}_{j}\right)+\phi V \frac{\partial u_{j}}{\partial s}-\frac{\partial}{\partial s}\left(\phi D_{L} \frac{\partial u_{j}}{\partial s}\right)=-\sum_{m=1}^{N_{m}} \nu_{j m} r_{m}
$$

where the quantity $\mathcal{R}_{j}=1+u_{j}^{i m} / u_{j}$ reflects the instantaneous state of partitioning between the aqueous and immobile fractions of species $j$ at a point in space and time, $(s, t)$.

In general, $\mathcal{R}_{j}$ may be a complicated function of $u_{j}$, the mineralogic characteristics of the porous medium, and the concentrations of aqueous species $k$ different from $j$, including other radionuclides, natural aqueous minerals, or the pH (Tompson, 1993; Tompson et al., 1996, Tompson and Jackson, 1996). However, under some limiting conditions ${ }^{23}, \mathcal{R}_{j}$ may become independent of one or all of the aqueous species concentrations or the $\mathrm{pH}$, such that, in the most "convenient" case, it reduces to a simple medium property.

In this situation, $\mathcal{R}_{j}$ is often referred to as a retardation coefficient, and the partitioning among the mobile and immobile fractions of species $j$ can be described by an easily measured constant. If the mineralogic conditions are constant in space, then the retardation or partitioning effect will be constant in space and time, and the net effect is to slow the migration rate of the aqueous species by a factor $\mathcal{R}_{j}$ relative to the groundwater velocity, $V$.

Streamline 100 - Models 10 and 10a. Figure 152 shows the value of $\mathcal{R}_{j}$ for $\mathrm{Cs}$, Sr and $\mathrm{Pu}$ along streamline 100, as calculated from GIMRT results using Mineralogic Model 10, at 100 and 600 years. The partitioning profile remains constant in space and time, largely as a result of sufficiently small radionuclide concentrations, sufficiently large mineralogic surface areas, relatively uniform

\footnotetext{
${ }^{23}$ Which may include, but are not be limited to, small concentrations of all radionuclide species, as achieved through dilution or low initial abundance, relatively large reactive mineral surface areas (i.e., a large number of total exchange or sorption sites that minimize competition effects), fixed or buffered $\mathrm{pH}$ conditions, etc.
} 
$\mathrm{pH}$ conditions, and homogeneous mineralogic properties. The large retardation values are consistent with the immobile nature of the species observed in the Mineralogic Model 10 simulations.

When the surface area of goethite is uniformly reduced to $50 \mathrm{~m}^{2} / \mathrm{g}$ in Model 10a (from $600 \mathrm{~m}^{2} / \mathrm{g}$ in Model 10), the retardation profiles of $\mathrm{Sr}$ and $\mathrm{Pu}$ are affected (Figure 153). Owing to the net reduction in available surface sites on goethite, the retardation levels for $\mathrm{Pu}$ and $\mathrm{Sr}$ decrease from 537 to 47 and from 2460 to 1446, respectively. The retardation level for $\mathrm{Sr}$ is affected less than that for $\mathrm{Pu}$ because $\mathrm{Sr}$ sorbs competitively onto smectite and clinoptilolite as well as goethite. The partitioning of Sr between fluid and solid is largely controlled by sorption onto goethite in Model 10, and by sorption onto clinoptilolite in model 10a. The retardation coefficient for $\mathrm{Cs}$ is unchanged because Cs is assumed to participate only in ion exchange reactions on illite/muscovite.

Streamline 145 - Models 10, 10a, and 10d. In contrast to streamline 100, calculated retardation profiles for $\mathrm{Cs}$, Sr and $\mathrm{Pu}$ along streamline 145 are not constant because of chemical interactions with the melt glass. Dissolution of melt glass results in increased $\mathrm{pH}$, changes in major element chemistry, and precipitation of secondary minerals, some of which are surface active. Surface complexation varies as a function of $\mathrm{pH}$, and changing mineral masses can change the number of surface sites for sorption and the capacity for ion exchange. Some major chemical species $\left(e . g ., \mathrm{K}^{+}\right)$compete with radionuclides $\left(e . g ., \mathrm{Cs}^{+}\right)$ for sorption and exchange sites. Hence, retardation profiles can change significantly along streamlines which intersect glass as a result of these types of chemical variations.

The retardation profiles for $\mathrm{Cs}, \mathrm{Sr}$ and $\mathrm{Pu}$ in Models 10, 10a and 10d (Figs. 154 through 159) reflect the impact of this chemical and mineralogical variability. The degree of retardation varies both spatially and temporally. This variability is most significant in model 10d (Figs. 158 and 159) because the model has a higher rate of glass dissolution.

Streamline 100 - Model 13a. From the differences in Figures 152 and 153, it is apparent that spatial variations in mineral abundance and reactivity can have a significant effect on the retardation coefficient. The existence of physical and chemical heterogeneities along the flow path can cause significant spatial variations in the retardation profile. Mineralogical model 13 provides an excellent example of the effect of mineralogical heterogeneity on retardation coefficients. The retardation coefficient of $\mathrm{Pu}$ varies between 47 and 1 depending on whether or not the streamline intersects a rock unit containing goethite (Figure 160). The assumption of a constant retardation coefficient in a transport simulation may therefore prove to be inadequate under some scenarios. 


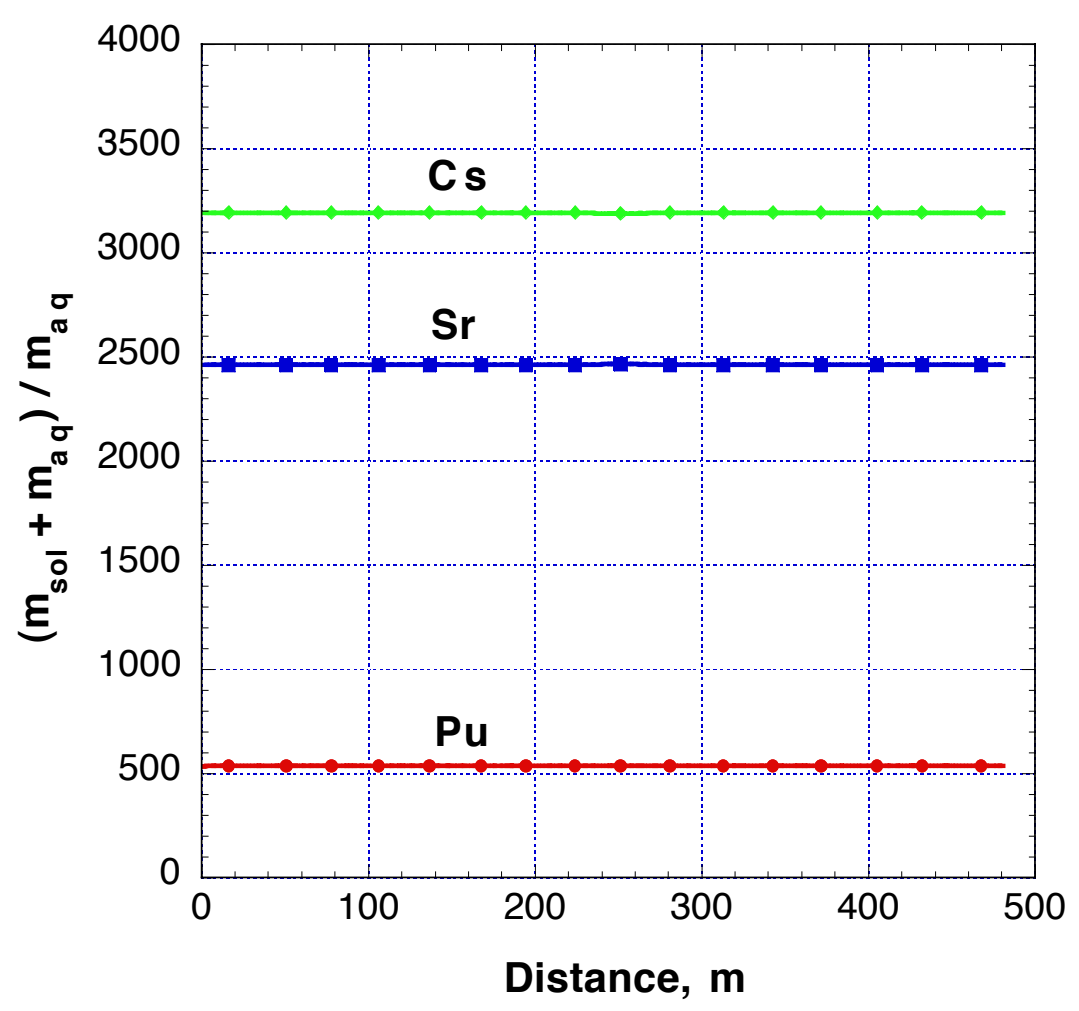

Figure 152: Retardation coefficients of $\mathrm{Cs}, \mathrm{Sr}$ and $\mathrm{Pu}$ in alluvium along streamline 100 in Mineralogical Model $10\left(600 \mathrm{~m}^{2} / \mathrm{g}\right.$ goethite surface area) at both 100 and 600 years. " $\mathrm{m}_{\text {sol }}$ " and " $\mathrm{m}_{a q}$ " represent $U_{j}$ and $U_{j}^{i m}$ in $(21)$, respectively, the sum of the molalities of sorbed and exchanged radionuclides, and the sum of the molalities of the radionuclide-bearing aqueous species in solution. 


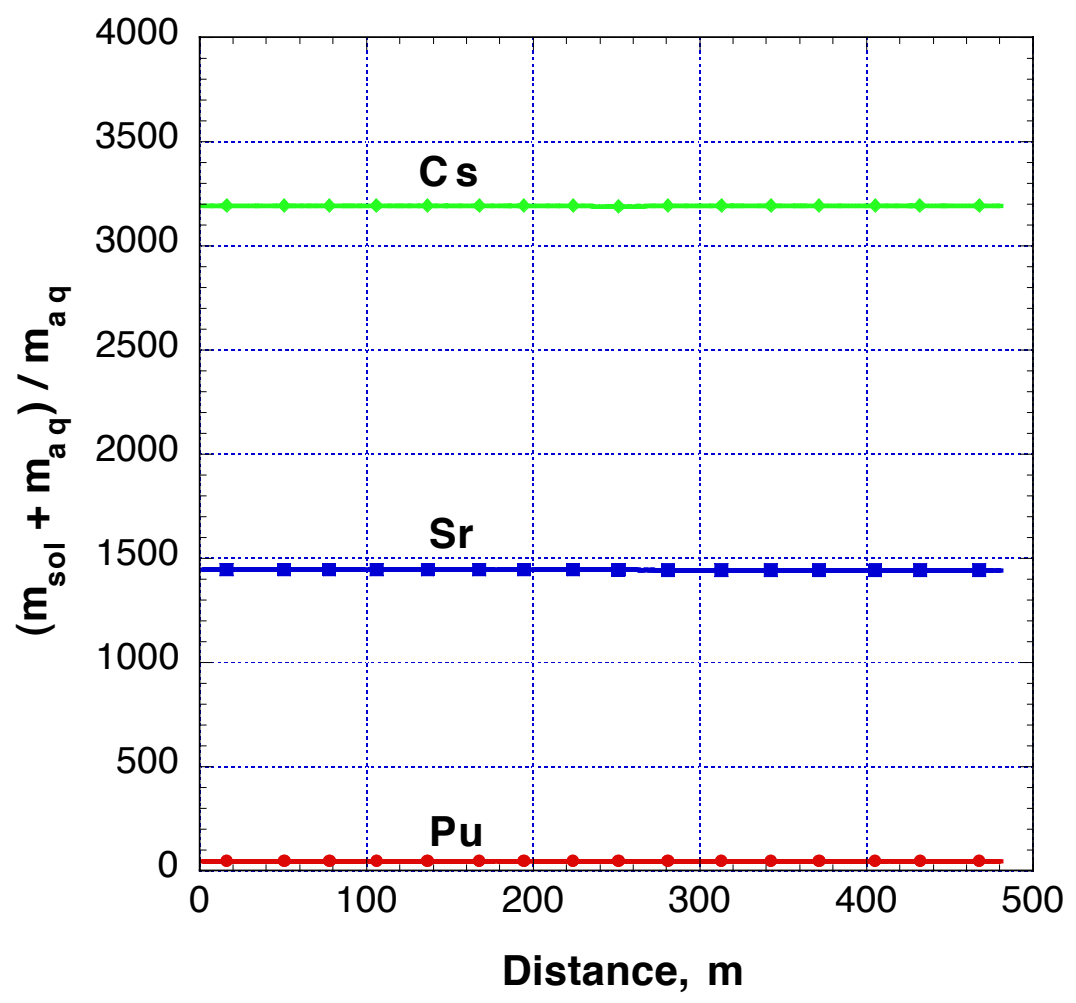

Figure 153: Retardation coefficients of $\mathrm{Cs}, \mathrm{Sr}$ and $\mathrm{Pu}$ in alluvium along streamline 100 in Mineralogical Model 10a ( $50 \mathrm{~m}^{2} / \mathrm{g}$ goethite surface area) at both 100 and 600 years. " $\mathrm{m}_{\text {sol }}$ " and " $\mathrm{m}_{a q}$ " represent $U_{j}$ and $U_{j}^{i m}$ in (21), respectively, the sum of the molalities of sorbed and exchanged radionuclides, and the sum of the molalities of the radionuclide-bearing aqueous species in solution. 


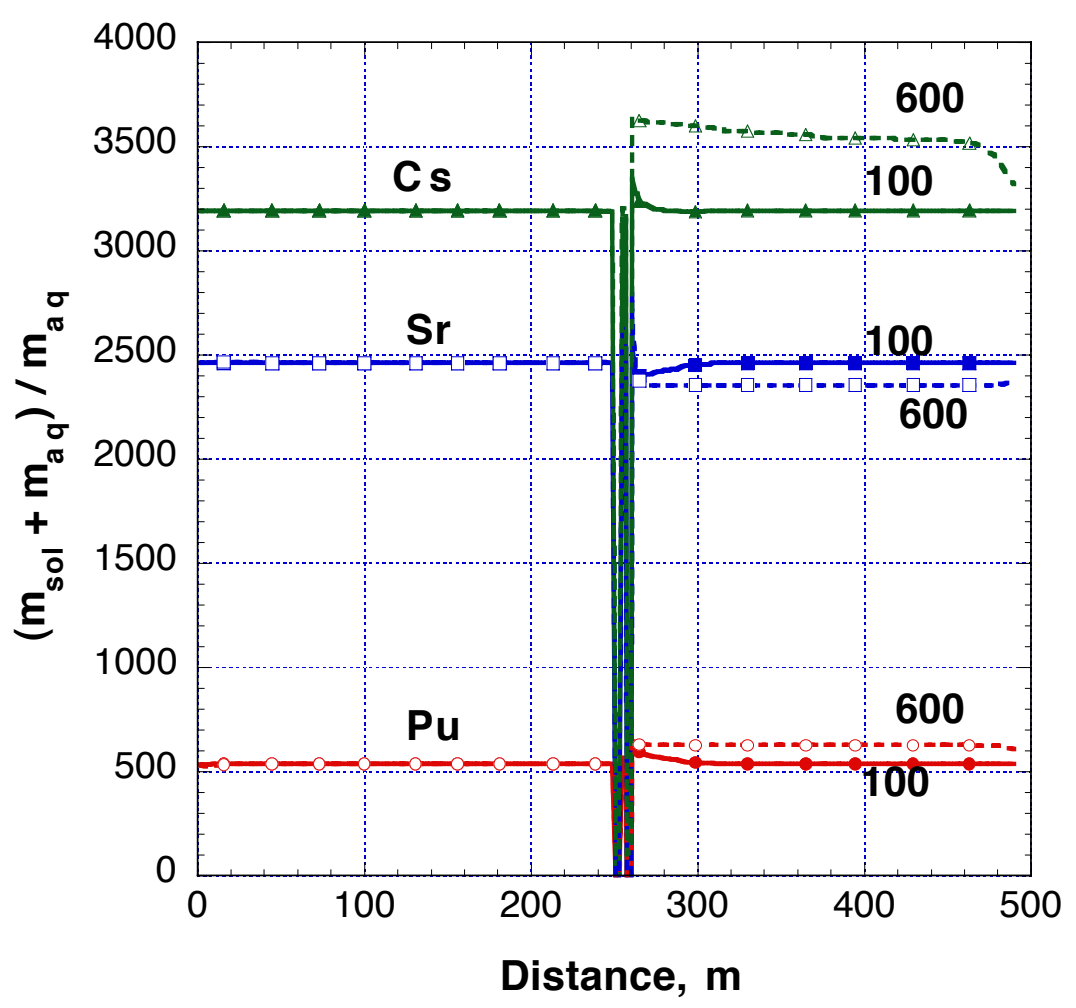

Figure 154: Retardation profiles of $\mathrm{Cs}, \mathrm{Sr}$ and $\mathrm{Pu}$ for Mineralogical Model 10 (goethite surface area $600 \mathrm{~m}^{2} / \mathrm{g}$ ) along streamline 145 at 100 and 600 years. " $\mathrm{m}_{\text {sol }}$ " and " $\mathrm{m}_{a q}$ " represent $U_{j}$ and $U_{j}^{i m}$ in (21), respectively, the sum of the molalities of sorbed and exchanged radionuclides, and the sum of the molalities of the radionuclide-bearing aqueous species in solution. 


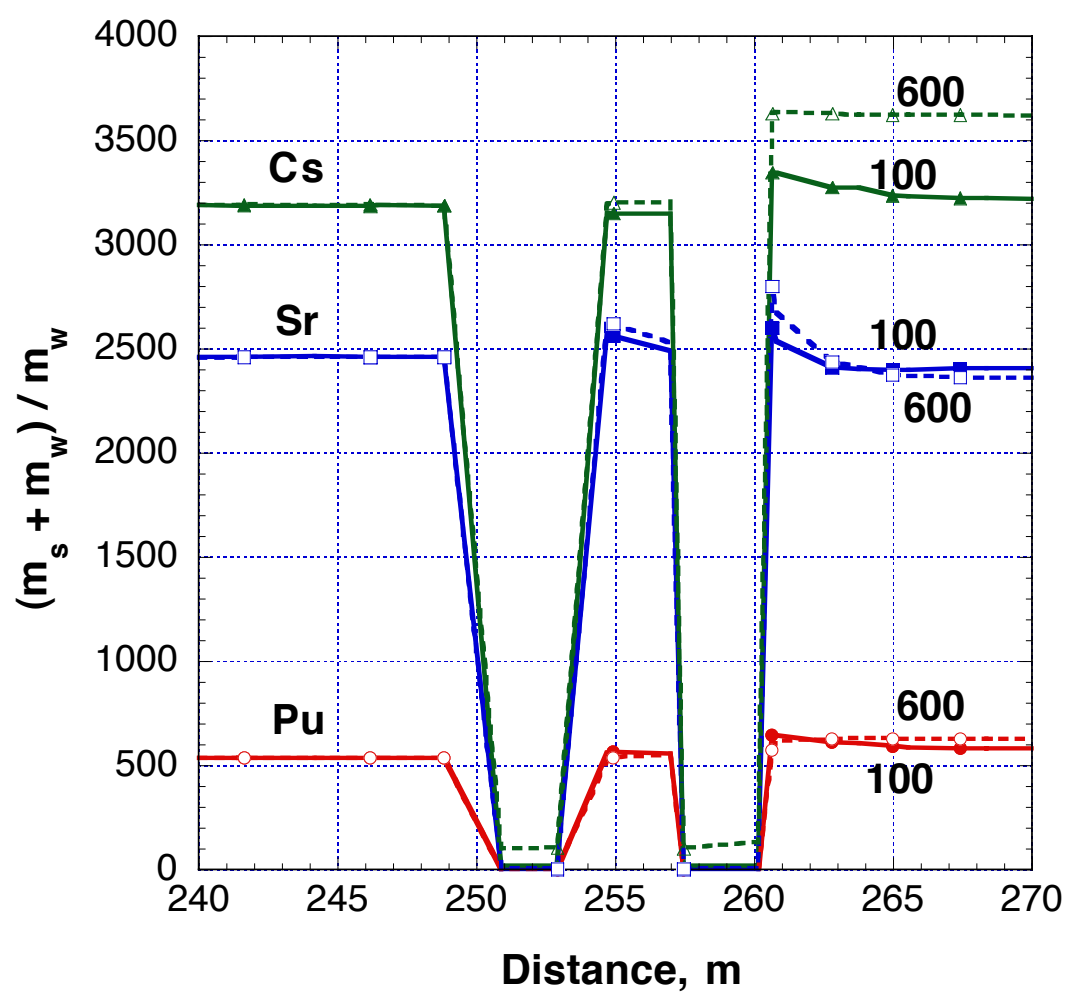

Figure 155: Retardation profiles of $\mathrm{Cs}, \mathrm{Sr}$ and $\mathrm{Pu}$ for Mineralogical Model 10 (goethite surface area $600 \mathrm{~m}^{2} / \mathrm{g}$ ) along streamline 145 near the glass zones at 100 and 600 years. " $\mathrm{m}_{\text {sol }}$ " and " $\mathrm{m}_{a q}$ " represent $U_{j}$ and $U_{j}^{i m}$ in (21), respectively, the sum of the molalities of sorbed and exchanged radionuclides, and the sum of the molalities of the radionuclide-bearing aqueous species in solution. 


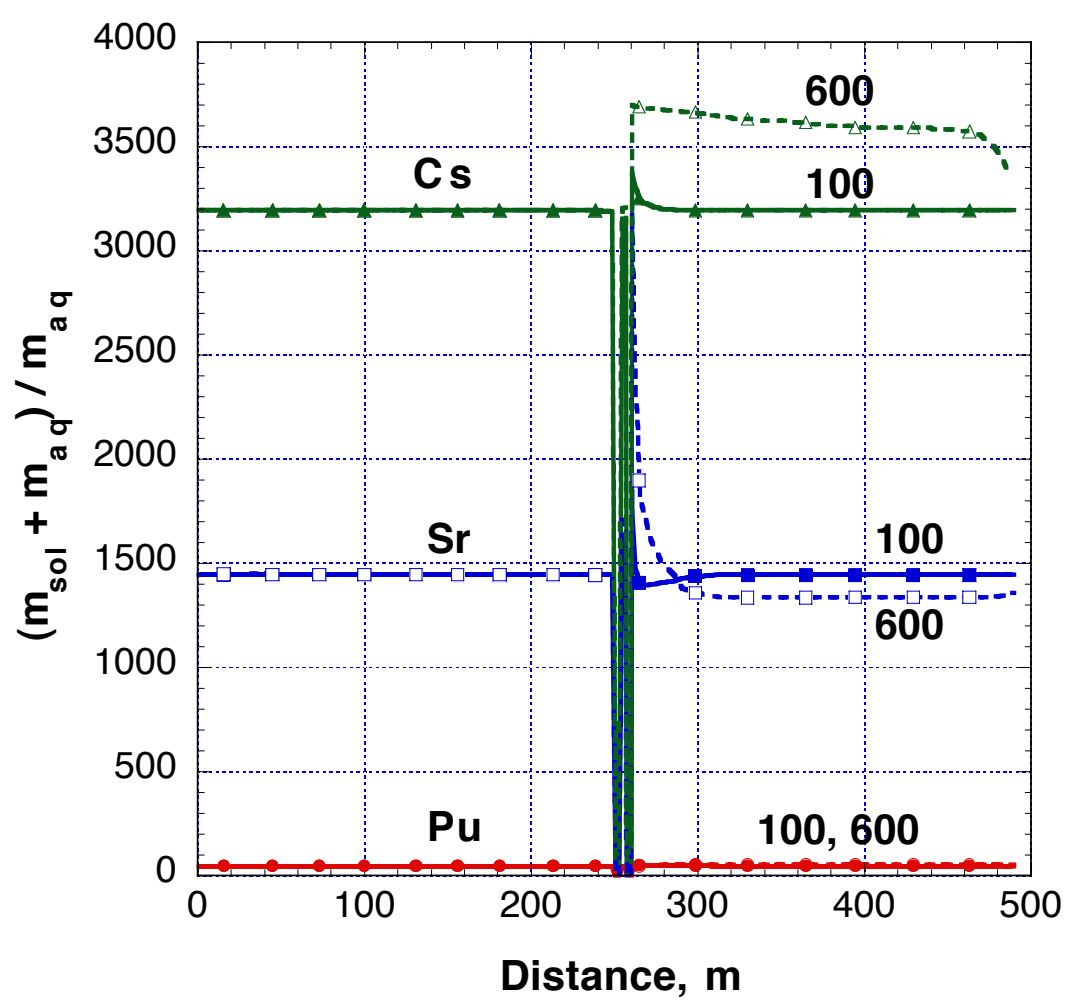

Figure 156: Retardation profiles of $\mathrm{Cs}, \mathrm{Sr}$ and $\mathrm{Pu}$ for Mineralogical Model 10a (goethite surface area $50 \mathrm{~m}^{2} / \mathrm{g}$ ) along streamline 145 at 100 and 600 years. " $\mathrm{m}_{\text {sol }}$ " and " $\mathrm{m}_{a q}$ " represent $U_{j}$ and $U_{j}^{i m}$ in (21), respectively, the sum of the molalities of sorbed and exchanged radionuclides, and the sum of the molalities of the radionuclide-bearing aqueous species in solution. 


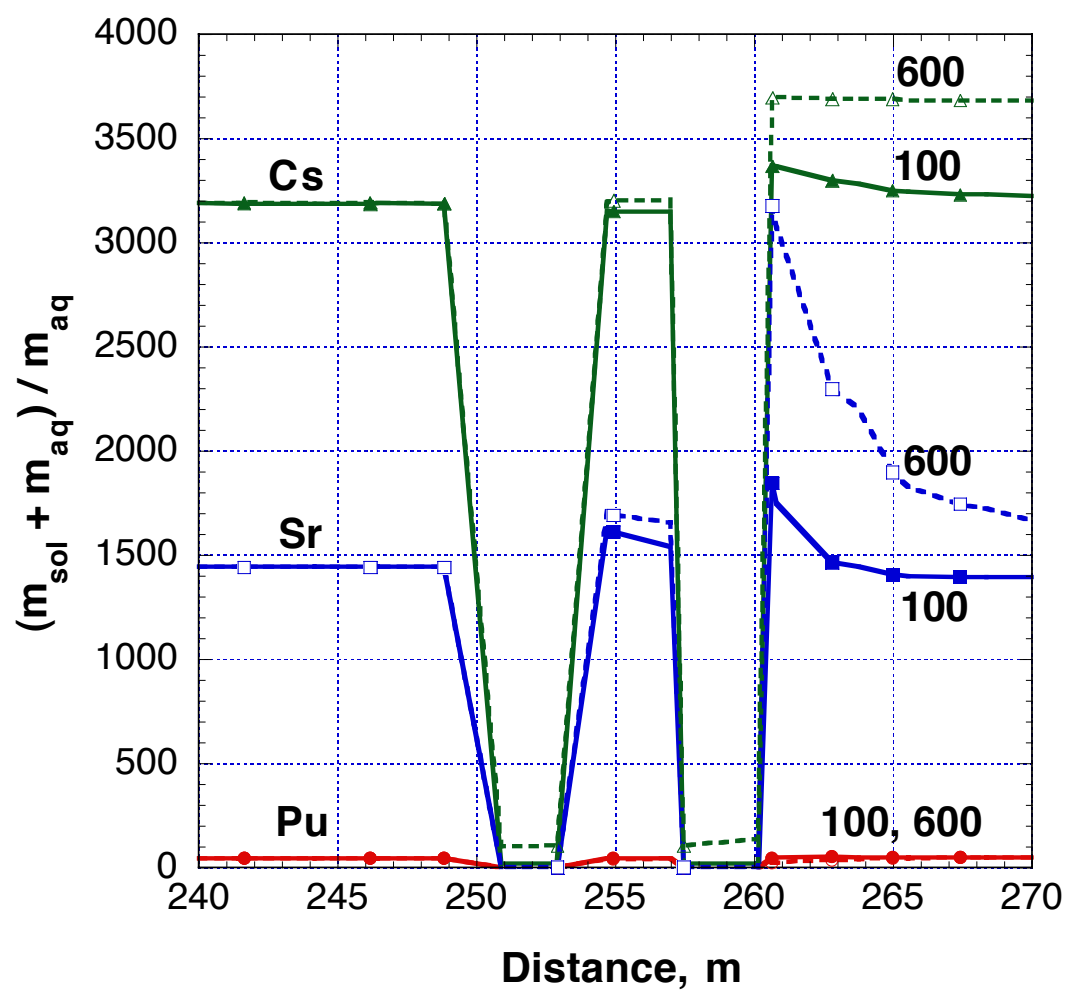

Figure 157: Retardation profiles of $\mathrm{Cs}, \mathrm{Sr}$ and $\mathrm{Pu}$ for Mineralogical Model 10a (goethite surface area $50 \mathrm{~m}^{2} / \mathrm{g}$ ) along streamline 145 near the glass zones at 100 and 600 years. " $\mathrm{m}_{\text {sol }}$ " and " $\mathrm{m}_{a q}$ " represent $U_{j}$ and $U_{j}^{i m}$ in (21), respectively, the sum of the molalities of sorbed and exchanged radionuclides, and the sum of the molalities of the radionuclide-bearing aqueous species in solution. 


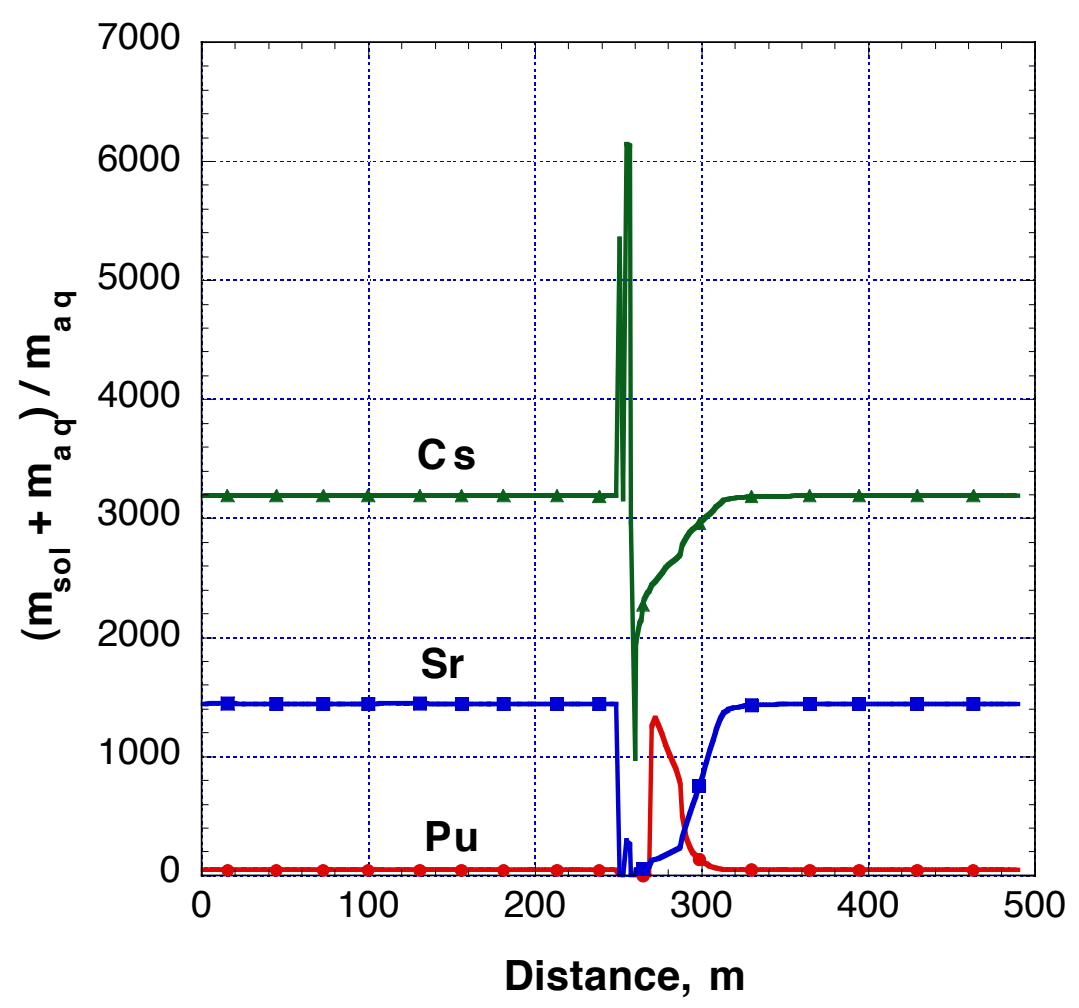

Figure 158: Retardation profiles of $\mathrm{Cs}, \mathrm{Sr}$ and $\mathrm{Pu}$ for Mineralogical Model 10d (glass surface area $5 \times 10^{-3} \mathrm{~m}^{2} / \mathrm{g}$ ) along streamline 145 at 100 years. " $\mathrm{m}_{\text {sol }}$ " and " $\mathrm{m}_{a q}$ " represent $U_{j}$ and $U_{j}^{i m}$ in (21), respectively, the sum of the molalities of sorbed and exchanged radionuclides, and the sum of the molalities of the radionuclide-bearing aqueous species in solution. 


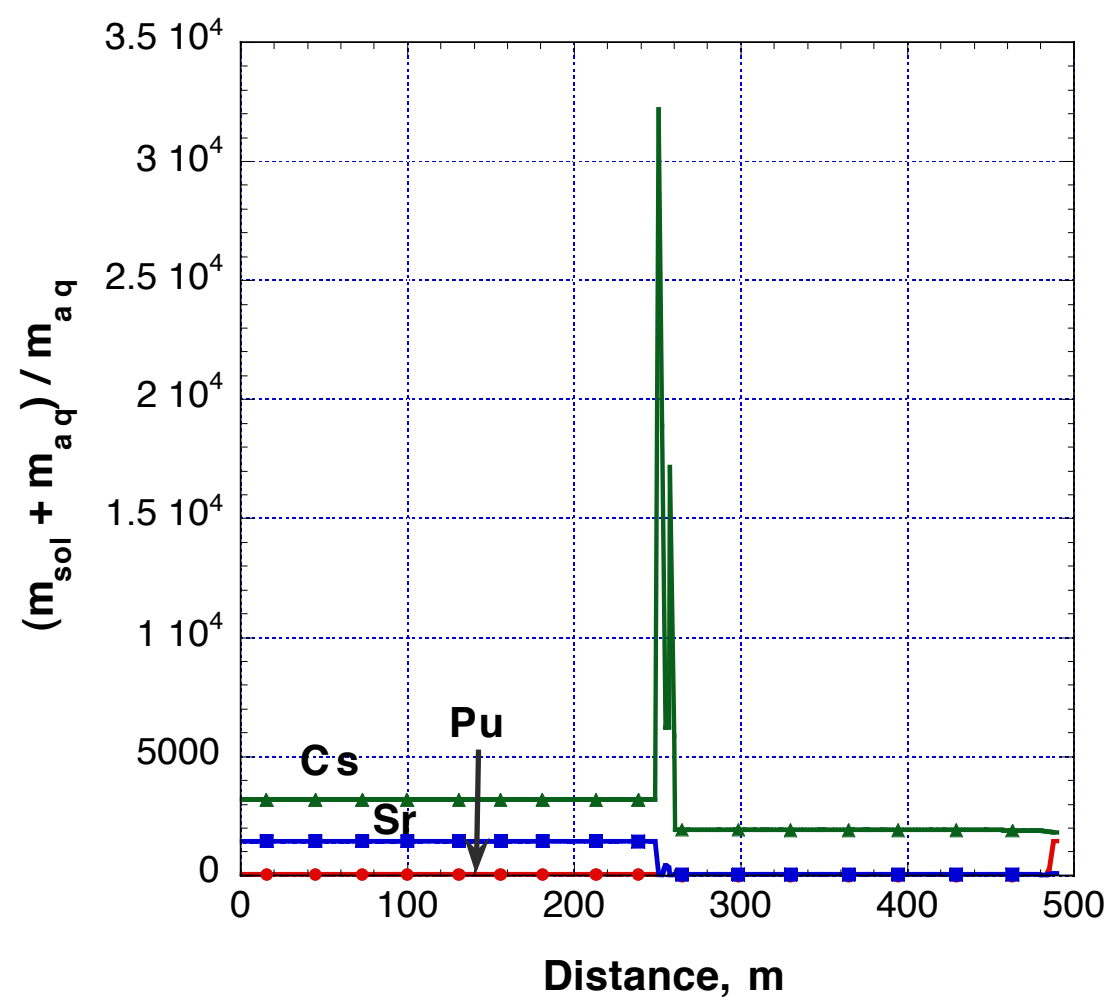

Figure 159: Retardation profiles of $\mathrm{Cs}, \mathrm{Sr}$ and $\mathrm{Pu}$ for Mineralogical Model 10d (glass surface area $5 \times 10^{-3} \mathrm{~m}^{2} / \mathrm{g}$ ) along streamline 145 at 600 years. " $\mathrm{m}_{\text {sol" }}$ and " $\mathrm{m}_{a q}$ " represent $U_{j}$ and $U_{j}^{i m}$ in (21), respectively, the sum of the molalities of sorbed and exchanged radionuclides, and the sum of the molalities of the radionuclide-bearing aqueous species in solution. 


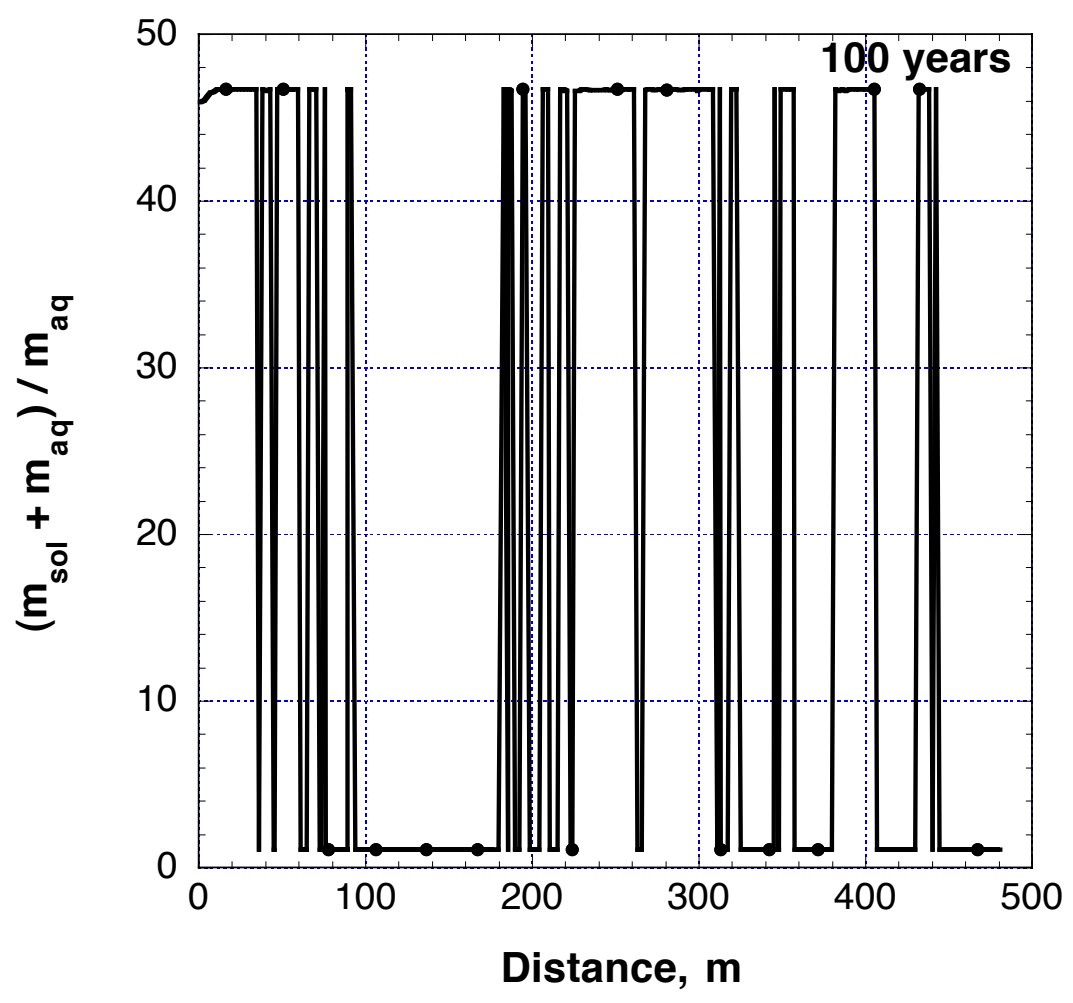

Figure 160: Retardation coefficient of $\mathrm{Pu}$ in alluvium along streamline 100 in Mineralogical Model 13a (heterogeneous distribution of reactive minerals) at 100 years. " $\mathrm{m}_{\text {sol }}$ " and " $\mathrm{m}_{a q}$ " represent $U_{j}$ and $U_{j}^{i m}$ in (21), respectively, the sum of the molalities of sorbed and exchanged radionuclides, and the sum of the molalities of the radionuclide-bearing aqueous species in solution. 
Retardation as a "medium constant". The use of retardation coefficients to describe partitioning behavior in a transport medium is an approximate, continuum scale concept that should ideally be based on fundamental, processbased descriptions of radionuclide-groundwater-glass-alluvium interactions that occur at the pore or mineral surface scale. The results shown in Figures 154 - 160 have been derived from simulations that are based upon use of these processes in averaged mass transport equations; they were not based upon traditional measurements of bulk retardation or partitioning coefficients. It is apparent from these figures that the assumption of a "constant" retardation effect may be a viable approximation in some scenarios and a totally inadequate one in others. In either case, comparison of retardation information inferred from both the process models and experimentally measured coefficients will offer a more scientifically defensible basis for predicting retardation behavior.

Although it may be difficult to carry out these complex, process-based transport simulations in larger, field scale settings (beneath, for example, all of Frenchman Flat), our current results, when viewed from an integrated perspective, might lead to useful simplifications for describing retardation behavior that can be implemented in larger scale transport models. This is discussed further below.

Retardation effects at the larger scale. When a multitude of streamlines are used to solve a fully 3D problem, as described in Chapter 11, the effective mobility or retardation of a reactive species, as viewed from the elution profiles, will be representative of the average retardation effects present along each streamline. Retardation behavior along individual streamlines may be constant in time and spatially uniform (as in Figs. 152 or 153), constant in time, yet spatially nonuniform (as in Fig. 160), or a much more complicated function of time, space, aqueous chemistry, and mineralogy (as in Figs. 154 through 159).

From a larger scale perspective, an "apparent" or spatially averaged retardation coefficient, $\left\langle R_{j}\right\rangle$, may be a useful quantity, if it can be demonstrated to be essentially a large scale constant of the medium. Such a value might be estimated from an approximation of eq. (26) of Tompson (1993) as

$$
\left\langle R_{j}(t)\right\rangle \approx \frac{\int_{A} \phi \mathbf{v} \cdot \mathbf{n} d A}{\int_{A}\left(\phi \mathbf{v} / \mathcal{R}_{j}\right) \cdot \mathbf{n} d A}
$$

where the domain of integration is that portion of the exit face crossed by radionuclides. As reviewed in Chapter 11, this quantity can be computed easily from the streamline results that were used to evaluate the total radionuclide fluxes crossing the domain boundary. In this sense, (46) can also be expressed as

$$
\left\langle R_{j}(t)\right\rangle \approx \frac{\sum_{i} Q_{i}}{\sum_{i} Q_{i} u_{j} /\left(u_{j}+u_{j}^{i m}\right)}
$$


in terms of the set of streamlines $\{i\}$ that move through the exchange volume and melt glass zones. Furthermore, if $\left\langle R_{j}\right\rangle$ can be shown to be effectively independent of time, either in an immediate or asymptotic sense, then its viability as a "larger scale medium constant" can be demonstrated.

In the same fashion, the numerator of (46) can be interpreted in terms of an average groundwater velocity,

$$
A \cdot \phi \cdot\langle V\rangle \approx \int_{A} \phi \mathbf{v} \cdot \mathbf{n} d A \approx \sum_{i} Q_{i}
$$

which may also be used in larger scale models ${ }^{24}$. As was mentioned in Section 11.1, the total flux identified along all 809 streamlines passing through the exchange volume and used in each of the transport simulations is $\sum_{i} Q_{i}=615.5$ $\mathrm{m}^{3} / \mathrm{yr}$.

It is important to recognize, however, that the values of $\langle V\rangle$ and $\left\langle R_{j}\right\rangle$ will clearly be functions of the physical and chemical variability specified in the near field (small scale) model, as will a larger scale dispersion effect that is evident in the elution profiles in Chapter $11^{25}$. Their broader use in a larger scale framework will require a reconciliation of the conceptual models of property and mineralogic variability used in both the small and larger scale models. This will be addressed further in future reports.

\section{Effective representation of glass dissolution and radionu- clide flux out of the melt glass environment}

For simplicity, consider a simplified version of equation (42) or (45) that is meant to apply along a streamline (or streamtube) passing through melt glass, as shown in the lower part of Figure 161. Under simplifying conditions of

- Constant porosity $(\phi)$ and cross-sectional area $(A)$ of the streamtube,

- Little or no physical dispersion (i.e., advectively dominated transport),

- Melt glass dissolution with no other precipitation or dissolution reactions,

- No sorption or ion exchange in alluvium such that $\mathcal{R}_{j}=1$, and

- A fixed and known temperature,

the mass balance for species $j$ can be expressed by

$$
\phi \frac{\partial u_{j}}{\partial t}+\phi V \frac{\partial u_{j}}{\partial s}=\nu_{j} r_{g}
$$

\footnotetext{
${ }^{24}$ Note that the domain of integration may be expanded here to include all of the downstream exit face if a sufficient number of streamlines are identified.

${ }^{25}$ The macroscopic dispersion effects can be estimated using a number of approaches, as reviewed by Dagan (1989) and Gelhar (1993).
} 
where the flow velocity $(V)$ is constant and $r_{g}$ is given by equation (2). As discussed below, this rate can be interpreted in a general way or in a more specialized sense for the CAMBRIC problem.

General case. In general, the quantity $Q / K$ in (2) can be approximated by the ratio of aqueous silica concentration to its equilibrium value, or $c_{S i}(s, t) / c_{S i, e q}$, so that equation (49) can be simplified to

$$
\frac{\partial u_{j}}{\partial t}+V \frac{\partial u_{j}}{\partial s}=\mathcal{W}\left(u_{0}-u_{j}\right)
$$

Here, we have substituted $u_{j}(s, t)=\nu_{j} \cdot c_{S i}(s, t)$ and defined the normalizing constant $u_{0}=\nu_{j} \cdot c_{S i, e q}$. In addition, the constant term

$$
\mathcal{W}=\frac{A_{s} k\left(\prod_{i}^{N} a_{i}^{p_{i}}\right)}{\phi c_{S i, e q}}
$$

has been introduced for notational simplicity. As discussed in section 3.3.3, radioactive decay is not explicitly included, but can be accounted for afterwards.

Specialized case at CAMBRIC. In the CAMBRIC simulations, the silica concentration in water contacting the glass was assumed to be fixed at a value, represented here by $c_{\beta}$, that is in equilibrium with $\beta$-cristobalite (Chapter 6). In this "specialized" case developed specifically for glass dissolution at CAMBRIC, the quantity $Q / K$ in (2) remains constant, and equation (49) simplifies to

$$
\frac{\partial u_{j}}{\partial t}+V \frac{\partial u_{j}}{\partial s}=\mathcal{W}\left(u_{0}-u_{\beta}\right)
$$

where we have defined $u_{\beta}=\nu_{j} \cdot c_{\beta}$. Radioactive decay is not explicitly included, but can be accounted for afterwards.

Analytic solutions. Given appropriate initial conditions, the solutions to (50) or (52) can be established analytically. Consider the system in Figure 161 where melt glass is distributed between $s=0$ and $s=L$. Assume that the flow proceeds from left to right, and that the glass begins dissolving at $t=0$ with no aqueous radionuclides initially in the lower streamtube $\left(u_{j}(s, 0)=0\right)$. The solutions can be described in terms of generic profiles for $t<V t$ and $t>V t$, as shown in Figure 162 for the generalized and specialized cases.

For $t<L / V$, the top figures in both cases show an increasing concentration profile from the upstream glass boundary to a point at $s=V t$ (marked with a red dot) where a fluid particle originally located at the left glass boundary has traveled. These profiles are described by

$$
u_{j}=u_{0}\left(1-e^{-\mathcal{W} s / V}\right)
$$




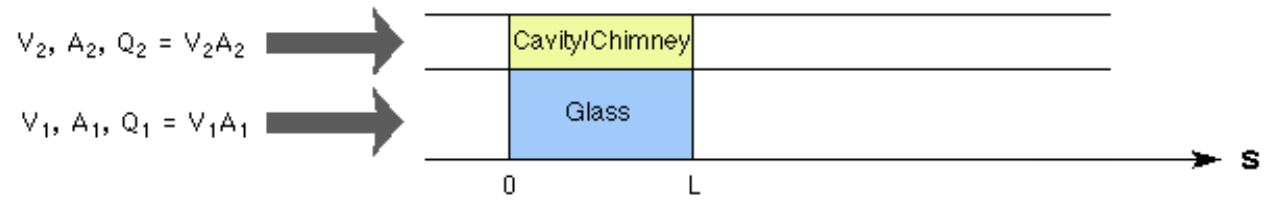

Figure 161: Simple conceptual model showing two parallel streamtubes (or streamlines) passing through a zone of melt glass and a cavity/chimney rubble region.

in the general case (Johnson, et al., 1998), and by

$$
u_{j}=\frac{\mathcal{W} s}{V}\left(u_{0}-u_{\beta}\right)
$$

in the specialized case, as shown for points in the red area [1] of the figures. Between the red dot $(s=V t)$ and the right edge of the glass $(s=L)$, the concentration profiles are fixed at values of

$$
u_{j}=u_{0}\left(1-e^{-\mathcal{W} t}\right)
$$

in the general case, and

$$
u_{j}=\mathcal{W} t\left(u_{0}-u_{\beta}\right)
$$

in the specialized case, as shown for points in the white area [2a] of the figures. Beyond the glass, a decreasing profile is shown to exist out to the green dot at $s=L+V t$, which tracks the furthermost advance of the dissolved radionuclide front. This profile is described by

$$
u_{j}=u_{0}\left(1-e^{-\mathcal{W}(t-(s-L) / V)}\right)
$$

in the general case, and by

$$
u_{j}=\frac{\mathcal{W}(L+V t-s)}{V}\left(u_{0}-u_{\beta}\right)
$$

in the specialized case, as shown for points in the green area [3] of the figures.

As time progresses, the red and green marker locations progress further to the right, and the peak concentration (in region $2 \mathrm{a}$ ) increases until the red dot reaches the right (downstream) edge of the glass ${ }^{26}$. At $t=L / V$, the peak

\footnotetext{
${ }^{26}$ For the purposes of this example, we assume that the peak concentration at the red dot never exceeds a point of aqueous saturation for species $j$, which might occur if $A_{s}, k$, or $L$ are sufficiently large, or if $V$ is sufficiently small.
} 
General Case

Specialized Case
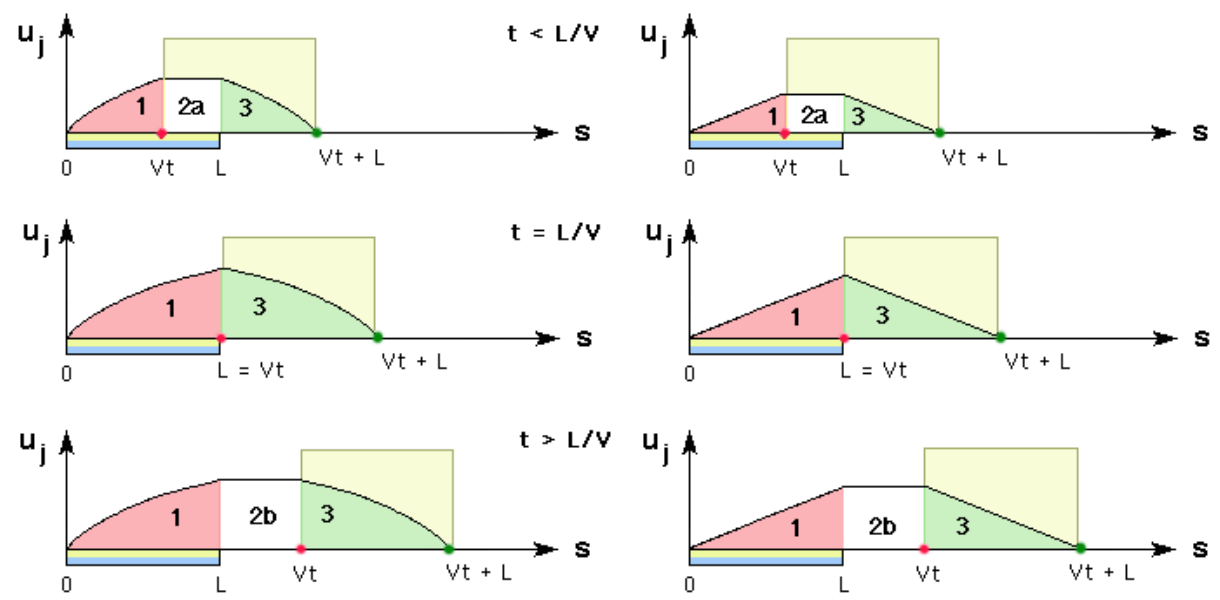

Figure 162: Radionuclide concentration profiles along two streamlines that pass through the melt glass and cavity/chimney rubble zones (located along the yellow and blue strips; Fig. 161) in the absence of decay or hydrodynamic dispersion. Glass-zone profiles (red, white, and green) shown for the general and specialized cases that are discussed in the text. Cavity/chimney profiles (yellow) are the same in each case. 
concentration is reached at the glass edge, as is shown in the middle profiles of Figure $162{ }^{27}$.

For $t>L / V$, the red and green markers progress further downstream. The concentration profile within the glass remains fixed, and is described by (53) or (54) over area [1] in the lower part of Figure 162. Beyond the glass, the profile is fixed at a maximum concentration of

$$
u_{j}=u_{0}\left(1-e^{-\mathcal{W} L / V}\right)
$$

in the general case, and by

$$
u_{j}=\frac{\mathcal{W} L}{V}\left(u_{0}-u_{\beta}\right)
$$

in the specialized case, as shown for points lying in the white areas [2b] of the lower figures.

The advancing front of the dissolution plume lies between the advancing red and green dots. It is described by (57) or (58) for points in the green area [3] of lower part of Figure 162. As time progresses, this frontal region moves forward without bound, while the profile behind it remains the same.

Maximum concentration. Outside of constraints on permeability changes arising from alterations in the glass, limits on the total glass available for dissolution, dispersion effects (none of which are considered), and radionuclide precipitation, the radionuclide plume in this problem will have a maximum concentration given by (59) or (60) that prevails over most of its length. In either of the general or specialized cases, the maximum concentration realized increases with

- Larger surface areas $\left(A_{s}\right)$ in the melt glass,

- Larger glass dissolution rate constants $(k)$ (e.g., at higher temperatures),

- Longer flow pathways through the melt glass $(L)$ or intrinsically larger melt zones, and

- Smaller groundwater flow velocities.

Maximum flux. The maximum radionuclide flux in either problem occurs at points in area $[2 \mathrm{~b}]$ in Figure 162. If the cross-sectional area (Appendix 6) along the streamline is assumed to be constant and unity in value, this flux is given by

$$
J_{j}=V u_{j}=V u_{0}\left(1-e^{-\mathcal{W L} / V}\right)
$$

\footnotetext{
${ }^{27}$ If saturation was reached at the red dot prior to $t=L / V$, precipitation would occur from this location to the glass boundary, and the eluting concentration will be fixed at the saturation value.
} 
in the generalized case, and by

$$
J_{j}=V u_{j}=\mathcal{W} L\left(u_{0}-u_{\beta}\right)
$$

in the specialized case. In either configuration, the maximum flux increases with

- Larger surface areas $\left(A_{s}\right)$ in the melt glass,

- Larger glass dissolution rate constants $(k)$, and

- Longer flow pathways through the melt glass $(L)$ or intrinsically larger melt zones.

One specific difference in these results is that the maximum flux in the specialized case (62) is completely independent of the groundwater flow velocity $(V)$, while its general case counterpart (61) is not. However, for small $\mathcal{W} L / V$, the general case result (61) can be approximated by

$$
J_{j} \sim u_{0} \mathcal{W} L
$$

which $i s$ independent of velocity.

Behavior along the cavity/chimney streamline. The light yellow profiles shown in Figure 162 reflect the distribution of radionuclides along the upper, parallel streamtube shown in Figure 161 that passes through a cavity or chimney rubble zone (but no glass). Along this streamline, radionuclides were initially distributed in the cavity/chimney region (as in Fig. 21) and allowed to move with the groundwater $\left(\mathcal{R}_{j}=1, D_{L}=0\right)$. The migration of this pulse with time can be traced with the corresponding front derived from glass dissolution.

The maximum aqueous concentration realized along this streamtube is unaffected by velocity, and would only differ as a result of dispersive or surface reaction processes (which were not included). The maximum radionuclide flux, on the other hand, is affected by the velocity, $V$.

If both streamtubes are taken in combination, then the maximum concentration or flux, as averaged over both streamtubes, will be affected by the behavior in each individual streamtube in a volume- or flux-weighted sense.

Matching elution fluxes. It should be possible to use or combine aspects of the simple analytic solutions presented in Figure 162 along several streamlines in order to fit or match the elution fluxes produced in the Chapter 11 simulations, albeit at some reduced level of accuracy. These solutions, if they can be obtained, would be rudimentary approximations useful for scoping or sensitivity purposes, and would not incorporate the more complicated chemical behavior, such as precipitation and dissolution, sorption, and influences of $\mathrm{pH}$. This will be pursued in a future publication. 



\section{DISTRIBUTION}

\section{External:}

Bangerter, Robert

DOE/NVOO

UGTA Project Manager

P.O. Box 98518, M/S 505

Las Vegas, NV 89193-8518

Finnegan, David

Los Alamos National Laboratory

P.O. Box 1663, CST-7, M/S J514

Los Alamos, NM 87545

Hawkins, Ward

Los Alamos National Laboratory

P.O. Box 1663, EES-1, M/S F659

Los Alamos, NM 87545

Hoar, Ken

DOE, Nevada Operations Office HRMP

P.O. Box 98518, M/S 505

Las Vegas, NV 89193-8518

Ortego, Ken

Bechtel Nevada

2621 Losee Road

M/S NLV082

Las Vegas, NV 89030

Pohlmann, Karl

Desert Research Institute

755 E. Flamingo Road

P.O. Box 19040, M/S 505

Las Vegas NV 89132-0040

Rehfeldt, Ken

HSI GeoTrans

2621 Losee Road, Building B-1

M/S 439

Las Vegas NV 89030

Russell, Chuck

Desert Research Institute

755 E. Flamingo Road

P.O. Box 19040 , M/S 505

Las Vegas NV 89132-0040

Sully, Mike

HSI GeoTrans

2621 Losee Road, Building B-1

M/S 439

Las Vegas NV 89030

Thompson, Joe

Los Alamos National Laboratory

P.O. Box 1663, CST-7, M/S J514

Los Alamos, NM 87545
Trudeau, Doug

USGS

Water Resources Division

6770 South Paradise Road

Las Vegas, NV 89119

Waddell, Rick

HSI GeoTrans

9101 Harlan St Suite 210

Westminster CO 80030

Willie, Janet

IT Corporation

2621 Losee Road, Building B-1

M/S 439

Las Vegas, NV 89030

Wolfsberg, Andrew

Los Alamos National Laboratory

P.O. Box 1663, EES-5, M/S F649

Los Alamos, NM 87545

U. S. Department of Energy

Nevada Operation Office

Technical Information Resources

P.O. Box 98518, M/S 505

Las Vegas, NV 89193-8518

U. S. Department of Energy

Office of Scientific \& Technical Info

175 Oak Ridge Turnpike

P.O. Box 62

Oak Ridge, TN 37831-0062

U. S. Department of Energy

Nevada Operations Office

Public Reading Room

P.O. Box $98512, \mathrm{M} / \mathrm{S}$ NLV 040

Las Vegas NV 89193-8521

Internal:

Bourcier, Bill L-219

Bruton, Carol L-219

Carle, Steve L-206

Kersting, Annie L-231

Maxwell, Reed L-221

Pawloski, Gayle L-221

Rard, Joe L-200

Shumaker, Dan L-561

Smith, Dave L-231

Tompson, Andy L-206

Zavarin, Mavrik L-219 




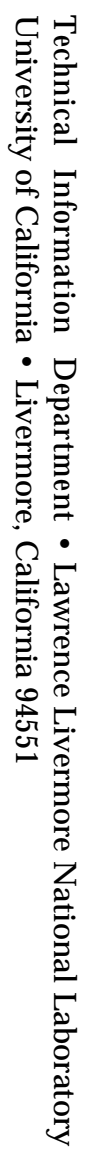

